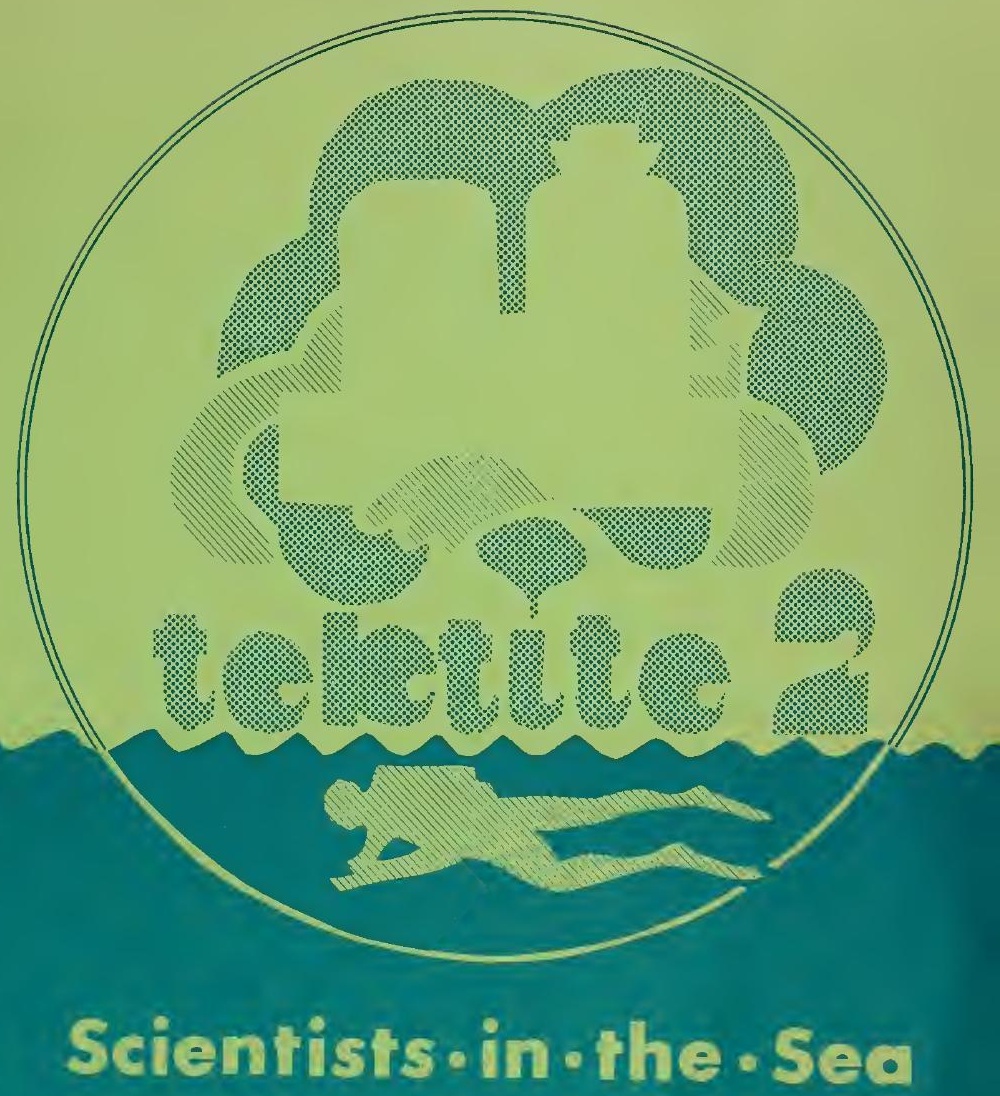

August 1971

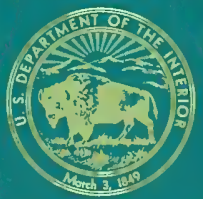

U.S. Department of the Interior

Washington, D. C. 

For sale by the Superintendent of Documents, U.S. Government Printing Office Washington, D.C. 20402 - Price $\$ 5.75$

Stock Number 2400-0682 


\author{
THE SECRETARY OF THE INTERIOR \\ WASHINGTON
}

\title{
PREFACE
}

Daily it becomes clearer that man's very survival on this planet is ultimately linked to his ability to use properly the natural resources of the lands and the oceans. We are now beginning to realize that while selfishness and greed may indeed play a role, most of our environmental ailments are the result, not of men scheming to despoil or destroy the environment for profit, but simply of lack of adequate foresight. We owe it to the generations that follow to look ahead as far as possible and to avert the thoughtless and expedient foreclosure of environmental options.

While the oceans have 1ong been studied from the surface, many information gaps still exist, and some aspects of marine research require a more direct approach than has been possible until now. Recent technological advances allow us safely to place scientists and engineers for prolonged periods on the ocean floor, where they can study and learn under conditions approaching those found in landbased laboratories. As this report indicates, aquanautscientists now can move freely beneath the sea in complete harmony with the marine ecosystem.

The TEKTITE II program, led by the Department of the Interior, was a "giant step" for man-in-the-sea . . . many steps must follow to find answers to the complexities of our planetary sea before we can fully assess and wisely utilize its potential for achieving a fuller life for mankind.

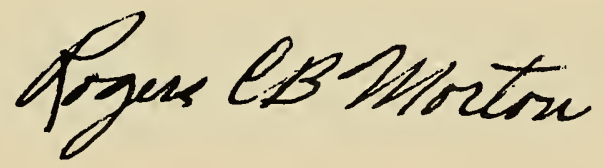



TEKTITE II had over 500 participants representing approximately 50 organizations. To appropriately acknowledge the dedicated efforts of all those deserving such recognition would in itself constitute a lengthy report. A highly visible but marginally budgeted program such as TEKTITE II can succeed only because of great dedication and personal sacrifice of many.

At each level there were individuals whose support served not only as an outstanding example of foresight or day-to-day output, but also as an inspiration to those closely associated with them.

The following individuals were singled out not only because of their specific contribution to the success of the program, but also because they represent contributions ranging from top management support to the daily effort so essential to field operations.

The program could never have been initiated without the strong farsighted support of Mr. Russel1 E. Train (at that time the Under Secretary of the Interior). His interest and enthusiasm gave us a much needed boost during the initial planning phases of the program.

The continued interest of the Secretary of the Interior, Walter J. Hicke1, reflected both through his office and on a personal basis, went far towards insuring broad support from the many participating organizations. A reflection of this interest was evidenced by his visit to the site for the dedication ceremony despite a full schedule.

The unselfish efforts of Mr. Harold L. Goodwin of the National Science Foundation's Sea Grant Program and Dr. James W. Humphreys, Jr., of the National Aeronautics and space Administration were instrumental in each case in gathering the considerable support of their agency throughout the program.

Without the untiring efforts of Mr. Harry E. Jackson of the Office of the Supervisor of Salvage, Department of the Navy, and Mr. Loran A. Weaver of the Nationa1 Oceanic and Atmospheric Administration, the acquisition of specialized pieces of equipment and logistics support so necessary to the program would not have been possible.

The on-site personal dedication and inexhaustible efforts of Mr. Robert $J$. Schmidt, Jr., of the General Electric Company served as an outstanding example to us a11. His willingness to devote long hours, day or night, to the technical maintenance and repair of equipment and to the training of aquanauts proved essential to a continuing operation.

Special thanks are due to Mrs. Emma Imhoff, Miss Dawn Granberry, and Mrs. Alice Mintz. Without their enthusiastic, diligent effort in the TEKTITE office, the program could never have succeeded.

We of the Program Office express our thanks and sincere appreciation to the individuals cited above and to all the men and women who contributed to the success of TEKTITE II. 

TABLE OF CONTENTS

Preface

Acknowledgements $\quad$ ii

Table of Contents ii

Chapter I

Introduction

Program Organization

I -1

List of TEKTITE II Aquanauts

I -4

$\mathrm{I}-13$

Chapter II

Facilities

II -1

Operations

II -19

Habitat Engineering

II -31

Logistics

Chapter III

Minitat Project

III -1

Chapter IV

Training

IV -1

Mark X Closed Circuit Rebreather Training

IV -7

Reflections of a Watch Director

IV -14

Chapter V

Public Affairs Program

$\mathrm{V}-1$

Chapter VI

Ocean Floor Program

Introduction

VI-1

Mission 1-50

Observations of Fish Behavior in Relation to Fish Pots VI-4

Precise In-Situ Measurements of Chemical Parameters

of Seawater

VI -15 
Mission 2-50

Continuation of Underwater Geologic Studies in Lameshur Bay Area VI-22 Part 1. Bioturbation

Ecology and Population Dynamics of the Spiny Lobster,

Panulirus, argus of St. John Island, U. S. Virgin Island

Mission 3-50

Feeding Behavior of a Tropical Predator Cyphoma gibbosum

Linnaeus

Continuation of Geologic Studies in Lameshur Bay Area

Part 2. Sea Level History

Mission 4-50

Passive and Experimental Bio-acoustical Studies on Marine Organisms in their Natural Habitat

Comparative Studies of Subtidal Vegetation in the Virgin

VI -106

Islands and the New England Coastline

Mission 6-50

The Influence of Herbivores on the Marine Plants of Great

VI -132

Lameshur Bay

Escape Response in a Pomacentrid Reef Fish

VI -201

The Ecology and Behavioral Patters of the Motile Fauna

VI -209

Associated with Tropical Marine Soft Bottom Communities

\section{Mission 8-50}

Observations on the Biology and Behavior of the Arrow Crab,

VI -213

Stenorynchus seticornix (Herbst), in Lameshur Bay

Biology of Cephalopods

VI -221

Mission 10-50

Effects of Man-Made Pollution of the Dynamics of Coral Reefs

VI -229

Photosynthesis in Coral - Algal Associations

Mission 12-50

Biochemical Studies of a Coral Reef Ecosystem

Mission 15-50

Activity Patterns of Coral Reef Fishes with Emphasis on

VI - 257

Nocturna1 Diurnal Changeover

Space Resource Sharing in a Coral Reef Fish Community

VI -261 
TABLE OF CONTENTS

Mission $17-50$

Seston Composition and Distribution in the Bottom Water of

VI -275

Great Lameshur Bay

Planktonic Distribution

Faunal Composition and Behavior of a Coral Islet in the

Sand-Flat

In-Situ Measurements of the Metabolic Activity of Tropical

VI -285

Benthic Communities

VI -294

Mission 18-50

Technical Aspects of Dome-Corrector-Ports and Flat-Ports

VI -295

Optics in Underwater Photography

Chapter VII

Ocean Survey Program

Introduction

Evaluation of Factors Affecting Resolution of Shallow-

Water Bottom Features

In-Situ Investigation of Ocean Sediments using the Deep

Ocean Sediment Probe (DOSP)

In-Situ Measurements of Small Angle Scattering of a Light

Beam in the Sea

Marine Geology of the Southern Virgin Island Platform

Factors Affecting Ozone Concentration in a Marine Atmosphere

Geological Sediment Study

Weather Program

Study of Sedimentation on the Virgin Island Platform in the vicinity of St. Thomas

Observations on the Effects and Behavior of Compressed

Municipal Refuse Bales in the Marine Environment

Processes of Primary Production in the Water of the Virgin

Islands

Bottom Current Measurements in the Virgin Island Passage

VII -1

VII -4

VII -18

VII -33

VII -41

VII -42

VII -42

VII -43

VII -44

VII -45

VII -46

VII -47

Ambient Hydrodynamic Flow Field Associated with the

VII -48

TEKTITE II Habitat

Chapter VIII

A Man-Systems Integration Study of the Behavior of Crews

VIII -1

and Habitability in Small Spaces

The TEKTITE II Human Behavior Program

An Introductory Study on the Effects of Two-Way Closed

VIII -15

Circuit Television on a Small Crew of Aquanauts Living

VIII -63

in an Isolated and Stressful Environment 
Chapter VIII (Continued)

Habitability Assessment Program

VIII -68

TEKTITE II Food System

VIII -90

Data Management Program

VIII-96

Chapter IX

Medica1 Support Program

IX -1

Decompression Table Development

IX -14

Chronic Nitrogen Exposure Study

IX -25

Microbiological Aspects

IX -36

Laboratory Medicine

IX -53

Chapter X

Studies of Diver Communication and Retrieval

$\mathrm{X}-1$ 
The project title comes from the small meteorites which survive the fiery plunge through the earth's atmosphere and often come to rest on the ocean's floor. The name was selected to symbolically link oceanographic and space scientific interests in national undersea programs.

TEKTITE I took place during the period February 15 to Apri1 15, 1969. Four aquanauts from the Department of the Interior spent the planned 60 days on the ocean floor in the Virgin Islands at a depth of approximately 50 feet. There were no significant medical or behavioral problems during the mission, and the results clearly indicated that it was safe to expose personnel to these depths while saturating their body tissues with a breathing mixture of $92 \%$ nitrogen and $8 \%$ oxygen.* In addition, a marine scientific program was initiated which revealed the many advantages of conducting such investigations while living on the ocean floor.

The success of TEKTITE I stimulated increased interest in sea floor habitation both nationa1ly and internationa11y. Because of this interest, other agencies of the Government as well as members of the academic and industrial community expressed a desire to continue such programs. This interest culminated in an interagency top-level meeting in September 1969 which provided the official impetus for developing a TEKTITE II program in which the Department of the Interior would serve as lead agency.

While TEKTITE I was primarily a feasibility program, TEKTITE II had many and various goals. As in TEKTITE I, the program was designed to permit marine scientists to carry out a variety of in situ research missions under saturated diving conditions. While these scientists were conducting their underwater research missions, they were under observation by behavioral and biomedical teams whose objectives were to add to and further refine the behavioral and physiological studies initiated in TEKTITE I.

While the basic science programs were the core and principal purpose of conducting TEKTITE II, there were other aspects to the program. A total of 53 aquanauts were given the opportunity to experience first hand the advantages and disadvantages of conducting research from the ocean floor. This significantly increases the cadre of this country's aquanaut scientists and gives the

* Saturation refers to the state of dissolved gases in the tissues of the diver. Under a saturated condition the tissues have absorbed all the nitrogen or other inert gases possible. Once this has occurred, the decompression time required at the end of the dive at a given depth does not increase with additional time spent at that depth. Under such conditions, the diver works out of a habitat whose atmosphere is maintained at approximately the same pressure as that of the water in which he will be working. His habitat may be an ocean floor installation or may be a pressurized chamber on board a surface vessel from which he travels to his work location in a pressurized personnel transfer capsule. In either case he does not undergo decompression between dives; he is decompressed only after the total dive sequence is completed. 
Nation an experience base on which to expand. In almost every instance, the aquanauts desired to stay longer and expand upon their work. Perhaps more importantly, they all felt that their perspective changed as a result of their ocean floor habitation. Many commented that, "If only I knew how it was, I could have planned my program better." This suggests that in the future, aquanaut scientists should live on the ocean floor for a few days for orientation, return to the surface, plan their investigations, and then return to the bottom to carry them out.

Another major aspect of the program was the training of scientific, technical, and support personnel. Over 30 diving technicians received direct training in support diving, decompression procedures, and many other skills associated with saturation and conventional diving. The constant contact with scientists considerably broadened their outlook on ocean science. In addition, approximately 20 divers from the Department of the Army had the unusual opportunity of participating in a program where their diving skills could be put to use and where they could take part in a marine research program.

The Ocean Survey Program provided an opportunity for training 296 student ocean science technicians. A total of 10,183 student training days were involved. This training was accomplished under the supervision of 19 faculty representatives from several educational institutions.

Further training and experience in psychology was provided to approximately 35 students from the University of Texas during execution of the behavioral science program.

Training was not 1 imited to students. About 30 middle management personnel were utilized as watch directors during the program. These individuals were assigned major responsibilities and essentially performed as "officers-of-thedeck." Much was learned that will provide an invaluable core of experience for future programs.

Advances were made in saturation diving with the development of new decompression tables for saturation exposures to depths of 100 feet using a breathing mixture of $95 \%$ nitrogen and $5 \%$ oxygen. These tables were successfully tested and were used upon completion of a 2-week saturation dive to 100 feet in the new hyperbaric chamber facilities of the University of Pennsylvania. Extensive medical tests during this program demonstrated clearly that it was safe to use nitrogen systems at this depth. While the open sea trials at 100 feet were not completed, the successful laboratory effort points the way for expanded shallow water diving programs.

A program such as TEKTITE has responsibilities over and above the scientific and technical achievements. One of these responsibilities is to inform the scientific community and the general public of the program and the benefits to be obtained. This report, together with the articles to be published in professional journals by the scientists, will go far towards informing the scientific community. The general public, however, must be informed through the standard news media. To this end a public affairs program was developed which resulted in broad dissemination of program information. Even here the benefits are numerous. As a result of this effort, we have received many requests from young people all over the world for information concerning the program and 
queries as to how they can "get involved." These are intangible but important benefits which frequently are not 1 isted as "accomplishments" in technical programs.

There were some 500 people involved in TEKTITE II representing many organizations. The following section reflects the nature of these organizations, their interest in participating in TEKTITE II, and the manner in which this was achieved. 
The organization of TEKTITE II was both complex and flexible. Because of the multitude and diversity of the participating organizations, the structure of the program was forced to change as needs shifted. TEKTITE II was not a line item in any budget plan, so equipment, personnel, time, and other aspects of the program had to respond to the momentary availability of the various support elements. Because of personnel requirements within each of the participating organizations, the number and skills of personnel for on-site operations varied. This required constant training and orientation of support staff. Likewise, it required restructuring of responsibilities. There were a few "core" staff who were involved throughout the long 8 to 9 month operational phase. Most on-site personnel, however, rotated in and out.

The following is a list of the participants and the general nature of their role in the program.

\section{GOVERNMENT AGENCIES}

Air National Guard

Airlift support

Department of the Interior

Prime contracting agency

Overall program management

Funding support

Overall safety responsibility

Personnel for planning and on-site operations

Direction of on-site operations

Coordination of overal1 scientific programs

Coordinating logistic support

Coordination of public affairs plan

Ocean floor program

Ocean survey program

Department of Health, Education and Welfare (Public Health Service)

Program Director

Medical and public health support on-site

Training of public health officers in underwater physiology

Medical/safety review

Ocean survey program (Bureau of Solid Waste)

Government of the Virgin Islands

Program Director

Funding support

Logistic support

Scientific support

Ocean floor program 
National Aeronautics and Space Administration

Program Director

Funding support

Operational support on-site

Man-system integration program

Behavioral data management and reduction

Earth resources overflight program

Habitability assessment

Hematology program

Food management program

Ocean floor program

Ocean survey program

\section{National Science Foundation}

Program Director

Funding support

Operational support

Training of marine scientists and marine technicians

Scientific program support

Ocean survey program

U.S. Coast Guard

Program Director

Logistic and material support

On-site support

Overall program safety review

U.S. Department of the Army

Operational diving support

U.S. Department of Commerce, Environmental Sciences and Services Administration

Air logistics coordination

Ocean survey program

U.S. Department of the Navy

Program Director

Funding support

Habitat support equipment

Transport primary habitat system and related equipment

Participation in behavioral program

Medical/physiological research

Microbiology program

Diver communication research

Safety review

Ocean Survey Program 
Program Director

Coordination of Ocean Floor Marine Science Program selection Funding support

\section{ACADEMIC INSTITUTIONS}

Academy of Natural Sciences of Philadelphia

Philadelphia, Pennsylvania

ocean floor program

American Museum of Natural History

New York, New York

Ocean floor program

Australian Museum

Sydney, New South Wales, Australia

Ocean flood program

Cape Fear Technical Institute

Wilmington, North Carolina

Ocean floor program

Logistic support

Student training

Ocean survey program

Operational support

College of the Virgin Islands

St. Thomas, Virgin Islands

Ocean floor program

Logistic support

Base camp management

Scientific support

Ocean survey program

Columbia University, Lamont-Doherty Geological Observatory

St. Croix, Virgin Islands

Ocean survey program

Fairley-Dickinson University

St. Croix, Virgin Islands

Ocean survey program

Florida State University

Tallahassee, Florida

ocean floor program

Harvard University

Cambridge, Massachusetts

Ocean floor program

Ocean survey program 
Highline Community College

Seattle, Washington

Operational/diving support

ocean floor program

Student training

Supervision of support diving

Marine Biological Laboratory

Woods Hole, Massachusetts

Ocean floor program

Marine Biomedical Institute, University of Texas Medical Branch/Texas A\&M

Galveston, Texas

Medical Director

Medical program coordination

Operational medical support

Physician training

Michigan State University

East Lansing, Michigan

Ocean survey program

North Carolina State University

Raleigh, North Carolina

Ocean survey program

Ohio University

Athens, Ohio

Ocean survey program

St. Croix Environmental Laboratory

Gallows Bay, St. Croix, Virgin Islands

Ocean survey program

Scripps Institution of Oceanography

LaJol1a, California

Ocean floor program

Southern Maine Vocational Technical Institute

South Portland, Maine

Ocean survey program

Operational support personnel

Marine technician training

Station Marine D'en Doume et Centre D'Oceanographie

Marseilles, France

Ocean floor program

Texas A\&M University

College Station, Texas

Ocean floor program

Ocean survey program 
Tulane University

New Orleans, Louisiana

Ocean floor program

University of California

Santa Barbara, California

ocean floor program

University of Connecticut

Noank, Connecticut

Ocean survey program

University of Florida

Gainesville, Florida

Diver communication study

University of Miami

Miami, Florida

Ocean floor program

Ocean survey program

University of New Hampshire

Durham, New Hampshire

Ocean floor program

University of North Carolina

Chapel Hill, North Carolina

Ocean survey program

University of Pennsylvania

Philadelphia, Pennsylvania

Program Director

Medical support

Safety review

Scientific program support

100-foot, 2-week saturation dive

University of Puerto Rico

Mayaguez, Puerto Rico

Ocean survey program

University of Rhode Island

Providence, Rhode Island

Ocean survey program

University of Texas

Austin, Texas

Behavioral science program

Operational support

University of Washington

Seattle, Washington

ocean floor program 
Wrightsville Marine Biomedical Laboratory

Wilmington, North Carolina

Ocean floor program

INDUSTRY

Battelle Memorial Institute

Columbus, Ohio

Technical and engineering assistance for safety and minitat programs

Be11 comm Incorporated

Washington, D.C.

Data analysis for behavioral research and microbiological programs

Systems analysis of overall program

Preparation of minitat operational program plan

General Electric Company

Philadelphia, Pennsylvania

Primary contractor

Program Director

Provision of primary habitat

MK 10 rebreather training

Habitat engineering support

Provision of Public Affairs Director to program

Habitat Engineer and Habitat Engineer training

Ocean survey program

J. \& J. Marine Diving Company, Inc.

Houston, Texas

Decompression schedules for 100-foot saturation dive

Westinghouse Ocean Research Laboratory

Miami, Florida

Ocean floor program

Wilson Industries

Houston, Texas

Lease of primary decompression system

Catamaran pontoon contract

Subcontract on mini habitat

Wor1dwide Development Corporation

Columbus, Ohio

Prime contractor - mini habitat

The program management is shown in Figure 1. It is worth noting that while the Department of the Interior provided overall management, several program elements were assigned to other organizations. If additional support was needed from the various agencies, it was handled initially through the program directors. Once direct liaison was established at the working level within an organization, however, personal communications were utilized rather than going back through the entire chain each time. 


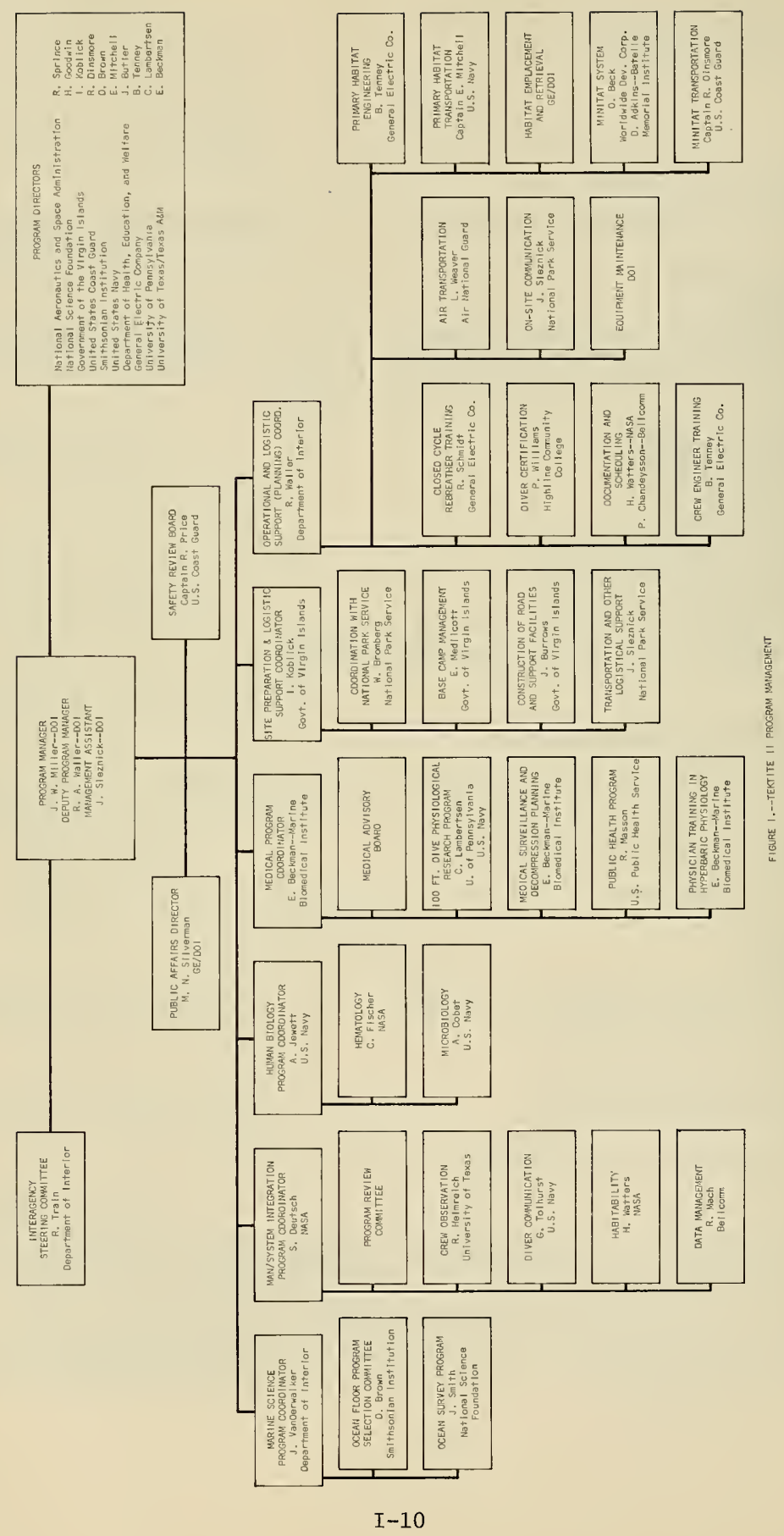


The on-site management organization is shown in Figure 2. Because of changing requirements and personnel rotation, it was necessary that assigned responsibilities and even the structure of the organization remain flexible. The major functions were the same throughout, but the degree of responsibility and overlap shifted depending upon the particular individuals on site at any given time. For these reasons, only organizational responsibility is identified in many cases in Figure 2.

The names shown are those whose responsibilities remained constant even though they may not have been on site the whole time and were represented by others from their own organization.

Table 1 shows major program milestones.

\section{Table 1.--Program Milestones}

Ju1y 2, 1969

Sept. 1969

Oct. 24,1969

Nov. 1, 1969

Feb. 2, 1970

Feb. 15, 1970

Mar. 3, 1970

Mar. 6, 1970

Mar. 19, 1970

Apr. 1, 1970

Apr. 4, 1970

June 22-

July 7,1970

Nov. 6, 1970

Nov. 19, 1970

Nov. 20, 1970

May 24, 1971

July 1971
Initial interagency meeting

Interagency Committee recommends program

Secretary of the Interior approves program

Program office opens

Aquanaut selection completed

Base camp activated

First press conference

Habitat and associated equipment arrived on site

Habitat emplacement complete

Dedication ceremony on site

First mission begins

100-foot, 14-day hyperbaric chamber dive

Last mission completed

Equipment leaves site

Base camp deactivated

Program office closed

Final report submitted to publisher 


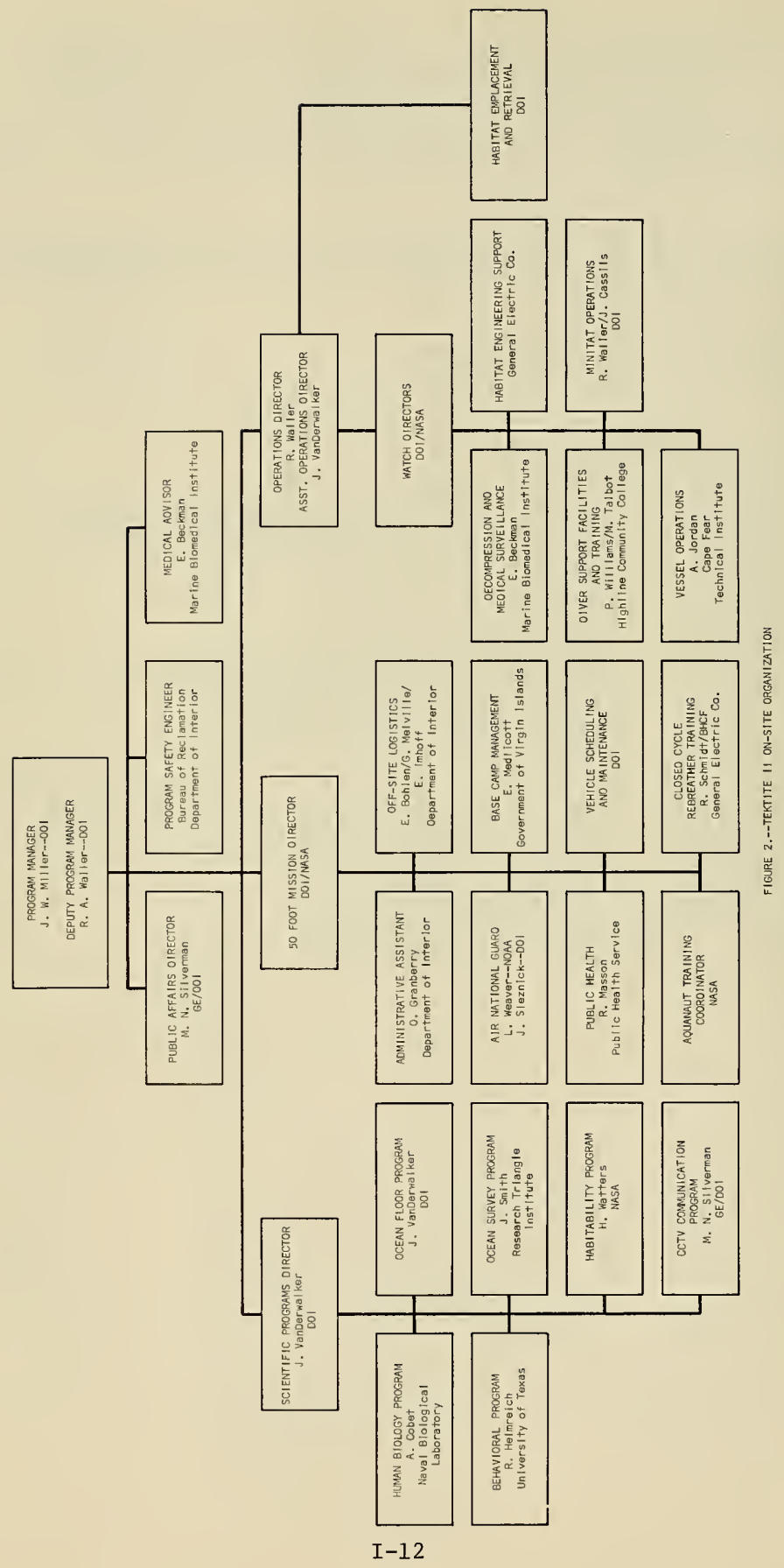




\section{MISSION 1-50}

Mr. William L. High

Department of the Interior

Dr. Alan Beardsley

Department of the Interior

Mr. Roger J. Dexter

University of Miami

Mr. Richard w. Curry

University of Miami

Mr. Edward Batutis

General Electric Company

MISSION 2-50

Dr. H. Edward Clifton

Department of the Interior

Dr. Ralph Hunter

Department of the Interior

Mr. John G. VanDerwalker

Department of the Interior

Mr. Ian G. Koblick

Government of the Virgin Islands

Mr. Charles Kubokawa

NASA-Ames Research Center

MISSION $3-50$

Mr. R, Lawrence Phillips

Department of the Interior

Mr. Denny Bowman

Marine Biomedical Institute

Mr. Brian D. Gregory

University of Washington
MISSION 3-50 (Cont'd)

Dr. Charles Birkeland

Smithsonian Tropical Research Inst.

Mr. Charles Cooper

NASA-Marshall Spaceflight Center

MISSION 4-50

Dr. Arthur C. Mathieson

University of New Hampshire

Mr. Richard Lralick

University of New Hampshire

Dr. William w. Schroeder

Texas A\&M University

Mr. Charles Cooper

NASA-Marshall Spaceflight Center

Dr. Thomas J. Bright

Texas A\&M University

MISSION 6-50

Dr. Sylvia Earle Meade

Los Angeles County Museum of Natural History

Dr. Renate Schlenz True

Tulane Medical School

Mrs. Ann Hartline

University of California

Miss Alina M. Szmant

Scripps Inst, of Oceanography

Miss Margaret Ann Lucas

University of Delaware 


\section{MISSION 8-50}

Dr. William F. Herrnkind

Florida State University

Mr. Louis M. Barr

Department of the Interior

Dr. John Couch

Department of the Interior

Mr. Frederick Hochberg

Department of the Interior

Mr. Richard T. Heckman

NASA-Marshall Spaceflight Center

MISSION $10-50$

Dr. Richard H. Chesher

Westinghouse Corporation

Dr. Lawrence McCloskey

Department of the Interior

Mr. Bates Littlehales

National Geographic Society

Dr. J. Morgan Wells, Jr.

Wrightsville Marine Bio-Medical Lab.

Mr. Todd Atkinson

Cape Fear Technical Institute

MISSION $12-50$

Dr. Richard/Cooper

Department of the Interior

Mr, Robert J, Ellis

Department of the Interior

Dr. M. A. Heeb

University of Miami

Dr. C. C. Lee

University of Miami

Mr. Todd Atkinson

Cape Fear Technical Institute
MISSION 15-50

Dr. Frank H. Talbot

The Australian Museum

Dr. Bruce B. Collette

Department of the Interior

Dr. C. Lavett Smith

The American Museum of Natural History

Dr. James C. Tyler

The Academy of Natural Sciences of Philadelphia

Mr. Jeffrey Wayne Marsten

Highline Community College

MISSION $17-50$

Dr. Merrill A. True

Bio-Oceanic Research, Inc.

Dr. Jean-Georges Harmelin

Faculte des Sciences de Marseille

Dr. Roland $T$. von Hentig

Biologische Anstalt, Helgoland

Dr. Wolfgang Hickel

Biologische Anstalt, Helgoland

Mr. Brooks Tenney

General Electric Company

MISSION $18-50$

Mr. Flip Schulke

Flip Schulke Photojournalist

Mr. Frank Pugliese

General Electric Company

Mr. Robert S. Farrelly

Underwater Explorers Club

Mr. Robert J. Schmidt, Jr.

General Electric Company

$\mathrm{Mr}$. R. Anderson

Miami, Florida 


\section{FACILITIES}

Richard A. Waller

Department of the Interior

Washington, D. C.

The TEKTITE II facilities (Figure 1) consisted of an underwater habitat, service barge, decompression barge, dive platform, surface support center, causeway pier, and base camp, all located in and around the Lameshur Bay operational site. The operational facilities and their locations closely parallel those of TEKTITE $I$, the principal difference being a shore-based surface support center and a towable decompression complex.

Additional facilities located on St. Thomas consisted of a public relations office at Red Hook and an administrative office at Sapphire Bay.

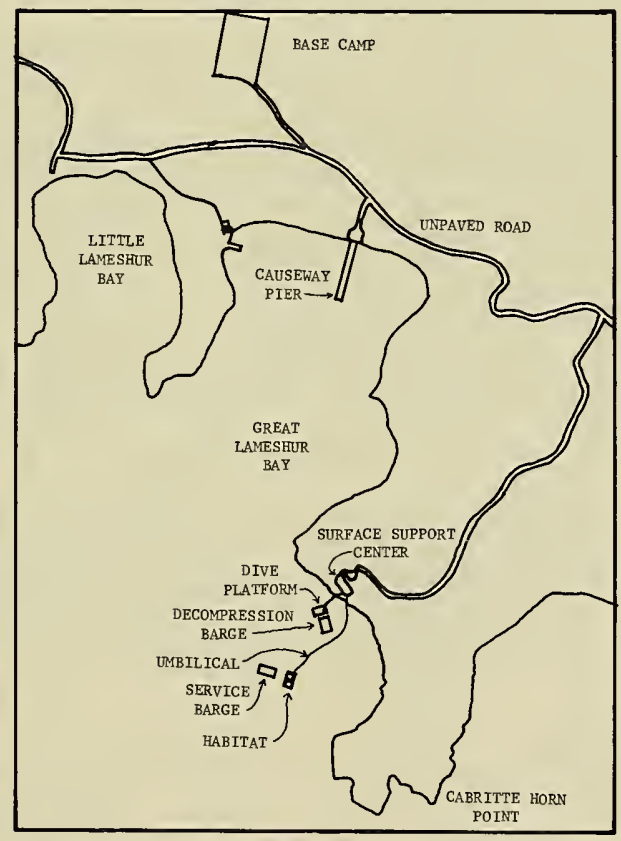

Figure 1. TEKTITE II operational site at St. John, U.S. Virgin Islands 
The underwater habitat, with some modifications, was the same as had been used in the TEKTITE I program. The habitat (Figures 2 and 3 ) consisted of two vertical steel cylinders attached to a rectangular steel base. The two cylinders were connected by a crossover tunnel, and each cylinder contained an upper and lower compartment designated as: crew quarters, bridge, equipment room, and wet room. Each cylinder was provided with three large hemispherical ports and a cupola atop the equipment room for crew observation. The habitat was designed and built in accordance with American Society of Mechanical Engineers (ASME) Boiler and Pressure Vessel Code for Unfired Pressure Vessels.

The base of the habitat system contained two passageways with barred gates at each end. One passageway permitted access to the open ingress/ egress wet room hatchway. The second passageway passed under the normally closed emergency escape hatch located beneath the raised floor in the crew quarters. In addition to providing a rigid attachment for the twin cylinders, the base contained variable sea-water ballast tanks and fixed ballast bins to hold the steel punchings and iron pigs necessary to offset the displacement on the sea floor.

The crew quarters (Figure 4, lower left) contained four built-in bunks, drawer space, a sink, stove, refrigerator, and a radio and television set. The bridge (Figure 4, upper left) contained the environmental control and alarm panels, the communications panel, and other ancillary instrumentation. It served as the habitat control center and as a dry laboratory for the scientists. It also contained a folding cot where the habitat engineer slept. The equipment room (Figure 4, upper right) contained the environmental control system, the electrical transformers and main breakers, a large freezer, and a toilet. The observation cupola was located above this compartment. The wet room (Figure 4, lower right) contained a fresh water shower, a clothes dryer, storage space for scuba gear, and stainless steel counters for specimen preparation and study.

\section{ATMOSPHERIC CONTROL}

The habitat was initially pressurized on the surface to the emplacement depth pressure of approximately 2.3 atmospheres by compressed air. The partial pressure of oxygen $\left(\mathrm{PO}_{2}\right)$ in the habitat during all saturation periods was 160 torr or millimeters of mercury (mm $\mathrm{Hg}$ ). The specified $\mathrm{PO}_{2}$ was obtained by displacing air with nitrogen after the habitat was secured to the ocean floor. This resulted in a mixture of $92 \%$ nitrogen and $8 \%$ oxygen.

During the operation compressed air was continually supplied to the habitat via an umbilical by low-pressure air compressors at the surface support center to provide metabolic oxygen to the aquanauts and maintain the $\mathrm{PO}_{2}$ between 151 and 165 . The required flow rate of inlet air to the 


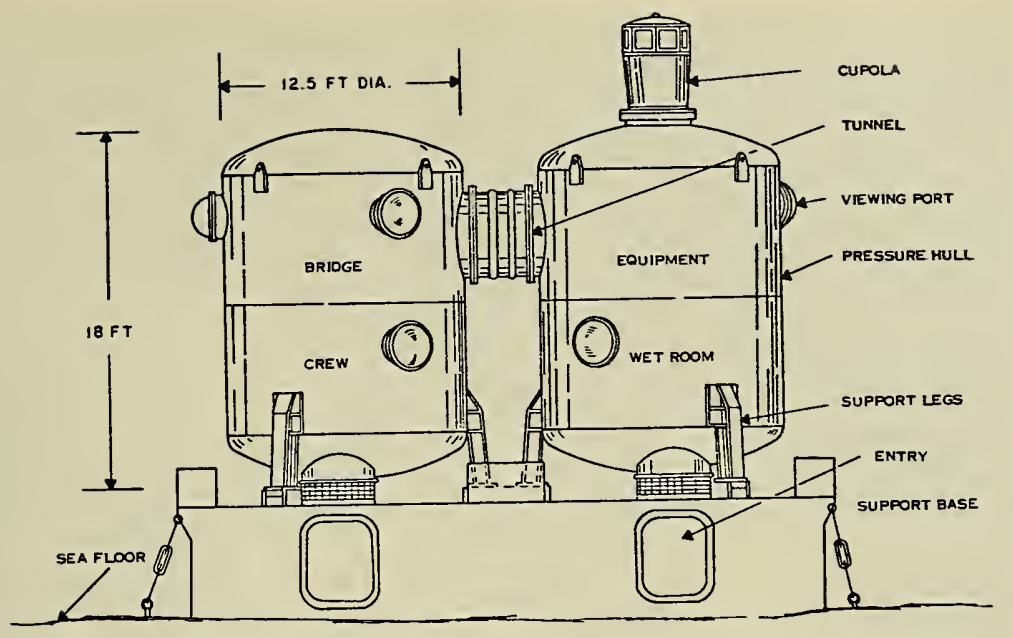

Figure 2. Side view of the TEKTITE II habitat

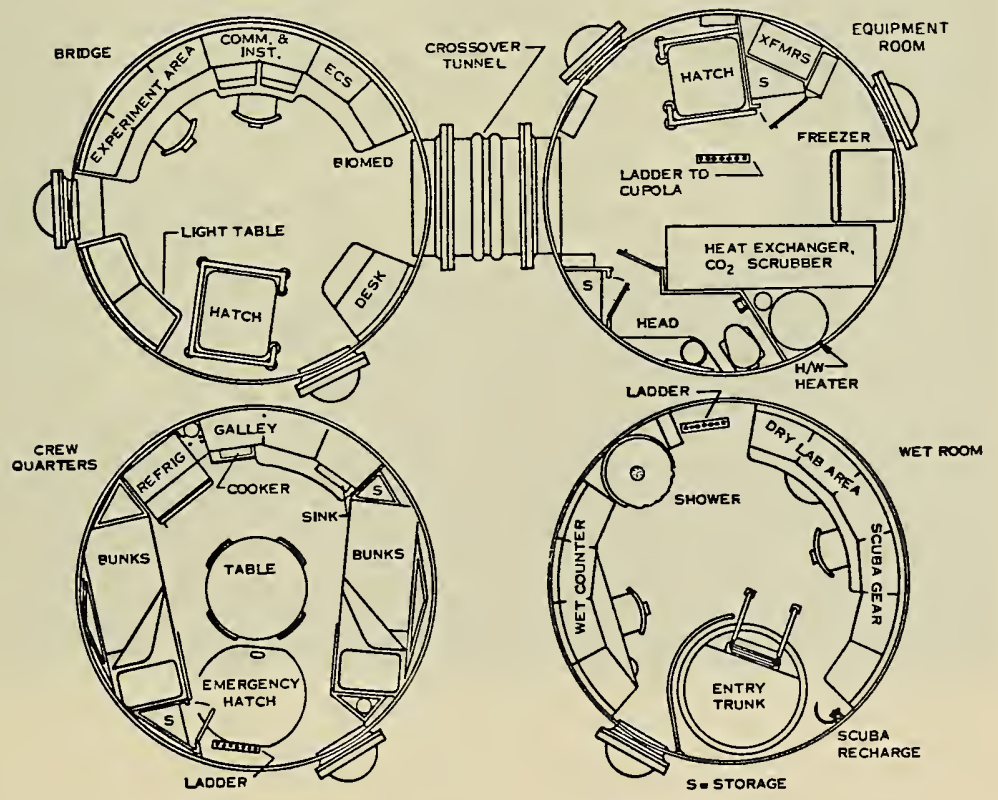

Figure 3. Plan views of the habitat compartments 


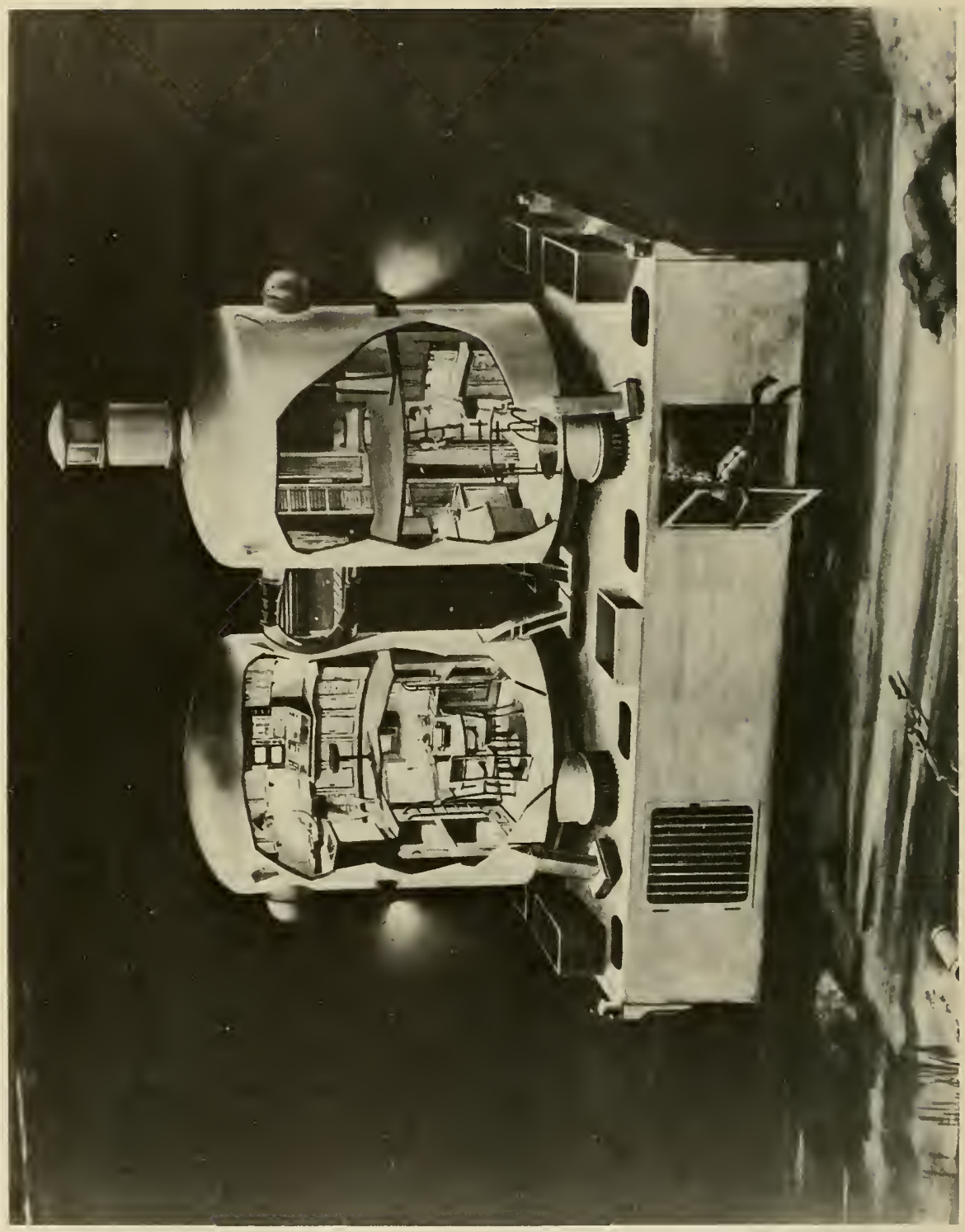

Figure 4. Cutaway of Habitat 
habitat was approximately $30 \mathrm{SCF} / \mathrm{hr}$ (standard cubic feet per hour). The flow rate was manually controlled but was based on measured $\mathrm{PO}_{2}$ levels . A continual stream of the habitat atmosphere was dumped through vents in the entrance trunk to the sea, thus maintaining the habitat pressure at the sea pressure at the trunk vents.

Carbon dioxide $\left(\mathrm{CO}_{2}\right)$ generated by the aquanauts was removed by a Baralyme scrubber. The scrubber system consisted of two blowers (one redundant), a Baralyme canister, and associated valves and piping. Habitat gas was forced by the blower through the Baralyme, where $\mathrm{CO}_{2}$ was absorbed, and the mixture then recirculated to each of the four compartments. The habitat scrubber system was designed to operate 12 hours on a 54-pound cannister. In actual practice, the average cannister maintained acceptable $\mathrm{CO}_{2}$ levels ( 8 torr or less) for 15 hours. Baralyme resupply from the surface was necessary because of lack of storage space.

The habitat atmospheric monitoring system, the monitored parameters, and the acceptable parameter limits are shown in Table 1.

\begin{tabular}{|c|c|c|c|c|c|c|}
\hline \multirow[t]{2}{*}{ Constituent } & \multirow{2}{*}{$\begin{array}{l}\text { Equipment } \\
\text { Monitoring } \\
\text { Range }\end{array}$} & \multirow{2}{*}{$\begin{array}{l}\text { Acceptable } \\
\text { Operating } \\
\text { Range }\end{array}$} & \multicolumn{2}{|c|}{ Equipment } & \multicolumn{2}{|c|}{ Backup Equipment } \\
\hline & & & Habitat & Surface & Habitat & Surface \\
\hline $\mathrm{O}_{2}$ & $0-450$ torr & 151-165 torr & $\begin{array}{l}\text { Servomex } \\
\mathrm{O}_{2} \text { sensor }\end{array}$ & $\begin{array}{l}\text { Servomex A0150 } \\
\mathrm{O}_{2} \text { analyzer }\end{array}$ & MSA $\mathrm{O}_{2}$ meter & $\begin{array}{l}\text { Beckman } \mathrm{F} 3 \\
\mathrm{O}_{2} \text { analyzer }\end{array}$ \\
\hline $\mathrm{CO}_{2}$ & $0-15$ torr & $0-8$ torr & $\begin{array}{l}\text { Lira } \\
\mathrm{CO}_{2} \text { sensor }\end{array}$ & $\begin{array}{l}\text { Varian gas } \\
\text { chromatograph }\end{array}$ & Detector tube & $\begin{array}{l}\text { Beckman 1R215 } \\
\text { infrared }\end{array}$ \\
\hline $\mathrm{H}_{2} \mathrm{O}$ & $0-100 \% \mathrm{RH}$ & $30-70 \% \mathrm{RH}$ & & $\begin{array}{l}\text { Varian gas } \\
\text { chromatograph }\end{array}$ & RH gage & $\mathrm{CO}_{2}$ analyzer \\
\hline $\mathrm{N}_{2}$ & $0-2000$ toxx & $1570-1600$ torr & & $\begin{array}{l}\text { Varian gas } \\
\text { chromatograph }\end{array}$ & Pressure gage & \\
\hline CO & $10-3000 \mathrm{ppm}$ & $0-15 \mathrm{ppm}$ & Detector tube & $\begin{array}{l}\text { Varian gas } \\
\text { chromatograph }\end{array}$ & & Detector tube \\
\hline Hydrocarbons & $1-5$ times & $\begin{array}{l}\text { See Spec. } \\
\text { TEK } 17-5001 \\
\text { (Navy) }\end{array}$ & Detector tube & $\begin{array}{l}\text { Varian gas } \\
\text { chromatograph }\end{array}$ & & Sample to G.C. \\
\hline $\begin{array}{l}\text { Freon } 12 \\
\text { and } 22\end{array}$ & $0-2000 \mathrm{ppm}$ & $0-1500 \mathrm{ppm}$ & Detector tube & $\begin{array}{l}\text { Varian gas } \\
\text { chromatograph }\end{array}$ & & \\
\hline Particulates & $0-100 \mathrm{mg} / \mathrm{m}^{3}$ & $0-25 \mathrm{mg} / \mathrm{m}^{3}$ & Air Sampler & & & Detector tube \\
\hline
\end{tabular}

Table 1. TEKTITE II Atmospheric Monitoring Parameters and Equipment

THERMAL CONTROL

The thermal control system maintained the atmospheric temperature and humidity, removing heat and excess moisture from the air. Four heat exchangers were used, one per compartment. Connected to each heat sxchanger was a blower for air circulation, a charcoal filter for odor 
removal, and an electrical reheater. The air was dehumidified by condensing water vapor on the heat exchanger coils, thus requiring reheating the air to the desired temperature of about $80^{\circ} \mathrm{F}$. Relative humidity was maintained between $45 \%$ and $55 \%$.

\section{EMERGENCY AIR SYSTEMS}

Emergency air systems provided were a surface air supply system, a purge system, a habitat emergency air supply system, a built-in breathing (BIB) system, and escape air bottles.

The surface emergency air supply was located at the surface support center and consisted of four 240-SCF (at 2200 psi) compressed air cylinders. This system served as a backup to the support center air compressors.

The purge system was designed to replace $90 \%$ of the habitat gas mixture with air within 4 hours in the event of major contamination and then equilibrate with nitrogen to the specified mixture. The system uses a 125-SCF/min, 100-psi diese1-driven air compressor and a nitrogen tube trailer located at the support center to supply gas to the habitat via the gas supply umbilical. In operation, air from the compressor would replace habitat air until gas sampling indicated that all contaminates had been removed. Nitrogen would then be introduced to the system to reduce the $\mathrm{PO}_{2}$ to within allowable limits. This procedure was followed on two occasions when electrical shorts occurred producing smoke. Normal atmospheric conditions were established shortly after each purge.

The habitat emergency air supply consisted of 23 240-standard cubic feet (SCF) compressed air cylinders in the habitat base. This emergency air supply could be activated by the crew in the event of normal air supply failure. The system was designed so that the emergency air would be introduced into the normal habitat air distribution system in the event of topside compressor or umbilical failure. In the event of atmospheric contamination within the habitat, the emergency air supply could be valved directly to the BIB system.

The BIB system provided 12 breathing stations within the habitat. In this mode, air was available for 12 hours duration. The line pressure to each BIB station was maintained at $100 \mathrm{psi}$, and demand regulator/ hose assemblies and face masks were attached at each station. Of the 12 BIB stations, 4 were in the crew quarters, 4 were in the wet room, and 2 each were in the bridge and equipment rooms. Each BIB had a hose long enough to reach the adjoining compartment.

Eight escape air bottles with regulators, hoses, and mouthpieces were available to provide capability to move about inside the habitat under conditions requiring $B I B$ breathing, and to escape from the habitat to the personnel transfer capsule. Each bottle had an 18-SCF capacity, 
sufficient for approximately 7 minutes breathing. Four bottles were in the crew quarters and two each were in the bridge and equipment room. None was required in the wet room since scuba gear stored there could serve the same purpose.

\section{COMMUNICATION, ELECTRICAL, AND SANITARY SYSTEMS}

The communications system (Table 2) provided voice and visual communication between the habitat and the support center. The bridge, which was the habitat communication center, was connected to the surface command facility via intercom and sound-powered phone. Each compartment was equipped with an intercom station connecting it with the other compartments and the surface, an open mike and closed-circuit television camera for the behavioral program, and audio and visual alarms. The bridge console could monitor the open mikes and the closed-circuit television cameras in each of the other compartments.

Electrical power was supplied to the habitat via a power cable contained within the umbilical bundle, from a variety of diesel generators at the surface support center. The habitat electrical system was a three-wire grounded system. The main power panel was located in the equipment compartment, and separate circuit breakers were provided in each compartment. Two flood valves were provided in the wet room, one at the hatchway level which set off a flood alarm, the other higher up on the wet room bulkhead tripped surface power when activated. Emergency battery-powered lamps in each compartment were activated when a power fialure occurred.

\begin{tabular}{|c|c|c|}
\hline PURPOSE & QUANTITY & HABITAT EQUIPMENT \\
\hline Behavioral data & 4 & TV cameras in habitat \\
\hline acquisition & 2 & TV monitors in habitat \\
\hline & 4 & Open microphones in habitat \\
\hline & 1 & Diver-in/out panel in wet room \\
\hline & 1 & $\begin{array}{l}\text { Crew activity monitoring switch set in } \\
\text { crew quarters }\end{array}$ \\
\hline Normal or & 1 & Sound-powered phone link in bridge \\
\hline emergency & 1 & Intercom system in habitat \\
\hline communication & 1 & Emergency alarm panel in bridge \\
\hline to shore & 2 & Warning bells and horn in bridge \\
\hline $\begin{array}{l}\text { Diver-to-diver } \\
\text { communications }\end{array}$ & 1 & Hardwire communication to way stations \\
\hline Entertainment & 1 & Commercial TV monitor \\
\hline & 1 & Commercial radio \\
\hline $\begin{array}{l}\text { Biomedical data } \\
\text { acquisition }\end{array}$ & $\begin{array}{l}4 \\
1\end{array}$ & $\begin{array}{l}\text { EEG electrodes and amplifiers in crew quarters } \\
\text { EKG recorder/amplifier in bridge }\end{array}$ \\
\hline
\end{tabular}

Table 2. TEKTITE II Communication System 
Fresh water was supplied through a hose in the umbilical bundle from the surface support center. The toilet was a salt water marine type which discharged through a 400-foot drain hose to the sea.

\section{ALARM SYSTEM}

The alarm system between the habitat and the surface support center is summarized in Table 3.

\begin{tabular}{|c|c|c|c|c|}
\hline \multirow[t]{2}{*}{ Sensor } & \multicolumn{2}{|c|}{ Habitat-Bridge Alarm } & \multicolumn{2}{|c|}{$\begin{array}{c}\text { Surface-Control-Center } \\
\text { Alarm }\end{array}$} \\
\hline & Visual & Audible & Visual & Audible \\
\hline $\mathrm{CO}_{2}$ partial pressure & Meter/1ight & Buzzer & Meter & - \\
\hline $\mathrm{O}_{2}$ partial pressure & Meter/light & Buzzer & Meter & - \\
\hline $120-V$ power loss & Light & Buzzer & TV & Speaker \\
\hline Entry trunk water leve1 & Light & Buzzer & TV & Speaker \\
\hline Wet room flooding & Light & Horn & TV & Horn \\
\hline
\end{tabular}

Table 3. TEKTITE II Alarm System

\section{SERVICE BARGE}

The service barge, referred to throughout the program as the "Pinafore," was a steel utility barge 45 feet long by 18 feet wide. It was moored to three concrete clumps and was located on the surface approximately 15 feet west of a point directly over the habitat. The Pinafore, acquired through surplus property listings from atop an oyster bar in South Carolina, provided outstanding service to the program, first as an equipment transport barge during the set-up phase, then as a work platform during ballast and emplacement of the habitat and laying of the umbilicals, and finally for umbilical recovery and site evacuation. During the operational phase, it served as the staging site for all materials and equipment transferred to and from the habitat. A hard-wire field telephone link between the Pinafore and the habitat wet room aided in coordinating transfers of personnel and material.

\section{DECOMPRESSION BARGE}

The primary decompression facility (Figures 5 and 6 ) was mounted on a pontoon catamaran decked over with 3/16-inch metal panels. Each pontoon was 50 feet long by 5 feet in diameter. The pontoons were joined on 20-foot centers by bolted transverse I-beams. When the catamaran was first assembled, the 4-inch transverse I-beams proved incapable of 


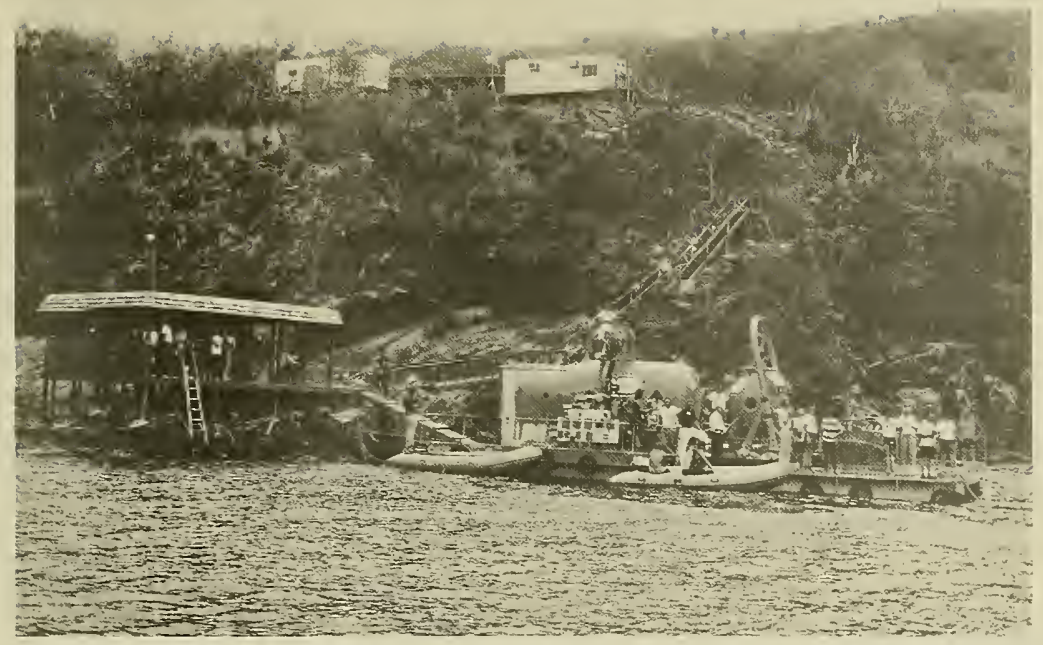

Figure 5. The Barge-Mounted Decompression Facility Moored Adjacent to the Dive Platform. The surface support center is shown in the top center of the Photograph.

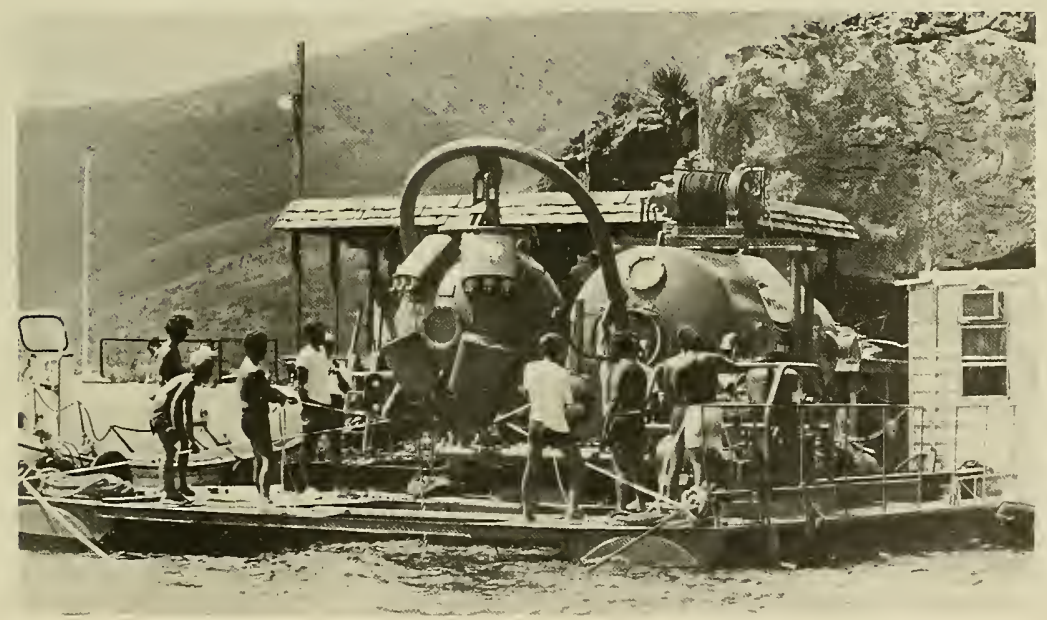

Figure 6, The Personnel Transfer Capsule (PTC) Being Mated to the Deck Decompression Chabmer (DDC) 
supporting the decompression complex and 10-inch wide lange beams were used as primary support members. The 25 by 50 foot catamaran deck area contained a 12 by 12 foot well through which the diving bell was operated. The water depth below the well at the mooring was approximately 25 feet.

The decompression complex consisted of a skid-mounted MK IV Personnel Transfer Capsule (PTC), a gantry handling system, a MK III Deck Decompression Chamber (DDC), designed and built by Reading and Bates, Incorporated, and a decompression console.

The PTC was a 66-inch diameter sphere with two double-door hatchways located on the bottom and side, the side hatch for mating and easy surface entry, the bottom hatchway for locking divers in and out. An umbilical attached through various penetrations contained compressed air, communication and gas sample lines. An on-board air and oxygen supply was available through high pressure bottles racked on the bell's exterior. Other equipment included internal and external pressure gauges, gas control valves, and a two-way communicator. The PTC was lowered and raised via a 7/8-inch strength cable.

The handling system consisted of an overhead pneumatic winch containing the PTC strength cable and a fairlead/alignment bracket attached to the underside of the gantry for raising and lowering of the PTC. The hydraulically operated gantry allowed fore and aft movement of the PTC from the deck well to a wheel track between the skids, positioning it so that hand winches could snub it against the DDC mating flange, where a tube-turn clamp allowed pressurized transfer into the DDC. A diesel driven air compressor with a capacity of $100 \mathrm{CFM}$ at 125 psi provided air to either or both locks of the DDC, the pneumatic winch, or two 200 SCF receiver tanks for storage. The hydraulic rams operating the gantry required 220 volt, 3-phase power from an external source.

The double lock decompression chamber consisted of a main chamber 12 feet in length, with a diameter of 84 inches. The outer chamber or entry lock was 5 feet in length, with a diameter of 54 inches. Side hinged pressure hatches are located at the entry lock end, between the entry lock and main chamber, and at the main chamber end. The main chamber has an extended flange with a tube-turn hub and tube-turn locking device, which is mated to a similar hub on the PTC flange for pressurized transfer of personnel. Pressurized transfer of personnel and supplies could also be accomplished through the entry lock into the main chamber. Several through-hull penetrations were provided for gas, water, and electrical lines. Each chamber lock contained adequate view-ports, oral-nasal masks for $\mathrm{O}_{2}$ or mixed gas input, two-way communicators, and overhead lights. The main chamber, shown in Figure 11, contained four bunks (the fifth crew member rested or slept on an air mattress in the aisle) and a coil 
and blower motor which were components of a small environmental control system located on the outside of the chamber. This unit provided temperature and humidity control during decompression. The outer lock contained a small pressure flushing commode and a fresh-water shower head.

The decompression console, along with certain gas monitoring equipment, was housed in a metal shed on one corner of the decompression barge. The shed was manned by a medical officer and chamber operator during each decompression event. The console contained the valving and gauges required for controlling pressure inside the PTC and either chamber of the DDC. It also contained the master unit for voice communication between the decompression station and the PTC or DDC. Gas monitoring equipment at the station included Beckman oxygen analyzers, carbon dioxide analyzers, and temperature probes. The $\mathrm{O}_{2}$ and $\mathrm{CO}_{2}$ analyzers monitored the atmosphere inside the chamber complex during decompression and, through a tee connection in the gas return line of the habitat umbilica1, provided redundant analysis of these same gasses in the habitat between decompression events. Rack-mounted cylinders of $\mathrm{O}_{2}$ and nitrogen were stored adjacent to the decompression station for use during the $\mathrm{O}_{2}$ phase of the decompression cycle and in the event a nitrogen purge was required.

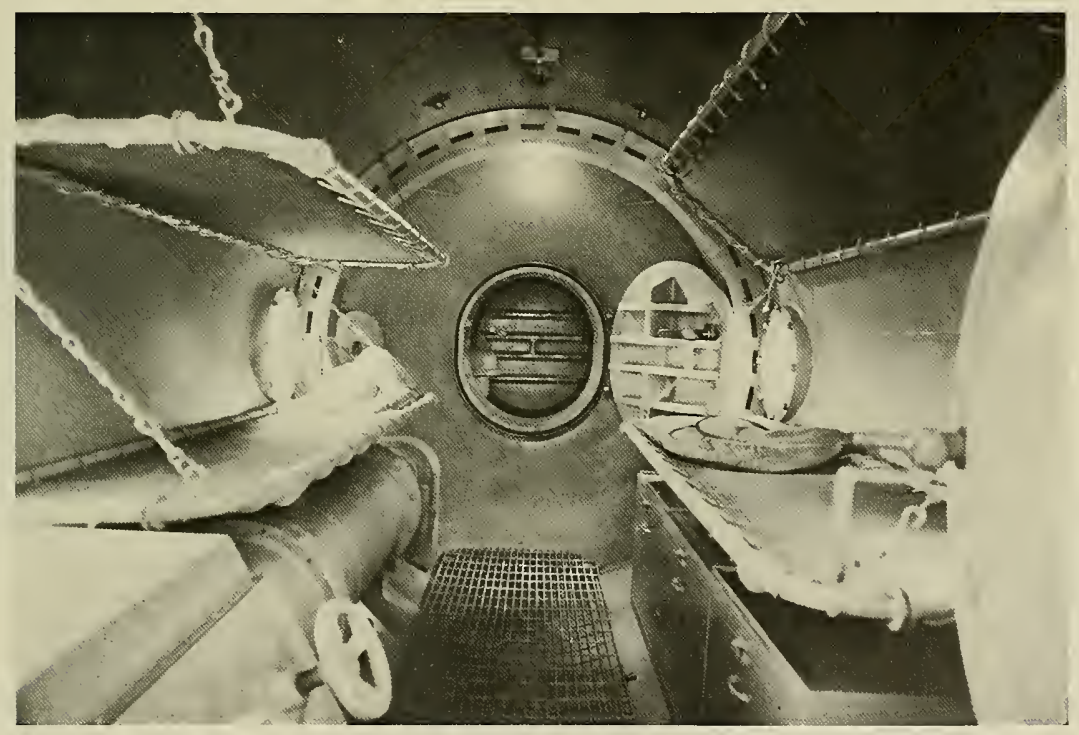

Figure 7. Decompression Chamber, Internal View 
The decompression barge received electrical power and a secondary lowpressure air source from the surface support center. The barge was moored to concrete clumps on the forward end and to steel cleats anchored in the rock outcrop supporting the dive platform on the after end, A gangway provided access between the barge and dive platform.

\section{DIVE PLATFORM}

The dive platform (Figure 8) was a roofed, wooden deck constructed on top of a large rock outcrop. It served as the duty station for the support divers and housed the dive locker or equipment area and a scuba charging compressor and air bank. A 60-foot steel girder bridge, over a surge channel, connected the dive platform to the wooden steps leading up to the surface support center, some 120 feet above the water line. Power, air, and communication lines from the surface support center were routed along the steps and bridge to the dive platform and to the decompression barge.

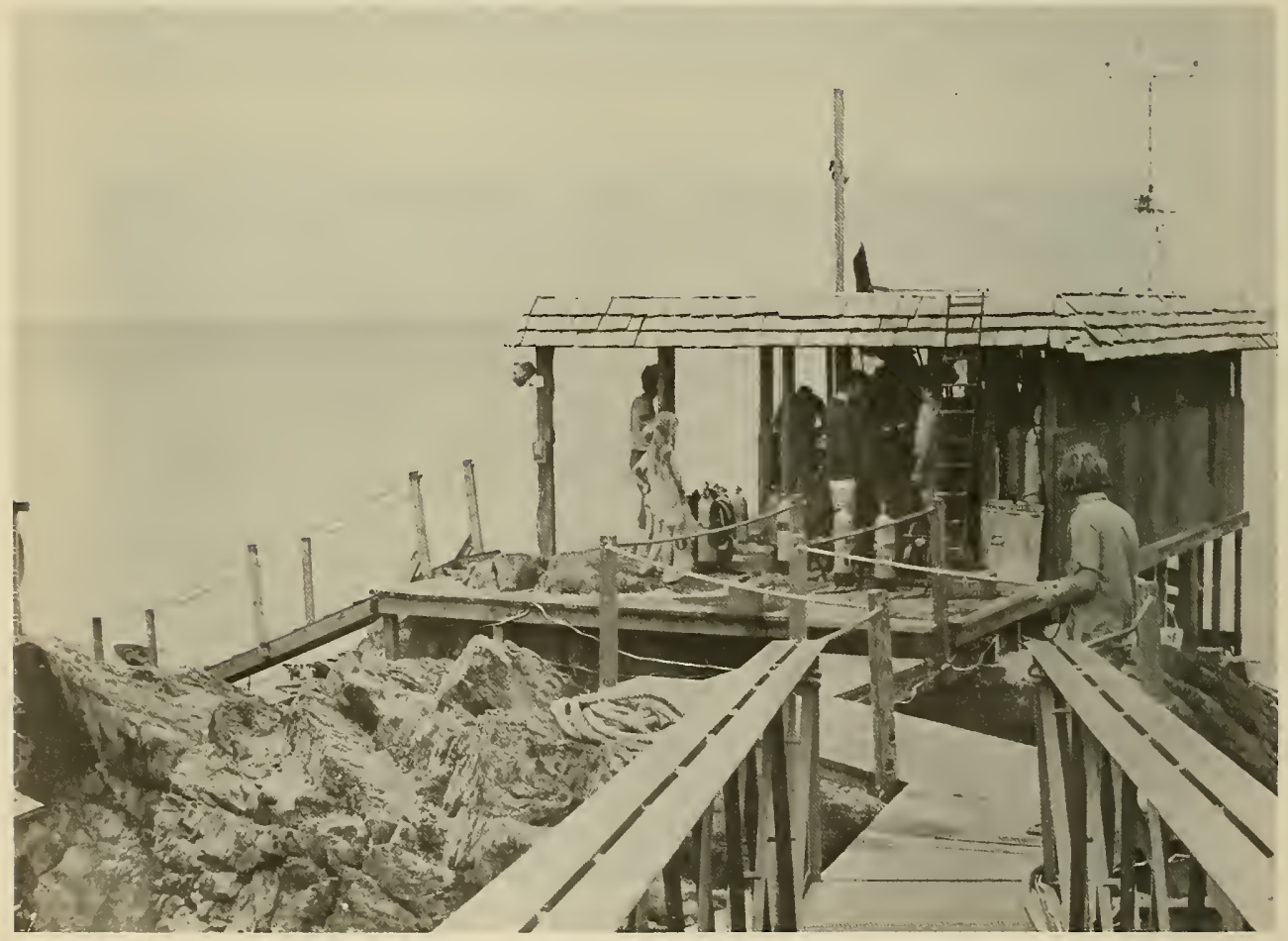

Figure 8. Dive Platform

II -12 
The surface support center was a cleared, partially filled area (Figure 9) containing the command van, the utilities trailer, a tube trailer, and a small parts trailer.

The command van layout (Figure 10) was a converted 30-foot semitrailer. It was divided into a watch director's section and a behavioral observer's section by a partition and an accordian door. The watch director's section was equipped to provide continuous monitoring of each compartment in the habitat by visual and aural means, and to provide continuous and intermittent monitoring of the habitat atmosphere and trunkway water level, either by gas analyzers or alarms. A control panel (Figure 11) contained: two television monitors which, through a selector switch, could be used to view either of the four habitat compartments; an intercom unit providing voice communication to each of the habitat compartments; a speaker output from the four open microphones in the habitat, which could be used by the watch director for certain specified monitoring functions; a remote readout from the habitat $\mathrm{O}_{2}$ and $\mathrm{CO}_{2}$ analyzers; an alarm panel. A sound powered phone on the watch director's bench provided voice communication to the habitat during power-outs.

A Varian Aerograph Model 1800 gas chromatograph located behind the watch director's station monitored $\mathrm{O}_{2}, \mathrm{CO}_{2}, \mathrm{~N}_{2}$, and several trace gases in the habitat. The gas sample was taken from the gas return line in the umbilical bundle, dried and analyzed.

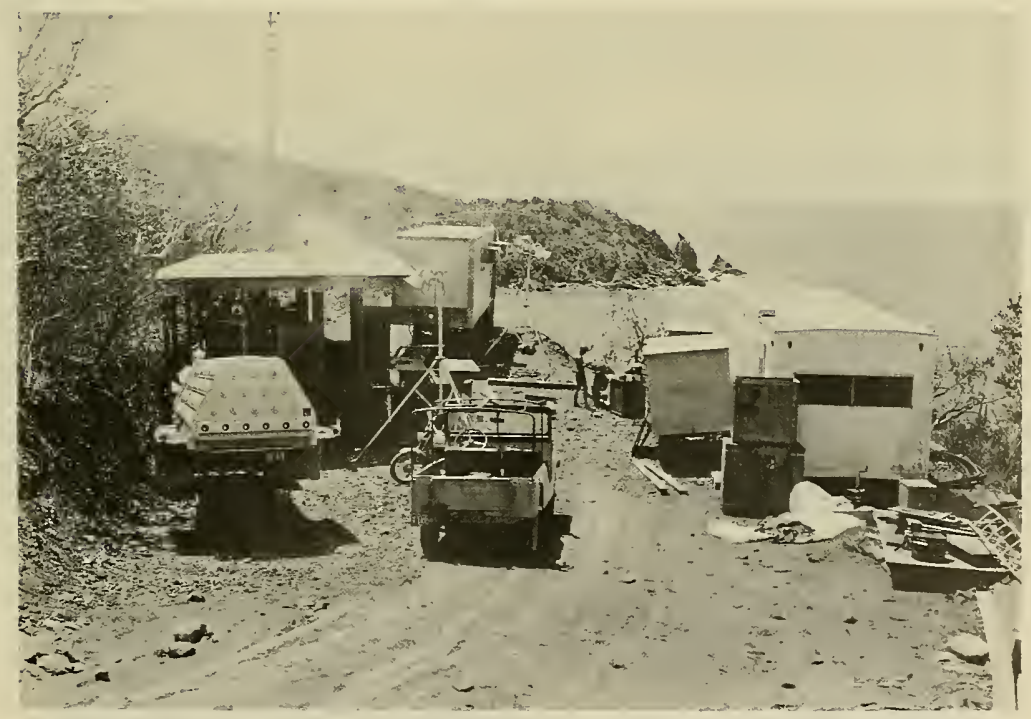

Figure 9. Surface Support Center 


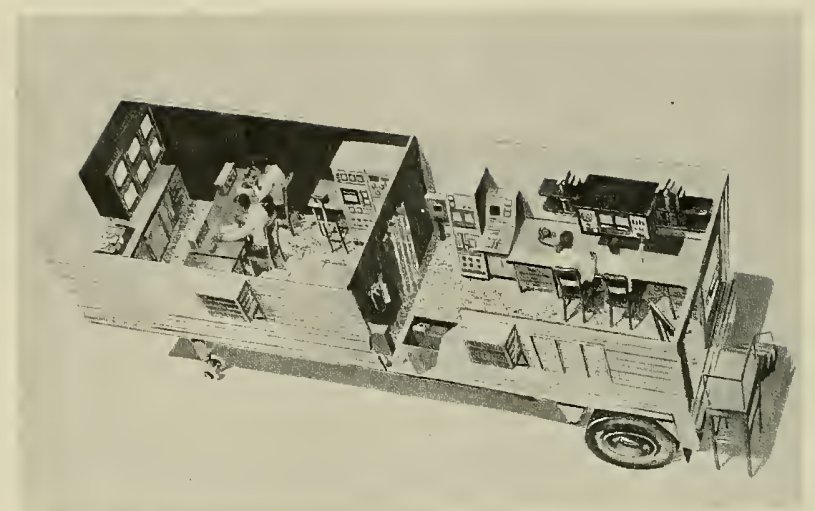

Figure 10. Command Van (Cutaway)

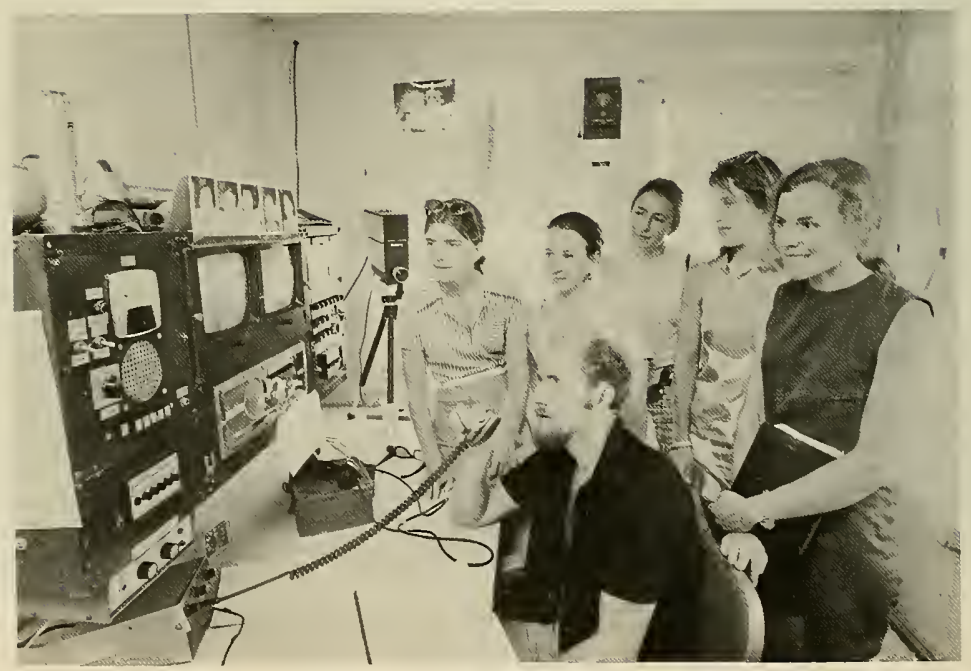

Figure 11. Command Van Control Console 
Additional communications equipment included: a hard-wire phone from the command van to the habitat crew quarters, which was used for private conversations; an FM transceiver providing two-way communication with identical units located at the base camp and both the public affairs office and administration office on St. Thomas; a hard-wire field telephone with interconnecting stations at the base camp; the causeway pier; and the dive platform.

A description of the audio and visual monitoring equipment and related instrumentation located in the behavioral observer's section of the command van can be found in the human behavior section of this report.

The utilities trailer shown in Figure 12 contained a variety of diesel generators providing electrical power to the command van, the dive platform-decompression barge, and the habitat. It contained a highpressure scuba charging compressor for the habitat charging station, a low-pressure, high-volume purge compressor which could provide purge air to the habitat or, through a tee connection, to the decompression barge as a backup low-pressure source. Redundant low-pressure, bellows-type compressors supplied the makeup air to the habitat at a rate of $30 \mathrm{SCFH}$. The trailer also contained step-down transformers for regulating the current to the habitat and a master panel of circuit breakers and switch boxes which permitted a choice of generator selection during normal shutdown or loss of power.

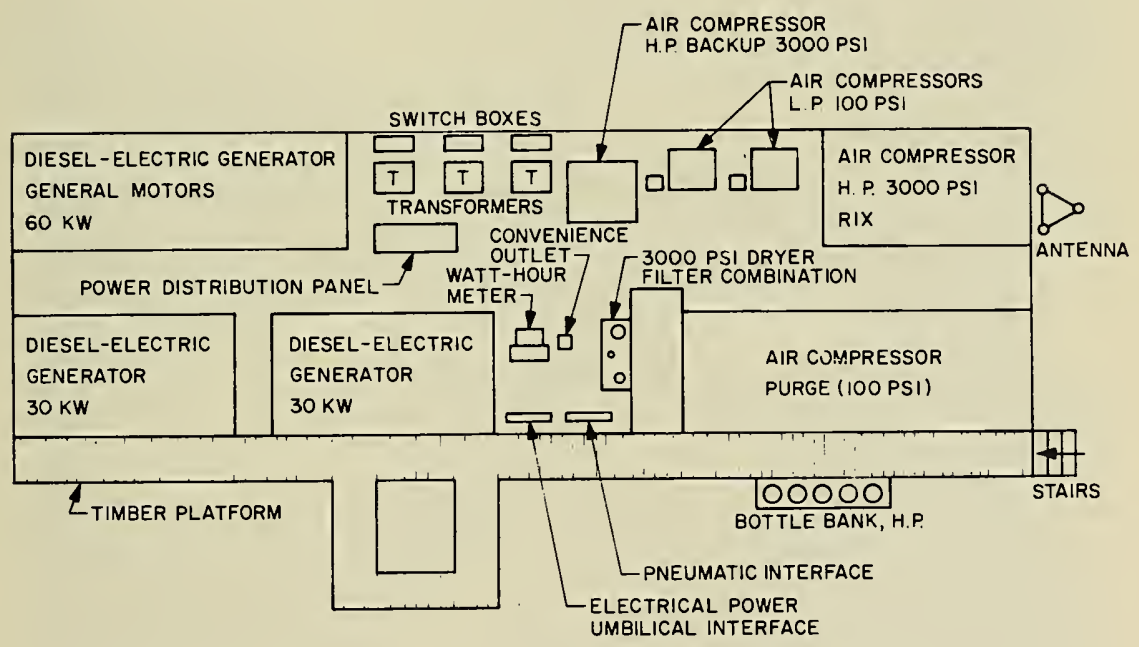

Figure 12, Utilities Trailer Layout

II -15 
The habitat fresh-water supply was stored in a 2,000-gallon tank at the surface support center. The fresh water was gravity-fed through a hose in the umbilical bundle to the habitat. Fresh water was trucked to the tank and chlorinated after each refill.

A small parts trailer adjacent to the fresh-water tank contained small spare parts for some of the utilities equipment and instrumentation.

The purge nitrogen for the habitat was stored in a 22,000 SCF tube trailer at the surface support center. The nitrogen was used to equilibrate the habitat atmosphere upon initial pressurization and remained on hand in the event further adjustment of the nitrogen-oxygen ratio was required.

Diesel fuel for the generators was stored in two 1,500-gallon tanks in a vehicle turning area up-grade from the support center. Resupply of the diesel fuel was normally carried out by pumping through a 700-foot run of rubber hose up the stairwell to the tanks from vessel or barge-borne fuel truck. The fuel was supplied to the generators by hand pump or gravity feed.

\section{CAUSEWAY PIER}

The causeway pier consisted of three causeway sections supplied by the Department of the Navy, each measuring 90 by 15 feet, joined together to form a pier, extending from the beach some 270 feet out into the bay. The water depth at the terminal end was approximately 26 feet. The pier served as the principal landing for all of the program small boats and the shuttle boat and larger vessels bringing supplies and personnel from St. Thomas. The pier was held by concrete moorings and anchors at the terminal end and at mid-length. A graded ramp was maintained at the shoreward end which was held in place by heavy lines attached to two 500-pound deadmen. The baralyme supply and the habitat spare parts were stored in two semi-trailer vans parked on an old road spur between the causeway pier and the main road between Lameshur Bay and Cruz Bay.

\section{BASE CAMP}

The base camp (Figure 13), which had been built a year earlier for the TEKTITE I program, was used as the principal accommodation facility during TEKTITE II. After the earlier program the camp was turned over to the College of the Virgin Islands, which managed it during the course of TEKTITE II. The camp was primitive, but quaint, consisting of 13 tropical huts with partial siding and screens. Several of the huts were connected for use as a kitchen-dining area, office-dispensary, and other special purpose uses. Toilet and shower huts were also available. Electricity for the camp was tied into the local power company line and proved to be fairly reliable. In cases of severe rains and storms, power was interrupted and the camp switched to diesel generators. Potable water was stored in two 10,000-gallon underwater tanks. Fresh water 
resupply was accomplished by pumping water from a surface vessel at the causeway pier, through approximately one-half mile of fire hose, laid along the road, to the tanks. This system worked reasonably well, when the ship appeared and when the fire hose wasn't riddled with punctures from marauding rats who seemed to thrive on the hose material. Although the fresh water supply was supplemented by rain runoff during squalls, salt-water bathing became fairly routine during periods when the tanks were dry.

Two of the more redeeming aspects of base camp living were the extremely pleasant and personable St. Johnian cooks and maintenance personnel who staffed the camp, and the camp social center. The social center, named "Hurricane Hole," was a small wooden structure made from packing crates, located behind the vehicle repair area. The walls and ceilings were covered with psychedelic art, done with multicolored phosphorescent paint, which was quite attractive under black light. Packing crate seats and Playboy centerspreads completed the decor. The establishment was "managed" by off duty support personnel. The drink list offered a wide variety of liquor types but you were always served rum, which was very inexpensive in the area. The most popular rum served was, in fact, much less expensive than the brand name mosquito sprays, which were always in short supply. The rum most certainly was not effective as an insecticide but it did make the mosquitos less objectionable.

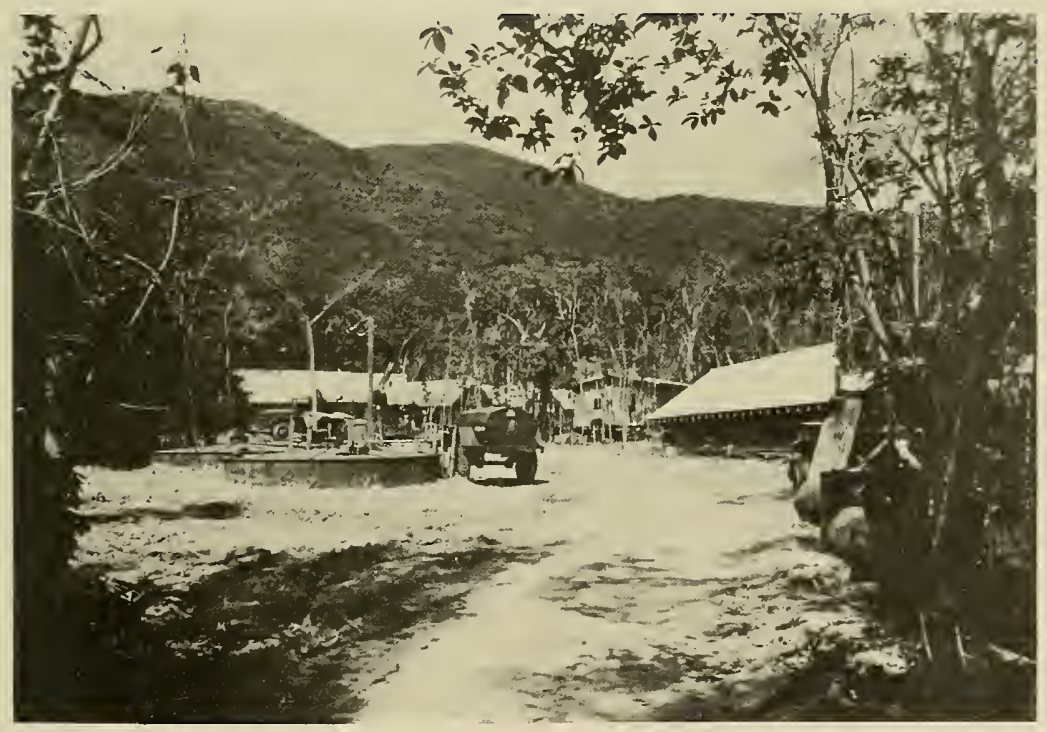

Figure 13. Base Camp 
Communications at the base camp consisted of two hard-wire field telephones, linked to the command van, the dive platform, and the causeway pier. An FM transceiver provided voice communication with the command van and to the two facilities on St. Thomas. A battery powered alarm bell in the base camp could be activated in the command van by depressing the "panic button," as it came to be known. The commercial telephone into the base camp routinely malfunctioned with each rain and was only about $50 \%$ reliable.

\section{PUBLIC RELATIONS OFFICE}

The public relations office was located at the National Park Service facility at Red Hook, St. Thomas. The office was staffed by the Public Relations Director for TEKTITE II, a receptionist, and several public relations officers who were detailed intermittently throughout the program. The structure was a 55 by 10-foot office trailer on lease from a local firm for the duration of the program. Although not originally scheduled as such, the public relations office served a vital link in the program communications network during telephone blackouts at St. John. It was anticipated that the commercial telephone into the base camp on St. John would malfunction occasionally, but it never occurred to us that it would be out of service each time it rained. For those unfamiliar with the climate in the Virgin Islands, the annual rainfall is considerable, occurring principally at the beginning of the year. After the first few telephone blackouts, an FM transceiver was installed in the public relations trailer which permitted communications between Red Hook, the Sapphire Bay administrative office, and the command van at Lameshur Bay. Messages from either location on St. Thomas to base camp were relayed via the command van radio. In this way, weather reports and other traffic could be maintained at the operational site. This system worked reasonably well except when commercial service was out at the two St. Thomas facilities because of rain.

\section{ADMINISTRATIVE OFFICE}

The program administrative office was located in a condominium apartment at Sapphire Bay on St. Thomas. It was staffed by the Program Manager and a secretary. The office handled the administrative aspects of the program and maintained a communication link with St. John via an FM transceiver and commercial telephone. 
OPERATIONS

Richard A. Wa11er

Department of the Interior

Washington, D. C.

\section{INTRODUCTION}

The operational phase of TEKTITE II consisted of: the various tasks necessary to maintain and support an underwater habitat and its rotating crews of scientists and engineers; the training and housing of the aquanaut crews and program support personnel; adequate procedures to insure the safety and we11-being of program personnel and site visitors; and, related activities associated with logistics, transportation, and communications.

This section will treat each of these tasks in order and will also describe other tasks including site preparation, installation of major equipment, and site evacuation.

\section{SITE PREPARATION}

The operational site for TEKTITE II was Great Lameshur Bay, St. John, U. S. Virgin Islands, the same site as had been used during the TEKTITE I program a year earlier. The principal difference was that a shore-based surface support center was used instead of the barge-mounted center used in the earlier program. The shore-based facility required the construction of a narrow road to the support site overlooking Beehive Cove, clearance of the site, the construction of a stairwe11 leading down 100 feet to the cove, and the construction of a bridge and dive platform which provided access to the decompression barge. Construction of these particular facilities was undertaken by the Government of the Virgin Islands during January and February 1970. Throughout this same period, the base camp, which had been turned over to the College of the Virgin Islands after TEKTITE $I$, was being prepared for program use under a contract with the Virgin Islands Government.

The initial contingent of support personnel, a group of diver technicians from Highline Community College, arrived on site February 15, 1970 . Work was begun shortly thereafter in the placement of 5-ton and 3-ton concrete clumps for mooring purposes in several strategic sites within Lameshur Bay. The clumps had been deposited in the Bay in January 1970 by the U. S. Coast Guard Cutter SAGEBRUSH, a Buoy Tender, operating out of San Juan, Puerto Rico. These clumps served as moorings for the ballast barge, causeway pier, the habitat (holding site), emplacement barge, and the decompression barge. These pre-mission sites are identified in Figure 14. Some of the clumps were later shifted to new locations after ballasting and emplacement of the habitat was completed. 


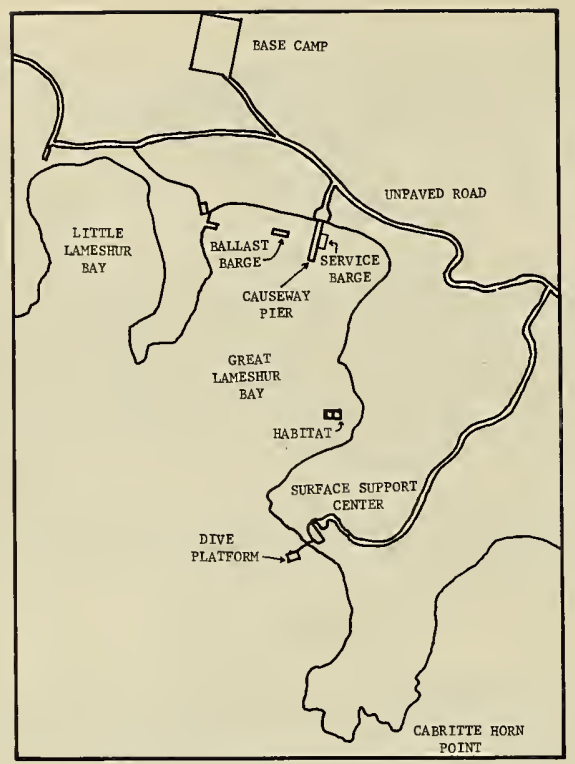

Figure 14. Pre-Mission Sites

\section{OFFLOADING AND EMPLACEMENT}

The U.S.S. PLYMOUTH ROCK, a U.S. Navy Landing Ship Dock (LSD), arrived off Lameshur Bay on the morning of March 7 and after ballasting down, commenced offloading. Another landing craft operated by the National Park Service served in a standby capacity.

The habitat, with six attached salvage pontoons providing additional buoyancy, was floated out of the LSD well deck and towed to its holding site (Figure 15). Two married causeway sections, loaded with vans, trailers, and vehicles, were then towed into the head of the bay to form a pier. One end was beached and ramped while the seaward end was moored to pre-positioned concrete clumps. (Note: After the causeway sections were unloaded, the shoreward end was pulled higher on the beach and lines extended out from each corner to two deadmen located behind the berm.) Additional barges, containing ballast, umbilicals and ancillary equipment were offloaded and moored at locations designated in Figure 14. As subsequent barges were being offloaded and positioned, a D-6 Caterpillar tractor, furnished by the Virgin Islands Department of Public Works, began the staging and distribution of the vans and trailers to designated sites. The only incident during the otherwise routine operation occurred when the tractor, with the heavily loaded utilities trailer in tow, was unable to overcome the steep grade leading to the surface support center. 
This rather critical slowdown occurred in mid-afternoon completely blocking the only traffic artery between Lameshur Bay and Cruz Bay. The problem was remedied when another Public Works tractor was borrowed, transported via one of the landing craft, and hooked in tandem with the stalled tractor. With hand flashlights lighting the way, the balky trailer was positioned at the surface support center late that night. The additional vans and trailers were positioned the next day and their installation and integration with other support facilities and equipment began.

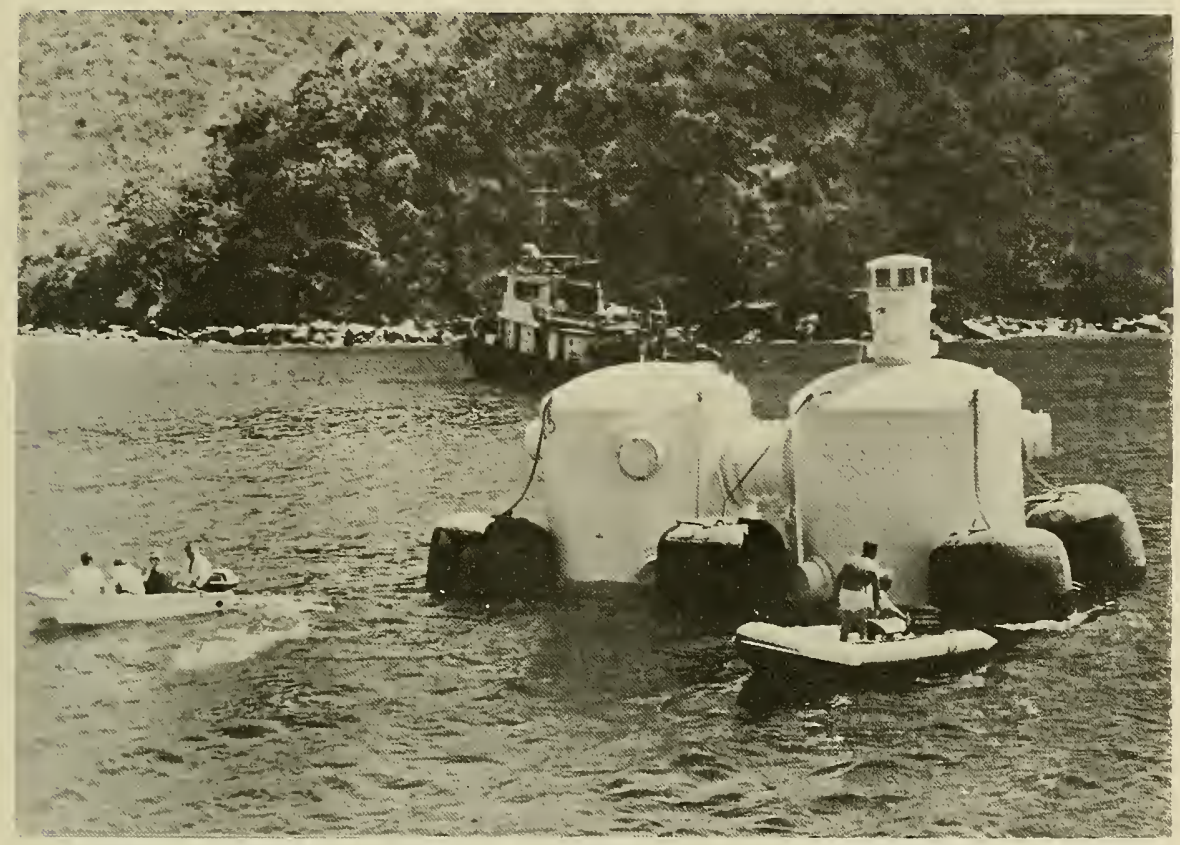

Figure 15. Habitat Moored at Ballasting Site Being Supported by Six 8.8 Ton Salvage Pontoons

\section{HABITAT BALLASTING}

Habitat ballasting operations began on March 16 on a rather disconcerting note. The ballasting procedure specified in the planning documents called for some type of lifting device to be installed on the service barge to handle the individual 54-gallon steel drums containing the 160,000 1bs. of steel punchings required for proper emplacement buoyancy. Such a device could not be located in the Virgin Islands, and in order to maintain the tight schedule, it was decided to hand load the ballast. The salvage 
pontoons were removed and the habitat shifted from the holding site to the ballasting site and moored tightly to prepositioned concrete clumps. Some $50,000 \mathrm{lbs}$. of ballast was transferred from the third causeway section onto the service barge and warped alongside the habitat. A flexible 4-inch pipe was then inserted into the habitat base and the opposite end lashed to the side of the service barge. The individual drums, each weighing about $1,800 \mathrm{lbs}$. , were then over-turned and the punchings shoveled into the pipe (Figure 16). The flexible metal pipe was sized to reach the base in the final ballast stage and consequently was too long in the initial ballast stage, requiring considerable separation between the barge and habitat. The weight of the punchings created a catenary in the pipe requiring constant adjustment of the warps and rigging. The ballasting procedure was made more difficult owing to the service barge having to be constantly shifted to new positions in order to load the ballast holds sequentially to maintain trim. By day's end, less than 10,000 1bs. of ballast had been loaded. The effects of the exertion and the frustration over how the setback might delay the schedule was evident throughout the group of young diver technicians, many of whom were badly sunburned due to exposure on the open barge. During the succeeding two days, however, out of sheer determination on the part of these support divers and the capable seamanship of their supervisor, the remaining 150,000 lbs. of ballast was hand loaded, completing the task which for a while, at least, had seemed almost insurmountable. Other similar feats accomplished by this particular group were almost commonplace during the preparation phase of the program.

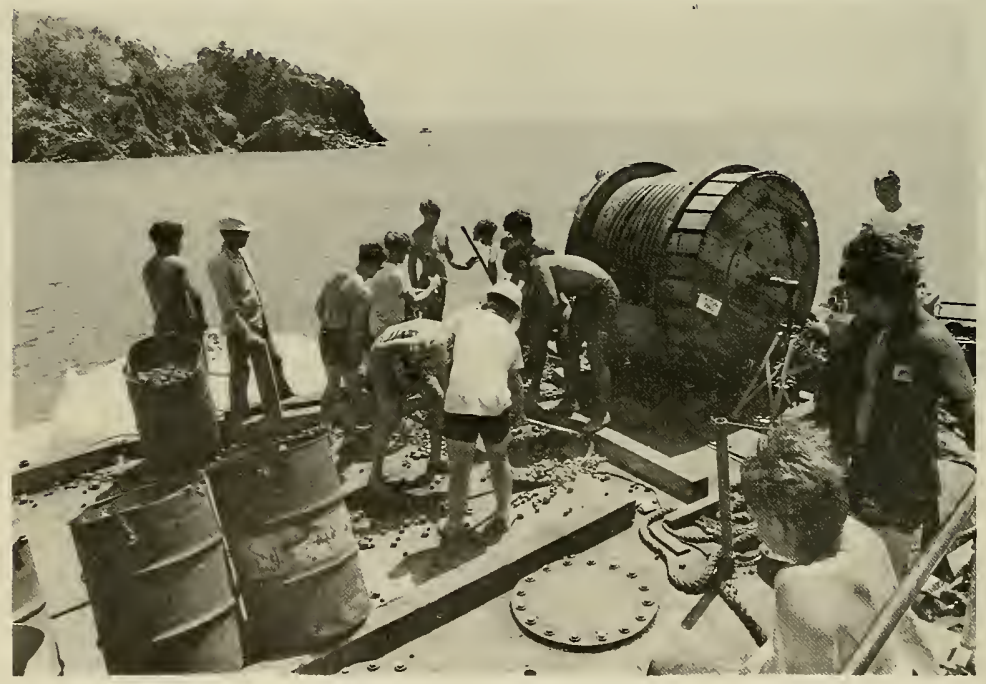

Figure 16. Drums of Ballast on Deck of Support Barge Being Shovelled into Tube Leading to Ballast Chambers in Base of TEKTITE II Habitat. 
With ballasting complete, the habitat had a reserve buoyancy of 5,000 1bs. It was then towed to the emplacement or experiment site and moored to four deadmen. The deadmen were steel bins, each filled with approximately $3,000 \mathrm{lbs}$, of iron pigs, adjacent to the four corners of the leveled habitat site on the ocean floor. The following day the internal pressure of the habitat was increased to $20 \mathrm{psig}$ and emplacement begun. Hand winches were attached between the four deadmen and the four corners of the habitat base and winching started, with equal tension applied to each cable during the downhaul process. This task was aided by the use of simple inclinometers attached to the habitat. When the habitat was suspended a short distance from the bottom (Figure 17) the hard ballast tanks in the base, exerting some 5,000 1bs. of buoyance, were flooded, allowing the habitat to settle on the bottom. Approximately 20,000 1bs. of iron pigs were then hand loaded into ballast trays on top of the base, securing the habitat firmly to the bottom.

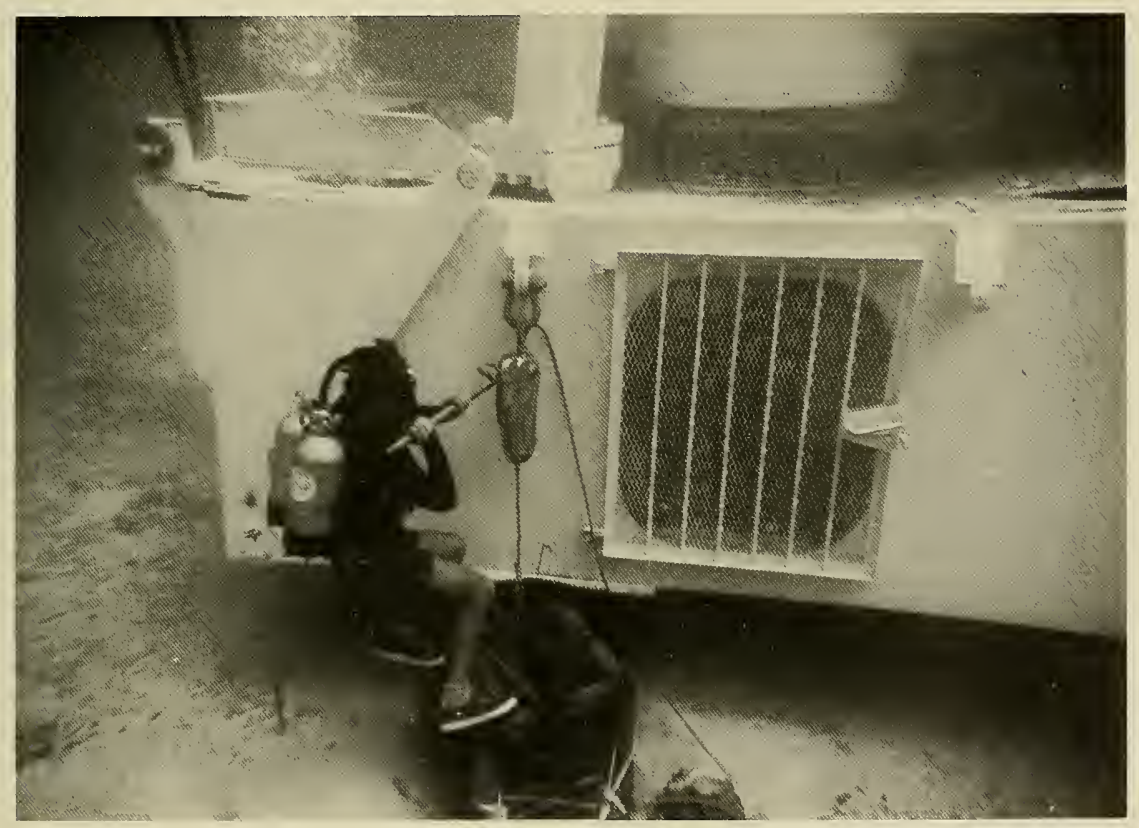

Figure 17. Final Stage of Hauldown

The various umbilicals were laid and hooked up individually. The small high pressure air line was completed first in order to maintain the internal pressure of the sealed habitat had it become necessary. The 
heavier power and communication cables were mounted to brackets on the barge. The service barge was maneuvered into a position just below the surface support center site, lines passed down the 100-foot high cliff face and attached to the terminal end of the power umbilical. Hand winches were used to haul the cable up to the support site where it was secured to holdfasts and connected to appropriate terminal boards on the utilities trailer. A polypropeline line connected between the service barge and the base of the habitat some 700 feet away was taken up, allowing the power umbilical to unreel and lay along a designated path along the bottom. The same procedure was used with the communication umbilical except that terminal pairs were connected to communication's terminal boards in the command van. The habitat ends of both umbilicals were waterproofed and lowered to the bottom. After opening the habitat, the cables were fed through a benthic tube in the wet room bilge and connected to appropriate terminal boards and instrumentation. The laying and hookup of the fresh water, purge gas, and gas return lines was accomplished in much the same manner using small boats and swimmers.

\section{DECOMPRESSION BARGE ASSEMBLY}

While these activities were taking place, the decompression barge was being assembled on St. Thomas. The barge had arrived from Houston, Texas, unassembled on two Air National Guard aircraft. The components were unloaded and trucked to a waterfront site a few miles from the airport for assembly. After the barge assembly was completed and the barge afloat, the decompression systems described in the facilities section was lifted aboard by crane. At this time it was discovered that the main strength members connecting the two pontoons were insufficient to support the weight of the chamber system by a factor of almost $50 \%$. Larger steel beams were obtained from a local contractor and welded together to form a support base adequate to support the decompression system. This major problem was resolved on March 28 by working a small crew almost round the clock for three days only to discover that the decompression console, a critical component of the system that had been scheduled to arrive on the 28 th would not arrive until the 31 st of March, one day before the scheduled mission start. A very brief consultation between the principal management personnel resulted in a decision to postpone the mission start. The Program Manager assumed the responsibility of issuing a press announcement and informing certain dignitaries who had arrived for the dedication ceremony, among them the then Secretary of the Interior, Walter J. Hickel, of the delay.

On March 31, the decompression console arrived from Houston, Texas, and installation and hookup was started on April 1, while the dedication ceremony was taking place at Lameshur Bay. The decompression complex when completed on April 4 was towed over to Lameshur Bay and moored in its designated site. Final installation and familiarization proceeded through the remainder of that day and into the following day before a low pressure leak was discovered in the mating made between the PTC and DDC. This problem was remedied early in the morning on April 4, allowing the 
Normal Mode - The assignments of duty personnel during routine operations are shown in Table 4.

Command Van

Watch Director

Engineer (contractual)

Behavioral Observers

(2 day, 1 night)
Dive Platforms

Chamber Operator

Asst. Chamber Operator

Support Divers (2)

\author{
Base Camp (on cal1) \\ Operations Director/Asst. Operations Dir. \\ Safety Officer \\ Diving Supervisor \\ Medical officer \\ Utilities Technician
}

\title{
Table 4. Assigned Duty Personnel
}

During each eight-hour duty period, the watch director was the designated supervisor of all on-duty personnel at the command van and the dive platform. He also supervised habitat operations. Supervision of the aquanauts while they were in the habitat was the responsibility of the crew leader who saw to it that they adhered to established procedures and operational directives in force. The aquanauts planned and scheduled their own activities. The watch director authorized routine excursions from the habitat when conditions were normal and apprised the duty support divers of the area to be monitored during such excursions. He served as a single point of communication between the surface and the habitat, maintained a current $\log$ of weather reports, and coordinated all activities affecting the surface support center, the dive platform-decompression barge and the habitat. Upon completing a duty period, he would brief the oncoming watch director of the status of the operation and notify the operations director of any important or unusual events.

The watch engineer, provided under contract from the General Electric Company, assisted the watch director with communications activities, maintained a $10 \mathrm{~g}$ on all habitat related system and support utilities, and was available to advise the aquanaut-engineer or watch director of any malfunction in the habitat system. (See section on habitat engineering.) 
operational phase of the program to begin when the first team of aquanauts occupied the habitat at 1:30 p.m. Table 5 shows a chronological sequence of significant events leading up to the start of the first mission.

3-7-70 LS arrived; offloading and distribution of vans
trailers, and other equipment.

3-8-70 Completion of van and trailer distribution. Began installation and integration of surface support center.

3-16/18-70 Habitat ballasting operation carried out.

3-18-70 Unloading and commencement of assembly of DDC barge which arrived on two C-124 Air National Guard aircraft.

3-19-70 Emplacement of habitat.

3-20-70 Installation of Umbilicals.

3-20/28-70 Habitat checkout.

3-26-70 Decompression facilities arrive at St. Thomas.

3-28-70 Modification and strengthening of DDC barge; Air National Guard flight scheduled to arrive with DDC equipment cancelled; Mission 1-50 postponed.

3-29-70 Completed modifications to DDC barge.

3-31-70 DDC console arrived three days late from Houston, Texas.

4-1-70 Program dedication on St. John; decompression barge completed on St. Thomas.

4-2-70 DDC barge tow began at 0500 against $6-8$ foot seas. Tie-up at Lameshur Bay causeway pier at 1000 after three breakdowns with locally leased tug with Spanishspeaking Captain who thought the barge's destination was Tortola, British Virgin Islands, and almost couldn't be talked out of that concept. Upon arrival at Lameshur Bay, the Captain in an effort to recover a hand-held radio repeatedly rammed the causeway with his tug.

4-3-70 Crew familiarization and shake-down of decompression system. A low-pressure leak in the mating flange was noted. Problem finally resolved at 0300 the following morning by shimming the PTC track with one-half dollar coins.

4-4-70 Begin Mission 1-50 at 1330 hours.

Table 5. Significant Events During March and Early Apri1 
The behavioral observers recorded pertinent data on the aquanauts via closed-circuit television monitors and audio equipment located in the behavioral sections of the command van. (See section on Human Behavior Program.)

The support divers were in a constant state of readiness on the dive platform. During each excursion from the habitat by the aquanauts, two support divers manned an outboard powered rubber boat, equipped with scuba gear for the support divers and emergency scuba gear for the aquanauts. The support boat was normally positioned over the aquanaut work area and upon receiving any one of three emergency signals, the support divers were instructed to dive down to the aquanauts carrying spare scuba gear.

Two support divers were stationed on the decompression barge when aquanauts were outside the habitat, ready to operate the PTC/DDC system in an emergency. Between aquanaut excursions, the support divers maintained the decompression complex and carried out drills simulating the various emergency conditions. The drills were conducted by the diving supervisor under both scheduled and unannounced conditions.

The operations director or designated director was on-site during each watch period. He coordinated all site activities, determined that support facilities were in a constant state of readiness, and in emergency conditions assumed full command.

The safety officer made frequent inspections of the facilities, observed emergency drills and routine operations, and advised the operations director and program manager of safety considerations or problems.

A medical officer, on call at the operational site, served as the physician for all support personnel, assured that health standards were maintained in food preparation and potable water supplies. He made daily observations on the medical status of the aquanauts. The medical officer was responsible for both normal and emergency decompression events.

The diving supervisor was responsible for the diving training and checkout of all support divers and aquanauts. He enforced diving regulations at the operational site and was responsible for underwater tasks related to the operation.

The utilities technician maintained the generators and related equipment insuring that adequate supplies of fuel and lubricants were on hand. He performed repairs and upkeep on support boats and vehicles and life support utilities at the surface support center.

In the event of an emergency, the behavioral observers were to report to the watch director for assignment to the communications console, the decompression barge, or as additional support divers, since all were qualified divers. 
Each team of aquanauts underwent crew training at the operations site with the exception of the habitat engineering training which had been completed earlier in Philadelphia, Pennsylvania. The on-site training included a diving checkout and physical examination, closed-circuit scuba training, habitat diving procedures and regulations, closed-cycle rebreather training, familiarization with decompression facilities, and general program orientation. (see training section)

One aquanaut was designated crew leader on each team. The crew leader was the primary point of contact with the watch director and was responsible for establishing habitat priorities and the daily excursion schedules. Each individual aquanaut was responsible for maintaining his own scuba gear, both open and closed-circuit, and related swimming and navigation equipment.

Before each excursion from the habitat, which always consisted of two or more swimmers, the aquanauts would inform the watch director of their work area and the anticipated duration of their dive. Each swimmer went through a pre-dive checkout of his gear and logged out with the watch director. In the case of excursions with closed-circuit gear, the pre-dive checkout was more extensive requiring each aquanaut to pre-dive his own equipment, then his partners, verbally calling out the checklist items to the watch director who logged checklisted items and observed the pre-dive check on closed-circuit television.

The aquanauts carried three emergency signaling devices. They were: A sma11 $\mathrm{CO}_{2}$ inflated float for daytime use; a flashing strobe light for night use; and, a sonic pinger which could be monitored through a receiver located under the dive platform. The emergency procedure called for the pinger to be activated first, followed by the release of a float in daytime or activation of a strobe flasher at night to guide the support divers to the aquanauts. The sonic pingers were very effective attention getting devices which caused several unintentional alerts throughout the course of the program by accidental triggering of the magnetic switches. Several aquanauts were more than a little surprised in their ocean floor research tasks to be confronted with a pair of support divers trying to give them scuba gear they didn't need and offering to lead them back to the habitat before they were ready to leave. While surprising, this quick response was very comforting to the aquanauts.

The aquanauts, particularly the engineering team member, maintained calibration and readings for the $\mathrm{PO}_{2}$ and $\mathrm{PCO}_{2}$ monitors in the habitat. Additiona1ly, they sampled and tested for trace gases at scheduled intervals. The team engineer kept a $l o g$ on the $\mathrm{PCO}_{2}$ levels and insured that fresh cannisters of baralyme were changed as needed. 
The aquanauts held walk-through emergency drills intermittently and were thoroughly briefed on procedures to follow in the event of fire, contamination, or flooding.

Only two emergencies occurred throughout the seven month operation. At the end of the first mission, just as the aquanaut team was preparing to leave the habitat and swim to the PTC, power surge overloaded a small motor creating smoke and fumes from the burned windings. After reporting the condition to the watch director, the team was ordered to depart for the PTC leaving the resolution of the problem to a repair team from the surface.

The second emergency involved a hurricane alert. The strength and directional trend of the hurricane necessitated a decision to prematurely decompress one aquanaut team. Within an hour or two after decompression was complete, the hurricane had veered to the west and the team was allowed to dive back down to the habitat with hardly a chance for a cigarette or whatever else they craved the most.

The greatest single problem during the program was that created by inadequate power generation equipment.

The problems associated with the generators were the result of assembling a variety of borrowed, leased, and surplus acquired diesel generators, and attempting to maintain them in an isolated part of the world.

Other problems, in retrospect, were minor largely due to the outstanding support personnel who participated in the program and the fine effort on the part of the aquanauts.

\section{LOADING AND EVACUATION}

The loading and evacuation process was generally a reversal of the offloading and installation phase with one exception. It appeared that there was twice the amount of material than we had arrived with, and there possibly was with the Air National Guard airlift that had been active for seven months plus the Coast Guard shipments.

The vans were removed from the support center without difficulty since the roads were by no means dry as they had been at the start. The support equipment was loaded and secured on the causeway sections, the service barge, and the decompression barge after the decompression system was offloaded in St. Thomas for air shipment. The umbilicals were recovered and loaded and the habitat raised and floated at its initial holding site. 
Dismantling and cleanup of the site took longer than expected because of a high incidence of "more pressing business elsewhere" by a11 but the hard-core group from Highline Community College and the group of divers from the Department of the Army who had supplemented the support diving crew.

All major tasks were complete when the LSD PORTLAND COURT with a green crew, a very knowledgeable captain, and a capable loading officer ballasted down at 1100 on November 21,1971 , completed loading at 1500 on the same day, and set sail for Philadelphia.

The overall mission schedule is shown in Table 6.

$\begin{array}{lll}\text { MISSION } & \text { MISSION DATES DURATION }\end{array}$

\begin{tabular}{lll}
\hline $1-50$ & April 4 to April 17 & 13 full days \\
$2-50$ & April 22 to May 12 & 20 full days \\
$3-50$ & May 12 to June 1 & 20 full days \\
$4-50$ & June 1 to June 20 & 20 full days \\
$6-50$ & July 6 to July 20 & 14 full days \\
$8-50$ & July 23 to August 12 & 20 full days \\
$10-50$ & August 12 to September 2 & 19 ful1 days \\
$12-50$ & September 2 to September 22 & 17 full days \\
$15-50$ & September 25 to October 12 & 14 full days \\
$17-50$ & October 15 to October 29 & 6 full days \\
$18-50$ & October 31 to November 6 & \\
\hline
\end{tabular}

Table 6. Mission Schedule 
John B. Tenney, Jr.

General Electric Company

\begin{abstract}
This report describes the engineering and field support role of the General Electric Company during the TEKTITE II program. Initial activities include planning and habitat refitting in Philadelphia. Habitat engineers were trained during this period. Work in conjunction with habitat emplacement and startup is described. After the habitat became fully operational, a field support team provided a 24-hour watch on the habitat. Between scientific missions, maintenance tasks were performed and the habitat was secured and recovered upon completion.
\end{abstract}

\title{
PLANN ING
}

Engineering planning activities for TEKTITE II were initiated immediately from the beginning of the program. Technical plans drew heavily upon the experience gained during TEKTITE I. During this precursor program, described in References 1, 2, and 3, the same habitat structure was used to support a 4-man crew for 60 days. As a result of this successful first mission, some changes were required both in system hardware and in program operational procedures. Several of the technical plans prepared for the Department of the Interior were incorporated into their inclusive Program Plan (Ref. 4). These included:

Habitat Emplacement Plan

Habitat Safety Plan

Public Affairs Plan

LSD Loading and Unloading Plan

Other technical planning documents which were prepared included:

Habitat Refurbishment Specifications

Field Operational Support Plan

Habitat Engineers Handbook

Emplacement and Startup Checklist

Refurbishment Checklist

Recovery Checklist

Atmospheric Monitoring Specifications

Maximum use was made of information and experience gained on TEKTITE $I$, and the amount of technical software required was considerably less than for the previous program. Many of the key technical personnel from TEKTITE I were available for TEKTITE II, and this increased efficiency during the planning phases. One area of vital concern during the planning stages was habitat safety. Detailed safety planning considered a wide range of credible accident conditions and identified procedures and techniques to respond in all cases. A discussion of TEKTITE safety planning is contained in Ref. 5. 
Refitting of the TEKTITE habitat was accomplished at the Philadelphia Naval Shipyard. This work included routine chipping, painting, and replacement of corroded parts which had been exposed to sea water in the previous program. Structural modifications were made to the habitat base to permit an alternative emplacement method. Lifting lugs were also added to permit the habitat to be more rapidly positioned inside the LSD. These lifting lugs are shown in Figure 19.

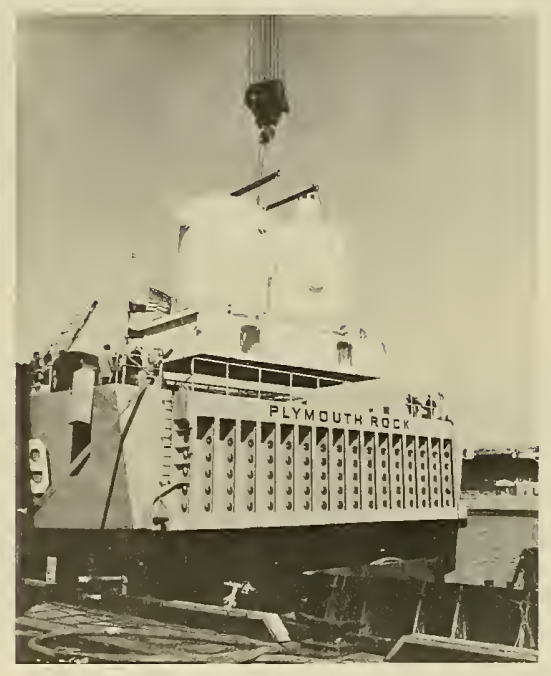

Figure 19. TEKTITE Habitat Being Lifted into the LSD

In addition, several improvements and changes were required based upon recommendations from the preceding program. Among these were the slight changes required to accommodate a fifth crew member and the considerable changes necessary to increase the efficiency of the carbon dioxide $\left(\mathrm{CO}_{2}\right)$ removal system. During TEKTITE I, it was demonstrated that the chemical absorbents in this system required replacement every four hours. For TEKTITE II, a minimum replacement interval of 12 hours was specified. In addition, new gas monitoring equipment was installed replacing equipment previously supplied by other participants.

Refitting activities both inside and outside the habitat were hampered by inclement weather. Subfreezing temperatures caused concern for the integrity of pipes, ducts, and seals. All lines containing water or moisture were carefully dried after each period of use and no problems were encountered. Every operating part of the habitat was thoroughly checked and reconditioned or replaced as needed. Reference 6 describes manufacturing problems encountered during TEKTITE I and 
provides an insight into the work and related problems that were encountered during the refurbishment of TEKTITE II.

\section{TEST ING}

Upon completion of habitat refitting, the on-board systems required verification by testing. In many cases, the test consisted of little more than operating the system or component under conditions which reasonably approximated its environment while in use. However, in some cases the tests were somewhat more complex. To verify the $\mathrm{CO}_{2}$ scrubber, for example, it was necessary to seal and pressurize the habitat, then operate the monitor the system while introducing $\mathrm{CO}_{2}$ at a known, controlled rate. A new larger capacity sea water condenser pump was installed. New high pressure external manifold piping for the emergency air supply and SCUBA charging system was fabricated from heavy wall monel tubing, fittings, and valves. A11 ECS components and systems were subjected to leak tests and performance testing. Components were replaced as required to place the system in an operable condition and gain confidence in the ability of the system to operate successfully over a 9-month period. All high pressure piping in the habitat was proof pressure tested at $1 \frac{1}{2}$ times operating pressure. The sea water condenser and piping was flushed and cleaned, and a new external sea water filter procured.

The habitat pressure test was performed to verify the adequacy of plexiglass viewing ports, 0 rings, seals, gaskets, and other structural elements subjected to internal pressurization when the habitat was pressurized on the surface prior to emplacement. Considerably fewer tests were required on TEKTITE II than on TEKTITE I. Table 7 compares various categories of tests performed on each program. Details of TEKTITE II tests are discussed in greater depth in Reference 7.

Table 7.--Comparison of Tests, TEKTITE I and TEKTITE II

\section{System}

Structure (Habitat and Base)

Environmental Control

Plumbing

Electrical

Communications

Atmosphere Monitoring

Interior

Utilities

Total

Number of Tests

TEKTITE I TEKTITE II

17

20

8

5

22

3

4

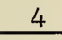

83

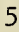

9

2

5

13

2

2

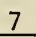

45 
During the TEKTITE II program, the habitat crew was augmented by the addition of a habitat engineer. These engineers were drawn from several participating agencies and in general had 1ittle or no prior knowledge of the habitat or its on-board systems. For this reason, training was essential and this training had to be undertaken prior to emplacement when access would be Iimited. Classroom and habitat familiarization training was given to selected candidates in Philadelphia. An informally prepared Habitat Engineers Manual served as the basis for this training. Each system was presented by the responsible system engineer using appropriate drawings and schematics. Class work was supplemented by several visits to the habitat during which time engineers were required to operate many of the on-board systems.

At the time of this training, not all of the habitat systems were fully operational. Furthermore, it was realized that considerable time would elapse for many of the engineers before their mission in the habitat. To compensate for these factors, it was required that each engineer perform at least two supervised dives into the habitat for refamiliarization. During these dives, each was specifically required to perform the following three tasks under supervision of a General Electric engineer:

\section{Change baralyme in $\mathrm{CO}_{2}$ scrubber}

2. Shut down and restart all electrical equipment

3. Operate and calibrate all on-board gas monitoring equipment

This requirement was satisfied by each habitat engineer without exception. The general success of the program indicates that the training accomplished its objectives. It should also be noted that during the mission, a General Electric engineer was available on the surface at all times. Supplied with a complete set of catalogs, drawings, and parts lists for various items in the habitat, the surface engineer was able to provide rapid information to the habitat engineer at any time it was required. Subjective evaluations by each of the habitat engineers have generally indicated their enjoyment of their tour underwater. References 8 and 9 indicate typical responses to the first and sixth missions by program engineers.

\section{SURFACE SUPPORT EQUIPMENT PREPARATION AND EMPLACEMENT}

One of the major tasks performed during the program was the preparation and installation of surface support equipment for use at the site. All supporting utilities were located on land and were connected to the habitat by suitable cables. Much of the support equipment used during the program was provided by participating agencies and detailed technical information was not available until late in the program. To facilitate installation, it was decided to mount all equipment on trailers which would permit delivery over the unimproved dirt road leading to the site. Accordingly, Philadelphia became a marshaling point for the generators, compressors, pumps, and other items of program support equipment. These items were secured to a flat bed trailer and connected by appropriate electrical and pneumatic lines. Each system was verified by testing.

$$
\text { II-34 }
$$


Plans were then made for loading the program support equipment on Navy causeway sections in preparation for loading into a Navy LSD. Supervision for loading activity was also provided. Upon delivery and offloading at the site, technical assistance was provided in the installation, hookup, and checkout at the command site.

While the command site was being prepared, the habitat was readied for emplacement. It should be noted that the emplacement techniques for TEKTITE II differed in several steps from those of TEKTITE I. For TEKTITE II, certain modifications were required since launching was performed from the LSD. When the habitat was secured to the bottom, the entry hatch was opened and a team of engineers began connecting all umbilical lines and performing final system checkout. To assure that these steps went quickly, they were planned and rehearsed by the men who would perform them. Typical pages from this checklist are shown in Figure 20 and suggest the level of detail that was considered. Upon completion of all system tests and checks, the operational habitat was turned over and the first mission began.

CONDITION li. Habitat is emplaced, anchored and the main entry
trunk is open. Umbilicals are in place but not
connected.

\begin{tabular}{|c|c|c|}
\hline Event & \begin{tabular}{|c|} 
Performed \\
By
\end{tabular} & Date \\
\hline 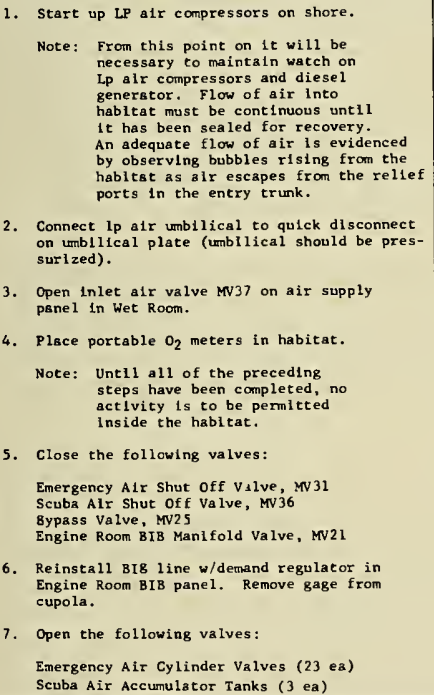 & & \\
\hline
\end{tabular}

\begin{tabular}{|c|c|c|}
\hline Event & \begin{tabular}{|c|} 
Performed \\
By
\end{tabular} & Date \\
\hline 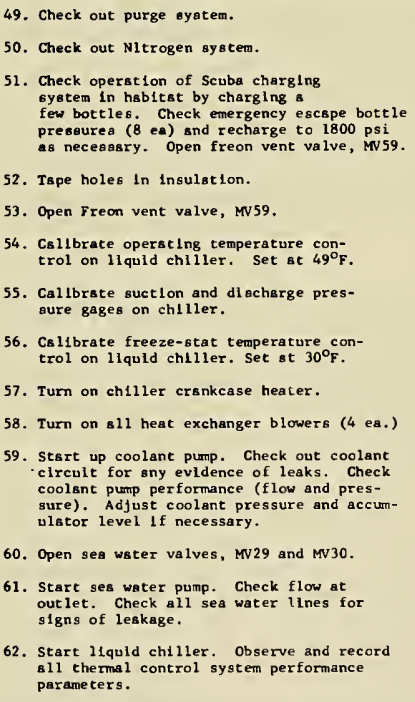 & & \\
\hline
\end{tabular}

Figure 20. Typical Checklist Pages - TEKTITE II Emplacement Checklist 
During operational phases of the program, an engineering watch was maintained at the command site on a 24 -hour basis. Individuals who filled this watch bill were engineers and technicians who had designed, tested, and built the habitat. All were trained to dive on the habitat and had been cross-trained to understand both habitat and surface support systems. During the mission, the surface engineer on watch provided technical assistance to the watch director manning the watch director's station.

\section{HABITAT SYSTEMS PERFORMANCE}

During the mission, the various habitat subsystems were monitored from the surface as well as from the habitat. With the exception of some minor component malfunctions, the habitat performed in a highly successful manner.

The Environmental Control System (ECS) performance during the mission was excellent. Prior to the start of a mission or consecutive series of missions, the oxygen level was adjusted to 11 to $12 \%$ by volume through a nitrogen purge. The aquanauts would then "breathe down" the oxygen over a few days until the partial pressure of oxygen $\left(\mathrm{PO}_{2}\right)$ was in the operating range (151-165 torr.) where it was maintained relatively constant. The $\mathrm{CO}_{2}$ scrubber had no problem in maintaining the partial pressure of carbon dioxide $\left(\mathrm{pCO}_{2}\right)$ below the required 8 millimeter of mercury ( $\mathrm{mm} \mathrm{Hg}$ ), and in most cases the level did not exceed $6 \mathrm{~mm} \mathrm{Hg}$. The few instances where the $\mathrm{pCO}_{2}$ exceeded this limit were caused by erroneous readings from the carbon dioxide $\left(\mathrm{CO}_{2}\right)$ analyzer. Baralyme change intervals were longer at night than in the day (due to difference in $\mathrm{CO}_{2}$ production rate) and averaged about 15 hours. Figure 21 indicates fluctuation in $\mathrm{pO}_{2}$ and $\mathrm{pCO}_{2}$ levels over a typical time period. The data points in Figure 21 are daily averages. In practice, gas monitoring instruments were watched continually and were recorded at 2-hour intervals. Daily variations occurred but were maintained within permissible limits. Figure 22 indicates typical daily variations in $\mathrm{pCO}_{2} 1$ evels.

The air temperature in the habitat, which was adjustable and selected by the crew, generally ranged from $78^{\circ}$ to $83^{\circ} \mathrm{F}$. Relative humidity was maintained at 45 to $55 \%$ which resulted in an extremely comfortable environment. Figure 23 shows changes in temperature and relative humidity in each of the habitat compartments during a typical 28-day period. All other subsystems in the ECS performed satisfactorily.

A number of component failures did occur that required repair and/or adjustment in the ECS. In the inlet air system, both air compressors (one redundant) required replacement of diaphragms and valves. In the $\mathrm{CO}_{2}$ scrubber, the bolt holding the lid on the baralyme canister housing failed twice and required replacement. Both a blower and a pump in the air conditioning system required replacement. It was subsequently determined that the capacitors of these motors burned out due to a large voltage fluctuation in the electrical power system. Late in the program, a leak developed in the external piping for the SCUBA charging system. This portion of the system was isolated by closing shut off valves and the HP air from the surface rerouted through the emergency breathing system to the SCUBA charging panel. Several failures also occurred with the surface high pressure air compressors.

$$
\text { II-36 }
$$




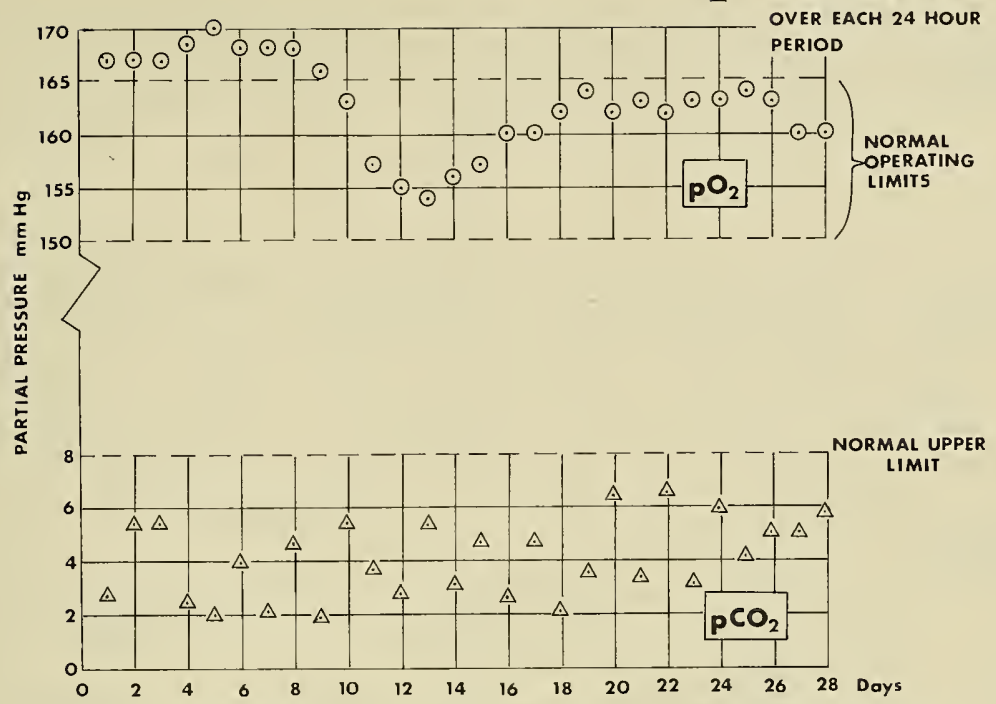

Figure 21. Fluctuation of $\mathrm{pO}_{2}$ and $\mathrm{pCO}_{2}$ over 28-day period.

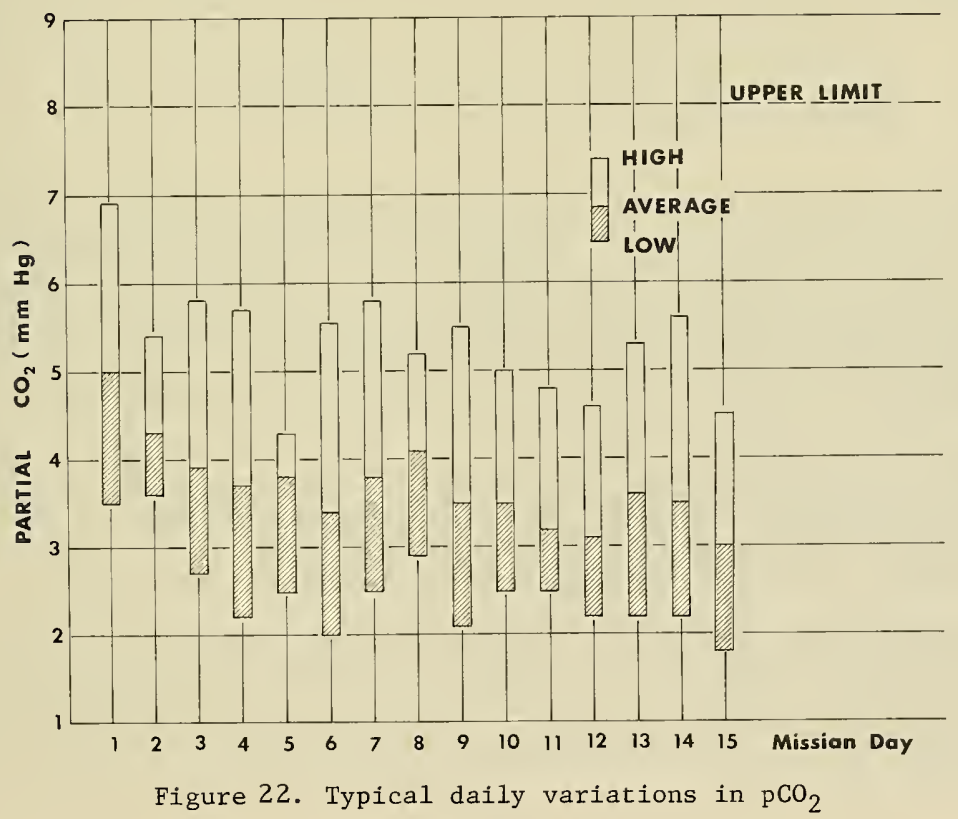



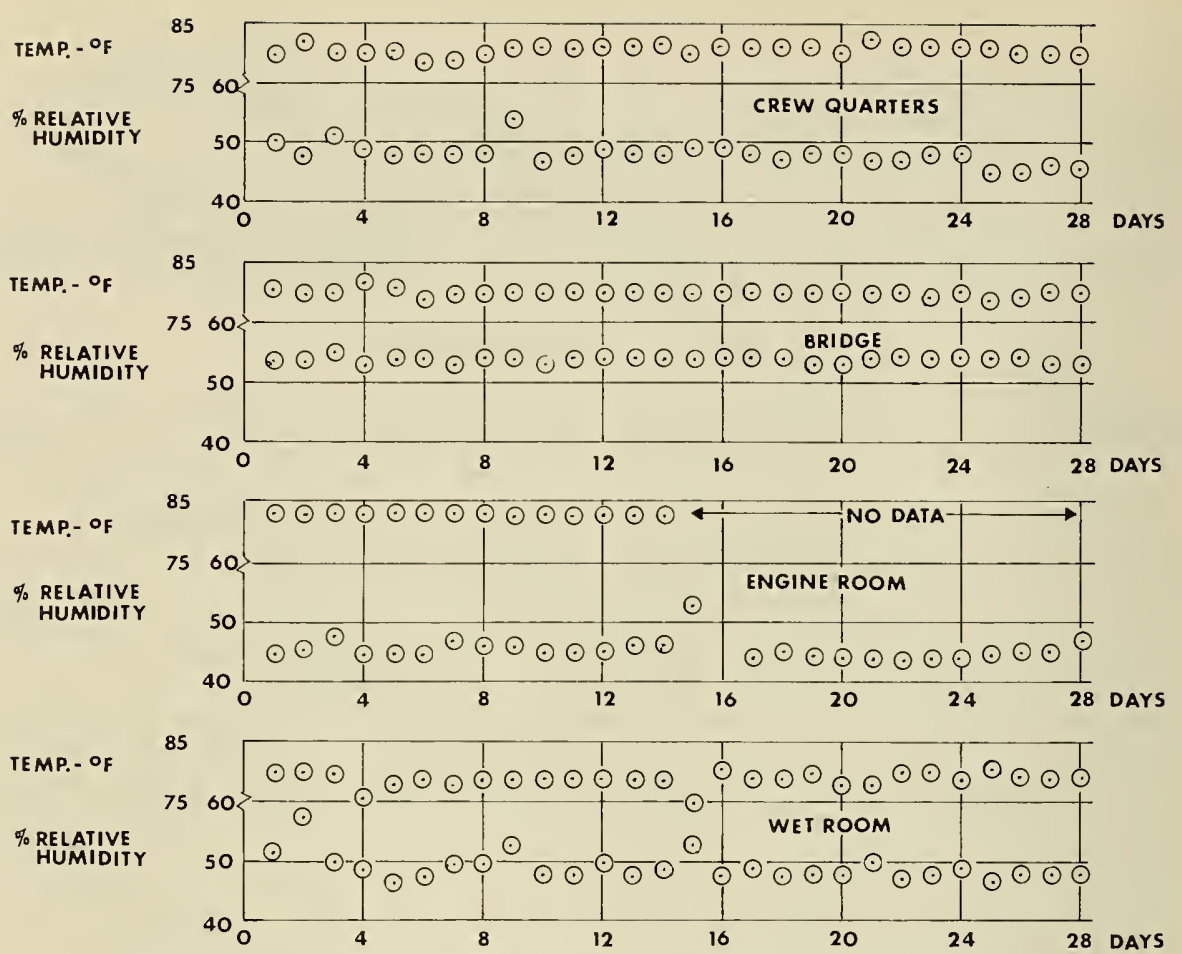

Figure 23. Changes in Temperature and Relative Humidity

The aquanauts never had need to utilize the emergency breathing or purge systems. However, there were several occasions during refurbishment between missions when these systems were required. One occurred when an analyzer power supply failed and filled the habitat with smoke. In both cases, a purge was initiated successfully and support divers working in the habitat utilized the Bib system until the contaminated atmosphere was cleared. Fresh charcoal was also installed in the air conditioning systems in these instances.

To maintain the quality of breathing gas in the habitat, careful attention was given to the selection of all materials used in the habitat and its furnishings and to all chemicals, equipment, and personal gear taken into the habitat. This approach in avoiding atmosphere contamination worked very well in both TEKTITE I and II and should continue to be used in future programs.

The umbilical which connected the generator system to the habitat was a $1,000-$ foot long armored submarine cable housing three 非/ 0 electrical conductors. This cable carried $3 \emptyset$ power at a 480 volt level to the habitat where it was transformed to three different operating voltages $(3 \emptyset-460 \mathrm{~V}, 2 \emptyset-240 \mathrm{~V}$, and 
$1 \emptyset-120 \mathrm{~V})$ which was distributed to the respective electrical systems throughout the four habitat compartments from one central distribution panel (Figure 24) located in the engine room. Each compartment had a secondary distribution panel as a safety measure to protect from individual circuit overload. These panels were placed in convenient locations in their respective compartments to allow easy access in the case of an emergency.

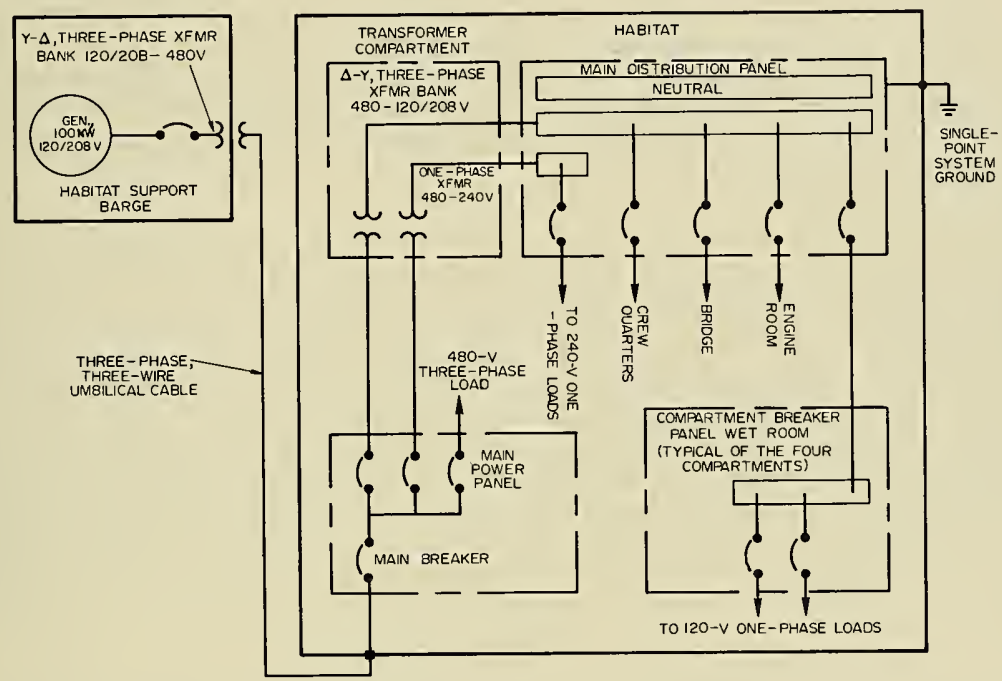

Figure 24. Single Line Diagram, TEKTITE Electrical Power Distribution System

Although the input power to the habitat was $3 \emptyset$ with a floating ground, all power on the secondary side of the transformers in the habitat was distributed with a grounded or neutral conductor. All electrical fixtures and equipment were both electrically and mechanically grounded to assure safety from shocks.

Power to the habitat was monitored by a watt-hour demand meter located at the power umbilical end on the surface. The accumulated watt-hours were read and recorded every two hours and an instantaneous power usage reading was also taken by timing the rotor of the watt-hour demand meter for ten revolutions.

The average daily power usage for the entire TEKTITE II program was $750.6 \mathrm{kilo-}$ watt hours per day. The maximum power consumed in one day was $895 \mathrm{KWH}$ which was a $37.3 \mathrm{Kw}$ demand.

The habitat electrical system had few problems during the program. Several motor capacitors failed after power surges caused by erratic operation of the 
surface generators. Toward the end of the program, several circuit breakers became difficult to switch on. This was probably caused by wear and corrosion of the breaker contacts. None of these problems were due to failures in the system design, however, and it may be concluded that the overall electrical system operated in a safe and efficient manner.

No habitat structural problems were encountered during the TEKTITE II program. An anti-corrosive, anti-fouling paint system protected the structure on all surfaces exposed to the sea water. The vinyl base anti-fouling paint inhibited marine growth to the extent that only infrequent brushing with a stiff bristled brush or plastic scrub pad was necessary to keep the exterior clean. The habitat was given a complete cleaning only twice during the eight months that it remained in the water. After recovery of the habitat, the paint was found to be chipped and scraped in many areas. However, the structure had suffered no serious corrosion damage.

The plumbing subsystem provided fresh water for drinking and washing, a toilet operating on sea water, and a drain system that carried all waste water a suitable distance from the habitat. An 80-gallon hot water heater in the habitat provided an adequate supply of hot water at all times. Sinks were located in the crew quarters, near the toilet in the engine room, and in the wet room. The wet room also provided a shower and a hose connection for washing down equipment. The toilet, located in the engine room, used sea water and included an emaciator and provisions for adding decontaminate to the water. Sewage from the toilet was pumped directly overboard while the waste water from the sinks and shower were collected in a sump before being pumped to the drain system. The wet room bilge also incorporated an electric pump that emptied into the sump. A11 drain 1 ines were connected external to the habitat, and a single hose carried all waste to a point approximately 400 feet from the habitat.

The most serious problem encountered with the plumbing system was during mission 2-50 when the toilet failed and remained out of service for two weeks until replacement parts were obtained. On several occasions, the bilge pump became clogged with debris and required forced flushing.

A dumbwaiter system provided for the habitat did not work satisfactorily. Failures resulted from problems with maintaining suitable tension in the cables. The dumbwaiter was subsequently removed when aquanauts complained that it interfered with the entry way, particularly when the rebreathers were employed.

The communications subsystem provided several modes of communicating between the habitat and the control as well as from one compartment to another within the habitat. The equipment installed included the following:

- Television cameras with wide angle lenses in each of the four habitat compartments, connected to monitors in the command van and bridge.

- An intercom system with stations in each of the four habitat compartments, in the cupola, and in the command van.

- Open microphones in each of the habitat compartments that could be monitored in the command van. 
- A D.C. powered telephone between the crew compartment and the command van.

- A sound-powered telephone between the bridge and the command van.

- A system of emergency alarms with visual and audible indicators in the bridge and command van.

- An alarm bell at two locations in the habitat operated from the command van.

In addition, communication links were operated between the habitat and the service barge anchored directly overhead. Linked to the normal television system were portable cameras located in the command van and in the habitat as part of a behavioral study. These two cameras proved to be of such value that they continued to be used for routine communications throughout the remainder of the TEKTITE program.

Routine adjustment of communications equipment and replacement of 1 ife-1imited components was performed by the habitat engineer and by refurbishment crews in the intervals between scientific missions. This, coupled with the redundancy in modes of communications ensured that there were no significant interruptions during the mission. The most common cause of minor difficulties in the intercom system was inadvertent use of selection switches or operation by personne1 unfamiliar with correct procedures. The alarm systems were checked routinely on a periodic basis. On the several instances of electrical power failure or rise in water level in the wet room trunk, the alarm system functioned correctly.

\section{CONCLUS IONS}

It can be concluded that the habitat satisfied most performance requirements and provided an excellent base for scientific saturation diving. Numerous areas for design improvement were noted. However, in most cases, these desired refinements are not of sufficient general interest to justify inclusion here. Perhaps one of the most significant areas which requires a better solution is that of material transfer techniques. Subsequent programs will do well to pay close attention to the manner by which equipment is transferred from the surface.

A suitable carbon monoxide monitoring device should be employed in subsequent programs to give frequent accurate determination of carbon monoxide (CO) levels. Techniques for removing and replacing bulky consumables such as baralyme and charcoal can be improved. In summary, it can be stated that the technical problems associated with shallow water, two gas habitats operating in benign conditions similar to Lameshur Bay are easily solved.

\section{REFERENCES}

1. "SUMMARY REPORT ON PROJECT TEKTITE I." A multiagency 60-day saturated dive conducted by the U.S. Navy, the National Aeronautics and Space Administration, the Department of the Interior, and the General Electric Company, edited by D. C. Pauli and H. A. Cole, Office of Naval Research, ONR Report DR 153S, Washington, D.C., January 16, 1970.

$$
\text { II }-41
$$


2. "THE NATURE AND SIGNIFICANCE OF PROJECT TEKTITE," Naval Research Reviews, Vo1. XXII, No. 7, July 1969.

3. "TEKTITE I - EXPERTMENTAL MANNED UNDERSEA HABITAT," Charles H. Meigs, The Society of Naval Architects and Marine Engineers, Spring Meeting, Washington, D.C., April 1-3, 1970.

4. "TEKTITE II PROGRAM PLAN," U.S. Department of the Interior, April 1, 1970.

5. "TEKTITE PROGRAM SAFETY PLANNING," John B. Tenney, Jr., American Astronautical Society 16th Annual Meeting AAS Paper No. 70-053, Anaheim, Calif., June $8-10,1970$.

6. "MANUFACTUR ING THE TEKTITE HABITAT," C. M. Lorenz and R. D. Cockfield, Society of Automotive Engineers, Paper No. 700753, New York, October 1970.

7. "TEST AND CHECKOUT PROCEDURES FOR THE TEKTITE OCEAN HABITAT SYSTEM," J. B. Tenney and D. J. Withey, Society of Automotive Engineers Paper No. 700583 in Proceedings of the 9th Reliability and Maintainability Conference, Detroit, Mich., Ju1y 20-22, 1970.

8. "LIVING AND WORKING AT NINE FATHOMS," E. Batutis, True Magazine, Vo1. 51, No. 400, September 1970 .

9. "TWO WEEKS IN A COTTAGE ON THE BOTTOM OF THE SEA," Peggy Lucas, Science Horizons, No. 107, United States Information Service, October 1970.

10. "UNDERWATER CONSTRUCTION - TEKTITE I," Cdr. Walter J. Eager, CEC, USN Progress Into the Sea, Transactions of the Symposium (Marine Technology Society), Washington, D. C., October 20-22, 1969. 


\section{James Sleznick, Jr. \\ Nationa1 Park Service \\ and}

Loran A. Weaver

National Oceanic and Atmospheric Administration

\section{INTRODUCT ION}

The massive logistic support required by the TEKTITE II program was undertaken through cooperative arrangements with the Department of Transportation and Department of Defense. Airlift coordination was provided by the National Oceanic and Atmospheric Administration (formerly Environmental Science Services Administration). Principals included the U.S. Coast Guard, U.S. Navy, and units of the Air National Guard. Arrangements for this assistance were negotiated early in the planning stages, thus assuring adequate and timely logistical support for both personnel and equipment.

\section{NAVY SUPPORT}

The staging area for the main habitat and related support equipment was the Philadelphia Naval Shipyard. The Landing Ship Dock (ISD), USS Plymouth Rock, was assigned the task of transporting the primary equipment and material to the Lameshur Bay site. An LSD was required for the transportation of the habitat and support equipment because of the limited accessibility of the project site to any adequate airfield, road, or off-loading facility.

Most major equipment items were loaded aboard the LSD at the Philadelphia Naval Shipyard as per loading plan developed jointly by the Department of the Interior, General Electric, and Navy Personnel. The loading was executed smoothly and on schedule with the ship sailing February 27, arriving on site March 6 .

Unloading of the LSD at Lameshur Bay occurred without major incident. Sea conditions were such that an orderly unloading operation could be conducted. The habitat was floated out and secured in the designated holding site. Causeway sections containing the command van, spare parts trailers, generators and nitrogen gas trailer and related equipment were floated to their designated sites for securing and further off-loading.

The Navy concluded its logistic role at TEKTITE II in November when the LSD, USS Portland Court, arrived on site to reload the habitat, minitat and related support equipment for its return to Philadelphia. The load plan was essentially the same except for the addition of the minitat. Sea conditions remained good and no loading difficulties were encountered. The USS Portland Court was a newly commissioned vessel on its first cruise, and the fresh crew is to be commended on their efforts in loading this unusual consignment.

The ship sailed the evening of November 19 and arrived at the Philadelphia Naval Shipyard late on the 22nd. Off-loading was conducted by Yard personnel early the next day according to plan. 
Transportation of the minitat and related pieces of equipment to the Virgin Islands from the continental United States was undertaken by the United States Coast Guard buoy tender, Salvia. Arrangements for the utilization of the Salvia were made through the Office of Chief, Marine Science Division, USCG. The minitat, wetroom, catamaran pontoons and ballast were loaded at Galveston, Texas. Approximately 10 days later the cargo was off-loaded at the West Indies dock, St. Thomas, for final assembly with the ship and personnel returning to regular duties and assignments.

Coast Guard involvement did not end with this particular exercise but continued as emergency backup transportation services should they be needed. These courtesies were extended by the Commanding Officer, St. Thomas coast Guard Station. Twenty-four hour emergency helicopter evacuation service was extended by the San Juan, Puerto Rico, Coast Guard Station. Although these emergency services were not required, the assurance of such assistance in cases of personnel injury or equipment failure was comforting.

\section{AIR NATIONAL GUARD SUPPORT}

Perhaps the greatest logistic involvement of men and equipment during TEKTITE II was undertaken by Air National Guard units. With the cooperation of the Defense Department, the Department of the Interior was able to utilize Air National Guard transportation for personnel and supplies. Coordination of this extensive airlift was accomplished by the National Oceanic and Atmospheric Administration. Most airlift missions were flown by the 166th Military Airlift Group of the Delaware Air National Guard. Remaining flights were conducted by 15 other Guard units including Aeromedical Airlift, Air Refueling, and Combat Crew Training groups. A total of 62 flights were made, carrying 1,358 passengers and 654,300 pounds of cargo. Approximately 981,000 ton-miles were flown by the Air National Guard during the TEKTITE II program.

Principal pickup points within the U.S. were Andrews AFB, Washington, D.C., Greater Wilmington Airport, Wilmington, North Carolina, and EIlington AFB, Houston, Texas. Flights were conducted generally nonstop into Harry $S$. Truman airport in St. Thomas, Virgin Islands. Operation into this airport was restricted to daylight hours due to the short length of the runway and adverse terrain in the immediate area. Primary route of travel was from Wilmington, Delaware, to Washington, D.C., where personnel and equipment loaded. Crew rest stops were at Wilmington, N.C. where additional personnel and equipment from Cape Fear Technical Institute were loaded. Flights continued nonstop to St. Thomas, Virgin Islands, arriving approximately six hours later.

Equipment utilized included:

$$
\begin{array}{ll}
\text { C-54 } & \text { Skymaster } \\
\text { C-97 } & \text { Stratocruiser } \\
\text { C-121 } & \text { Constellation } \\
\text { C-124 } & \text { Globemaster } \\
\text { C-130 } & \text { Hercules }
\end{array}
$$


Units of the Air National Guard providing air support to the TEKTITE II program included:
116 th MAG $^{1}$ Dobbins AFB, Georgia
118th MAG Nashville, Tennessee
139 th $\mathrm{AAG}^{2}$ St. Joseph, Missouri
145 th MAG
146 th TAG $^{3}$
147 th $\mathrm{CCTG}^{4}$
151st MAG
157 th MAG
Charlotte, North Carolina
Van Nuys, California
E11ington, Texas
Salt Lake City, Utah
Pease AFB, New Hampshire

161st MAG Phoenix, Arizona

164th MAG Memphis, Tennessee

165th MAG Savannah, Georgia

166th MAG New Castle, Delaware

167th AAG Martinsburg, West Virginia

170th MAG McGuire AFB, New Jersey

172nd MAG Jackson, Mississippi

3 Tactical Airlift Group

4 Combat Crew Training Group
1 Military Airlift Group

2 Aeromedical Airlift Group

The logistic support received from the participating units of the civilian and military agencies mentioned above made it possible to transfer TEKTITE II equipment within the time frame and budgetary limits of the program.*

* A vote of thanks likewise is due the commercial airlines serving the Virgin Islands. In particular, the local personnel of Pan American Airlines deserve our gratitude for their cooperation and many special favors. 


\title{
MINITAT PROJECT
}

\author{
Richard A. Waller \\ Department of the Interior \\ Washington, D.C.
}

\section{INTRODUCTION}

TEKTITE I provided a clear demonstration of the advantages of extended habitation within the marine environment for accomplishing various specific research tasks which heretofore have only been marginally effective when conducted from the surface, either by bounce diving or shipboard sampling. The advantages afforded by allowing the marine scientists almost unlimited opportunity for direct observation and study are minimized on some occasions, however, by the limited range of activity imposed on the aquanaut-scientist while working from a permanently moored underwater habitat.

It became apparent during TEKTITE I that the advantages of a movable underwater habitat which could be easily and quickly moved from site to site during a single dive or a series of dives would provide far more flexibility than a fixed habitat. An additional incentive to this approach was provided by the speculation on the part of several physiologists that saturation diving with oxygen/nitrogen mixtures should be possible to depths in excess of 100 feet. If the speculation proved to be true, extended depth capability in saturation diving would render large portions of the shallow continental shelf accessible to exploration and study through in-situ techniques without invoking the expense and other problems associated with helium gas mixtures.

Thus, the rationale for a movable habitat which could be relocated between an established vertical gradient as well as along a horizontal plane appeared to offer a logical course to follow beyond TEKTITE I. Within this framework a prototype habitat project was scheduled as an adjunct to the TEKTITE II program early in the planning. The following sections describe the habitat, its support vessel, and the results of the effort.

\section{THE MINITAT}

The scaled-down habitat, illustrated in figures 1 and 2 , is a vertical cylinder mounted on a pontoon catamaran which provides flotation during surface transport and a self raising/lowering capability. An ambient pressure wet room is connected to the underside of the pressure vessel and slightly recessed in the open work deck of the catamaran. Primary services, such as power, atmospheric gas, and fresh water were supplied from the surface support vessel R/V UNDAUNTED.

The main chamber or pressure vessel is vertically oriented, eight feet in diameter and 11 feet high overall. This section is structurally designed, according to ASME Code, Section VIII, to serve as a decompression chamber at pressures up to $165 \mathrm{FSW}$. The design and fabrication of the pressure vessel, piping, valves, and fittings subject to system pressure are according to Section VIII and Section IV of the ASME Boiler Code. All welds are 100 percent with 100 percent radiographic inspection. Hydrostatic testing of the finished system was to one and one-half times working pressure or 247 feet. 


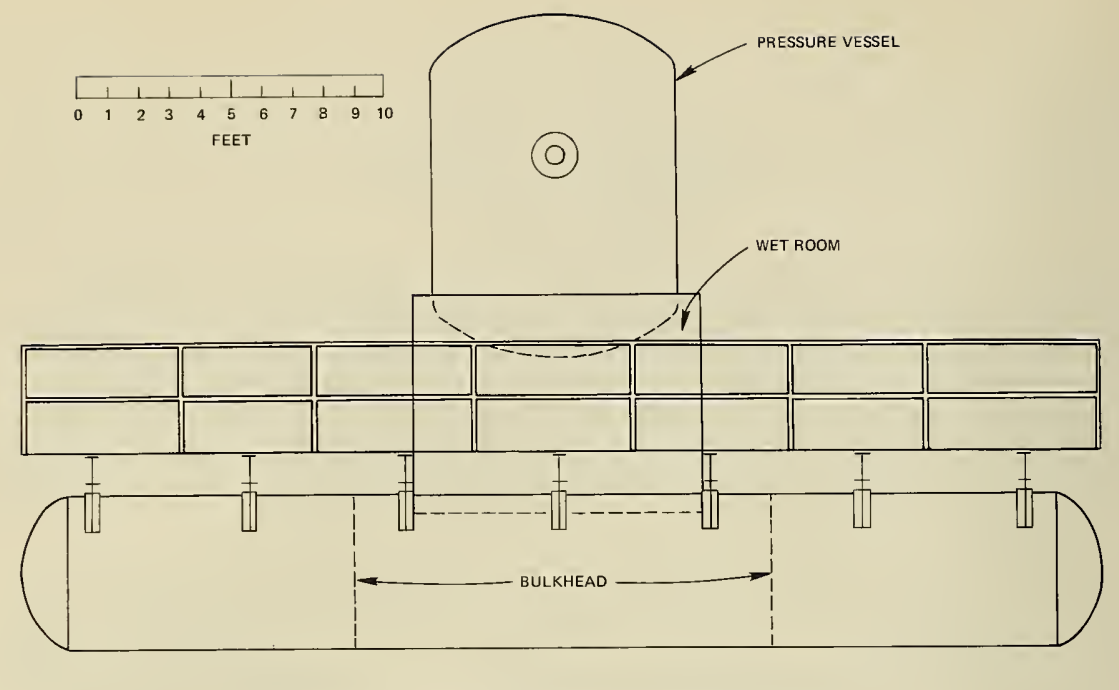

FIGURE 1.--MINITAT PORT SIDE ELEVATION.

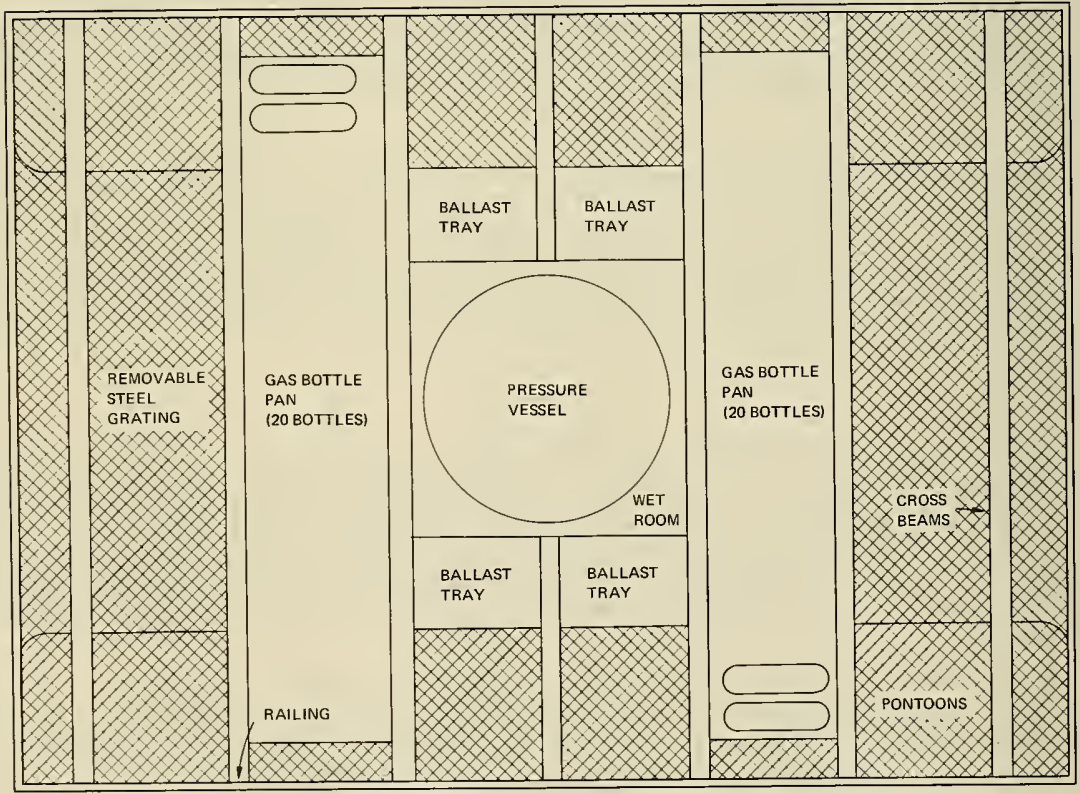

FIGURE 2.--MINITAT PLAN VIEW. 
The pressure vesse 1 weighs less than 10,000 pounds including internal equipment and supports, and displaces about 27,000 pounds. Internal volume of the pressure vessel is 425 cubic feet and the internal volume of the ambient pressure wet room is approximately 400 cubic feet.

There are four 8-inch diameter view ports equally spaced around the cylinder. A false deck is installed at a level which provides seven feet of head room. A 36-inch transfer lock is provided in the bottom of the pressure vesse 1 between the false deck and the dished head.

Seals, gaskets, and lubricants were selected on the basis of oxygen compatibility, corrosion cracking, galvanic corrosion, etc. While the minitat is not a certified system according to DOD standards, every effort was made, within the time and appropriation available, to conform to such standards.

The pressure vesse 1 mates with and seals to the wet room which is an integral part of the catamaran deck (see figure 1). The wet room is $9 \times 9$ feet with a maximum head room at the edges of 7 feet. Only 5 feet of the wet room appears above deck level. The wet room is used as a work room, storage area, and diving station. It is not designed, however, to withstand any appreciable pressure differential. After the habitat is on the bottom the wet room is blown dry and activated. The wet room contains a 42 inch hatchway in the steel deck for ingress/egress, a pneumatic collar for sealing to the habitat, four vent valves attached to the top-exterior to allow gas to escape during flooding, and a wet room skirt. An entry trunk is located on the wet room deck to permit entry of umbilical and other lines. Twenty four inch diameter plexiglass ports are installed in each side of the wet room and one wall has a water-tight door that swings inward for ease of access while on the surface.

The habitat is attached to the pontoon catamaran via four upright steel I-beams which bolt to an I-beam ring welded around the pressure vessel and to transverse I-beams connecting the pontoons. Four additional steel I-beams are bolted to the upright beams and angled down to bolting pads on transverse beams. The bolted steel support beams are sized to allow proper mating between the pressure vessel and the wet room sealing flange.

The pontoon catamaran consists of two steel pontoons; 35 feet in length, 5 feet in diameter, and $1 / 4$ inch wall thickness with ellipsoidal caps welded on the ends. The pontoons have a spread of 20 feet center to center and are bolted together with 6 transverse I-beams. Each pontoon is compartmentized with welded transverse steel bulkheads at a point 9 feet from each cap. This results in three separate compartments in each pontoon, two about 8 feet in length and the center compartment approximately 17 feet long.

Each of the six compartments can be flooded with sea water and emptied with compressed air in a controlled manner to aid in raising and lowering the minitat. Each compartment is equipped with a water valve for flooding and a vent tube leading to the control console shown in figure 3 . At the control console air can be vented from the compartments to allow them to flood in diving the minitat. Compressed air can be admitted from on-board storage bottles or from the support ship via the umbilical for emptying the pontoons to raise the minitat. Sufficient compressed air storage capacity is provided under the deck to very nearly blow dry all six compartments at a depth of 
100 feet - far more than needed to raise the minitat. Each compartment of the pontoons is also fitted with a pressure relief valve pre-set at 50 psi.

\section{PORT PONTOON}

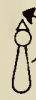

8) Center Tank 8

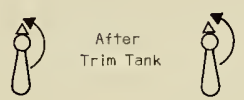

Purge Valving
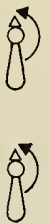

Vent Valving
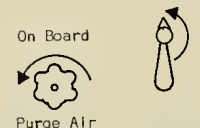

Forward
Trim Tank<smiles>O=C1CCCCC1</smiles>

Center Tank

Auxiliary

(?)

Purge Alr

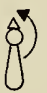

After
Trim Tan

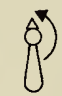

Purge

valving
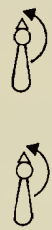

Vent
Valving

FIGURE 3.--CONTROL CONSOLE.

Forty 240 SCF (2200 psi) compressed gas bottles are stored under the deck with manifolding to blow the pontoons dry for ascent or to provide compressed gas for scuba charging or emergency breathing. Each pontoon displaces about 630 cubic feet of water, exerting about 40,000 pounds of buoyancy when submerged. Ballast trays having a capacity of 47,000 pounds of cast iron ingots (100 to $500 \mathrm{lb}$. size) are built into the deck. Deck supports are 12 inch wide flange steel beams and the deck is galvanized steel mesh. The deck extends over the pontoons, and fenders are provided. Towing kingposts are provided on each corner of the barge.

\section{ENVIRONMENTAL CONTROL SYSTEM}

The minitat environmental control system (ECS) controls the composition, pressure, temperature, and humidity of the minitat breathing gas. It consists of a thermal control subsystem, a $\mathrm{CO}_{2}$ removal subsystem, a breathing gas supply subsystem, and a breathing gas monitoring subsystem.

The thermal control subsystem provides dehumidification, heating and cooling. A refrigeration unit mounted outside the pressure vessel provides both heating and cooling. The evaporator and condenser are placed in hot and cold reservoirs in two separate water/ethylene glycol heat exchange loops. The water/glycol mixture is pumped to hot and cold heat exchangers in the vessel. The breathing gas is circulated past the cold heat exchanger for dehumidification and through the hot heat exchanger as necessary for comfort. The thermal control subsystem is designed to maintain the atmosphere at temperatures between $70^{\circ}$ and $85^{\circ} \mathrm{F}$ and the relative humidity between $45 \%$ and $65 \%$. Figure 4 is a schematic diagram of the thermal control subsystem. 


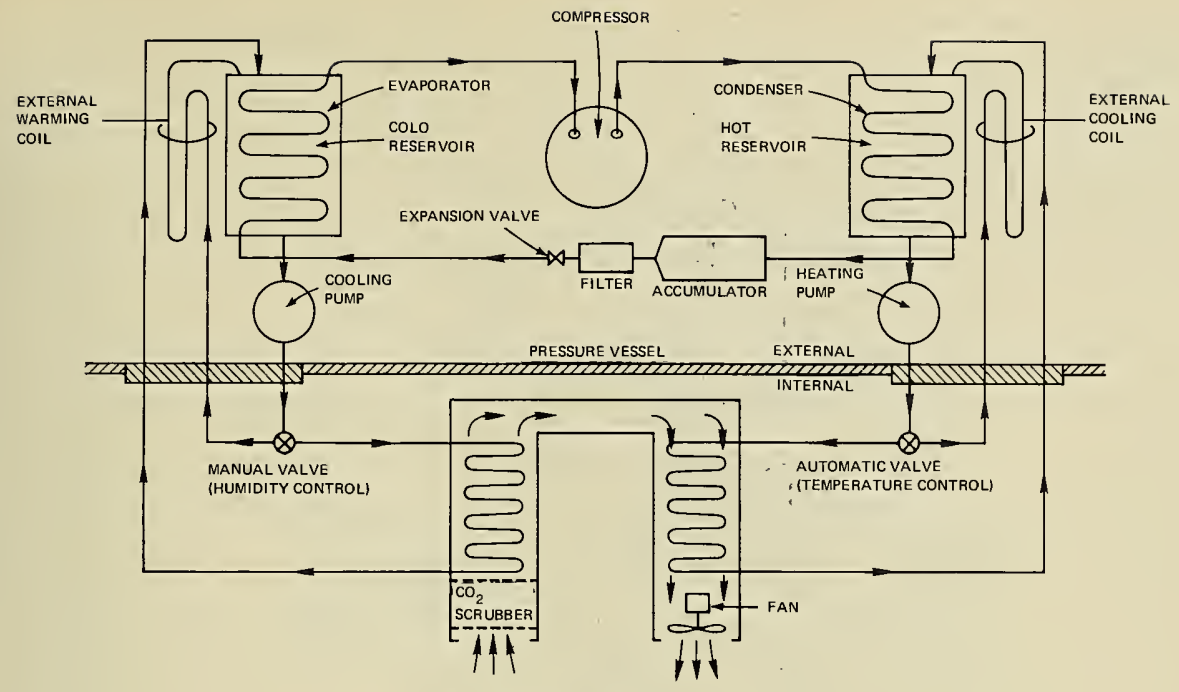

FIGURE 4.--THERMAL CONTROL SUBSYSTEM SCHEMATIC

A $\mathrm{CO}_{2}$ scrubber containing baralyme granules is attached to the inlet of the thermal control subsystem heat exchanger assembly. An electrically powered blower pulls air through the canister and then through the heat exchangers. The canister is designed to hold the $\mathrm{CO}_{2}$ partial pressure below $0.5 \%$ atmospheric ( $3.8 \mathrm{~mm} \mathrm{Hg}$ ) for 60 man hours per canister filling. A second blower is provided for operation of the scrubber on battery power if the primary blower fails.

The breathing gas subsystem consists of the gas storage and handling equipment for making up, sustaining, and purging the minitat breathing gas, supplying the built-in-breathing (BIB) masks, and charging SCUBA bottles. It also provides compressed air for emptying the catamaran pontoons. Figure 5 is a schematic diagram of the breathing gas subsystem.

The minitat breathing gas is a mixture of oxygen and nitrogen having a partial pressure of oxygen in air at one atmosphere. The initital breathing gas is provided by pressurizing the pressure vessel with air to the appropriate calculated pressure and then pressurizing it to full depth pressure with nitrogen. After the minitat is emplaced, the hatch is opened and the wet room is blown dry using air to force the water level down to a reference mark on the inside wall of the wet room and then nitrogen to empty the wet room. These gasses are pumped through the low pressure gas line and controlled by a flow control console aboard the support vessel.

Metabolic oxygen is supplied by adding a small amount of compressed air through the low pressure line. An oxygen controller automatically admits air to the minitat to maintain the desired oxygen concentration. Excess nitrogen escapes through the entry trunk. Any loss in pressure as might be caused by a leak will be detected by water rising in the entry trunk and 
activating a float valve. This adds air from the support vessel and sounds an alarm.

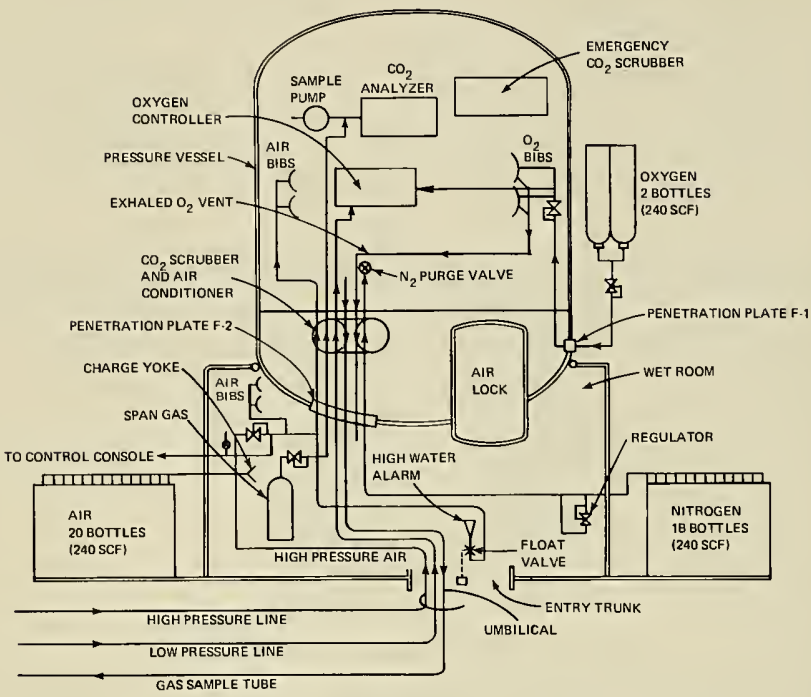

FIGURE 5. - -BREATHING GAS SUBSYSTEM SCHEMATIC

If the breathing gas becomes contaminated, it can be purged slowly with air pumped through the low pressure line or quickly by using the compressed air stored on board. After air purging, nitrogen must be added to reduce the oxygen partial pressure to the desired level. This may be done using nitrogen stored on board or on the surface support vessel.

The compressed air stored on board also supplies air to the emergency BIB masks for use if the minitat floods or the breathing gas becomes contaminated. The compressed air can be used for charging SCUBA bottles and blowing the pontoons of the catamaran barge. The compressed air storage bottles can be recharged from the surface.

High pressure oxygen is stored on the minitat in two cylinders that are attached to the pressure vessel. These cylinders supply oxygen for decompression. Oxygen masks have vents to dump exhaled oxygen overboard.

The breathing gas monitoring subsystem consists of a Biomarine oxygen controller having three galvanic $\mathrm{O}_{2}$ sensors, an MSA LIRA infrared absorbtion $\mathrm{CO}_{2}$ analyzer with a display and an alarm, remote $\mathrm{O}_{2}$ and $\mathrm{CO}_{2}$ indicators in the support vessels, and a breathing gas sampling tube in the umbilical. The latter allows an independent and more extensive assessment of the breathing gas in the pressure vessel and wet room to be made from the support vessel.

The minitat receives 220 volt A.C. three phase power from the surface via the umbilical. Three phase 220 volt power is used by the ECS compressor and $\mathrm{CO}_{2}$ removal blower motors. Single phase 220 volt power is used by external 
underwater lights, ECS circulation motors, and the hotplate. All other loads are supplied 110 volt power by a pair of step down transformers. The oxygen controller turns off internal electrical circuits if the oxygen level increases beyond a pre-set point. A 12 volt battery pack will supply emergency power for the $\mathrm{CO}_{2}$ analyzer, oxygen controller, and $\mathrm{CO}_{2}$ removal subsystem for 12 hours. The emergency power is automatically turned on if the A.C. power fails. Emergency lighting is provided by battery powered waterproof lanterns. Figure 6 is a block diagram of the minitat electrical system.

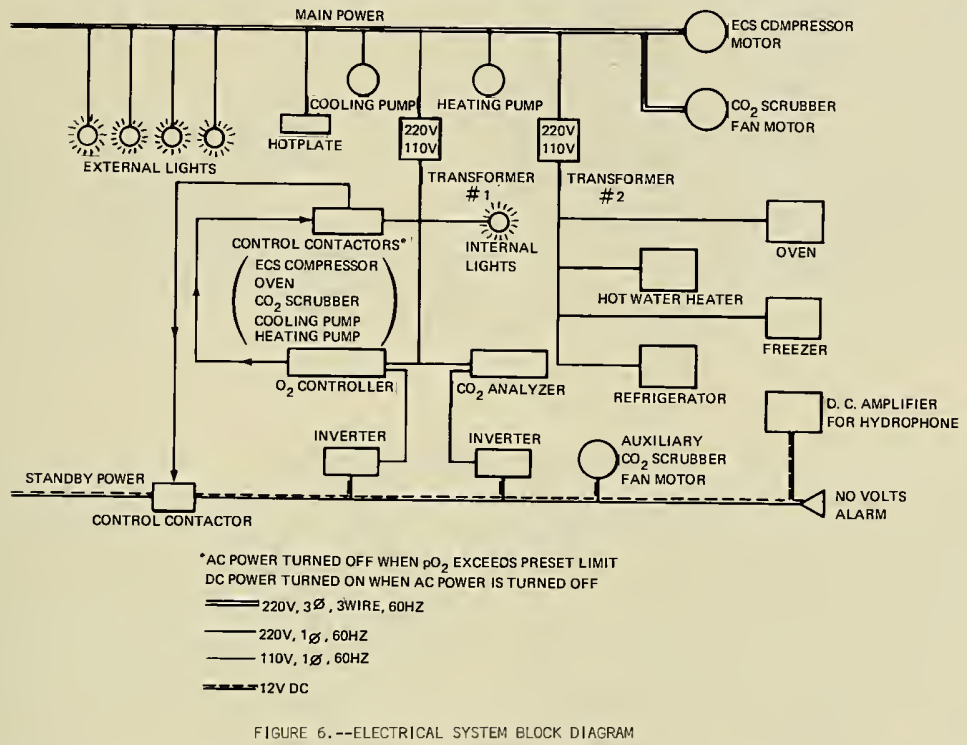

The primary communications system is a Bogen intercom with master stations in the pressure vessel, and the support ship and a remote station in the wet room. A Stromberg-Carlson sound powered telephone provides backup communications in case of power failure. A wide angle television camera and an open microphone are provided for observing the aquanauts. A hydrophone connection from the open microphone allows the aquanauts to talk to divers in the water outside the minitat. Figure 7 is a schematic diagram showing the location of the communications system.

The minitat is equipped with a 10 gallon electric water heater (with a two hour recovery time), a hot water shower, a sink, and a marine-type toilet with a macerator and a holding tank. A 200 foot long polyvinal chloride pipe will carry run-off from the holding tank to a site away from the minitat. Fresh water is supplied to the minitat from the support ship via the umbilical.

\section{SURFACE SUPPORT}

The surface support vessel for the minitat during TEKTITE II was the R/V UNDAUNTED. It was operated by the Cape Fear Technical Institute under a contract from the Office of Sea Grant Programs, National Science Foundation. The vessel was built for the U. S. Navy in 1944, as a seagoing tug, and converted 


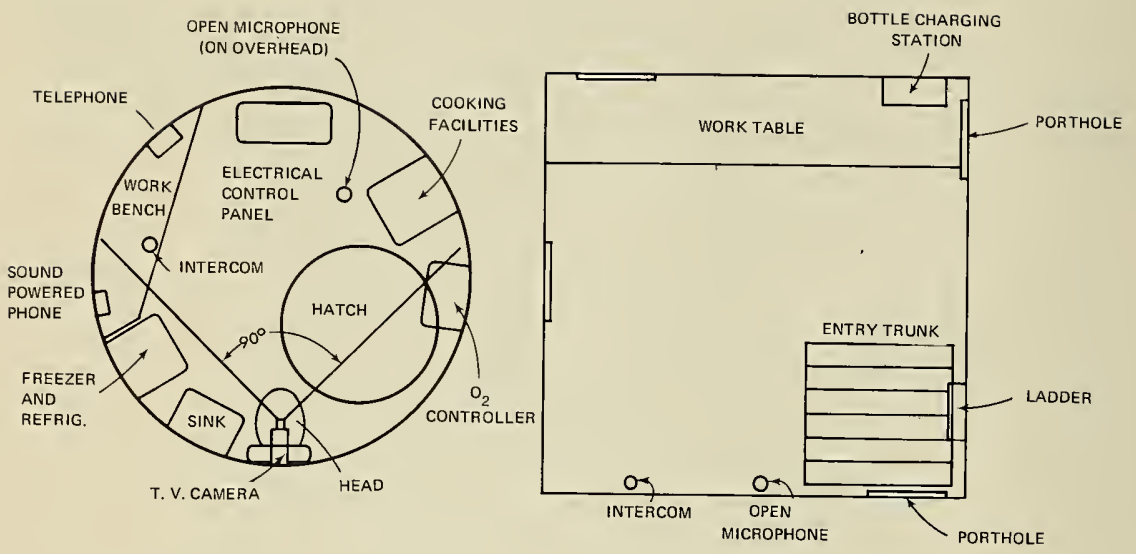

FIGURE 7.--LOCATION OF MINITAT COMMUNICATIONS

to a research vessel in 1965. The steel hull is $143^{\prime}$ long with a beam of 33 feet and a draft of 14 feet. Displacement is 900 tons full. The 1450 SHP diesel electric propulsion system gives a cruising speed of 11.5 knots and a top speed of 12.5 knots. Endurance is 45 days and range is 9600 miles. Her normal complement is 16 men but during the station keeping duties of TEKTITE the crew was reduced to ten men. Figure 8 shows the arrangement of the minitat support equipment on the UNDAUNTED.

The breathing gas supply system consists of a high pressure air subsystem, a low pressure surge air subsystem, a low pressure air subsystem, a low pressure purge air subsystem, a nitrogen makeup gas subsystem, an oxygen supply subsystem, and a gas flow control console shown in figure 9. All of which were located on the main deck of the UNDAUNTED.

The high pressure air subsystem provides high pressure air to the minitat for charging on the on-board air storage bottles. It also supplies high pressure air to the deck mounted decompression facility (DDC). It consists of the high pressure (3000 psi, $20 \mathrm{scfm}$ ) side of a HYDAP high pressure/10w pressure electric motor-driven RIX compressor, a backup KIDDE gasoline engine-powered high pressure (3000 psi, $3.8 \mathrm{scfm}$ ) SCUBA charging compressor, a high pressure receiver bank of sixteen 240 SCF bottles, fittings for charging SCUBA bottles on the UNDAUNTED, and appropriate plumbing to supply high pressure air to the gas flow control console and to the DDC. A high pressure hose leading from the compressors to the receiver bank is fed through a protective rigid conduit welded to the deck.

The low pressure surge air subsystem provides a low flow rate of air to the minitat to maintain the oxygen concentration in the breathing gas at the desired level during normal operations. It consists of a Bell and Gossett motor driven low pressure (175 psi, $2.2 \mathrm{scfm}$ ) teflon ring piston compressor 


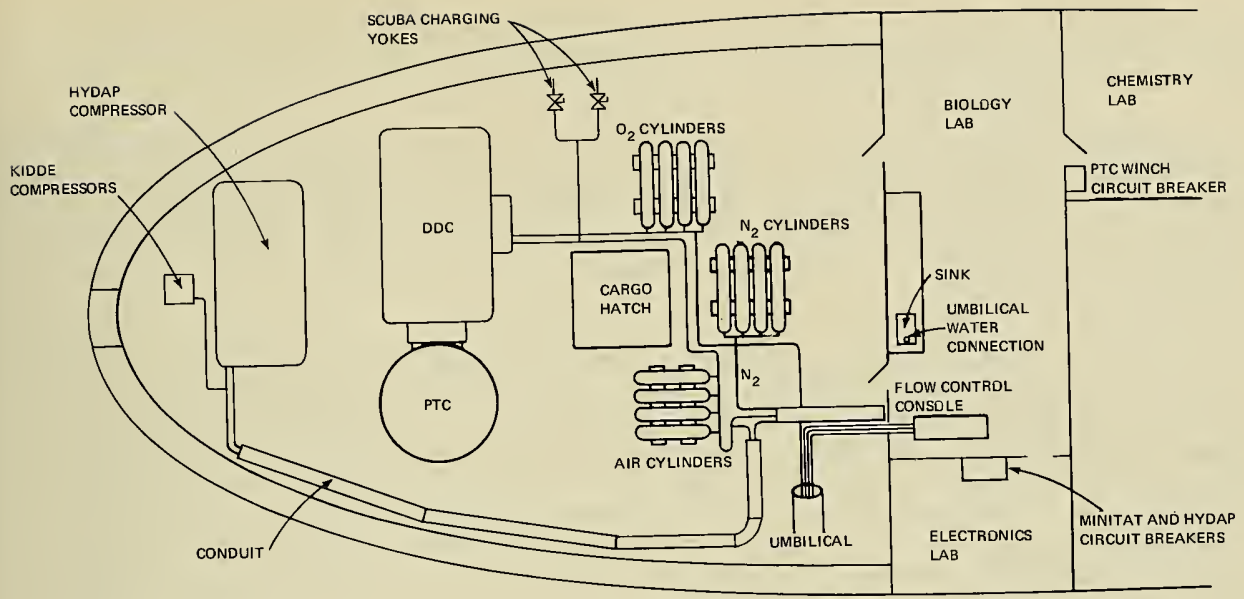

FIGURE 8.--SUPPORT EQUIPMENT ARRANGEMENT

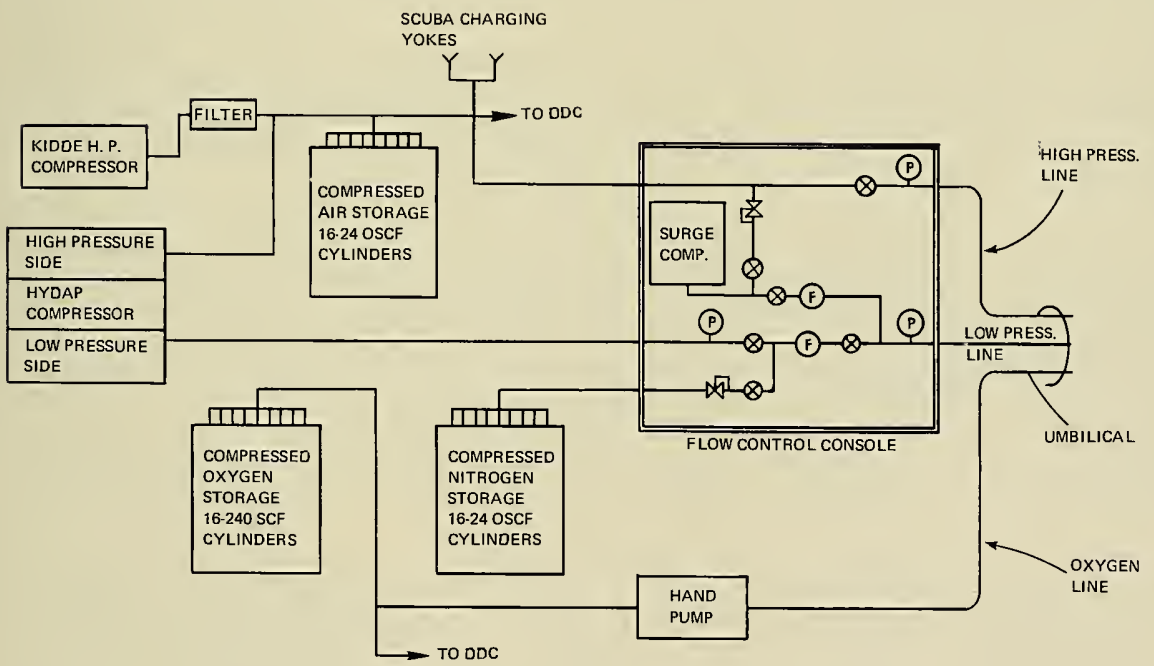

FIGURE 9.--BREATHING GAS SUPPLY SYSTEM 
with an integral 10-gallon surge tank and pressure regulating equipment built into the flow control console. The compressor plugs into a 110-VAC outlet in the biology laboratory.

This compressor must be able to supply enough air to the minitat to replenish the metabolic oxygen consumed. Oxygen consumption was projected at an average rate of 1.3 (surface) liters per minute; therefore, the surge compressor should supply an average of 14.6 liters per minute of air $(0.52 \mathrm{cfm})$ to support the two divers in the minitat. The surge compressor supplies over four times the necessary flow rate.

The low pressure purge air subsystem provides a medium flow rate of low pressure air to purge the minitat if the breathing gas becomes contaminated. The low pressure purge air subsystem can change the gas in the minitat in 3.3 hours. (Using high pressure air from the on-board compressed air supply it is possible to purge the gas in the minitat in a few minutes). The low pressure purge air subsystem also acts as a backup for the surge air system. It consists of the low pressure $165 \mathrm{psi}, 20 \mathrm{scfm}$ side of a HYDAP motor-driven compressor and the necessary plumbing to deliver low pressure purge air to the flow control console. The air hose connecting the compressor to the flow control console is also routed through the protective conduit on the deck.

The nitrogen make-up gas subsystem provides high pressure nitrogen to make up the minitat breathing gas after emplacing or purging the minitat. The nitrogen is used to dilute the air in the minitat to achieve the desired concentration of oxygen. It consists of a bank of sixteen, 240 SCF cylinders with appropriate plumbing to deliver high pressure nitrogen to the flow control console.

The flow control console controls the flow of gas from the other four breathing gas supply subsystems to provide the desired pressure, flow rate, and composition of breathing gas to the minitat. It consists of valves, pressure gauges, and flow rate meters on a panel in the Minitat Control Center (MCC). Figure 10 shows the arrangement of the flow control console.

The electrical distribution system supplies power from the ships main power distribution panel in the engine room to the minitat, the HYDAP compressor, and the PTC winch motor, Three phase, three wire, 60 cycle power is generated at 230 volts giving about 220 volts at the minitat. Circuit breakers provide 100 amps for the minitat and 100 amps for the HYDAP compressor. The minitat draws a maximum of 75 amps and the compressor an average of 27 amps. The PTC winch motor draws about 6 amps. The UNDAUNTED has two $150 \mathrm{KW}$ three phase generators. The ship normally requires $80 \mathrm{KW}$ of electrical power, therefore, with one generator operating, $70 \mathrm{KW}$ is available to support the minitat.

The communications system on the UNDAUNTED consists of the minitat communications gear in the Minitat Control Center (MCC), the psychological observers station and the ships communications equipment. In the MCC are the control intercom station, a sound powered telephone, an amplifier and speaker for the open microphone, a television monitor, and a dual channel strip chart recorder for the $\mathrm{O}_{2}$ and $\mathrm{CO}_{2}$ sensors. Figure 11 shows the minitat commications equipment in the MCC. 'A television monitor and an open microphone speaker are mounted in the chemestry laboratory for the psychological observer. The ships communication equipment consists of an RCA transmitter covering 4 to $32 \mathrm{MHz}$, a Collins receiver, an RCA receiver, an APELCO radio-telephone, and an RCA $500 \mathrm{KHz}$ auto-alarm transmitter. 


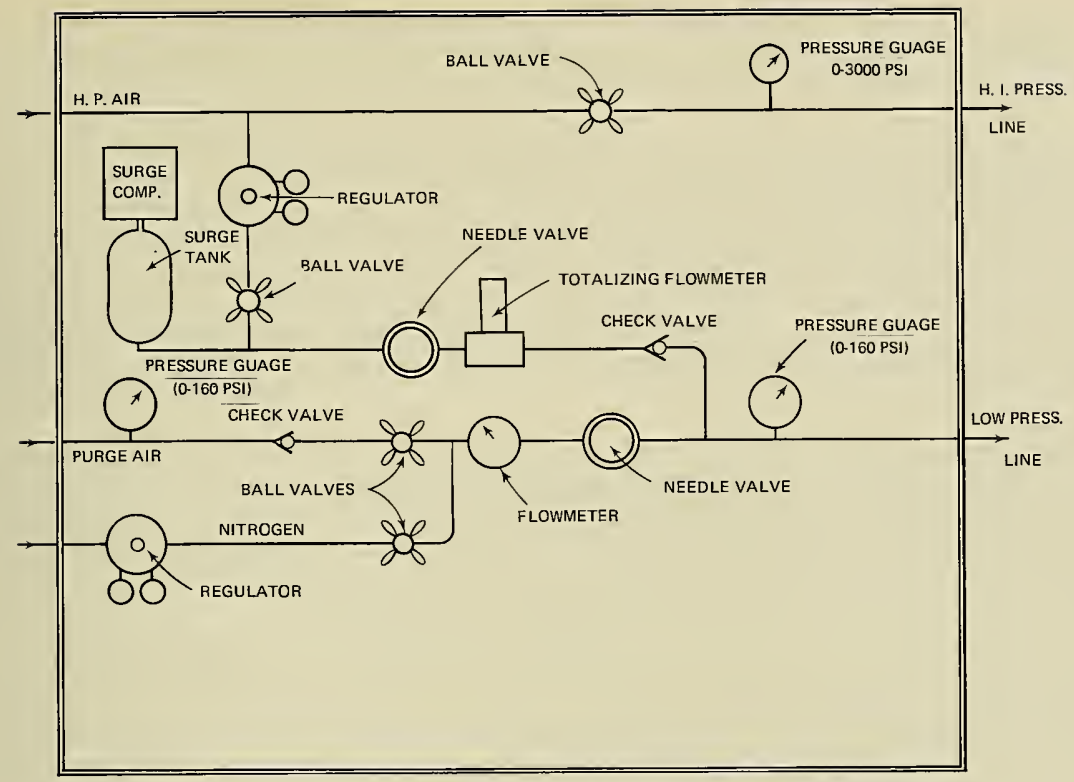

FIGURE 10.--GAS FLOW CONTROL CONSOLE

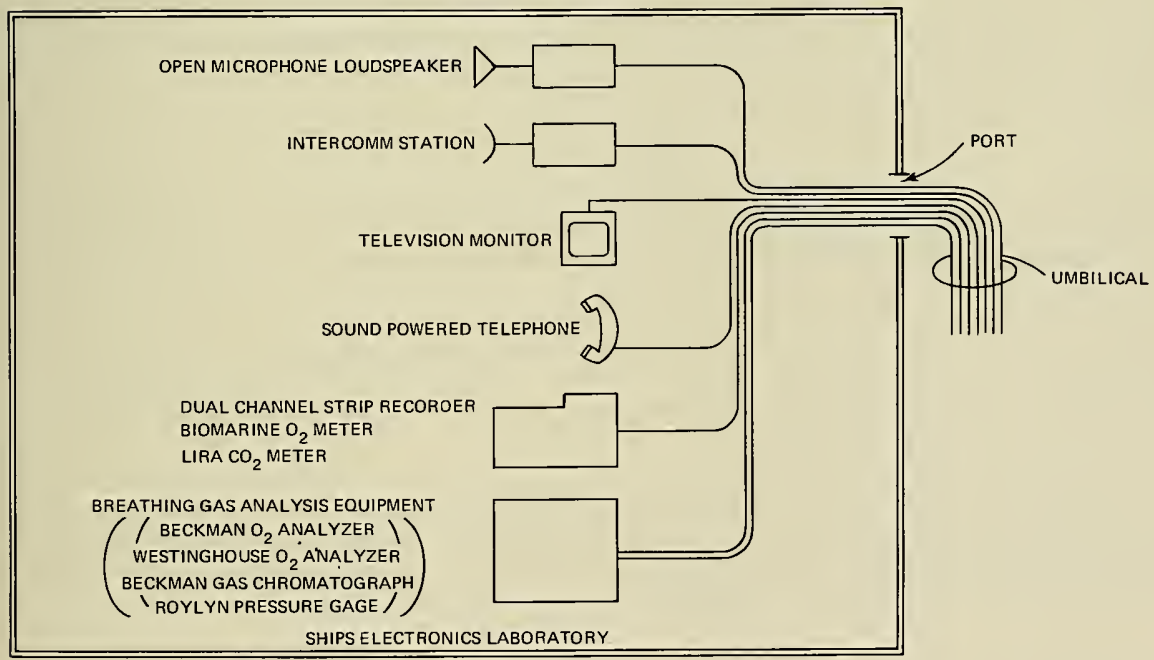

FIGURE $\mid 1 .--M I N I T A T$ CONTROL CENTER COMMUNICATIONS 
The minitat fresh water supply comes from the ships water supply via one of the three umbilicals. The ship has four fresh water tanks with a total capacity of 14,000 gallons, but no salt water conversion equipment.

Habitat services from the vessel were furnished through three separate umbilicals lashed together. The communications umbilical consists of 7 shielded pairs of 18 gauge wire and a coaxial TV cable. The fluids/gas umbilical contains a $1 / 2$ inch high pressure air line, a $1 / 2$ inch low pressure air line, a $1 / 2$ inch water line, and a $1 / 4$ inch breathing gas sampling tube. The power umbilical is a 4 gauge, 4 wire cable, encased in butyl rubber and fitted with Viking connectors. The effective length of the umbilical is 250 feet although the power umbilical itself is 320 feet long to accomodate the additional distance to the vessel breaker panel.

The minitat control center (MCC) is in the electronics laboratory of the UNDAUNTED located on the main deck amidships. It contains the minitat communications gear and gas analysis instruments. The flow control console is just outside the door in the biological laboratory, as shown in figure 8 . The MCC serves as the watch station for the minitat watch director.

The pressure vessel of the minitat is designed to serve as a decompression facility at pressures equivalent to 165 feet of seawater. A personnel transfer capsule (PTC) designed for operating depths of 1000 feet is located adjacent to the minitat in the event emergency evacuation of the minitat is necessary. The PTC is a 66" diameter sphere with on-board life support equipment, communications and an electric winch powered via surface connected umbilical. The PTC could be lifted aboard with the ships boom and mated to a decompression chamber (DDC) mounted athwartships on the support vesse1. The DDC is 54 " in diameter and contains a $7^{\prime}$ inner chamber and a $4^{\prime}$ lock. It is designed for a pressure equivalent to $450^{\prime}$ of sea water. It contains four oxygen masks and an intercom station. A control panel for the DDC and PTC is located adjacent to the DDC. It contains all valves and pressure gauges for controlling the blowdown and venting of the PTC and both chambers of the DDC.

\section{OPERATIONS}

The TEKTITE II minitat operations are described in three sections: transportation and systems tests; personnel training and shallow water trials and; site selection and pre-mission trials.

The minitat pressure vessel and other major components were transported from Houston, Texas to St. Thomas on board the U. S. Coast Guard Cutter SALVIA. Assembly of the minitat and surface support equipment aboard the UNDAUNTED took place during May and June 1971.

During this period all major and supporting systems were exercised and several minor dificiencies were detected and corrected. Installation and component testing of all support facilities on the vessel was carried out simultaneously with the minitat assembly and testing.

In late June the minitat was towed to Lameshur Bay, St. John where training and shallow water trials were conducted. Principle support personnel were drawn from the Highline College diver technician group. Other assigned personnel consisted of Public Health Service physicians, engineers and technicians from government organizations and assorted personnel from Cape Fear Technical Institute and Southern Maine Technical Institute. Personnel training was carried out along with the various unmanned tests of the minitat. 
A series of unmanned trial emplacements and recoveries were made at Lameshur Bay to determine the correct amount and placement of ballast and the proper procedure for flooding and dewatering the pontoons of the catamaran during emplacement and recovery.

The system proved to be unstable because of a shift between the center of gravity and the center of buoyancy when passing through the air/water interface. The instability resulted in an uncontrolled heeling over of the pressure vessel until its buoyancy took effect. This generally resulted in the pressure vesse1 assuming a 45 degree angle at either one of four quarters. The heeling motion did not constitute a severe problem because a correct attitude could be established soon after it occurred by additional flooding of the pontoons. It did appear ungainly, however.

To remedy the situation, the emplacement procedures were changed. The new procedure involved flooding of the forward end compartments to establish a positive down angle, followed by a sequential partial flooding of the center and after end compartments. This procedure worked well and allowed the minitat to level out with only the top of the pressure vessel above water prior to winching down operations. Figures 12 and 13 show the minitat descending through the interface and in a stable altitude after leveling out.

When the minitat is in a level attitude, with only about two feet of the pressure vessel above water the haul down procedure is started. Two hand winches having a 3,300 pound capacity are attached between bridles from the two forward corners and the two after corners of the habitat and hauldown cables connected to two 4,000 pound clumps on the bottom. When the structure is a few feet off the bottom, final flooding of the pontoons allows it to settle to the bottom.

During the shallow water trials it became apparent that the flooding and venting sequence during emplacement and recovery was not in conformity with previous calculations. Each pontoon had been divided into three separate compartments in order to eliminate much of the free-surface effect of sea water in the 35-foot long cylinders. Upon cutting into the pontoons it was discovered that the transverse bulkheads were improperly welded, permitting free exchange of sea water ballast and internal pressures between compartments. The steel bulkheads were repaired and emplacement procedures modified to prevent excessive pressure differentials which might rupture the bulkheads again. Following these repairs the minitat was emplaced in shallow water for further trials in a manned mode. The trials were carried out at a depth of 20 feet so that diver decompression would not be required.

After all systems were functional the minitat was occupied by two man teams rotated in eight hour shifts. This procedure accelerated the usage of the systems compared to occupancy by a single team of men who would have to sleep and rest about half the time. All systems were tested including the emergency systems. Meals were cooked, plumbing and life support equipment operated, scrubber canisters changed, and sleeping facilities tried out. Several minor modifications were made in the course of this manned all systems checkout.

The PTC and DDC were also exercised at this time to reveal any hardware or procedural difficulty. A team of two divers entered the PTC which was about 10 feet below the surface. The PTC was lifted aboard using the ships boom and mated to the DDC. A 5 hour simulated emergency decompression was carried out 


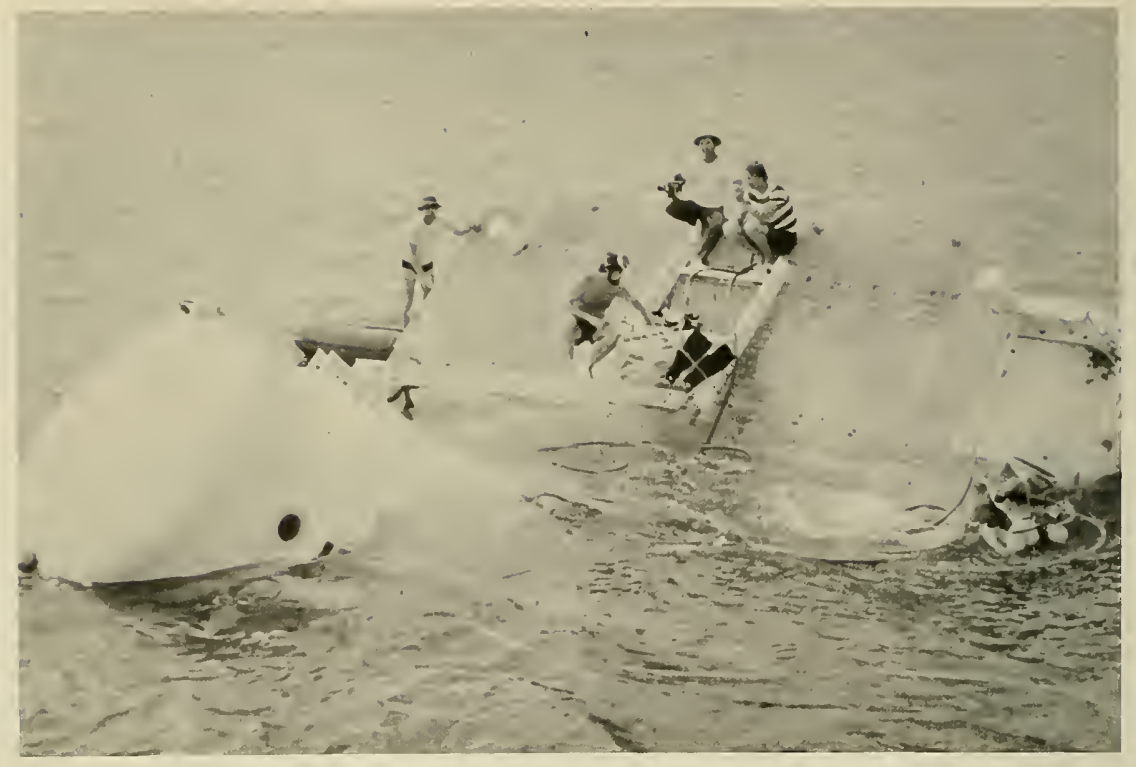

FIGURE 12:--MINITAT DESCENDING THROUGH INTERFACE

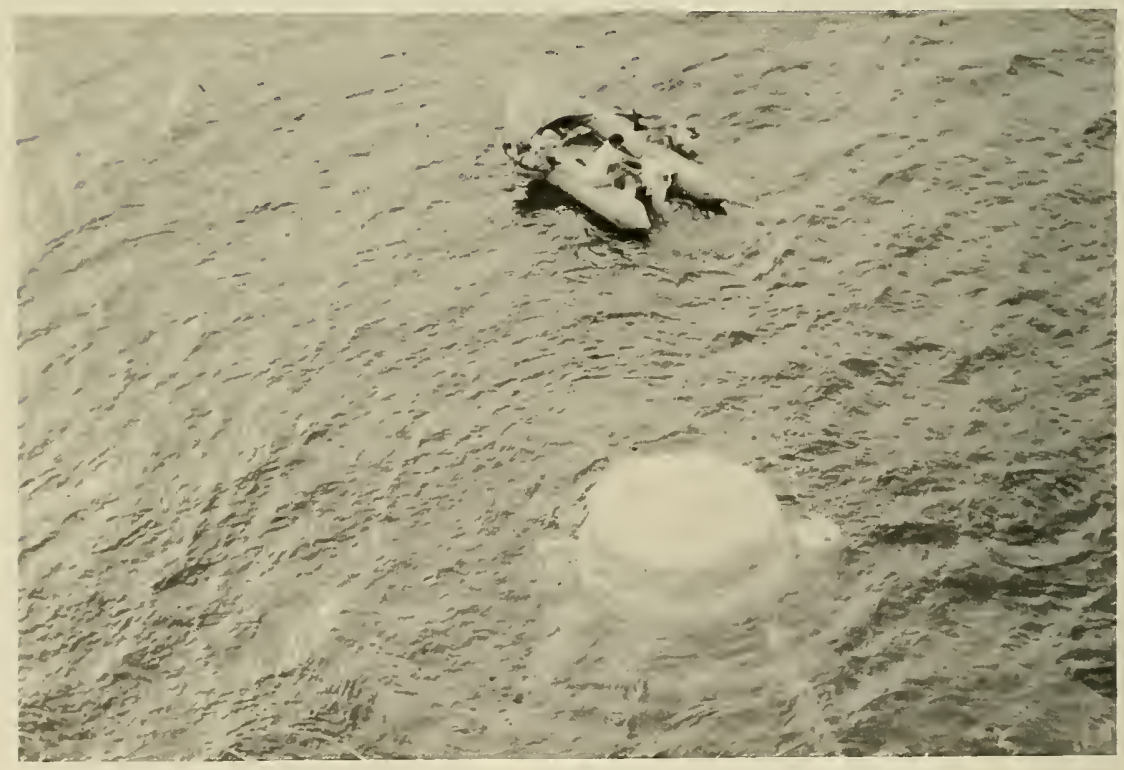

FIGURE 13.--MINITAT IN STABLE CONFIGURATION PRIOR TO DOWNHAUL 
using the 100 foot minitat decompression table (See section IX of this report) with times and depths divided by 10 . A third man was locked into the DDC to simulate a physician entering the chamber, and the medical lock exercised.

After the 20 foot trials were successfully concluded, the support vessel towed the minitat to the site selected for the operational phase. The site is in British waters (Figure 14) about 600 feet west of Pelican Island which is located off the northwestern tip of Norman Island. The site is in 100 feet of water and is well protected from wind and sea effects from all directions except out of the southwest. One of the best anchorages in the Virgin Islands, known as the Bight, is located on the northwestern tip of Norman Island about one mile from the operational site. The Bight offers excellent weather protection from all directions except out of the north-northeast. Should winds from this direction occur, weather protection would be sought in the lee of Flannigan Island or between Flannigan Island and the eastern tip of St. John Island (about 1 mile from the operational site).
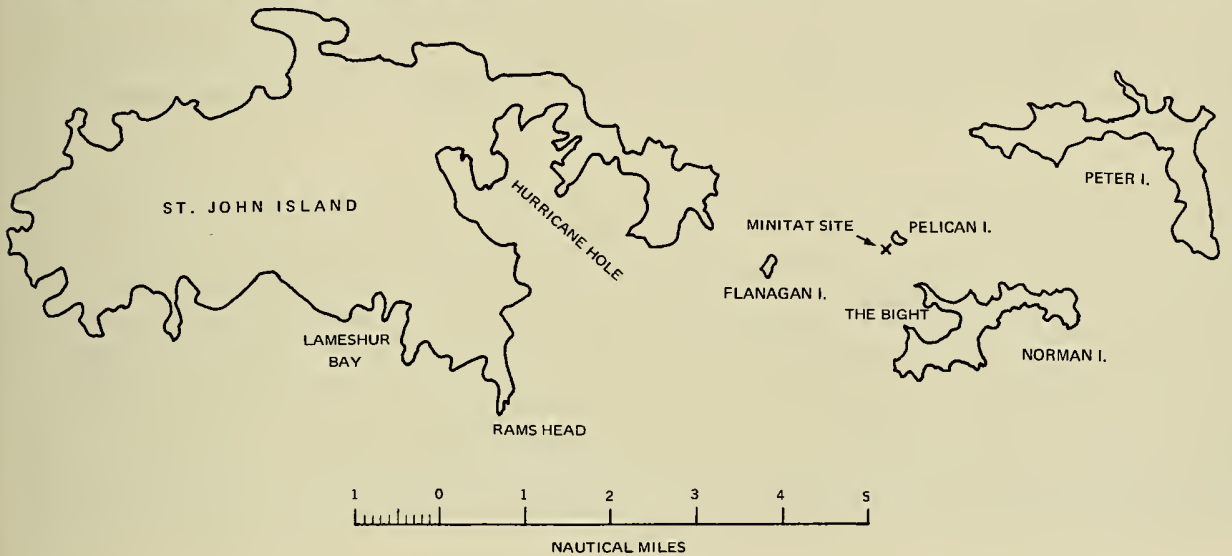

FIGURE 14.--MINITAT OPERATIONAL SITE

The bottom at the operational site has dense algal growth and many coral outcrops. From the minitat site, depths of 75 feet occur within 200 feet horizontal distance and 150 foot depths within 500 feet horizontally. These gradients allow for wide vertical excursions within fairly short horizontal distances. The observed current speeds range between zero and one half knots with excellent underwater visibility.

Once on site the support vessel assumed station using a six point mooring configuration in the lee of Pelican Island. Shortly after pre-mission trials were initiated, however, a tropical storm, out of the south, delayed furthur trials for approximately two weeks.

When the trials were recommenced it was with a certain knowledge that, due to the several delays, the time remaining to accomplish an operational dive was 
growing short. This awareness created a quicker pace and increased effort on the part of all project personnel, until inevitably, an accident occured.

During the final phase of pre-mission trials, the minitat was emplaced on the bottom and all systems activated. At the conclusion of this test it was planned to lock in two divers on the bottom and raise the minitat to the surface with the divers still pressurized to the equivalent depth of $100 \mathrm{FSW}$. Upon surfacing the divers would undergo the necessary decompression required for the length of their dive while simulating decompression from a saturation dive.

Through a critical breakdown in communications, so common in diving operations, a series of errors occured. The pontoons were partially dewatered until positive buoyance was attained and the minitat raised 25 feet off the bottom by releasing tension on the two hand winches. At this juncture the minitat was unmanned with the hatch open suspended from the bottom at a water depth of 75 feet. Due to the tension on the hand winches, and in accordance with Murphy's Law, one of the divers attempted to adjust the buoyancy in order to reduce the winch tension and make the winching operation easier. Apparently too much sea water ballast was added, creating a slightly negative condition. The minor settling caused compression of the air in the open pressure vessel, further reducing the buoyancy. This resulted in a rapid plunge to the bottom.

Upon sealing the hatch and recovering the minitat, according to specified procedures, it was found that approximately 100 to 200 gallons of sea water had entered the bilge of the minitat. After pumping out the sea water, all electrical components located near the false deck were flushed with fresh water and dried. Through a concerted effort on the part of a weary crew all of the systems were functional the following day. Inspection of the minitat revealed no apparent structural damage as a result of the hard contact with the bottom and the entire crew was eager to get on with the job. The project termination date was firm, however, based on transportation arrangements and personnel assignments scheduled earlier and with but three weeks remaining in the alloted schedule the project was suspended. A regretable decision, but in retrospect, a necessary one. 
TRAIN ING

H. H. Watters

National Aeronautics \& Space Administration

George C. Marshall Space F1ight Center

\section{ABSTRACT}

There were three primary training efforts associated with TEKTITE II: A habitat systems course in Philadelphia, Pa. for engineer aquanauts, premission aquanaut training on St. John, and watch director training, also conducted on St. John. These programmed sessions were supplemented by written familiarization materials, previously distributed to participants. Instructors for St. John training were drawn from the operational organization; training activities were coordinated by the NASA onsite representative. In addition to a cursory description of aquanaut selection procedures, each training effort is discussed below.

\section{ENGINEER TRAINING}

Aquanaut engineers were selected from a number of candidates submitted by several participating organizations. The diver qualifications of each candidate were thoroughly reviewed, each having to have completed a recognized course of SCUBA training. Each candidate received a thorough physical examination administered by his personal physician prior to arriving onsite. The results of this and final onsite medical examinations were reviewed by the TEKTITE II medical officer. Aquanaut engineer applications were reviewed by a joint NASA, DOI, Smithsonian Institution Committee which evaluated candidates' qualifications including formal or practical education in relevant technical disciplines.

In early February 1970, a11 prospective aquanaut engineers were required to attend a 3-day course conducted by the General Electric Company in Philadelphia, $\mathrm{Pa}$. The course, which consisted of combined classroom and practical exercises in the habitat, began with a description and discussion of anticipated engineer duties and responsibilities. System operation and maintenance were emphasized in this introduction. It was also explained that the engineer had the responsibility for training the four scientist aquanauts in system operation as required for safety and routine housekeeping chores.

After this general introduction, structural plumbing, environmental control, atmospheric monitoring, electrical power and communications systems were examined in depth. The general format for each system discussion consisted first of a system description, then a detailed listing of normal and contingency operating procedures (including emergency and maintenance instructions). Emphasis in each case was placed on step-by-step procedures familiarization. The final phase of the course consisted of a review of emergency procedures for fire, flooding, contamination, and habitat evacuation. In addition to discussions of actions to be taken in these circumstances, engineers were asked to name probable failures that might lead to the emergency and to recommend possible emergency repairs. 
Each engineer participant received a training manual at the beginning of the course. This document later served as a systems and procedures handbook for use during the mission. Final engineer training was completed during the 2week premission aquanaut training program described below with a special

familiarization dive to the habitat, led by an onsite General Electric engineer.

\section{SCIENTIST AQUANAUT TRAINING}

Proposals for oceanographic research were solicited from the scientific community. Aquanaut scientist candidates were selected from respondants primarily on the basis of the research proposals they submitted. Selection was made by the Ocean Floor Research Selection Panel. In addition, the diving qualifications of each aquanaut were reviewed. All aquanauts were to have completed a recognized course of SCUBA training. Results of a thorough physical examination were submitted for review by the Medical Advisory Committee.

Each team of aquanauts was required to arrive at St. John approximately two weeks prior to the scheduled start of their mission. During this period all crew members received training and briefings in operational procedures and mission rules, experimental programs, diving and support equipment, and habitat systems.

Table 1 shows a typical aquanaut training schedule; similar schedules were produced for each aquanaut team.

Table 1. Aquanaut Training Schedule

\begin{tabular}{|c|c|c|}
\hline Date & Time & Activity \\
\hline $\begin{array}{l}\text { Monday } \\
\text { Sept. } 14\end{array}$ & $\begin{array}{l}9-10 \text { a.m. } \\
10 \text { a.m. - Noon } \\
1: 30-4 \mathrm{p} \cdot \mathrm{m} \\
7-9 \mathrm{p} \cdot \mathrm{m} .\end{array}$ & $\begin{array}{l}\text { Briefing-Program Overview } \\
\text { Crew Physicals } \\
\text { Checkout Dive; Decompression Facility Familiarization } \\
\text { Briefing - Habitat Systems \& Operations }\end{array}$ \\
\hline $\begin{array}{l}\text { Tuesday } \\
\text { Sept. } 15\end{array}$ & $\begin{array}{l}9-12 \\
1-4 \mathrm{p} \cdot \mathrm{m} \\
7-9 \mathrm{p} \cdot \mathrm{m}\end{array}$ & $\begin{array}{l}\text { Rebreather Classroom } \\
\text { " " } \\
\text { Briefing - Saturation Diving Physiology }\end{array}$ \\
\hline $\begin{array}{l}\text { Wednesday } \\
\text { Sept. } 16\end{array}$ & $\begin{array}{l}9-12 \\
\text { Afternoon }\end{array}$ & $\begin{array}{l}\text { Rebreather Classroom } \\
\text { Rebreather C1assroom and 1/2-hour Dive }\end{array}$ \\
\hline $\begin{array}{l}\text { Thursday } \\
\text { Sept. } 17\end{array}$ & $\begin{array}{l}9-12 \\
\text { Afternoon }\end{array}$ & $\begin{array}{l}\text { Rebreather Classroom } \\
\text { Classroom and 2-hour Dive }\end{array}$ \\
\hline $\begin{array}{l}\text { Friday } \\
\text { Sept. } 18\end{array}$ & $\begin{array}{l}9-12 \\
\text { Afternoon }\end{array}$ & $\begin{array}{l}\text { Rebreather Classroom } \\
\text { 4-hour Dive }\end{array}$ \\
\hline
\end{tabular}


Table 1. Aquanaut Training Schedule (cont)

\begin{tabular}{lll}
\hline Date & Time & Activity \\
\hline
\end{tabular}

Saturday

Sunday A11 Day Personal Preparation

Sept. 19,20

$\begin{array}{lll}\text { Monday } & 9-12 & \text { Rebreather Written Exam } \\ \text { Sept. } 21 & 1-3 \mathrm{p} . \mathrm{m} . & \text { Briefing Questionnaires Behavioral Program }\end{array}$

$\begin{array}{lll}\text { Tuesday } & 9-12 & \text { Briefing - Habitability Assessment Program } \\ \text { Sept. } 22 & 1-2 \text { p.m. } & \text { Briefing - Microbiology Program } \\ & \text { 4-8 p.m. } & \text { Rebreather Night Dive }\end{array}$

Wednesday Morning Crew Exits DDC

Sept. 23 Personal Preparation

$\begin{array}{lll}\text { Thursday } & \text { 8-9 a.m. } & \text { Hematology Program (Blood samples, no breakfast) } \\ \text { Sept. 24 } & 9-10 \text { a.m. } & \text { S1it Lens Eye Examination } \\ & 1-2: 30 \mathrm{p} . \mathrm{m} . & \text { Briefing - Program Safety }\end{array}$

Friday Al1 Day

Personal Preparation

Sept. 25 4-5 p.m.

Habitat familiarization Dive (Engineer mandatory a11 others optiona1)

$\begin{array}{lll}\text { Saturday } & 9-10 \mathrm{a} . \mathrm{m} . & \text { Habitat Familiarization Dive - Engineer On1y } \\ & 1200 \mathrm{hrs} . & \text { Begin Mission - Dive off DDC Barge, Swim to Habitat }\end{array}$

As shown, crew physicals and qualifying dives constituted the first items on the agenda. The physicals, described elsewhere, were aimed at assuring that the crewman's health had not significantly changed since he submitted his initial medical report early in the selection process. Even though all candidate aquanauts had been required to supply evidence of diving qualifications, each was taken on a qualification dive before further training proceeded. This dive, conducted by the onsite diving safety officer, confirmed the candidate's proficiency and comfort in the water.

Early in the training schedule trainees were given a general orientation or program overview by an onsite program official. This briefing described the overall scope of activities and familiarized candidates with the local operational situation. The roles of all participants and their relationship to the aquanauts were briefly discussed. Also described were Park Service and College of Virgin Islands rules and regulations. 
Habitat, decompression and support systems were the subject of special discussions and demonstrations. All crewmen were required to demonstrate proficiency in the operation of the various valves and hatches of the Personnel Transfer Capsule (PTC) and Deck Decompression Chamber (DDC). From the command site, the duty systems engineer described the habitat and the various shorebased facilities.

The physiology of saturation diving was discussed with the trainees by the Medical Officer. This presentation of specially prepared slides and text traced physiological effects of saturation and stressed possible hazards.

It was necessary during the 2-week premission period for trainees to complete a number of psychological questionnaires to be used as normative data by behavioral and habitability researchers. The administration of these questionnaires was combined with briefings explaining the objectives of the program and outlining the need for further aquanaut participation during the mission.

Other experimental programs such as microbiological assessment were the subjects of special briefings.

The most extensive training effort was aimed at creating thorough proficiency in the use of the Mark 10 rebreather unit. This training, conducted by General Electric personnel, included detailed classroom preparation supplemented by at least $10 \frac{1}{2}$ hours of actual rebreather diving, including a 4-hour night dive. In all phases of this training, off nominal as well as normal system operation was discussed and practiced. Each candidate was thoroughly trained in the pre and postdive maintenance procedures for his unit. No aquanaut was permitted to use the Mark 10 operationally without completing this course and passing a written examination covering the subject matter.

It was found that the aquanauts needed approximately two complete days for personal preparation prior to their scheduled missions. The best time to schedule this "free time" seemed to be near the end of the training cycle when they had a better understanding of special gear they might need.

Program Safety was the topic of one of the last scheduled aquanaut briefings. During this briefing, all items of safety gear (pingers, emergency balloons, and strobe flashers) were explained and demonstrated. Safety procedures, excursion limits, dive plan reporting requirements, possible hazards, etc. were thoroughly discussed.

\section{SUPPORT CREW TRAINING}

Prior to the beginning of Mission 1, extensive training and familiarization with support facilities was carried out. The support divers were thoroughly indoctrinated in the functioning and operation of the decompression system. Constant drills were executed prior to and during all missions.

Similarly, training was carried out with all diving and safety equipment. As support diver replacements arrived, they were trained (primarily on the job) and were scheduled systematically with experienced crews until they were completely familiar with all the essential systems. 
Orientation and training on the utilities support equipment was also a continual task. This was performed by detailed checkout of routine and emergency procedures.

In general, training rather than a specific block of schedule was a constant process. This was necessary due to changing requirements and to personnel turnover.

\section{WATCH DIRECTOR TRAINING}

Watch directors were chosen primarily from Department of the Interior middle management and professional career employee ranks, with grade levels GS-11 and above and approximately 10 years of field, professional, or related experience.

Watch director teams arrived onsite one to two weeks prior to going on duty. A typical watch director training schedule is shown in Table 2 . In cases where new watch directors and aquanauts arrived simultaneously, many briefings served both groups.

Most of the watch director training consisted of on-the-job training with the incumbent watch directors leading trainees to assume an ever greater share of responsibility.

New watch directors were given a copy of the Mission Operations Handbook (a document written and frequently updated onsite) which they were encouraged to discuss with the incumbent watch directors and the mission director.

At some point during the on-the-job training, candidate watch directors participated in a simulated emergency situation which involved aquanauts and the entire watch section. This drill usually included a "power down" associated with a simulated wet room flood.

Near the conclusion of the training session, all incoming and outgoing watch directors met with the mission director for an intensive "skull session" during which the Mission Operations Handbook was thoroughly reviewed and any questions answered.

During the training period and all during their tours, those watch directors without a diving background were encouraged to learn as much as they could about SCUBA diving. It was found that relations between aquanauts and "topside" were enhanced if watch directors had a firsthand understanding of diving. 
Table 2. Training Schedule Watch Directors

\begin{tabular}{|c|c|c|}
\hline Date & Time & Activity \\
\hline Monday & $\begin{array}{l}9-10 \mathrm{a} \cdot \mathrm{m} \\
1: 30-4 \mathrm{p} \cdot \mathrm{m} \text {. } \\
\text { Evening }\end{array}$ & $\begin{array}{l}\text { Briefing - Program Overview } \\
\text { Decompression Facility Briefing; Habitat Familiar- } \\
\text { ization } \\
\text { Individual Study Program Plan and Mission Operations } \\
\text { Handbook }\end{array}$ \\
\hline Tuesday & $\begin{array}{l}\text { Morning } \\
\text { Afternoon } \\
7-9 \text { p.m. }\end{array}$ & $\begin{array}{l}\text { On-the-job Training } \\
\text { " " " } \\
\text { Briefing - Saturation Diving }\end{array}$ \\
\hline Wednesday & $\begin{array}{l}\text { Days \& } \\
\text { Nights }\end{array}$ & $\begin{array}{l}\text { Trainees will stand regular watches gradually } \\
\text { assuming greater share of duties }\end{array}$ \\
\hline Tuesday & $\begin{array}{l}0930 \\
1-2: 30 \mathrm{p} \cdot \mathrm{m} \\
7-9 \mathrm{p} \cdot \mathrm{m}\end{array}$ & $\begin{array}{l}\text { Crew Exits DDC } \\
\text { Rebreathers Briefing } \\
\text { Behavioral and Habitability Briefings }\end{array}$ \\
\hline Wednesday & $\begin{array}{l}10-12 \\
7-9 \mathrm{p} \cdot \mathrm{m} \text {. }\end{array}$ & $\begin{array}{l}\text { Program Safety Briefing (Aquanauts and Watch } \\
\text { Directors } \\
\text { Sku11 Session - Review of Mission Operations } \\
\text { Handbook }\end{array}$ \\
\hline Thursday & A11 Day & Free Time \\
\hline Friday & $1200 \mathrm{hrs}$. & Next Mission Begins \\
\hline
\end{tabular}


Robert J. Schmidt, Jr.

General Electric Company

\begin{abstract}
During the TEKTITE II Man-In-The-Sea Program, 48 aquanaut scientists were exposed to a seven day training course in the use and maintenance of the Mark X Closed Circuit Rebreather. This course included 30 hours of classroom instruction on the use and maintenance of the Mark $X$ and at least 10 hours of in-water use of the unit. A sample training schedule and written test are included in this report.
\end{abstract}

\title{
EQUIPMENT
}

The equipment used for this course was the General Electric Company's rebreather Mark X, Mod 1 and Mod 3, the Mod 3 being the newer version of the Mark X. The Mod 1 was used by the aquanauts on Missions 2-50,3-50, and 4-50, and on subsequent missions was used as a backup training unit. From mission 5-50 on, the Mod 3 was the prime unit for the aquanaut habitat missions.

The Mod 3 rebreather is a self-contained, back mounted, closed-circuit rebreather featuring automatic and manual control of the oxygen partial pressure. It weighs approximately 65 pounds, has a canister containing enough baralyme for a twelve hour dive, and a depth capability of 1500'. The main differences between the Mod 3 and the Mod 1 are easier and quicker maintenance of the Mod 3, the Mod 3's breathing bag configuration versus the Mod 1's diaphragm unit, the disposable scrubber cartridge of the Mod 3 versus the repackable scrubber in the Mod 1, and finally the lighter weight and better packaging of the Mod 3.

For the first few missions of TEKTITE II the rebreathers were limited to one dive per baralyme canister not to exceed four hours of use. Later, as the program progressed and more experience and a higher level of confidence in the Mark $\mathrm{X}$ was achieved, the time limit was changed to six hours use within an eight hour period. This later time limit allowed more versatile use of the Mark $X$ and was still well within design and safety constraints.

\section{OBJECTIVE}

The main goal of the Mark $X$ closed circuit rebreather training course was to give the TEKTITE II aquanauts a thorough knowledge of the functioning and maintenance of the Mark $X$. No diving or diving principles were taught during the course so that the total time allowed could be devoted exclusively to the use and maintenance of the Mark X. 
The course gave each aquanaut an intimate understanding of the functions and malfunctions of each system in the Mark $X$ so that in the case of an emergency, an aquanaut could think his problem through and apply the right corrective action without endangering his safety. The written test given the aquanauts at the close of their training determined their level of understanding of the Mark X. The swimming portion of the training course was primarily to observe the aquanaut and determine his proficiency in the use of the Mark X.

\section{PROCEDURES}

The training program that gave the aquanauts a thorough understanding of rebreather maintenance, functioning, and malfunctioning was designed with the help of an on-site diving officer and the operations director. The water portion of the course was programmed to allow the aquanauts to gain familiarity with the Mark $X$ while swimming and working with the unit. The training schedule was a seven day program defined as follows:

Sample Training Schedule

\section{First Day - Morning and Afternoon Session}

Morning

1. Discussion of rebreather operation

2. Description of rebreather parts

\section{Afternoon}

1. Description and discussion of rebreather malfunctions and solutions

2. Beginning of maintenance

\section{Second Day - Morning and Afternoon Session}

\section{Morning}

1. Review of rebreather functioning and malfunctioning

2. Maintenance

\section{Afternoon}

1. 45 minute swim - shallow water - escorted - no program $\underline{\text { Third Day - Morning and Afternoon Session }}$

\section{Morning}

1. Review of malfunctions

2. Maintenance 


\section{Afternoon}

1. 2 hour swim - escorted. One hour manual - remove mouthpiece underwater - 30-40 feet

\section{Fourth Day - Morning and Afternoon Session}

\section{Morning}

1. Review of malfunctions

2. Maintenance

\section{Afternoon}

1. 4 hour swim - unescorted. Surface support - no program

\section{Fifth Day - Morning and Afternoon Session}

Morning

1. Rebreather review

2. Rebreather quiz

\section{Afternoon}

1. Nothing

\section{Sixth Day - Morning and Afternoon Session}

\section{Morning}

1. Rebreather maintenance

\section{Afternoon}

1. 4 hour swim - no escort. Surface support - 2 hour daylight time 2 hour night time

\section{RESULTS}

At the completion of each training period, a written test (see Appendix 1 for sample test) was given and the results of these tests were discussed by the class members. The score on this test was one factor used to judge a candidates ability to use the unit during their dive. The rebreather training program resulted in a team of aquanauts who individually had a minimum of ten hours supervised water time using the Mark $X$ and a sufficient working knowledge and understanding of the maintenance and functioning of the rebreather to carry them safely through their mission. 
The major conclusion reached from the rebreather training course on TEKTITE II is that it safely fulfilled its primary purpose to train aquanauts in the maintenance and use of a closed circuit diving apparatus. More divers spent more in-water hours on a closed circuit diving unit than ever previously recorded. This feat alone speaks very highly of the training and of the reliability of the Mark X rebreather. Although the units suffered from the problems associated with the introduction of any new gear, the problems that did arise were diagnosed and corrected by the aquanauts. Their training and personal diving capability are what kept malfunctions from becoming serious problems.

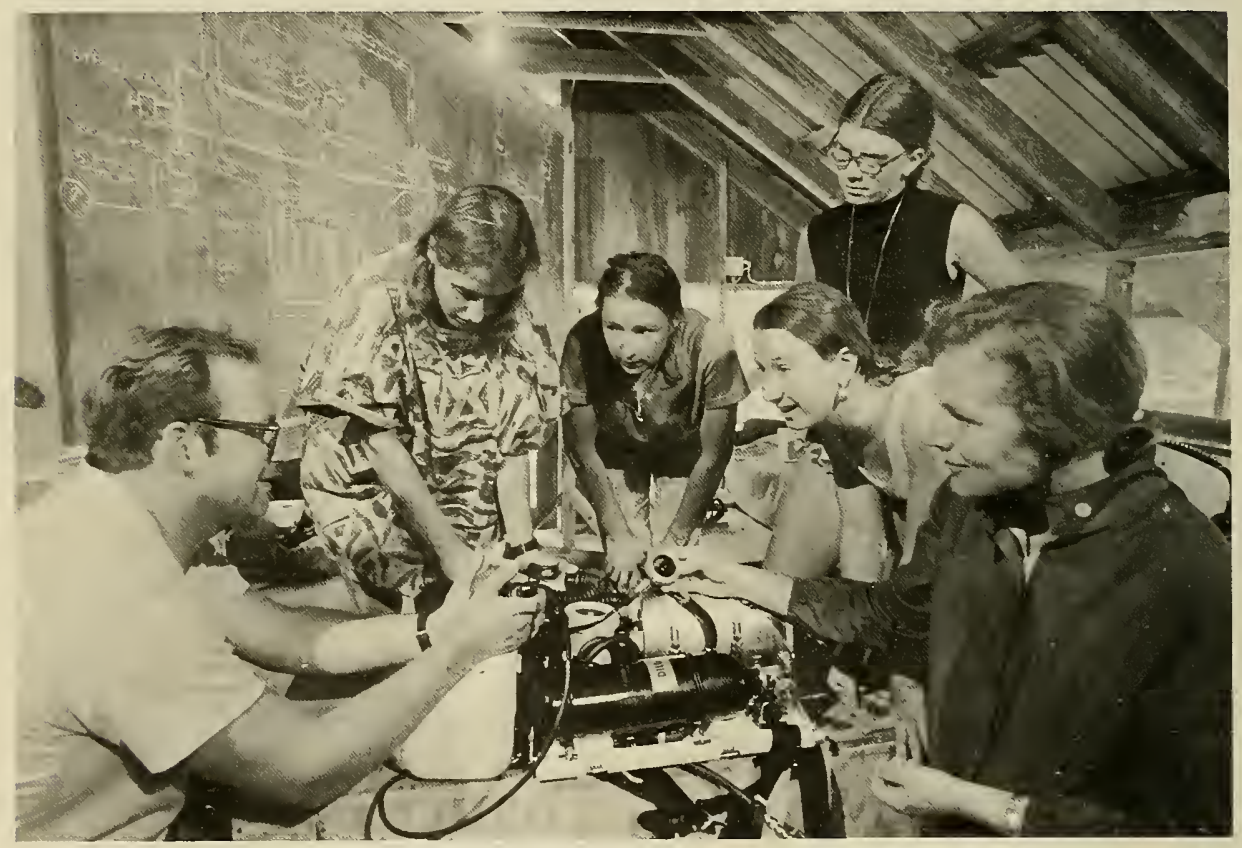

Figure 1. Mark $\mathrm{X}$ maintenance and function instruction prior to Mission 6-50. 
NAME

DATE

1. The MK-X diving apparatus contains oxygen sensor devices?
a. 2
b. 3
c. 4
d. 5

2. A red warning light in the wrist display of the MK-X would indicate:
a. low battery voltage
b. oxygen level above range
c. oxygen level below range
d. any of the above

3. The minimum voltage in the battery pack at the start of a swim will be volts.
a. 25
b. 26
c. 28
d. 30

4. The main oxygen indicator in the $\mathrm{MK}-\mathrm{X}$ is the:
a. wrist sensor display
b. yellow or red warning light
c. chest display
d. any of the above

5. When starting a dive, using the MK-X, what is considered the minimum cylinder pressure?
a. oxygen 2200 psi, diluent 2200 psi
b. oxygen 2000 psi, diluent 2000 psi
c. oxygen 1700 psi, diluent 2200 psi
d. oxygen 1500 psi, diluent 2000 psi

6. The MK-X diving apparatus is:
a. closed circuit, mixed gas unit
b. semi-closed circuit, mixed gas unit
c. closed circuit, oxygen breathing unit
d. semi-closed circuit, oxygen breathing unit 
7. The canister 1 ife is considered to be hours, regardless of depth.
a. 3
b. 4
c. 5
d. 6

8. The red alarm light would be actuated by low battery voltage if the voltage drops below volts.
a. 22
b. 22.5
c. 23
d. 23.5

\section{TRUE OR FALSE}

9. In the event of automatic oxygen supply system failure, the diver may swim the MK-X in the manual mode at any depth.

10. If the chest display switch is in the off position, the diver will receive no reading as to the amount of oxygen in his breathing.

11. On the MK-X, both the diluent and oxygen system loops have manual bypass valves.

12. In the MK-X diving apparatus, the volume of breathing bags is approximately 6 liters.

13. When operating the MK-X unit in a manual mode, the automatic control must be in the off position.

14. During normal swims, the MK-X unit will maintain the oxygen content in the breathing media at 0.4 atmospheres.

15. While using the MK-X unit, the baralyme cartridge need not be changed if the first swim was of a short duration according to mission rules.

16. While swimming the MK-X unit, if the red light goes on and stays on, then the swimmer should go to a manual mode of operating.

17. As long as the oxygen content in the breathing media stays in range or above range, the red warning light will not go on in the wrist display.

18. The battery may be stored indefinitely connected to the charger without damage.

19. The risk of the diver getting the bends is greatly reduced by using closed circuit SCUBA instead of the open circuit type at deeper depths. 
20. The wrist display sensor in the MK-X unit works completely independent of battery and electronics pack.

21. In the event of a malfunction to a MK-X unit during a swim, it is possible to buddy breathe from one unit with two divers.

22. A fully charged battery package should last for approximately 8 hours at any depth.

23. A divers primary observation during a dive is the condition of the red or yellow warning light on the wrist display.

\section{SHORT WRITTEN ANSWERS}

24. Under normal conditions, what are the two main causes for loss of diluent?

25. Give a brief description of the control breathing check.

26. Which hand controls the diluent bypass valve? The oxygen bypass valve?

27. Describe the procedure for transfer of a unit to the surface from the habitat.

28. If your chest display is in the low battery position, at what level will the oxygen level be controlled?

29. What are the normal display readings for the wrist and chest display while conducting an air check on the surface?

IN EACH OF THE FOLLOWING CONDITIONS, GIVE THE PROBABLE CAUSE, IF APPLICABLE, AND COURSE OF ACTION YOU WOULD TAKE:

30. $\mathrm{A} 11 \mathrm{pO}_{2}$ sensors reading within range, a red light is on.

31. Both the yellow and red lights are lit on the wrist display.

32. $\mathrm{A} 11 \mathrm{pO}_{2}$ sensors reading within range, no yellow 1 ight, no red light.

33. Any one of the three $\mathrm{pO}_{2}$ sensors is fluctuating every 5 seconds.

34. You are having trouble inhaling and equalizing.

35. You are having no trouble breathing, but you feel you are not getting enough air and you sense a change in your well-being.

36. Exhalation effort is increasing. 
37. You are experiencing a tired and dizzy feeling, or twitching sensation, wrist display is reading low, no lights.

38. One of your control sensors is reading very low or negative, the other control sensor is reading normal, unit functioning normally.

39. You are flooding with air, oxygen sensors rising rapidly, unit venting.

40. One of the control sensors is reading abnormally high, the other control sensor is falling and in agreement with the wrist display, red light is on.

41. Your wrist display is falling, dim yellow light, no chest display readings.

42. Al1 sensors reading low, red light on, bottle pressures ok, oxygen bypass is hard to push, battery level ok. 


\section{EDITORS NOTE}

The following treatise, prepared by one of the TEKTITE watch directors from the Department of the Interior, was forwarded to the program office several months after the program was completed. The document so aptly describes conditions existing throughout much of the program that it was decided to include it as part of the program report. It conveys quite well the spirit of the program which is so difficult to describe in an otherwise formal report.

People, and what they did, is what this report is all about. Scientific accomplishment was the purpose of TEKTITE II and many people's reward for their efforts. Not only the efforts of the aquanaut scientists who performed brilliant research tasks underwater, but the equally strenuous and inspired efforts of support personnel above water. It was they who watched over the aquanauts and insured them against the many hazards that might disturb their lives beneath the sea.

Little has been said for those topside who provided vital "logistic support" for the 11 missions of TEKTITE II. Since their efforts were crucial to the success of these missions, how and what they did is just as important as what the aquanauts themselves accomplished. This treatise is devoted to what motivated the topside team to perform their tasks so well.

Early in the project the judgment was made to staff the project from a wide range of disciplines. And rather than fix solely upon specific required talents, to look as well for what else each selected individual could offer the program: There indeed proved to be nothing routine or ordinary about the tasks these individuals would be called upon to do; thus, this method of selection proved to be an immensely sound judgment.

Life in a bush camp was a brand new experience for many of these people. And a bush camp it was, complete with all the "amenities" of damp cots, humid sticky weather, drenching rains, the ever-present contingents of bugs, lizards, spiders, and other crawling things they'd have to make friends with--and roads that were forever a sea of mud.

After a brief period of shock, each fell to, many finding themselves doing things they never thought they could. Nowhere had there been earlier mention of such tasks in their list of duties: They found that much of what they were called upon to do fell within that classic last line of most job descriptions, "... and other duties as assigned." Now, far from their nine-to-five coat-andtie desk jobs, they quickly abandoned both: There were jobs to do all the time, and a dress fashioned somewhat along the lines of Blackbeard's crew proved to be their best choice of habit for bush camp living.

A sense of humor became every man's best friend--and the grease that allowed this strange society of talents, so far from home, to function smoothly. This 
humor soon infected all and became a vital part of how each man 1ooked upon his lot and dealt with others. It would crop up in the oddest circumstances: With a perfectly straight face, one old hand (a commuting medic) dryly observed on one of the few days the road to Base Camp was uniquely dry, "You're going to have to get a crew busy pumping water back on this road: It's almost dry, you know!"

Strangers to Base Camp and TEKTITE II's operations sometimes reacted adversely to what might on first sight have made a bad impression: "You can't run a government operation like this!" "Isn't there anybody in charge here?"

It was unsightly, at times. (Particularly after a storm.) And there was someone in charge (although you couldn't tell by looking at him): Most every individual there, at one time or another, was called upon to fulfill a vital role in order to handle one or another of the constant string of unique problems that beset TEKTITE II. And they did so, consistently and well.

What often seemed illusive to newcomers was TEKTITE II's greatest asset: An esprit and elan that no amount of money could have bought. TEKTITE II was indeed not blessed with vast sums of money. While there was enough to do the job, it meant that though the needs of the aquanauts were met, the material needs at Base Camp were sometimes wanting: When the aquanauts were dining on frozen Apo11o-type dinners, the menu at Base Camp often featured goat or salt fish (both healthy fare, but courage-taxing for the newly initiated).

But this was good. There proved to be just the right measure of paucity to bring out the best in everyone. "Make do" became a basic mode of doing business. Repair, rather than replace, was a prime requirement. "Can you fix it" was asked about until someone was found who could, rather than ship the malfunctioning device away and be deprived of its use for want of minor repair.

Positions of rank simply couldn't--and didn't--mean much here. Besides, you couldn't tell who was what by looking at them anyway. One big burly bald and bearded fellow, dressed in what looked like surplus garb from a pirate vessel, was one of the accomplished physicians whose job it was to keep people healthy. The sandaled feet sticking out from under an ailing jeep sometimes belonged to a middle management government executive who just happened to be gifted at transmission repair: If he didn't pitch in during his off hours and help the beleaguered mechanic, the jeep would be idle yet another day awaiting repair.

It brought out the best in each of the incredible mix of disciplines that were collected here and--most important--a will and commitment on each person's part to perform his assigned tasks at "best-effort" levels, all the time. Because of this, no one turned down a request if he could do it (simply because "it isn't in my job description"). "No sweat" was the usual answer--later expressed as "no big 'ting, mon," as the local Virgin Island term for it took hold.

A healthy social structure grew out of this that made an otherwise stark bush camp come to life as a focal point of continual excitement, interest, and thriving activity. When not patching something vital, leisure hours were increasing1y exploited in fruitful ways. Each person's interest was satisfied in a wide variety of actions: Exploration, underwater photography, orchid hunting; coconut-carvings and driftwood sculpture hung in many huts. 
Bureaucratic squares were rounded, and they found the long haired youth supporting the project were people after all. Midnight "dialogues" became vital. People melded into friendships that will last for years to come.

TEKTITE II had its moments of alarm and anxiety. Equipment failure is a way of life in such a place. The problem of meandering hurricanes kept watch directors and project managers pouring over charts--and very much on the qui vive.

The feeling of humor, esprit, and elan--that kept support functions ticking-served equally to oil the vital judgment mechanism that was so important to the program's undersea missions. Little happened of an unexpected nature that took anyone by surprise. There was never any panic, for no one had cause to over-react to crises. Since who could do what was well known, it was always easy to muster a gang of the right people to tackle any chore--above and beyond assigned duties.

Strangers might witness what seemed to be an unwarranted casualness on everyone's part, but casualness it wasn't. Rather they had a handle on things that helped them find the broadest and most knowing approach possible in solving what often seemed to outsiders insurmountable problems. This hidden confidence coupled with a basic rapport and commitment is what kept scrubbed missions to a minimum and enabled TEKTITE II to enjoy a perfect safety record.

TEKTITE II is over, and the members of its unique society are gone. Some left reluctantly, for they knew full well what they were leaving behind. Those few who left eagerly--to realize, too late, what they got out of it--suffer the most: They now wish they'd made better use of their time.

TEKTITE III was born at Lameshur Bay. Not by program plans, or by decrees, but in the wishful minds of those who had so rewardingly exercised their newly discovered "best" at TEKTITE II. It was only natural to hope an opportunity to repeat such successes would offer itself. It was this "best" in people that was brought out by the informal manner in which operations at TEKTITE II were executed, and that contributed so much to the success it was. The impact of this on those who helped make it successful is eloquently echoed in many of the letters that have since been exchanged by them:

"...we are finally managing to absorb the...cultural shock of re-entry... A necktie is very like a noose, isn't it?"

"I really did so enjoy my sojourn... I will never be that which I was before."

"For sure, in retrospect those wet, buggy, insane islands look better and better as the days pass."

"...most of us no longer respond to organizational 'imperatives' in a way our superiors understand."

And in a11 their letters there is the unspoken regret that it now seems so long ago and far away. If ever there is a TEKTITE III, a host of veterans from 
TEKTITE II will be the first to prick up their ears at its mention and rush to get in the recruiting line.

If a similar mission does indeed materialize at some future date, from the onset it should seek to profit from TEKTITE II's experience and to capture this same illusive spirit that served TEKTITE II so well. No sum of money nor the finest of equipment and facilities can substitute for this spirit when it comes to insuring such a program's safety and success.

(One of the Topside Crowd from Lameshur Bay) 
PUBLIC AFFAIRS PROGRAM

Mark N. Silverman

\section{ABSTRACT}

The objectives, policies, organization, and operation of the Public Affairs Program are described. While problems were encountered, many specific achievements are pointed out. Over a thousand persons visited the site under the direction of the Public Affairs Office including the Prime Minister of Canada. Suggestions are made as to how future programs might benefit from our experience.

\section{OBJECT IVE}

The initial objective of the TEKTITE II Public Affairs Program was: to satisfy the requirements of the news media and interested agencies and to inform the public of the nature, scope, and significance of the TEKTITE Program and its research objectives. Additionally, it attempted to stimulate public interest in the exploration and development of the ocean's resources as a worthy national objective, and document activity for historical purposes.

\section{POLICY}

The stated public affairs policy was as follows: "The Public Affairs policy will be implemented by the Director of Public Affairs, or his designated representative. All participants will be given equitable and appropriate coverage. All participants are further encouraged to develop their own public affairs programs; however, each participant must obtain prior approval for news releases, advertisements, etc. from the Director of Public Affairs, and then are encouraged to aggressively implement these. Cooperation will be extended to a11 newsmen and other guests within the limits of safety and scheduling."

\section{ORGANIZAT ION}

The Director of Public Affairs reported to the Program Manager. It was envisioned that each participating agency would send at least one public relations professional to the operational site for a minimum period of two weeks at a time. Thus there would be a minimum of two professionals and a secretary on duty in the office of Public Affairs. Plans also called for additional professionals to be on site during major events where heavier press attendance was expected. Unfortunately, personnel shortages did not permit these plans to be fulfilled.

\section{OPERATIONS}

The public affairs program was conducted primarily from a three room house trailer located at the National Park Service Dock at Red Hook on St. Thomas. The Office of Public Affairs opened on March 15, 1970, and remained open until November 10, 1970. The staff consisted of the Public Affairs Director, a secretary/receptionist, and intermittently. a public relations officer from one of the participating organizations. 
Equipment in the Office of Public Affairs, other than such normal items as typewriters, included: a radio relay to the Command Van and, when atmospheric conditions were right, to the Base Camp; a Xerox 660-1 copy machine which proved margina11y adequate--a larger machine should be used in future operations; and a telephone system that included three lines with extensions on each of the five desks.

The Office of Public Affairs not only processed all visitors to the site but also arranged tours and itineraries for these visitors, set up interviews for the press, arranged dives to the habitat where they did not conflict with operations, and provided technical guidance for both still and motion picture photographers of the news media.

Whenever possible, the Director of Public Affairs or another representative of the Office of Public Affairs met visitors at the airport and provided necessary transportation and assistance during their visit.

For the first two-thirds of the program, the office was kept open from 7:00 A.M. to $6: 30$ P.M., seven days a week. However, with the decrease in personnel the last third of the program, it was necessary to close the Office on Sunday. On two occasions, during a hurricane alert, the Office was kept open around the clock in order to insure that communications with the operational site were maintained.

\section{COMMUNICATIONS}

As indicated above, in addition to the telephones there was a citizen's band radio connecting the Public Affairs Office with the Command site and the Base Camp. For field operations of this type where high public interest potential exists, there should also be a teletype system and/or radio link directly to the parent organization's headquarters to both speed the release of information and expedite communications between the field and home offices. Future operations might also include a Xerox telephone transmitter which can send "hard copy" directly in four minutes.

\section{DISCUSSION}

Three organizations sent personnel to provide support to the program: the Department of the Interior, the Department of the Navy, and the General Electric Company. A total of seven support personnel were distributed over the 8-month period. On special occasions there were adequate personnel but generally the on-site staff worked long and hard to keep up.

Although the Public Affairs Office was understaffed, an average of two news releases were made each week and at least one press conference was conducted per week in the Virgin Islands. An average of 25 visitors were accommodated each week as well.

Every effort was made by the Public Affairs office to insure that all agencies received credit for their role in the program. This proved to be a most interesting aspect of the multiagency program. Each participant contributed significantly to the success of TEKTITE II, and it was appropriate, even advisable, to insure that everyone's role was acknowledged. To that end, virtually every release issued contained at the very least a concluding paragraph crediting each 
participating organization. In addition, separate releases were generated on the roles of the Highline Community College students, the University of Texas students, the medical personnel from the University of Texas Medical Branch, and the support divers from the Department of the Army. Stouffers Foods Company prepared a separate press kit and conducted a press conference in Cleveland, Ohio, after clearing the material with the Public Affairs Office. The General Electric Company also prepared a number of stories and hand-outs. Additionally, more than 2,000 requests for CACHETS were honored from philatelists throughout the United States and more than a dozen other countries.

\section{VISITORS}

Among the list of distinguished visitors were Prime Minister Pierre E. Trudeau of Canada, Secretary of the Interior Walter J. Hickel, Assistant Secretaries of the Interior Leslie L. Glasgow and James R. Smith, Assistant Secretary of the Army Eugene M. Becker, the Ambassadors to the United Nations from Yugoslavia, Australia, and the Sudan as well as some 30 other members of the United Nations Seabed Committee and nearly 30 of the Washington based foreign science community. Official observers came from such countries as Korea, Japan, Canada, Argentina, Mexico, France, and Sweden. Several members of Congress also visited the program, including Senator Ernest F. Hollings, member of the Banking and Currency Committee and Commerce Committee, Congressman A1ton Lennon, Chairman of the House Subcommittee on Oceanography, and Congressman George E. Shipley of the Appropriations Committee.

In general, the visitor program went well, especially in terms of results. An effort was made such that all visits would be coordinated through the Public Affairs Office. When this was done, Program personnel operated with the efficiency and flexibility necessary to insure the visit's success.

Generally, visits began with a briefing by the Director of Public Affairs, progressed via the Program boat to the Dive Platform for a briefing, demonstration and, where possible, a dive in the Personnel Transfer Capsule; then, to the Command Van for briefings by the watch director and the resident psychologist; and finally to the Base Camp for additional briefings. Program personnel cooperated such as to make this a most effective public affairs tool. The resident coordinator from the General Electric Company proved most cooperative and rendered invaluable assistance in providing housing, boat transportation and frequently diving support. One of the most successful techniques employed was to have each visitor become as directly involved in the program as he wished. Usually this meant at least a ride in the Personnel Transfer Capsule. Frequently it included snorkelling over the habitat; and whenever possible, it also meant a SCUBA dive to the habitat. Several visitors also gained new insights into marine research when they learned, for the first time, how to SCUBA dive. The only problems occurred when either an organization failed to coordinate a visit or a visitor showed up unexpectedly. These cases were rare, however, and were generally worked in satisfactorily.

\section{RESULTS}

Press clippings have come in from almost every conceivable location. Coverage virtually encircled the globe. Television spots were run in the evening news shows throughout the country and in many countries around the world, including

$$
\mathrm{V}-3
$$


Brazil, Argentina, Great Britain, France, Germany, and Japan. Press conferences were held in Washington, New York, Chicago, Cleveland, San Diego, and San Francisco with resultant press and television coverage. The Mayor of Chicago hosted the female aquanauts on a whirlwind tour which included a parade through downdown Chicago, being made honorary citizens, a proclamation (see attachment), and a reception at the Shedd Aquarium. In addition, the female aquanauts appeared on television shows in Philadelphia, New York, Washington, and Chicago. One or more also appeared on the nationally syndicated Mike Douglas and Dick Cavett shows.

Furthermore, the large number of requests for information from school children across the country (several hundreds) indicates that we not only reached this potentially important audience, but that we also gained support for future "man-in-the-sea" programs.

\section{CONCLUSIONS}

The Public Affairs Program met or exceeded its objectives. However, this is not to say that it could not have been more effective or accomplish more than it did.

The Office served in many capacities not normally expected of a Public Affairs office. This was due to personnel shortages in the program and the remoteness of the operational site on St. John. The Office also served as the primary link between the operation and the world. It was responsible for the dispatch of the shuttle boat, the visitor bureau, and a haven for all program personnel who wanted a cool place to sit or a cool glass of water. In addition, the office of Public Affairs obtained the daily weather forecast from the Weather Bureau in San Juan, made hotel and travel accommodations, and acted as liaison for the Air National Guard flights. The office also provided secretarial services for the program management including mission directors, watch directors, and medical directors and rendered assistance in preparing and dispatching necessary documents. The office on two occasions relayed calls for emergency medical treatment and had ambulances standing by to meet the incoming boat. A11 the above activities proved vital to the life and morale of the program and its personnel, but did on occasion detract from the primary purpose of the office.

A major reason for the success of the Public Affairs Program must be attributed directly to the flexibility and accessibility of the Program Manager, Deputy Program Manager, and Scientific Coordinator. All three displayed a high regard and understanding for public affairs and the objective and operations of the Public Relations program.

\section{ACKNOWLEDGEMENTS}

Special thanks are extended to the following persons for their on-site assistance during the program. They are: Mr. Richard Bassett, Mr. Val Bergins, Mr. Charles Boatner, Mr. Peter Borzelleca, Miss Vivian Manuel, Mr. Frank Pugliese, Mr. Anthony Sinopoli, Mr. Samuel Sobelman, and Mr. Cecil Stoughton.

$$
\mathrm{V}-4
$$


John G. VanDerwalker

Department of the Interior

Washington, D. C.

The TEKTITE II program's primary goal was to expose marine scientistdivers to the technique of saturation diving. Accomplishment of this goal would (1) provide a cadre of marine scientist-aquanauts, (2) who would contribute to our general knowledge of the oceans and (3) be qualified to answer the question: Why put men into the sea?

Prior to the operational phase of TEKTITE II an open invitation was published in journals and distributed to marine-oriented institutions inviting scientists to submit research proposals to be considered for inclusion in the Ocean Floor Program. These proposals were reviewed by a panel of marine scientists from government and private institutions. The panel then recommended which programs should be accepted. The scheduling of these teams was arranged by a member of the Scientific Review Board, the Scientific Coordinator, and the NASA Behavioral Programs Coordinator. Every effort was made to match teams of researchers that would benefit by working together. Final approval for participation was given on-site after each scientist had completed the aquanaut training successfully.

Those scientists that participated as aquanauts had only a brief stay on the bottom, no more than 20 days. The scientific and support equipment was severely limited. There were no swimmer-delivery vehicles to extend their range, no navigation equipment other than wrist compasses and depth gauges. Underwater communication ranged from the primitive hand signals to the sophistication of pencil and note pad. Those few land instruments waterproofed for in-situ measurements of various environmental parameters rarely, if ever, worked. In spite of these limitations the aquanauts had their most vital scientific need fulfilled: 24 hour a day access to the ecosystem they wished to study and complete freedom to schedule their time to fit their needs. They traveled around the reef with a freedom not experienced by the majority of marine scientists. Utilizing the General Electric Mark X closed-cycle rebreather, these scientists could spend up to four hours in the water at a time and routinely worked 350 meters away from the habitat both in daylight and dark.

Figure 1 is an aerial photograph of Beehive Cove. The large white square in the center is the support barge located above the habitat, which can be seen as two white circles immediately below it. Surrounding the habitat, and extending south of it to Cabritte Horn Point, is a massive solid coral reef rising as much as 4.5 meters above the adjacent sand-algal plains lying to the west and south (Figure 2). The edge of this reef ranges from 13 meters deep adjacent to the habitat to 16 meters deep south of Cabritte Horn Point. The area immediately northeast of the habitat is a large gently sloping sand plain that is covered with patch reefs, many of them rising three or more meters above the sea floor. The area closer inshore and extending from the dive platform on around Cabritte Horn Point is characterized by small clumps of coral anchored on bedrock. These reefs provide 
homes for hundreds of species of animals. Smith and Tyler (this report) found 54 species of fish inhabiting a patch reef seven meters in diameter. Only 34 species of plants were found on the reefs and most of these were diminutive. However, on the sand-algal plains lying to the west and south of the reefs there were 153 species of plants identified (Mathieson et. al. and Earle, this report). This pasture land is separated from the reefs by a band of bare, sand--the result of intensive grazing by fish living on the reef.

TEKTITE II's primary goal has been reached; we have added a cadre of 50 marine scientists to those who are experienced in man-in-the-sea technology. The summary reports that follow are an indication of the quality of the papers that will be appearing in the literature in the near future. As to the question, Why put scientists into the sea? it has not as yet been answered to everyone's satisfaction, but it's not being asked as often as, When are scientists going into the sea?

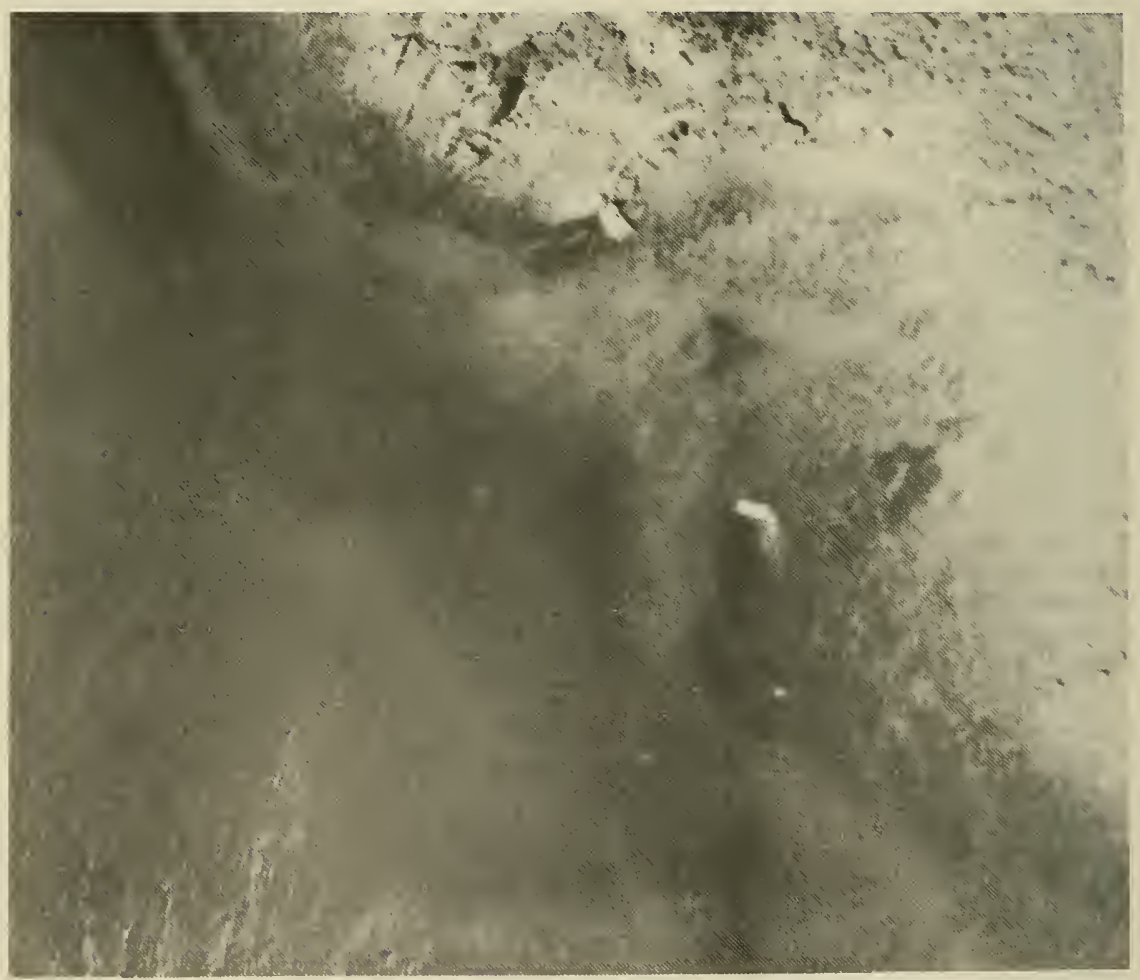

Figure 1. Aerial photograph of Beehive Cove

$$
\mathrm{VI}-2
$$




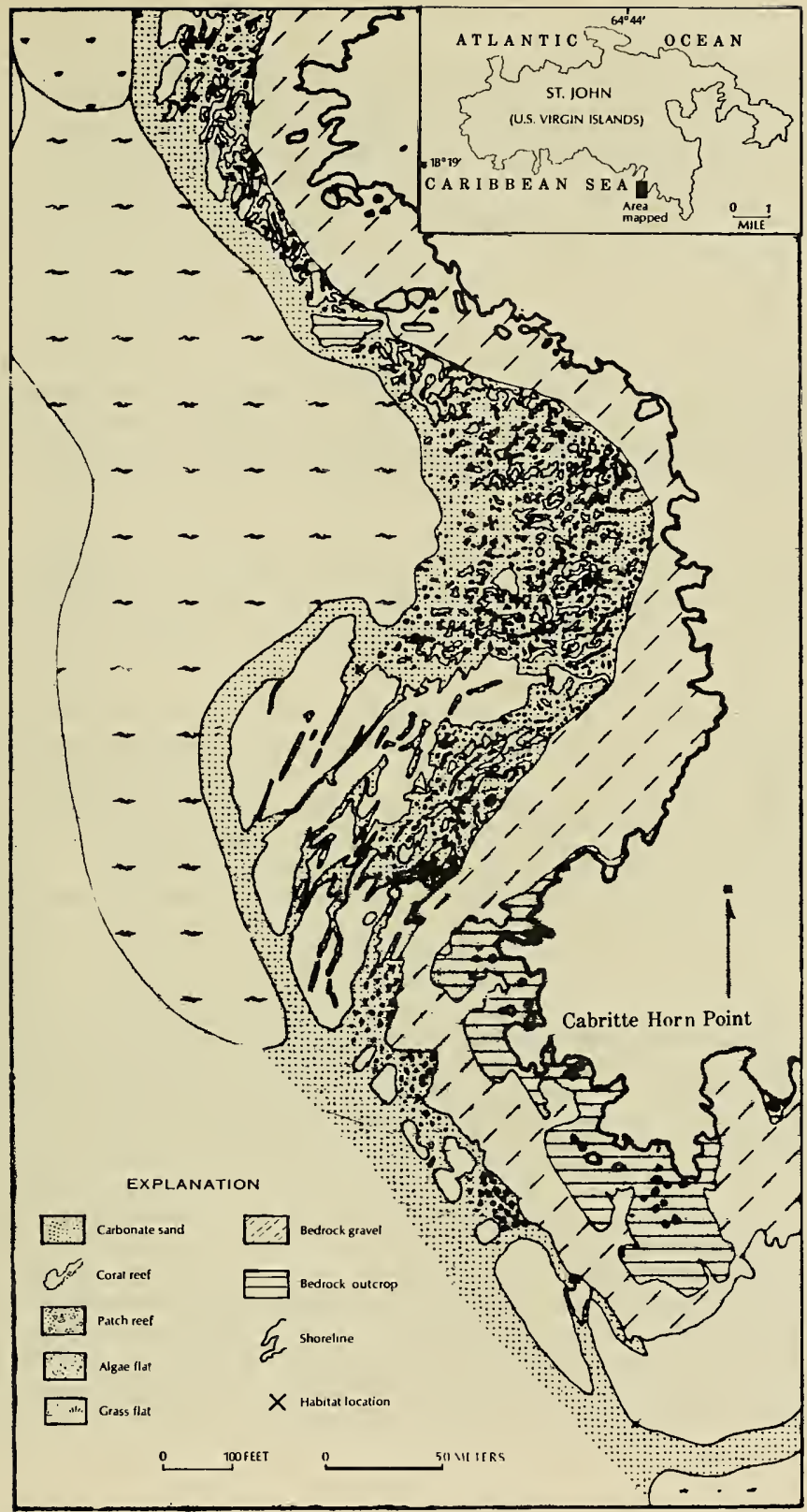

Figure 2. Map of Beehive Cove showing bottom types. 
William L. High and Alan J. Beardsley

Department of Commerce

National Oceanic and Atmospheric Administration

National Marine Fisheries Service

Exploratory Fishing and Gear Research Base

Seattle, Washington

\section{ABSTRACT}

During Mission I of TEKTITE II the authors conducted studies of reef fish behavior near and within fishpots. The results of this study have application to the Virgin Island pot fishery as well as to an embryonic pot fishery for sablefish in the northeastern Pacific Ocean.

Three pot designs were studied: (1) the typical Virgin Island pot of chicken wire and wood strips, (2) an experimental collapsible pot utilizing nylon web and an aluminum frame, and (3) a commercially manufactured molded plastic pot.

The Virgin Island pot captured the greatest number of fish, a1though they were generally smaller than those captured in the collapsible experimental pot. The plastic pot caught few fish. Numerous behavioral characteristics relating to fishes within the influence of the pots were noted, including territorial defense, social behavior, ar. $A$ predator-prey relationships. Bait seemed to play a minor role in attracting fish to the pots.

\section{OBJECTIVE}

The objective of our research from the TEKTITE habitat was to observe the behavior of reef fishes to fish traps and to evaluate several different pot designs on the basis of the number of fish and number of species caught. This investigation has direct application to current research programs being conducted by our Exploratory Fishing and Gear Research Base in Seattle. At our Base studies are being conducted on the utility of traps in the capture of commercial quantities of sablefish (Anoplopoma fimbria) in waters of the northeastern Pacific Ocean. Direct observations of sablefish by divers in these waters is not possible because of the depths (100-500 fathoms) these fish inhabit. This study also has relevance to the existing commercial trap fishery for reef fishes in the Virgin Islands since little is known about the efficiency of these pots and the behavior of fish to them. Waters adjacent to the Virgin Islands are a particularly 
productive area to conduct such a study as over 300 species of fish are represented in nearby waters (Randal1, 1968). Fishery scientists have effectively utilized SCUBA diving as a research tool for over 15 years. The ability to descend beneath the surface to directly observe fish harvesting gear in action and to study animal behavior has provided valuable information for the development of improved fishing gear and techniques (High, 1969). The use of undersea habitats such as TEKTITE is one way in which the scientist-diver can remain under pressure for extended periods resulting in a significant increase in the amount of research conducted.

\section{EQUIPMENT}

Observations were made on a total of six pots, two each of three different designs. Duplicate pots permitted modification in one pot while the other was being used as a control.

\section{Virgin Is 1 and Pots}

Two identical pots (Figure 1) were borrowed from a local Virgin Island commercial fisherman. These pots were constructed of chicken wire ( $1 \frac{1}{2}$-inch mesh) supported by a frame made of $3 / 4$-inch by $1 \frac{1}{2}$-inch wooden stringers. External dimensions were 20 inches high, 3 feet across and 9 feet long. The tunnels, constructed of chicken wire, were oval shaped and terminated in a right angle with the trap tunnel opening downward (Figure 2). Fish were removed and the pots were baited through a plywood door at one end of the pot (now shown in Figures 1 and 2).

\section{Experimental Collapsible Pots}

These pots (Figure 3 ) were constructed in Seattle, Washington and shipped to the Virgin Islands. The pot frames were constructed of 5/8-inch diameter aluminum rod and 2-inch nylon web was hung on this framework forming the walls. The same nylon web material was used to form the tunnels which led directly into the pot interior. Overall dimensions of these pots were 3 feet high, 3 feet across and 6 feet long. Both of the 3-foot square frames used for the top of the pot could be swung open for access to the pot interior.

\section{Molded Plastic Pots}

The remaining two pots were oval and constructed of black molded plastic (Figure 4). The external dimensions for these pots were 2-3/4 feet in diameter by 1 foot high, with a mesh size of $1-3 / 4$ inches. Flexible plastic "spears" projecting inward from the 8-inch diameter tunnels discouraged the escape of either fish or lobsters. 


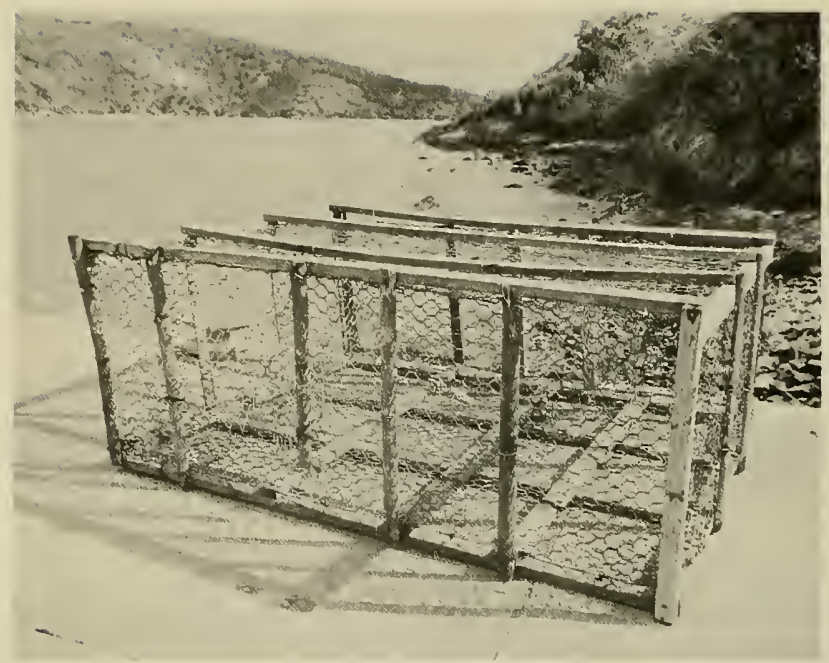

Fig. 1 Side view of a typical fish pot used by Virgin Island fishermen. Materials consist of wood strips and chicken wire. These pots were very effective for capturing small tropical reef fishes such as squirrelfish and groupers.

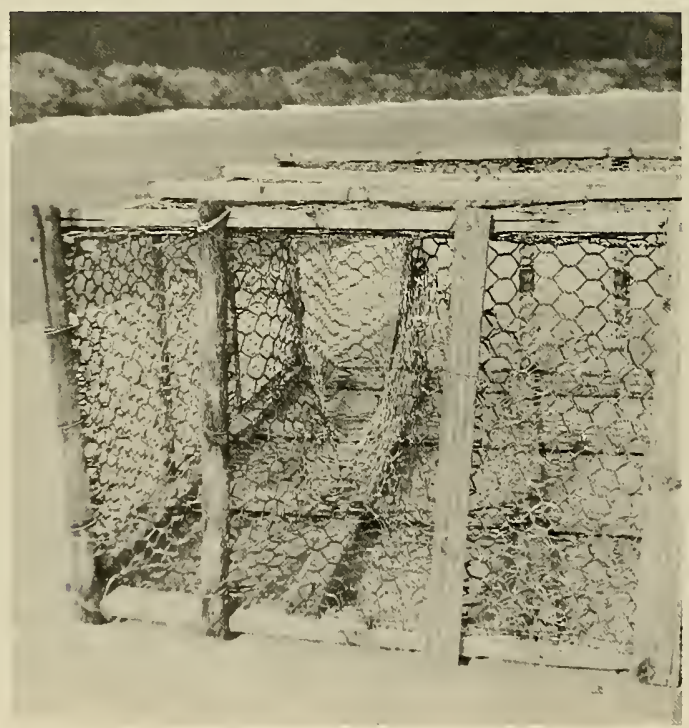

Fig. 2 Detailed view of the tunnel and gate of a typical Virgin Island fish pot. The tunnel exit is positioned at the bottom; therefore, fish must swim downward into the pot. 


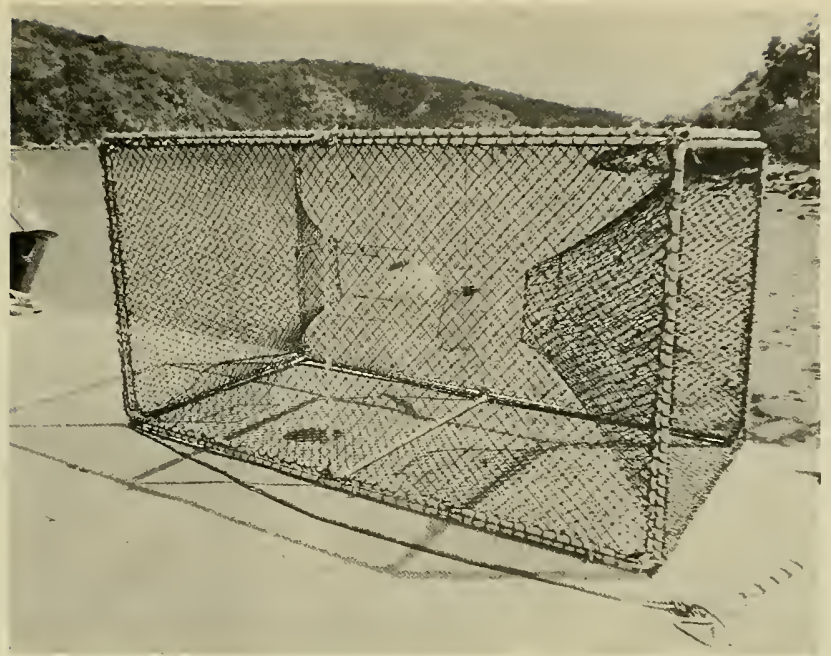

Fig. 3 The lightweight experimental pot could be easily collapsed for shipment. One cone-shaped tunnel was placed in each end.

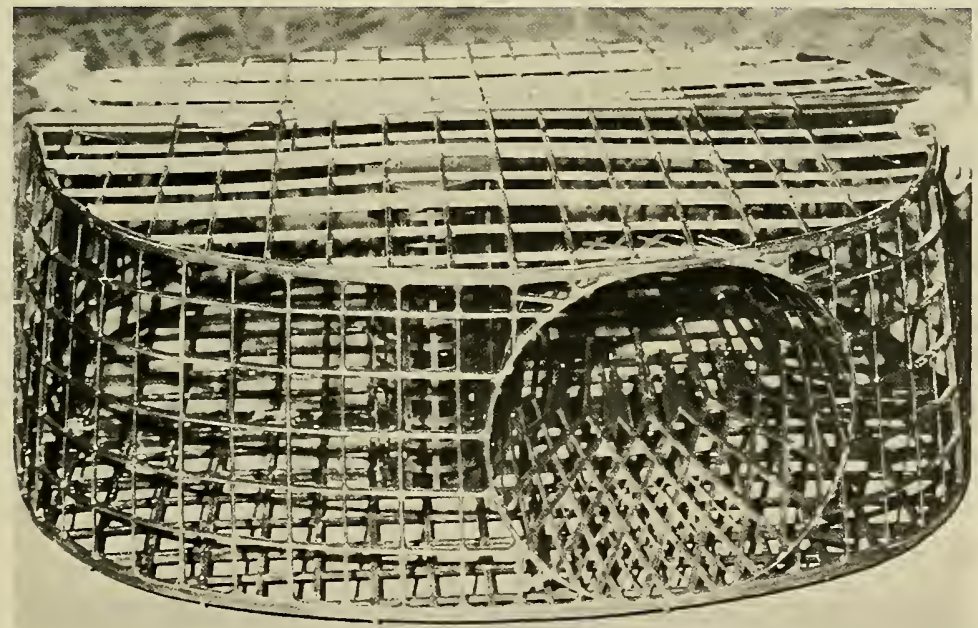

Fig. 4 This small, molded-plastic pot proved ineffective for either fish or lobsters. 
Baits included crushed sea urchin, fish meal, conch, chopped fish and a local cactus commonly used by Virgin Island fishermen. The fish meal bait is sold commercially in the United States and the cactus was collected and frozen prior to our entering the habitat. Bait was placed in a plastic container perforated with holes and hung near the center of the pot. Bait was changed at the conclusion of designated fishing periods, and all fish were enumerated by species and then released.

During the 13-day experiment the pot parameters which were changed included: triggers on tunnel openings, size of tunnel openings, type of bait, length of time pots were fished, covering on pots, and location of the pot relative to the reef. Burlap was used in the pot covering experiments. Pots were transported near the bottom by divers using inflatable lift bags.

\section{RESULTS}

\section{Species Composition and Number of Fish Caught}

During comparative fishing experiments on the coral reef, the three pot types exhibited distinct differences in their rate of fish capture and in species composition of the catch. The black plastic pots rarely caught fish, so catch records for these pots have not been included. In genera1, the Virgin Island-style pots caught greater numbers of fish than the experimental collapsible pots (Figure 5), but the fish were smaller in size. Only in the experimental collapsible pots were the larger 4- to 5-pound Nassau groupers caught. This selectivity by size of fish can be attributed to the larger tunnel and overall pot size. Spiny lobsters entered only the experimental collapsible pots with as many as four caught during a 24-hour period.

It was possible to make many valuable observations of the behavior of fishes, both undisturbed on the reef and in the vicinity of pots. The behavior of an individual fish species appeared to be as characteristic. of that species as body morphometry or color. For example, some species were found consistently as solitary individuals and approached the pot with caution (groupers); other schooling species either would enter the pot readily as a group (squirrelfishes, goatfishes) or independent1y (parrotfishes, bigeyes); paired fish would follow their mates readily into the pots (butterflyfishes and some parrotfishes).

\section{Effect of Pot Location on Catch}

We found that the location of the pot on the reef is an important factor in determining the number and species of fish caught. Although squirrelfish were numerous on all reef areas surrounding the habitat, they tended to congregate in localized areas, including a soft coral 
seawhip located on the sand flats three feet from the reef. One Virgin Island pot was placed 15 feet from the coral seawhip for two 24-hour periods. The pot caught five fish; only one was a squirre1fish. When the pot was moved within 5 feet of the coral seawhip, catches increased to 25 squirrelfish in 24 hours. On another occasion, when the experimental pots were placed over the "territory" of a grouper, the grouper would enter the pot to chase away intruders within the pot.

In general, the largest catches of fish were made when the pots were placed on sand bottoms between or near the reef, instead of directly on top of the coral. The motivation causing fish to enter pots is not clear. It probably results from complex and interacting stimuli. Even if the biologist makes direct observations, it is difficult for him to quantify objectively the individual stimuli responsible for fish entry.

\section{Effect of Bait}

Although it was assumed bait plays an important role in attracting fish into pots, we could detect no difference between bait types: cactus, crushed sea urchin, fish meal, conch, and chopped fish; a11 bait types attracted about the same number of fish. Moreover, unbaited pots caught as many fish as baited ones. Once fish were inside the pots, they immediately attempted to escape, ignoring the bait.

We observed these alternate reasons for fish entry: (1) use of the pot as a residence or territory which was defended against intruding fish of the same species (groupers); (2) random movements of fish on the reef (butterflyfishes, parrotfishes); (3) curiosity (butterflyfishes, squirrelfishes); (4) social behavior or gregariousness with one or more fish attracting others into the pot (butterflyfishes, squirrelfishes); and (5) predator-prey relationships, where the predator (groupers, parrotfishes) would chase the prey squirrelfishes, parrotfishes) into the pot, or the predator would be attracted into the pot by the already captured prey (groupers, parrotfishes). Although parrotfish are not generally considered cannibalistic, they were observed on numerous occasions attacking weak and dead parrotfish in the trap.

\section{Behavior of Fish Around and Within Pots}

Once inside the pots, butterflyfishes, goatfishes, squirrelfishes, and parrotfishes would swim in circles continuously--compared to groupers' intermittent search behavior. The fish would congregate in the corners of the pot and, on several occasions, fish (we assume parrotfishes) bit through the nylon web creating holes large enough for fish to escape (Figure 6). Fish spent little time near the tunnel openings of the experimental pots, and only two fish were seen escaping through these openings. The complexity of the Virgin Island-type tunnel 


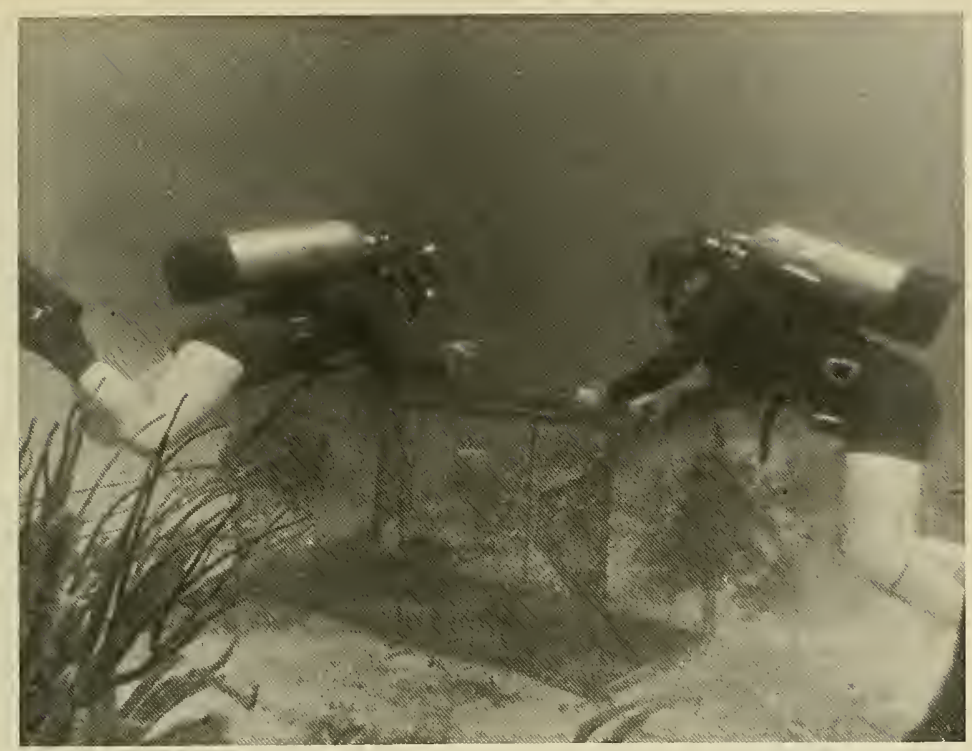

Fig. 6 Broken meshes in the pot were repaired by the authors.

largely prevented escape by all fish species. However, the number of parrotfish in a Virgin Island pot decreased from four to two during - 4-hour interval.

After several days observation of freshly baited Virgin Island pots, it was concluded that the rate of fish entry follows a relatively consistent pattern. Many observations were made on pots placed near the squirrelfish school under the soft coral seawhip. This school was large enough about ( $60 \mathrm{fish}$ ) that some fish were active near the pot at all times. Following release of fish from the previous study period, fish would investigate the pot and, eventually one would enter. The time before first entry would vary, but once the first fish was inside, other fish followed rapidly. Daytime catch rates were higher than those during darkness. When the number of fish inside approached 25, the rate of entry would drop off sharply (Figure 7). It appeared that the relatively large number of fish swimming inside and trying to escape frightened other fish from the area.

This "saturation effect" always occurred long before the volume of the pot limited fish entry. The saturation effect, is not unique to Virgin Island reef fishes; it has also been inferred from catches of sablefish in the northeastern Pacific. 


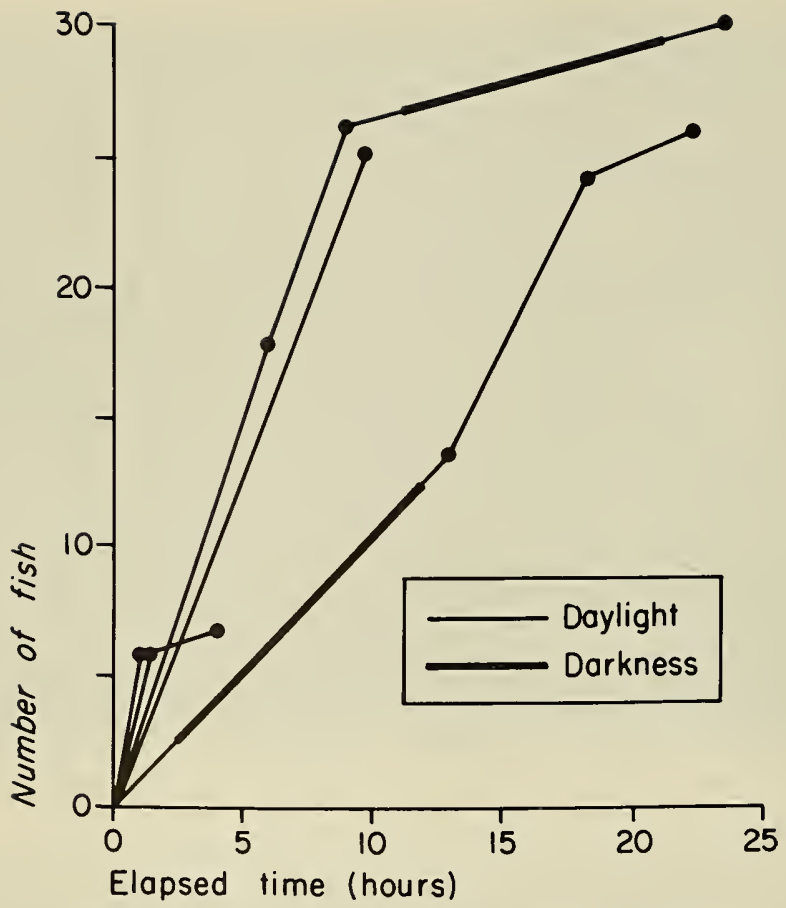

Fig. 7 Time of fish entry into Virgin Island pots during five different sets. Dots indicate the time of fish enumeration.

Observations of fish outside the pots reacting to captured fish were common. Butterflyfishes and goatfish became particularly active when one of their species was captured. An experiment was conducted to see if a reduction of visual stimulus by fish inside the pot to those outside would alter the catch rate for a particular pot. Olive green burlap covers were placed over the pots during these experiments. Tunnels were not covered. No change in catch rate between covered and uncovered pots was noted.

Our attempts at capturing the larger pelagic fishẹ (jacks, mackerels, and snappers) proved futile. An experimental pot was buoyed upward by flotation bags until it hung some 25 feet above the seabed. A low intensity light inside the pot attracted many small fishes and invertebrates after darkness, but none of the large pelagic fishes (up to 50 pounds) would enter. These large fish also would circle under the habitat's lights each night, but we did not observe any foraging on the numberous smaller animals similarly attracted. 


\section{CONCLUSIONS}

One objective of this research was to provide local Virgin Island pot fishermen with data describing fish behavior that relates directly to their fishing success. We concluded that the tunnel in the Virgin Island pots was effective in the capture of small reef fishes and its complexity reduced fish escape. The small size of the tunnel opening, however, may reduce the catch of larger fish and probably prevent lobsters from entering. The collapsible experimental pots may have application in the local fishery, particularly if larger fish and/or lobsters are desired. This pot appears to be a relatively efficient method of capturing 1obster, since 10 were captured during our research and another TEKTITE II team studying lobsters estimated the population in the area at that time numbered about 40 animals.

The relevance of our studies on reef fishes during TEKTITE II to research on sablefish in the northeastern Pacific may not be as straightforward. After our early observations we concluded that a broad spectrum of behavior patterns are exhibited by the different species of reef fishes. One would expect similar differences between the reef fishes and sablefish. We do feel observations during TEKTITE II have presented reasonable explanations for phenomena we have witnessed in sablefish catches. A good example is the "saturation effect" encountered in both pots which now appears caused by behavior rather than physical conditions. Other observations from TEKTITE II research may be implemented in sablefish pots in the future with the result that catch rates are being increased for this gear.

It is indeed unfortunate that closed circuit breathing apparatus was not available during our mission. In behavior studies exhaust bubbles from open circuit SCUBA may have considerable impact on the behavior of animals. Although we felt most fishes seemed to adjust rapidly to the diver's presence, one must remain at a greater distance from the animals when open circuit gear is used.

The advantages of saturation diving over conventional scuba techniques are obvious. However, to most scientists the experience is so nove1 that it is difficult to preplan experiments due to a lack of experience and knowledge of the full potential this type of diving offers. Scientist-divers in coming years will profit greatly from the experience gained by aquanauts trained during the TEKTITE program.

\section{LITERATURE CITED}

High, William L.

1969. SCUBA diving--a valuable tool for investigating the behavior of fish within the influence of fishing gear. Proceedings of the FAO conference on fish behavior in relation to fishing techniques and tactics. FAO Fish. Rep. No. 62, Vo1. 2, pp. 253-267. 
High, William L. and Alan J. Beardsley

1970. Fish behavior studies from an undersea habitat.

Comm. Fish. Rev. 32 (10): pp. 31-77.

Randa11, John E.

1968. Caribbean Reef Fishes. T.F.H. Publications, Inc., New Jersey. 318 p. 
PRECISE IN SITU MEASUREMENTS OF

CHEMICAL PARAMETERS OF SEAWATER:

A REPORT OF MISSION 1-50, TEKTITE II

Pau1 D. Cratin, Ph.D., Principal Investigator

Professor and Chairman, Department of Chemistry

Central Michigan University

Mt. Pleasant, Michigan 48858

Roger J. Dexter, M.S., Co-Principal Investigator

Graduate Student, Department of Oceanography

Texas $A$ and $M$ University

College Station, Texas 77843

Richard W. Curry, B.S., Co-Principal Investigator

Graduate Student, Department of Functional Biology

University of Miami

Miami, Florida 33149

\section{INTRODUCTION}

Oceanographers have 1ong been concerned about the possibility that many important parameters change as a sample of sea water is removed from its environment and brought to the surface. Because of this concern, they have sought to develop instrumentation capable of measuring these oceanographic parameters in situ. Obviously, if the oceanographer were able to bring the instrumentation into the marine environment itself, it would be possible to analyze the sample precisely at the time and position it had been taken. Although this is not yet feasible in all cases, the use of submerged habitats enables us to approximate the ideal situation.

It has long been our feeling that many pressure-dependent processes occur as a sample of sea water is brought from its native environment to the surface. Two such phenomena are the degassing of oxygen and the continuation of biological activity in the sample. Whereas many equilibrium processes can be calculated by using conventional physico-chemical methods, virtually no understanding of kinetic processes exists. Even if such an understanding did exist, it would be impossible to account for, let alone prevent, these changes with conventional sampling equipment and techniques. The undersea research and living facilities offered by TEKTITE II afforded us an opportunity to check the validity of our hypotheses. The results which are discussed below not only offer conclusive proof that our hypotheses were correct but, furthermore, attest to the fact that undersea laboratories can serve very real and useful purposes--without which we would probably not have been able to answer those questions that had "bugged" us for many years. 
Our role in TEKTITE II as part of Mission 1-50 was successful to such an extent that the National Science Foundation saw fit to fund a return visit for two of us (PDC and RJD) at the conclusion of the TEKTITE II program.

\section{OBJECTIVES}

The objectives which we had hoped to accomplish during our TEKTITE II were the following: (1) To determine the advantages of in situ sample collection and fixing and of chemical analysis performed at a stable station (i.e., Habitat) as opposed to analysis which cannot be done aboard ship without significant loss of accuracy. (2) To provide the geologist, the biologist, and the physical oceanographer as well as the chemist, with useful quantitative information about diurnal fluctuations in $\mathrm{pH}$, oxygen, alkalinity, salinity, phosphates, calcium and magnesium, and internal wave motion. (3) To provide two graduate students as an integral part of their professional education with underwater habitat training in research. (4) To train a nucleus of chemical oceanography personnel for subsequent instruction in habitat research techniques.

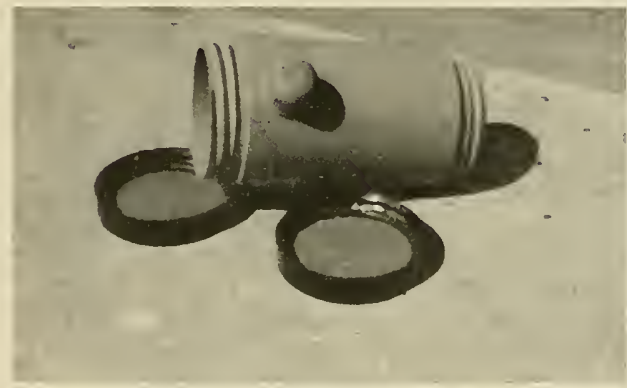

Figure 1. Photograph of PVC Sampler

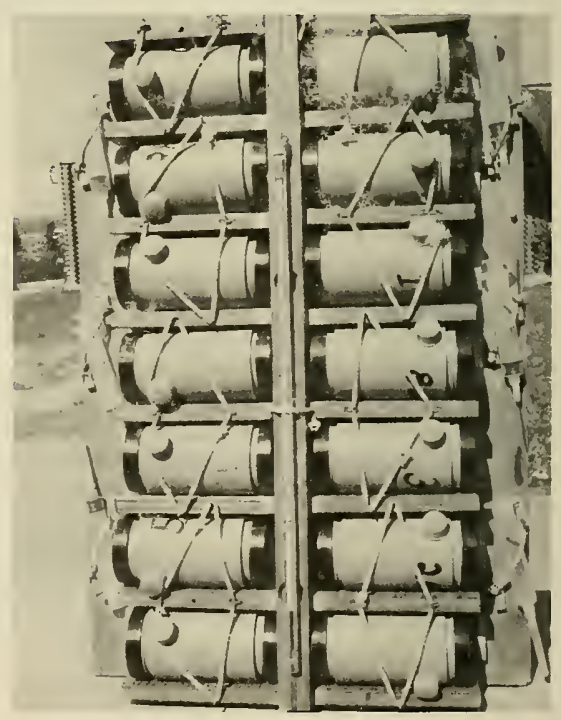

Figure 2. Photograph of Sample Back-pack 
As pointed out above, conventional sampling techniques can neither prevent nor account for changes which may occur as a sample of sea water is brought from its native environment to the surface. Special sample bottles capable of this were designed by one of us (RWC) and approximately 100 bottles were fabricated for use on this project. Figure 1 is a picture of one such bottle which has a volume of approximately 225 milliliters. The bottles are made of polyvinyl chloride (PVC) tubing with a screw cap at either end. (The openings on both ends are to facilitate flushing of the bottle at the sample site.) The screw caps are made of plastic with an inner lining of PVC and an o-ring to assure sealing. A hole is drilled into the side of the bottles and a small piece of PVC is then sealed into it; finally, a rubber septum is fitted into and over the small piece of PVC tubing for the addition of reagents "in situ". The reagents are added by means of disposable syringes which are inserted into the septum, injected into the bottles, and then withdrawn.

In order to facilitate the taking of large numbers of samples, a special back-pack was developed that would fit over double scuba tanks as shown in Figure 2. With each of two divers wearing a back-pack containing 14 sample bottles, a total of 28 samples could be taken during a given dive. In addition to housing the sample bottles, the back-packs contained the disposable syringes with fixing agents, additional venting needles for the injection process, and a thermometer which allowed each diver to record the temperature at which the sample was taken.

Three sample stations were selected: the first of these was located in the heart of the lush reef where plant and animal life abounded; the second station was located on a barren sand flat; and, a third was chose at the edge of the reef and the sand flat. A total of four dives per 24-hour period were scheduled: two divers of the habitat team would take samples at 0600,1200 , and 1800 , and the surface support team would make one dive per day, i.e., at 2400. Approximately half of the 800 analyses performed in our Mission 1-50 were carried out in the laboratory setup in the wet room of the habitat: the other half were carried out in a topside laboratory located at the College of the Virgin Islands Ecological Research Station on St. John.

The salinity determinations were made on the surface with a Hytech portable salinity bridge; calcium and magnesium determinations were carried out in the habitat laboratory using the conventional EDTA titration; pH measurements were made on the surface as well as in the habitat with Beckman Expandomatic $\mathrm{pH}$ meters. The oxygen analyses were performed both on the surface and inside the habitat. Originally, plans called for use of an oxygen meter (Beckman Instruments) as well as the standard Winkler titration. Due to a malfunction of the meter, all oxygen samples were analyzed by the Winkler method. Unfortunately, no reliable data were obtained on phosphate concentrations; a11 phosphate reagents were ruined in a "pot transfer" from the surface into the habitat. 
of special interest is the technique developed to analyze for oxygen. Four samples of sea water were taken at each station: (1) The first was fixed in the water and taken to the habitat for analysis: (2) The second was fixed in the habitat and analyzed therein: (3) The third was fixed in the habitat and sent to the surface for analysis: (4) And the fourth was sent to the surface for fixing and analysis. The procedure was carried out in this manner so that the following information could be obtained: By comparing the results of (1) and (2), one could determine the effects of time, i.e., biological activity on the sample. (This would be true because the sample would have seen only ambient pressure, about 2.5 atmospheres.) A comparison of (3) and (4) would tell quantitatively the effects of a pressure change and the biological activity on the samples. A comparison of (2) and (3) would give information about the dependence of the analysis on pressure (which would probably be negligible) and would serve as a check on the relative precision on the analyst below and topside.

\section{RESULTS}

The data given in Table 1 below are average values based on 24 runs. TABLE 1 .

\begin{tabular}{l} 
Group \\
\hline$(1)$ \\
$(2)$ \\
$(3)$ \\
$(4)$
\end{tabular}

$\mathrm{m} 1 \quad 0_{2} / 1 \quad$ seawater
5.26
5.26
5.32
4.22

There is no doubt that the greatest change occurs when a sample of sea water is taken from native environment and brought to the surface for fixing and analysis--an average decrease of $20 \%$ in the oxygen content was noted: These data strongly suggest that the hypothesis made in the introduction of the paper has real merit: indeed, the changes in pressure as a sample of sea water is brought from its environment to the surface are large enough to effect degassing of the sample provided that the concentration of oxygen at depth exceeds the surface saturation values. (The saturation values for oxygen-saturated sea water is about 4.3 milliliters per liter. This value is indeed the limit to which most of the samples tend.)

It should be pointed out that on our return trip to TEKTITE II in October the concentration of oxygen at depth was considerably less than the surface saturated value, and because of this no degassing of oxygen occurred as: the sample was brought from the bottom to the surface. On the basis of elementary thermodynamic reasoning, it is eminently reasonable to assume that samples of sea water would degas as they undergo decreases in pressure; the rates at which this degassing effect occurs is still unknown but it appears to be approximately $2-6 \%$ per hour. If this is true, then certainly much of the data accumulated on the oxygen concentration as functions of depth should be reconsidered in the light of these new findings. 
Equally interesting are data which were collected as functions of time and station:

Table 2.

\begin{tabular}{|c|c|c|c|c|}
\hline Station number & $\underline{0600}$ & $\underline{1200}$ & 1800 & 2400 \\
\hline 1 & 2.93 & 3.25 & 3.25 & 2.99 \\
\hline 2 & 2.98 & 3.25 & 3.27 & 3.01 \\
\hline 3 & 2.94 & 3.17 & 3.25 & 3.05 \\
\hline
\end{tabular}

Data expressed in $\mathrm{ml} / \mathrm{Na}_{2} \mathrm{~S}_{2} \mathrm{O}_{3}$ solution used to titrate samples.

Table 2 suggests that the water mass generally is well mixed; it also shows that there are significant diurnal variations. Although it is not possible to define exact maxima and minima in these cycles from the data accumulated from Mission 1-50, it appears that the maxima occur between 1.200 and 1800 , and that the minima probably occur at the beginning of the daylight hours. On our return trip to TEKTITE II the diurnal oxygen samples were taken once every hour for a period of 24 hours: those observations confirmed those made during the first mission. It appears that the maximum in the oxygen content is a broad one between 1400 and 1600 hours, and that the minimum, also extremely broad, occurs between 0300 and 0600 .

Perhaps the most intriguing facet of the study was the discovery of an induction period: when samples of sea water were suddenly sealed off from sunlight, the oxygen concentration remained constant for about three hours. The fact that it did not increase shows that the photosynthetic process did not continue past the time of sealing; because it did not decrease indicates that respiration, $i . e .$, using up of available oxygen to produce $\mathrm{CO}_{2}$ did not commence immediately. The organisms responsible for this process seemed to be in a state of "limbo" for about three hours, after which time the oxygen concentration decreased very rapidly. (An alternate explanation for this phenomenon based on the existence of a steady state with a rate of oxygen consumption equal to the rate of oxygen production over such a long period of time must be rejected on kinetic grounds.) On the return trip to TEKTITE induction period measurements were made both at night and during the day. These measurements were made by taking down a number of sample bottles and sealing all off at once. One sample was then fixed and returned to the surface for analysis and the rest remained at the sample site. One sample was fixed every hour for a period of four or five hours thereafter. Securing the samples at the sampling site until they were fixed minimized the effects of pressure and temperature changes. Again there was conclusive evidence that an induction period does indeed exist during the daytime and, to our surprise, even at night: It is our feeling that as a sample of sea water is suddenly sealed from sunlight, the organisms responsible for the production--and consumption--of oxygen are shocked into a state of inactivity; at first glance it would seem that this "explanation" could not account for the existence of a nocturnal induction period. It is possible that the dive lights used at night could effectively shock these organisms into a state 
of inactivity, thus prolonging the induction period even more (it was noted in the second mission that the induction period at night extended for a period of about 5-5 1/2 hours.)

A third plausible explanation for this phenomenon is due to Dr. John Bunt of the University of Miami. Dr. Bunt states that the induction period could be explained on the basis of a build-up of bacteria in the sample container. To account fully for the cause of this phenomenon will not be any easy task; indeed, much additional work will be required before a satisfactory mechanism can be proposed. It is hoped that this work may be extended in the very near future, not only to additional seawater systems, but also to fresh water lakes as well.

Additional data obtained during Mission 1-50 may be summarized thusly: (1) $\mathrm{pH}$ fluctuations follow very closely those for oxygen, i.e., when the oxygen concentrations are high, likewise are the pH values; (2) alkalinity minima occurred at approximately the same times as oxygen maxima; (3) ca1cium and magnesium concentrations were independent of time and of station; calcium ion concentrations equal $0.01 \mathrm{M}$ and the magnesium ion concentra 0 tions equal $0.06 \mathrm{M}$. (4) The temperature showed a steady increase from $25.4^{\circ}$ to $25.7^{\circ} \mathrm{C}$ during Mission $1-50$ with perceptible diurnal fluctuations. (5) Salinities ranged from 35.4 - 36.0 parts per thousand.

Data gathered on the visibility experiment and on the internal wave motion in Lameshur Bay have not yet been analyzed by the physical oceanographer and the optical physicist; we trust when these data are analyzed the results will be forthcoming at an early date.

\section{ADDENDUM}

If one were to depict graphically the concentration of oxygen (as the ordinate) and the time (as the abscissa) a smooth sine wave curve would result. Not infrequently we would note abrupt discontinuities in a few of our values; at first, we attributed these to errors in sampling, fixing, analysis, or a combination of these.

During our return trip, we experienced a phenomenon that not only explained these discontinuities in our data, but lends a strong argument for man-in-the sea programs as well: during a night session, two of us (PDC and RJD) were in the process of taking a sample for oxygen analysis when a surge of cold water intruded. It came with such force that one of us (PDC) was 1iterally upended (and very nearly set upon a large black sea urchin). Fortunately, the sampler was open during the surge of the cold water. Immediate fixing and analysis of the sample showed an oxygen concentration equal to three times that found in the maximum of our daylight samples.

And herein lies the explanation: Since the solubility of oxygen in water is greater at lower temperatures, the cold water was, obviously, rich in $\mathrm{O}_{2}$; 
such occurrences were probably responsible for "spikes" in our otherwise smooth curves. Had we not been "in situ", these "spikes" would still be attributed to errors in our sampling, fixing, and analysis.

\section{SUMMARY}

Mission 1-50 represented man's first attempt to carry out as closely as possible in situ chemical analysis; the predictions that were made and the hypotheses that were formulated were more than validated in the eleven days of Mission 1-50. But this is not the entire story--it was merely a start in what we hope to be the first of many such programs in which man will be able to work in a laboratory on the ocean floor and carry out analysis with a greater degree of accuracy than he has ever known previously.

This work has provided for us an opportunity to pioneer in the field which we all hope will grow; perhaps our greatest enjoyment comes from the knowledge that this scientific endeavor, like all true chemical research, did indeed answer some fundamental questions for us, but, more importantly, it served to raise many new questions that need to be answered. And many of these answers will come only through effective use of manned underwater laboratories.

\section{ACKNOWLEDGEMENT}

We wish to express our sincerest appreciation to everyone associated with the TEKTITE II program, to the University of Miami, and to the National Science Foundation for their support in permitting us to participate in both missions of TEKTITE II. A special note of thanks is extended to Beckman Instruments of Fullerton, California for their lending to us at no charge a Beckman DU2 Spectrophotometer for our phosphate analysis, And finally, a special note of thanks is extended to our wives who looked forward to Mission 1-50 with as much apprehension as we did with anticipation. 
Continuation of Underwater Geologic Studies in Lameshur

Bay Area, St. John, U. S. Virgin Islands

Part I. Bioturbation

H. Edward Clifton and Ralph E. Hunter

U. S. Geological Survey

Menlo Park, California and Corpus Christi, Texas

\section{ABSTRACT}

Bioturbation, the mixing of sediment by organisms, is one of the most important continuous sedimentary processes in the semiprotected coral reef environment. Experiments conducted during Tektite II documented specific effects of the organisms on the sediment and established rates and styles of bioturbation in different environmental settings near a coral reef. Organisms affect the sediment in various ways: they rotate empty pelecypod valves to a concave-up position, control the distribution of coarse clasts along the reef front, bury pebbles and cobbles on the sea floor, destroy sedimentary structures on and beneath the sea floor, and create new structures.

\section{INTRODUCTION}

Nearly all sedimentary rocks bear the imprint of processes that were active at the time the sediment was deposited. Such imprints are manifested by primary structures in particular--features formed in the sediment in response to different processes within the depositional environment. Among such processes is bioturbation, the mixing of the sediment by organisms living on or within it. Bioturbation may produce distinctive structures, such as specific burrow forms or it may obliterate all internal structures. Little is known about the rate at which bioturbation reorganizes the sediment, either internally or at the surface and few data exist regarding the relation between the style of bioturbation and the environmental setting.

The Tektite experiments provided an excellent opportunity to study bioturbation the dominant everyday geological process involving sediments in the area of the habitat. At no time during the 80 days' undersea habitation of Tektite I and II were waves or currents observed to disturb the carbonate sand in water deeper than $6 \mathrm{~m}$ in eastern Lameshur Bay. Preliminary studies conducted by Clifton and others (1970) during Tektite I indicated that bioturbation rates in this environment were remarkably high and that certain previously undocumented effects, such as bioturbational burial of pebbles and cobbles and the effects of organisms on pelecypod shell orientation, are of considerable geologic importance in the reef environment of the West Indies. During Tektite II, specific aspects of bioturbation were examined in detail before, during, and after the period 
of undersea habitation: the orientation of empty pelecypod valves; the significance of Malacanthus plumieri (sand tilefish) as a geologic agent; the rate of surface and internal biogenic modification as a function of environment: the rate and depth of bioturbational burial of pebbles as a function of environment and of size, shape, and composition of the clasts; nocturnal as compared with diurnal bioturbation; the duration of surface integrity; the degree of lateral sand transport by organisms; and the effects of specific organisms.

\section{ORIENTATION OF EMPTY PELECYPOD VALVES}

Empty pelecypod valves traditionally have been thought to lie preferentially in their most hydraulically stable position, concave side down. This attribute has been used as a criterion for determining the tops of beds in sequences of deformed sedimentary rocks. Observations made during Tektite I indicate that empty valves in unagitated water lie predominantly concave side up. This orientation theoretically could result from either the action of predators and scavengers or bioturbation (Emery, 1968, p. 1268). An objective during Tektite II was to determine the effect of bioturbation on shell orientation and the function of shell size and shape of bioturbational rotation.

In order to determine the effect of bioturbation on shell orientation, nearly 1200 shells were placed near a coral reef on unvegetated sand at a depth of about $10 \mathrm{~m}$ and left for 40 days. The shells were divided among four plots, two 2 meters distant from the reef, two 6 meters distant. Each contained an identical assemblage of seven shell species in five different size classes. In two of the plots, one at 2 meters, one at 6 , all shells were placed concave side up; in the other two, all were placed concave side down. As the bottom at the experiment site was not disturbed by waves or currents during the 40 days of observation any changes in shell orientation that occurred during this time resulted from bioturbation.

A tabulation, at the end of the experiment, of shell orientation by size, species, and whether or not the shells are buried provides considerable data concerning rotation of shells by bioturbation. Most of the shells (61.4 percent) lay concave-side up, demonstrating that bioturbation is capable of producing a surficial assemblage of dominantly concave-up shells. The concave-up tendency in general increased with increasing shell size, both overall and within individual species. The orientation also depends on shell shape, the rounder, more gibbous valves showing a greater rotation to a concaveup position than flatter shells. Of the shells that were buried beneath the sediment surface, 51.5 percent lay concave-up, of those remaining on the surface, 70.6 percent; the difference is probably related to a difference in the net rate of rotation to a concave-up position between buried and exposed shells. A more complete description of the shell orientation studies is given in Clifton (in press). 
Along West Indian coral reefs, the sand tilefish Malacanthus plumieri selectively builds nests that are roofed with coarse shell and coral fragments. This fish may be largely responsible: for the distribution of the coarse debris (shells $3-6 \mathrm{~cm}$ across and coral fragments $1-2 \mathrm{~cm}$ in diameter and $5-10 \mathrm{~cm}$ long), and thus a potentially significant geologic agent.

Several experiments were conducted to determine the extent to which M. plumieri collects and segregates coarse shell and coral fragments along the reef fronts. At a selected nest, fragments were removed from the outer part, marked, and scattered within 2 meters of the nest. Eight days later the outer part was again disassembled, and the number of fragments restored to the nest tabulated. These fragments were separated into groups containing equal assemblages of fragments by size and shape. Each group was color coded and dropped at specific intervals of $0-3,3-6,6-9$, and $9-12 \mathrm{~m}$ from the nest. The distance over which the fish restored fragments to the nest and selectivity for shape of fragment could be established by inspecting the color mark. In another experiment, 150 fragments were scattered in a meter-square plot at two different sites near occupied

M. plumieri nests. In each plot, 50 of the fragments were irregular pieces of coral (more than two forks), 50 were simple cylindrical coral rods (mostly Acropora cervicornis), and 50 were shells taken from M. plumieri nests elsewhere in the area. The number of shells and fragments removed from the plots was checked periodically to provide an estimate of the rate at which the fish collects different types of fragments from the sea floor.

Within the 8 days of the first experiment, the individual studied returned 460 shells and pieces of coral from the 2-meter area. During the second, he collected fragments over a distance from the nest greater than 9 meters. In the preliminary stage of construction, the fish selectively collects irregular coral fragments to form the "rafters" of his roof, then adds "shingles" in the form of shells and more regularly shaped fragments. Tabulation of marked shells and coral fragments collected by $M$. plumieri during the time the nest was maintained, undisturbed from the two plots that contained 150 fragments and shells each suggests that he may selectively collect shells and irregular fragments of coral in preference to simple coral cylinders. Mapping of $\mathrm{M}$. plumieri nests indicated the presence of 59 nests along a 250-meter stretch of reef from southwest of the habitat. Twenty-four of these showed evidence of occupation. With the given potential for a single fish to transport and segregate coarse debris, the number of fish present along the reef front is probably sufficient to insure that most of the material in the 3 to $10-\mathrm{cm}$ range is concentrated in their nests. 
In order to establish the role of environmental setting a series of experiments was conducted at four localities (fig. 1): (1) unvegetated sand near the mouth of the channel through the reef which extends southwest from the habitat site; (2) the unvegetated sand strip that borders the reef; (3) a sand substrate approximately 30 meters from the reef, where the bottom was moderately vegetated by algae, largely of the genus Udotea; (4) sparsely vegetated sand about $50 \mathrm{~m}$ northeast of the habitat in the patch reef area. The biota at each site was not recorded. The texture of the sand at the channel mouth differs from that at the other sites by containing a far greater percentage of fine sand. The channel-mouth site is distinctive in the abundance of fauna living in burrows within the sand.

At each site several experiments were monitored daily. To determine the rate at which wave or current-generated structures were disrupted by organisms, a set of eight similated ripples, $5 \mathrm{~cm}$ high and $100 \mathrm{~cm}$ long and $20 \mathrm{~cm}$ apart were shaped by hand in the sand and left to the activity of the organisms. An area of undisturbed bottom approximately 4 meters square was photographed daily to establish the rate of general surface modification. To determine the rate at which internal structure near the sediment surface was disrupted, bedding was artificially produced in a small plot $25 \mathrm{~cm}$ wide by $100 \mathrm{~cm}$ long. This bedding consisted of 2 layers of dyed sand, each $2 \mathrm{~mm}$ thick, separated and covered by layers of indigenous carbonate sand, 3 to $5 \mathrm{~cm}$ thick. This structured sand was cored at 4-day intervals with small senckenberg boxes, which provided undisturbed sections about $15 \mathrm{~cm}$ wide by $5 \mathrm{~cm}$ deep.

The artificial ripples at each site became progressively modified and finally totally obliterated. Differences in the degree and style of modification among the sites were obvious after the first day. At that point, the ripples in the channel mouth were covered with 20 to 30 craters and mounds 2 to $5 \mathrm{~cm}$ across. In contrast, the sand strip and patch reef showed only one or two mounds or craters each, and the algae flat only numerous small (less than $1 \mathrm{~cm}$ across) pock marks.

The ripples in each plot tended to follow a similar pattern of day to day modification. At first they became subdued, their crests becoming rounded and less high. In a second phase, part of the ripple pattern became indiscernible, and ultimately none of the pattern could be discerned. An exception to this pattern occurred in the patch reef site, where the ripples were nearly totally obliterated by a feeding stingray on the second day of the experiment. A second ripple plot, which replaced the first in this environment followed the general pattern. 


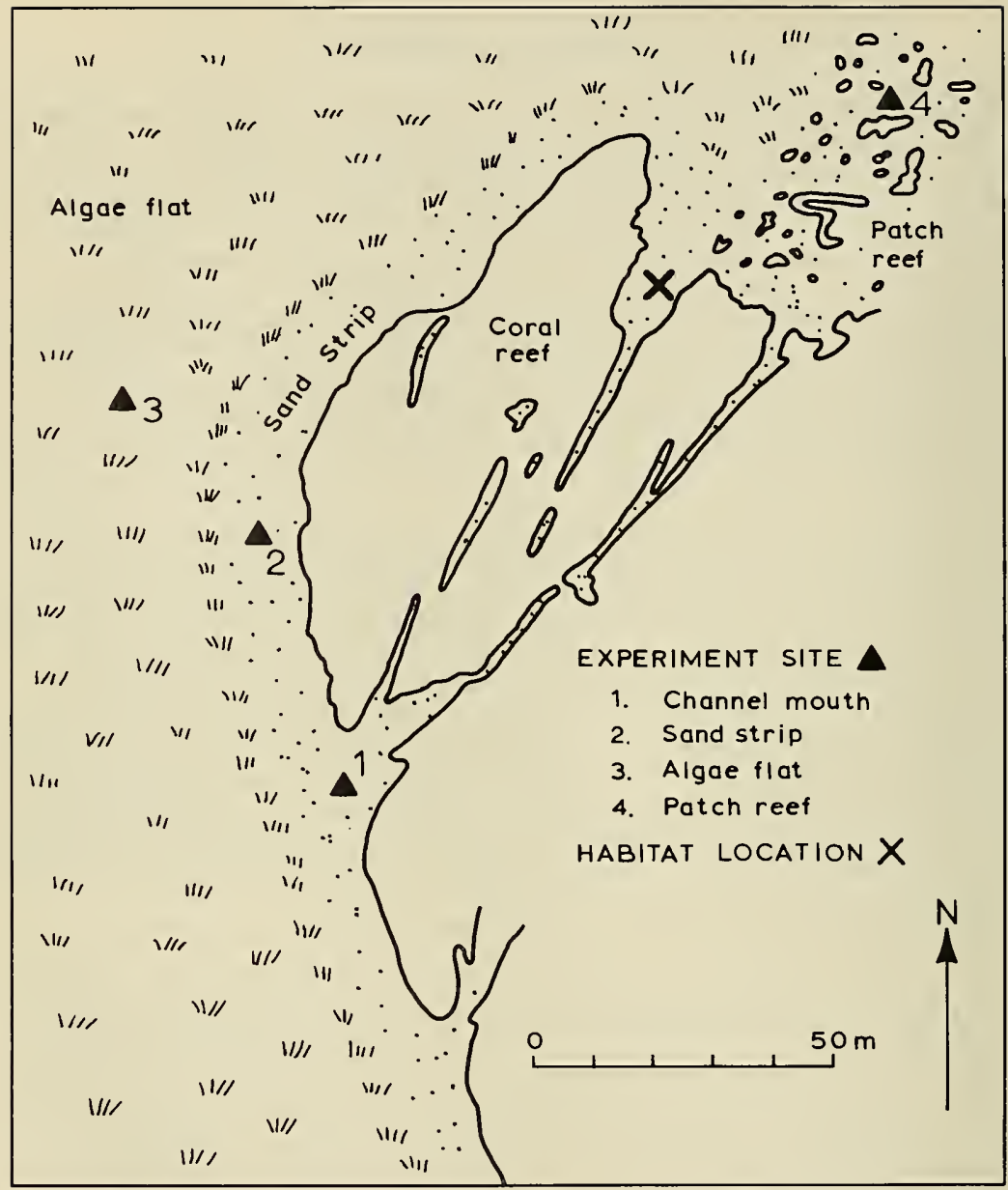

Figure 1. Location of sites of bioturbation experiments. Water depths at each site are as follows: $19.8 \mathrm{~m}$ at $1 ; 19.5 \mathrm{~m}$ at $2 ; 18.0 \mathrm{~m}$ at 3 and $12.5 \mathrm{~m}$ at 4 . 
The rate of the day to day modification differed among the plots. The ripples at the channel mouth site were noticeably subdued after 2 days; the intervals after which ripples were first noticed to be subdued in the other sites were: the sand strip, 15 days; the algae flat, 22 days; the patch reef, 9 days. The ripple plot was partly obliterated in the channel mouth after 7 days, in the algae flat, after 30 days, in the patch reef, after 22 days. The ripples on the sand strip were never only partly obliterated. The point at which the ripple pattern completely disappeared was channel mouth, 15 days; algae flat and patch reef, 30-35 days; and sand strip, 24 days. The ripples clearly were modified and obliterated more rapidy at the channel mouth than at the other sites.

The style of modification also differed. At the channel mouth site, the ripples were destroyed by the construction of mounds and craters formed by burrowing organisms within the sand. On the sand strip and in the patch reef, the ripples gradually lost their relief and became discernible only by linear aggregations of algal debris that had collected earlier in the ripple troughs. On the algal flat, where the ripples remained sharply defined for a longer period of time, they were destroyed largely by unidentified organisms that dug small holes in the sand.

The style of disruption of internal structures as shown in box cores taken through the artificially layered sand also differed among the experiment sites. At the channel mouth site the laminations were largely destroyed by small isolated vertical burrows. At the other sites, a general mixing of the sand obliterated the layering. This mixing, which was most intense near the sediment-water interface and decreased with depth, probably was caused by organisms crawling across the bottom or feeding in the uppermost part of the sediment.

The rate of disruption of the layering depended both on the depth of the layer beneath the surface and the style of reworking. In all plots, the lower layer of dyed sand tended to be preserved longer than the upper layer. At the channel mouth site, both layers tended to persist longer than they did at the other sites. This difference in disruption rate resulted from the nature of the mixing and from the fact that sediment cast upon the sand surface by burrowing organisms tended to bury and therefore protect the layering from the activity of organisms that disturbed the uppermost part of the sediment.

The rate of general sediment surface modification as indicated in daily photographs of the bottom also differed between the canyon mouth and the other sites. The rapid construction of 
mounds and holes by burrowing organisms tended to change the sediment surface more at the channel mouth. At all sites, however, a progressive change of bottom configuration occurred daily.

\section{BIOTURBATIONAL BURIAL}

Objects lying on the sea floor near West Indian reefs are prone over a period of weeks on months to become buried. This phenomenon was first observed during Tektite $I$, when metal plates (used as locational grid markers) placed on a carbonate sand substrate at the beginning of the experiment were found completely buried 60 days later (Clifton and others, 1970). This burial was not due to an influx of sand; for the level of the sand surface referenced to metal stakes emplanted in the sand showed no significant buildup. Rather the burial seems to result from an undermining of the plates by organisms burrowing beneath them. As the plate or other object is undermined, it sinks into the sand until it becomes completely covered. Because such a process incorporates clasts into the sediment where they are protected from further transport or erosion on the sea floor, it has considerable geological significance.

The depth to which objects are buried differs. The top of one grid plate emplaced during Tektite I lay $1.5 \mathrm{~cm}$ beneath the surface a year later. As the plate is $2.7 \mathrm{~cm}$ thick, the total depth of sinking of the plate exceeds $4 \mathrm{~cm}$. The top of another plate lay $4 \mathrm{~cm}$ beneath the surface; it had sunk $6.7 \mathrm{~cm}$ into the sand. Concrete blocks, probably emplaced on the sand during the Tektite I program, were commonly at least half buried (about $9 \mathrm{~cm})$. The most deeply embedded block was found on the algal flat $400^{\prime}$ from the reef southwest of the habitat. This block lay in a hole, its upper surface approximately $10 \mathrm{~cm}$ below the sand surface level. The block itself was about $20 \mathrm{~cm}$ thick, the total depth of sinking approximately $30 \mathrm{~cm}$.

To determine the rate at which clasts of differe.st size, shape, and composition are buried by the activity of organisms, a set of 22 pebbles was placed on the bottom at each of the experiment sites described in the previous section. Each set consisted of two each of the following: small round (about $4 \mathrm{~cm}$ in diameter) pebbles of bedrock and coral, small flat (about 2 by $5 \mathrm{~cm}$ ) pebbles of bedrock and coral, medium round (about $6 \mathrm{~cm}$ in diameter) pebbles of bedrock and coral, medium flat (about 3 by $8 \mathrm{~cm}$ ) pebbles of bedrock and coral, round (about $10 \mathrm{~cm}$ in diameter) cobbles of bedrock and coral, and flat (about 5 by $10 \mathrm{~cm}$ ) cobbles of bedrock. The pebble plots were monitored periodically and all pebbles were excavated after 32 days to determine the depth of burial of each. 
Several different effects were observed during the course of the experiment. Very commonly the pebbles would be lightly to heavily covered with a dusting of sand thrown into the water by organisms digging near by. In all plots the pebbles, particularly the flatter ones tended to sink a centimeter or two into the sand. In the channel mouth plot, many of the pebbles covered small burrows, most of which seemed to be dug by small fish, mainly gobies. Such pebbles rather rapidly sank into depressions in the sand. In every plot pebbles were displaced by the passage of organisms across the sand; one of the largest bedrock cobbles was moved several centimeters and some of the smaller pebbles were displaced even farther. A medium flat coral pebble was taken from the channels mouth plot by an octopus, who used it as a door to his den about 5 meters away.

After 32 days, two parameters were measured for each pebble remaining in the plots. The first of these was the distance from the top of the pebble to the surface of the sand above or below, which indicates the degree of burial of the pebble. The second was the distance from the base of the pebble to the sand surface above, which indicates the depth to which the pebble sand and, unlike the first parameter, is independent of the size (thickness) of the clast.

By averaging the data for each type of clast from all four plots, the depth of burial and depth of sinking can be related to clast size, shape, and composition. The averages indicate that depth of sinking, approximately $2 \mathrm{~cm}$ for all types, is unrelated to the dimension or the density of the clast. The depth of burial is related to size and shape but not to composition of the clast. Such a relation to size and shape is predictable; for pebbles and cobbles which sink more or less the same distance into the sand, the smaller and flatter are likelier to become buried.

The experiment demonstrated that the depth of sinking and burial is related to the style of bioturbation. In the channel mouth plot, where undermining was active, the top of the pebbles lay on the average nearly even with the sand surface; in the other three plots, the tops of the pebbles averaged 2.5 to $3.5 \mathrm{~cm}$ above the sand surface. The average depth of sinking of the pebbles in the channel mouth plot was nearly $4 \mathrm{~cm}$, whereas that in the other plots was only about $1-2 \mathrm{~cm}$. Of the clasts in the channel mouth plot, the most deeply buried were a large flat bedrock cobble that sank to a depth of $8 \mathrm{~cm}$ and lay (from its top) $3.5 \mathrm{~cm}$ beneath the surface and a small flat coral pebble that sank to a depth of $5 \mathrm{~cm}$ and lay (from its top) $4 \mathrm{~cm}$ beneath the surface. The plots in the sand strip and the patch reef sites contained 2 or 3 pebbles 
that were completely buried. On the algae flat, none of the pebbles were completely buried, and this plot contained the only pebbles in the experiment that showed no sinking whatever.

The experiment regarding biotrubational rotation of shells described provides further information on bioturbational burial. After 40 days, nearly half of the shells were buried, originally concave-up shells and originally concave-down shells in nearly equal numbers. A much greater amount of shell burial took place in the 2 plots $6 \mathrm{~m}$ from the reef than in the 2 plots 1 to $2 \mathrm{~m}$ from the reef. As with the pebbles, the number of shells buried depends on their size and shape; small or flat shells are likelier to be buried than larger or more gibbous shells. The density or weight of the shell may also be a factor; of two species of approximately equal gibbosity used in the experiment, distinctly more of the relatively thickshelled Anadara lienosa floridana were buried than the much thinner-shelled Laevicardium laevigatum.

\section{OTHER ASPECTS OF BIOTURBATION}

Nocturnal and diurnal: A thin layer of dyed sand was dusted over an area of approximately a square meter of bottom at each of the experimental sites at dusk one evening. At dawn the following morning, each surface was broken by 6 to 12 small cones produced by burrowing organisms. In the sand strip, small gobies were disturbing the sand around an abandoned conch shell, and in the patch reef small trails 1-2 $\mathrm{mm}$ wide crossed the fresh surface. After 3 hours of daylight each plot showed considerably more disruption than it had at dawn. By dusk, the surface in the channel mouth was much pocked by small craters, crossed by a trail, and disrupted in general. In the sand strip the sand was thoroughly stirred within $5 \mathrm{~cm}$ of the conch shell; but the surface was otherwise less disrupted than at the canyon mouth. On the algae flat, the surface was broken by numerous small shallow holes and by sand cast up from burrows. In the patch reef, small mounds and burrows interrupted the dyed sand surface. The observations indicate that the sediment surface is more disrupted by organisms during daylight than it is at night.

Integrity of sand surface: The dyed sand surfaces were monitored daily to determine how long the integrity of the surface would persist. The surface became undistinguishable in the patch reef after 4 days and in the channel mouth after 5 days. At the other sites, small ( 2 by $5 \mathrm{~cm}$ ) areas of the original surface remained undisturbed, but even these had a scattering of undyed sand on the surface. Observations of this experiment attest to the rapid bioturbational alteration of the sediment 
surface in the coral reef environment.

Lateral movement of sand: To determine the rate at which organisms could move sand laterally at the sediment surface, a plastic sheet, $35 \times 80 \mathrm{~cm}$ in size, was staked upon the sand surface in the channel mouth and left for 6 days. Sand accumulated more or less evenly over the sheet; it was collected, dried and weighed. Texturally this sand was poorly sorted, the particles ranging in size from silt to granules. A total fo 212 grams accumulated on the sheet during the 6-day period; the daily rate of lateral movement to produce this accumulation averages 126 grams per square meter. If this rate of lateral transport obtains along all the reef front, the amount of sand shifted by organisms is considerable. In a 10-m-wide strip bordering the $500 \mathrm{~m}$ of reef front in the reefs near the habitat, $225,000 \mathrm{~kg}$ of sand is shifted yearly by organisms.

\section{EFFECTS OF SPECIFIC ORGANISMS:}

The time spent in the water during the Tektite program permitted observation of the effect on the sediment of a number of specific organisms. These organisms could be classed as exofauna if they live in the water or above the sediment, endofauna if they actually live within the sediment.

The exofauna can be subdivided by their activity; some mix the sediment, whereas others excavate holes in it. The mixing organisms include both vertebrates and invertebrates. Most conspicuous among the fish that mix the sediment are the mullidae (goatfishes), commonly seen in schools, stirring up clouds of suspended material as they work the sediment with long chin barbels in their search for food. Other fish, such as the synodontidae (lizard fishes) stir the sand by partly burying themselves within it. Invertebrate exofauna also can greatly disturb the sand. Large gastropods, in particular strombus gigas, leave a prominent track where they cross the sand. Hermit crabs occupying large gastropod shells greatly stir the sediment to a depth of several centimeters as they feed, backing across the sand and churning it with their claws.

Holes are excavated either in a search for food or in construction of a burrow. The largest holes are dug by rays, which, by pumping their wings, generate currents that create broad shallow excavations, generally a 1 to 1.5 meters across and 10 to $15 \mathrm{~cm}$ deep. Within a few minutes a ray less than a meter across dug with its nose a hole about $40 \mathrm{~cm}$ across and $13 \mathrm{~cm}$ deep, the steepest measured. Commonly the excavations made by rays show a slightly positive rim. 
Certain fish, such as ostraciontidae (trunkfishes) and balistidae (trigger fishes), blow holes in the sand. A Balistes vetula (queen triggerfish) was observed (pers. comm., John van Derwalker 1970) blowing a hole that was later measured as about $40 \mathrm{~cm}$ across and $15 \mathrm{~cm}$ deep. Holes blown in the sand by fish are distinctive in that they have very steep walls.

Less was ascertained about the effects of organisms that spend their lives within the sand. Mounds that have the form of small volcanoes of sand are highly abundant in certain areas. These mounds are formed by the casting of sand from small burrows that vertically intersect the sandwater interface. The organisms responsible were not identified, but the burrows are similar to those produced by burrowing shrimp (Shinn, 1968, p. 883). Other organisms, such as small gastropods, tend to stir the sand by burrowing horizontally. Some vertebrates such as Ophichthus ophis (spotted snake eel) apparently have the ability to "swim" through the uppermost part of the sediment. Numerous other endofauna, including pelecypods, crustaceans, and worms, undoubtedly contribute greatly to bioturbation of the carbonate sand.

\section{CONCLUSIONS}

The studies conducted as part of Tektite II have documented the great importance of bioturbation as a geologic process in the semiprotected coral reef environment. The faunal disturbance of sediment has a wide variety of effects. Bioturbation can create or destroy sedimentary structures. It can produce an assemblage of empty pelecypod valves that lie predominantly concave side up, an orientation that contrasts markedly with that produced by waves or currents. This difference in shell orientation provides a useful means of interpreting the energy regime under which a fossiliferous sedimentary rock was deposited. The activity of organisms may control the distribution of sediment on the sea floor, in particular, the aggregations of coarse shells and coral fragments produced by $M$. plumieri and the lateral shifting of sediment at the surface.

The style and rate of bioturbation depend on environmental factors such as proximity to the reef and substrate. At the canyon mouth site, the substrate is distinctly finer grained than at the other experimental sites, and more organisms live in burrows within the sand. The style of bioturbation by these organisms differs considerably from that at the other sites and the rate of sediment modification differs accordingly. A prolific burrowing fauna generate a higher rate of destruction of sedimentary surface structures such as ripple marks but a lower rate of disruption of internal structures. In each of the environments examined, the rate of 
destruction of internal structure depends directly on the proximity of the structure to the sediment surface. Structures within a few centimeters of the surface are probably obliterated within a few months. In an area of active bioturbation, surface structures will probably be obliterated within a few weeks.

The saturation diving and underwater habitation provided by the Tektite II project are of great advantage in studying bioturbation. They permit a significantly greater amount of underwater. observation than would be possible in the same period of diving from surface nearly continuous monitoring of experiments that document the geologically significant effects of organisms living on or within the sediment.

References cited:

Clifton, H. E., in press, Orientation of empty pelecypod shells and shell fragments in quiet water: J. Sedimentary Petrology.

Clifton, H. E., Mahnken, Conrad V. W., Van Derwalker, J. S., and Waller, R. A., 1970, Tektite, Man-in-the-sea experiment of marine science program, description and preliminary results: Science v. 168,: 659-663.

Emery, K. O., 1968, Positions of empty pelecypod valves on the continental shelf: J. Sedimentary Petrology 38: 1264-1269.

Randall, J. E., 1967, Food habits of reef fishes of the West Indies: in Proc. Internat. Conf. on Tropical Oceanography, Nov. 15-24, 1965, Miami Beach, Fla., Studies in Tropical Oceanography No. 5, Univ. of Miami Inst. Marine Sciences: 665-847.

Shinn, E. A., 1968, Burrowing in recent lime sediments of Florida and the Bahamas: J. Paleont. 42: 879-894. 
ECOLOGY AND POPULATION DYNAMICS OF THE SPINY LOBSTER, PANULIRUS $\underline{\text { ARGUS }}$, OF ST. JOHN ISLAND, U.S. VIRGIN ISLANDS

\author{
Mr Louis Barr \\ National Marine Fisheries Service \\ Auke Bay, Alaska \\ Dr. Richard Cooper \\ National Marine Fisheries Service \\ Boothbay Harbor, Maine \\ Mr. Robert E1lis \\ Nationa1 Marine Fisheries Service \\ Auke Bay, Alaska \\ Dr. William Herrnkind \\ Florida State University \\ Tallahassee, Florida \\ Mr. Ian Koblick \\ College of the Virgin Islands \\ St. Thomas, Virgin Islands \\ Mr. John Van Derwalker \\ National Marine Fisheries Service \\ Washington, D.C.
}

\begin{abstract}
A 6-month study was conducted on the population dynamics and ecology of the spiny lobster, Panulirus argus, by aquanauts working from the TEKTITE II habitat in conjunction with surface support diverscientists. Population structure by size and sex was defined. Mark and recapture experiments determined population levels for four adjacent study areas. Population turnover occured at the rate of 45 to 90 percent per month. Nocturnal periodicity was defined through frequent observations of tagged individuals at marked dens. A homing ability and apparent learned familiarity with the dens of the reef were documented through sonic tracking studies and periodic surveys of the dens of the reef. Population structure and distribution was significantly altered from diver harassment. Information on growth, feeding behavior, and habitation was obtained.
\end{abstract}

\title{
OBJECTIVE
}

The TEKTITE II Lobster Research Project was initiated in Apri1 1970 as a 1-year study of the ecology and population dynamics of the spiny lobster, Panulirus argus, of Saint John Island, U. S. Virgin Islands. Specific objectives were to define the population structure by size and sex, population size, migratory behavior, patterns of behavior re: time of day, growth, mortality, and habitat selection. Results presented herein represent the scientific findings during the first 6 months (late April to late October) of the study, and integral part of the TEKTITE II program. 
This study was conducted by six coprincipal investigators with financial support from the Office of Sea Grants through the College of the Virgin Islands, the TEKTITE II Program Office, Florida State University, and the National Marine Fisheries Service Biological Laboratories at Auke Bay, Alaska, and Boothbay Harbor, Maine.

\section{STUDY AREA}

The area of study on the south shore of St. John Island included Greater Lameshur Bay, the region west of Cabritte Horn Point (Beehive Cove) and most of Grootpan Bay to the east of the point (Figure 1). To conduct studies of movement patterns, and for comparative purposes, the above region was divided into four study areas: Area 1 - eastward from the promontory separating Greater from Little Lameshur Bay to about the midline (offshore-onshore axis) of Great
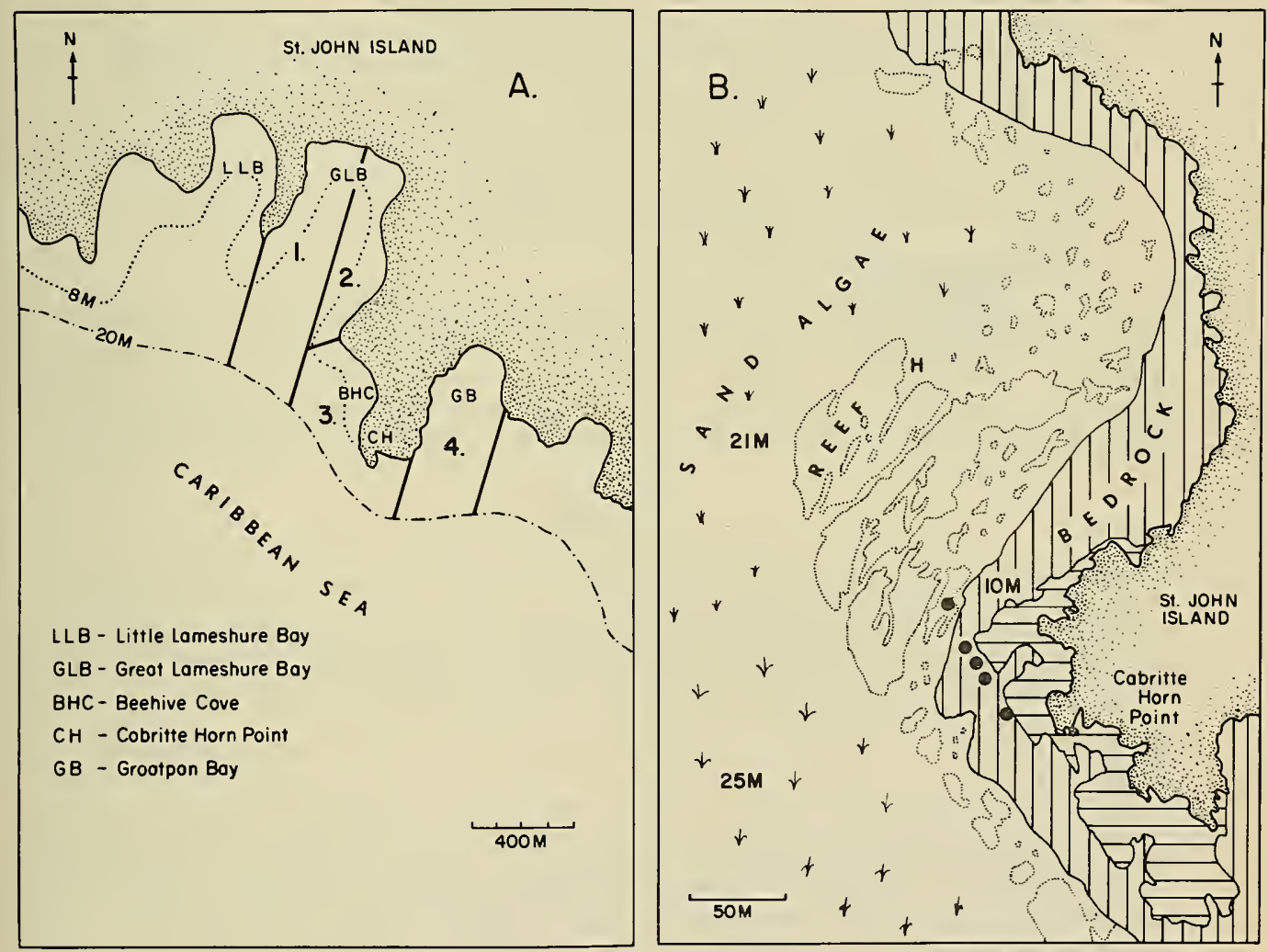

Figure 1. Study Area. A, section of south shore of St. John Island showing study areas 1, 2, 3, and 4; B, Topography of Area 3. Dots on B represent dens most frequently occupied. 
Lameshur; Area 2 - from this point eastward to the area of Beehive Cove; Area 3 - Beehive Cove and immediately seaward of Cabritte Horn Point; and Area 4 - Grootpan Bay. The main aquanaut stidy area, Area 3, encompassed approximately $150,000 \mathrm{~m}^{2}$, approximately one-third being reef and hard bottom (inshore), the remainder sand-algal flats (offshore). The area is described by Clifton, et al (1970), a portion of which is excerpted below.

"The habitat was anchored in a reentrant in the coral reef on the eastern side of the Bay. The massive reef structure extending south from the habitat to Cabritte Horn Point is crossed by several 1inear sets of grooves partly filled with carbonate sand. A wide variety of stone corals compose the reef, which has a relief of 3 to 4.5 meters above the adjacent sand flats. The deeper parts of the seaward reef wall are typical of deep Caribbean coral reefs .... and Montastrea annularis is the primary hermatypic species. Landward from the deep reef is an extensive patch reef area of isolated coral heads on sandy bottom .... The patch reef area is bordered ... on the landward side by an area of slightly coral-encrusted bedrock cobbles and boulders that locally adjoin submerged outcrops of bedrock, largely volcanic rock .... Acropora palmata, an indicator of high-energy zones, occurs along this rock outcrop near Cabritte Horn Point. On the seaward side of the reef lie extensive sand flats that are either barren or vegetated by Thalassia or by Udotea and are sprinkled with sporadic patches of Penicillus and Halimeda. An unvegetated sand strip 9 to 15 meters wide along the reef separates it from the Thalassia and algae flats."

The other study areas similarly were hard bottom near shore, sand, algal beds (Area 4) or Thalassia (Areas 1 and 2) offshore (see Mathieson and Mead for more complete description of plants). Areas 1 and 2 were relatively shallower than Areas 3 or 4 and lacked massive reef formations; Area 1 lobster habitat was largely coral heads and patch reef while Area 2 provided both patch reef and boulder overhang.

\section{METHODS}

A major portion of the research was conducted by the above investigators operating from the TEKTITE habitat during three 20-day missions, April 22-May 11, July 25-August 13, and September 3-22. Research efforts during the remainder of the 6-month period were conducted by a team of diver-scientists operating from the surface and in coordination with the aquanauts.

Mark and recapture experiments with lobsters were initiated in the primary study area on Apri1 23; May 20 in Area 1; May 26 in Area 4; and June 9 in Area 2. Each area was searched by divers over a period of 1-2 weeks to locate, tag, and release an estimated 80 to 90 percent of the lobster population. Divers operating from the TEKTITE habitat searched Area 3 from the deepest portions of the reef up to the 8 meter depth contour (the shallow excursion limit imposed on the "saturated" divers). Portions of Area 3 shallower than 8 neters were searched by the surface support team, in addition to Areas 1,2 , and 4 . Divers attempted to systematically search each study area for lobsters. The sample of lobsters captured for tagging is considered representative of the local population, especially since it represents an estimated 80 to 90 percent of the individuals present during the initial marking period. 
Lobsters were captured from their dens using standard "lobster snares." Carapace length in millimeters, sex, completeness of appendages, color code of tag, den number, the investigator making the measurements, and time of day were recorded for each lobster tagged. Lobster dens were marked with styrofoam floats and numbered accordingly. Physical disturbance of the lobsters was kept at a minimum during measuring and tagging.

Color coded back tags (Figure 2), similar in format to the tags reported by Cooper (1970) for the American lobster, were inserted into the dorsal masculature between the abdomen and thorax with the aid of a No. 20 syringe needle. The colors used in various combinations were yellow, white, brown, blue, black, and red. Color coding permitted recognition of individuals and the study area of initial tagging.
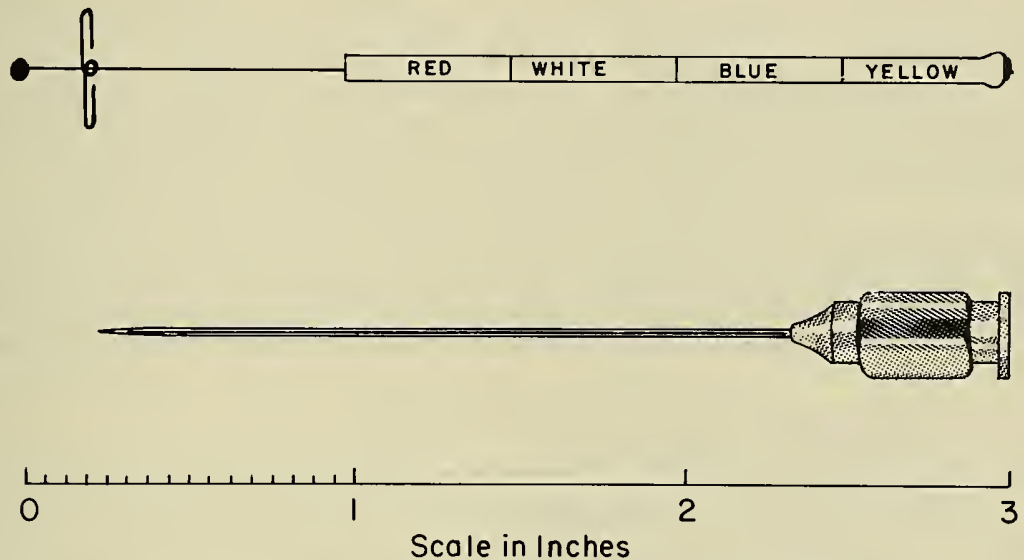

Figure 2. Color coded back tag with needle for insertion

In addition to tagging with the back tag, termed the "primary mark" in this study, a "secondary mark" was given to each tagged animal. A 4-millimeter hole was punched into one of the five tail fan sections to denote an animal that had been tagged and its respective study area. This secondary mark is retained through at least one molt and permits recognition of a lobster that has lost its "primary mark."

After the initial tagging was completed, periodic survey dives were made to collect census data for population estimation, defining migratory behavior, daytime-nighttime behavior, feeding behavior, growth, predation, and choice of habitat. Tagged lobsters were recaptured in Area 3 during September to estimate rate of tag loss and growth. During the remainder of the study tagged lobsters were, in general, observed but not physically disturbed. Untagged lobsters from Area 3 were captured, tagged, and released periodically throughout the study.

Movements and location of lobsters by night and from long distances were determined by sonic tagging-tracking techniques. The saddle-shaped sonic tags 
measured about $3 \times 5 \times 1 \mathrm{~cm}$, weighed only a few grams underwater, and produced a $70 \mathrm{KH}$ signal detectable by directional hydrophone as far away as $300-400 \mathrm{~m}$ on open bottom and remained detectable from 10-20 m when the lobster withdrew into a crevice. Several sonic trackers were used (Smith-Root, Ametec-Straza, and a unit custom built by the National Marine Fisheries Service Biological Laboratory in Seattle, Washington (see Clifton, et al, 1970).

Lobsters to be sonic-tagged were snared and hand carried back to the habitat. There, the dorsal cephalothorax was dried with toweling and Eastman 910 adhesive applied to both carapace and rubber "feet" on the tag. After several seconds, the tag was firmly placed and the adhesive allowed to set for 10-12 minutes. Tags so attached seldom detached from a free moving lobster, even in the den and on the reef.

The rate of back tag loss was estimated from reexamining a randomly selected sample of lobsters from Area 3 on or about September 15, 3 months after June 15, the point in time at which half of the tagged lobsters in Area 3 had been released. Ten percent of the lobsters examined with the secondary mark had lost the back tag, indicating a rate of tag loss of 3.3 percent per month. Assuming this rate to be constant with time, the number of tagged lobsters at large $\left(M_{t}\right)$ prior to the $t^{\text {th }}$ day of sampling was adjusted accordingly.

Multiple census population estimates were made of the lobster populations in the four study areas from each day survey diving, excluding the initial day of tagging. The Modified Schnabel formula from Ricker (1958) was used to calculate population size $(\mathrm{N})$. Census dives produced the following information necessary for computing $\mathrm{N}$ :

$$
\begin{aligned}
M_{t}= & \text { total number of tagged } \begin{array}{l}
\text { lobsters at large } \\
\text { at the start of the } t^{t h} \text { day. }
\end{array} \\
C_{t}= & \text { total number of lobsters seen on the } t^{\text {th }} \text { day. } \\
R_{t}= & \text { total number of tagged lobsters in the sample } C_{t} . \\
\Sigma R_{t}= & \text { total number of tagged lobsters seen up to and } \\
& \text { including the } t^{\text {th }} \text { day. }
\end{aligned}
$$

The formula used was,

$$
\mathrm{N}=\frac{\Sigma\left(\mathrm{C}_{t} \mathrm{M}_{t}\right)}{\Sigma \mathrm{R}_{\mathrm{t}}+1}
$$

Tagging and sampling was sufficiently intensive in Area 3 to permit a single census estimate, using Petersen's formula from Ricker (1958), of population size during May and September. These estimates were based on releases and resightings made during approximately one week periods in May and September. The Petersen formula is:

$$
N=\frac{M(c f 1)}{R+1}
$$


where,

$M=$ total number of lobsters tagged $=31$ (April 23 to April 30) and 17 (August 31 to Sept. 7), for the April and September estimates.

$\mathrm{C}=$ total number of lobsters seen during census sampling $=47$ (May 1 to May 4) and 26 (Sept. 8

to Sept. 13) for the April and September estimates.

$\mathrm{R}=$ total number of tagged lobsters in the sample $\mathrm{C}=27$ and 9 for the April and September estimates.

RESULTS

\section{Population Estimation}

Modified Schnabel population estimates for successive days of census sampling are presented in Tables 1, 2, 3, and 4 for the lobster populations of Areas 1 through 4, respectively. Al1 estimates are based on a corrected $M_{t}$, the number of tagged lobsters at large prior to the $t^{\text {th }}$ day of sampling, discussed above. Schnabel estimates of $\mathrm{N}$ were relatively constant over the duration of the study, excluding the first few estimates for Areas 1 and 2 (Figure 3 ). This constancy in $\mathrm{N}$ suggests that these populations were relatively stabile with minimal natural mortality, emigration or immigration. Fishing mortality is theoretically zero since commercial or sport fishing for lobsters was not permitted in Lameshur Bay. Lateral movements along the shore, between study areas, were virtually non-existent as will be discussed below.

Schnabel estimates for Areas 3 and 4 increased at a linear rate with significant changes occurring in July and September in Area 3 and during late July and ear1y August in Area 4 (Figure 4). These increases in $N$ indicate that tagged lobsters were emigrating from their respective areas at a given rate and/or that significant natural mortality was occurring selectively on the tagged individuals. Total counts of lobsters seen by divers during these periods suggest that the population sizes of Areas 3 and 4 were relatively constant or were declining gradually; therefore, either tags were being lost at a rate significantly greater than that estimated above or immigration of untagged lobsters was balancing the loss of tagged lobsters from the population through natural mortality and/or emigration. Emigration is considered the primary source of loss of tagged individuals. Observations on the behavior of tagged and "harassed" lobsters support this hypothesis (see section on Impact of Divers). The sudden increase in $\mathrm{N}$ in July for Area 3 and July-August for Area 4 probably represents a period of relatively great immigration of untagged lobsters. Actual counts by divers during these times support this contention. The relatively high rate of increase in $\mathrm{N}$ during September in Area 3 probably reflects an increased rate of emigration of tagged lobsters as a result of intensive pressure (recapture and observation) by divers operating from the TEKTITE habitat. 
Table 1.--Census data in tagging study of lobsters in study area number 1 .

\begin{tabular}{|c|c|c|c|c|c|c|c|c|}
\hline \multirow[t]{2}{*}{$\begin{array}{l}\text { Date of } \\
\text { census } \\
\text { sample } \\
(1970)\end{array}$} & \multirow{2}{*}{$\begin{array}{l}\text { Number } \\
\text { of } \\
\text { lobsters } \\
\text { seen } \\
C_{t}\end{array}$} & \multicolumn{2}{|c|}{$\begin{array}{l}\text { Number of } \\
\text { tagged } \\
\text { lobsters } \\
\text { seen }\end{array}$} & \multirow[t]{2}{*}{$\begin{array}{l}\text { Number } \\
\text { tagged } \\
\text { less } \\
\text { removals }\end{array}$} & \multirow{2}{*}{$\begin{array}{l}\text { Tagged } \\
\text { lobsters } \\
\text { at large } \\
\text { (corrected) } \\
\quad M_{t}\end{array}$} & \multirow[b]{2}{*}{$\mathrm{C}_{\mathrm{t}} \mathrm{M}_{\mathrm{t}}$} & \multirow[b]{2}{*}{$\Sigma\left(C_{t} M_{t}\right)$} & \multirow[b]{2}{*}{$\mathrm{N}$} \\
\hline & & $R_{t}$ & $\Sigma \mathrm{R}_{\mathrm{t}}$ & & & & & \\
\hline $5 / 20$ & 3 & 0 & 0 & 3 & 0 & 0 & 0 & -- \\
\hline $6 / 5$ & 2 & 0 & 0 & 2 & 3 & 6 & 6 & 6 \\
\hline $6 / 10$ & 11 & 3 & 3 & 7 & 5 & 55 & 61 & 15 \\
\hline $6 / 18$ & 7 & 2 & 5 & 2 & 12 & 84 & 145 & 24 \\
\hline $6 / 25$ & 5 & 1 & 6 & 0 & 14 & 70 & 215 & 31 \\
\hline $7 / 6$ & 8 & 0 & 6 & 2 & 14 & 112 & 327 & 47 \\
\hline $7 / 9$ & 2 & 1 & 7 & 0 & 16 & 32 & 359 & 45 \\
\hline $7 / 13$ & 3 & 2 & 9 & 0 & 16 & 48 & 407 & 41 \\
\hline $7 / 28$ & 6 & 2 & 11 & 1 & 16 & 96 & 503 & 42 \\
\hline $7 / 30$ & 0 & 0 & 11 & 0 & 16 & 0 & 503 & 42 \\
\hline $8 / 13$ & 6 & 3 & 14 & 3 & 15 & 90 & 593 & 39 \\
\hline $8 / 24$ & 2 & 2 & 16 & 0 & 18 & 36 & 629 & 37 \\
\hline $8 / 25$ & 5 & 3 & 19 & 2 & 18 & 90 & 719 & 36 \\
\hline $9 / 8$ & 2 & 2 & 21 & 0 & 19 & 38 & 757 & 34 \\
\hline $10 / 14$ & 7 & 2 & 23 & 0 & 19 & 133 & 890 & 37 \\
\hline $10 / 24$ & 7 & 3 & 26 & 0 & 18 & 126 & 1016 & 38 \\
\hline
\end{tabular}

Table 2.--Census data in tagging study of lobsters in study area number 2 .

\begin{tabular}{|c|c|c|c|c|c|c|c|c|}
\hline \multirow[t]{2}{*}{$\begin{array}{l}\text { Date of } \\
\text { census } \\
\text { sample } \\
(1970)\end{array}$} & \multirow{2}{*}{$\begin{array}{l}\text { Number } \\
\text { of } \\
\text { lobsters } \\
\text { seen } \\
C_{t}\end{array}$} & \multicolumn{2}{|c|}{$\begin{array}{l}\text { Number of } \\
\text { tagged } \\
\text { lobsters } \\
\text { seen }\end{array}$} & \multirow[t]{2}{*}{$\begin{array}{l}\text { Number } \\
\text { tagged } \\
\text { less } \\
\text { removals }\end{array}$} & \multirow{2}{*}{$\begin{array}{l}\text { Tagged } \\
\text { lobsters } \\
\text { at large } \\
\text { (corrected) } \\
M_{t}\end{array}$} & \multirow[b]{2}{*}{$\mathrm{C}_{\mathrm{t}} \mathrm{M}_{\mathrm{t}}$} & \multirow[b]{2}{*}{$\Sigma\left(C_{t} M_{t}\right)$} & \multirow[b]{2}{*}{$\mathrm{N}$} \\
\hline & & $R_{t}$ & $\Sigma \mathrm{R}_{\mathrm{t}}$ & & & & & \\
\hline $6 / 9$ & 5 & 0 & 0 & 5 & 0 & 0 & 0 & -- \\
\hline $6 / 17$ & 4 & 1 & 1 & 1 & 5 & 20 & 20 & 10 \\
\hline $6 / 23$ & 6 & 2 & 3 & 1 & 6 & 36 & 56 & 14 \\
\hline $7 / 10$ & 8 & 4 & 7 & 3 & 7 & 56 & 112 & 14 \\
\hline $7 / 17$ & 3 & 1 & 8 & 0 & 10 & 30 & 142 & 16 \\
\hline $7 / 27$ & 0 & 0 & 8 & 0 & 10 & 0 & 142 & 16 \\
\hline $8 / 11$ & 3 & 0 & 8 & 0 & 9 & 27 & 169 & 19 \\
\hline $8 / 14$ & 2 & 1 & 9 & 0 & 9 & 18 & 187 & 19 \\
\hline $9 / 15$ & 1 & 1 & 10 & 0 & 9 & 9 & 196 & 18 \\
\hline $10 / 16$ & 8 & 3 & 13 & 0 & 8 & 64 & 260 & 18 \\
\hline
\end{tabular}


Table 3.--Census data in tagging study of lobsters in study area number 3 .

\begin{tabular}{|c|c|c|c|c|c|c|c|c|}
\hline \multirow[t]{2}{*}{$\begin{array}{l}\text { Date of } \\
\text { census } \\
\text { sample } \\
(1970)\end{array}$} & \multirow{2}{*}{$\begin{array}{l}\text { Number } \\
\text { of } \\
\text { lobsters } \\
\text { seen } \\
C_{t}\end{array}$} & \multicolumn{2}{|c|}{$\begin{array}{l}\text { Number of } \\
\text { tagged } \\
\text { lobsters } \\
\text { seen }\end{array}$} & \multirow[t]{2}{*}{$\begin{array}{l}\text { Number } \\
\text { tagged } \\
\text { less } \\
\text { removals }\end{array}$} & \multirow{2}{*}{$\begin{array}{l}\text { Tagged } \\
\text { lobsters } \\
\text { at large } \\
\text { (corrected) } \\
\mathrm{M}_{\mathrm{t}}\end{array}$} & \multirow[b]{2}{*}{$C_{t} M_{t}$} & \multirow[b]{2}{*}{$\Sigma\left(C_{t} M_{t}\right)$} & \multirow[b]{2}{*}{$\mathrm{N}$} \\
\hline & & $R_{t}$ & $\Sigma \mathrm{R}_{\mathrm{t}}$ & & & & & \\
\hline $4 / 23$ & 20 & 0 & 0 & 1 & 0 & 0 & 0 & -- \\
\hline $4 / 24$ & 27 & 0 & 0 & 8 & 1 & 27 & 27 & 27 \\
\hline $4 / 25$ & 17 & 2 & 2 & 10 & 9 & 153 & 180 & 60 \\
\hline $4 / 26$ & 21 & 8 & 10 & 1 & 19 & 399 & 579 & 53 \\
\hline $4 / 27$ & 16 & 8 & 18 & 7 & 20 & 320 & 899 & 47 \\
\hline $4 / 28$ & 17 & 7 & 25 & 3 & 27 & 459 & 1358 & 52 \\
\hline $4 / 29$ & 11 & 8 & 33 & 0 & 30 & 330 & 1688 & 50 \\
\hline $4 / 30$ & 8 & 1 & 34 & 1 & 30 & 240 & 1928 & 55 \\
\hline $5 / 1$ & 12 & 9 & 43 & 2 & 31 & 372 & 2300 & 52 \\
\hline $5 / 2$ & 3 & 2 & 45 & 0 & 33 & 99 & 2399 & 52 \\
\hline $5 / 3$ & 17 & 7 & 52 & 0 & 33 & 561 & 2960 & 56 \\
\hline $5 / 4$ & 15 & 9 & 61 & 5 & 33 & 495 & 3455 & 56 \\
\hline $5 / 5$ & 4 & 4 & 65 & 0 & 38 & 152 & 3607 & 55 \\
\hline $5 / 6$ & 9 & 9 & 74 & 0 & 38 & 342 & 3949 & 53 \\
\hline $5 / 7$ & 4 & 2 & 76 & 0 & 38 & 152 & 4101 & 53 \\
\hline $5 / 8$ & 14 & 5 & 81 & 2 & 38 & 532 & 4633 & 56 \\
\hline $5 / 9$ & 12 & 6 & 87 & 2 & 40 & 480 & 5113 & 58 \\
\hline $5 / 10$ & 12 & 7 & 94 & 1 & 42 & 504 & 5617 & 59 \\
\hline $6 / 8$ & 26 & 21 & 115 & 5 & 43 & 1118 & 6735 & 58 \\
\hline $6 / 11$ & 4 & 4 & 119 & 0 & 48 & 192 & 6927 & 58 \\
\hline $6 / 16$ & 11 & 6 & 125 & 5 & 48 & 528 & 7455 & 59 \\
\hline $6 / 22$ & 16 & 10 & 135 & 5 & 52 & 832 & 8287 & 61 \\
\hline $6 / 30$ & 17 & 8 & 143 & 7 & 56 & 952 & 9239 & 64 \\
\hline $7 / 1$ & 1 & 0 & 143 & 1 & 63 & 63 & 9302 & 65 \\
\hline $7 / 20$ & 31 & 7 & 150 & 5 & 63 & 1953 & 11255 & 75 \\
\hline $7 / 31$ & 8 & 5 & 155 & 1 & 68 & 544 & 11799 & 76 \\
\hline $8 / 8$ & 10 & 7 & 162 & 3 & 68 & 680 & 12479 & 77 \\
\hline $8 / 10$ & 5 & 3 & 165 & 1 & 71 & 355 & 12834 & 77 \\
\hline $8 / 18$ & 7 & 3 & 168 & 0 & 71 & 497 & 13331 & 79 \\
\hline $8 / 20$ & 7 & 3 & 171 & 0 & 71 & 497 & 13828 & 80 \\
\hline $8 / 31$ & 6 & 3 & 174 & 3 & 70 & 420 & 14248 & 81 \\
\hline $9 / 3$ & 11 & 3 & 177 & 0 & 73 & 803 & 15051 & 85 \\
\hline $9 / 4$ & 11 & 9 & 186 & 2 & 72 & 792 & 15843 & 85 \\
\hline $9 / 5$ & 2 & 0 & 186 & 0 & 74 & 148 & 15991 & 85 \\
\hline $9 / 6$ & 7 & 5 & 191 & 2 & 74 & 518 & 16509 & 86 \\
\hline $9 / 7$ & 9 & 4 & 195 & 4 & 76 & 684 & 17193 & 88 \\
\hline $9 / 8$ & 5 & 5 & 200 & 0 & 80 & 400 & 17593 & 87 \\
\hline $9 / 9$ & 5 & 4 & 204 & 0 & 80 & 400 & 17993 & 88 \\
\hline $9 / 10$ & 6 & 4 & 208 & 0 & 79 & 474 & 18467 & 88 \\
\hline $9 / 11$ & 12 & 7 & 215 & 0 & 79 & 948 & 19415 & 90 \\
\hline $9 / 12$ & 7 & 4 & 219 & 0 & 79 & 553 & 19968 & 91 \\
\hline $9 / 13$ & 5 & 3 & 222 & 1 & 78 & 390 & 20358 & 91 \\
\hline $9 / 14$ & 7 & 5 & 227 & 1 & 79 & 553 & 20911 & 92 \\
\hline $9 / 15$ & 6 & 5 & 232 & 1. & 80 & 480 & 21391 & 92 \\
\hline $9 / 16$ & 13 & 8 & 240 & 0 & 80 & 1040 & 22431 & 93 \\
\hline $9 / 17$ & 6 & 6 & 246 & 0 & 80 & 480 & 22911 & 95 \\
\hline $9 / 18$ & 8 & 7 & 253 & 0 & 80 & 640 & 23551 & 93 \\
\hline $9 / 20$ & 8 & 8 & 261 & 0 & 79 & 632 & 24183 & 92 \\
\hline
\end{tabular}


Table 4.--Census data in tagging study of lobsters in study area number 4 .

\begin{tabular}{|c|c|c|c|c|c|c|c|c|}
\hline \multirow[t]{2}{*}{$\begin{array}{l}\text { Date of } \\
\text { census } \\
\text { sample } \\
\text { (1970) }\end{array}$} & \multirow{2}{*}{$\begin{array}{l}\text { Number } \\
\text { of } \\
\text { lobsters } \\
\text { seen } \\
C_{t}\end{array}$} & \multicolumn{2}{|c|}{$\begin{array}{l}\text { Number of } \\
\text { tagged } \\
\text { lobsters } \\
\text { seen }\end{array}$} & \multirow[t]{2}{*}{$\begin{array}{l}\text { Number } \\
\text { tagged } \\
\text { less } \\
\text { removals }\end{array}$} & \multirow{2}{*}{$\begin{array}{l}\text { Tagged } \\
\text { lobsters } \\
\text { at large } \\
\text { (corrected) } \\
\mathrm{M}_{\mathrm{t}}\end{array}$} & \multirow[b]{2}{*}{$\mathrm{C}_{t} \mathrm{M}_{t}$} & \multirow[b]{2}{*}{$\Sigma\left(\mathrm{C}_{\mathrm{t}} \mathrm{M}_{\mathrm{t}}\right)$} & \multirow[b]{2}{*}{$\mathrm{N}$} \\
\hline & & $R_{t}$ & $\Sigma R_{t}$ & & & & & \\
\hline $5 / 26$ & 2 & 0 & 0 & 2 & 0 & 0 & 0 & -- \\
\hline $5 / 27$ & 5 & 0 & 0 & 5 & 2 & 10 & 10 & 10 \\
\hline $6 / 3$ & 8 & 6 & 6 & 0 & 7 & 56 & 66 & 9 \\
\hline $6 / 11$ & 5 & 3 & 9 & 0 & 7 & 35 & 101 & 10 \\
\hline $6 / 19$ & 6 & 3 & 12 & 3 & 7 & 42 & 143 & 11 \\
\hline $6 / 26$ & 10 & 4 & 16 & 3 & 10 & 100 & 243 & 14 \\
\hline $7 / 13$ & 2 & 1 & 17 & 0 & 13 & 26 & 269 & 15 \\
\hline $7 / 24$ & 12 & 4 & 21 & 6 & 13 & 156 & 425 & 19 \\
\hline $7 / 30$ & 11 & 1 & 22 & 6 & 18 & 198 & 623 & 27 \\
\hline $8 / 10$ & 12 & 5 & 27 & 2 & 23 & 276 & 899 & 32 \\
\hline $8 / 13$ & 8 & 5 & 32 & 1 & 25 & 200 & 1099 & 33 \\
\hline $10 / 14$ & 15 & 5 & 37 & 0 & 23 & 345 & 1444 & 38 \\
\hline
\end{tabular}

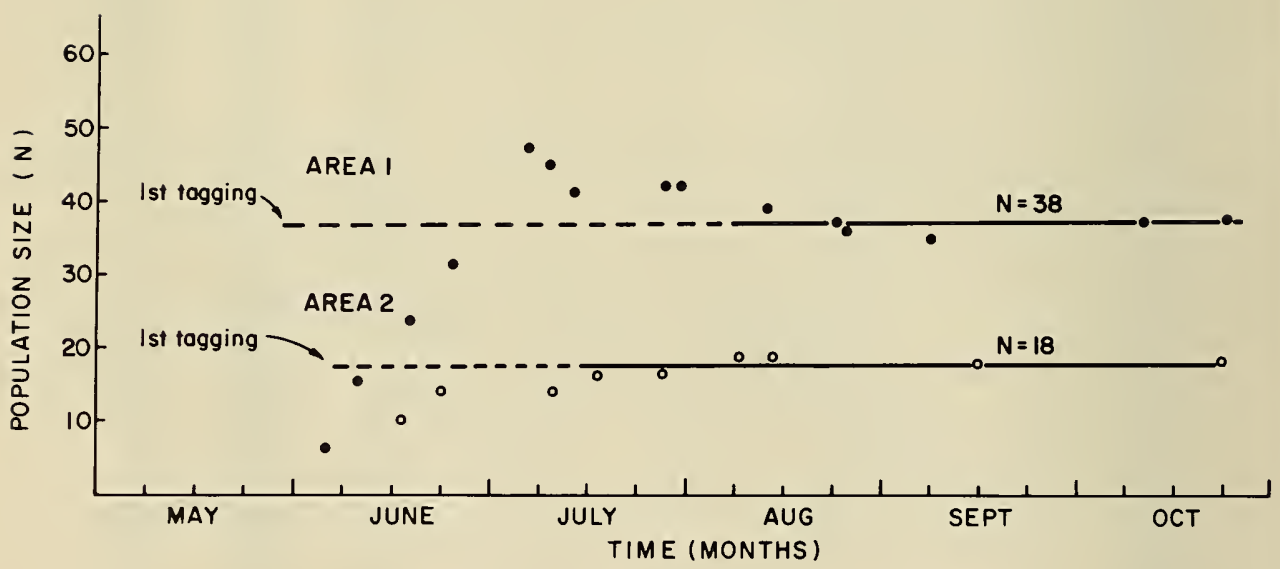

Figure 3. Trend in modified Schnabel population estimates (N) with time for study areas 1 and 2 


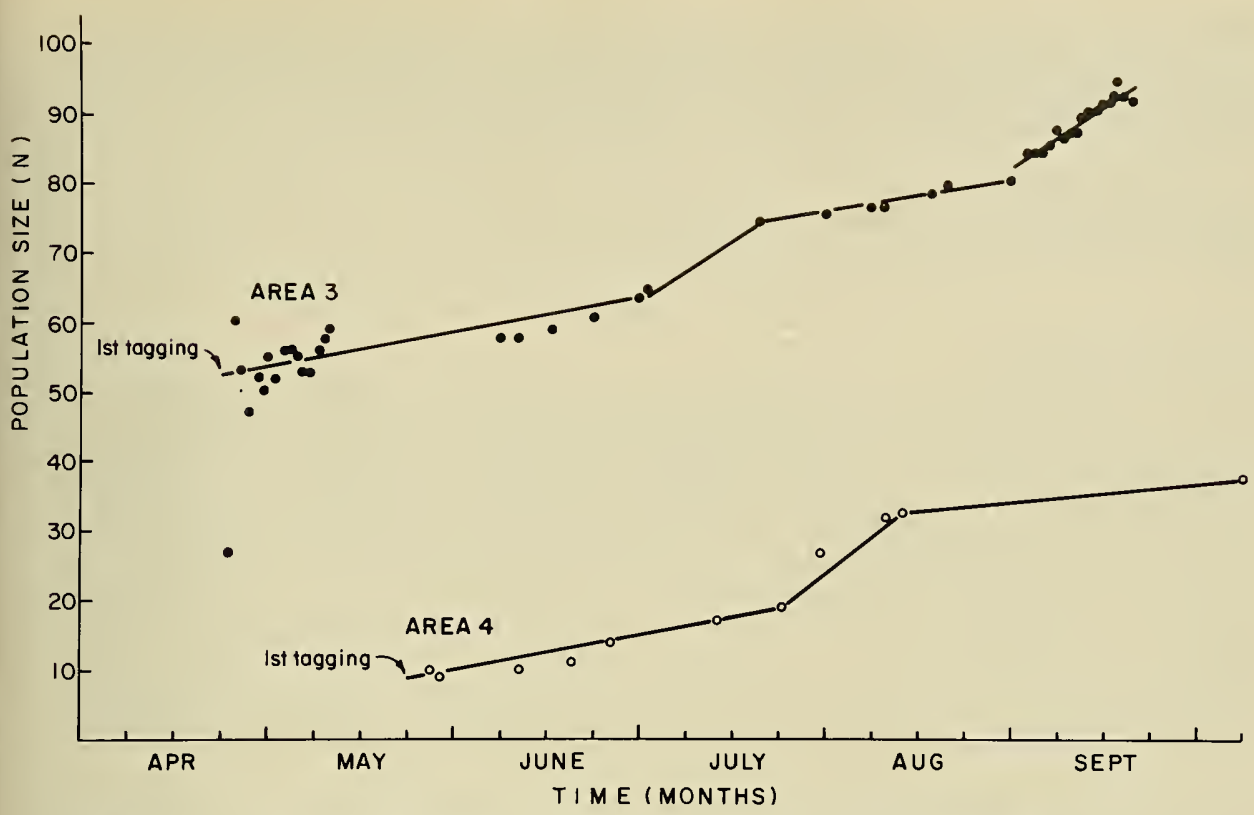

Figure 4. Trend in modified Schnabel population estimates (N) with time for study areas 3 and 4

The observed rate of change in $\mathrm{N}$ for Areas 3 and 4 are not considered to be natural seasonal fluctuations since the lobster populations of Areas 1 and 2 remained relatively constant throughout the study period. Mortality through predation by nurse sharks, Ginglymostoma cirratum, and jewfish, Epinephalus itajara, is considered likely in Areas 3 and 4. Nurse sharks and jewfish were sighted in Areas 3 and 4 during July and September. Similar sightings were non-existent or infrequent in Areas 1 and 2.

Petersen estimates of $N$ for area 3 are $N-53$ (April) and $N=46$ (September). The computation of these estimates is as follows:

$$
\begin{aligned}
& \text { (Apri1) } \frac{N=M(c+1)}{R+1}=\frac{(31)(48)}{28}=53 \\
& \text { (September) } \frac{N=M(c+1)}{R+1}=\frac{(17)(27)}{}=46
\end{aligned}
$$

The estimate for April is similar to the Schnabel estimates for the same period (Table 3). The Petersen estimate of 46 for September is accepted as a relatively unbiased estimate (Ricker, 1958) compared to the highly biased 
estimates of $N$ (Table 3) using the Schnabel formula. Consequently, the population size in Area 3 is considered to have been either relatively constant throughout the study period or declining gradually to September. Counts of lobsters by divers suggest that the population decreased in size.

The population size in Area 4 is also considered to have been stable, even though the Schnabel estimates of $\mathrm{N}$ indicate a population increase. Again, these estimates are biased in the positive direction for reasons discussed above.

\section{Population Turnover}

The rates of immigration and emigration were estimated using two independent methods. As was stated in Population Estimation, if emigration of tagged and non-tagged individuals is exactly balanced by immigration (stabile population) of non-tagged lobsters, the Schnabel estimate of $\mathrm{N}$ increases with time. Assuming varying rates of emigration and that tagged and non-tagged lobsters demonstrate equal tendencies to emigrate, Schnabel estimates can be recalculated by correcting $\mathrm{M}_{t}$ (number of tagged lobsters at large in the study area) accordingly. That rate of emigration which results in a relatively constant $N$ over time is considered an estimate of the total rate of tag loss. Since the original estimates of $\mathrm{N}$ considered tag loss from the animal, the above estimate represents the combined effect of natural mortality and emigration. Emigration is considered to be the primary source of tag loss from the population.

An average 1.5 percent emigration per day or 45 percent per month coincides with a constant $\mathrm{N}$ for Area 3 during late April to mid-June; 2 percent (60 percent per month) from mid-June through August; and 3 percent (90 percent per month) during September. A 1.6 percent rate ( 48 percent per month) is estimated for Area 4 from late May to late July and 2.5 percent ( 75 percent per month) from late July through September. A balancing of immigration with emigration, with resulting increases in $\mathrm{N}$ over time, was not apparent in Areas 1 and 2.

The second method of estimating rate of population turnover involves calculating the percent of a given study period's tagged lobsters absent during the following study period (Table 5). Data sufficient for such comparisons were available only for Area 3. Four consecutive study periods are considered for this comparison: period 1 from April 22 to May 11 (20 days); period 2 from May 12 to July 24 (74 days); period 3 from July 25 to August 13 (20 days); and period 4 from August 14 to September 22 (40 days). Subtracting the number of resighted tagged lobsters seen during a given period from the number known to be at large during the previous period and expressing this as a percentage of the number that were present during the previous period yields an estimate of the rate of emigration for that previous period. This technique assumes that all tagged lobsters present are sighted and recognized during periods 2,3 , and 4 and that the accepted number of resights are made early during the mission so that the calculated magnitude of emigration can be related to an accurate time interval. Neither assumption is completely valid, although the resultant error in calculating percent emigration is relatively small. In either case the estimate of emigration would be too large.

Both methods of estimating rate of movement out of the study area indicate that there was a significant rate of emigration of tagged lobsters from Areas 3 and 4 
throughout a 5-6 month period. Since the population sizes for these areas were relatively constant over time, an overall rate of population turnover of approximately 45 percent per month is indicated for April through June and 60 to 90 percent from July through September. A similar rate of turnover occurred in Area 4, but not in Areas 1 and 2.

Table 5.--Calculations of emigration from study area 3.

\begin{tabular}{lllll}
\hline $\begin{array}{l}\text { Study } \\
\text { period } \\
\text { number } \\
\begin{array}{c}\text { and } \\
\text { duration } \\
\text { (days) }\end{array}\end{array}$ & $\begin{array}{l}\text { Number } \\
\text { of } \\
\text { tagged } \\
\text { lobsters } \\
\text { resighted }\end{array}$ & $\begin{array}{l}\text { Number } \\
\text { lobsters } \\
\text { newly } \\
\text { tagged }\end{array}$ & $\begin{array}{l}\text { Total } \\
\text { number } \\
\text { tagged } \\
\text { in area }\end{array}$ & $\begin{array}{l}\text { Percent } \\
\text { emigration } \\
\text { (calculations) }\end{array}$ \\
\hline $1(20)$ & 0 & 45 & 45 & \\
\hline
\end{tabular}

Apri1 22

-May 11

\begin{tabular}{|c|c|c|c|c|c|}
\hline $2(74)$ & 16 & 37 & 53 & $\frac{45-16}{45} \times$ & $100=63 \%$ \\
\hline $\begin{array}{l}\text { May } 12- \\
\text { July } 24\end{array}$ & & & & $\frac{63 \%}{20 \text { days }}$ & $\begin{aligned}= & 3.1 \% \text { per } \\
& \text { day dur- } \\
& \text { ing } \\
& \text { period } 1\end{aligned}$ \\
\hline $3(20)$ & 28 & 8 & 36 & $\frac{53-28}{53} \times$ & $100=47 \%$ \\
\hline $\begin{array}{ll}\text { Ju1y } 25- \\
\text { Aug. } 13\end{array}$ & & & & $\frac{47 \%}{74 \text { days }}$ & $\begin{aligned}= & 0.6 \% \text { per } \\
\text { day } & \\
& \text { during } \\
& \text { period } 2\end{aligned}$ \\
\hline $4(40)$ & 19 & 19 & 38 & $\frac{36-19}{36} \times$ & $100=47 \%$ \\
\hline $\begin{array}{l}\text { Aug. 14- } \\
\text { Sept. } 22\end{array}$ & & & & $\frac{47 \%}{20 \text { days }}$ & $\begin{aligned}= & 2.4 \% \text { per } \\
\text { day } & \\
\text { during } & \text { period } 3\end{aligned}$ \\
\hline
\end{tabular}


The mean carapace length of males and females in Area 3 remained relatively constant throughout the study (Table 6). It is assumed that the size structure of the population for Areas 1,2, and 4 also remained constant with time. The relatively infrequent collections of carapace length data from lobsters in these areas support this assumption. Males exceed females in average carapace length by $17.7 \mathrm{~mm}$.

Table 6.--Mean carapace lengths of male and female lobsters by study period from Area 3 .

\begin{tabular}{ccc}
\hline $\begin{array}{l}\text { Period } \\
\text { number }\end{array}$ & $\begin{array}{c}\text { Mean Carapace Length } \\
\text { Males (sample size) }\end{array}$ & $\begin{array}{c}\text { (millimeters) } \\
\text { Females (sample size) }\end{array}$ \\
\hline 1 & $114.2(32)$ & $92.0(11)$ \\
2 & $113.3(15)$ & $95.4(14)$ \\
3 & $119.0(5)$ & $95.7(8)$ \\
4 & $113.4(14)$ & $100.9(16)$ \\
\hline $\begin{array}{l}\text { Al1 } \\
\text { periods }\end{array}$ & $114.2(66)$ & $96.5(49)$ \\
\hline
\end{tabular}

The size structure, by sex, was relatively constant regardless of study area. Males averaged 118, 101, 114, and 120 and females $115,89,96$, and 105 for Areas 1 through 4, respectively. Significant differences in mean carapace lengths at the $95 \%$ confidence level do not exist between study areas for a given sex. Males ranged from 53 to $170 \mathrm{~mm}$; females from 56 to $140 \mathrm{~mm}$. A size distribution by size and sex, all areas combined, is presented in Figure 5 .

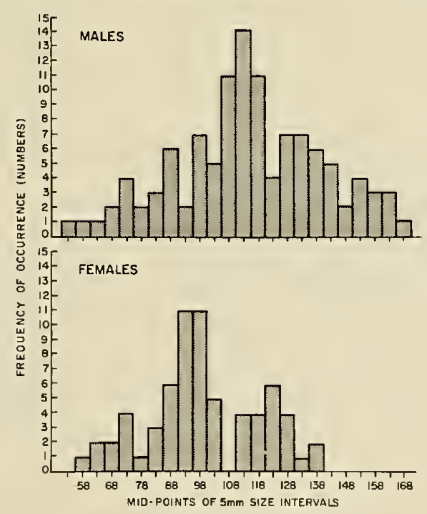

Figure 5. Length frequency distributions for all lobsters sampled from study Areas 1-4, by sex 
A significant trend in the predominance of males occurred in Area 3 throughout the study. Males comprised 75 percent of the population during study period 1 , 69 percent in 2, 65 percent in 3, and 54 percent in 4 . To avoid bias generated by repeated resightings of a few individuals, each tagged lobster resighted during a given study period was counted just once, either as newly tagged or resighted (i.e., tagged during a prior period). Untagged lobsters were excluded since individuals could not be identified during successive resightings. The less intensively collected data from Areas 1, 2, and 4 support, in general, this trend in sex ratio.

The increase in relative abundance of females indicates that as the population turnover progressed throughout the study, males were selectively moving out of the study area and females were moving in. If a moderate decrease in population size occurred, as may be indicated, then the selective emigration of males exceeded the immigration of females. It is not known whether this phenomenon is a naturally occurring event or whether it was related to a relatively high level of harassment by divers working from the TEKTITE habitat. Sex ratio data collected during the remainder of this 1-year study will help to determine the cause of this trend.

\section{Habitation Patterns}

The live reef and hard-bottom regions within the study areas have literally thousands of interstices and crevices in which at least one lobster could withdraw. Yet the initial surveys showed that the 99 lobsters present (all areas) occupied only 26 dens, an average of 3.8 lobsters per den. The frequency profile suggests that multiple habitation was as frequent as individual habitation even though many more small, single-lobster crevices were available (Table 7). Multiples were particularly characteristic in Area 3 (worked by the aquanauts at depths greater than 8 meters) in which an observed total of 46 lobsters initially occupied only 7 dens ( 6.6 lobsters per den), the same dens frequented by lobsters during TEKTITE I, March-Apri1 1969.

Table 7. Frequency of habitation of lobster dens

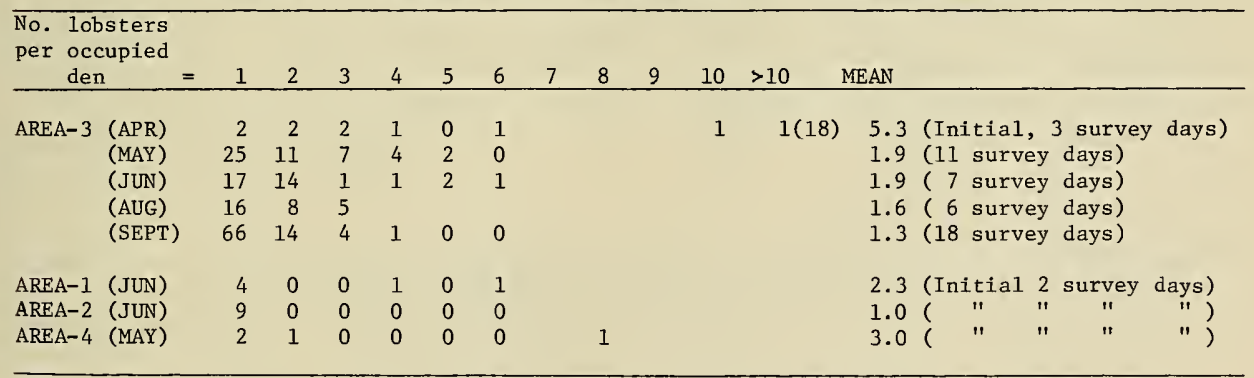

The most frequented dens in Area 3, below 8 meters, are concentrated in a contiguous area of less than $6000 \mathrm{~m}^{2}$ out of a total habitable area (the area where lobsters were observed in dens during the course of study) of approximately $45,000 \mathrm{~m}^{2}$ (Figure 1). Most of these dens (e.g., 3, 5, 14, 9, 10, 7) 1ie proxima1 


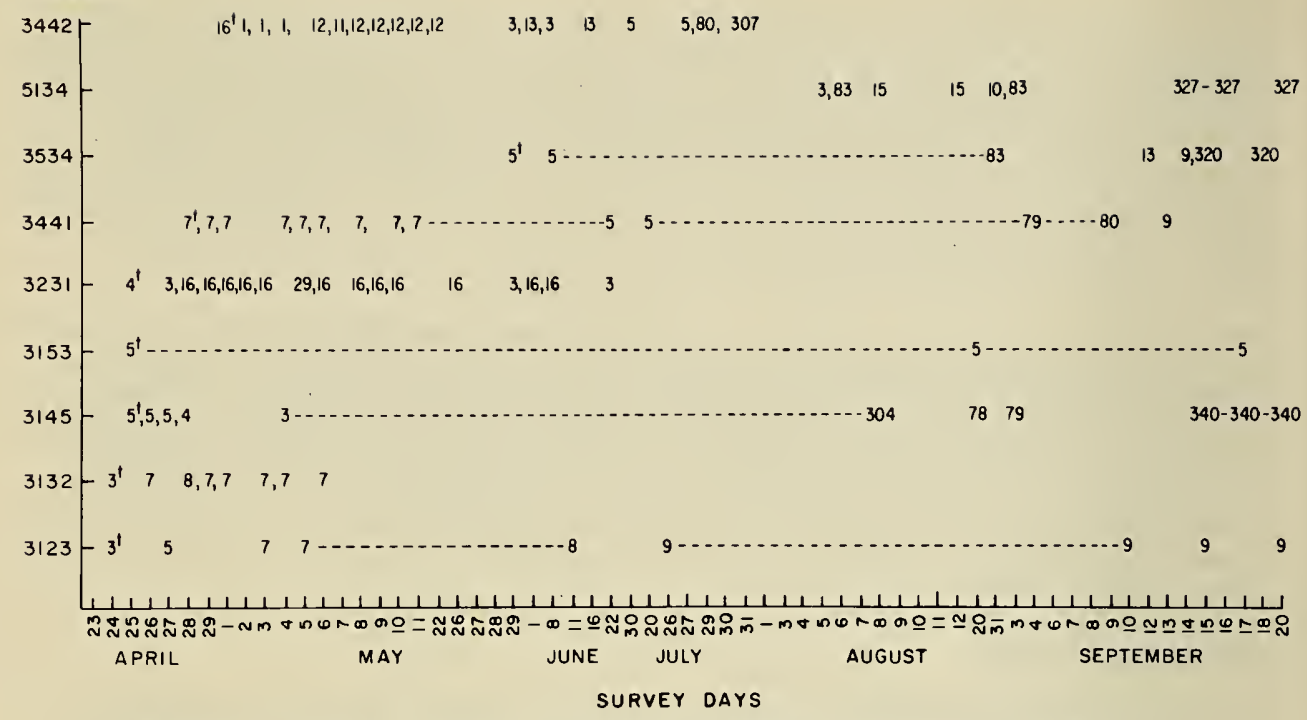

Figure 6. Den occupancy of selected tagged 1obsters in Area 3. Broken line represents apparent absence of lobster. Superscript " " represents initial tagging.

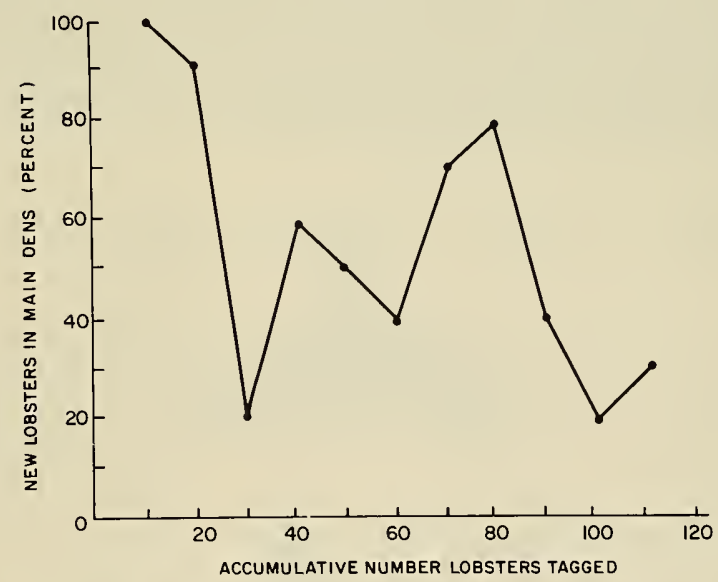

Figure 7. Percentage of "new" (untagged) lobsters first located and tagged in dens 3, 5, 7, 9, and 14 in Area 3. 
to a ridge of sharp relief running to the south and doglegging eastward near the tip of Cabritte Horn Point. At this ridge the patch reef-sand substrate to the west at $15 \mathrm{~m}$ depth meets rock outcrop to the east and, further shoreward, boulder and rock rubble at depths of 10-12 meters.

The den structures occupied were, variously, rock crevices (dens 9 and 14), boulder or rock-shelf overhangs (dens 5 and 10), or live coral platforms with caverns beneath (dens 3 and 6 ), all typified by having an entrance, or some internal portion, restrictive to anything larger than a lobster. In addition, most of the dens initially occupied had hard substrate floors, although at a later time sand-floored dens were often occupied and other hard-floored dens were often vacant.

Selectivity for specific dens, as suggested by the initial concentration of the Area 3 population, was also shown by the following ( 1 and 2 are discussed in more detail later in the report):

1. Certain individuals, sonically monitored, returned to the original, or other established den, after nocturnal movements.

2. Lobsters displaced up to $200 \mathrm{~m}$ during sonic tracking studies homed to the original den, another commonly frequented den, or a crevice proximal to one of these.

3. Certain individuals, observed daily, frequented the same den or one of the 7 original dens, for periods of up to 7 days (e.g., lobsters 3231 and 3442,5134 and 3132 in Figure 6).

4. Certain individuals apparently left the entire study area but reappeared up to several months later in one of the 5 main dens (e.g., lobsters $3123,3153,3441,3534$, and 3145 in Figure 6).

5. Thirty-eight percent of the new individuals first appeared in the 5 main dens $(3,5,7,9$, and $14 ;$ Figure 7$)$; that is, only 7 percent of the total number of dens established by the end of the study.

6. Even with the disrupting factor of diver presence, 42 percent of the successive daily resights were at the den occupied the day previously (however, some 8 percent of these may not have left the dens during the interim period).

7. Lobsters molested during capture (for tagging or measurement) have been observed shortly thereafter to travel directly to, and enter, one of the other established burrows.

These data and observations show that a significant number of lobsters in the study areas demonstrate selectivity of habitation. Not only do they apparently distinguish these den sites from other crevices but demonstrate remarkable familiarity with the relative location of them during spontaneous and forced movements. 
It has long been known that $\underline{\mathrm{P}}$. argus is nocturnally active, with the exception of autumal, mass emigrations, although few field studies have obtained information as to the temporal and behavioral characteristics of the activity period. Information during the TEKTITE study was obtained in the following ways:

1. Consistent and frequent diurnal monitoring (a11 missions)

2. Series of diurnal-nocturnal surveys (8-50)

3. Sonic tracking studies (2-50, 8-50, interim studies by surface support)

4. Short internal (1-2 hour) sequential den checks during the crepuscular and night periods $(12-50)$

From these various sources it was determined that diurnal movements are extremely infrequent except when a lobster has been molested, as during a capture. Scattered observations during the dawn twilight suggested occasional movement about the reef but virtually none afterward. Movement out of the dens begins at about sunset and peaks about one to two hours later (Figure 8). During September, one 1obster (of 27 observed) left a den at 1830 hours and six others as early as 1900. By midnight virtually all active lobsters have left the dens although not all lobsters leave every night; 2 of 27 remained inactive during the nocturnal surveys made during 12-50. Upon leaving the burrow, lobsters moved various distances with some staying on the reef in the vicinity of the den, others migrating onto the sand algal plain, and others moving entirely out of the study area. Lobsters observed out of their dens at night and those tracked sonically often traveled westward onto the sand-algal plain up to $300 \mathrm{~m}$ from their den and returned before dawn (Clifton, et al, 1970). Nearly half ( $48 \%$ ) of the lobsters observed to leave a den returned to either the original den or one of the other monitored dens. The earliest return was at about 2300 hours, only two hours after the lobster left the den. Those moving out of the den area returned between 0400 and 0700 , augmenting the occasional observation of eastward traveling lobsters in the immediate predawn hours.

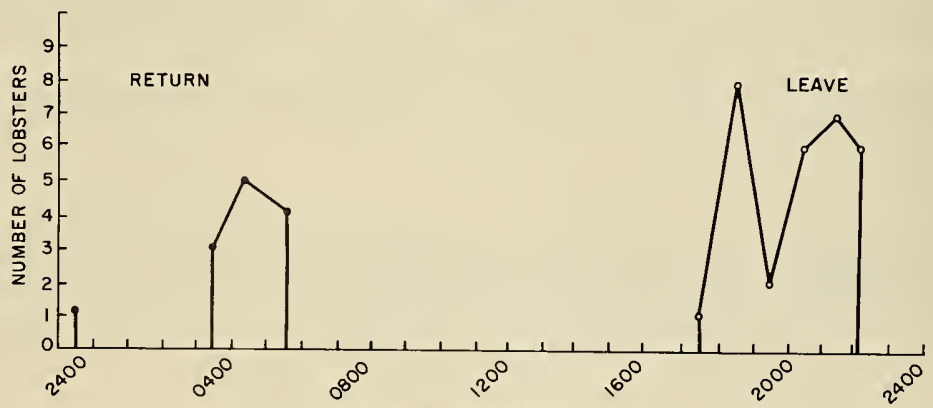

HOURS OF THE DAY

Figure 8. Periodicity of lobsters vacating and returning to their dens. 
tracked sonically often traveled westward unto the sand-algal plain up to $300 \mathrm{~m}$ from their den and returned before dawn (C1ifton, et a1, 1970). Nearly half $(48 \%)$ of the lobsters observed to leave a den returned to either the original den or one of the other monitored dens. The earliest return was at about 2300 hours, only two hours after the lobster left the den. Those moving out of the den area returned between 0400 and 0700 , augmenting the occasional observation of eastward traveling lobsters in the immediately pre-dawn hours.

Homing behavior, documented by successive day and night monitoring of dens, was further characterized by sonic tracking using spontaneous and displacement techniques. In spontaneous studies, a lobster was tagged during the day and returned to its den, then monitored by tracking gun during the night period to determine its typical nocturnal behavior (Clifton, et al, 1970). Most frequently active lobsters, i.e., those that left a den, moved out onto the sand-algal flat where they presumably fed, then returned to the reef. On TEKTITE I and mission 2-50 of TEKTITE II, such lobsters were observed to return by direct routs; at least one followed a similar path on several consecutive nights. This suggests a formidable orientation mechanism and familiarity with the region.

The latter hypothesis was further tested by displacement studies in which a tagged lobster was carried to a point on the sand-algal plain about $200 \mathrm{~m}$ from the den and some $70 \mathrm{~m}$ from the nearest portion of the reef. Eight lobsters tested on 13 runs demonstrated homing ability as follows:

1. Six of the eight returned to either the original den (3 1obsters on 3 runs) or to a den proximal to one of the main dens (6 lobsters on 8 runs) by the following morning.

2. Two lobsters took up bearings in a beeline toward the site of capture but one could not be located thereafter and the other proceeded past the main den area and was subsequently found at Cabritte Horn Point.

Typically, lobsters released during the day either headed directly to the reef where they withdrew in a convenient crevice until dark or moved in a random direction, becoming quiescent in a shallow depression. Resumption of movement and actual homing occurred after dark for all those monitored during the appropriate periods. Hence, the orientation occurs during the period of lowest visibility suggesting a non-visual mechanism. Indeed, two lobsters tested with opaque tape over the entire eye and eyestalk showed direct orientation toward the capture site and one was relocated the next morning within $30 \mathrm{~m}$ of the point of capture. The other lobster was tracked to the reef edge but could not be relocated later in the evening.

Regardless of the mechanism(s) involved, the lobsters demonstrated a strong preference for a home region, efficient orientation, and an apparent familiarity of spatial reference throughout the study area.

While some portion of the population apparently remained in the study area for periods of a few days to several months, others were observed only once and 
virtually all lobsters eventually emigrated out of the entire study area ( 1,1 , 3,4 ) with some (about $12 \%$ ) reappearing up to several months later (Figure 6 ). Since unmarked lobsters continually appeared, the population was transient on a time scale of several months or less (discussed above). The fact that of 184 lobsters tagged in all three study areas, only two were resighted in other than the original study area, which suggests that emigrants move either offshore or for distances exceeding one kilometer alongshore. They do not move by sma11 increments alongshore. The consistent appearance of untagged lobsters in the main dens $(3,5,14,9,7)$, and the reappearance there of tagged animals after long periods of absence, suggests that many of the lobsters coming into the area (perhaps $50 \%$ ) are already familiar with the region.

No striking seasonal pattern of movement or degree of immigration/emigration is apparent. There were no indications of mass movements involving a large proportion of the resident population or any large influx of immigrants.

Diver Impact on Habitation/Movement Patterns

At the end of mission 2-50 it was noted that the distribution of lobsters in Area 3 had changed markedly since the first week. Intensive tagging and ather handling was hypothesized as a possible disruptive influence. Indeed, newly tagged lobsters were significantly more prone to vacate a den by the next day than lobsters marked previously and merely surveyed visually; e.g., $84 \%$ of the newly tagged lobsters left the original den site by the next day as compared to $58 \%$ of the resighted lobsters. Changes in behavior noted, but not quantitatively analyzed, were (1) immediate travel to another den, even by day, by some newly tagged lobsters; (2) increase in wariness by tagged lobsters and a tendency to readily retreat when approached by a diver; and (3) increasing avoidance to snare capture by tagged lobsters caught frequently for sonic tagging.

The most apparent change in the Area 3 population was dispersal out of the originally frequented dens (such as $3,5,14,9$ ) into atypical, previously empty crevices. Figure 9 shows the steady increase in number of dens established in Area 3 from the original 7 in the early part of 2-50 to a total of 70 by the end of 12-50. The original dens continued to be the most frequent sites of first appearance of untagged lobsters. At the same time, the frequency of habitation of these dens by marked lobsters decreased. This suggests active avoidance of these dens by lobsters after capture there. The dispersal appeared also as an initial decrease in the number of lobsters per occupied den, from 5.3 to 1.9 , which, after the first two weeks of mission 2-50, remained relatively constant (Figure 10). While the number per occupied den remained constant or decreased slightly, the number of lobsters per den, considering all dens checked, decreased steadily as more new dens were established. The frequency profiles of occupancy for the periods late April - early May, late May - early June, and late July - early August are similar and show that multiple occupancy continued to be as frequent as individual occupancy. However, there were few dens with as many as five individuals, whereas originally several dens had from 6-18 lobsters (Table 7). 
It is suggested that diver "harassment" caused the dispersal described above although the additive effect of some other factor cannot be entirely eliminated.

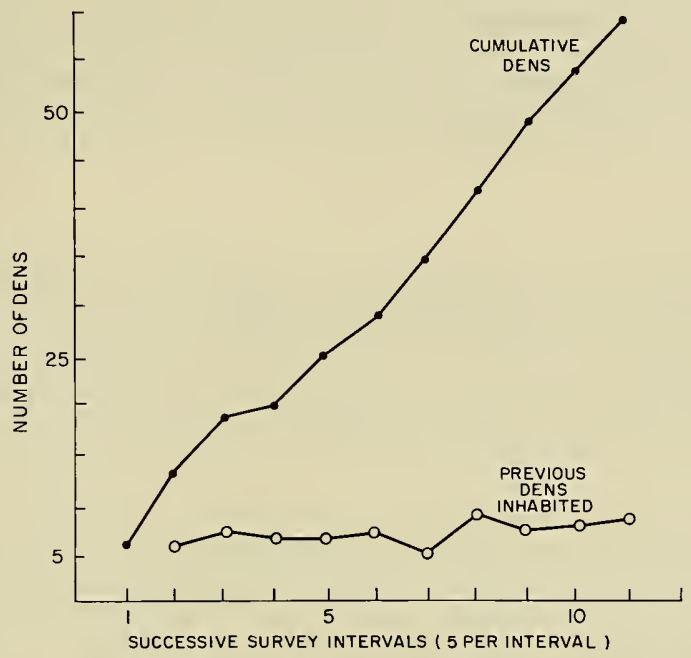

Figure 9. Increase in number of new dens established (solid circles) and the trend in number of previously established dens occupied (open circles)

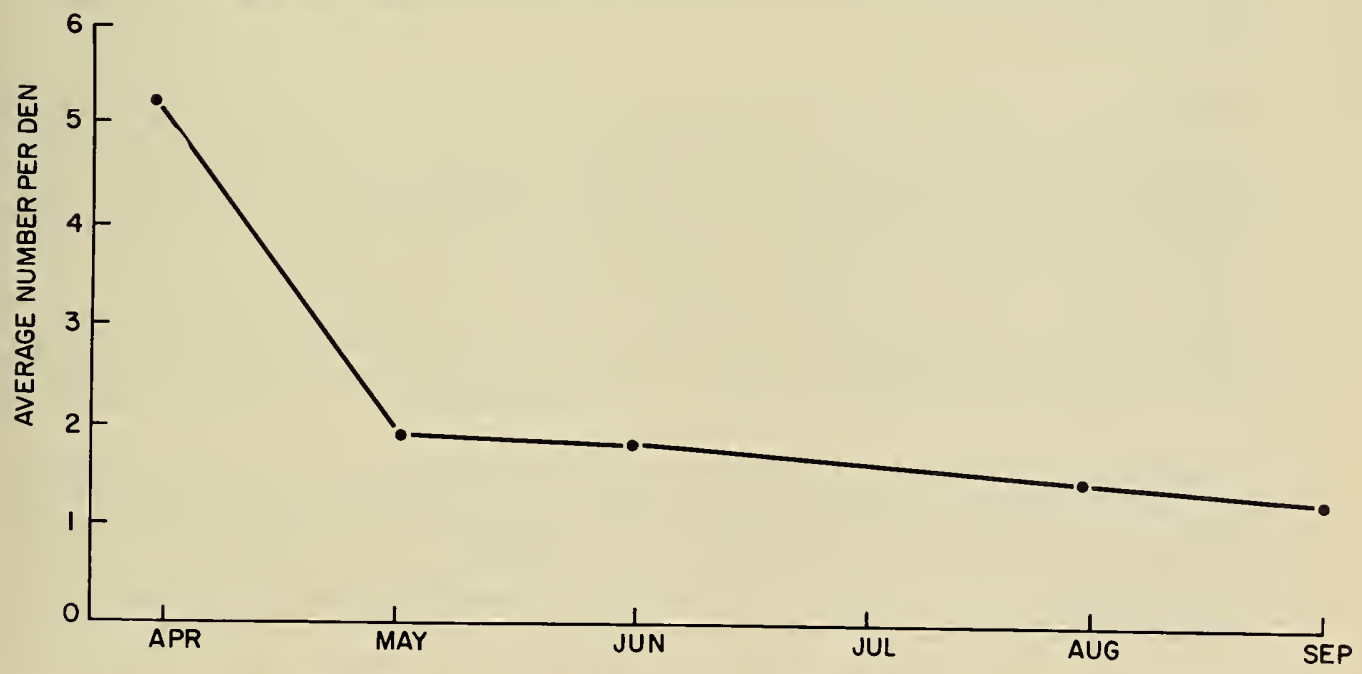

Figure 10. Average number of lobsters per occupied den with time 
Assuming that dispersal and learned avoidance are the typical responses to diver harassment, several implications consequential to population dynamics and fisheries are suggested. First, such fishing pressure on a population by divers using non-lethal capturing devices (hand, snare, etc.), by which many lobsters escape, would result in dispersal rather than total population decrease. The effect would be to make subsequent location and capture more difficult. Second, one might postulate that diver harassment mimics predator pressure. Thus, heavy natural predation might be indicated by a dispersed population where individuals frequently change dens. Last, field studies aimed at determining base level, typical patterns of lobster behavioral ecology must control for the disruptive effect of handling and repetitive capture in order to make valid conclusions.

\section{Predation}

Predation was observed only indirectly and infrequently. Known lobster predators, primarily the nurse shark (Ginglymostoma cirratum) and the jewfish (Epinephalus itajara), were observed in the study area. Nurse sharks from 1.5 to $3 \mathrm{~m}$ in length were particularly common and were observed with high frequency, by day, in the area of dens 10 and 9 where they rested under the prominent ledges. One large jewfish of several hundred pounds and a large (30-35 1bs.) snapper (Lutjanus sp.) were observed infrequently in this general area.

The only apparent predation witnessed occurred during a night sonic tracking study when the sonic signal abruptly began to move rapidly, at least 3 knots, over a distance of several hundred meters and could not be overtaken by divers. This rate and duration of movement negated the possibility of lobster locomotion, and the area to which the signal was traced, off Cabritte Horn Point, suggests either a nurse shark or a jewfish to be the predator.

Although nurse sharks were not observed at night, it is known that this is an active period of feeding for this species and it is assumed they prey primarily at this time.

\section{Feeding}

No thorough attempt was made to determine the source of food for lobsters in the study areas since this would have required sacrificing the specimens. Occasional observations and indirect evidence from shell debris near dens indicate lobster predation on mollusks. Large spiny lobsters are known to break open and feed on conchs (Strombus gigas). On 2-50, a lobster was observed opening a milk conch and on 8-50 a lobster in a den was observed gnawing on a freshly broken piece of conch shell. Conch shells, characteristically broken about the whorl, were frequently found on the sand-algal plain where the live conchs are abundant and lobsters are known to frequent.

Gut contents from six lobsters collected early in the morning outside the study areas in a region of similar habitat yielded the following: mollusk shell and opercular, urchin spines (both Diadema and Eucidaris), exoskeleton fragments, polychete (?) "teeth," sponge and holothurian spicules. The presence of urchin spines suggests feeding occurs also on the reef itself as well as on the sandalgal plain. 


\section{Growth}

Information obtained on growth, the increase in carapace length at molting, and the frequency of molting during this 6-month study is minima1. Because of the high rate of population turnover, only six recaptured lobsters could be recognized as having molted. The percent increase in carapace length for these six lobsters (sexes combined) is shown in Figure 11. A significant decrease in relative growth increment with an increase in size is indicated. Additional

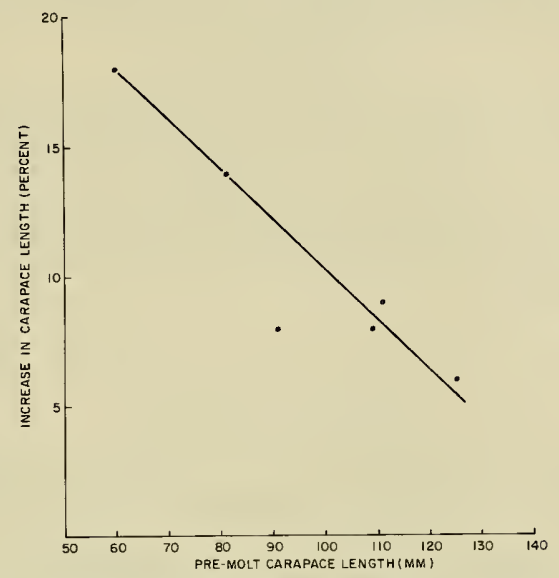

Figure 11. Relationship between percent increase in carapace length and pre-molt carapace length

data are obvious1y needed to substantiate this relationship. The time intervals between initial tagging and recapture ranged from 38 to 127 days. The $60 \mathrm{~mm}$ lobster that increased in carapace length by $18 \%$ (Figure 11) and the $81 \mathrm{~mm} 1 \mathrm{ob}-$ ster by $14 \%$ were at large for 60 and 54 days, probably insufficient time intervals to have molted twice. Information on frequency of molting is non-existent.

\section{CONCLUSIONS}

The following conclusions pertain to the scientific findings of the 6-month TEKTITE II portion of a l-year study on the ecology and population dynamics of the spiny lobster.

1. Multiple and single census population estimates indicated that the population size in each of the four study areas remained relatively constanc with time or decreased slightly from April through October.

2. Estimating population size using the diver-total count method results in negatively biased or minimal estimates of $\mathrm{N}$. Diver counts do provide a meaningful estimate of changes in relative abundance. 
3. Lobsters are highly localized to a given area of reef for a period of one to several months. Total population turnover occurred within this time interval with immigration and emigration occurring continuously. Some portion of the emigrants, weeks or months later, returned to the same den or general area of the reef, demonstrating a homing and orientation mechanism and an apparently learned familiarity with the region. The magnitude of emigration was roughly balanced by immigration.

4. Emigrants do not move alongshore for relatively small distances but instead, are hypothesized to move offshore for some unknown distance. Likewise, immigrants probably come from offshore waters.

5. The mean carapace length of males and females remained relatively constant throughout the study with males averaging $114 \mathrm{~mm}$ and females $96 \mathrm{~mm}$.

6. Lobsters smaller than $50 \mathrm{~mm}$ in carapace length were absent from the study areas, indicating that preferred habitat changes with size or age of the lobster. Total size range for the population studied was 70 to $170 \mathrm{~mm}$ (males) and 56 to $140 \mathrm{~mm}$ (females).

7. Males comprised $75 \%$ of the population in April, then declined gradually to $54 \%$ in September. As population turnover progressed, males selectively moved out of the study area as compared to females.

8. The spiny lobster is highly social in behavior. Multiple habitation of dens was as frequent as individual habitation during most of the study.

9. Al1 dens were typified by having an entrance, or some internal portion, restrictive to anything larger than a lobster. Most of the commonly occupied dens had hard substrate floors.

10. Lobsters demonstrate a high degree of selectivity for a specific den and readily "home" to that den or nearby den when displaced up to 200 meters.

11. The spiny lobser is nocturnally active, leaving the den at about sunset to 2 hours after sunset and returning 1 to 2 hours before sunrise. Movements out of the den during daylight hours, unless forced through "harassment," was non-existent.

12. The mechanism for "homing" to a given area of the reef appears to be non-visual since orientation occurs during periods of lowest visibility.

13. Diver presence and "harassment", whether it be casual or directed (capture and tagging), resulted in a significant alteration in the distribution of the population. As the study progressed, lobsters dispersed from originally frequented dens into atypical, previously empty crevices. The average number of lobsters per occupied den went from 5.3 to 1.3 from April through September. Tagged lobsters reacted more strongly to diver presence than untagged lobsters. 
14. Relative growth (percent increase in carapace length at molting) decreases with an increase in size. Sixty $\mathrm{mm}$ lobsters increased by $18 \%$ compared to $6 \%$ for $120 \mathrm{~mm}$ lobsters. Frequency of molting was not defined.

\section{AUTHORSHIP}

Dr. Richard Cooper was largely responsible for designing and writing the population dynamics sections of this study. Dr. William Herrnkind assumed major responsibility for directing the field research after the TEKTITE program was completed and wrote the behavioral sections of this report.

\section{ACKNOWLEDGEMENT}

We thank the surface support team of diver/scientists for the many hours of diving, data collection and analysis which has made this study possible. They are Messrs. Steven Serfling, William Rainy, and Nickolas Hylton.

We also wish to acknowledge the support given by the Office of Sea Grant to this project through a grant to College of the Virgin Islands, Ian Koblick principle investigator.

\section{LITERATURE CITED}

Clifton, H., C. Mahnken, J. VanDerwalker, and R. Waller. 1970. TEKTITE I, Man-In-The-Sea Project: Marine Science Program, Science, 168: 659-663.

Cooper, R. A. 1970. Retention of marks and their effects on growth, behavior, and migrations of the American lobster Homarus americanus. Trans. Amer. Fish. Soc. 99: 409-417.

Ricker, W. E. 1958. Handbook of computations for biological statistics of fish populations. Bull. Fish. Res. Bd. Canada 119, 300 p. 
Charles Birkeland* and Brian D. Gregory

Department of Zoology, University of Washington

Seattle, Washington 98105

\begin{abstract}
Individual Cyphoma gibbosum demonstrate the same feeding preferences as the entire species; we found no evidence that this preference was influenced by previous meals. Cyphoma often leaves a prey individual with apparently little damage and moves on to another. Time spent traveling is less than $1 \%$ of time spent on prey. Predation may be far more important in reducing recruitment to gorgonacean populations than in affecting survival of adults. Cyphoma lives in the midst of a morethan-adequate food supply. The selectivity in choice of prey exhibited by Cyphoma corroborates this conclusion.
\end{abstract}

\title{
OBJECTIVE
}

Several taxa of marine organisms reach their greatest local diversity in coral reef communities. Although the processes producing this diversity are poorly known, predator-prey interactions are implicated by two observations: the experimental demonstration that predators can increase local diversity by preventing the monopolization of limiting resources by superior competitors (Paine, 1966; Harper, 1969), and the greater proportion of species in tropical communities which are predators than in temperate communities (Hiatt and Strasburg, 1960). Thus, to understand the forces structuring the coral reef community, we look to the factors influencing prey selection by predators.

The variety of food selected or taken by a predator is affected by two opposing sets of factors. Efficiency increases with specialization; e.g., to digest a wider variety of foods requires a greater variety of enzymes; to produce and maintain these enzymes is expensive. A predator should thus limit its diet to those prey that it exploits most efficiently (Emlen, 1966; MacArthur and Pianka, 1966). Germane to this is the demonstration by Provasoli et al. (1959) of

\footnotetext{
*Present Address: Smithsonian Tropical Research Institute
} P.0. Box 2072, Balboa, Canal Zone 
the extremely specific nature of nutritional relations between predators and their prey. The same arguments, of course, apply to behavioral and morphological defense or capturing mechanisms. On the other hand, if prey individuals are widely dispersed or unpredictable in space or time, then a specialist would have problems maintaining a positive energy budget in the temporary absence of the specific prey. The diet should be broad enough to assure that a sufficient supply of prey are present during the predators' active periods.

The environments of coral reefs are generally thought to be climatically stable (Wells, 1957). If a prey species is common and, more importantly, consistently present, then one would predict that the predator should tend to specialize upon it. Furthermore, a prey which is consistently present must rely on complex (or specific) escape or defense responses (e.g., Bakus, 1970), requiring a correspondingly complex (or specific) capturing mechanism on the part of the predator, which would favor specialization. One would generally expect to find more restricted diets in tropical predators of common prey. Yet predators which accept a variety of common prey species are not unusual in the tropics. However, it is not clear whether these populations of species with generalized diets consist of individuals with equally generalized diets or if they consist of individuals with a preferred diet, each on a different organism.

The flamingo tongue, Cyphoma gibbosum Linnaeus, is a particularly promising species with which to investigate this problem. Cyphoma is much smaller than its prey, to the extent that it would appear conceivable for an individual to spend much of its life on a single prey individua1. Even if Cyphoma attacked many prey in its 1 ifetime, the time period spent on a single prey may be great enough relative to the time spent in hunting that an increased feeding efficiency would warrant passing by other potential prey species.

Thus we wished to find whether Cyphoma gibbosum has marked feeding preferences among gorgonaceans, whether individual preferences always reflect general preferences of the species, whether individual preferences are influenced or determined by past experience and whether Cyphoma seriously damages its prey before leaving it.

\section{EQUIPMENT}

Vernier calipers were used to measure the area of gorgonacean tissue removed by Cyphoma each day. Certain Cyphoma were tagged by placing spots of Sea Goin' Poxy Putty in a distinctive pattern on the back of the shell. Field notes were recorded on sheets of plastic. 
Our basic method of collecting data was to merely follow the movements of individual Cyphoma as they browsed on gorgonaceans and moved from one prey individual to another. To determine the effect of previous experience on prey choice, we took Cyphoma from different prey species and released them in positions where 2 or 3 species of gorgonaceans arose from adjoined bases. The Cyphoma were placed lengthwise on the border between two gorgonaceans so that its right half lay on one prey species and its left half lay on the other. The removal of coenenchyme by Cyphoma was measured at least once per day for each gorgonacean prey. The daily increase in surface area of damaged tissue was measured with Vernier calipers. Several branches of each gorgonacean prey species were collected and permanent spicule mounts were made. Identifications were based upon these specimens.

\section{RESULTS}

The population of Cyphoma gibbosum in Lameshur Bay preferentially feeds on gorgoniid gorgonaceans and tends to reject plexaurids. This is suggested in a comparison of the relative frequencies of gorgonacean species in the diet with the frequencies of these species in the environment (Table 1). An "index of electivity" (e) is used which rates prey species on a scale from -1 to +1 ; "- 1 " indicates total rejection of the prey species; "o"indicates that the prey is taken precisely in proportion to its abundance; " +1 " indicates preference of the prey species to the exclusion of all others; while positive and negative fractions indicate relative degrees of acceptance and rejection (Ivlev, 1961). The gorgonacean abundances are based on counts made in 11 quadrats of $4 \mathrm{~m}$ each. Only 8 Cyphoma were found in these quadrats with 283 gorgonaceans, or 1 predator to every 35 potential prey. Cyphoma were found preying upon other gorgonaceans, such as Pterogorgia quadalupensis, Muricea muricata or Muriceopsis flavida on sand or patch reef areas. Our discussion is limited to prey found within the quadrats.

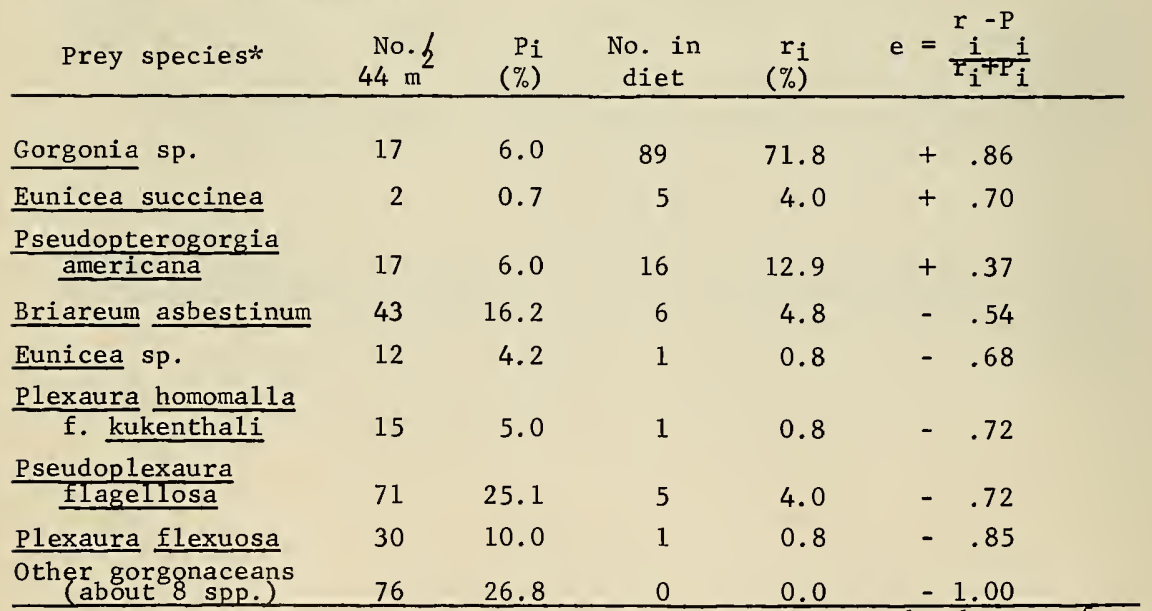

Table 1. The diet of Cyphoma gibbosum and the relative abundances of prey species on the reef at Lameshur Bay. Identification of prey tentative. 
The question now becomes whether all Cyphoma prefer Gorgonia spp. or whether many prefer Gorgonia but a few prefer other genera. If individual preferences differ, we also ask if this appears due to previous experience. To determine this we took Cyphoma which naturally occurred on particular species of gorgonaceans and released them in positions where 2 or 3 species of gorgonaceans arose from adjoined bases. The "choices" made by Cyphoma are given in Table 2. In all cases, Gorgonia spp. is preferred over other gorgonaceans. Two Cyphoma taken from Pseudopterogorgia americana selected $\underline{P}$. americana over Gorgonia spp., otherwise Gorgonia was invariably selected.

Cyphoma often moved from one prey individual to another. During the three weeks of our mission, 20 (36\%) of 56 Cyphoma switched prey (Table 3). Of particular interest is the fact that in all these cases the prey were left with apparently negligible damage.

\begin{tabular}{|c|c|c|}
\hline$\frac{\text { Cyphoma }}{\text { taken from* }}$ & given choice of $*$ & $\begin{array}{l}\text { \# found on } \\
\text { each prey }\end{array}$ \\
\hline \multirow[t]{2}{*}{ Gorgonia sp. } & Gorgonia sp. & 6 \\
\hline & Pseudopterogorgia americana & 0 \\
\hline Pseudopterogorgia & Gorgonia sp. & 3 \\
\hline americana & Pseudopterogorgia americana & 2 \\
\hline \multirow[t]{2}{*}{ Gorgonia sp. } & Gorgonia sp. & 1 \\
\hline & Plexaura flexuosa & 0 \\
\hline \multirow{3}{*}{$\frac{\text { Pseudoplexaura }}{\text { flagellosa }}$} & Gorgonia sp. & 2 \\
\hline & Pseudoplexaura flagellosa & 0 \\
\hline & Plexaura homomalla homomalla & 0 \\
\hline Plexaura homoma11a & Gorgonia sp. & 1 \\
\hline kukenthali & Plexaura flexuosa & 0 \\
\hline \multirow[t]{2}{*}{ Gorgonia sp. } & Pseudoplexaura flagellosa & 0 \\
\hline & $\begin{array}{l}\text { Plexaura flexuosa } \\
\text { other }\end{array}$ & $\begin{array}{l}2 \\
3 * t\end{array}$ \\
\hline
\end{tabular}

Table 2. Selections made by Cyphoma when placed on the border of abutted gorgonaceans.

* Identifications tentative.

** One moved $110 \mathrm{~cm}$ to Gorgonia sp., one $65 \mathrm{~cm}$ to Gorgonia sp., other disappeared. 


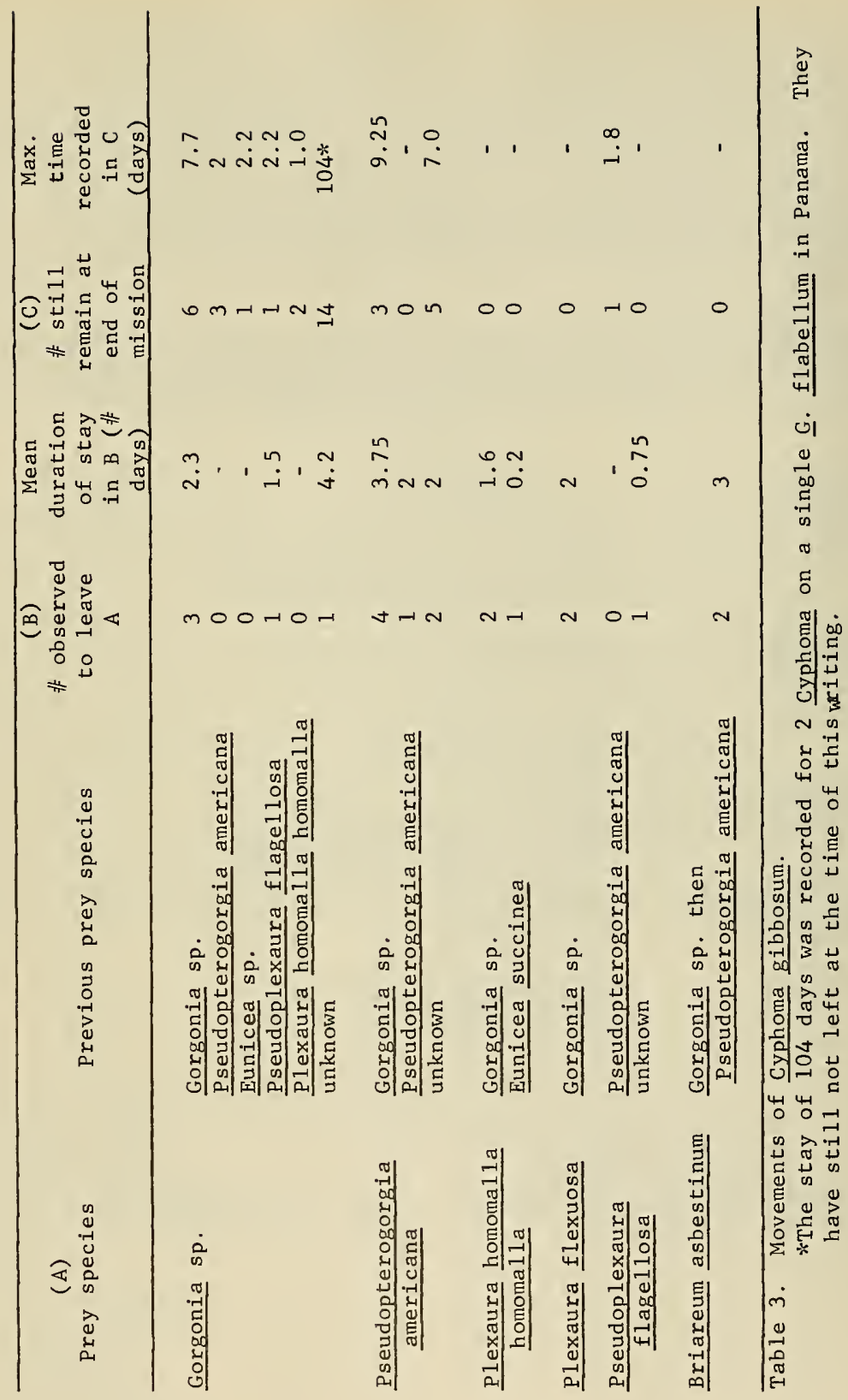


Four observations of serious grazing damage to gorgonaceans by Cyphoma were exceptional but warrant individual attention. A small, unbranched gorgonacean $(10.7 \mathrm{~cm}$ tall), which appeared to be a Pseudoplexaura sp., was completely cleaned of polyps and coenenchyme by an adult Cyphoma (2.6 cm long). In Panama, a $44 \mathrm{~cm}$ tall Gorgonia flabellum was grazed by two adult Cyphoma for at least 104 days, during which period they were joined by 3 other Cyphoma (including 1 juvenile $1.4 \mathrm{~cm}$ long). During the last 48-day period of these observations, only a few scattered clumps (about $1 \mathrm{~cm}^{2}$ each) of living polyps remained. Most of the Gorgonia had died and was already covered with a rich, yellow-brown carpet of diatoms. Perhaps due in part to the isolation of the Gorgonia on a solitary coral head which was separated by sand from the rest of the reef, none of the Cyphoma had left. Similarly, in Lameshur Bay, a single Cyphoma remained on a Gorgonia sp. for at least 19 days. During this time, the Cyphoma had almost totally grazed half of the Gorgonia which was overgrown with diatoms. The other half of the Gorgonia, which grew from a single base into two "fans," separate except for the base, appeared perfectly healthy. The Cyphoma still had not crossed to the healthy part when the observation period had terminated. Finally, four Cyphoma which had remained on a single Pseudopterogorgia americana for at least seven days, had seriously damaged several branches of the gorgonacean.

Although Cyphoma often does move from one prey individual to another, the amount of time spent traveling is very small, on the order of $1 \%$ of the time spent actually on its prey. Only 2 of 108 Cyphoma observed around the Tektite habitat were found moving along on dead coral rubble, the rest were observed on living gorgonaceans. Similarly, all but 1 of 150 Cyphoma observed in Panama were on gorgonaceans.

No significant difference in size distribution of adult Cyphoma (larger than $2 \mathrm{~cm}$ long) was found between groups taken from the eight species of prey ( $\mathrm{P}<50 \%$, ANOVA, $\mathrm{N}=106$ ). However, very smal1 individuals $(1.4,1.2,1.1,1.1,0.9,0.6,0.5$ and $0.3 \mathrm{~cm}$ long, respectively) were found only on Pseudopterogorgia americana. In Panama, slightly larger individuals (1.5, 1.6 and $1.9 \mathrm{~cm})$ were found on Gorgonia flabellum. Table 4 gives the rate of removal of coenenchyme by Cyphoma for each of the eight prey species.

\section{CONCLUSIONS/RECOMMENDATIONS}

Individual Cyphoma gibbosum demonstrate the same feeding preferences as the entire species; we found no evidence that this preference was influenced by previous meals. A peculiar aspect of the foraging strategy of Cyphoma is that it often leaves a prey individual with apparently little damage and moves on to another. (However, the 


\begin{tabular}{|c|c|c|c|c|}
\hline \multirow{2}{*}{ Prey Species } & \multicolumn{2}{|c|}{$\begin{array}{c}\text { Rate of tissue removed } \\
\left(\mathrm{cm}^{2} / \mathrm{hr}\right) \text { by an adult } \\
\text { Cyphoma }\end{array}$} & \multicolumn{2}{|c|}{$\begin{array}{l}\text { No. observations } \\
\text { in hours }\end{array}$} \\
\hline & average & maximum & hours & Cyphoma \\
\hline \multicolumn{5}{|l|}{ Gorgonia sp. } \\
\hline vane & 0.53 & 1.64 & 398.5 & 11 \\
\hline axis & 0.15 & 1.07 & 252.5 & 9 \\
\hline \multicolumn{5}{|l|}{ Pseudopterogorgia } \\
\hline americana & 0.15 & 1.01 & 316.5 & 11 \\
\hline Briareum asbestinum & 0.35 & 0.47 & 125 & 3 \\
\hline Plexaura flexuosa & 0.16 & 0.19 & 100 & 3 \\
\hline \multicolumn{5}{|l|}{ Pseudoplexaura } \\
\hline flagel losa & 0.14 & & 48 & 1 \\
\hline Eunicea sp. & 0.19 & & 42.5 & 1 \\
\hline \multicolumn{5}{|l|}{ Plexaura homomalla } \\
\hline homomalla & 0.06 & 0.12 & 94 & 4 \\
\hline Eunicea succinea & 0.19 & & 127.5 & 3 \\
\hline
\end{tabular}

Table 4. Feeding rate of adult Cyphoma $(2.4$ to $2.9 \mathrm{~cm}$ long) on several gorgonacean species.

amount of time spent traveling was estimated to less than $1 \%$ of the time spent on prey.) The destruction of a very small plexaurid gorgonacean by Cyphoma and the usually negligible damage to large prey suggests that predation may be far more important in reducing recruitment to gorgonacean populations than in affecting survival of adults.

The relative sizes and abundances of predator and prey, the recorded feeding rates, and the observation that Cyphoma will often leave prey relatively undamaged all suggest that Cyphoma lives in the midst of a more-than-adequate food supply. The selectivity in choice of prey exhibited by Cyphoma corroborates this conclusion (Ivlev, 1961; Emlen, 1966; Holling, 1966). In order to interpret the impact of predation by Cyphoma on gorgonacean populations, we need data on the recruitment of gorgonaceans and their growth rates. 
Two problems are suggested by these findings. First, why do Cyphoma often leave prey essentially undamaged? Second, in the midst of a superabundant food supply, what prevents Cyphoma from increasing in numbers until they begin to reduce the gorgonacean populations to levels below those which they can efficiently exploit?

\section{NOTES ON FORAGING STRATEGIES OF CERTAIN CORAL REEF INVERTEBRATES.}

\section{MUREX POMUM}

An interesting defense reaction by the thorny oyster, Spondylus americanus, to Murex pomum was observed. We had tagged and released the Murex at noon on 16 May. At 1000 hours the next morning, Denny Bowman called our attention to the Murex which was attached to the upper valve of the Spondylus. The oyster repeatedly slamed its upper valve open-and-shut onto its lower valve at a rate of 2.5 slams/second, while the Murex presumably drilled into the upper valve with its radula. During the next three days, the Murex continued drilling as the oyster continued slamming. At 1945 hours on 20 May, the Murex was found laying upside down at the base of the rock, $8 \mathrm{~cm}$ below the Spondylus with its foot stretched upward towards the oyster. A characteristic drill-hole of the muricid was present in the upper valve of the Spondylus. The Murex had repositioned itself on the Spondylus by 1100 hours the following day. The Spondylus was slamming in bursts of up to $10 / 4$ seconds, but these would be followed by periods in which the valves would open and close only 3 times in 45 seconds. The slamming had ceased by the following day (22 May) and the Murex had disappeared by noon on 23 May, leaving the empty Spondylus she11. We found no signs of drilling by the Murex other than the single hole.

The capture and ingestion of the oyster (upper valve $6.6 \mathrm{~cm}$ long) took the $7.95 \mathrm{~cm}$ Murex roughly 6 days. The defense response may have been more effective if the oyster was situated higher on the rock, forcing the Murex to climb further after having been dislodged. Conversely, the ability of the Murex to overcome this defense response appears contingent upon relocating and drilling the same hole when dislodged, rather than starting a new one each time.

\section{DIADEMA ANTILLARUM}

The sea urchin, Diadema antillarum is an abundant, generalized grazer of plant material and detritus on Caribbean reefs (Randall et al., 1964). Urchin grazing is probably important in affecting the structure of the benthic community (e.g., algal diversity) in the tropics as it has been shown to be in temperate waters (Kain and Jones, 1965; Leighton et al., 1965; Paine and Vadas, 1970). During a stay in the 
Eastern Tropical Pacific (Playas del Coco, Costa Rica), it was noted that Diadema mexicanum often foraged during dark hours and spent daylight hours in precisely the same individual locations in crevices, holes or spaces under rocks. These observations were based on $13 \underline{D}$. mexicanum, tagged with individually numbered FD-67 Floy Tags, over an 18-day period (1-18 March, 1970). During our stay in Tektite, we were interested in determining how far Diadema antillarum travels at night, in what kind of path and whether consistent patterns of movement could be discerned. We could then find areas possibly ungrazed by Diadema and compare the algal flora with that in grazed areas. We also cleared two $16 \mathrm{~m}^{2}$ areas of urchins, one on the reef itself and the other in a patch reef area, in hopes of producing changes in the flora experimentally.

Twenty Diadema antillarum were individually numbered in situ with FD-67 Floy Tags on the second day of the mission. We were surprised to find, in contrast to the data for Diadema mexicanum, no strong evidence for a homing tendency. After 18 days, 3 of the Diadema had returned to the same hole or crevice for each daylight observation. Within their respective crevices, however, their location varied greatly, e.g., the upper left wall, the rear right lower corner, the lower left just inside, etc. At night these urchins were seen to range as far as $50 \mathrm{~cm}$ from their respective crevices, but no pattern could be discovered in the direction or distance traveled with any of the urchins. A fourth Diadema returned to the same hole for four days, disappeared for two days, and was back for the next four days, after which it was never seen again. Three Diadema each spent the first day in the crevice in which they were tagged, then spent the next day in holes under coral $21 \mathrm{~cm}, 28 \mathrm{~cm}$ and $30 \mathrm{~cm}$ away, respectively. Two disappeared by the next day but the individual which had traveled $28 \mathrm{~cm}$ the first night spent the next two days in the same hole, spent a third day $10 \mathrm{~cm}$ away from the new hole, and was then never seen again. The thirteen remaining tagged Diadema were not found after intensive searching.

Sixteen square meter areas of coral reef and patch reef were each cleared of Diadema antillarum. A total of 137 and 61 were removed, respectively. Within 7 and 5 days 61 new Diadema had invaded the coral reef area while 19 had invaded the patch reef. This constitutes $44.5 \%$ and $32.1 \%$ of the original population densities (cf., Randall et al., 1964). This further indicates that Diadema does not return to the same crevice each night in the Caribbean.

Similar observations were made for Eucidaris tribuloides and Echinometra viridis. Individuals of these species would leave their 
positions in niches and crevices to come out in the open after dal Neither were seen to travel more than $10 \mathrm{~cm}$ from the outer lip of the crevice in any one night. The following day they were always found in the same hole or in a hole within a distance of $10 \mathrm{~cm}$.

The difference in homing behavior between Diadema antillarum and D. mexicanum may merely reflect a difference in habitat and may not be due to a biological difference. The rocky reef in which $\underline{D}$. mexicanum was studied consisted generally of large boulders and appeared to have much fewer crevices and holes adequate as refuge for Diadema as compared with the reef in Lameshur Bay which has a complex topography. It is curious, however, that the $\underline{D}$. mexicanum were never observed to exchange positions among themselves.

\section{SHRIMP}

1. Alpheus armatus. The sea anemone, Bartholomea annulata, is often associated with the snapping shrimp, Alpheus armatus. Limbaugh et al. (1961) found that when shrimp were removed from an anemone, the anemone was preyed upon within a few days. However, the predator was not identified. In order to identify the predator of the anemone and to test the significance of the shrimp-anemone association, we removed snapping shrimp from 13 Bartholomea. Five anemones from the main reef were cleared of Alpheus, one for a 14-day period, the others for 4 days. Six anemones from the patch reef area north of the Tektite habitat were cleared of Alpheus for four days each. In no case was the Bartholomea damaged by predators during the observation period. The predator of the anemone appears to have been scarce in the vicinity of the Tektite habitat during the latter part of May, 1970.

Two additional Bartholomea annulata from the main reef area (west of the Tektite habitat) were found naturally lacking associated Alpheus armatus and apparently surviving quite we11. The Bartholomea from which a pair of shrimp had been removed for 14 days was naturally recolonized by a single shrimp, apparently after the eleventh day. This shrimp was removed as soon as it was discovered.

Alpheus armatus generally occurred in pairs and would not tolerate additional Alpheus under their anemone. We attempted to introduce additional Alpheus to one Bartholomea. Six and eight individuals were added on two occasions. In each case, all the shrimp quickly disappeared into the burrow of the anemone and no interaction with the resident pair was observed. However, only 2 Alpheus were present by the following morning on each occasion.

2. Periclimenes spp. and Stenopus spp. Shrimp of several species which remove parasites and damaged tissues from reef fishes may be extremely important functionally in the coral reef community in spite 
of their relatively small contribution in biomass. Experimental removal of these shrimp from isolated coral heads resulted in a "reduced number of reef fishes and a high incidence of fishes with frayed fins and ulcerated sores" (Limbaugh et al., 1961). The grazing activities of these reef fishes, in turn, have a major influence on the nature of the reef community.

In an attempt to quantify the significance of the activity of these shrimp for resident fish populations, we selected 4 coral heads which were isolated by a distance of 5 to $9 \mathrm{~m}$ from similar coral heads. The resident fish populations were determined by recording all fish observed in each of 7 days, with observations made in the morning, afternoon and/or evening. We quickly began to recognize individual fish, and the population estimates were very consistent. One set of observations was made at night, but the majority of the fish were hidden asleep in crevices or away, probably foraging on the algal plain. Thirty to thirty-four species, represented by totals of about 160 to 200 individuals were associated with each of the coral heads which measured $1.6 \mathrm{~m}$ to $1.8 \mathrm{~m}$ long, $0.7 \mathrm{~m}$ to $1.2 \mathrm{~m}$ wide and 0.4 to $0.8 \mathrm{~m}$ tall.

After the population estimates had been made, all Periclimenes spp. and Stenopus spp. were removed from two of the coral heads and the changes in population numbers and apparent health of the fish were followed for the remaining 7 days of the mission. From the first coral head 22 Stenopus hispidus, 2 s. scutellatus and 3 Periclimenes pedersoni were removed. From the second coral head 28 stenopus hispidus, 16 Periclimenes pedersoni and 7 Periclimenes sp. were removed. The other two coral heads were left as controls.

In al1 cases, no deterioration in health nor increase in parasite infection was noted and some populations actually increased in abundance. This increase was due to the recruitment of juvenile Chaetodon capistratus ( 1 to each of 3 coral heads), Pomacanthus paru (1), Eupomacentrus partitus (11, 7, 5 and 2, respectively) and Ocyurus chrysurus (1 to each of 2 heads). The lack of deterioration in health may indicate that effects of the removal of shrimp do not become apparent for at least a week. This seems quite likely. However, when removing the shrimp, we left the cleaning gobies, Gobiosoma (Elacatinus) spp., in order to be certain we were testing the importance of theshrimp themselves. Even before removal of the shrimp, all the cleaning activity we observed was performed by these fish rather than the shrimp. These fish, 2 or 4 individuals per coral head, may be able to buffer what effect the lack of cleaning shrimp may have on the fish populations. 
Bakus, G. J. 1970. Energetics and feeding in shallow marine waters. International Review of General and Experimental Zoology, 4: $275-369$.

Emlen, J. M. 1966. The role of time and energy in food preference. Am. Nat., 100: 611-617.

Harper, J. L. 1969. The tole of predation in vegetational diversity. In: Diversity and Stability in Ecological Systems. Brookhaven Nationa1 Laboratory Symposium 非2.

Hiatt, R.W. and D. W. Strasburg. 1960. Ecological relationships of the fish fauna on coral reefs of the Marshall Islands. Ecol. Monogr., 30: 65-127.

Holling, C. S. 1966. The functional response of invertebrate predators to prey density. Memoirs of the Entomological Society of Canada, 48: $88 \mathrm{pp}$.

Ivlev, V. S. 1961. Experimental Ecology of the Feeding of Fishes. Yale Univ. Press, New Haven, 302 pp.

Kain, J. M. and N. S. Jones. 1965. Algal colonization after removal of Echinus. International Symposium on Seaweed, vol. V, E. G. Young and J. L. McLachlan, eds., pp. 139-140.

Leighton, D. L., L. G. Jones and W. J. North. 1965. Ecological relationships between giant kelp and sea urchins in Southern California. In: International Symposium on Seaweed, vol. V, E. G. Young and J. L. McLachlan, eds., pp. 141-153.

Limbaugh, C., H. Pederson and F. A. Chace, Jr. 1961. Shrimps that clean fishes. Bul1. Mar. Sci. Gulf and Carib., 11: 237-257.

MacArthur, R. H. and E. R. Pianka. 1966. On optimal use of a patch environment. Am. Nat., 100: 603-609.

Paine, R. T. 1966. Food web complexity and species diversity. Am. Nat., 100: 65-75.

Paine, R. T. and R. L. Vadas. 1970. The effects of grazing by sea urchins Stronglylocentrotus spp., on benthic algal populations. Limnol. and Oceanogr., 14: 710-719.

Provasoli, L., K. Shiraishi and J. Lance. 1959. Nutritiona1 idiosyncrasies of Artemia and Tigriopus in monoxenic culture. Ann. N. Y. Acad. Sci., 77: 250-261.

Randa11, J. E., R. E. Schroeder and W. A. Stark, III. 1964. Notes on the biology of the echinoid Diadema antillarum. Carib. J. Sci. 4: 421-433.

We11s, J. W. 1957. Coral reefs. In: Treatise on Marine Ecology and Paleoecology, Geological Society of America Memoir 67, J. W. Hedgpeth, ed., pp. 609-631. 
Continuation of Underwater Geologic Studies in Lameshur Bay Area, St. John U. S. Virgin Islands_Part 2. Sea Level History

By R. Lawrence Phillips

U.S. Geological Survey, Menlo Park, Calif. and Denny $W$. Bowman

University of Texas, Galveston, Texas

\begin{abstract}
Relict shoreline features which represent former stillstands of the sea occur at approximate depths of 24 feet and 43 feet below mean sea level on the south coast of St. John near the Tektite experiment. These features include submerged beachrock conglomerate that parallels the present shoreline, uncemented gravel composed of rounded bedrock cobbles and boulders on the carbonate sand flats, and exoded wave-cut platforms at depths of 18 to 30 feet and 45 to 55 feet. The changes in sea level are believed to be caused by a combination of tectonic movement and eustatic sea level rise.
\end{abstract}

\title{
INTRODUCTION
}

Part of the U. S. Geological Survey research program during Tektite I and II was directed toward determining the submerged record of the sea level history of St. John. This report describes two submerged beachrock conglomerates and other evidence indicative of two stillstands of the sea late in the geologic history of the island.

The southern coast of St. John is composed of water-laid volcanic rocks consisting of keratophyre flows, flow breccias, tuffs, spilite flows, and radiolarites of the water Island Formation of Donnelly (1966). The general structure of the island is a northward dipping homocline.

The rugged shoreline of St. John suggests a submergent coast. High cliffs, many of which are not notched at sea level, drop off to depths of 20 to 35 feet. Beaches are absent or steep and narrow. All the beaches but two are composed of cobbles and boulders; these two are sand beaches. Meyerhoff (1926) defined the St. John coast as an embayed mountain shoreline.

Fluctuations of sea level have formed a complex record of sea level history on St. John and the adjoining shelf. Vaughn (1916) postulated that three stages of recent submergence of the Virgin Islands produced marine terraces at depths of 156-180 feet, 84-120 feet, and 36-60 feet below the present sea level. A depth-restricted coral reef is associated with each of the three

Publication authorized by the Director, U.S. Geological Survey VI-70 
terraces. Barrier reefs at the outer edges of the two deeper terraces presumably were formed during submergence of the St. John platform. Meyerhoff (1926) postulates an older geologic age for the formation of the Virgin Island platform. The platform initially underwent deposition in the oligocene. Emergence and fluvial dissection of the platform followed in the late Tertiary. Two stages of recent submergence drowned the platform and established a stillstand 27 feet below the present sea level (Meyerhoff, 1926, p. 119). The sea then advanced to the present level. A fossil coral deposit discovered during this investigation on White Point at an elevation of 65 feet above the present sea level may represent another strand deposit.

This study investigates the most recent part of the complex sea level history, that preserved beneath the sea in depths of less than 70 feet.

\section{BEACHROCK}

Beachrock consists of sand or coarser clastic beach material cemented by calcium carbonate into an indurated deposit. The cementation takes place in the intertidal zone. The mechanism of beachrock cementation, though not fully understood, is discussed by Ginsburg (1953), Emery and Cox (1956), Kaye (1959), Russell (1960, 1962), Deboo (1962), Stoddart and Cann (1965), and others. Beachrock deposits lying above or below the present day intertidal range therefore indicate a former position of sea level. The submerged conglomerates on the south side of St. John are interpreted herein as initially forming at lower sea levels. The depths of the submerged beachrock represents the approximate depth of a temporary stillstand below the present mean sea level.

The distribution of both the contemporary and the submerged beachrock along a part of southeast St. John is discontinuous and patchy (figure 1 ). Along the present shoreline, beachrock exists only on the cobble-boulder beaches at the head of the bays or on the margins of the bays where the cobble-boulder beaches are developed. The submerged beachrock deposits are extensive, long and narrow, and trend parallel to the present shoreline. The deposits are best developed on the west side of the bays. Of the six occurrences of submerged beachrock, five are at depths of 22 to 26 feet on the seaward border, extending to $81 / 2$ feet on the landward border below the present mean sea level. The sixth deposit off Cabritte Horn Point lies between 40 and 46 feet below mean sea level. The submerged deposits stand above adjacent coral reefs and bedrock outcrops.

Beachrock along the present shore and that which is submerged consists of poorly sorted, well-rounded carbonate and noncarbonate pebbles, cobbles, and sand cemented by calcium carbonate. The carbonate clasts consist of coral, hydrozoan, and algae fragments. The noncarbonate clasts are composed of volcanic material derived from the erosion of the bedrock on St. John. Carbonate fragments 


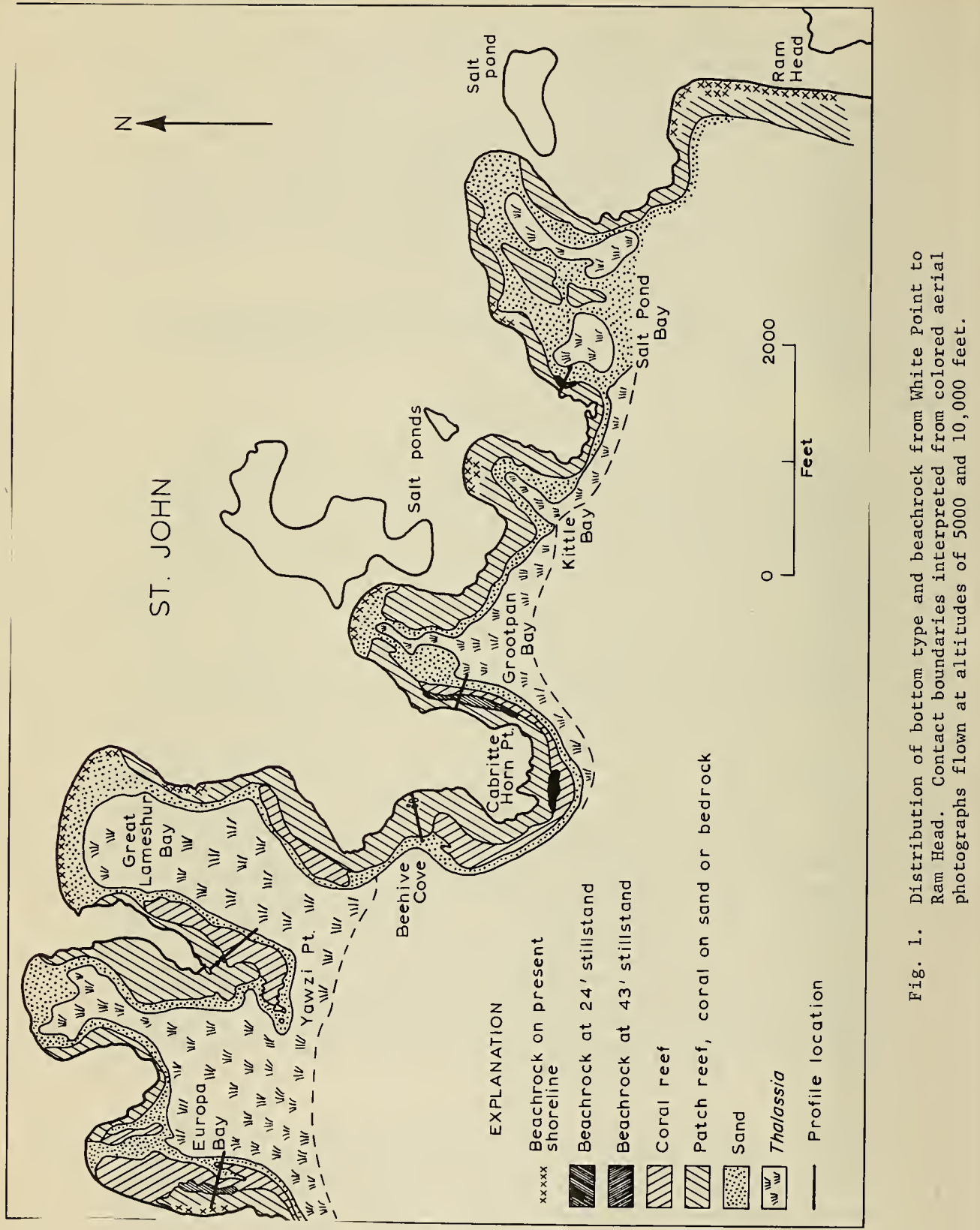


make up $50 \%$ of the clasts in beachrock on the present shore but less than $20 \%$ of the clasts in the submerged beachrock. The clast size in each deposit ranges from sand to cobbles and boulders as large as 4 feet in greatest dimension. The size of the clasts in the submerged beachrock decrease toward the top of the deposit and generally toward the seaward edge. Both contemporary and submerged beachrock contain parallel graded beds inclined as much as 12 degrees seaward.

\section{RELICT SEA LEVEL AT $43+3$ FEET}

The submerged beachrock at Cabritte Horn Point (figure 2) is more than 300 feet long, 90 feet wide, and reaches a maximum of 5 feet in thickness. Channels through the beachrock expose bedrock substrate on which the beachrock rests. The beachrock is eroded and undercut as much as 10 feet along the beachrock-bedrock contact. Corals, alcyonarians, and hydrozoans grow in isolated colonies on the beachrock surface and coalesce to partly cover the seaward part of the deposit. A cobble-boulder gravel (fig. 2, profile 1) partly covers the landward edge. The contact between the beachrock and the cobble-boulder gravel defines a change in slope, for the surface of the gravel is more steeply inclined seaward. The cobble-boulder gravel consists of well-rounded carbonate and noncarbonate clasts, similar in size and composition to those in the beachrock and partly encrusted by calcareous algae, coral, and hydrozoans. Cobble and boulder gravel occur landward from beachrock on the present beaches in Greater Lameshur Bay, Grootpan Bay, Kittle Bay, and Salt Pond Bay. As in the submerged deposits, the gravel surface slopes seaward more steeply than the beachrock surface.

Beachrock occurs on the southwest side of Cabritte Horn Point as small patches of indurated conglomerate at the landward edge of an erosional bedrock platform (figure 2). Most of the deposits are thin and rest on bedrock; coral covers their seaward surfaces. Where beachrock is absent, uncemented cobbles and boulders occur at the landward edge of the platform. Seaward of the platform, a veneer of coral growth forms a reef that covers the bedrock surface. From the coral reef, a broad plain, floored by carbonate sand, extends seaward. Except for a narrow unvegetated strip adjacent to the reef, the plain is vegetated by the calcareous algal flora Halimeda, Udotea, and Pennicilus.

On the algal plain, concentrations of well-rounded noncarbonate cobbles and boulders exist locally (figure 2) at depths of 40 to 45 feet and 62 to 73 feet. Most of the clasts are less than one foot in diameter, but rounded clasts up to 3 feet long are found at depths of 72 feet (figure 2, station 1 and 2). These noncarbonate clasts may have been deposited when the sea level was considerably lower than its present level; their emplacement under present conditions seems unlikely.

The substrate on the algal plain northwest of Cabritte Horn Point at a depth of 48 feet was investigated to a depth of 34 inches. 


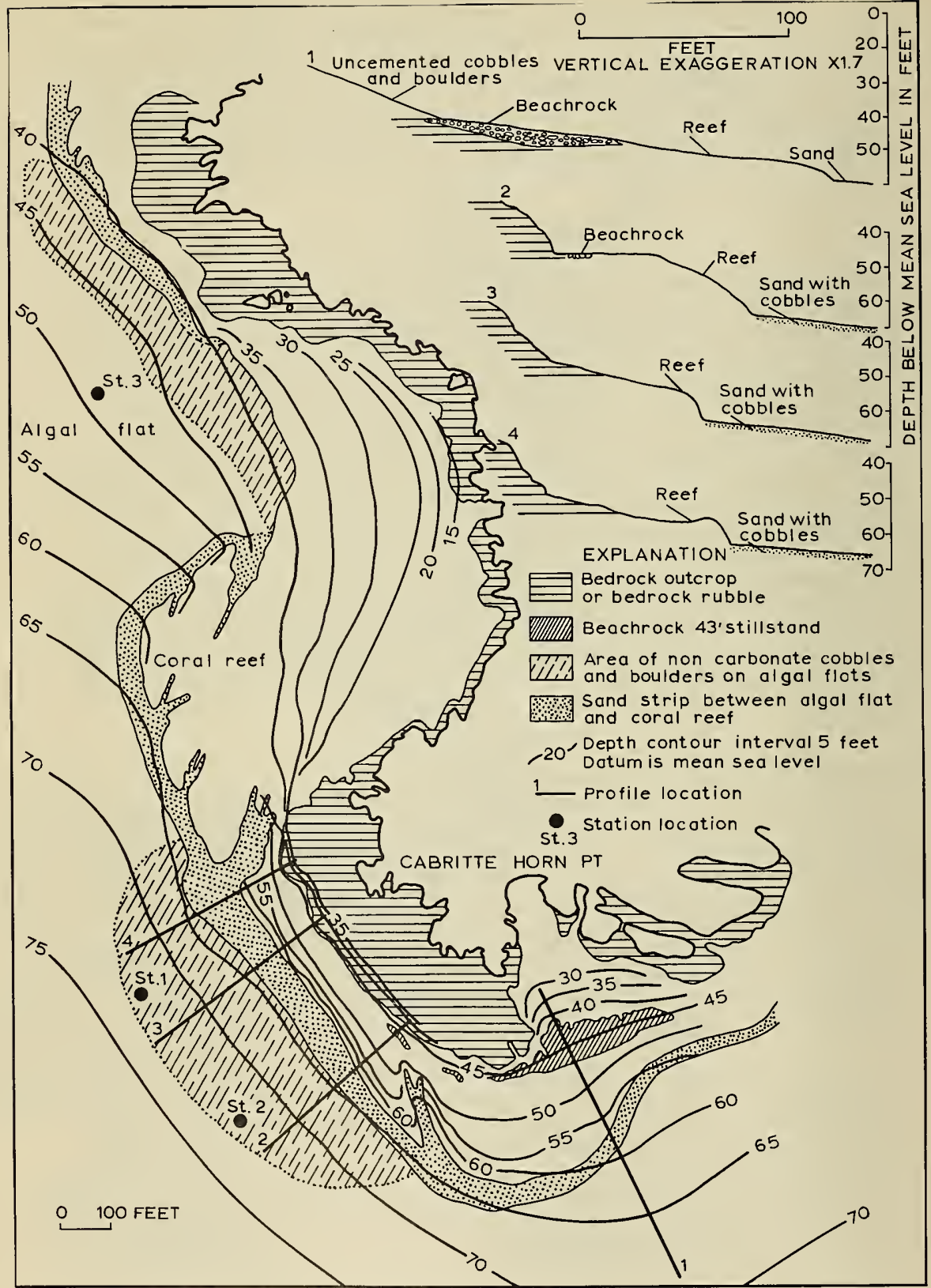

Fig. 2. Distribution of subsurface features, depth contours, profile locations and beachrock locations off Cabritte Horn point. 
The upper 22 inches of the sediment is medium to coarse carbonate sand containing nelecypod, gastropod, and coral fragments and represents material deposited on the algal plain. Beneath this, a drastic change in grain size and composition occurs. Approximately one-third of the clasts in the lower part are well-rounded, noncarbonate cobbles with a maximum diameter of 6 inches. The other two-thirds are rounded clasts of the corals Montastrea annularis, Siderastrea siderea, Acropora cervicornis and Porites porites plus smaller fragments of corals, pelecypods, and gastropods. The corals making up the larger clasts are species that do not live on the algal plain at present. This fact, plus their roundness and the presence of rounded bedrock clasts, suggests deposition under higher energy conditions than those now present at these depths on st. John. The deposits are readily explained, however, by the postulated stillstand of the sea at approximately 43 feet below the present mean sea level.

An erosional platform more than 1000 feet long and varying in width from 30 feet to approximately 200 feet is cut into the bedrock at depths of 45 to 55 feet below the present mean sea level along the southwest end of Cabritte Horn Point. Landward of the eroded bedrock platform is a bedrock cliff or large blocks of bedrock rubble. The cliff and the rubble slope rise to a depth of 30 to 35 feet where another platform is partially cut into the bedrock.

Additional evidence for a stillstand at $43+3$ feet is at the east end of St. John, where an erosional platform is cut into the bedrock on the east side of Ram Head at a depth of 44 to 50 feet, and broad constructional platforms exist at depths of 40 to 50 feet at Eagle Shoal and at LeDuck Island. The beachrock at 43 feet may represent part of the beach of Vaughn's (1916) 36-60 foot erosional platform.

\section{RELICT SEA LEVEL AT $24 \pm 2$ FEET}

The five other extensive areas of beachrock conglomerate (figure 1) are widely scattered, but the base at their seaward edge lies consistently beneath 22 to 26 feet of water. The depths of the landward margin of the deposits are more variable, ranging from $151 / 2$ to $81 / 2$ feet below mean sea level. The deposits extend parallel to the present shoreline for distances of 27 feet to more than 700 feet, and their width varies from 9 feet to 108 feet. In cross-section the conglomerate deposits are wedge shaped, ranging from 2 to 7 feet (averaging 5 feet) in thickness seaward, thinning to $11 / 2$ to 2 feet landward. The margins of the submerged deposits are vertical and usually are undercut as much as 15 feet on the lower beachrock-bedrock contact. Landward the beachrock rests on bedrock; seaward it may rest partly on bedrock or on carbonate sand or on coral rubble.

Profiles across the beachrock deposits (figure 3) show them in relation to the bottom slope and coral reef development. Seaward of the beachrock, the bottom slope is gentle and coral reefs are fully developed. Landward of the beachrock, the bottom slope 


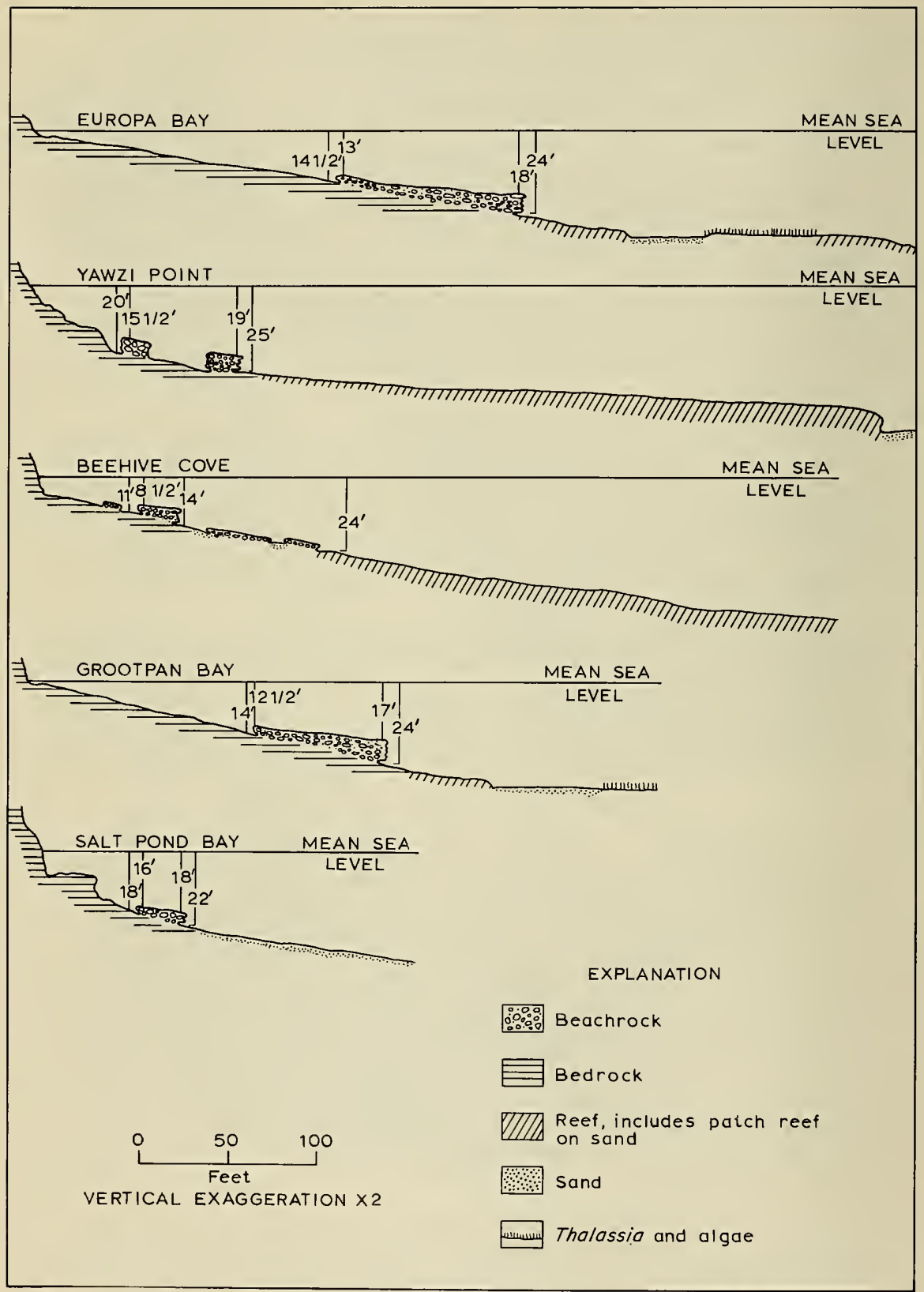

Fig. 3. Profiles through beachrock deposits at the 24 foot level. Location of profiles is shown in Figure 1. 
steepens and is irregular. Corals grow only as isolated colonies on the beachrock itself and landward on the bedrock and bedrock rubble surfaces. The geometry of the submerged beachrock deposits resembles closely that of present day beachrock deposits on the east side of salt Pond Bay.

At Yawzi Point cemented conglomerates at depths of 15 to 23 feet bridge the bedrock walls across four channels. The bottom of the beachrock bridges lies 3 to 6 feet above the floor of the channels. Coarse clasts, such as cobbles and boulders, are not found on the surrounding bedrock surfaces nor in the channels, indicating that higher energy conditions than present during this investigation have removed uncemented material from beneath the beachrocks. The higher energy conditions may have occurred during a lower sea level or during recent storms. Beachrock exists in Salt Pond Bay at a depth of 6 feet and in Kittle Bay at a depth of 10 feet. Both deposits are at depths below beachrock formation on the present shoreline, indicating possible formation during a rising sea level.

Other evidence supports a stillstand of the sea at approximately 24 feet below its present level. Uncemented concentrations of noncarbonate pebbles are at depths of 20 to 25 feet on carbonate sand flats on the east side of Salt Pond Bay and Grootpan Bay. Such concentrations may have formed along a previous shoreline. Erosional platforms cut into bedrock of 18 to 30 feet are located on the southwest end of Salt Pond Bay, on the west side of Greater Lameshur Bay, and on the southwest side of Europa Bay. A steep bedrock rubble slope marks the landward sides of the platforms. The presence of beachrock at five widely scattered locations at a consistent lower depth of $24+2$ feet indicates that sea level remained near that depth for some period of time at least. It is unlikely that localized submarine cementation could occur at the same depth over so wide an area. Moreover, the concentrations of noncarbonate clastic material and eroded bedrock platforms at the same depth support a stillstand of the sea at an approximate depth of 24 feet below the present mean sea level.

The stillstand of the sea at $24+2$ feet below mean sea level concurs with Meyerhoff's (1926, p. 119) Contention that a stillstand occurred at a depth of 27 feet below the present mean sea level. This hypothesis is based on the numerous terraces or "wave-beaten gaps" at the 27 foot depth throughout the Virgin Island chain. Kaye (1959) suggests that a stillstand occurred at 25 feet below the present mean sea level off the Puerto Rico coast.

CEMENT

$\mathrm{X}$-ray diffraction using nickel-filtered copper $\mathrm{K} \alpha$ radiation, and chemical staining methods (Friedman 1959, Warne 1962, Davies and Till 1968) established the initial mineralogic and chemical composition of the beachrock cement. The method of Chave (1952) and Goldsmith and Graf (1958) is used to determine the mol percent of magnesium 
carbonate in calcite. High-magnesium calcite is defined as containing greater than four mol percent $\mathrm{MgCO}_{3}$ in calcite. The methods of Chave (1954) and Lowenstam (1954) determined the percentages of aragonite and calcite.

The submerged beachrock at the two stillstand levels are extremely well cemented with a tan carbonate cement. The cement, which consists of microcrystalline high-magnesium calcite and aragonite, contains coral fragments, coralline algae, Foraminifera, sponge spicules, fxagments of gastropod and pelecypod shells and scattered carbonate and noncarbonate grains. Marine organisms have intensely bored the outer part of the cement.

Cement from beachrock on the present shoreline occurs mineralogically either as aragonite or, as in two samples, as a mixture of aragonite and high-magnesium calcite. In the contemporary beachrock, most of the clasts contain a thin 50-100 micron rim of acicular calcite crystals oriented perpendicular to the clast surface. The space between the clasts with acicular rims may be open, or may be filled with a microcrystalline cement. Marine organisms have also intensely bored the present day beachrock. Mineralogically, the cements of the submerged and recent beachrock consist of unstable forms of calcite that will revert with time to calcite and low-magnesium calcite.

$\begin{array}{lccc}\text { Cement } & \text { Aragonite } & \text { High- } \mathrm{MgCO}_{3} & \text { Calcite } \\ & \text { wt } \% & \text { wt } \% & \text { mol } \% \mathrm{MgCO}_{3} \\ \text { Present beach } & 30-100 & 70 & 8-17 \\ 24^{\prime} & 8-50 & 45-92 & 14-19 \\ 43^{\prime} & 13-46 & 54-87 & 14-19\end{array}$

All values $\pm 10 \%$

The cements in the submerged beachrock are similar in mineralogy and $\mathrm{MgCO}_{3}$ content, but are reduced in aragonite as comoared with the contemporary beachrock. The aragonite reduction may be due to marine organisms removing the initial aragonite cement by repeated boring; filling of the borings with fecal pellets and clastic debris, followed by lithification and precipitation of high-Mg calcite as described by Alexandersson (1969). All of these processes may have reduced the aragonite content. No evidence of biogenetic structures (such as algal layers) or recrystallization was observed in the submerged beachrock cement.

\section{AGE OF BEACHROCK}

Radio-carbon age determinations have been made by the U. S. Geological Survey on two samples of carbonate cement from the 24-foot beachrock 
of Grootpan Bay and Europa Bay. The ages, 1,800 +200 years BP for Grootpan Bay and $1,050+200$ years BP for Europa Bay, indicate an average submergence ratē greater than a foot per hundred years. This rate far exceeds the rate of eustatic sea rise as reported by scholl and others (1968) for Florida, by Emery (1967) and by Wigley and others (1968) for the Atlantic continental margin. These dates, however, must be considered tentative owing to possible introduction of younger carbonate material by marine organisms. Further radiometric age dating will be required to establish approximate ages of beachrock cementation and corresponding rates of sea level change.

If the dates are accurate, they indicate that local structural movement has affected the rate of sea level advancement in the St. John area. Post-Pleistocene faulting on the shelf southwest of St. Thomas has produced prominent scarps 5-10 meters in height (Donnelly, 1965); this suggests that recent structural movement resulted in the partial submergence of $\mathrm{St}$. John.

\section{CONCLUSIONS}

Changes in sea level caused by a combination of tectonic movement and eustatic sea level rise have formed a complex record of sea level history on the St. John shelf. Near the site of the Tektite experiment, a stillstand of the sea seems to have occurred approximately 43 feet below the present sea surface. Beachrock formed along the shoreline, an erosional platform was cut into the bedrock slope, and constructional platforms formed on the east side of St. John.

The sea advanced to approximately 24 feet below the present sea level. Beachrock formed in numerous locations and erosional nlatforms were cut into the bedrock along the south coast of St. John. After formation of an erosional platform, at 18-30 feet, the sea level rose, accompanied by continual formation of beachrock, to depths of at least 6 feet below the present mean sea level.

Tentative radio-carbon age dates suggest that the sea level rise is controlled by both eustatic and tectonic factors. Further age dating may establish the rate of tectonic subsidence of St. John in the recent past. 
Alexandersson, T., 1969. Recent littoral and sublittoral high-Mg calcite lithification in the Mediterranean. Sedimentology $12(1 / 2): 47-61$.

Chave, K. E., 1952. A solid solution between calcite and dolomite. J. Geol. 60: 190-192. 1954. Aspects of the biogeochemistry of magnesium, 1. Calcareous marine organisms. J. Geol. 62: 266-283.

Davies, P. J., and Till, R., 1968. Stained dry cellulose peels of ancient and Recent impregnated carbonate sediments. J. Sedimentary Petrology 38 (1): 234-237.

Deboo, P. B., 1962. A preliminary petrographic study of beach rock. Proc. lst Nat. Coastal and Shallow water Conf., Tallahassee 1961: 456-458.

Donnelly, T. W., 1965. Sea-bottom morphology suggestive of postPleistocene tectonic activity of the eastern Greater Antilles. Geol. Soc. Am. Bull. 76: 1291-1294. 1966. Geology of St. Thomas and St. John, U. S. Virgin Islands. Geol. Soc. Am. Mem. 98: 85-176.

Emery, K. O., 1967. The Atlantic continental margin of the United States during the past 70 million years. The Geol. Assoc. of Canada Spec. Paper No. 4, Geol. of the Atlantic Region: 53-70.

Emery, K. O., and Cox, D. C., 1956. Beach rock in the Hawaiian Islands. Pacific Sci. 10: 382-402.

Friedman, G. M., 1959. Identification of carbonate minerals by staining methods. J. Sedimentary Petrology 29 (1) 87-97.

Ginsburg, R. N., 1953. Beach rock in South Florida. J. Sedimentary Petrology 23(2) 85-92.

Goldsmith, J. R., and Graf, D. L., 1958. Relation between lattice constants and composition of $\mathrm{Ca}-\mathrm{Mg}$ carbonates. Am. Mineralogist 43: 84-101.

Kaye, C. A., 1959. Shoreline features and Quaternary shoreline changes, Puerto Rico. U. S. Geol. Survey Prof. Paper 317-B: 49-140.

Lowenstam, H. A., 1954. Factors affecting the aragonite: calcite ratios in carbonate - secreting marine organisms. J. Geol. 62: $284-322$.

Meyerhoff, H. A., 1926. Scientific survey of Porto Rico and the Virgin Islands. New York Academy of Sciences 4(1) 71-141.

Russell, J. J., 1960. Preliminary notes on.. Caribbean beach rock. Trans. 2nd Caribbean Geol. Conf. Mayaguez, Puerto Rico, 1959: 43-49.

1962. Origin of beach rock. Proc. 1st Nat. Coastal and Shallow Water Research Conf., Tallahassee 1961: 454-456.

Scholl, D. W., Graighead, Sr., F. C., and Stuviver, M., 1969. Florida submergence curve revised: Its relation to coastal sedimentation rates. Science 163: 562-564.

Stoddart, D. R., and Cann, J. R., 1965. Nature and origin of beach rock. J. Sedimentary Petrology 35(1): 243-273. 
Vaughn, T. W., 1916. Some littoral and sublittoral physiographic features of the Virgin and northern leeward islands, and their bearing on the coral reef problem. J. Wash. Acad. Sci. 6:53-66.

Warne, s. St. J., 1962. A quick field or laboratory staining scheme for the differentiation of the major carbonate minerals.

J. Sedimentary Petrology $32(1): 29-38$.

Wigley, R. L., Bartlett, A. S., Rubin, M., and Barghoorn, E. S., 1967. Freshwater peat on the Continental Shelf. Science 158: 1301-1307. 
PASSIVE AND EXPERIMENTAL BIO-ACOUSTICAL

STUDIES ON MARINE ORGANISMS IN

THEIR NATURAL HABITAT

Thomas J. Bright and William W. Schroeder

Texas A\&M University

College Station, Texas

\section{ABSTRACT}

A total of 13 sounds, or assemblages of sounds, observed and recorded during TEKTITE II Mission 4-50 are analyzed, described and compared in terms of their frequency, amplitude and temporal structure. Major components of reef associated noise appear most intense at frequencies of approximately 200 to 600,3500 and 5500 Hertz. An amplitude heirarchy of sounds is recognized and briefly discussed, as are certain cyclical and ethological aspects of sound production on reefs.

\section{OBJECTIVES}

Our primary objective during Mission 4-50 was to gather information concerning the nature, origin and significance of biologically generated sounds in and around the reefs adjacent to the TEKTITE II habitat. Specifically we sought to: (1) obtain a detailed bio-acoustical survey of selected study areas, paying particular attention to diel (24 hour) fluctuations in content and level of ambient biological noise; (2) assess sound production patterns in individual species and determine when and to what extent they contribute to the overal1 background noise; (3) investigate experimentally and by passive observation and the natural and artificial stimuli which elicit sound production in species involved, both in the field and under laboratory conditions; (4) determine as far as possible the role of sound production in the behavior and biology of acoustical dominants in their natural habitat; and (5) assess the results of these efforts when compared to those of a similar study to be made in the same or an adjacent area but utilizing conventional diving gear and surface based techniques.

\section{EQUIPMENT}

The acoustical apparatus used consisted of two basic recording units. One was portable, self-contained, and could be carried by a diver. The other made use of a recording unit mounted inside the habitat. Figure $1 \mathrm{~A}$ illustrates the configuration of our portable unit. Basically, it consisted of a Sony TC-110 cassette recorder housed in a plexiglass case built by us. Input to this recorder was through $25^{\prime}$ of shielded cable from an Atlantic Research LC-50 hydrophone. This system had an effective frequency response of 40-cycles per second $(\mathrm{Hz})$ to $10-\mathrm{kilocycles}$ per second $(\mathrm{KHz})$. We had the option of mounting to the recorder a Kodak M-24 Super-8 movie camera in an Ikelite underwater housing. Circuitry was provided which allowed us to operate either camera or recorder independently, or both simultaneously. 


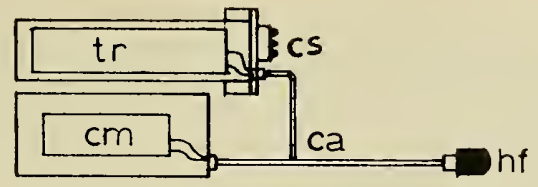

A

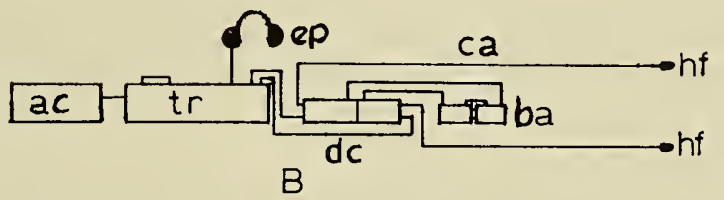

Figure 1. A. Portable underwater recorder-camera.

B. Habitat based recording system. Symbols: ac, A.C. amplifier and speaker; ba, 12 volt batteries in series; ca, single conductor shielded cable; cm, movie camera; cs, control switches; dc, D.C. amplifiers; ep, earphones; hf, hydrophone; $t r$, tape recorder.

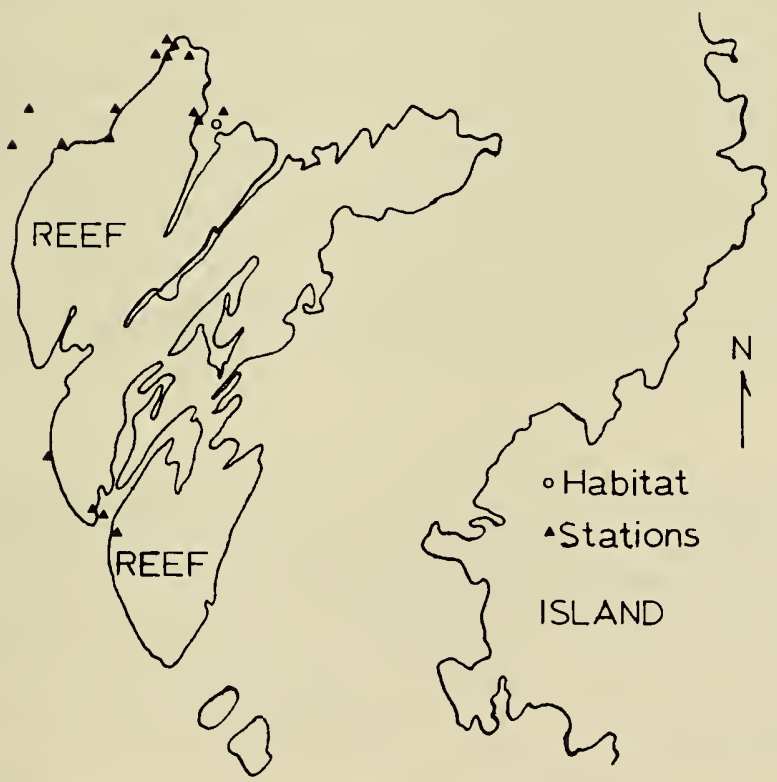

Figure 2. Locations of stations and habitat

VI -83 
Our most effective acoustical monitoring device was the habitat based Sony 630-D tape deck. Figure $1 \mathrm{~B}$ illustrates the stationary recording system consisting of a Sony 630-D tape deck, time switch, two $500 \mathrm{ft}$. lengths of single conductor shielded cable type $\mathrm{Rg} 59 \mathrm{~A} / \mathrm{u}$, two Atlantic Research LC-10 hydrophones, two 24 vo1t D.C. amplifiers powered by 12 volt dry cell batteries, stereo earphones, and an amplifier with speaker.

A $3^{\prime} \times 2^{\prime} \times 1 \frac{1}{2}^{\prime}$ cage of $\frac{1}{2} \prime$ mesh hardware cloth was used to impound live specimens for detailed monitoring purposes. The cage was located on the sand flat east of the habitat.

Spectral analyses of recorded sounds were performed on a Kay Electric Company, Mode1 7030-A, vibralyzer with a Mode1 6070-A contour display unit.

\section{PROCEDURE}

Our efforts during Mission 4-50 involved observation, monitoring and recording at 17 stations (Figure 2) in the vicinity of the habitat, plus observation and recording at various locations upon the reef using the portable recorder. The portable Sony TC-110 cassette recorder proved useful in recording sounds produced by fishes of tenacious territorial habits; however, it did not provide us with the degree of mobility we had expected, primarily because when we pursued potential subjects with it, we quickly found that their tendencies to produce sounds were greatly reduced or destroyed. Most effective use of this and our other instruments was made in conjunction with extended periods of quiet observation at one location. It is unfortunate that on June 11 the portable unit, but not the camera, was lost due to careless placement and an exceptionally strong current running in a southeasterly direction in one of the channels separating the northern and southern portions of the reef.

The habitat based Sony 630-D tape deck was our most effective acoustical monitoring device. This system enabled us to monitor and record sounds from two stations simultaneously. The technique of recording and observing involved use of a time switch which automatically turned the recorder on for 3 or 5 minutes each hour. On the occasions when we left the habitat to observe the subjects at the station being monitored, the recorder was customarily run continuously. During these observation periods, the divers pinpointed events on the recordings by simply tapping code on clipboards. This practice did not seem to appreciably alter the behavior of the organisms observed and provided a later reference by which our observations could be correlated in time with the recordings.

The wire cage was used to impound five individuals, three Longjaw Squirrelfishes, Holocentrus ascensionis, and two Smooth Trunkfishes, Lactophrys triqueter. They were monitored for a period of three days in an attempt to detect a sound we had designated "frog chorus." Although $\underline{H}$. ascensionis is known to be a loquacious sound producer, and relatives of Lactophrys have been implicated in frog-1ike sound production in the past, we detected only a few weak staccatos during the monitoring period. Normally, we would have expected three $\underline{H}$. ascensionis to produce a great deal of noise. The absence of significant sound production by either species indicates the inhibitory effect confinement apparently has on expression of normal behavior, when confinement is carried out in the organism!s 
natural habitat. Understandably, perhaps the experimental aspects of our project were overshadowed by the more productive techniques of passive observation.

Diving techniques involved use of both open circuit SCUBA and the closed circuit G.E. Mark X rebreather. The ability to leave the habitat at will any time of the day or night provided the freedom necessary for effective observation of the behavior of our subjects in relation to sound production. Bubbles produced by open circuit diving gear hampered our attempts to observe organisms while using it. Not only did the bubbles create a great deal of noise but they frightened the subjects to the point of appreciably altering their behavior. We, therefore, customarily used open circuit apparatus while performing work tasks not directly associated with behavioral observation. Nevertheless, we did obtain a significant amount of data while using the SCUBA units.

The rebreather units were invaluable to us during the observational periods indicated above. Their low noise level and lack of bubbles allowed us to approach the subjects very closely without interfering with the organisms normal behavior pattern or with the recordings we were making. At times while wearing the rebreather and remaining quite still, we were treated as a portion of the substrate. With the rebreather on we found that after a short while we were able to detect with the unaided ear both the background noises and the sounds produced by fishes and certain invertebrates. This was developed into a method by which we were able to trace the source of at least one interesting sound commonly only heard at night, the frog chorus.

Some of the most interesting observations were made at station 1 while looking out of the wet room window from the habitat. The view from these hemispherical windows is superior to that experienced by a diver in the water because of its panoramic nature. One can detect a great deal more of what is actually happening in the environs of the subjects being observed while looking through these domes. At the same time, while inside the habitat, it was a simple matter to don earphones and listen directly to the organisms while taking notes on their behavior. Unfortunately, the habitat produced such a high-level of noise and the closest part of the reef was so far away from the window, ten meters, that the full potential of such dry observation could not be realized.

The sound spectrum analyzer is presently being employed on a continuing basis to provide us with visual representations of the recorded sounds which enable us to describe them in terms of frequency, amplitude and temporal structure.

\section{DESCRIPTION OF SOUNDS}

The volume of data collected during Mission 4-50 was such that its thorough assessment is taking longer than anticipated. We are currently in the process of enumerating and quantifying the sounds recorded in an effort to abstract a picture of the diel variations in the nature and intensity of sound production by several species of squirrelfishes and by grazers and coral feeders in general. A final phase in analysis of our data will involve assessment of sound production in relation to behavioral observations made by divers.

At the present time, it is possible to present spectral analyses and descriptive discussions of certain sounds which have been abstracted from our tapes for 
reference purposes. Our methodology, however, makes it convenient to delay further spectral analyses until particular sounds are encountered during playback procedures.

\section{Spectral Analyses}

The sound spectrum analyzing system described in a previous section is capable of producing visual displays (sonograms) of sounds fed into it from previously recorded tapes. A choice of two types of sonograms is available. A standard sonogram, Figure 3, provides a representation of the sound structure in terms of frequency on the vertical axis and time on horizontal. Amplitude is related to the degree of darkening of the marks produced on the paper but cannot be determined with any certainty.

A second type of sonogram, Figure 4A, provides a contour display with contour outlines spaced at six decibel increments. The darkest of the seven levels is the region of greatest amplitude and the overall dynamic range is 42 decibels. Absolute acoustic magnitudes are not attainable without some point of reference and a calibration procedure which we have not undertaken. Relative amplitudes, however, are readily detected and using the ever present background noise as a rough base, some idea of the amplitude of the sounds relative to background noise is attainable. Care must be exercised here, however, because the distance of the subject from the hydrophone during recording has a profound effect upon the relative intensity and apparent quality of a sound as detected by the Iistener or recorder. This becomes quite apparent in the case of staccatos and cooing sounds of certain squirrelfishes of the genus Holocentrus.

\section{Background Noise}

Snapping, crackling, and frying pan noises:

The sonograms in Figure $5 \mathrm{~A}$ and $\mathrm{B}$ are of special interest in a consideration of the nature of the pervasive and ever present background snapping and crackling which occurs in the vicinity of coral reefs. This sonogram represents a waxing sequence of innumerable snapping sounds which, when perceived together, create the impression of a piece of cold bacon being flung into a pan of hot grease. This apparent flush of background noise lasts for a few seconds after which the more stable but less intense level is regained. What the sound appears to be is an increase in the frequency of occurrence and to some extent the amplitude of the background snaps. Analysis of the frying pan noise emphasizes and clarified to some extent the nature of the snapping. Two predominant modes in amplitude are evident, one at around $3500 \mathrm{~Hz}$, and the other at around $5500 \mathrm{~Hz}$. When sonograms made during the analyses of other sounds are examined, it is found in almost all cases that the majority of the background noise is distributed around these frequencies. A more dramatic representation which illustrates the two amplifying modes of the frying pan noise quite clearly appears in Figure $5 \mathrm{~B}$. This sonogram was produced by analyzing the noise at a very low gain setting, thereby reproducing only those components of the sounds which were highest in energy content.

Two individual snaps appear in Figure $3 \mathrm{~A}$ along with a pop from a reef squirrelfish. Consideration of the plots of the two snaps indicates that the bimodal nature of the background noise is a result of bimodality in individual snaps 

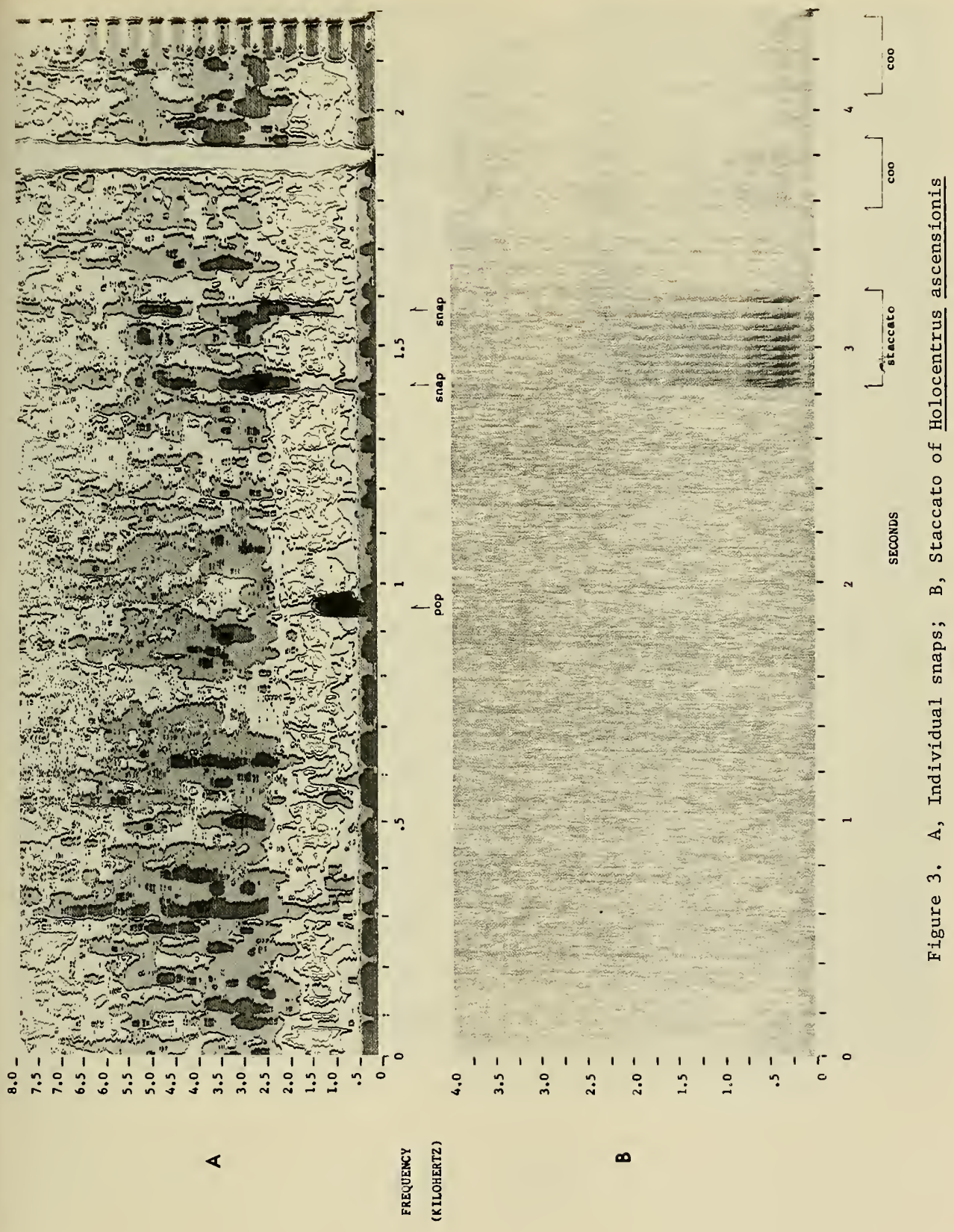
-

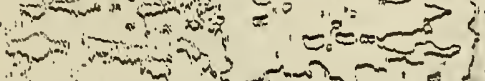
$\therefore$, actions

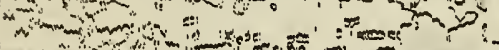
(20) $\lim _{n=1} m_{0}$ a n

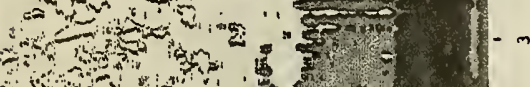
71 1 0 1 is " : and ans $-1, y=0,150$ 10: $x$ in ? in $\therefore \quad 010$ $\therefore=0=0$

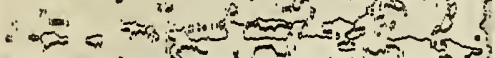
$=$ T-3 - =

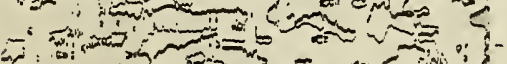
$E=2=0$ - $x^{2}=x^{2}$

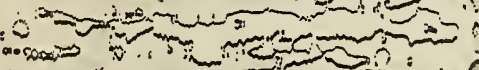

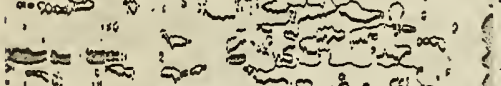

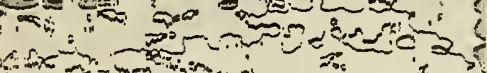
rencin

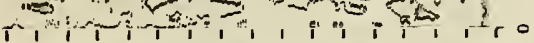

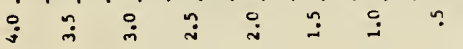
(n)

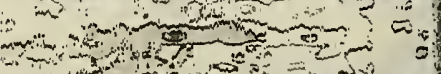
管

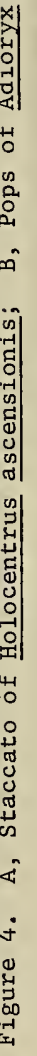



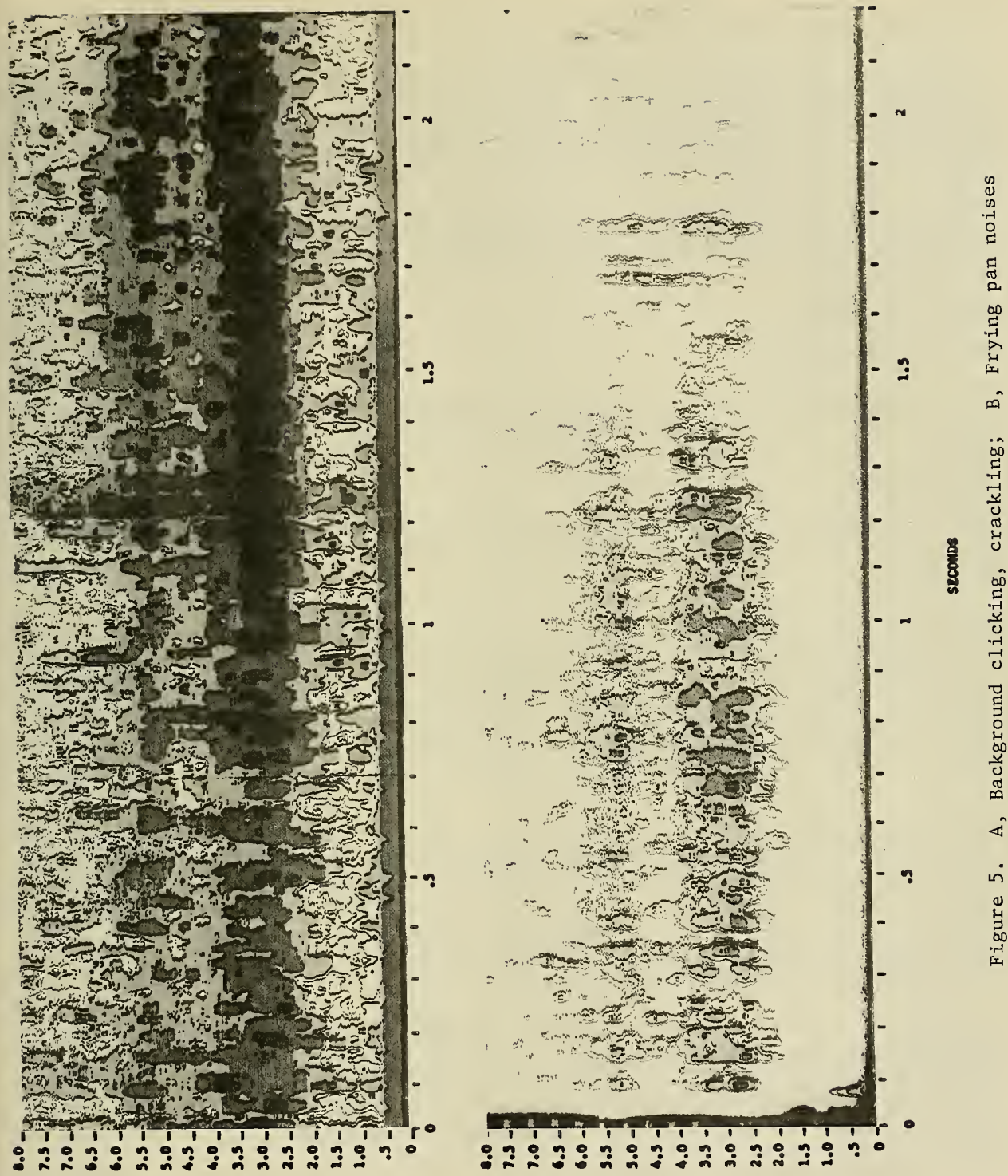

홀 
and not a result of a combination of two sounds having only one amplitude mode each but at different frequencies.

An indication of the origin of the background noise came to light during a trip to Quintana Roo in August 1970. A student, Chris Tresslar, and I were snork1ing on a reef off Puerto Morelos. Chris, a geologist, was banging on the reef with his pick. He noticed that occasionally during this pounding a flush of crackling became apparent. Upon investigation, we found that there are certain places on the reef which, when pounded upon, would emit sounds similar to the frying pan noises discussed above. Apparently, this is a result of disturbance of localized pop':-ation of small sound producers, possibly snapping shrimp.

\section{Purposeful Sounds}

Staccatos and coos:

These two apparent sounds are lumped here because it is evident that they are in fact the same. The staccato represented in Figure $3 \mathrm{~B}$ and $4 \mathrm{~A}$ was taken from a sequence of sounds produced spontaneously by a single squirrelfish, probably $\underline{H}$. ascensionis, as it approached and passed the hydrophone. During this sequence the cooing sounds were quite evident. When both were represented on a sonogram, they were found to possess certain features in common, confirming a previous opinion that the cooing sounds are simply staccatos some distance away from the hydrophone.

The staccato is composed in this case of 10 pulses. The first two pulses are run together but there is a gradual widening of the time interval between pulses and the centers of the final two are separated by a $.06 \mathrm{sec}$. time interval. When the recording was analyzed after slowing the tape to $1 / 4$ speed (from $71 / 2$ inches per second to $17 / 8$ inches per second) each of the 10 individual pulses could be further resolved into 5 to 7 apparent subpulses with their centers separated by approximately $.0025 \mathrm{sec}$. time intervals.

Temporally this provides us with a picture of a rather complex superposition of pulse trains. The basic subpulses seem quite regularly spaced temporally, indicating that possibly the time interval between subpulses is governed by some mechanical aspect concerning operation of the sound producing mechanism, viz., swim bladder and associated muscles and bones. Variation in number of subpulses per pulse may indicate a control mechanism employed by the fish to vary the actual duration of each pulse of the staccato sound.

The number of pulses per staccato sound, although 10 in the case of the sound represented in Figure $3 \mathrm{~B}$ and Figure $4 \mathrm{~A}$, is quite variable within the same individual. During the sequence in question, the fish produced a staccato consisting of only eight pulses which was followed $1.7 \mathrm{sec}$. later by a sound composed of seven pulses. It appeared that the staccato sounds consisting of the greatest number of pulses were separated from one another by the greatest time interval but this is not definitely confirmed.

It is probably safe to assume that the Longjaw Squirrelfish, $\underline{H}$. ascensionis, while spontaneously producing staccato sounds at night, is capable of modulating the frequency of occurrence of the sounds, the number of pulses, and possibly the number of subpulses and, therefore, the length of pulses. 
In terms of frequency, the staccato pulses cover a wide width. Most of the acoustical energy, however, seems to be focused in two areas of the spectrum. The most intense expenditure of energy occurs between 200 and $400 \mathrm{~Hz}$ where the amplitude appears to rise at least 30 decibels (db) above the lowest level of background noise (Figure 4A). A secondary mode in amplitude occurs at around $600 \mathrm{~Hz}$ and here the amplitude rises to $30 \mathrm{db}$ above background only in the first pulse. The rest of the pulses shown an amplitude $6 \mathrm{db}$ lower at this frequency.

Coos can barely be detected in sonogram 3B but are plainly visible in 4A. Their similarity to staccatos is readily apparent. The one conspicuous modal amplitude occurs between 200 and $400 \mathrm{~Hz}$ just as in the staccato. Obviously, the higher frequency components have been extinguished but this is consistent with the nature of sound transmission in water where lower frequency sounds persist over greater distances than do those of high frequency. A11 this seems to indicate that the sounds referred to as coos are actually distant staccatos given a different tonal quality by a reduction in overall intensity and a greater relative amplitude loss at the higher frequencies than at the lower.

\section{Pops :}

These sounds (Figure 4B were produced by the Reef Squirrelfish, Adioryx coruscus. The individual responsible for them was sole inhabitant of a small crypt in the reef. Commonly, however, these fishes were found under coral heads in the company of numerous cardinal fishes and a few small Longspine Squirrelfishes, Flammeo marianus. Both the Reef Squirrelfish and the Longspine are sound producers and encounters between the two species led to some interesting acoustical exchanges. This relationship is one which we hope to look into further in the near future. Popping sounds have been elicited from a captive Reef Squirrelfish in our lab, but these are quite different in nature from those detected in the natural habitat due in part to the acoustical properties of the small tank.

Basically, the pops recorded on the reef consisted of one pulse each and are spaced very irregularly. It seems likely that each pop pulse is individually initiated and one is not specifically linked to another in the way pulses of the previously discussed staccato sounds are.

Most interesting is the frequency structure of each pulse. The presence of two predominant frequencies in a pulse of this sort is not especially unique; however, the two frequencies, in this case approximately $850 \mathrm{~Hz}$ and $5 \mathrm{Ho} 40 \mathrm{~Hz}$, are separated by a rather broad band of about $800 \mathrm{~Hz}$. The lowermost frequency is somewhat lower than any major component of the other sounds analyzed during this study. This observation may be of particular significance in separating these pops from similar sounds produced occasionally by the Longspine Squirrelfish.

The amplitudes at both predominant frequencies rose approximately $36 \mathrm{db}$ above the quietest background.

Pops elicited from the reef squirrelfish in a 10-gallon tank show a much broader apparent range of frequencies than do the pops recorded in the environment. This could be due in part to the conditions under which the sounds were emitted. In the laboratory, a great deal of agitation of the fish, which was considerably 
larger than those encountered in the environment, was necessary before it would produce a sound. In the environment, the stimulus eliciting sounds was quite likely much more subtle, or the sounds may even have been spontaneous. There are also reverberation, resonance and reflection phenomena associated with the acoustical properties of the tank which may be significant.

\section{Quacks :}

Quack-like sounds have been detected from two apparent sources. That illustrated in Figures $6 \mathrm{~A}, \mathrm{~B}$, and $7 \mathrm{~A}$ is produced by the Longspine Squirrelfish, Flanmeo marianus, while the other, to be discussed later, is of unknown origin.

Each quack in Figure $6 \mathrm{~A}$ consists basically of two pulses spaced $.0108 \mathrm{sec}$. apart. The duality of pulses per quack is not evident in Figure $6 \mathrm{~A}$ but is shown quite well in Figure $7 \mathrm{~A}$, which is an analysis of the sounds played at $1 / 4$ speed ( $17 / 8$ inches/sec. rather than $71 / 2$ inches/sec.). Each pulse consists of two predominant frequencies, approximately $800 \mathrm{~Hz}$ and $1200 \mathrm{~Hz}$. It is apparent in Figure 7A that the lower frequency components of each pulse persist longer than the higher, and indeed those of the first pulse run over into the second. Taken together, the two pulses of each quack span a time interval of approximately .022 seconds.

Because bimoda1 frequencies have been encountered often in other sounds recorded, it is not 1ikely that this in itself is responsible for the quack-1ike quality of the sounds in question. Possibly, the duration of the low frequency components and their apparent running together are responsible. It would be interesting to duplicate individual components of the pulses involved and then put them together on tape piece by piece until a quacking quality is produced.

In Figure 6B, quacks 2 to 5 are accompanied by a series of sing1e pulses of less intensity spaced much farther apart temporally than the component pulses of the quacks. Whether or not these pulses were produced by the same fish which produced the quacks is unclear.

In addition to the quack-1ike sounds produced by the Longspine Squirrelfish, we have detected similar sounds of unknown origin, although we suspect juvenile Holocentrus.

The sequence discussed here consists of 14 individual quacks. Figures $8 \mathrm{~A}$ and 7B represent quacks 1 through 9 and 9 through 14 respectively. Quacks 1 and 11 are partly obscured by unrelated low frequency, high energy sounds.

The time interval between quacks varies from $.3 \mathrm{sec}$. between the first and second to $1 \mathrm{sec}$. between the last two. There is a more or less steady increase in the time interval between succeeding quacks as the sequence progresses.

Each quack consists of a series of pulses which vary in number from 3 in the first quack to 12 in the last. There is a general but not uniform increase in the number of pulses per quack as the sequence progresses. For instance, quacks 1 through 14 consist of the following numbers of pulses respectively: $3,4,4,3,4,4,3,6,9,7, ?, 8,7,12$. In most cases, the pulses were separated by $.013 \mathrm{sec}$. intervals. 


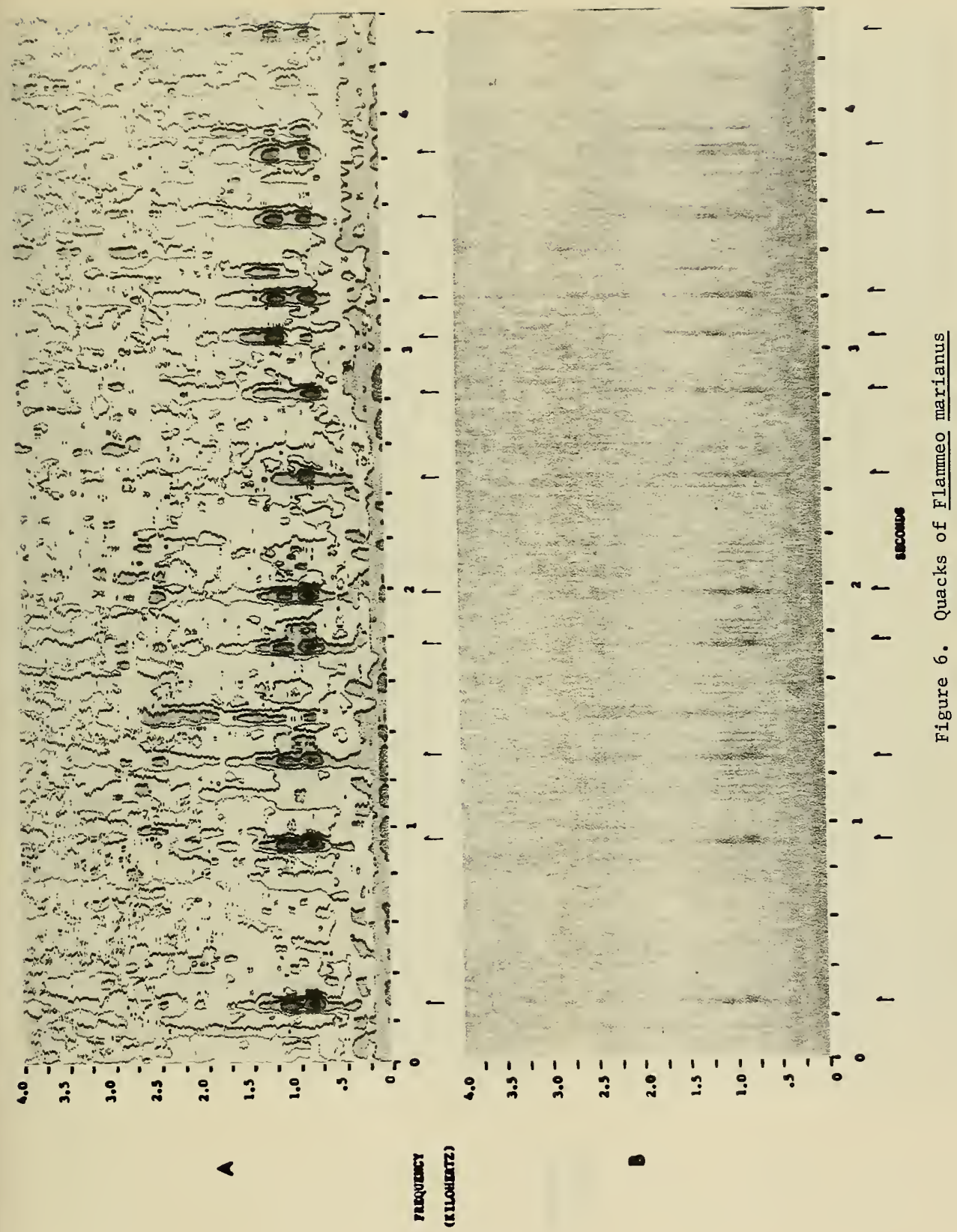




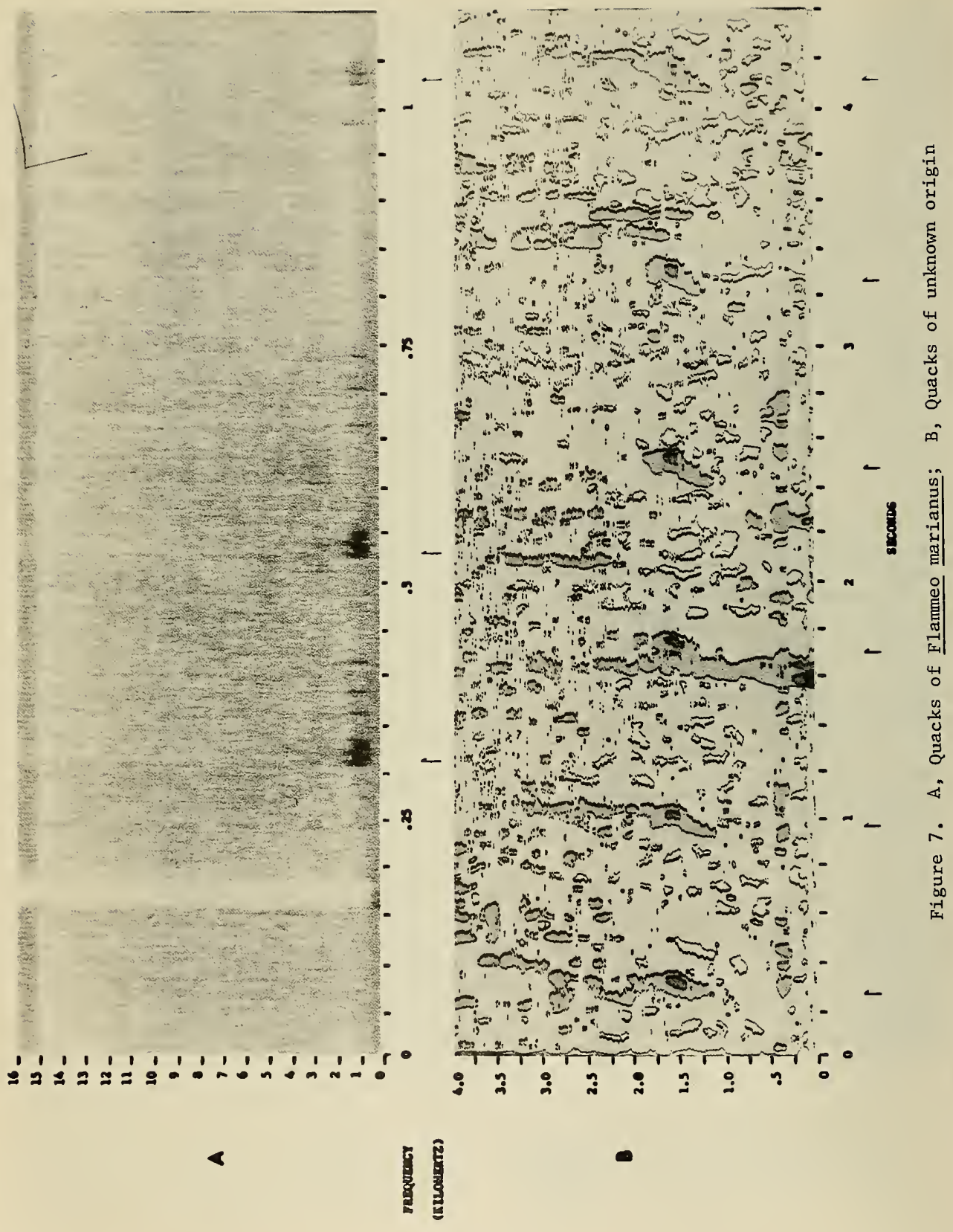




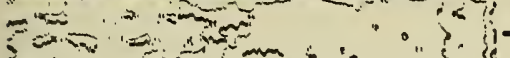

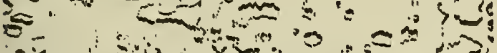

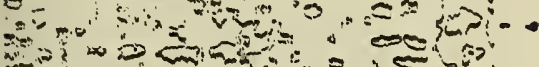

$\therefore=2$ क

:

3ita

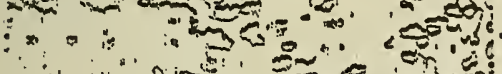

$\therefore$ :"

$\therefore$ :

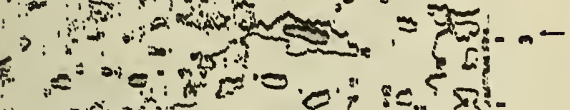
* 1."

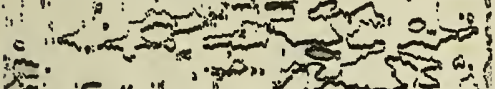

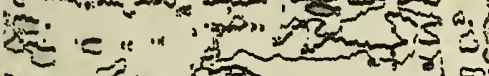
$=0=0$ $=0$ $\because 2^{2}=8$

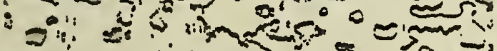
:50: $\quad$ :

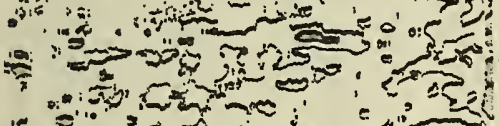

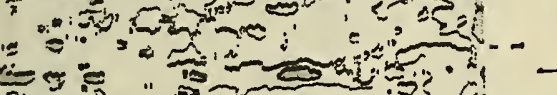

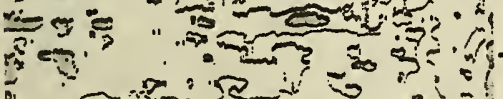
${ }_{0}={ }_{0}$ -

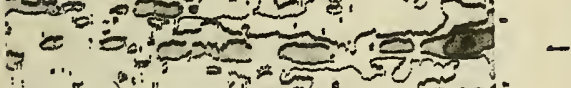
$\because$ : : के

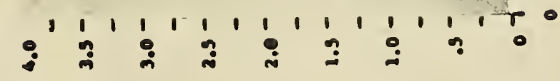
है을 
Frequency modulation seems apparent, occurring in this case from pulse to pulse within each quack. In all quacks the average maximum energy expenditure seems to be at around $1500 \mathrm{~Hz}$. In most cases, however, with each succeeding pulse within a quack, the dominant frequency increases somewhat. This is easily seen in the contour displays where, although individual pulses cannot be distinguished, the axis of the amplitude contours for each succeeding quack becomes increasingly inclined upward to the right. In the last several quacks there are a relatively large number of pulses per quack involved. This increase in pitch from start to finish of a quack is quite evident to the listener. Again, as in the case of the Longspine Squirrelfish quacks, it would be interesting to isolate individual pulses and recombine them in various manners in order to determine the factors responsible for the quacking quality of the sounds.

Squeaking Door Sound:

The Longspine Squirrelfish produces an occasional intense burst of pulses which together sound much like a door being swung slowly on dry hinges. Quite a bit of variability in temporal spacing of the pulses is evident, and intervals as short as $.01 \mathrm{sec}$. and as great as .26 sec. appear in Figure 8B. A pair of double pops precedes the major sound sequence in this and other squeaking door sounds examined.

The frequency distribution is broad within most of the pulses but a slight bimodality is demonstrable. Slightly greater energy expenditures are distributed around $900 \mathrm{~Hz}$ and $1500 \mathrm{~Hz}$. There is, however, a fair amount of frequency modulation associated with this sound, and in actuality it is composed of four distinct types of pulses including the bimodal one described above.

The last 5 pulses of the series represented in Figures $8 \mathrm{~B}$ and $9 \mathrm{~A}$ are of two types. One, represented by the last pulse and the third and fifth from last, is dominated by frequencies centering at about $1250 \mathrm{~Hz}$, with slight additional modal tendencies at $800 \mathrm{~Hz}$ and $300 \mathrm{~Hz}$. The second and fourth from the last pulse and also the 12th pulse from the beginning of this sequence demonstrate maximum amplitude at a relatively high frequency, $2100 \mathrm{~Hz}$, without appreciable low frequency components.

Near the center of the sonogram is a short purr-like sequence of four pulses dominant around the $900 \mathrm{~Hz}$ level without any apparent second mode at higher frequencies.

Although it would seem that innumerable combinations of the four types of pulses described above are possible, the significance of such combinations in transmitting information is as yet poorly understood.

Roar :

This is another jound of unknown origin. It consists of a series of thumps and pulses of variable amplitude and temporal spacing (Figure 9B). The thumps are composed of from 2 to 3 individual pulses and are spaced from .04 sec. to .15 sec. apart. They initiate the sequence and give way after $.6 \mathrm{sec}$. to a series of closely spaced pulses and thumps of greater amplitude. Whereas the preliminary thumps rise 24 decibels above the quietest background in the 100 to $400 \mathrm{~Hz}$ range, the more intense roaring segment of this sound attains this level at 
$=$

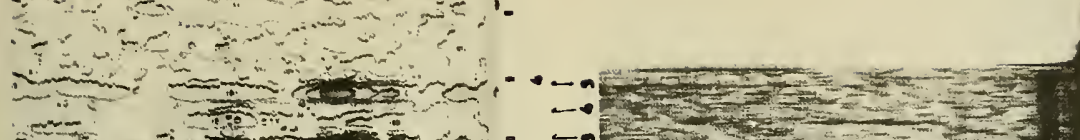

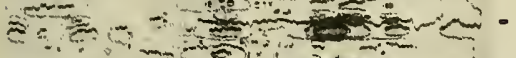

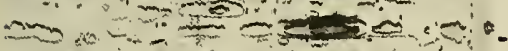

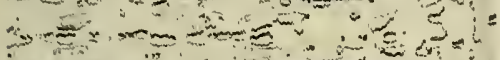

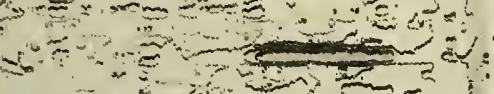

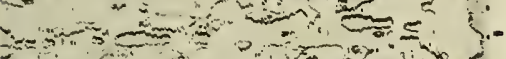
$=0$

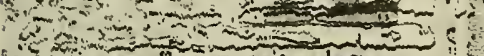

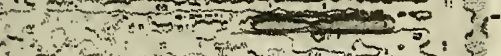

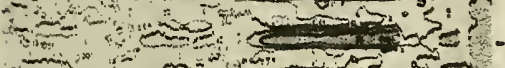
$-2-200000$

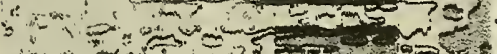

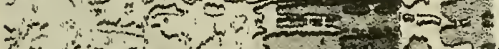

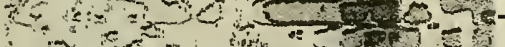

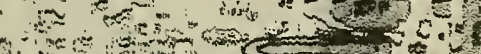

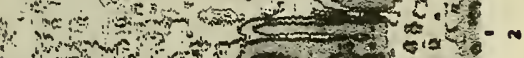
ind

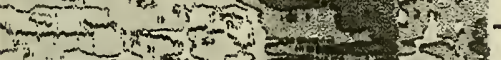

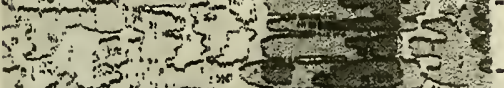

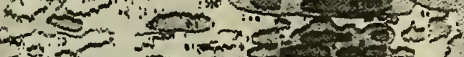

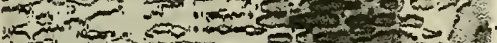

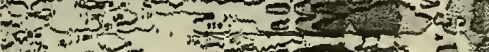

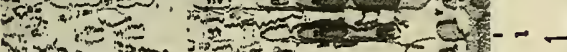

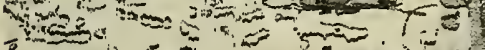
$=0$

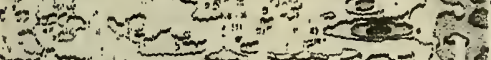

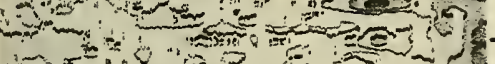
and $x^{2}=0$ $\rightarrow=\infty$ $\frac{1}{20}=0$ De 200 -

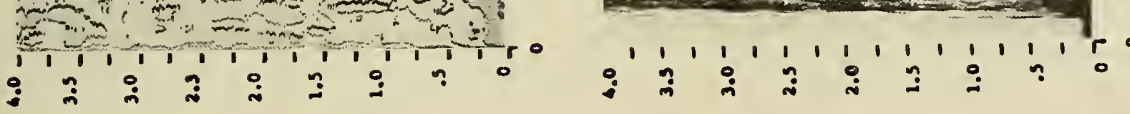

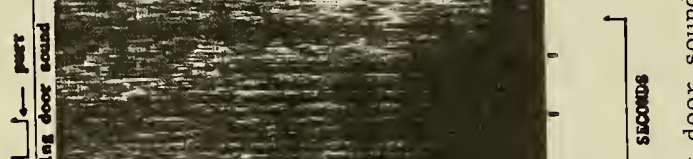

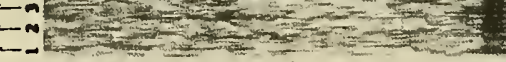

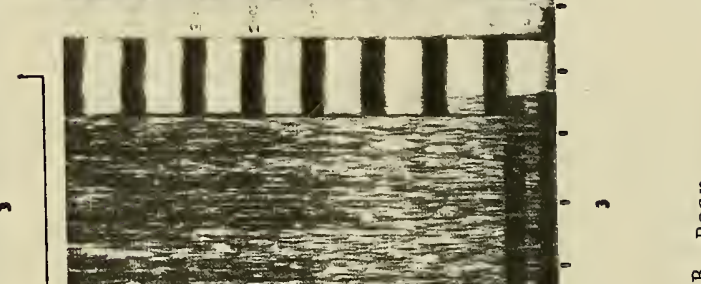
范 $\ddot{d}$
$\dot{a}$
$\dot{0}$
$\dot{0}$
$\dot{0}$ $\stackrel{\substack{c \\-1}}{-1}$

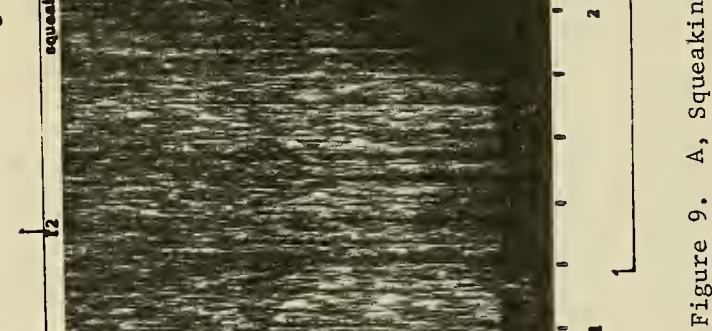

ํㅗㄹ

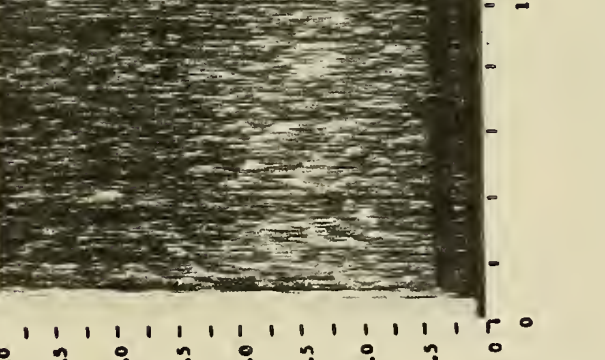


frequencies below $1000 \mathrm{~Hz}$ and attains a 30 decibel level at frequencies below $300 \mathrm{~Hz}$.

\section{Frog Sound:}

Qualitatively, this sound, which on the basis of efforts during several night dives we suspect emanates from $\mathrm{H}$. ascensionis, is similar to the sustained chorus of a single frog. It could also be compared to the frequent honking of a small bulb horn similar to those used on bicycles.

The individual pulses comprising the "honks" or "croaks" (Figure 10A) are bimodal where energy expenditure is concerned possessing peaks at 400 and $700 \mathrm{~Hz}$. The modes are more discrete than the two modes of the staccato sound apparently produced by the same fish. In other words, the amplitude falls off faster up and down the frequency scale from the peaks in the frog sound than in the staccato. The lower frequency peak appears to be the stronger of the two and in three instances rises $24 \mathrm{db}$ above the background. The staccato sound represented at the end of the frog sequence demonstrates a definite similarity to the frog sound in structure but differs as pointed out above and also in the fact that the amplitude modes are slightly higher in frequency. In addition, the individual pulses of the staccato are of shorter duration and are grouped together whereas those of the frog sound are solitary.

The bimodal frog sounds in some cases, viz., sounds 3 and 4, show a preliminary short pulse at about $400 \mathrm{~Hz}$. Whether this is truly a part of the sound or a coincidental occurrence is not yet clear.

Grunts :

Figure $10 B$ represents a series of 10 grunis produced by a Nassau Grouper, Epinephelus striatus, which had been disturbed and was in the process of flight. After the 10 th, the grunts seem to degenerate into a sequence of staccato-1ike sounds of lower intensity. The grunts are simple, possessing a single energy peak at $200 \mathrm{~Hz}$. They are strong sounds rising $42 \mathrm{db}$ or more above quietest background.

Preceding and following the gi. ting sequence, bubble noises from the experimenting diver are apparent, as is the scrape of the diver's hand contacting the substrate when startling the grouper.

Rasps:

The Spiny Lobster, Panulirus argus, frequents the reefs and isolated coral heads in the vicinity of the habitat. Although the lobster is known to produce rasping sounds when disturbed, we did not attempt to audition the species during our mission due to possible interference with another study in progress at the time. Later, however, in the Florida Keys, we did obtain recordings of the distress sounds while operating from a $14 \mathrm{ft}$. skiff near Hen and Chickens Reef.

The frequency range of these squeaking rasps is quite wide, extending from below $80 \mathrm{~Hz}$ to above $10,000 \mathrm{~Hz}$. The maximum energy expenditure (Figure 11B) is at the low frequencies, below $500 \mathrm{~Hz}$, and tapers gradually up scale. The rasps are composed of a variable number of discrete pulses. In Figure 11A the three 


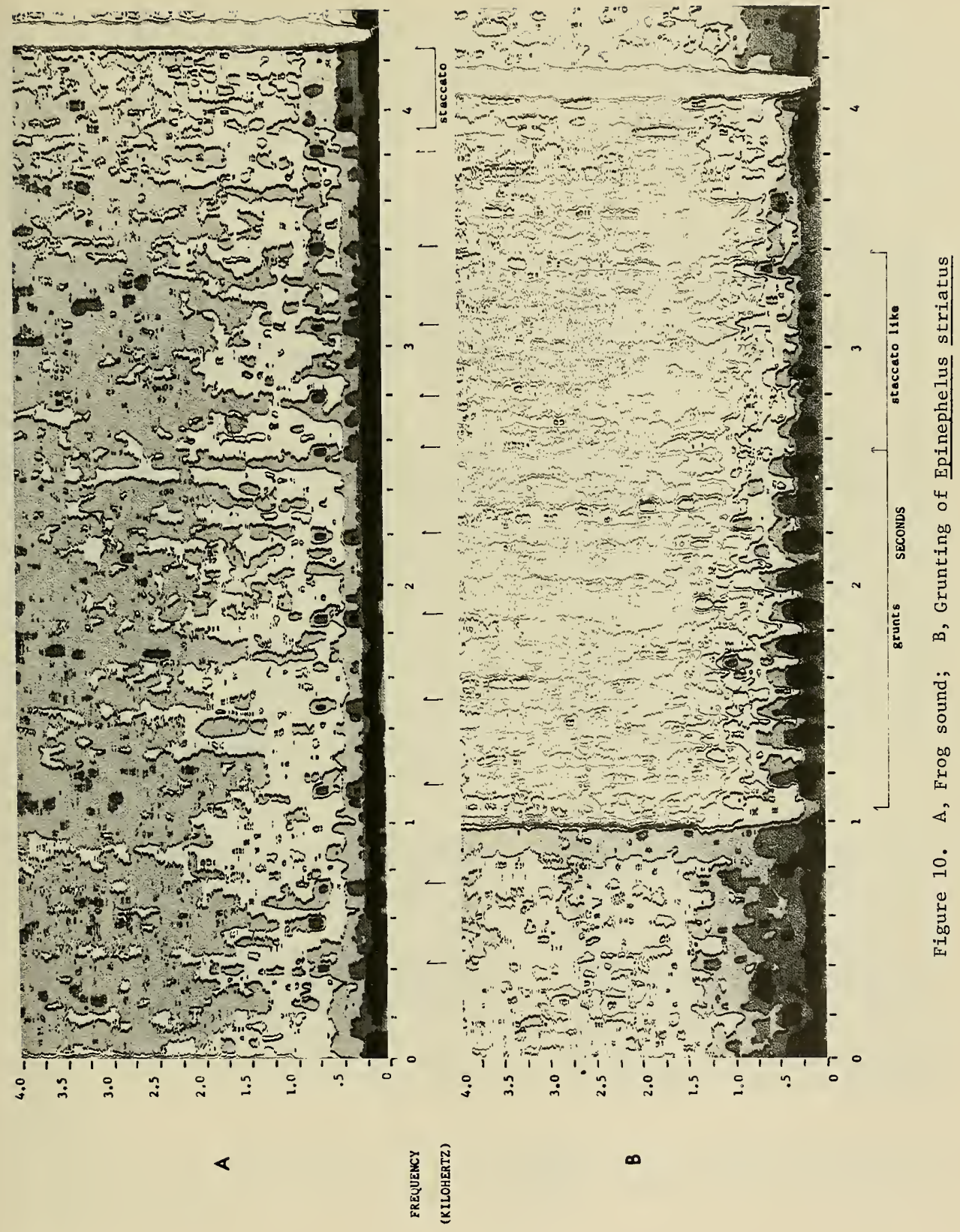




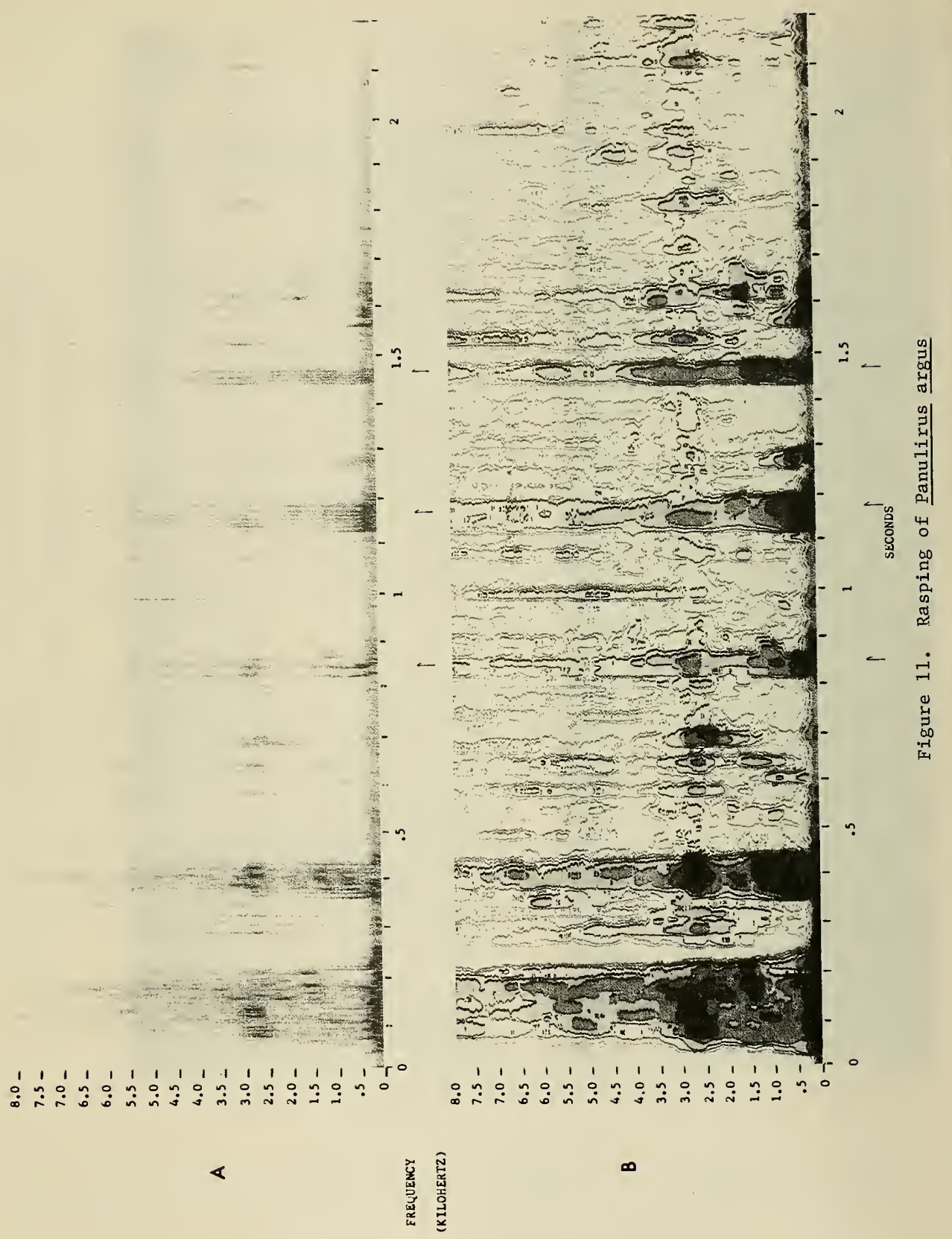


sounds in the center of the sonogram are composed of 2, 7, and 5 pulses each. It is obvious that the time between pulses can be varied by the lobster, .02 $\mathrm{sec}$. in one case and less than half that in others. The duration of each sound is, therefore, dependent upon time between pulses and number of pulses emitted.

Adventitious Fish Sounds

Crunches:

Parrotfishes (Scaridae), surgeonfishes (Acanthuridae), and a number of other "grazing" fishes customarily produce crunching sounds in the process of biting epifaunal organisms from the reefs or other hard surfaces. The sound analyzed in Figures 12A and $\mathrm{B}$ is apparently due to the feeding activities of a parrotfish although we have not yet determined the specific differences in spectral or temporal structure between such feeding sounds produced by various species of fish.

The crunches analyzed here are characterized by a relatively b oader range of component frequencies than the purposeful sounds discussed earlier. Most of the acoustical energy, however, seems concentrated below $4000 \mathrm{~Hz}$. A comparatively great amount of variation in the frequencies of maximum energy expenditure between pulse components of the .15 second long crunches is apparent. Each such pulse is 1ikely a result of the momentary impact of the fishes teeth upon the hard substrate across which they are being dragged. Such frequency variations are, therefore, not unexpected in view of the irregular nature of the substrate being scraped and the probable instantaneous variation in velocity at which the teeth are traveling across the substrate from start to finish of a crunch. It is likely also that at times during the scraping process certain parts of the tooth complex are not even in contact with the substrate while other parts are. Al1 this results in the production of a series of irregularly spaced pulses which vary considerably in frequency structure and result in rather disorganized crunching sound.

Swooshing Crunch:

This sound, which also can be likened to the crack of a low calibre rifle, is a result of the lunge of a Trumpetfish, Aulostomus maculatus, in an effort to seize prey. This fish often drifts vertically, head down, over the reef, occa sionally lunging downward after small fish or crustaceans. The sound thus produced is variable to some extent but basically as represented in Figure $13 \mathrm{~A}$. The first of the two temporal components of this sound appears to be trimodal with respect to energy expenditure with peaks at approximately $700 \mathrm{~Hz}, 300 \mathrm{~Hz}$, and below $40 \mathrm{~Hz}$. This would imply a complex source for the sound involving possibly three generating mechanisms. The $300 \mathrm{~Hz}$ mode rises $30 \mathrm{db}$ or more above quietest background. The second temporal pulse, which lends a ricochet-like quality to the sound, is simpler, having only one amplitude maximum at around $500 \mathrm{~Hz}$.

Both pulses are somewhat obscrured ir. the 300 to $500 \mathrm{~Hz}$ range by noise emanating from air compressors, blowers, pumps and other equipment associated with the underwater habitat. 


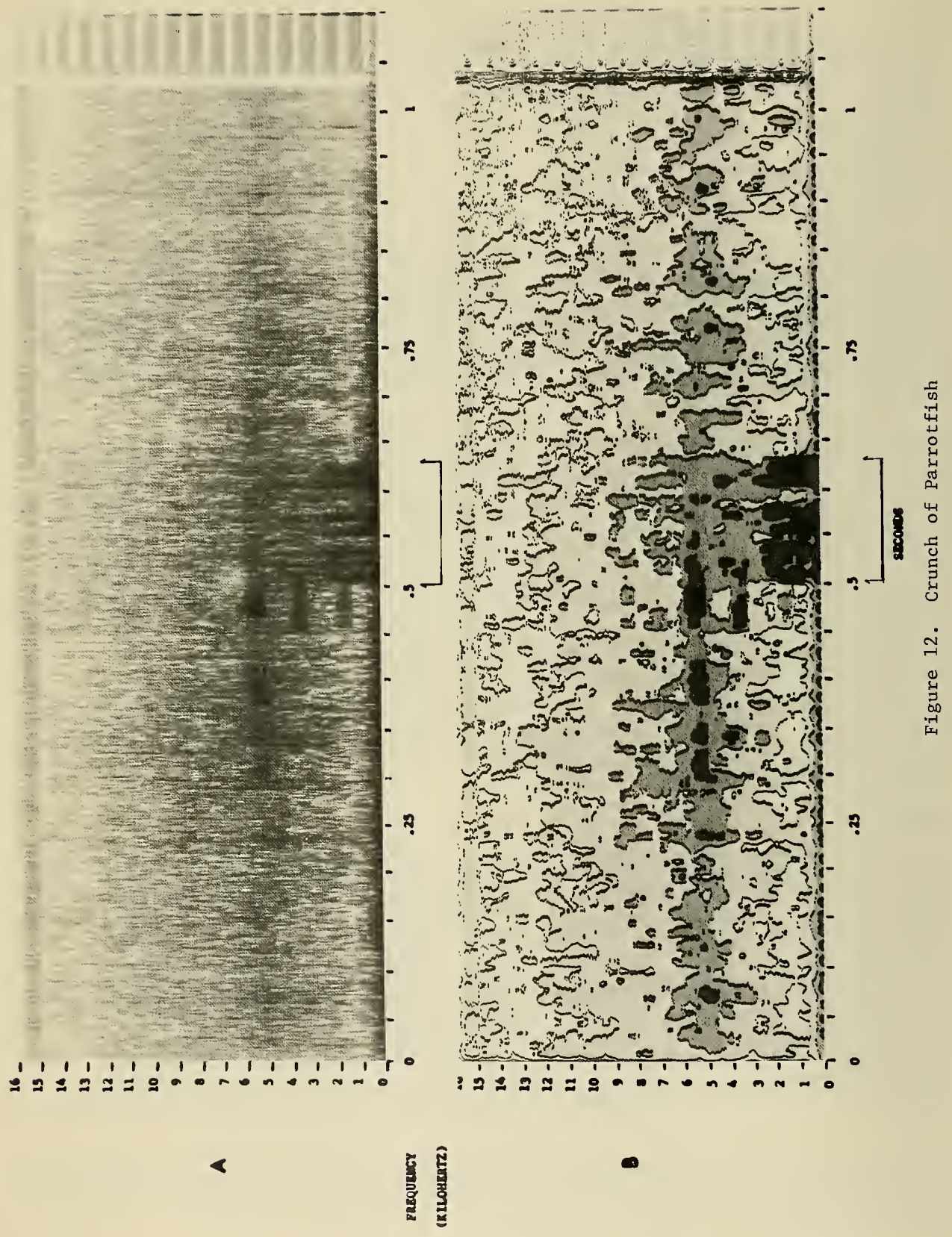


$\left.x^{2}+2+2\right]$

gerpar,

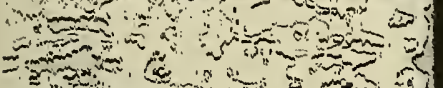
is

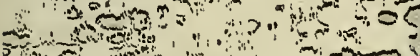
and a $40+20$

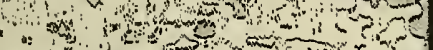
$x=0$

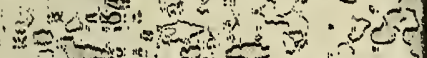

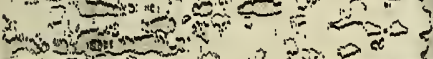

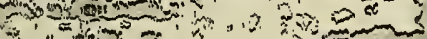
" : 0 , a 政

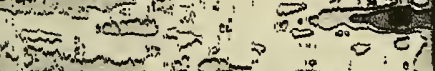
$0=0$ $4=-70-2 E_{0}=5$

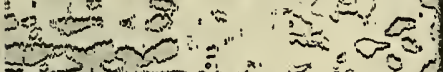
ard

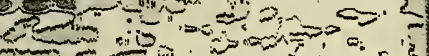
皮 3

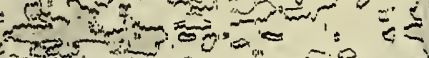

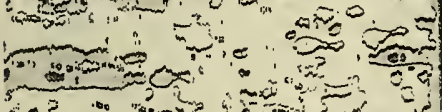
$00^{2}-0^{2}+x^{2}-x^{2}=0$

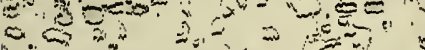
(a)

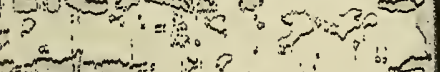

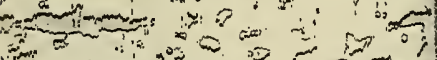
$=0$ and

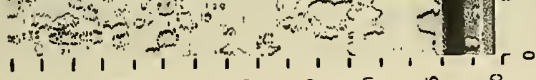
j

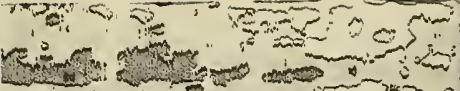

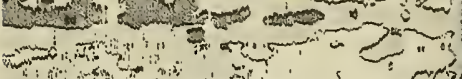
Y) , क : औ 172. 1" .

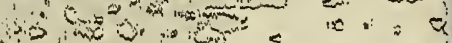
a

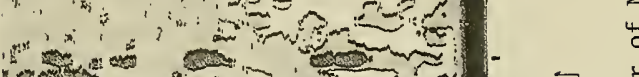
ati 30 2.

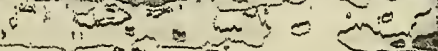
(n) arsin

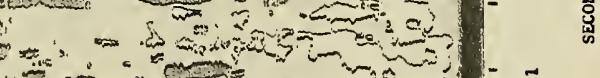
in ;: : 20 :

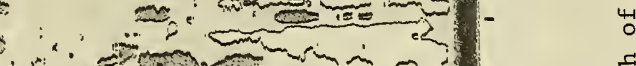
$\therefore$.

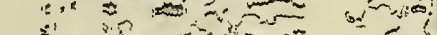

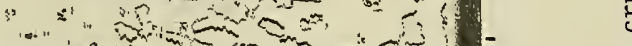
1:

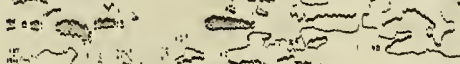

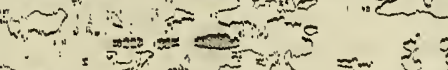
$=3=0=0$ $\therefore, 0$ तो * $\rightarrow>\rightarrow x^{2}$ (n) 1) $p:$ is

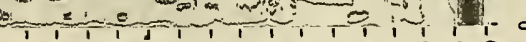
๓

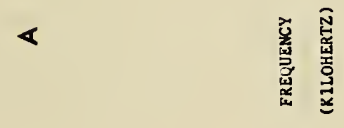


During aggressive displays involving apparent territorial defense and/or chasing, violent movements of the fishes bodies and fins create a disturbance accompanied by fluttering sounds. We successfully recorded many such sounds in the case of the Blackbar Soldierfish, Myripristis jacobus. This fish customarily hovers above a particular coral head in a more or less constant location, turning back and forth to keep its head toward the direction of the surge. Occasionally when a fish of the same or another small species approaches too closely, a fluttering chase will ensue and the invader will retreat. Figure 13B illustrates one of these flutters. The region of maximum acoustical energy for the flutter sound is partially obscured by the habitat noise between 100 and $500 \mathrm{dbs}$. Nevertheless, it is apparent that the last two of the five basic pulses comprising the flutter reach $30 \mathrm{db}$ above the quietest background detected. Pulses $1,2,4$, and 5, therefore, demonstrate an energy maximum at about $300 \mathrm{~Hz}$ with recognizable components ranging from below $100 \mathrm{~Hz}$ to nearly $2000 \mathrm{~Hz}$. Pulse 3, however, demonstrates an energy maximum at about $800 \mathrm{~Hz}$ and apparent1y lacks the pronounced lower frequency structure of the other four pulses. Fluttering sounds such as this can be expected to demonstrate a great deal of variability and it is unlikely we will find any two exactly alike.

\section{CONCLUS IONS}

The sounds associated with coral reefs in the vicinity of Lameshur Bay, St. John, U.S. Virgin Islands, predominate in a frequency range below $6000 \mathrm{~Hz}$. The most conspicuous sounds, background clicking and crackling and frying pan-like noises, are quite energetic at 3500 and $5500 \mathrm{~Hz}$. The often equally important chorus of larger squirrelfishes, $\underline{\mathrm{H}}$. ascensionis, and possibly $\underline{\mathrm{H}}$. rufus, expend maximum energy at much lower frequencies, 200 to $600 \mathrm{~Hz}$.

Definite cyclical patterns are evident for certain conspicuous sounds, vis., squirrelfish chorus and frog-like sounds, whereas the clicking and crackling, attributed at present to the activities of snapping shrimp and physical occurrences, demonstrate not as yet definable periodicity. Periodicity also seems less pronounced in the case of some of the less evident purposeful sounds. An in-depth consideration of the cyclical aspects of the various sounds described herein must await further analysis.

Most of the sounds possess distinctive frequency, amplitude and temporal relationships which may serve to distinguish them when analyzed with the aid of a sound spectrum analyzer. Some sounds, particularly staccatos and pops, pulses of which appear very similar and almost indistinguishable to the unaided ear, are obviously separable upon examination of their respective sonograms. On the other hand, sounds easily distinguished by ear (frog-like sound vs. staccato) appear quite similar on sonograms but still separable due to subtle variations in frequency amplitude relationships.

Most of the sounds are obviously associated with some behavioral occurrence or activity pattern, viz., feeding crunches of Parrotfish, lunging swooshing crunch of the Trumpetfish, flutter of the Blackbar Soldierfish chase, popping, quacking and squeaking door sounds of the Longspine Squirrelfish-Reef Squirrelfish relationship, grunts of alarmed Groupers, etc. Many of these situations are yet to be investigated in detail. It is felt that, when well understood, the behavior 
related sounds, whether purposeful or adventitious in nature, will become very useful tools in monitoring activity patterns and occurrences upon the reef.

An amplitude heirarchy of acoustical phenomena associated with the reef can be erected if one resists the impulse to relegate sounds to discrete categories and recognizes only that there is a continuum of sounds varying in the degree of conspicuousness from nearly unnoticeable to deafening. Clicking and crackling is pervasive and extremely audible at all times of the day. These sounds are easily detectable by a diver's unaided ear. At night, the squirrelfish staccatos and coos often rival the clicking and crackling but are generally of inferior amplitude when heard from a distance of over 100 feet. Certain other cyclical sounds, specifically the frog-like sounds, are audible at a moderate distance from the source but tend to be more localized in nature and do not possess the pervasiveness of the previously mentioned sounds. The degree of pervasiveness of the sounds is likely a reflection of the population distribution of the sound producers on the reef.

Sounds of a more individualized or singular nature tend not to be as conspicuous as the more pervasive ones. Many, however, are easily detected by a diver providing he is within a few meters of the source. Parrotfish, Trumpetfish, and Surgeonfish crunches are particularly good examples of this as are Grouper grunts, Spiny Lobster sounds and disturbances perpetrated by large predators chasing prey. Other sounds appear to be generally detectable only with the aid of electronic devices or upon extremely careful listening by the unaided diver. Flutters associated with chase or escape of small fishes during aggressive encounters, scrabbling sounds of deposit feeders such as goatfishes, purposeful pops, quacks, and various other sounds produced by very small fishes living under coral heads or in holes account for many of these nearly inaudible sounds. Generally, in order to detect and record such sounds, the hydrophone must be placed within a few feet of the source.

The study of the bio-acoustical phenomena detected by us and their relationship to the ecology and ethology of the coral reef community has just started. This report represents only the first phase of analysis of the data collected during the 20-day mission. We anticipate another year of analytical work before we will have abstracted most of what is meaningful from the data collected during that time. It is evident that in the future our experiments and data gathering techniques will have to be carried out in a manner compatible with computerized analysis.

\section{ACKNOWLEDGEMENTS}

In addition to aid received directly from the TEKTITE II Program, support for this project was supplied through the Texas A\&M University Sea Grant Program, Texas A\&M Organized Fund, and the Office of Naval Research. 


\section{COMPARATIVE STUDIES OF SUBTIDAL VEGETATION IN THE \\ VIRGIN ISLANDS AND THE NEW ENGLAND COASTLINES}

Arthur C. Mathieson, Richard A. Fralick, Richie Burns and William Flahive*

Department of Botany and the Jackson Estuarine Laboratory of the University of New Hampshire, Durham, N. H.

\section{ABSTRACT}

A comparison of the species composition and vertical distribution of algae in New England and the Virgin Islands is given. The depths at which maximum species numbers were recorded in the Virgin Islands corresponded to depths of minimal species numbers in New England. Light is considered to be a major factor causing the differential displacement of the two floras, while availability of solid substrate is of secondary importance. The subtidal flora of New England is primarily composed of red and brown algae, while green and red algae dominate in the Virgin Islands.

Fish grazing is a major factor influencing the species diversity and biomass of algae in shallow subtidal waters in the Virgin Islands. A diminutive flora is available in the vicinity (depth) of a coral reef, with its extensive populations of herbivorous $\mathrm{fish}$, and there is a significant increase in plant material with increased linear distance (to 117-165m) from a reef. Reduced grazing pressure was apparent at about $30 \mathrm{~m}$ from a reef, and it caused a corresponding increase in plant materials. A series of cage experiments was conducted to exclude herbivorous fish grazing. Although the experiments were of limited duration (19 days) and the mesh screen employed $\left(1.3 \mathrm{~cm}^{2}\right)$ was too large to exclude many of the smaller fish, an increased diversity and abundance of plants were recorded under two cages. Transplant studies of selected plants were made from the sea grass beds to the coral reefs near the habitat. Many of the plants were rapidly eaten (particularly Halimeda incrassata) by the reef fish, and there was a general correlation between the linear distribution of algae on the sea grass beds and the feeciing preferences of fish. Thus, selective grazing of plants may occur. Even so, all of the species present from $2.4-30 \mathrm{~m}$ from a reef were exposed to heavy grazing pressure, and they exhibited either an increase in size or abundance with increased linear distance from a reef.

*Richie Burns and William Flahive were support personnel for the botanical studies of Mission 4-50. 
The major objectives of the botanical studies of Mission 4-50 were as follows :

(1) To provide a detailed quantitative evaluation of the species composition, distribution and abundance of the subtidal seaweeds of Great Lameshur Bay.

(2) To evaluate (in general terms) the effects of fish grazing on seaweed populations around the habitat.

(3) To compare and contrast the subtidal flora of the Virgin Islands (an area which is well known intertidally) with those of New England, where we are presently conducting detailed seasonal observations.

(4) To compare the efficiency of a surface team and a habitat team while conducting identical work.

\section{EQUIPMENT}

Metered transect 1ines, a 200-foot metal tape measure, a $0.6 \mathrm{~m}^{2}$ guadrant frame and several metal cages $\left(0.9 \mathrm{~m} \times 0.6 \mathrm{~m} \times 0.45 \mathrm{~m}\right.$ and of $1.3 \mathrm{~cm}^{2}$ mesh hardware cloth) were employed in the field investigations. A drying oven and an analytical balance were employed (by our support personnel) to determine the dry weight of plant materials. The identification of seaweeds was made (in the habitat) with a research grade binocular microscope.

\section{DESCRIPTION OF TRANSECTS AND STUDIES}

Prior to entering the habitat, we made a number of preliminary collections and observations of the subtidal vegetation in the vicinity of Great and Lesser Lameshur Bays. In addition, we established two $180 \mathrm{~m}$ transect lines in the vicinity of the habitat. The lines were marked off at $3 \mathrm{~m}$ intervals, and the distance from the reef (designated as zero $\mathrm{m}$ ) was recorded. The transect lines were held in position by driving pitons into the substrate. Transect 1 was oriented at $240^{\circ}$ from the reef near the diving platform. Its depth varied from $12.4-18.7 \mathrm{~m}$, between $120 \mathrm{~m}$ to $180 \mathrm{~m}$ was relatively flat (Fig.1). Transect 2 was oriented at 2780 from the reef, due west of the habitat. Its depth varied from $17.3-21.5 \mathrm{~m}$ (Fig. 1). Transect 2 showed a more uniform distribution of depths than 1 . Both transect lines were established on sandy flat areas (algal plains) below the coral reefs. An area of scattered patch reef was found on both transects from about $0-13.5 \mathrm{~m}$. Thereafter, only a few isolated coral heads, rocks or shells were present. Table 1 summarizes the composition of the sand grains on transect 2. The substrate was very silty towards the end of the transect. Although it is not illustrated, transect 1 did not show such a gradation. Most of our field work from the habitat was conducted on transect 2. Transect 1 was monitored by two support divers from the surface. The following types of studies were conducted on the transects: 


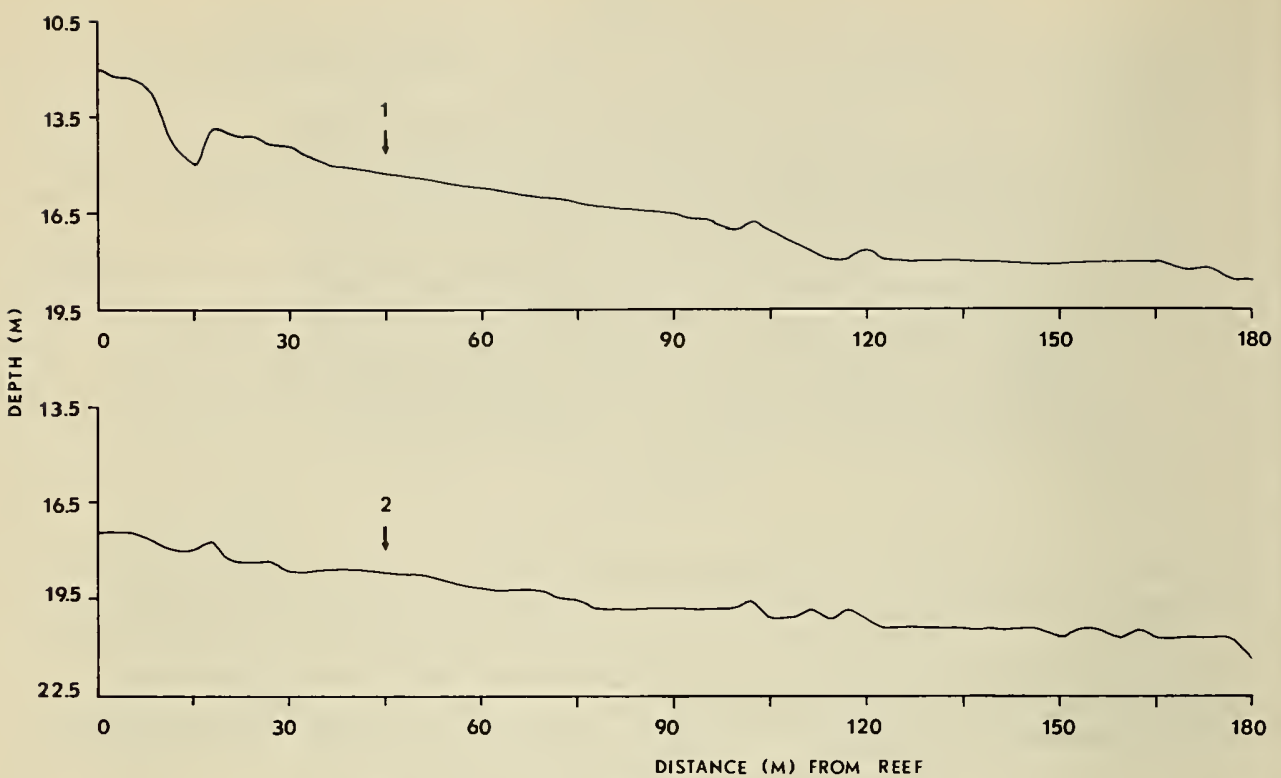

Figure 1. Depth Profiles on Transects 1 and 2

Table 1. Size Distribution of Substrate on Transect 2

Size $15 \mathrm{~m}$ $45 \mathrm{~m}$

\section{2}

52.4

39.6

$2.6 \%$

$1000-500 \mathrm{~m} \quad 7.2$

$500-297 M-$

$297-250 \mu-$

$250-210 N-$

$210-125 \mu-$

4
$75 \mathrm{~m}$ $105 \mathrm{~m}$ $135 \mathrm{~m}$ $165 \mathrm{~m}$ $180 \mathrm{~m}$

$$
4.1
$$

4.9

3.1

5.3

4.7

29.7

62.3

20.0

19.6

20.3

57.9

27.3

34.1

$40.2 \quad 33.0$

\section{2}

4.4

28.7

33.1

39.3

$\begin{array}{ll}- & 1.1\end{array}$

1.4

2.1

$-$

$-$

.03

.50

VI-108 
(1) Depth profiles were established relating linear distance from the reef and depth.

(2) A quadrant frame $\left(0.6 \mathrm{~m}^{2}\right)$ was employed for quantitative analysis of the vegetation along the transect lines. The species composition, per cent occurrence, size and/or standing crop (grams dry weight $/ 0.6 \mathrm{~m}^{2}$ ) of the plants within the quadrants were recorded at approximately $15 \mathrm{~m}$ (transect 1) or $9 \mathrm{~m}$ (transect 2 ) intervals. The plant materials were sorted and identified in the habitat, and then dried and weighed by the two support personnel.

(3) A series of cages (see above section for dimensions) was placed at different intervals $(3,60,120$ and $180 \mathrm{~m})$ along transect 2 , in order to exclude fish grazing and evaluate the regrowth of seaweeds.

Prior to positioning the cages, a $0.6 \mathrm{~m}^{2}$ area was denuded and retained for evaluation of species composition and biomass. The cages were fixed so that $0.3 \mathrm{~m}^{2}$ of the denuded area was within the cage.

Two other studies were conducted from the habitat. The first was an extension of the quadrant studies. A $15 \mathrm{~m}$ rope was drawn out perpendicular to the line transect (transect 2), with $7.5 \mathrm{~m}$ north and south of the line. Observations were then made in a rectangular area of $15 \times 9 \mathrm{~m}$ or $135 \mathrm{~m}^{2}$. The shortest dimension of the rectangle (i.e., $9 \mathrm{~m}$ ) was oriented along the transect line from east to west. Twenty separate $15 \mathrm{x} 9 \mathrm{~m}$ areas were studied from $0-180 \mathrm{~m}$. Representative samples of all the different species present within an area were collected for subsequent identification and enumeration. In addition, approximately 100 specimens of several larger algae (i.e., Udotea conglutinata, Avrainvillea nigricans and Halimeda incrassata) were collected to determine the length of their thalli. After all of the previous studies were completed, selected specimens of algae from the sandy flat area were transported to the reef in order to observe the feeding habits and/or specificity of the reef fish.

\section{NUMBER OF SPECIES AND BIOMASS AT VARIOUS DEPTHS}

Figure 2 is a comparative illustration of the number of subtidal species found at different depths in the Virgin Islands and in New England. The depth distribution curve for the former area is a compilation of over 40 dives in Great Lameshur Bay, and it represents a "typical" situation where a shallow water reef community is present. The New England information has been rpeviously summarized by Mathieson, Hehre and Reynolds (in press), and it is based upon three years of diving observations at Jeffrey Point, New Hampshire. Several points are obvious when one compares the two distributional curves. Foremost, there is a conspicuous reduction in species numbers in the immediate vicinity (depths) of the reef. Above and below the reef the species numbers are higher. A conspicuous increase in species was evident from $13.5-19.5 \mathrm{~m}$. No reduction in species numbers was recorded in shallow waters of nearby locations which lacked coral reefs (e.g., Lesser Lameshur Bay). The distributional 


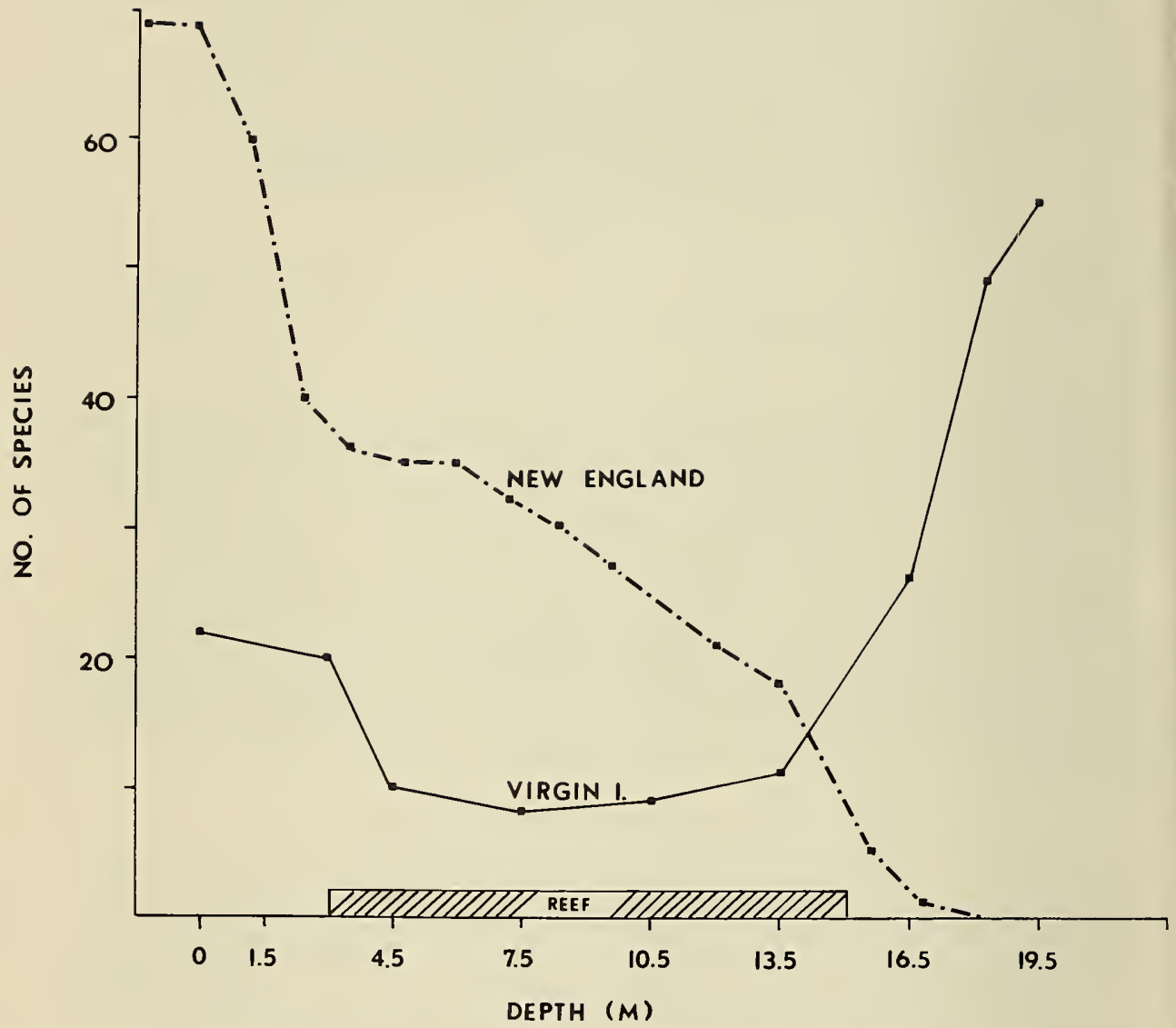

Figure 2. Number of Species at Various Depths (m)

curve for New England is essentially the reverse of that for the Virgin Islands. The maximum number of species was found around the zero tide level and there was a consistent reduction in species numbers to $19 \mathrm{~m}$. A total of 71 species was found in the subtidal zone at Jeffrey Point, New Hampshire. Most of these species were red and brown algae; very few green algae were evident. In contrast, a total of 68 taxa were found in the sublittoral zone near the habitat (Table 2). Most 


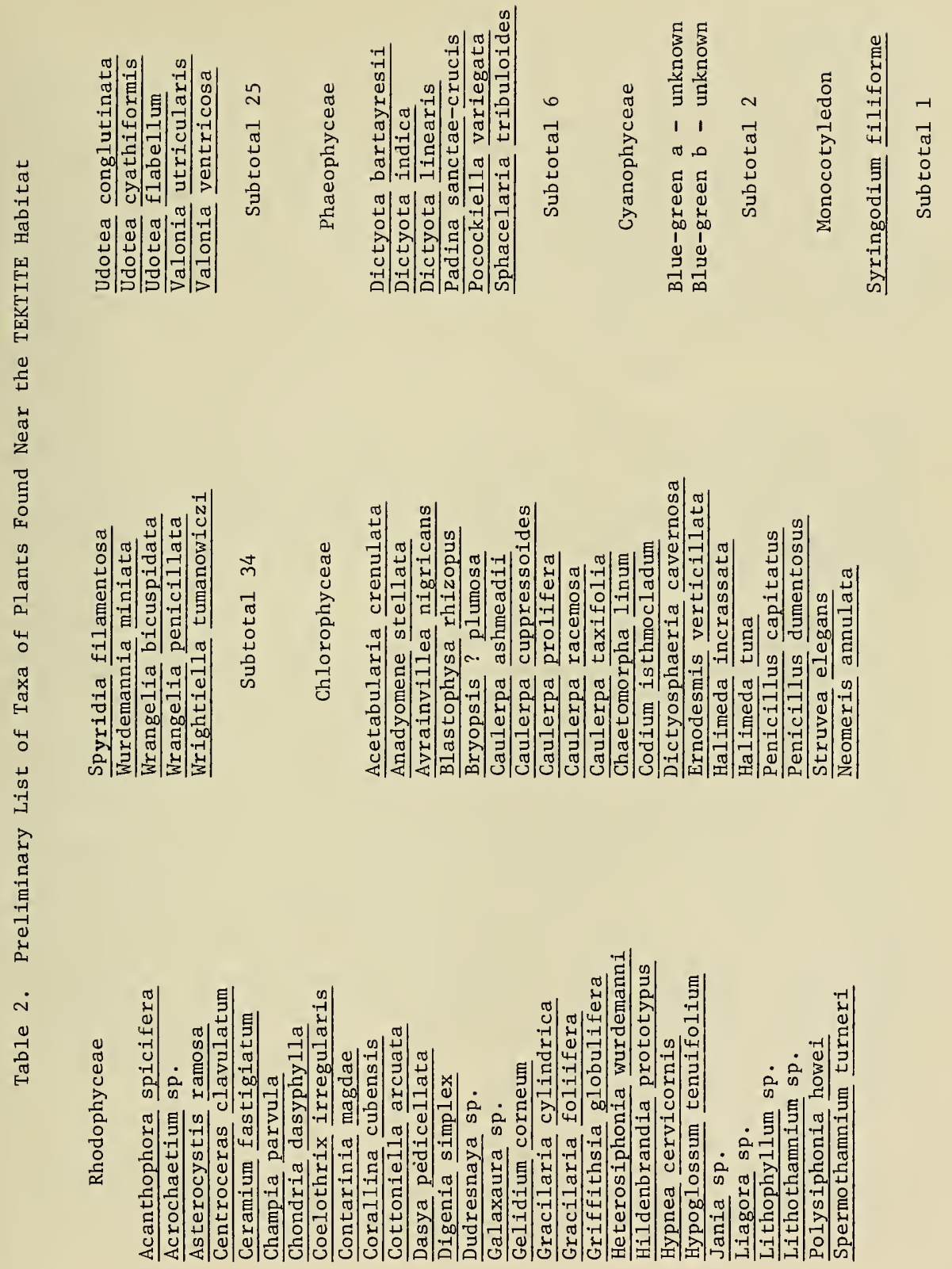


of these were red ( 34 taxa) or green algae (25 taxa). Six species of brown algae, 2 blue-green and one flowering plant (Syringodium filiforme) were also recorded.

Figure 3 illustrates the amount of biomass at different depths in the Virgin Islands. A wide range of measurements was found at similar depths and no consistent pattern was evident. Thus, the maximum $\left(467.6 \mathrm{~g} / .6 \mathrm{~m}^{2}\right)$ and minimum $\left(16.9 \mathrm{~g} / .6 \mathrm{~m}^{2}\right)$ biomass values recorded on transect 1 were found at the same depth. Similar trends were evident for transect 2. A summarization of algal biomass at various depths in New England is given in Figure 4. It is a compilation of 31 separate dives on the New Hampshire coastline. Again, a wide range of biomass readings was found. Even so, there was a peak area of production in $3-9 \mathrm{~m}$ and a significant reduction towards $12-15 \mathrm{~m}$.

\section{GENERAL PATTERNS OF LINEAR DISTRIBUTION}

Very few plants were found in the reef areas near the habitat. In most cases the algae were restricted to cracks and crevices and they were diminutive in size. The following species were recorded after an exhaustive search: Bryopsis plumosa, Neomeris annulata, Struvea elegans, Udotea conglutinata, Valonia ventricosa, Padina sactaecrucis, Pocockiella variegata, Sphacelaria tribuloides, Jania sp., and Wurdemannia miniata.

The perimeter of each reef examined in Great Lameshur Bay (particularly in the vicinity of the habitat) also showed areas in which no vegetation was evident. The barren areas varied in length from $2.4-3.7 \mathrm{~m}$. Thereafter, a transitional area was evident to about $30 \mathrm{~m}$, where sequentially the first plants occurred and there was an increase in both species diversity and biomass. Communities of unattached bluegreen-a and brown algae (Dictyota bartayresii) were the first plants to appear on the sandy flat areas of the transitional zones. Subsequently, the green algae Udotea conglutinata was evident. Of five areas measured, the barren zone extended between 1.5 to $3.7 \mathrm{~m}$ from the reefs. In four of the five areas, Dictyota bartayresii was the first species to occur between 1.5 to $3.7 \mathrm{~m}$. The second species to occur was bluegreen-a, between 3.2 and $6.7 \mathrm{~m}$. Udotea conglutinata was the third species to occur, generally between 6.0 and $9.0 \mathrm{~m}$. In the fifth area blue-green-a occurred at $3.4 \mathrm{~m}$ and Dictyota bartayresii was not found. Pocockiella variegata, Digenia simplex, Wurdemannia miniata, Dictyota bartayresii, Valonia ventricosa and Jania sp. were sometimes found as diminutive plants on scattered coral heads. Beyond the transitional areas, more extensive populations of sea grasses (Syringodium filiforme) and algae were evident.

\section{LINEAR DISTRIBUTION AND ABUNDANCE OF PLANTS ON QUADRANTS}

Tabulations of species distributions (with respect to distance from the reef) were made for about 70 species near the habitat. Figure 5 


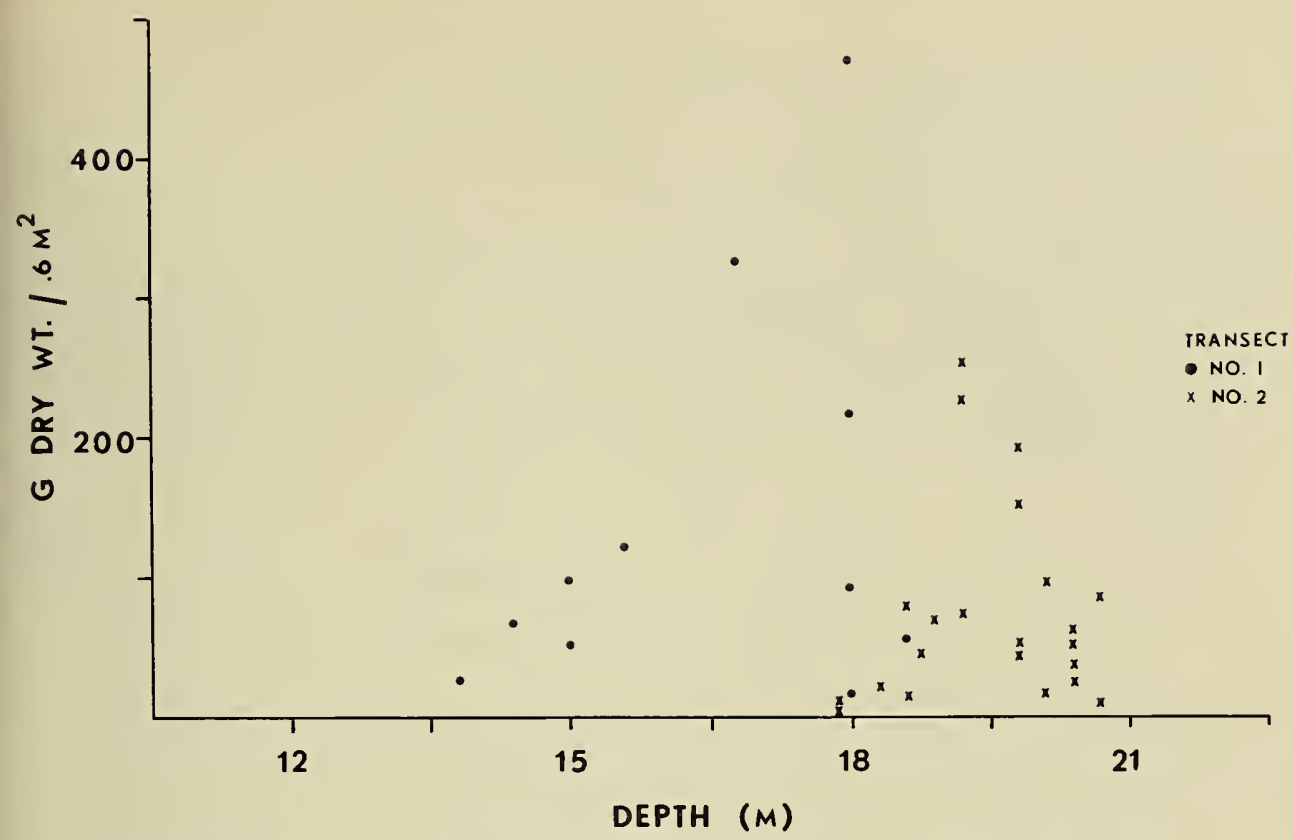

Figure 3. Algal Biomass at Different Depths - Virgin Islands

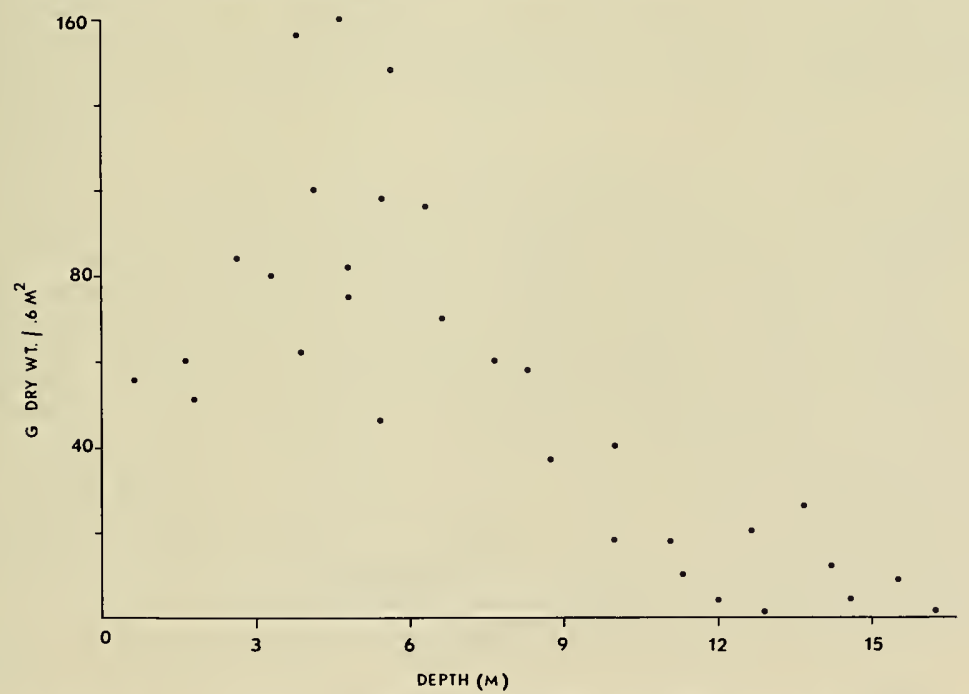

Figure 4. Algal Biomass at Different Depths - New England 


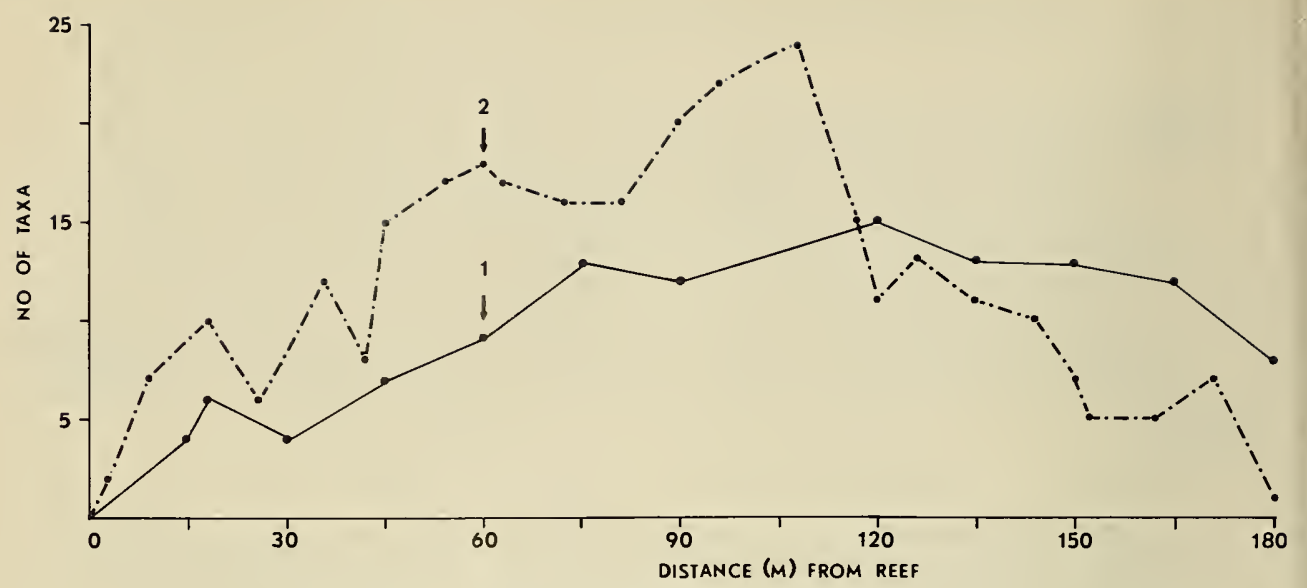

Figure 5. Number of Taxa on Transects 1 and 2

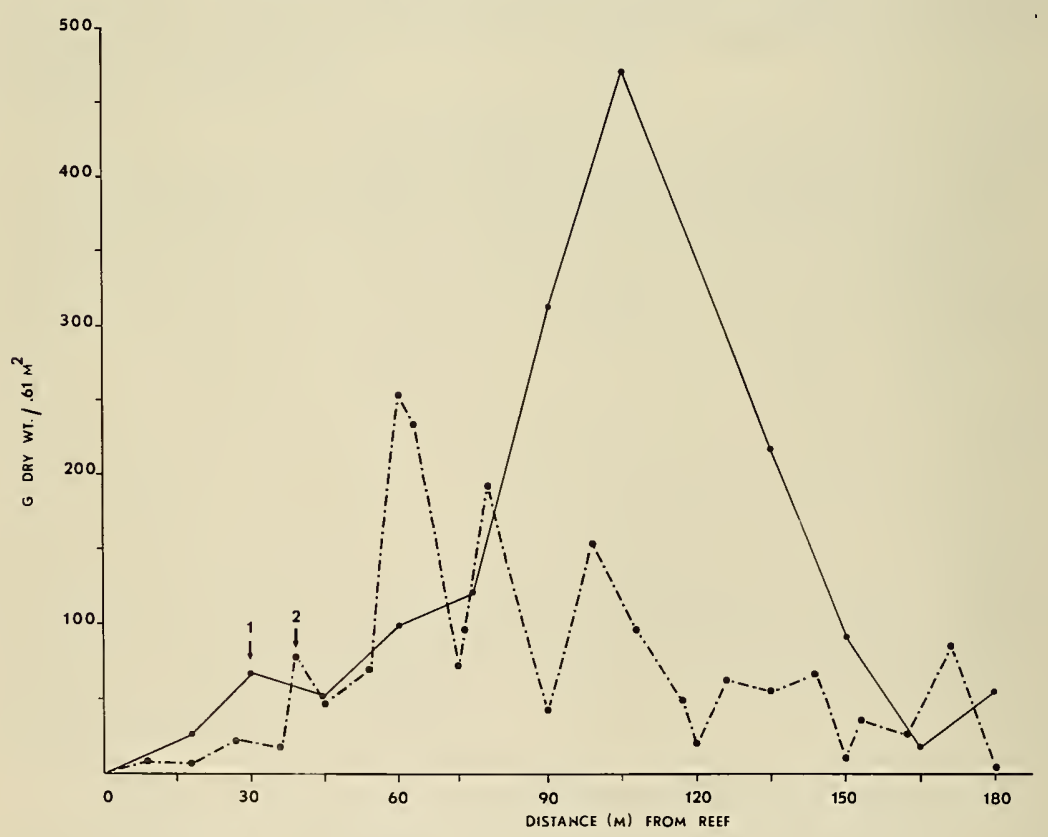

Figure 6. Biomass of Plants on Transect 1 and 2 
illustrates the number of taxa on transects 1 and 2. The species diversity increased with a linear distance to about $108-120 \mathrm{~m}$. On transect 2 the greatest number of species was found between $45-117 \mathrm{~m}$. A maximum of 24 taxa were recorded at $108 \mathrm{~m}$; thereafter, the species numbers decreased rapidly. Transect 1 showed a relatively uniform distribution between $75-165 \mathrm{~m}$. A maximum of 15 species were recorded at $120 \mathrm{~m}$, while 8 were still evident at $180 \mathrm{~m}$. Thirteen species found on transect 2 (Dictyota linearis, Acetabularia crenulata, Chaetomorpha linum, Penicillus capitatus, Coraliina cubensis, Cottonielia arcuata, Griffithsia globulifera, Hil denbrandia prototypus, Hypoglossum tenuifolium, Lithothanmium sp., Lithophyllum sp., Wrightiella tumanowiczi and Wurdemannia miniata) were not found on transect 1. Three species found on transect 1 (Caulerpa ashmeadi, Caulerpa cuppressoides, and Spyridia filamentosa) were absent on transect 2 . A comparison of the frequency calculations for the more common species on both transects shows that they are very similar.

Many of the species which had the widest distributions (i.e., the greatest frequencies of occurrence) on both transects also showed the highest percent coverage. In addition, many of the commonest species on both transects also showed comparable percent coverages (e.g., Pocockiella variegata, Anadyomene stellata, Avrainvillea nigricans, Caulerpa taxifolia, Halimeda incrassata, Udotea conglutinata, Udotea cyathiformis, Valonia ventricosa and Syringodium filiforme). However, other species (e.g., Chondria dasyphylla, Cottoniella arcuata, Jania sp., Wrangelia penicillata, Dictyota bartayresii and blue-green-a) showed obvious differences between the two transects. It should be noted that many of the latter species are microscopic. A comparison of the average percent coverage of each species for both the total number of quadrants evaluated and for each quadrant occupied indicates that many species had localized distributions on each transect. Such differences are reflected in variations in species composition on the two transects.

Transect 2 was much less productive than 1 (Figure 6). The biomass on transect 2 increased with linear distance from the reef to $60 \mathrm{~m}$, where a maximum of $252 \mathrm{~g} / .6 \mathrm{~m}^{2}$ was recorded. Beyond $60 \mathrm{~m}$ the biomass fluctuated greatly, but there was a significant reduction towards $180 \mathrm{~m}$ at which point only $10 \mathrm{~g} / .6 \mathrm{~m}^{2}$ was found. Transect 1 showed a substantial increase in biomass with linear distance to $105 \mathrm{~m}$, where $468 \mathrm{~g} / .6 \mathrm{~m}^{2}$ was recorded. Beyond $105 \mathrm{~m}$ the biomass decreased rapidly to $55 \mathrm{~g} / .6 \mathrm{~m}^{2}$ at $180 \mathrm{~m}$. A comparison of Figures 5 and 6 indicates that there is no clear-cut correlation between productivity and species diversity, for peak populations of species were not always associated with high values of biomass. In addition, even though transect 2 had more species than transect 1 , it was not as productive. It should be noted that many species which were restricted to transect 2 were either microscopic or small, crustose forms. Pocockiella variegata, Anadyomene stellata, Avrainvillea nigricans, Halimeda incrassata and Udotea conglutinata were the major contributors of biomass in the most 
productive areas of transect 1 . Pocockiella variegata, Halimeda incrassata and Udotea conglutinata were also very important on transect 2, but they were not present in the same abundance as on transect 1.

Table 3 and Figure 7 summarize the abundance of selected macroscopic plants on transect 2 , i.e., those which could be easily counted in the quadrants. Udotea conglutinata and Halimeda incrassata were the most abundant species. All of the other taxa occurred infrequently, and except for Avrainvillea nigricans, they contributed little biomass (compare Table 4). The abundance of Udotea conglutinata and Halimeda incrassata showed an interesting contrast. Thus, the number of Udotea plants increased substantially to $63 \mathrm{~m}$ where $188 \mathrm{plants} / .6 \mathrm{~m}^{2}$ were recorded. Thereafter, the number of plants decreased significantly and no specimens were found at $180 \mathrm{~m}$. In contrast, Halimeda incrassata was not found in the

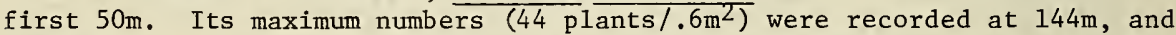
thereafter it decreased in abundance. It is of interest to note that only two specimens of Penicillus capitatus were found at the $180 \mathrm{~m}$ quadrant.

\section{LINEAR DISTRIBUTION AND SIZE OF PLANTS ON LARGER $\left(15 \times 9 \mathrm{~m}^{2}\right)$ STUDY AREAS}

Figure 8 illustrates the number of taxa of red, brown and green algae found in twenty rectangular areas $\left(15 \times 9 \mathrm{~m}\right.$ or $\left.135 \mathrm{~m}^{2}\right)$ located at different intervals along transect 2 (see previous procedures for details). Each one of the $15 \times 9 \mathrm{~m}^{2}$ rectangles sampled is represented in Figure 8 by the $9 \mathrm{~m}$ width. Conspicuous fluctuations of species numbers were evident along the transect. Even so, there was a broad band of high species diversity from $36-171 \mathrm{~m}$. A maximum of 38 taxa were found between $126-135 \mathrm{~m}$. The lowest number of taxa were found between $0-18 \mathrm{~m}$. The increase in number of species from $0-45 \mathrm{~m}$ corresponds with that shown in Figure 5. However, peak numbers of species were not found between 126 - $171 \mathrm{~m}$ in the quadrant studies (see Figure 5). The red and green algae were the major components on transect 2 (Table 4 ). Few brown algae were evident. It should be noted that no records of blue-green algae or flowering plants (Syringodium filiforme) are included in Figure 8 , but they are summarized in Table 4 . Even so, the maximum number of species shown in Figure 8 is 15 more than in Figure 5 . Seventeen species of red algae (Acrochaetium sp., Asterocystis ramosa, Centroceras clavulatum, Ceramium fastigatum, Champia parvula, Coelothrix irregularis, Contarina magdae, Dasya pedicellata, Dudresnya sp., Gelidium corneum, Gracilaria foliifera, Heterosiphonia wurdemanni, Hypnea cervicornia, Polysiphonia howei, Spermothamnium turneri, Spyridia filamentosa and Wrangelia bicuspidata), 9 green algae (Blastophysa rhizopus, Caulerpa cuppressoides, Codium isthmocladum, Ernodesmis verticillata, Halimeda tuna, Penicillus dumetosus, Struvea elegans and Udotea flabellum) and 3 brown algae (Dictyota indica, Padina sanctaecrucis, and Sphacelaria tribuloides) were recorded on the larger rectangular areas but not on the quadrants. Each species found on the quadrants 


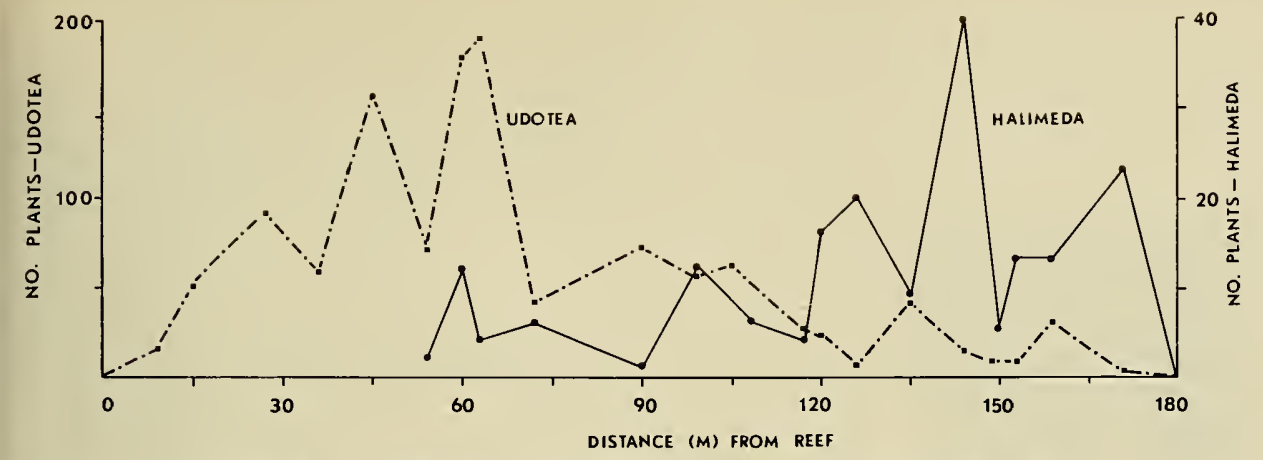

Figure 7. Number of Plants of Halimeda incrassata and
Udotea conglutinata on Transect 2

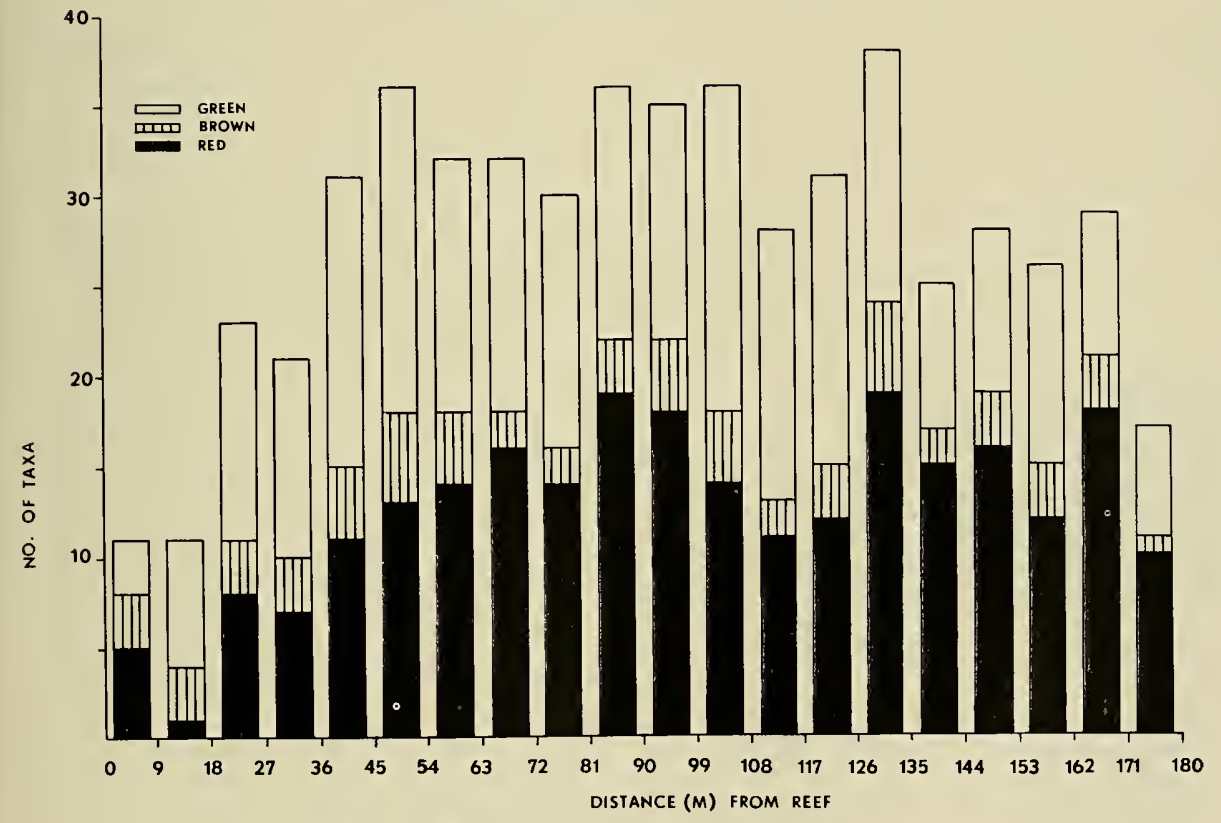

Figure 8. Number of Taxa of Red, Brown and Green Algae Found in $15 \times 9 m$ Rectangular Areas 
Table 3. Number of Plants/Quadrant on Transect 2

Acetabularia crenulata Avrainvillea nigra Gracilaria cylindricum Halimeda incrassata Penicillis capitatus Udotea cyathiformis Udotea conglutinata Valonia ventricosa
Acetabularia crenulata Avrainvillea nigra Gracilaria cylindricum Halimeda incrassata Penicillis capitatus Udotea cyathiformis Udotea conglutinata Valonia ventricosa

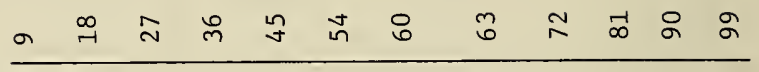

$\begin{array}{cccccccccccc}1 & 1 & 1 & 1 & 2 & & & & & & \\ & & & & & 2 & 6 & 3 & & & \\ & & & & & 2 & 12 & 4 & 6 & 1 & 12 \\ & 1 & & & & & 3 & 2 & & 2 & \\ & & & & 1 & & & & & & \\ 16 & 51 & 90 & 58 & 157 & 70 & 177 & 188 & 41 & 72 & 56 \\ 1 & & & 6 & & 5 & 4 & & 16 & 11 & 7\end{array}$

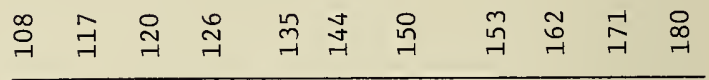

$\begin{array}{lllllllllllll} & 2 & & 1 & & & & & & & \\ & & & & & & & & & & & \\ & & 4 & 16 & 20 & 9 & 40 & 5 & 13 & 13 & 23 & \\ 1 & & & & & & 2 & & & & 2 \\ 1 & & & & & & 2 & & & & \\ 61 & 25 & 22 & 6 & 42 & 14 & 9 & 8 & 30 & 3 & - \\ 3 & & & & & & & & & & \end{array}$

VI-118 


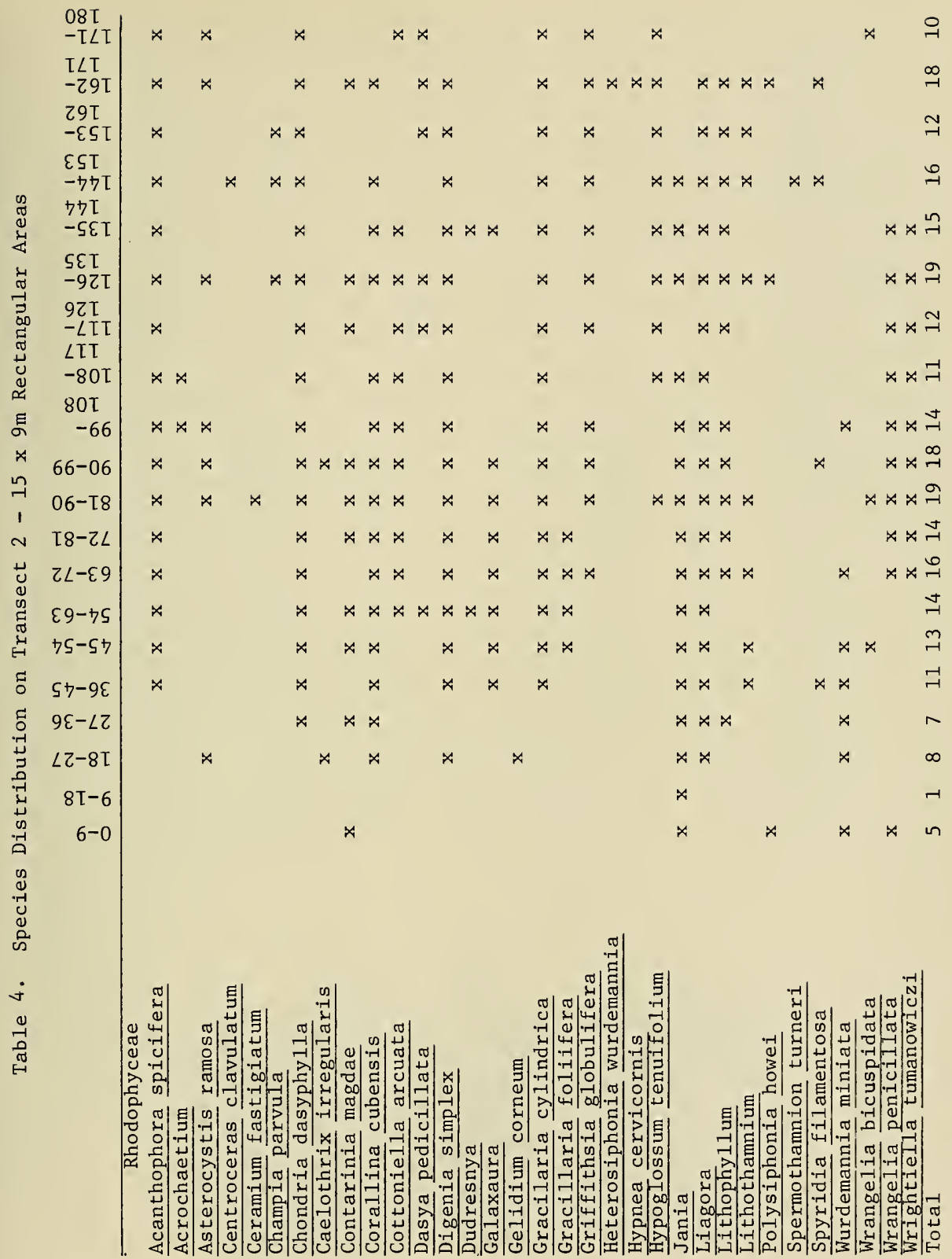




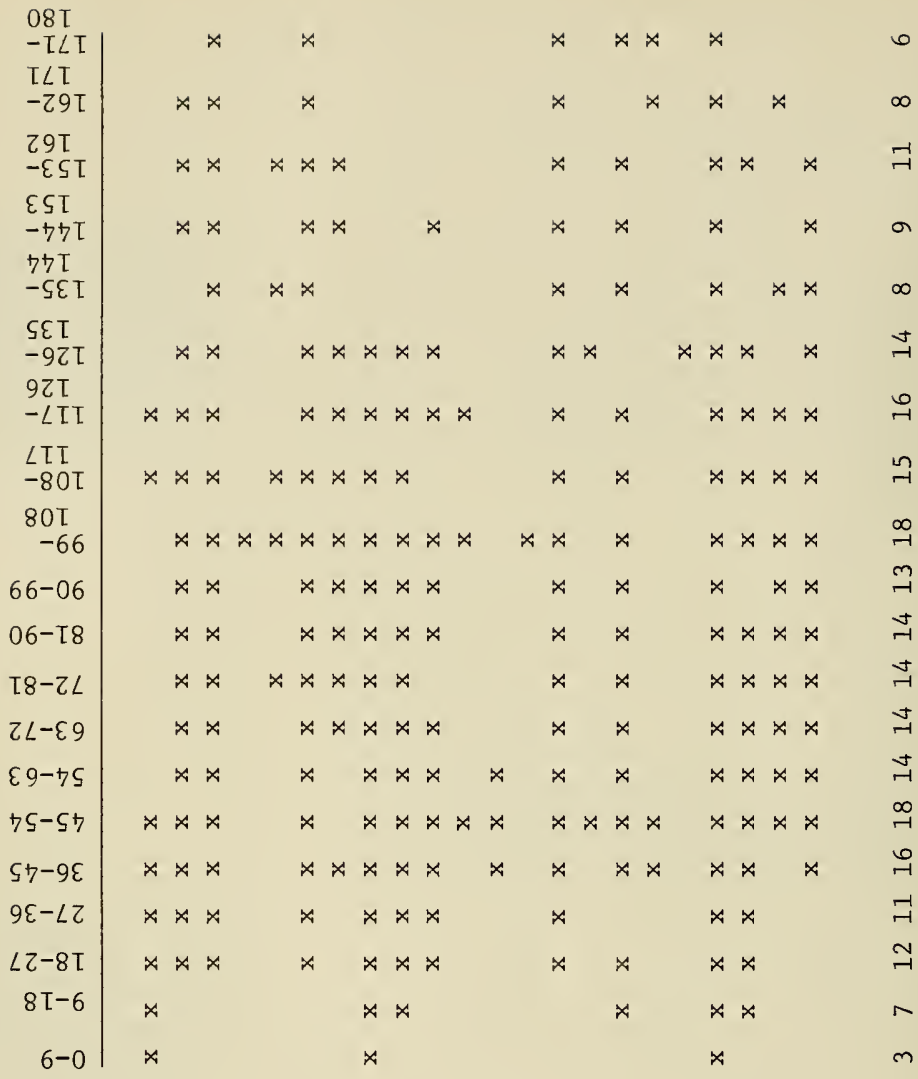

تิ

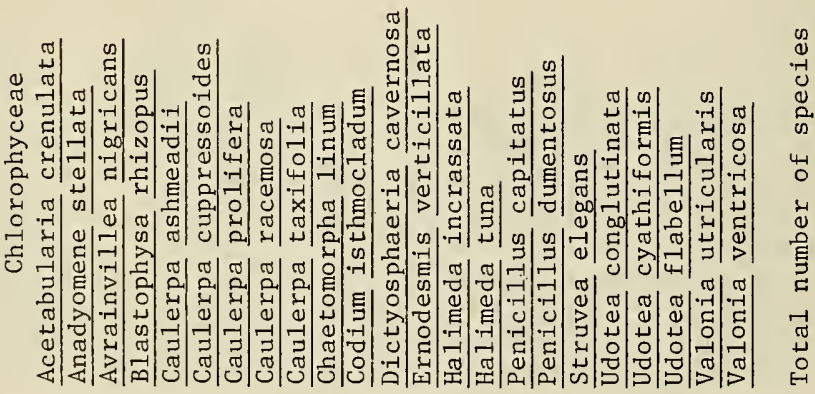




\begin{tabular}{|c|c|c|c|c|c|c|c|c|}
\hline$-\mathrm{T} \angle \mathrm{T}$ & $x$ & & & & -1 & & & \\
\hline $\begin{array}{l}\mathrm{I} L \mathrm{~T} \\
-29 \mathrm{~T}\end{array}$ & $x$ & & $x$ & $x$ & $m$ & & & \\
\hline $\begin{array}{l}29 I \\
-\varepsilon \subseteq T\end{array}$ & $x$ & & $x$ & $x$ & $m$ & & & \\
\hline $\begin{array}{l}\varepsilon \subseteq T \\
\text { ーカ†T }\end{array}$ & $x$ & & $x$ & $x$ & $m$ & & & \\
\hline $\begin{array}{l}\text { ฑ } \mathrm{I} \\
-\varsigma \varepsilon \mathrm{I}\end{array}$ & $x$ & & & $x$ & $\sim$ & & & \\
\hline $\begin{array}{l}\varsigma \varepsilon \mathrm{I} \\
-9 \tau \mathrm{T}\end{array}$ & $x$ & & $x \times$ & $x$ & $x$ เก & & & \\
\hline $\begin{array}{l}9 Z \mathrm{I} \\
-\angle \mathrm{TI}\end{array}$ & $x$ & & $x$ & $x$ & $m$ & & & $x-1$ \\
\hline $\begin{array}{l}\angle T T \\
-80 \mathrm{~T}\end{array}$ & & & $x$ & $x$ & $N$ & & & $x-1$ \\
\hline $\begin{array}{l}80 \tau \\
-66\end{array}$ & $x$ & $x$ & $x$ & $x$ & t & & & $x-1$ \\
\hline $66-06$ & $x$ & $x$ & $x$ & $x$ & $\checkmark$ & & & $x-1$ \\
\hline 06-T8 & $x$ & & $x$ & $x$ & $m$ & $x$ & -1 & $x-1$ \\
\hline $\mathrm{T} 8-\mathrm{ZL}$ & $x$ & & & $x$ & $N$ & & & $x-1$ \\
\hline$\zeta \angle-\varepsilon 9$ & & & $x$ & $x$ & $N$ & $x$ & $x \sim$ & $x-1$ \\
\hline$\varepsilon 9-7 \varsigma$ & $x$ & $x$ & $x$ & $x$ & $\checkmark$ & & & $x-1$ \\
\hline 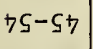 & $x$ & $x$ & $x x$ & $x$ & n & & & $x-1$ \\
\hline$\zeta \succcurlyeq-9 \varepsilon$ & $x$ & $x$ & $x$ & $x$ & + & $x$ & -1 & $x-1$ \\
\hline $9 \varepsilon-\angle \tau$ & $x$ & & $x$ & $x$ & $m$ & $x$ & -1 & \\
\hline$\angle Z-8 I$ & $x$ & & $x$ & $x$ & $m$ & $x$ & -1 & \\
\hline $8 \tau-6$ & $x$ & & $x$ & $x$ & $m$ & $x$ & -1 & \\
\hline $6-0$ & $x$ & & $x$ & $x$ & $m$ & $x$ & -1 & \\
\hline
\end{tabular}

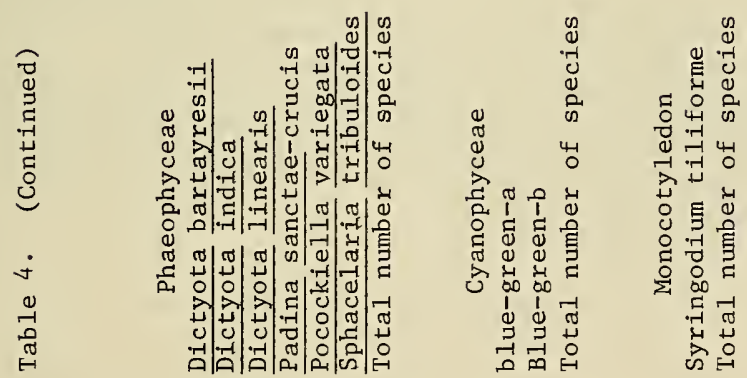


was also evident in the larger rectangular areas. The random positioning of the quadrants and their smaller size probably accounted for the differences in the two studies.

Figure 9 summarizes the average thallus length (based on 100 specimens per $15 \times 9 \mathrm{~m}^{2}$ ) of Avrainvillea nigricans, Halimeda incrassata and Udotea conglutinata at different locations on transect 2. Halimeda showed a substantial increase in length from $15-50 \mathrm{~m}$. Thereafter, its length fluctuated somewhat, but there was no noticeable difference. Less than 20 specimens of Avrainvillea nigricans were found from $0-25 \mathrm{~m}$. The plants' mean length fluctuated somewhat throughout the remaining portion of the transect, but it was not significantly different. Udotea conglutinata also exhibited limited variation in length throughout the transect. Figures 10 to 12 illustrate the percent frequency of different size classes of fronds of Halimeda, Avrainvillea and Udotea throughout transect 2. From 18 - 36m Halimeda was primarily represented by populations of small plants. Beyond $36 \mathrm{~m}$ Halimeda was represented by a broader spectrum of size classes and it was relatively uniform to $180 \mathrm{~m}$. A comparison of Figures 9 and 11 suggests that Avrainvillea exhibited a relatively consistent population from 27 to $180 \mathrm{~m}$. Similar results were evident for Udotea conglutinata, except that it tended to decrease somewhat in size from $162-180 \mathrm{~m}$.

\section{CAGE EXPERIMENTS}

Although the cage experiments were not of long duration (about three weeks), some interesting results were obtained. A summary of observations is given after 19 days of "regrowth" on June 17 . No change in quantity or type of vegetation was recorded for the 3 and $180 \mathrm{~m}$ cages. Seventeen new plants of Udotea cunglutinata were evident under the $60 \mathrm{~m}$ cage. The plants had an average length of $37 \mathrm{~mm}$; they probably regenerated from residual portions of rhizomes in the quadrant. Acanthophora spicifera, Cottoniella arcuata, Dasya pedicellata and Dictyota bartayresii were found for the first time on June 17. Cottoniella arcuata was a conspicuous epiphyte under the cage. Four new specimens of Udotea conglutinata were visible under the $120 \mathrm{~m}$ cage on June 17. The plants had an average length of $62.5 \mathrm{~mm}$. Again, they had probably regenerated from residual portions of rhizomes. Syringodium filiforme showed conspicuous regeneration on the denuded areas both inside and outside the cages. Three other algae were found for the first time on June 17 (Dasya pedicellata, Wrightiella tumanowiczi and Dictyota bartayresii). Dasya pedicellata was conspicuously reproductive (cystocarpic). Cottoniella arcuata completely covered the cages and it was a dominant epiphyte on many of the plants within and without the cages. It is of interest to note that all new species found in the 60 and $120 \mathrm{~m}$ cages were evident in adjacent areas (compare Table 3 ). 


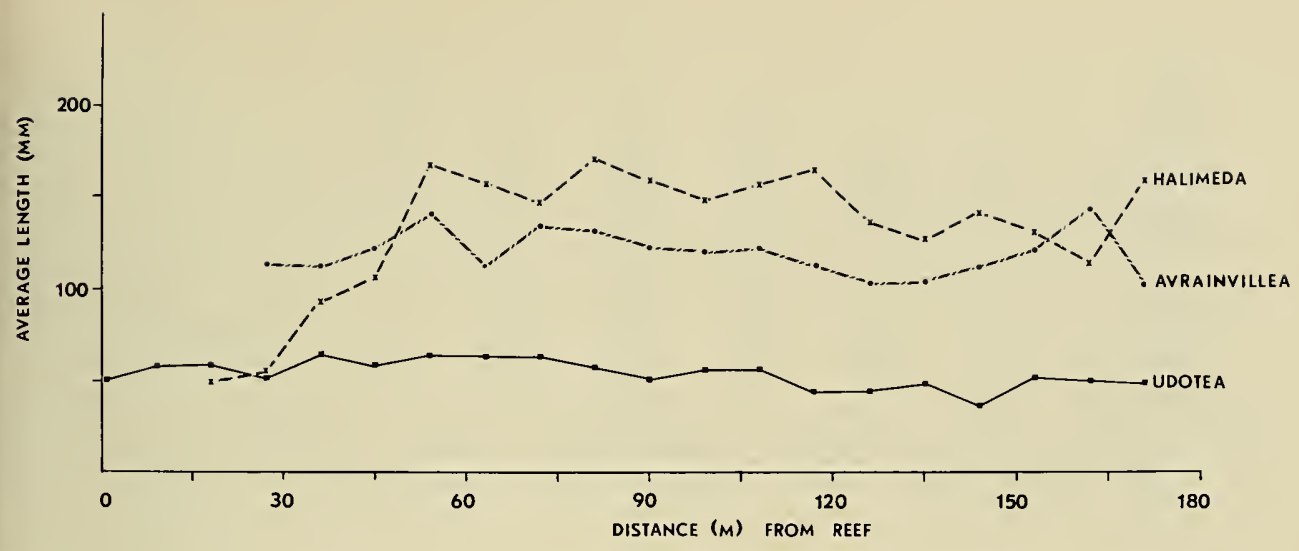

Figure 9. Average Size of Avrainvillea nigricans, Halimeda incrassata and Udotea conglutinata on Transect 2
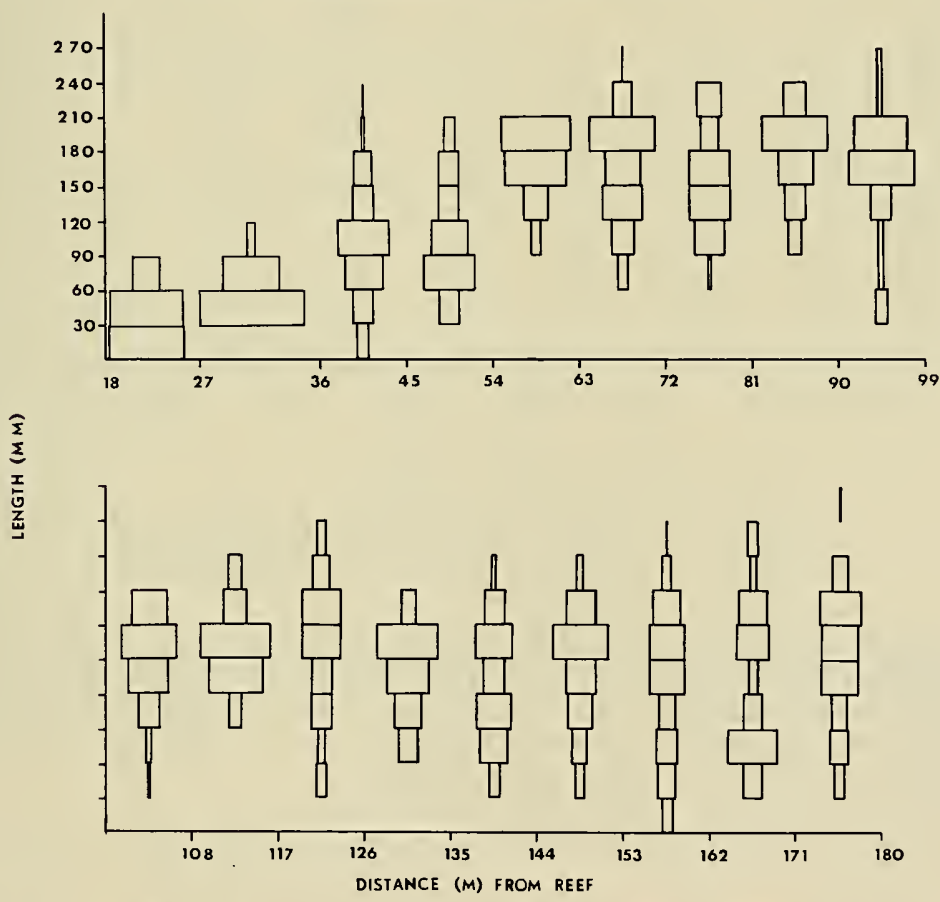

Figure 10. Percent Frequency of Different Size Classes of Thalli in Halimeda incrassata 


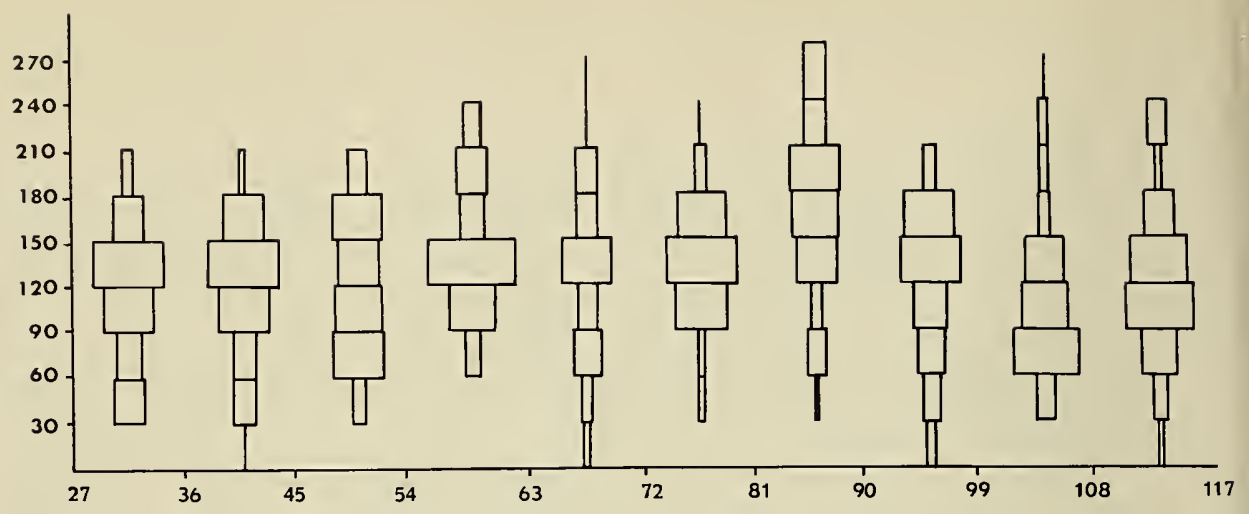

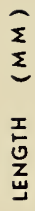

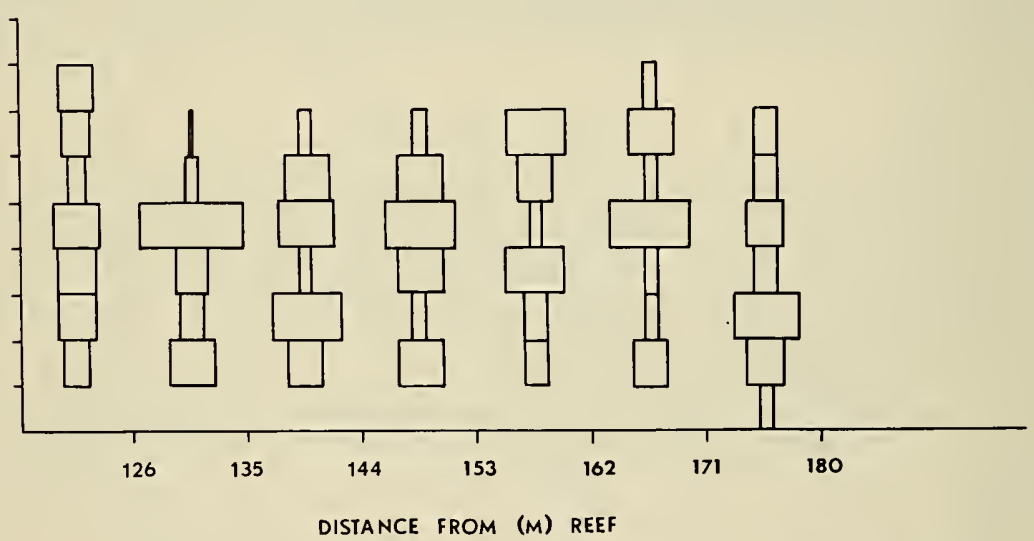

Figure 11. Percent Frequency of Different Size Classes of Tha11i in Avrainvillea $\underline{\text { nigricans }}$

Some general comments should be made regarding the cages and the fish populations. Foremost, the mesh screen we selected was too large $\left(1.3 \mathrm{~cm}^{2}\right)$ to exclude all of the smaller fish. Indeed, some fish even sought out the cages for safety from the divers. However, the larger fish were excluded from the study areas. 

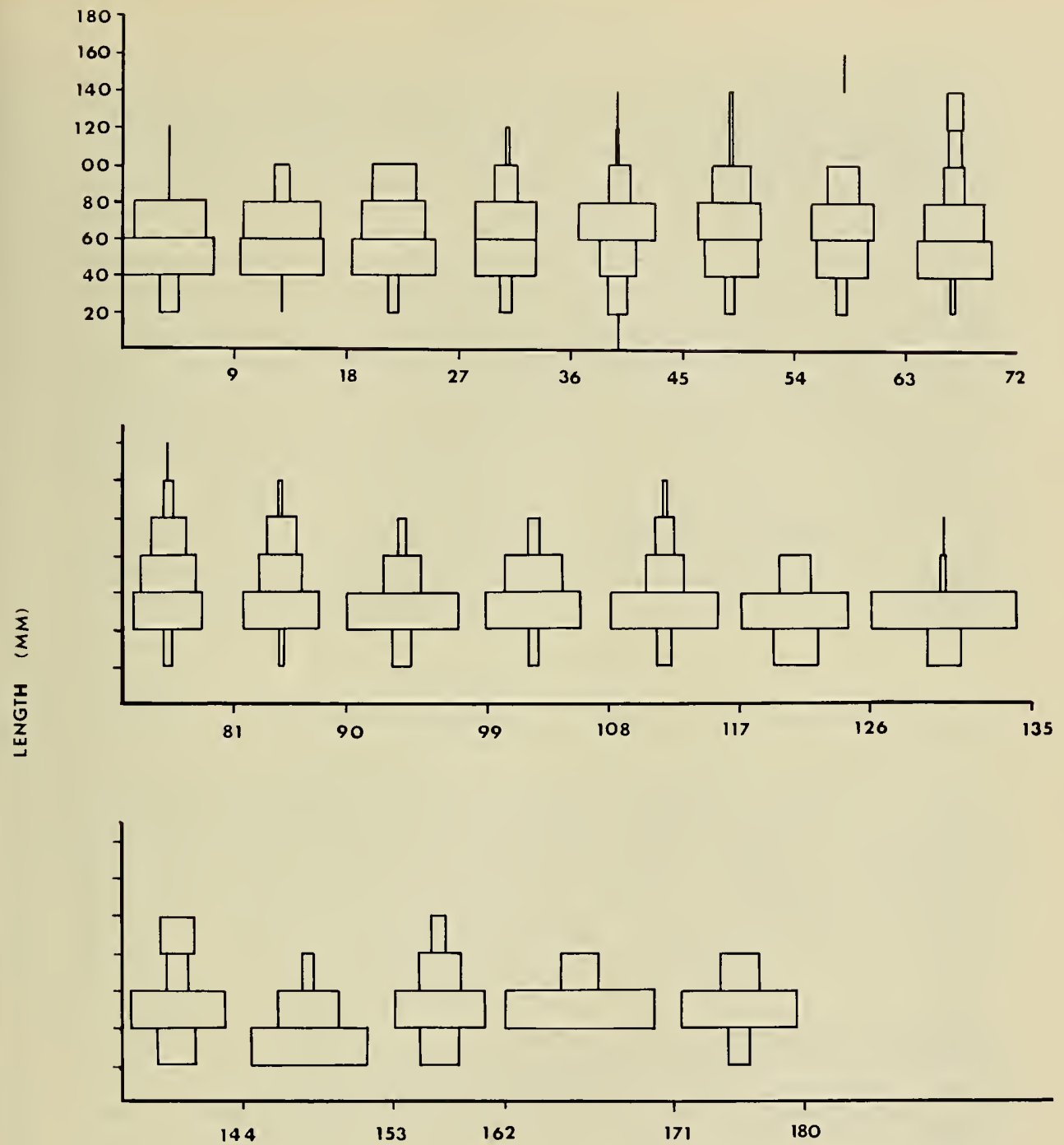

DISTANCE (M) FROM REEF

Figure 12. Percent Frequency of Different Size Classes of Thalli in Udotea conglutinata 
The feeding experiments were conducted by transporting large quantities of selected algae (e.g., Avrainvillea nigricans, Caulerpa cuppressoicies, Caulerpa prolifera, Halimeda incrassata, Penicillus capitatus, Udotea conglutinata, Dictyota bartayresii, Pocockiella variegata, Gracilaria cylindrica and Wrightiella tumanowiczi) from transect 2 to the reef near the habitat. In essence, separate piles of different diets were prepared in order to observe the feeding habits and/or specificity of the reef fish. Observations, totaling 12 hours, were made for three consecutive days. It soon became evident that some of the algae were of little interest to the fish (particularly Avrainvillea nigricans), whereas other species seemed to be actively eaten. The Parrot fish were particularly interested in Halimeda incrassata, and the plants were systematically cut up into small fragments. Many of the other fish did not eat Halimeda incrassata. The Grey Angel fish was most interested in the more succulent portions of Caulerpa spp., Wrightiella tumanowiczi and Gracilaria cylindrica. After three days the the samples were examined to determine what quantities were still remaining. Halimeda incrassata, Gracilaria cylindrica, Wrightiella tumanowiczi and Caulerpa spp. were reduced to very small quantities. Limited amounts of Udotea conglutinata, Penicillus capitatus, Dictyota bartayresii and Pocockiella variegata were still evident. Very 1ittle Avrainvillea nigricans was eaten.

\section{EPIPHYTIC ALGAE}

A total of 31 species of epiphytic algal flora were recorded, consisting of 19 species of red algae, 9 green and 3 brown. The red algae were found on the widest variety of plants, in part because of their small size. Four green (Blastophysa rhizopus, Caulerpa racemosa, Caulerpa taxifolia and Halimeda incrassata) and four red algae (Digenia simplex, Dudresnaya sp., Liagora sp. and Spyridia filamentosa) were restricted to a single host plant. Each of these species, except Blastophysa rhizopus and Dudresnaya sp., was also found on sand, shells or other solid substrates. Although no quantitative evaluation was made, it was apparent that the epiphytic flora was much higher in silty areas than in sandy portions of the transect. Thus, a high diversity and quantity of epiphytes was found from $42-171 \mathrm{~m}$, where maximum numbers of Halimeda incrassata and Avrainvillea nigricans were also evident. Twenty-five species of epiphytes were found on Avrainvillea nigricans, 14 of which were red algae. In addition, 17 species of epiphytes were found on Halimeda incrassata and 13 on Udotea conglutinata. Again, most of the epiphytes on the latter species were red algae. Avrainvillea was the largest plant and Udotea the smallest (compare Figure 9). Thus, there is a good correlation between availability of space and diversity of epiphytes. 
Among others, Gail (1922), Gilmartin (1960), Klugh and Martin (1927) and Larkum et a1. (1967) have emphasized that light is a major factor influencing the distribution and growth of subtidal algae, for both the quantity and quality of illumination changes with increased depths. Neushul (1965) has recorded shallow vegetational limits in turbid (northern) locations as compared to deeper limits in clear (southern) waters. Larkum et a1. (1967) emphasize that light penetrates to a much greater depth in clearer tropical waters than in northern coastal waters, and that it is blue rather than green at such depths. A comparison of the species composition and vertical distribution of algae in New England and the Virgin Islands shows obvious differences. Foremost, the depths at which maximum species numbers were recorded in the Virgin Islands corresponded to depths of minimal species numbers in New England. In addition, the subtidal flora of New England is primarily composed of red and brown algae, while green and red algae dominate in the Virgin Islands.

Substrate availability is also an important factor limiting subtidal vegetation, for it can determine both the quantity and types of vegetation. In New England the deep subtidal zone $(12-20 \mathrm{~m})$ is often composed of a silty-sandy substrate, which restricts the potential development of the flora when light is not limiting. The lower productivity (biomass) and high frequency of epiphytism at the outer limits of transect 2 in the Virgin Islands is probably also due to adverse substrate, for it was very silty. The higher productivity of plant materials on transect 1 was probably due to more suitable substrate.

Neushul (1965) has discussed the importance of several other environmental factors upon subtidal vegetation (the depth at which the thermocline reaches the bottom, shading effects, tidal currents and grazing). The effects of sea urchin grazing have been documented by several workers (Jones \& Kain, 1967; Kain \& Jones, 1966; Leighton, Jones \& North, 1966; North, 1964), primarily in northern areas. Sea urchin grazing may be extensive (particularly in areas of domestic pollution) and a residual flora of crustose algae and a few hardy plants may only remain (Mathieson, Dawes and Humm, 1969).

A major factor influencing the species diversity and biomass of algae in shallow subtidal waters in the Virgin Islands is fish grazing. Thus, there is a diminutive flora in the vicinity (depth) of a coral reef, with its abundant populations of herbivorous fish. In addition, there is a conspicuous increase in plant materials with increased linear distance (at least to $117-165 \mathrm{~m}$ ) from the reef. Limited information is available in botanical literature concerning the interaction of fish grazing on tropical algae (e.g., Dawson, et al., 1955; Gilmartin, 1960; Larkum, et al., 1967). The fish studies of Hiatt and Strasburg (1960) have provided a detailed account of the ecological relationships between fish and coral 
reefs in the Central Pacific (Marshal Islands). In addition, the latter authors categorized the algal feeding fish into four categories as follows, depending on the nature of their foraging habits: (1) consumers of unicellular algae; (2) grazers on algae; (3) browsers on algae; (4) incidental algal feeders. Herbivorous fish were found to dominate the reef, as in the Virgin Islands. Many of the fish described from the Marshal Islands are represented by comparable types in the Virgin Islands (Randal1, 1968).

Our studies indicate that reduced grazing pressure is apparent at about $30 \mathrm{~m}$ from a reef and that it causes a corresponding increase in plant material. Most of the reef fish probably do not swim $20-30 \mathrm{~m}$ from the reef, for they are afraid of other predatory fish. Localized patches of coral heads serve as a source of protection for reef fish, which live on the sea grass beds. In addition, migratory fish and possibly juvenile stages of reef fish were observed grazing on algae on the flats. It should be emphasized that the depths on transects 1 and 2 were reasonably uniform, and that linear changes in plant materials (biomass and diversity) were much greater than any recorded at different depths.

The results of our cage experiments, although of only 19 days duration, confirmed the importance of fish grazing on the plant communities. Thus, we recorded an increased diversity and abundance of plant materials under two of the cages. No change was noted for the 3 and $180 \mathrm{~m}$ cages. The silty substrate at $180 \mathrm{~m}$ probably restricted the establishment of new plants. The $3 \mathrm{~m}$ cage was located in the disturbed barren zone near the perimeter of the reef, and one would expect a longer time for regrowth to occur.

Randal1 (1965) has given a detailed account of fish grazing on sea grasses in the West Indies (including observations in Lameshur Bay). After a combination of cage and transplant experiments, he concluded that the bands of bare sand separating coral reefs and beds of sea grass (Thalassia testudinum and Syringodium filiforme) resulted from heavy grazing by Parrot fish (Scarus and Sparisoma) and Surgeon fish (Acanthurus). The present studies confirm his findings.

Our feeding experiments showed that many plants (particularly Halimeda incrassata) were rapidly eaten by herbivorous fish. In addition, the feeding experiments also showed some correlations between the linear distribution of algae on transect 2 and the feeding preferences of the fish. For example, Halimeda incrassata occurred as small plants and in limited quantities near the reef, and it was actively eaten in the feeding experiments. Such information suggests that it may be selectively grazed upon. In contrast, Udotea conglutinata was recorded as one of the closest algae to the reef and it was not grazed upon like Halimeda. It should be noted that although selective fish grazing may occur, all of the species present in the transitional areas $(2.4-30 \mathrm{~m})$ on transect 2 were exposed to heavy grazing. Thus, each species found in the transitional area exhibited either an increase in size or abundance with an 
increase in linear distance from the reef. Thus, there is a gradient in fish grazing, which is dependent upon the proximity of a reef. Our preliminary observations on fish grazing were encouraging enough to suggest that significant findings could be made with a coordinated botanical-zoological investigation.

In conclusion, I would like to make a few general comments regarding the usefulness of the habitat for our studies. Foremost, the results of our investigations on transect 2 were $3-5$ times greater than those accomplished by the support divers of our crew. No doubt a large part of this was because of the greater number of hours of diving time. We averaged $3-4$ hours of diving per day, and with that amount of diving (which was minimal compared to other missions) we had another $5-6$ hours of laboratory work. There can be little doubt in our minds that the habitat provided us with an unprecedented amount of diving time and it is a very effective tool. We could never have studied 20 individual $15 \times 19 \mathrm{~m}$ areas (a total area of $2700 \mathrm{~m}^{2}$ ) in New England. 
Dawson, E. Y., A. A. Aleem and B. W. Halstead, 1955. Marine algae from Palmyra Island with special reference to the feeding habitats of reef

fishes. Allan Hancock Foundation. Pub1. Occ. Pap. no. 17, 39 pp.

Gail, F. W. 1922. Photosynthesis in some of the red and brown algae as related to depth and light. Pub1. Puget Sound mar. biol. St.3: 177-193

Gilmartin, M. 1960. The ecological distribution of the deep water algae of Eniwetok Ato11. Eco1. 41: 210-221.

Hiatt, R. W. and D. W. Strasburg. 1960. Ecological relationships of the fish fauna on coral reefs of the Marshall Islands. Ecol. Monog. 30: 65-127.

Jones, N. S. and J. M. Kain. 1967. Subtidal algal colonization following the removal of Echinus. Helgo1. Wissen. Meeres. 15: 460-466.

Kain, J. M. and N. S. Jones. 1966. Algal colonization after removal of Echinus. In: Proc. V Int. Seaweed Symp., Halifax, Canada, pp 139-140.

Klugh, B. and J. R. Martin, 1927. The growth rate of certain marine algae in relation to depth of submergence. J. Ecol. 8: 221.

Larkum, A.W.D., E.A. Drew and R.N. Crossett. 1967. The vertical distribution of attached marine algae in Malta. J. Ecol. 55: 361-371.

Leighton, D.L., L.G. Jones and W.J. North. 1966. Ecological relationships between giant kelp and sea urchins in Southern California. V Int. Seaweed Symp. pp 141-153.

Levring, T. 1947. Summer daylight and the photosynthesis of marine algae. Goteborgs Vetensk. Samh. Hand1. Sjatte Folj B. 5: 1-90.

Mathieson, A. C., C.J. Dawes and H.J. Humm. 1969. Contributions to the marine algae of Newfoundland. Rhodora 785: 110-149.

Mathieson, A.C., E.J. Hehre and N.B. Reynolds. Investigations of New England marine algae I: A floristic and descriptive ecological study of the marine algae at Jeffrey Point, New Hampshire. Nova Hedwigia (in press).

Neushu1, M. 1965. SCUBA diving studies of the vertical distribution of benthic marine plants. Botanica bothoburg. 3: 161-176. 
North, W. J. 1964. Ecology of the rocky nearshore environments in Southern California and possible influences of discharged wastes.

Rept. Int. Cong. Water Pollution Res., Sept. 1962: 247-274.

Randa11, J. E. 1965. Grazing effect on sea grasses by herbivorous reef fishes in the West Indies. Ecology 46: 255-260.

- 1968. Caribbean Reef Fishes. T.F.H. Publications Inc., Jersey City, N. J., 318 pp. 


\begin{abstract}
Thirty-five species of plant-eating fishes in 14 families were observed in Lameshur Bay, St. John, Virgin Islands during TEKTITE II Mission 6-50. One hundred fifty-four species of marine plants were found, including 26 species newly reported for the Virgin Islands. Activities of the fishes were noted, particularly feeding behavior and choice of diet, and their influence on vegetation assessed. Fish distribution was described and compared with plant distribution. In general, in areas where physical requirements for plant growth were met, attached vegetation was abundant where herbivores were sparse, and where herbivores were abundant, vegetation was sparse. Cages designed to exclude fishes were established along two transect lines and growth of plants within compared with adjacent plants outside. After seven weeks, appreciable growth was noted inside cages where plant-eating fishes were abundant, but there was little difference inside and outside of cages in areas where these fishes were rare. Most adult plant-eating fishes remained, day and night, close to the reef, but young of many lived on the algal plain as much as $200 \mathrm{~m}$ from a reef. All plant-eating fishes observed were active by day, at rest during the night. Herbivorous fishes were concluded to be a major influence on the abundance, diversity and distribution of benthic marine plants in tropical seas, with invertebrate herbivores of relatively small significance. This is in contrast to cold and temperate situations where herbivorous fishes are rare, but invertebrates of great importance as grazers. The role of predators and their indirect influence on vegetation is discussed. Annotated lists of plants and plant-eating fishes in Lameshur Bay are included.
\end{abstract}

\title{
INTRODUCTION
}

Perhaps the most striking aspect of plant life on a coal reef is the general lack of it. It seems anomalous to even the casual observer that tropical reefs, notable for their dazzling profusion of animal life, are almost devoid of conspicuous plants. Frequently, not only the reef proper, but also an area 8 to 30 or more feet surrounding a reef may be almost bare, although beyond this area attached plants may be quite abundant. Odum and Odum (1955) found that a substantial part of the plant food available on a reef may be growing on and within corals. 
Dr. John Randal1 (1967) concluded that two factors may hold large plants on a reef in check. One is simply strong competition for a foothold amid the numerous sessile animals; the other, the dramatic influence on the abundance and diversity of plants caused by heavy grazing of numerous plant-eating fishes. Randall reported on the food habits of 212 species of West Indian fishes. More than 125 species of red, green-brown and blue-green algae, assorted diatoms and five kinds of aquatic vascular plants were obtained from the stomach contents of 59 species in 16 families of reef fishes. Of these, three families are almost entirely herbivorous, dependent on algae as their primary food. To many others, plants form an important part of the diet. Most fishes are carnivores. The we11known patter - big fish eat little fish, little fish eat lesser fish, lesser fish eat shrimp, shrimp eat "mud" - by and large is true. But in the tropics, and only among several rather highly advanced, recently evolved families of fishes, are there numerous species that tap the bottom of the food chain.

\section{OBJECTIVE}

Although Randall's work has been extensive, clearly more information is needed on the specific food habits and day-to-day activities of grazing fishes. Taking the standpoint of a botanist, that is, to see how fishes affect the plants instead of visa versa, I began during June 1970 first to survey and catalog the benthic plants in Lameshur Bay, St. John, Virgin Islands, then to concentrate on watching to see what fishes ate what plants, and when, during the 24-hour cycle, the grazers were active. The study was undertaken as a part of Project TEKTITE II Mission 6-50.

\section{METHODS}

In collaboration with Dr. Arthur Mathieson and Mr. Richard Fralick of TEKTITE Mission 4-50, two $180 \mathrm{~m}$ transect lines were established during May 1970 in the vicinity of the TEKTITE habitat. Transect 1 was oriented at $240^{\circ}$ from the reef near the diving platform and ranged from 12.4 to $18.7 \mathrm{~m}$ depth. Transect 2 was oriented at $278^{\circ}$ from the reef, due west on the TEKTITE habitat, and ranged from $17.3 \mathrm{~m}$ to $21.5 \mathrm{~m}$. Wire cages $1.35 \mathrm{~m} \mathrm{x} .6 \mathrm{~m} \mathrm{x} .45 \mathrm{~m}$ of $1.3 \mathrm{~cm}^{2}$ mesh were placed at intervals along the lines (Figures 1, 2, 3). The purpose of the cages was to exclude large plant-eating animals in an effort to determine what effect grazing might have on the abundance and diversity of plants in the area.

During the two weeks of aquanaut-training, June 27 to July 5, I made observations and collections in the Lameshur Bay area using scuba for 23 hours and a rebreather unit for 11 hours in depths to $31 \mathrm{~m}$. 


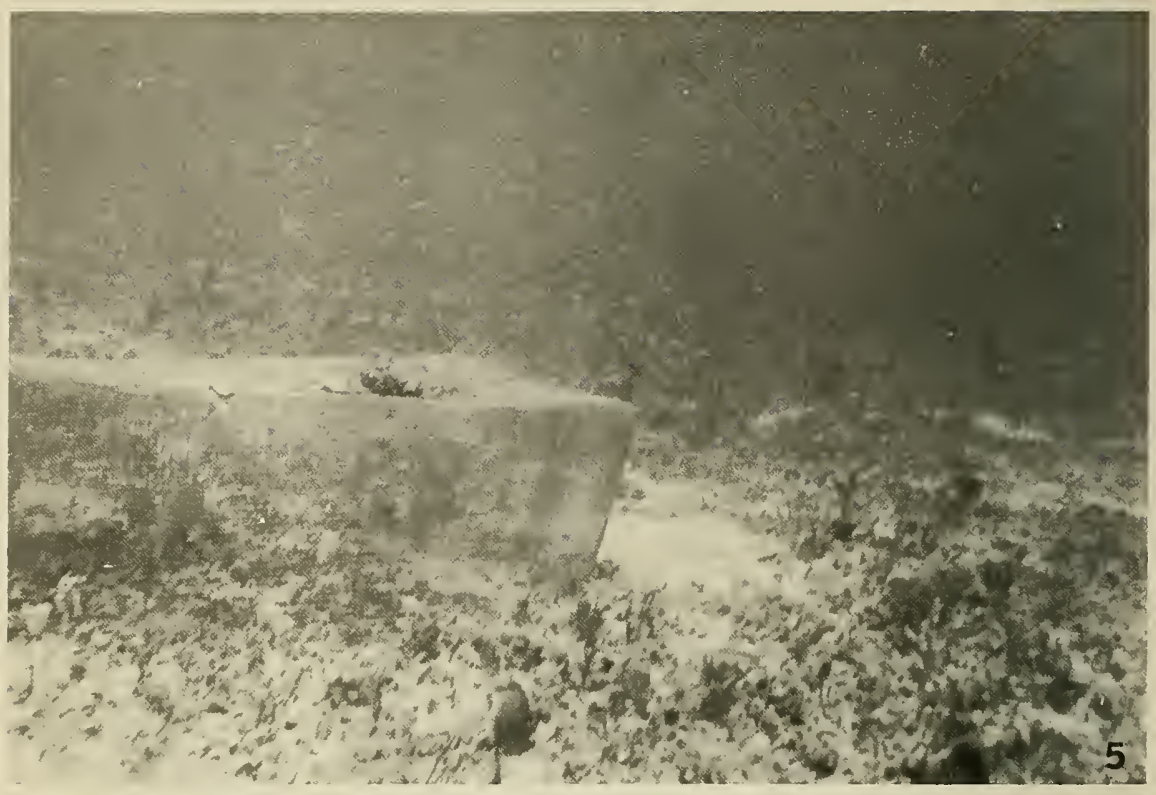

Fig. 1. Wire cage $100 \mathrm{~m}$ from the face of the reef on transect 1.

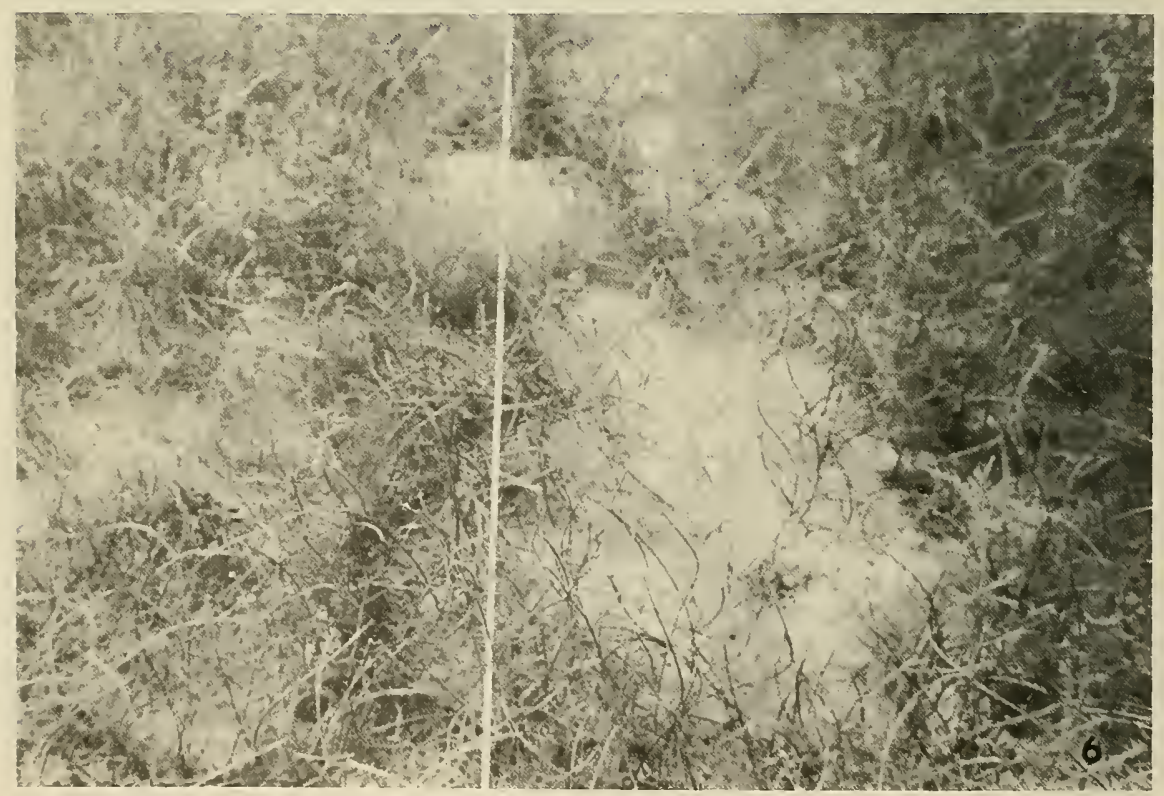

Fig. 2. Part of a bed of the sea grass, Syringodium filiforme, $350 \mathrm{~m}$ north of the TEKTITE habitat, showing transect line. 
On July 6, I began saturation diving from the TEKTITE habitat and during the two weeks that followed used scuba for about 40 hours and a rebreather for 46 hours in depths of 10 to $24 \mathrm{~m}$.

Using a plastic slate for notes, I recorded distribution of plants and plant-eating fishes, and observed individual fishes, as well as the activities of groups of mixed species that foraged together during the day. Fishes near the TEKTITE habitat were offered samples of various plants from the plain and the responses were recorded.

Selected samples of plants were collected and sent to the surface for preservation and later critical examination. Voucher herbarium specimens were prepared of all plants species recorded, and these will be deposited at the U.S. National Herbarium, Washington, D. C.

A single Eupomocentrus partitus was collected to document the study on this small damselfish. The specimen will be deposited at the Los Angeles County Museum of Natural History.

\section{RESULTS}

\section{Reef Vegetation}

On the reef proper in 3 to $20 \mathrm{~m}$ depth, few plants are evident. In crevices, the spherical green algae, Valonia ventricosa is common, and a turf of fine filamentous blue-green, green, red and brown algae and diatoms occurs on some rocks, hard coral and artificial substrates, including the habitat itself. (Fig. 4).

Brown algae (Phaeophyta) predominate in this area. Species of the microscopic filamentous genera Ectocarpus, Giffordia, Sphacelaria, Myrionema, and the decumbent Dictyota bartayresii and Lobophora variegata grow on hard surfaces, especially the bases of stony corals. A few small plants of Padina sanctae-crucis occur in protected places. Red algae (Rhodophyta) on the reef include the filamentous Goniotrichum alsidii, and Acrochaetium spp., several species of Ceramium, the small stiff Gelidium corneum, occasional Laurencia plants, and several encrusting and corraline species. Certain green algae (Chlorophyta) occur within the living stony corals, and are probably utilized for food by fishes that scrape and bite pieces of coral. But green algae other than the endozoic forms include only Valonia spp., Neomeris annulata, a few sprigs of Cladophora, the minute epiphyte Diplochaete solitaris, well-protected Bryopsis pennata plants, and in occasional open sandy places within the main reef, patches of Udotea verticillosa and $\underline{U}$. conglutinata. 


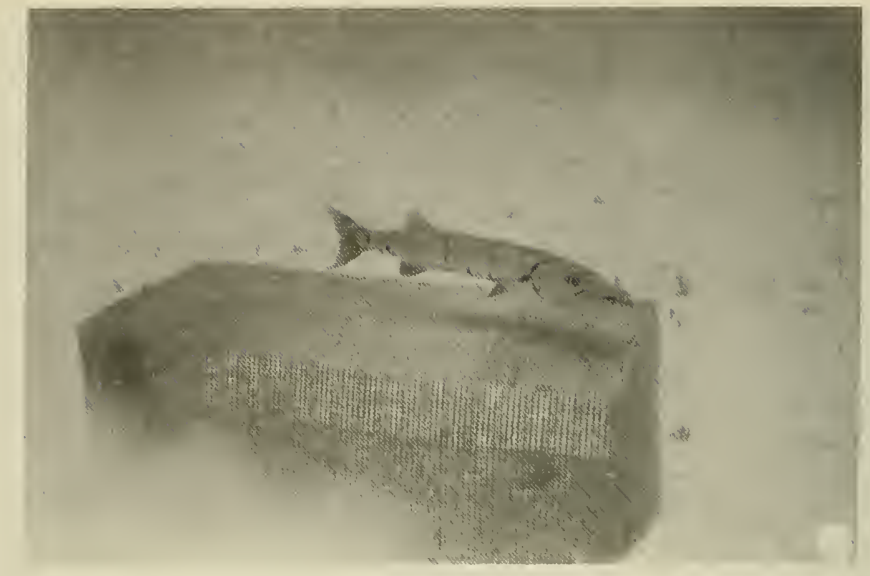

Fig. 3. Wire cage $180 \mathrm{~m}$ from the face of the reef on transect 2, with great barracuda, Sphyraena barracuda, hovering.

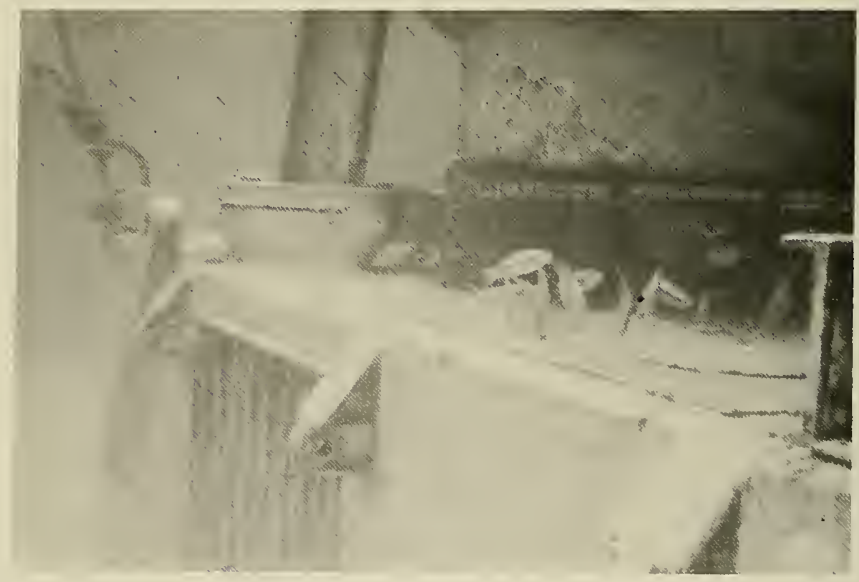

Fig. 4. Parrotfishes grazing on filamentous algae attached to the outer surface of the TEKTITE habitat. 
Excluding endozoic algae, 9 species of Chlorophyta, 13 Phaeophyta and 12 Rhodophyta were obtained on the reef.

\section{Plain Vegetation}

Bordering reefs in most $\mathrm{p}$ łaces in Lameshur Bay there is a bare expanse 2 to 10 or more meters wide. The most dramatic delineation seen was at the edge of a bed of sea grass and algae along a shallow reef ( 3 to $7 \mathrm{~m}$ ) at Salt Pond, south of the habitat, observed on June 24 , but the pattern held for all reef areas seen in the Lameshur Bay area.

Mathieson, Fralick, Burns, and Flahive (this report) assembled excellent detailed quantitative data during TEKTITE Mission 4-50 that documents the readily apparent change in vegetation seaward from the reef near the TEKTITE habitat location. They show plant abundance and composition with depth profiles along two transect lines extending $180 \mathrm{~m}$ away from the reef.

West of the bare border along the face of the reef there is a gradual development of plant covering starting with species of Udotea, Dictyota, and sometimes masses of filamentous blue-green algae (Fig. 5). Seaward, abundance and diversity of species increases in an transition area extending to about $35 \mathrm{~m}$ (Fig. 6). From 35 to $150 \mathrm{~m}$ away from the reef the algal cover resembles from a human standpoint, a densely vegetated plain, but to the small resident fishes and invertebrates, this region must be likened to a forest approximately $15 \mathrm{~cm}$ high, with some tall Avrainvillea, Codium, and Halimeda plants attaining $30 \mathrm{~cm}$ (Fig. 3). Here a total of 150 species of plants were obtained during the study: 52 Chlorophyta, 24 Phaeophyta, 70 Rhodophyta, and 4 Spermatophyta. Most conspicuous are numerous kinds of siphonous green algae, including species of Avrainvillea, Penicillus, Caulerpa, Udotea and Anadyomene, and the spermatophyte, Syringodium filiforme. Among the browns, the flat, crisp blades of Lobophora variegata are most evident and abundant, and species of Dictyota are common. Red algae are represented by the greatest number of species, but are the least conspicuous because nearly all present are minute. Only Acathophora, Cottoniella, Dasya, Digenia, Gelidium, Galaxura, Gracilaria, Griffithsia, Hypnea, Hypoglossum, Jania, Laurencia, Liagora, Spyridia, Wrangelia, and Wrightiella are readily apparent macros copically.

Again there is an area of transition, beginning between 60 and $100 \mathrm{~m}$, with a gradual thinning of plant cover and drop in species number. At the far edge of the algal plain, scattered plants of Halimeda, Avrainvillea, Caulerpa, Udotea, and the sea grass, Syringodium, may be found, with an assortment of epiphytes (Figs. $7,8,9$ ). In the distant, peripheral area approximately $180 \mathrm{~m}$ from the reef, 9 species of Chlorophyta, 2 Phaeophyta and 12 Rhodophyta were obtained. 


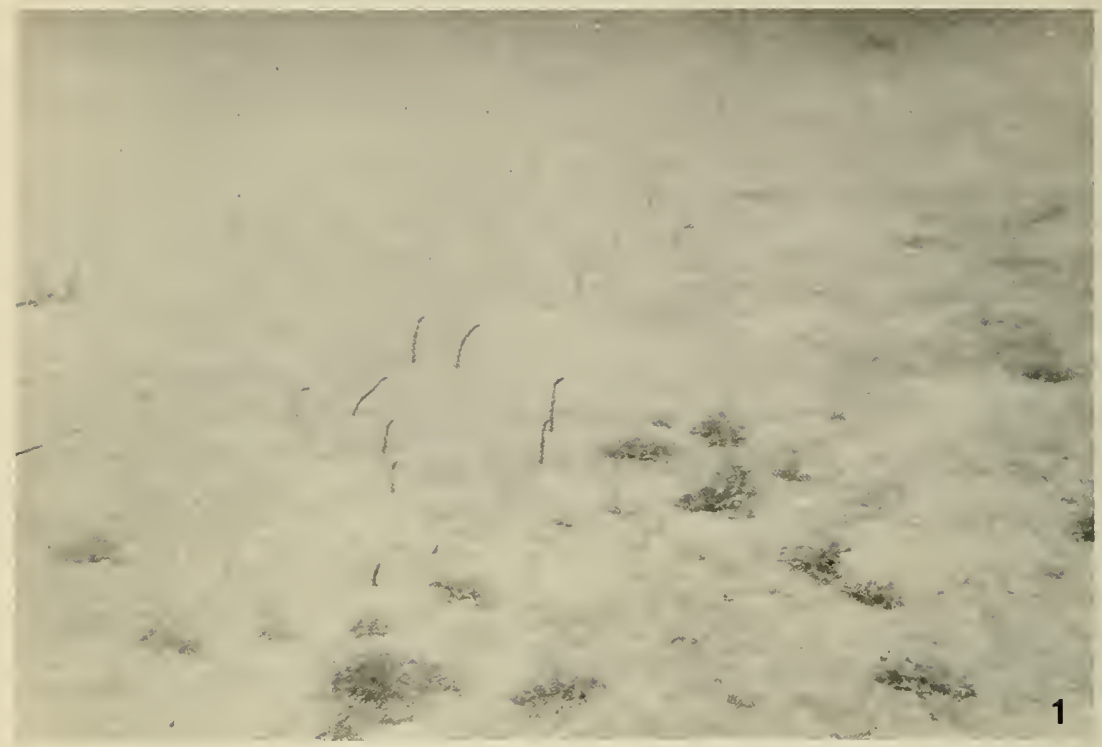

Fig. 5. Portion of bare area $10 \mathrm{~m}$ from the face of the reef visited by numerous grazing fishes. Small Dictyota plants and partially emergent garden eels, Nystactichthys halis, are shown.

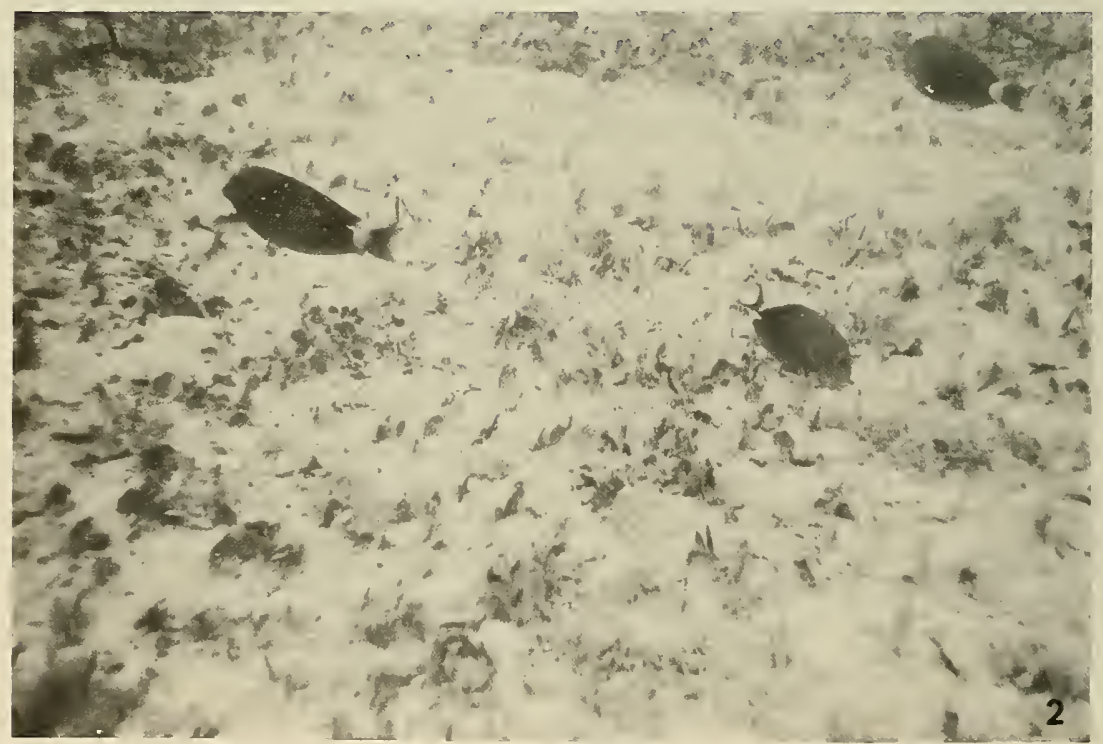

Fig. 6. A heavily-grazed part of the algal plain $30 \mathrm{~m}$ from the face of the reef, with surgeonfishes. Species of Udotea predominate in the area. 


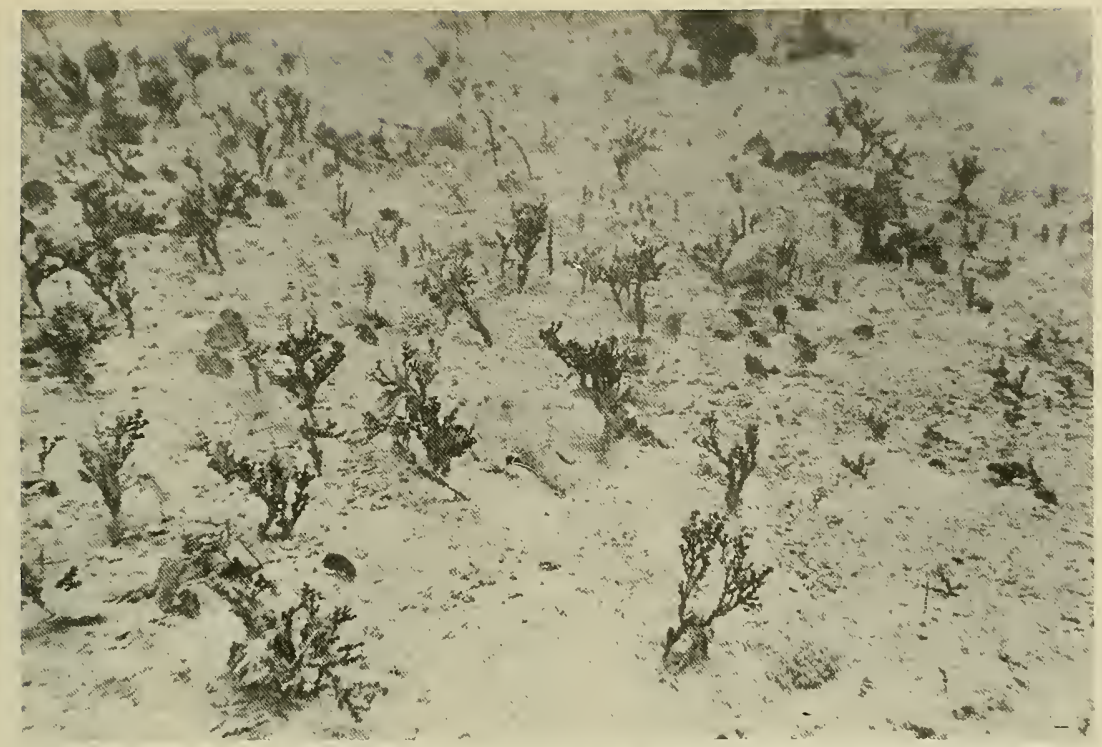

Fig. 7. A part of the algal plain $180 \mathrm{~m}$ from the face of the reef, near the limit of plant cover. Species of Halimeda, Udotea, and Avrainvillea are shown.

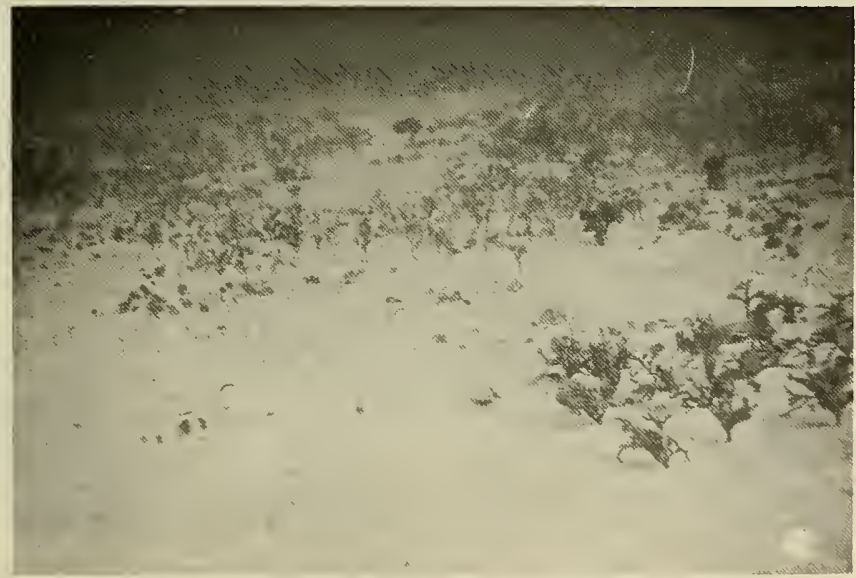

Fig. 8. Aspect of algal plain at outer limit of vegetation, $180 \mathrm{~m}$ from the face of the reef. 


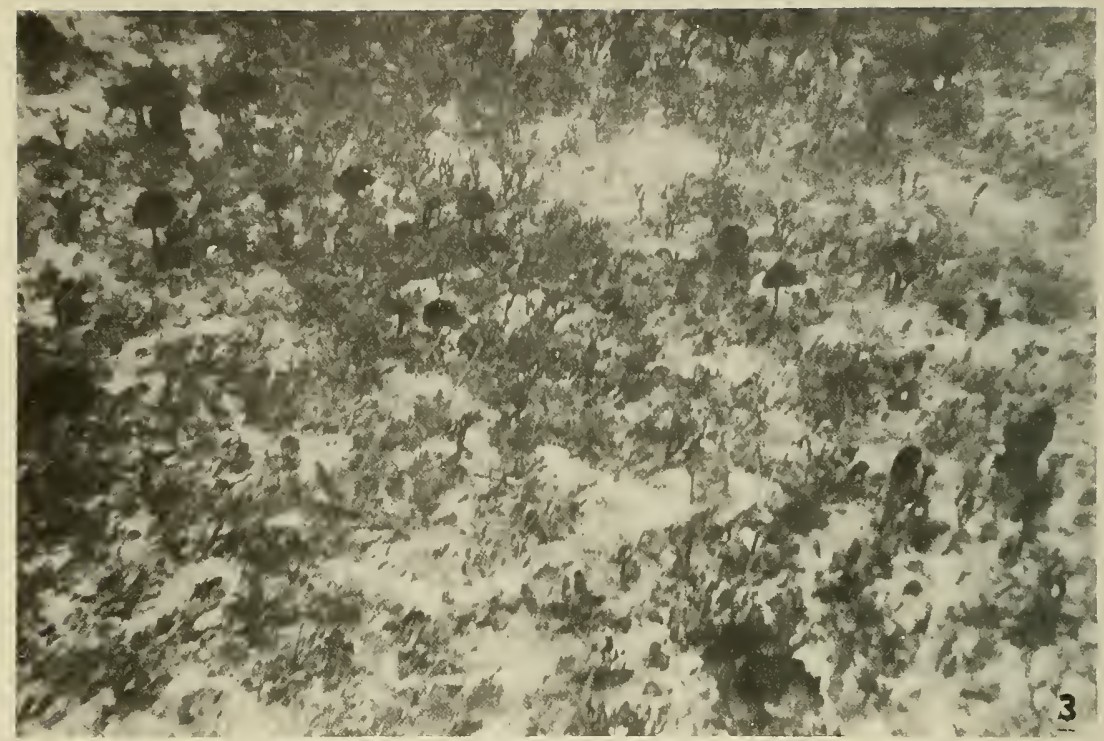

Fig. 9. A part of the algal plain $100 \mathrm{~m}$ from the face of the reef, lightly grazed by fishes. Conspicuous plants in this area include Avrainvillea, Udotea, Penicillus, Lobophora, Caulerpa, and Halimeda.

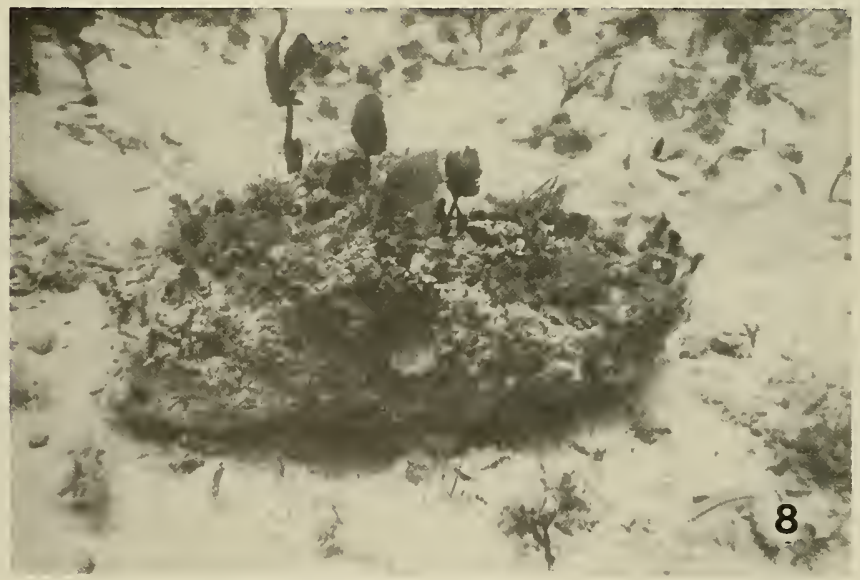

Fig. 10. Isolated rock lump, one of many scattered over the algal plain, supporting growth of Avrainvillea and other algae, and providing cover for numerous small fishes. 
Beyond the vegetated plain, a calcareous sand plain extends seaward, gradually increasing in depth. No excursions were made beyond $230 \mathrm{~m}$ west of the reef, and during the mission, the greatest depth attained was approximately 24 meters. During the training period, however, a dive was made approximately one mile south of Lameshur Bay in $31 \mathrm{~m}$ depth. There growing on a calcareous sand bottom that resembled the sand plain near the TEKTITE habitat, 21 Chlorophyta, 3 Phaeophyta, and 32 Rhodophyta were found. Plant cover was moderate, the conspicuous plants including species of Udotea, Caulerpa, Codium, Halimeda, Avrainvillea, Neomeris, Anadyomene, Lobophora, Dasya, Gracilaria, Scinaia, Laurencia, Griffithsia and Jania.

To assess the influence of grazing activity on the attached vegetation members of Mission 4-50 placed cages at intervals along the two transect lines previously described. On transect 1 , cages were placed at $20 \mathrm{~m}, 100 \mathrm{~m}$ and $180 \mathrm{~m}$; on transect 2 at $3 \mathrm{~m}, 60 \mathrm{~m}, 120 \mathrm{~m}$, and $180 \mathrm{~m}$. An area $.6 \mathrm{~m}^{2}$ was denuded before the cages were positioned and the plants enumerated and weighed. The cages were then fixed so that half of the denuded area was within the cage. Mathieson, Fralick, Burns and Flahive (this report) found after 19 days that no change in quantity or type of vegetation had occurred for the $3 \mathrm{~m}$ and $180 \mathrm{~m}$ cages along transect 2 , but there was a conspicuous increase in growth under the $60 \mathrm{~m}$ cage; seventeen new plants of Udotea conglutinata were evident, as well as newly-recorded Acanthophora spicifera, Cottoniella arcuata, Dasya pedicellata and Dictyota bartayresii. Under the $120 \mathrm{~m}$ cage, four new Udotea conglutinata and conspicuous regeneration of Syringodium filiforme had occurred, and Dasya pedicellata, Wrightiella tumanowiczi and Dictyota bartayresii were obtained for the first time.

Observations were continued on the growth within the cages and grazers present in the vicinity throughout Mission 6-50, beginning on July 6 and ending July 19 to 20, seven weeks after the cages were put in place.

On transect 1 , cage $1,20 \mathrm{~m}$ from the reef, the amount of plant material inside appeared equivalent to that outside, including abundant Gelidium corneaum, but several small plants of Padina sanctaecrucis were within the cage and none were found nearby outside. Several small dusky damselfishes (Eupomocentrus fuscus) moved in and out of the cages at will, and small surgeonfishes (Acanthrus chirurgus) and puffers (Canthigaster rostrata) nibbled diatoms and filamentous algae from the cage surface. In the vicinity were numerous grazing surgeonfishes, parrotfishes, and others. 
On transect 1 , cage 2 , $100 \mathrm{~m}$ from the reef, 3 large triggerfishes sometimes accompanied by several goatfishes and a number of small jacks, were in and out of the cage frequently. Surprisingly, the vegetation inside was approximately the same in diversity and abundance as that outside, despite fish activity inside. Udotea conglutinata, $U$. verticillosa, Halimeda incrassata, Caulerpa cupressoides, Lobophora variegata, and the seagrass Syringodium filiforme all occurred inside the cage and in the immediate vicinity outside. A moderate amount of filamentous algae and diatoms occurred on the cage screen. No large grazing fishes were seen on the plain in this area.

On transect 1 , cage $3,180 \mathrm{~m}$ from the reef, plant cover was sparse. Inside the cage were 5 Halimeda incrassata plants, and on the cage mesh diatoms and attached filamentous algae, notably Cottoniella arcuata, were abundant. Halimeda and Cottoniella, as well as occasional Acanthophora spicifera, Dasya pedicellata, Gracilaria cylindrica, Griffithsia globulifera, Hypoglossum tenuifolium, Wrightiella tumanowiczi, Anadyomene stellata, Avrainvillea nigricans, Caulerpa cupressoides, Caulerpa ashmeadii, Penicillus capitatus,, p. dumetosus, Udotea spp., Lobophora variegata, and Dictyota dichotoma, all with assorted epiphytes, occurred in the vicinity. No large grazing fishes were observed in the area, but some juveniles and the batfish, ogcocephalus nasutus, were seen at the site.

On transect 2, cage $1,3 \mathrm{~m}$ from the reef, plant cover inside the cage was significantly greater than outside, and the contents more stable Udotea, Dictyota, and Lobophora outside the cage appeared frayed, split, nibbled, inside, blades and fronds were entire. Outside, mats of blue-green algae were rolled and turned, and were generally brown; inside the substrate appeared to be stable, and the blue-green mat had a green cast. A moderate amount of algae and diatoms was attached to the mesh of the cage.

Grazers in the vicinity were numerous including numerous surgeonfishes, parrotfishes, angelfishes and triggerfishes. Spotted goatfishes, while apparently not feeding on the algae directly, worked over the bottom, vigorously stirring and mouthing the sand and bluegreen mats, creating small clouds of sediment to rise wherever they fed. No fishes were observed inside this cage, although numerous mysid shrimp frequently gathered under the screen. 
On transect 2, cage 2, $60 \mathrm{~m}$ from the reef, Udotea was much more abundant inside than outside the cage. As with cage 1 , blades were entire, not frayed, and the bottom sediment and blue-green growth was more stable and more concentrated inside than out. In the surrounding area, Udotea cover was sparse. Inside the cage, the following species were noted: Acanthophora spicifera, Laurencia sp., Digenia simplex, Anadyomene stellata, Halimeda incassata, Udotea, spp., Lobophora variegata, Dictyota dichotoma, and Syringodium filiforme. All of these occurred outside the enclosed area, with occasional plants of many additional species, notably Gracilaria cylindrica, Dasya pedicellata, Hypoglossum tenuifolium, Avrainvillea spp., Codium isthmocladium, and numerous others.

Large plant-eating fishes were not common in the area, but the surgeonfish, Acanthurus chirurgus, the redband parrotfish, Sparisoma aurofrenatum, the gray angelfish, Pomocanthus arcuatus, and spotted goatfishes were occasionally seen. No small fishes gathered inside the cage, but juvenile surgeonfishes (A. coeruleus) sometimes were observed nibbling the moderate growth of diatoms and filamentous algae on the outside of the mesh.

On transect 2 , cage $3,120 \mathrm{~m}$ from the reef, plant cover within the cage appeared only slightly greater than outside. Udotea spp. was most abundant, together with conspicuous amounts of the seagrass, Syringodium filiforme, Anadyomene stellata, Halimdea incrassata, Dictyota dichotoma, Lobophora variegata, Acanthophora spicifera, and Laurencia sp. All of these, plus occasional plants of numerous other species occurred in the area. Among the large plant-eating fishes, only gray angelfishes were encountered at this site, but juvenile surgeonfishes were common. Numerous small yellow-tailed snappers remained in or close to the cage, day and night. A heavy growth of filamentous algae, notably Cottoniella arcuata and Giffordia indica occurred with diatoms and blue-green algae on the mesh of the green.

On transect 2 , cage 4, $180 \mathrm{~m}$ from the reef, vegetation was sparse. Filamentous algae (again principally a mixture of Cottoniella, Giffordia, diatoms and blue-green algae) were very abundant on the screen, in places completely spanning and covering the holes. No large algae were inside the case. Six garden eels (Nystactichthys halis) had established burrows in the calcareous sand bottom under the screen, and were common in the area adjacent. 
It is likely that numerous mollusks, certain echinoderms, crustaceans and other invertebrates feed on attached plants in Lameshur Bay, but information on the food habits of most is lacking. Bardach (1959) suggested that the largest fraction of herbivores on a Bermuda reef probably consists of mollusks, crustaceans, and annelids.

Two invertebrate species in Lameshur Bay are known to be important herbivores: the queen couch, Strombus gigas, and the black-spined urchin, Diadema antillarum, studied in detail by Randall (1964) and Randa11, et al. $(1964)$ The stomach contents of 59 adult strombus gigas contained principally plant material including 25 genera of algae, disregarding diatoms. During the present study, adults of this species were frequently observed on the sand-algal plain, and were most conspicuous within $100 \mathrm{~m}$ of the reef. Adults were notably abundant in grass beds in Salt Pond, southeast of the study area, in accord with Randall's earlier observation (1964).

Diadema antillarum apparently feeds principally on sea grasses and algae. These urchins were particularly abundant in little Lameshur Bay, northwest of the study area, and were common, often locally abundant, on the reef near the TEKTITE Habitat. They were not observed on the algal plain, however, other herbivorous echinoids in the area $f a r$ less numerous than Diadema were Lytechinus variegatus and Tripneustes esculenta, known to feed on sea grass, Thalassia testudinum (Margalef and Rivero, 1958; Moore, et a1., 1963a; Moore, et al., 1963b).

\section{PLANT-EATING FISHES}

Randal1 (1967) noted 59 species of plant-eating fishes from the West Indies in the families Hemiramphidae, Mullidae, Sparidae, Kyphosidae, Pomocentridae, Scaridae, Monacanthidae, Ostraciontidae, Canthigasteridae, Diodontidae, Tetraodontidae, Ogcocephalidae, Gobiidae, Blenniidae, Ephippidae, Chaetodontidae, Acanthuridae, and Balistidae. During Mission 6-50 observations were made on the habits of 35 plant-eating species in 14 families. General comments follow on each of these families with individual species notes.

Identification of some species was difficult because positive determinations require a fish in hand and collection of specimens at the study site was necessarily prohibited. I feel confident of family level determinations, however, and regard most species identifications reliable but, where appropriate, have indicated uncertainty. 
Because collecting specimens of fishes was not allowed for this study, the data gathered by Randall (1967) on stomach contents is especially valuable.

\section{Pomocentridae, The Damselfishes}

These small, usually highly territorial, of ten aggressive fishes are among the most common and conspicuous reef residents. At least ten species occur in the Caribbean. Nearly every large rock and coral head of the reefs in Lameshur Bay supports a complement of damselfishes. Active by day, they typically retreat to a wellguarded crevice from which they emerge at dawn. Most damselfishes are omnivorous, with plants locally present usually nibbled throughout the daylight hours, but within the family, food habits range from characteristically herbivorous for the night sergeant, Abudefduf taurus, to a diet totally consisting of zooplankton for two species of Chromis. During feeding trials, no pomocentrids left their territory to sample algae brought from the plain to the reef.

\section{Abudefduf saxatilis (Linnaeus). Sergeant major}

These species were seen occasionally in groups on the reef in depths to five meters but were more common in Little Lameshur Bay near docks in shallow water. The stomach contents of 35 specimens by Randal1 (1967) included $8.8 \%$ algae of 13 species, nearly all fine or filamentous forms. Contents of three specimens examined by Longley and Hildebrand (1941) contained mostly algae, and Randall (1967) states that in areas of high algal cover, $\mathrm{A}$. saxatilis may be found with up to $100 \%$ algae in their stomach. Elsewhere, diet varies, sometimes including mostly invertebrates, suggesting that this species will feed fortuitously on whatever is handy.

Abudefduf taurus (Muller and Troschel). Night sergeant

Night sergeants were occasionally seen in shallow reef areas, $3.5 \mathrm{~m}$ depth, but were not noted elsewhere. They are primarily herbivorous. Stomach contents of 17 specimens examined by Randall (1967) included $94.0 \%$ algae of 32 species plus diatoms. Most of the plants consumed were filamentous, but included 1 calcareous, 4 leafy, and 8 fleshy species.

Eupomocentrus fuscus (Cuvier and Valenciennes). Dusky Damselfish

This rather nondescript species was frequently observed on the reef in 5 to $18 \mathrm{~m}$ depth, sometimes grazing on filamentous algae nearby, but usually simply hovering. Randall (1967) indicates a wide range of food for $\underline{E}$. fuscus, but with more algae and detritus than animal material. of 51 specimens examined, $56.2 \%$ of the stomach 
contents consisted of organic detritus, diatoms and 25 species of algae, mostly filamentous, but including 5 fleshy, 2 calcareous, and 2 leafy species, plus diatoms. Beebee and Tee-Van (1928) suggest dusky damselfishes eat algae, small organisms, and "all manner of bottom detritus."

\section{Eupomocentrus leucostictus (Muller and Troschel). Beaugregory}

Beaugregories were occasionally observed on the main reef in depths to ten meters, always close to or occupying a crevice. Fourty-one specimens examined by Randall (1967) contained $22.6 \%$ algae and organic detritus, including diatoms, 5 filamentous, 1 fleshy, and 1 calcarenus species.

\section{Eupomocentrus planifrons (Cuvier). Yellow Damselfish}

This small, colorful species was common on the reef, several adults often occupying the same large coral head. Apparently most abundant in 3 to $10 \mathrm{~m}$ depth, yellow damselfishes were occasionally observed to $20 \mathrm{~m}$, sometimes in association with isolated coral heads on the algal plain. Juveniles were seen alone over small coral lumps, in accord with observations by Bohlke and Chapin (1968) in the Bahamas, where the species has been recorded from 4 to 85 feet. Randall (1967) examined 18 specimens that contained $24.4 \%$ algae and detritus including diatoms, 5 filamentous species, and fragments of the sea grass, Thalassia.

\section{Eupomocentrus partitus (Poey). Bicolor Damselfish}

This species was seen on the reef in 5 to $23 \mathrm{~m}$ depth, but was most evident in deeper parts of this range in association with isolated rocks and coral heads on the algal plain. Randall (1968) described two color phases correlated with depth; both were observed in Lameshur Bay, the "typical" color on reefs to about $15 \mathrm{~m}$ depth and the "deep water phase" on the algal plain.

Twenty meters from the face of the reef on a rock lump approximately $11 / 2 \mathrm{~m} \times 1 / 2 \mathrm{~m} \times 1 / 2 \mathrm{~m}$. there were at least 15 individuals of this species including two approximately $6 \mathrm{~cm}$ long, three $4 \mathrm{~cm}$ long, and ten $2 \mathrm{~cm}$ or less in length. On July 15, an attempt was made to see when the damselfishes left their nighttime crevices. None were apparent at 0534 hours when the observations were begun, but at 0545 , as darkness shaded to light, the two largest damselfishes came out of the rock, and within 15 minutes, all of the smaller fishes appeared to be up and active. At dusk, the damselfishes returned to hollows (apparently specific) in the rock. 
No previous records of food habits of this species have been found, but during this study individuals of all sizes were frequently observed nibbling filamentous algae that grew upon the rock, and one was seen taking large pieces of the flat-bladed brown algae, Dictyota. Other algae in the area apparently browsed upon by this or other species included the red algae Acanthophora, Dasya, Digenia, and Laurencia; the green algae Anadyomene, Halimeda, and Udotea, and the brown algae, Lobophora. Conspicuously perfect, however, were blades of the green algae, Avrainvillea, growing upon the rock home of the damselfishes. Eggs were attached to these blades with filaments, then guarded. Four such sites were located during the study, all on the algal plain in 22 to $23 \mathrm{~m}$ depth. Avrainvillea does not occur on the reef proper and no eggs were found with bicolor damselfishes living on the main reef.

Notes on the behavior and early development of E. partitus will be reported upon separately, based on frequent observations at three sites of breeding and egg guarding behavior, and collections of eggs taken. The observations agree well with comments by Bohlke and Chapin (1968) regarding $\underline{E}$. partitus in the Bahamas where the species is common on isolated patch reefs in depths between 25 and 75 feet. Males have been seen there guarding eggs attached to a firm substrate.

Microspathodon chrysurus (Cuvier). Yellowtail Damselfish

This small species was common on the reefs in Lameshur Bay associated with coral heads in depths at least $18 \mathrm{~m}$. They were often observed nibbling the fine algal turf growing upon rocks, dead coral, and the bases of living coral heads. Randall (1967) regards them as one of the most common reef fishes in the West Indies. He found stomach contents of 45 specimens to contain $89.3 \%$ algae plus some diatoms. All the algae, 16 species are filamentous. Beebee and Tee-Van (1928) recorded stomach contents; mostly chewed algae and bottom debris. Bohlke and Chapin (1968) commented that in the Bahamas M. chrysurus browses algae from dead coral surfaces, with no more than a few individuals occurring together at any given time.

\section{Labridae. Wrasses}

Although characteristically carnivorous, plant material may be taken by some species. Wrasses are common and conspicuous on coral reefs. Ahout 15 species are recorded for the Caribbean.

\section{Halichoeres bivittarus (Bloch). Slippery Dick}

This species is common on shallow reefs in Lameshur Bay. Although clearly preferring invertebrates, Randall (1967) found about 5\% of the stomach contents of 5 specimens to be the sea grass, Thalassia testudinum. 
This species was occasionally seen on reefs in Lameshur Bay active by day in depths to at least $15 \mathrm{~m}$. During feeding trials on the reef near the habitat, several $\mathrm{H}$. poeyi responded quickly, swimming directly from a coral head to Codium isthmocladium and Halimeda incrassata placed on open sand $\overline{1 / 2} \mathrm{~m}$ away. Bites were repeatedly taken from each clump of plants. Stomach contents of 34 specimens examined by Randall (1967) included only animal material, and the species is recorded by Randall (1968) and Bohlke and Chapin (1968) as primarily a resident of sea grass beds.

Scaridae. The Parrotfishes

Parrotfishes are perhaps the most conspicuous and abundant resident fishes on the reefs observed in Lameshur Bay. The 13 species known in the Caribbean are principally herbivorous, and therefore are of particular interest for this study, but most are difficult to determine in the field because of general similarity of form, great color variations, sexual differences and general lack of good distinguishing features. Spotting a scarid as a scarid is usually easy; determining species is usually difficult. Treatment of the family by Bohlke and Chapin (1968) is especially helpful in making identifications.

In general, all parrotfishes observed were seen during the day on the reef and to at least $60 \mathrm{~m}$ seaward on the algal plain. By night, several individuals were found inactive, in crevices. Notes included here are on fishes that I believe were accurately identified.

Scarus coeruleus (Bloch). Blue Parrotfish

Young individuals were occasionally seen, usually alone, but on July 17, a group of five moved along the reef edge to the algal plain and began to graze on Udotea at 0625 hours. No large humped adults were observed.

No reports have been found on the stomach contents of this species, but individuals during feeding trials were observed eating Halimeda, Udotea, and the sea grass, Syringodium. Longley and Hildeb $\overline{\text { rand (1928) }}$ reported that food is usually taken by browsing over the bottom, but once a school of $\underline{S}$. coeruleus was observed eating great mouthfuls of filamentous algae, and they were sometimes seen feeding actively on what seemed to be "perfectly hare sand." 
This is one of the most conspicuous and numerous fishes on reefs in Lameshur Bay, usually seen in groups that sometimes include other fish species. It is easily confused, even in the adult phase, with the princess parrotfish, S. taeniopterus. On July 27, from 0603 to 1018 hours, ten striped individuals of assorted sizes were observed feeding on diatoms and detritus collected on the "screen" of a sea fan; on July 8, midday, three moved together from the reef to the plain and began eating Avrainvillea, ignoring Udotea and other algal species in the area. On July 15, midday, six traveled together and on July 17, four large individuals were seen moving over the plain, pausing occasionally to graze. One to several (apparently of this species) were commonly seen in company with surgeonfishes, goatfishes and other species of parrotfishes in grazing groups on the algal plain. By day, several $\underline{\text { s.croicensis }}$ were always actively scraping filamentous algae (mostly Phaeophyta) from the habitat's surface. Among samples of 15 species of plants brought from the plain to the reef for feeding trials, $\underline{\text { s. croicensis }}$ selectively chose Halimeda.

Beebee and Tee-Van (1928) indicate that $\underline{\mathrm{S}}$. croicensis is common in beds of sea grass and that diet consists of algae, crustaceans, etc. Stomach contents of nine specimens examined by Randall (1967) included $100 \%$ algae of nine species, all filamentous or leafy.

$\underline{\text { Scarus taeniopterus (Desmarest). Princess or Painted Tail Parrotfish }}$

This species, difficult to distinguish from $\underline{\mathrm{S}}$. croicensis, was only seen on the reef. During feeding trials, one adult surveyed the assortment of 9 plant species offered, then selectively fed upon the sea grass, Syringodium. Randall (1967) examined stomach contents of eight specimens and found $81.2 \%$ filamentous algae (one had fed almost entirely on Polysiphonia ferulacea) and $17.3 \%$ consisted of the sea grass, Thalassia testudinum.

$\underline{\text { Scarus vetula (B1och and Schneider). Queen Parrotfish }}$

Individuals apparently of this species were occasionally seen on the main reef, but were not found on the algal plain. Randall examined 14 specimens and obtained $94.0 \%$ algae in the stomach contents, including 8 filamentous and 5 fleshy species. An additional $3.2 \%$ consisted of the sea grass, Thalassia testudinum.

Sparisoma aurofrenatum (Valenciennes). Redband Parrotfish

The redband parrotfish, commonly seen alone on the main reef, sometimes occurred with groups of grazing fishes on the algal plain. On July 20, at 0708 hours, seven $\mathrm{S}$. aurofrenatum were seen moving quickly away 
from the reef toward the plain where they began to graze. On the plain S. aurofrenatum was observed eating Udotea, which was bitten off in large pieces. In general individuals of this species seemed unconcerned about the presence of divers, often coming to within inches to feed on samples of plants brought to the reef from the algal plain. Among an assortment of nine plant species, a young $\underline{\mathrm{S}}$. aurofrenatum repeatedly selected Halimeda incrassata, twice sampled Udotea verticillosa, and once nibbled Lobophora during 15 minutes of observation. On another occasion, among samples of 12 plant species, a young redband parrotfish first tried Laurencia, then Iobophora, to which it returned three times, then moved to Udotea, and finally to Halimeda incrassata where it remained eating for several minutes, even driving away $\underline{\text { s }}$ croicensis of equivalent size that showed interest in the Halimeda. A second $\underline{S}$. aurofrenatum arrived during the observation and fed compatibly with a S. viride on a clump of Lobophora. This species commonly grazed on filamentous algae on the surface of the habitat.

Randa11 (1967) found 97.8\% algae in the stomach contents of 11 specimens, including 6 filamentous and 2 fleshy species, as well as $1.3 \%$ of the sea grass, Syringodium filiforme.

Sparisoma rubripinne (Valenciennes). Yellowtail Parrotfish

This species was often seen grazing on the algal plain northwest of the habitat in approximately $12 \mathrm{~m}$ depth, apparently feeding on species of Udotea and their epiphytes, as well as the sea grass, Syringodium.

Randal1 (1967) examined 18 specimens and found $92.6 \%$ algae in the stomach contents including 14 filamentous, 5 fleshy, 2 leafy, and one calcareous species, as well as $7.0 \%$ of the sea grass, Thalassia. Habits of $\mathrm{S}$. rubripinne are described in detail by Randal and Randa11 (1963).

\section{Sparisoma viride (Bonnaterre). Stoplight Parrotfish}

This species was occasionally seen on the reef and the adjacent algal plain. During feeding trails, $\underline{S}$. viride sampled the brown alga Lobophora variegata. Randall (1967) found $97.3 \%$ algae in the stomach contents of 20 specimens, including 8 filamentous, 2 leafy, and 2 fleshy species, plus $2.5 \%$ of the sea grass, Thalassia.

Longley and Hildebrand (1941) observed S. viride eating algae, and Beebee and Tee-Van (1928) recorded food of this species as "unrecognizable detritus." 
Gobiidae. The Gobies

Gobies are typically very small carnivorous fishes, common on tropical reefs. Seven species are known from the Caribbean.

Gnatholepis thompsoni (Jordan). Goldspot Goby

Fishes that I believe to be goldspot gobies were occasionally seen in open sandy areas within the main reef. Randall (1967) found $74.0 \%$ algae and detritus in the stomachs of ten specimens, and as much as $50 \%$ fine sand in the stomachs of some. Bohlke and Chapin (1968) indicate that these gobies feed by taking sand in their mouth, sorting out the food material, and ejecting residual sand from the gill openings.

Blennidae. The Blennies

Blennies are small fishes with varied food habits, common on tropical reefs. Several herbivorous species are known from the Virgin Islands, but only one species was observed during this study.

Ophioblennius atlanticus (Valenciennes). Redlip Blenny

Two redlip blennies lived in a crevice in a coral head near the entrance to the habitat. They were seen there frequently during daylight, as early as 0600 and as late as 1830 hours, often grazing on the attached filamentous algae. Randall (1967) examined 50 specimens and found $99.0 \%$ of the stomach contents to be algae and organic detritus, including 13 filamentous, 1 calcareous, 1 fleshy, and 1 leafy species.

Chaetodontidae. The Butterflyfishes and Angelfishes

Chaetodontids are common reef fishes with varied food habits, some members primarily herbivorous. Two main divisions are recognized; the butterflyfishes and the angelfishes. Eleven species are known from the Caribbean.

Chaetodon striatus (Linnaeus). Banded Butterflyfish

Individuals of this species were occasionally seen on the main reef, during daylight, occasionally pecking at the surface of rocks and corals, but it was difficult to determine just what material was being ingested. During a feeding trial on July 17, one fed upon Dictyota divaricata, ignoring 8 other plant species. Sixteen 
specimens examined by Randall (1967) contained no plant material, but Beebee and Tee-Van found algae with crustaceans and organic matter in specimens from Haiti.

\section{Holocanthus ciliaris (Linnaeus). Queen Angelfish}

Adult queen angelfishes were occasionally seen on the main reef, most often during the early morning hours, but presumably the species is active throughout the day. Twenty-six specimens examined by Randa11 (1967) contained mostly sponge material, but included two species of Dictyota, constituting $1.4 \%$ of the stomach contents.

\section{Holocanthus tricolor (Bloch). Rock Beauty}

Rock beauties were occasionally seen on the main reef, and several were associated with coral heads on the algal plain in depths to $23 \mathrm{~m}$, as much as $35 \mathrm{~m}$ from the main reef. Randall (1961) examined 24 specimens with stomach contents including mostly sponge material, but with $0.8 \%$ algae of three species. Beebee and Tee-Van (1928) indicate that food for this species is "algae and scrapings."

Pomacanthus arcuatus (Linnaeus). Gray Angelfish

Gray angelfishes were encountered every day throughout the mission, sometimes singly, but more often in groups of two to six. Because these fishes are unafraid of divers (often approaching to mouth bubbles from a scuba tank), numerous observations were made. They were among the first fishes up and active in the morning, and often appearing along the face of the main reef as night shaded to dawn, between 0530 and 0545 hours. Individuals were seen grazing on the algal plain as late as 1830 hours, but only once was one found at night, "resting" but exposed against a large coral head.

Once when filamentous and encrusting algae were being scraped from one of the plexiglass shark retreats in $18 \mathrm{~m}$ depth, six gray angelfishes approached and began eating the fragments that floated free in the water. They were often seen grazing on the algal plain, most frequently within $35 \mathrm{~m}$ of the reef, but three were observed $65 \mathrm{~m}$ distant on July 17 eating Udotea and Halimeda.

During feeding trials, $\underline{P}$. arcuatus nibbled most species that were brought from the algal $\bar{p}$ lain: the green algae Halimeda, Avrainvillea, Udotea, and Caulerpa, the red algae Acanthophora, Galaxura, Gracilaria, Hypoglossum, the brown algae Lobophora and Dictyota, and the sea grass, Syringodium. But a decided preference was shown for the large green 
alga, Codium, only found some distance from the reef on the algal plain. Among assorted species offered, Codium, was selectively chosen. On several occasions, gray angelfishes approached divers holding Codium and ate it from their hand. (They sometimes also chewed strings from the collecting bags and even pulled on long wisps of hair).

On July 20 at 0708 hours, a single gray angelfish appeared to be unusually still on a sand bottom near a small rock in $17 \mathrm{~m}$ depth close to the habitat. The fishes' pectorals were spread. It remained stationary as I approached until $I$ was less than 1 meter away; it then moved, and I saw that it had been parked at a cleaning station. Several transparent shrimp tumbled free when the angelfish moved away, and quickly returned to the tentacles of an anemone that lived along the side of the rock.

Randa11 (1967) found stomach contents of 34 gray angelfishes to contain $8.3 \%$ algae including 13 leafy, and 4 fleshy species, and $0.1 \%$ seagrass, Ruppia maritima. The remainder was mostly invertebrate, principally sponges and tunicates. A juvenile contained $75 \%$ filamentous algae.

Reports from others also indicate a mixed diet, including sponges (Lowe, 1962); mixed algae, hydroids, etc. (Beebee and Tee-Van 1928); algae and crustaceans (Gudger, 1929); invertebrates and vegetation (Breder, 1948); algae and sedentary animals (Longley and Hildebrand, 1941).

Pomacanthus paru (Bloch). French Angelfish

One large individual was seen on the main reef at midday; another (possibly the same one) was found nearby along the face of the reef at night (2130 hours), immobile, but exposed.

Sponges dominate the diet of 23 specimens examined by Randal1 (1967) but algae comprised $13.4 \%$ including 2 filamentous, 5 leafy, and 8 fleshy species, but one individual, the largest examined, contained only filamentous algae.

Acanthuridae. The Surgeonfishes

Three species of surgeonfishes occur in the West Indies, all of them common in Lameshur Bay, and all vegetarians. Their teeth are spathulate and denticulate on the edge, and the digestive tract very long (Breder and Clark, 1947), characteristics suited for obtaining and digesting plant material. Two species, Acanthurus chirurgus and A. bahianus have a thick-walled stomach. An attempt was made to see if the eating habits of the three species differed. 
Ocean surgeonfishes were frequently seen traveling over the reef, occasionally stopping to graze on filamentous algae, but they were most conspicuous and abundant on the algal plain, often in company with other surgeonfishes or mixed species of parrotfishes and spotted goatfishes. Adults were seen actively grazing on the plain as early as 0600 hours, and as late as 1830 hours, but none were found at night. Longley and Hildebrand (1941) suggest that the species is basically a bottom fish, with distribution correlated with the occurrence of the plants upon which they feed. In Lameshur Bay, adult ocean surgeonfishes were usually less than $35 \mathrm{~m}$ away from the reef, but one adult was observed at 0800 hours $60 \mathrm{~m}$ from the reef, and several juveniles (approximately $9 \mathrm{~cm}$ long) were seen at the most distant experimental cage along transect II, $180 \mathrm{~m}$ seaward.

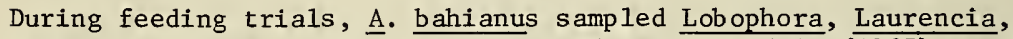
Halimeda, Udotea, Codium, and Syringodium. Randal1 (1967) examined 23 specimens and found $91.8 \%$ of the food present was algae including 13 filamentous, 5 leafy, 5 fleshy, and 3 calcareous species, plus diatoms, as well as 3 species of sea grasses, Syringodium filiforme, Halophila baillonis, and Thalassia testudinum, which comprised $8.2 \%$ of the total. About half of the stomach contents consisted of fine shell and sand.

\section{Acanthurus chirurgus (Bloch). Doctorfish}

Adults and juveniles of this species were occasionally seen in reef areas, but were most evident during the day on the algal plain as much as $35 \mathrm{~m}$ from the reef. One juvenile ca. $10 \mathrm{~cm}$ long was repeatedly observed associated with an isolated rock lump populated with bicolor damselfishes. The surgeonfish was seen emerging from a crevice in the rock at 0535 to 0540 hours on three occasions, just at first light. During the day, the fish (or one of that size) often was seen near the rock, nibbling algae, sometimes in company with a juvenile parrotfish).

During feeding trails, $\underline{A}$. chirurgus fed upon Halimeda, Udotea, Lobophora, Acanthophora, and the sea grass, Syringodium. On the algal plain, they were often seen in company with other surgeonfishes, one or more species of parrotfishes and spotted goatfishes, grazing on assorted algae, particularly Udotea, Dictyota, and Lobophora.

Randall (1967) examined 20 specimens and found food in the stomachs to contain $93.9 \%$ algae and organic detritus, including 9 filamentous, 3 calcareous, 4 leafy, 2 fleshy species, plus diatoms, and $5.7 \%$ sea grasses, Syringodium and Thalassia. Sand and other inorganic matter 
comprised 25 to $75 \%$ of the total contents. Longley and Hildebrand (1941) found this species to be almost entirely herbivorous with stomach contents holding $2 / 3$ to $3 / 4$ foreign material, and Beebee and Tee-Van (1928) described stomach contents for this species as "unidentifiable vegetable matter and animal matter."

Acanthurus coeruleus (Bloch and Schneider). Blue Tang

Adults and the bright yellow young of this species are common on reefs in Lameshur Bay. Juveniles were seen around experimental cages, isolated rocks, and occasionally among dense stands of mixed algae on the algal plain almost to the limit of attached vegetation ( 150 to $180 \mathrm{~m}$ seaward). Adults were observed as much as $35 \mathrm{~m}$ from the reef, grazing on the algal plain. On two occasions, adults were seen, immobile, in hollows (but exposed) in the reef at night. By day, A. coeruleus traveled in groups of 4 to 6 , and frequently accompanied $A$. bahianus or $A$. chirurgus, together with one or more species of parrotfishes and several spotted goatfishes.

During feeding trials, A. coeruleus took samples of the sea grass, Syringodium, and the algae Lobophora, Caulerpa cupressoides and Halimeda incrassata from assortments including 9 to 15 plant species. Several individuals were usually present during the day, grazing on the fine turf of filamentous plants growing on the surface of the habitat. On the plain species of Udotea appeared to be the principal food taken, but A. coeruleus was also observed feeding upon Lobophora, Dictyota, and frequently browsed on filamentous species on coral heads and rocks.

Randa11 (1967) examined stomach contents of 27 specimens and found algae and detritus to comprise $92.8 \%$ of the diet, including 16 filamentous, 3 calcareous, 6 fleshy, and 5 leafy species, plus diatoms and $6.8 \%$ of the sea grasses, Syringodium and Halophila. Randa11, as well as Longley, Schmitt, and Taylor (1925) found little foreign matter mixed with the algal food of this species, in contrast to sand and gravel that was common in the gizzardlike stomachs of $\underline{A}$. chirurgus and $\underline{A}$. bahianus. No striking differences in the food habits among the three species were observed during this study, however, except that $A$. coeruleus was more frequently seen on the reefs, browsing on fine algae attached to hard surfaces, and was less common than the other surgeonfishes on the algal plain.

Balistidae. Triggerfishes

Balistids are common reef fishes with small mouths and powerful jaws, typically carnivorous, but there are several plant-eating species. One West Indian triggerfish, Melichthys niger, that reportedly shows a preference for plant food. (Randall, 1967), was not seen during the study. 
Queen triggerfishes were often observed on the main reef, and were commonly seen on the algal plain, rarely in company with a group of mixed grazing fishes, but usually solitary. Once, four B. vetula were seen grazing close together on the algal plain, but they behaved as individuals, without group organization.

Single fishes were commonly observed during the day as much as $35 \mathrm{~m}$ from the reef, but range to at least $100 \mathrm{~m}$ distant, as was shown by the occurrence of three queen triggerfishes inside experimental cage 2 along transect $I$. They apparently slipped under the side of the cage, and could move in or out at will, although the edges of the cages were in firm contact with the substrate. On July 9 at 1830 hours, all three triggerfishes were inside the cage, one about $35 \mathrm{~cm}$, the second about $30 \mathrm{~cm}$ and the last $20 \mathrm{~cm}$, standard length. With them were two spotted goatfishes, and hovering over the cage was a barracuda approximately one meter long. The same scene was present at 1500 hours on July 10: the cage intended to exclude grazers held three triggerfishes, two goatfishes, and a school of small snappers, and on the top was parked a barracuda.

The cage was examined frequently thereafter, day and night, and during the next ten days, at least one, and sometimes all three triggerfishes (apparently the same individuals) were present, sometimes in company with one or more goatfishes. A barracuda was often seen during the daylight observations, but was not present at night. The last observations were made on July 18 . At midday, all three triggerfishes were in the cage; at 2330 hours, the largest was absent.

Several queen triggerfishes were observed repeatedly returning to a selected site for the night. One small individual occupied a rock lump inhabited principally by bicolor damselfishes. It was seen emerging from the same crevice several mornings within a minute or two of 0545 hours, and returning at dusk.

One large rock on a north-south transect line approximately $100 \mathrm{~m}$ north of the habitat was occupied at night by a triggerfish about $20 \mathrm{~cm}$ long, S.L. It was first observed at dusk, 1920 hours, on July 9. A small grouper was in the desired crevice, and was quickly driven out by the triggerfish. The triggerfish then circled the rock, lowered near the entrance, swam away a few feet, returned, hovered near the entrance, again rose above the rock, lowered, then deftly, quickly, ducked into the crevice and wedged there. The same 
indiyidual (apparently) was seen several times in the same hollow at night until July 16. Then and for three days following, the place was occupied by a grouper at night, but on July 19, the triggerfish was again in the crevice at 1930 hours.

The night resting places of nine queen triggerfishes were found in a11. All that were visible were resting on one side except those that stayed inside the experimental cage.

During the feeding trials, no queen triggerfishes came to sample plants, but on the algal plain, they were observed taking bites of Halimeda, Udotea, and Lobophora, Randa11 (1967) examined 97

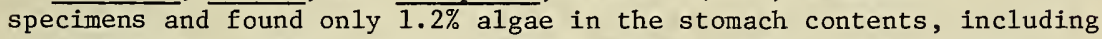
5 calcareous, 2 leafy, and 1 fleshy species. The principal food appears to be echinoids ( $72.8 \%$ in Randall's study), although the diet may vary depending on the food available. Beebee and Tee-Van (1928) found Thalassia and small crustaceans in the stomachs of two specimens from Haiti.

\section{Monocanthidae. Filefishes}

Filefishes, closely related to triggerfishes, have varied food habits. Eight species are known from the West Indies, including five kinds that eat plants, but only small individuals of one (or perhaps two) species were observed during the study.

\section{Monocanthus ciliatus (Mitchell). Fringed Filefish}

Numerous small filefishes that I believe to be of this species were frequently observed associated with algae and sea grasses on the plain as far distant as plant cover extended. Individuals were often seen head downward, close to a frond of Halimeda or Syringodium, and occasionally were seen nibbling filamentous epiphytes.

Randal1 (1967) found stomach contents of 14 specimens to contain $21.2 \%$ algae, all filamentous, with organic detritus, as well as $15.4 \%$ of the sea grass, Thalassia testudinum.

The habits of these filefishes observed agree we11 with observations recorded by Longley and Hildebrand (1941) and Bohlke and Robins, who most commonly found $\underline{M}$. ciliatus associated with beds of sea grass. 
Trunkfishes comprise a small but often conspicuous element of the fish fauna of a reef. Their occurrence in exposed places on the reef and plain, day and night, suggests some measure of immunity from predation that may be afforded by the bony box that encases the fishes' body. Food habits are varied, but many eat some plant material. Five species are known from the West Indies; three were encountered during the study.

Acanthostracion quadricornis (Linnaeus). Scrawled Cowfish

Solitary individuals apparently of this species were commonly seen on the algal or sand plain within 35 meters of the reef. At night, they were inactive but exposed on the same plain where they occurred during the day.

None responded to feeding trials, but one was seen biting a tip from a Halimeda plant on the plain. Randall (1967) examined six specimens and found Halimeda and blue-green alga to comprise $7.2 \%$ of the stomach contents, and the sea grass, Thalassia, $3.0 \%$.

\section{Lactophrys trigonus (Linnaeus). Trunkfish}

Several large trunkfishes of this species were observed along the face of the reef and on the plain to at least $25 \mathrm{~m}$ distant, day and night. They were not seen eating, but Randall (1967) reported that 21 specimens contained $4.9 \%$ algae ( 4 filamentous, 2 calcareous, 2 fleshy, and 1 leafy species) as well as $3.0 \%$ of the sea grasses, Syringodium and Thalassia. Randall (1968) suggested that the species is primarily a resident of the sea grass habitat.

\section{Lactophrys triquerter (Linnaeus)}

Lone smooth trunkfishes were occasionally encountered on the reef and at night, on the plain within $30 \mathrm{~m}$ of the reef. They were not observed eating, but food habits apparently may range from primarily herbivorous (Beebee and Tee-Van, 1928; Longley and Hildebrand, 1941) to primarily carnivorous (Randal1, 1967). Randall examined 17 specimens from the West Indies and found only $0.9 \%$ of the alga, Halimeda, and $1.2 \%$ of the sea grasses, Halophila and Thalassia. 
Two members of this family are known from the West Indies but only one species was found during the study. Food habits are varied with plant material included among a wide assortment of invertebrates.

Sphaeroides spengleri (Bloch). Bandtail Puffer

Only juveniles of this species were encountered, all on the densely vegetated algal plain and sea grass beds. They were often observed picking at the tufts of fine filamentous epiphytic algae growing on Syringodium. Thirty-one specimens were examined by Randall (1967) and were found to contain $3.5 \%$ algae and detritus, and $5.3 \%$ of the sea grasses, Halophila and Thalassia, and indicated that plant material did not exceed $25 \%$ in any single specimen, the usual amount less than $5 \%$.

Canthigasteridae. The Sharpnose Puffers

Sharpnose puffers, often included with the Tetraodontidae, are represented by a single but common species in the West Indies.

\section{Canthigaster rostrata (Bloch). Sharpnose Puffer}

Individuals 5 to $6 \mathrm{~m}$ long were occasionally seen by day in reef areas and associated with isolated rock and coral heads on the algal plain. Smaller individuals were observed among plants on the plain. None were seen at night. Randall (1967) examined the stomach contents of 31 specimens and found $2.2 \%$ to consist of organic detritus and two species of algae, Eucheuma and Laurencia. Four fishes examined by Randall (from Puerto Rico) contained $78 \%$ Syringodium, and $20 \%$ of contents of three other fishes consisted of the sea grass, Halophila. Indo-Pacific specimens of the related $\mathrm{C}$. solandri were reported by Hiatt and Strasburg (1960) to contain $\overline{81 \%}$ algae.

\section{Diodontidae. Porcupinefishes}

Only one of the four species of this family recorded for the West Indies was encountered during this study. Most feed exclusively upon invertebrates. 
This species was encountered twice, once at midday, once just before dawn on the main reef in $15 \mathrm{~m}$ depth. Although primarily carnivorous, Beebee and Tee-Van (1928) indicate that food includes algae. Three specimens examined by Randall (1967) included plant material (Dictyota and sea grass), but Randall suggests that the plants may not have been eaten intentionally.

Ogcocephalidae. The Batfishes

Two members of this family have been reported from the West Indies by Randall (1968), and one species was observed during the present study. Although primarily carnivorous (and equipped with "lure" on the head), plant material is sometimes taken.

Ogcocephalus nasutus (Valenciennes). Shortnose Batfish

A shortnose batfish was found $180 \mathrm{~m}$ away from the reef in $24 \mathrm{~m}$ depth at the edge of the algal plain in an open area of calcareous sand. It was easily captured by hand, and when released, was immediately pursued and bitten by a large Lutjanus, probably the mutton snapper, L. analis. After the one bite, the snapper ignored the batfish and swam away. The batfish, after a short, vigorous swim, settled down and became partially covered and concealed by the calcareous substrate.

Randall (1967) found principally invertebrates in the stomachs of 9 specimens examined, but $11.1 \%$ of the total consisted of the spherical green alga, Valonia utricularis. A diet consisting totally of invertebrates was recorded by Reid (1954) in 20 specimens from Florida. 
Observations were made on the mixed assemblages of fishes that ate together. There is great temptation to regard these groups as herds or flocks because of the resemblance to sheep or cattle grazing in a pasture. Typically, individuals of several species traveled as a group, but separated by species to feed. In groups consisting of single species of different sizes, members commonly sorted out by size to feed.

Examples of mixed groups that were seen include the following:

June 30,1130 hours. As a group, 8 parrotfishes ( 2 species), 7 surgeonfishes ( 3 Acanthurus coeruleus, 4 A. chirurgus), 4 spotted goatfishes, traveled over the reef in $9 \mathrm{~m} \mathrm{depth}$. They converged on a single dead coral head covered with fine filamentous algae and nibbled it thoroughly for 2 or 3 minutes, then moved to an open sandy area.

June 8, 1100-1130 hours. A group consisting of five parrotfishes ( 2 species), 9 surgeonfishes ( 3 A. coeruleus, 6 A. chirurgus), 3 queen triggerfishes, and three spotted goatfishes moved together over the algal plain 20-25 m from the reef in $20 \mathrm{~m}$ depth. The group broke apart and reconvened several times during 30 minutes of observation, with all of one species usually splitting off together. When separated, the area covered was approximately $10 \mathrm{~m}^{2}$; when reunited, approximately $3 \mathrm{~m}^{2}$. Triggerfishes traveled with the group but grazed as individuals. Ground cover included species of Udotea, Dictyota, Avrainvillea, Anadyomene, and mats of blue-green alga.

July 9, 1730 hours. Fourteen parrotfishes (Scarus croicensis) and 1 surgeonfish (A. coeruleus) traveled together, nibbling on plants on the algal plain in $19 \mathrm{~m}$ depth, $20 \mathrm{~m}$ from the base of the reef.

July 15, 1600 hours. Six surgeonfishes ( 3 A. coeruleus, 3 A. bahianus) traveled together, then grazed separately by species $15 \mathrm{~m}$ from the face of the reef on the plain in $17 \mathrm{~m}$ depth.

July 16, 0700 hours. A group consisting of 9 surgeonfishes ( 6 A. bahianus, 3 A. coeruleus) 4 spotted goatfishes, 2 parrotfishes (Sparisoma aurofrenatum)? traveled together over the reef in 16-18 $\mathrm{m}$ depth, then moved onto the plain and began to graze.

July 18,1200 hours. Numerous grazers were active on the algal plain $35-40 \mathrm{~m}$ from the face of the reef in $20 \mathrm{~m}$ depth. One group consisted of 7 parrotfishes ( 2 species), 12 surgeonfishes ( $8 \mathrm{~A}$. coeruleus, 4 A. chirurgus), and 6 spotted goatfishes. 
July 20, 0725 hours. A group consisting of 2 parrotfishes (Sparisoma aurofrenatum), 8 surgeonfishes (A. bahianus), and 4 spotted goatfishes, moved together over the plain in $15 \mathrm{~m}$ depth $20 \mathrm{~m}$ from the reef.

\section{FISH FEEDING TRIALS}

On eight occasions, samples of plants were collected on the algal plain and brought into the habitat, sorted by species, tied in bundles, and weighted with small pieces of lead. The bundles were then placed on level sand between the habitat and the reef, and notes were made on the responses of fishes in the area during the hours and days that followed:

Chlorophyta included in the trials were Anadyomene stellata, Avrainvillea nigricans, Caulerpa ashmeadii, $\underline{\text { C. cupressoides, }}$ C. mexicana, C. prolifera, Codium isthmocladium, Halimeda incrassata, $\overline{\mathrm{H}}$. $\overline{\text { simulans, }}$ Penicillus capitatus, $, \overline{\text { P. dumetosus }}, \overline{\text { P. pyriformis, }}$ Ũdotea conglutinata, Udotea cyathiformis, U. verticillosa; the Phaeophyta were: Dictyota dichotoma, D. divaricata, and Lobophora variegata; the Rhodophyta: Acanthophora spicifera, Digenia simplex, Galaxura flagelliformis, Gracilaria cylindrica, Laurencia intricata, L. papillosa and Wrightiella tumanowiczii; the Spermatophyta: Syringodium filiforme.

Some plants attracted more attention than others, and were consumed rapidly. Codium, Halimeda, and Wrightiella were most readily taken, and usually were totally eaten within 24 hours. Syringodium, Acanthophora, Anadyomene, Galaxura, Gracilaria and species of Gaulerpa, Udotea, Dictyota, and Laurencia, were readily eaten by several fish species, but remained after 24 hours. Species of Penicillus and Avrainvillea were largely ignored, and plants remained almost intact several days after presentation. 
To understand dynamics of life on a reef, some knowledge about predator-prey relationships is essential. Pages 27, 28, 29 and 30 are a listing of fishes and invertebrates in Lameshur $B$ ay and some of their known predators, based principally on data obtained by De Sylva (1963), Randall (1964, 1967), and Randall, Schoroeder and Starck (1964).

\section{Plant-eating Species}

Fishes

Abudefduf $\underline{\text { saxatilis }}$

Acanthurus sp.

Acanthurus sp., juvenile and larval

Acanthurus bahianus

Acanthurus bahianus, larval

Acanthurus coeruleus

Acanthurus coeruleus, juvenile

Alutera scripta

Balistes vetula

\section{$\underline{\text { Predators }}$}

Myctoperca venenosa (yellow fin grouper); Petrometopon cruentatum (graysby).

Ginglymostoma cirratum (nurse shark); Dasyatis americana (sting-ray); Tylosurus crocodilis (houndfish); Aulostomus maculatus (trumpetfish); Epinepheleus striatus (Nassau grouper); Myctoperca tigris (tiger grouper).

Caranx ruber (bar jack); Alphestes afer (mutton hamlet); Cephalopholis fulva (coney); Scorpaena plumieri (spotted scorpionfish).

Sphyraena barracuda (great barracuda); Myctoperca tigris (tiger grouper); M. venenos a (yellowfin grouper); Lutjanus analis (mutton snapper).

Aulostomus maculatus (trumpetfish).

Sphyraena barracuda (great barracuda).

Myctoperca tigris (tiger grouper); Caranx ruber (bar jack).

Sphyraena barracuda (great barracuda). Sphyraena barracuda (great barracuda). 
Plant-eating Species

Cantherhines pullus

Ginglymostoma cirratum (nurse shark); Cephalopholis fulva (coney); Epinephelus adscensionis (rock hind); E. guttatus (red hind); E. striatus (Nassau grouper); Lutjanus apodus (schoolmaster).

Cantherhines pullus, juvenile Myctoperca tigris (tiger grouper).

Canthigaster $\underline{\text { rostrata }}$

Diodon sp.

Hemiramphus brasiliensis

Holocanthus tricolor

Lactophrys sp.

Microspathodon chrysurus

Monocanthus sp.

Monocanthus tuckeri

Ophioblennius atlanticus

Eupomacentrus sp.

Eupomacentrus Euscus

Eupomacentrus pictys

Eupomacentrus planifrons
Sphyraena barracuda (great barracuda).

Sphyraena barracuda (great barracuda); Epinephelus itajara (jewfish).

Scomberomorus regalis (Cero).

Lutjanus jocu (dog snapper).

Priacanthus cruentatus (glasseye).

Epinephelus striatus (Nassau grouper).

Galeocardo cuvier (tiger shark); Lutjanus analis (mutton snapper).

Cephalopholis fulva (coney).

Aulos tomus maculatus (trumpetfish); Myctoperca tigris (tiger grouper); Caranx ruber (bar jack).

Aulostromus maculatus (trumpetfish); Myctoperca venenosa (yellowfin grouper).

Epinephelus striatus (Nassau grouper); Myctoperca tigris (tiger grouper); M. venenosa (yellowfish grouper); Lutjanus apodus (schoolmaster).

Aulostomus maculatus (trumpetfish).

Myctoperca tigris (tiger grouper); M. venenosa (yellowfin grouper); Caranx ruber (bar jack). 
$\underline{\text { Plant-eating Species }}$

$\underline{\text { Scarid }}$

Scarus sp.

Scarus coeruleus

$\underline{\text { Scarus }}$ croicensis

S carus guacamaia

Scarus vetula

Sparisoma sp.

Sparisoma aurofrenatum

Sparisoma viride

\section{Predators}

Sphyraena barracuda (great barracuda); Cephalopholis fulva (coney); Epinephelus guttatus (red hind); E. striatus (Nassau grouper); Myctoperca tigris (tiger grouper); Lutjanus analis (mutton snapper);

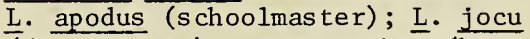
(dog snapper); Caranx ruber (bar jack).

Gymnothorax vicinus (moray); Lutjanus iocu (dog snapper).

Sphyraena barracuda (great barracuda).

Myctoperca interstitialis (yellowmouth grouper); $M$. venenosa (yellowfin grouper); Caranx ruber (bar jack); Sphyraena barracuda (great barracuda).

Sphyraena barracuda (great barracuda).

Epinephelus striatus (Nassau grouper); Myctoperca venenosa (yellowfin grouper).

Lutjanus apodus (schoolmaster); L. jocu (dog snapper); Caranx bartholomaei (yellow jack); Sphyraena barracuda (great barracuda); Epinephelus adscensionis (rock hind); E. tigris (tiger grouper).

Epinephelus striatus (Nassau grouper); Lutjanus apodus (s choolmas ter); Caranx ruber (bar jack).

Lutjanus jocu (dog snapper); Caranx ruber (bar jack). 
Plant-eating Species

Sphaeroides sp.

Sphaeroides spengleri

\section{Echinoid}

Diadema antillarum $\underline{\text { Predators }}$

Cephalopholis fulva (coney).

Lutjanus analis (mutton snapper); Sphyraena barracuda (great barracuda).

Mollus c

$\underline{\text { Strombus gigas }}$
Fishes: Balistes vetula, Canthidermis sufflamen, Trachinotus falcatus, Diodon hystrix, Bodianus rugus, Halichoeres radiatus, Lactophrys bicaudalis, Anisotremus surinamensis, Haemulon carbonarium, $\underline{\mathrm{H}}$. macrostomum, H. plumeri, $\underline{H}$. sciurus, Calamus bojonado, C. calamus, Sphaeroides spengleri; Molluscs: Cassius;
Crustacean: Panulirus argus.

Fishes: Galeocarda cuvieri, Aetobatis narinari, Dasyatis americana, Epinephelus striatus, Petrometopon cruentatum, Lutjanus analis, L. jocu, L. griseus, Ocyurus chrysurus, Haemulon plumieri, H. sciurus, Trachinotus falcatus, Lachnolaimus maximus, Balistes vetula, Diodon hystrix; Loggerhead turtle: Caretta caretta; Molluscs: Fasciolaria tulipa, Murex pomum, Pleuroplca gigantea, Octopus vulgaris; Crustacea: Petrochirus diogenes, Panulirus argus.

VI-166 
Relationships among plants and herbivores on a tropical reef are obyiously complex, yet certain patterns are clear. Evidence gathered during the present study supports the findings of Randall (1961, 1965, 1967), Hiatt and Strasburg (1960) and Stephenson and Searles (1960) suggest that tropical marine vegetation is markedly influenced by herbivores, especially fishes, and fishes are affected by the availability of food plants.

\section{Distribution of Plants and Plant-eating Fishes}

Distribution of benthic plants in Lameshur Bay is basically limited by availability of suitable substrate, light conditions, and other physical factors in the environment. But the diversity and abundance of vegetation on and in the immediate vicinity of the reef is directly related to the occurrence of herbivorous fishes. This is illustrated by the gradual increase in number and kind of attached plants along two transect lines extending seaward from the reef, with concurrent diminuition of herbivorous fishes. Further evidence is provided by the increase in plant growth within cages designed to exclude grazing fishes. After seven weeks, within cages placed in areas where grazing fishes were common, there was appreciable increase in plant growth. Within cages placed where grazing fishes were rare (more than $100 \mathrm{~m}$ from the reef), plant growth was comparable with the adjacent unprotected area, and in some, there was apparent reduction in plants within the cages in this area, perhaps in part because of the activity of small fishes that entered the cages, in part because of light reduction due to heavy growth of filamentous algae on the outside of the cages (much greater than on cages close to the reef). At the outer margin of plant cover, approximately $200 \mathrm{~m}$ from the reef, physical factors, notably light and unsuitable substrate, may limit growth.

Results compare favorably with a study of Randall (1961) in Hawaji, where growth of plants within wire enclosures on a reef attained as much as 15 to $30 \mathrm{~mm}$ while algal outside averaged $1 \mathrm{~mm}$ in height, the difference attributed by Randall to heavy grazing outside the enclosure. In Lameshur Bay, Randall (1961) also observed appreciable growth of attached algae within a wire enclosure over one square yard of reef during ten weeks of observation, although the enclosure contained at least 16 herbivorous urchins, Diadema antillarum, that were being studied. The urchins tripled in size during the study, but algae inside the cage nonetheless grew much more than algae outside. 
Soon after the cage was removed, parrotfishes and surgeonfishes began grazing on the plants.

Except in local areas where certain large herbivorous echinoids or molluscs may be abundant, the influence of plant-eating invertebrates in Lameshur Bay is probably minimal compared to the influence of grazing fishes. This stands in striking contrast to the situation in several cold-water regions where herbivorous echinoids dramatically affect the diversity and abundance of marine plants (Leighton, et al., 1966; Kain and Jones, 1966; Jones and Kain, 1967). It is perhaps significant that these areas have few plant-eating fishes.

Some species of fishes in Lameshur Bay showed clear preference for certain kinds of plants, including species that were not found within the normal grazing range. This suggests that favored species may be eaten as fast as they sprout close to the reef, and that survival in the area is in part limited by the distribution of herbivores. Some plants, notably species of Avrainvillea, Udotea, Dictyota, and the sea grass, Syringodium filiforme, were able to thrive close to the reef despite heavy grazing, although abundance increased away from the reef.

Distribution of animals in a given area is influenced by availability of food, suitable physical surroundings (including appropriate shelter for many species), and distribution of predators.

Randall (1967) illustrated the influence of plants on fish distribution in Lameshur Bay by comparing concentration of fish on two natural reefs and an artificial reef. Although the natural reef seemed to provide more favorable habitats, concentration of fishes on the artificial reef was eleven times that of the natural, apparently because of proximity of the artificial reef to a sea grass bed, and thus a ready source of food.

Most adult plant-eating fishes live on or close to reef areas in Lameshur Bay with a few individuals occupying crevices at night on scattered rock or coral heads on the open plain (Fig. 10). Most stay within $30 \mathrm{~m}$ off the reef, but occasionally groups of surgeonfishes and parrotfishes were seen as much as $60 \mathrm{~m}$ seaward on 
the algal plain, as were long queen triggerfishes and one or more gray angelfishes. Queen triggerfishes, at least, range further, clearly shown by three individuals that were in-and-out residents of cage two along transect line one, $100 \mathrm{~m}$ from the face of the reef.

Food is abundant well beyond the normal foraging range, including some plant species that feeding trials showed to be preferred to the species growing close to the reef. Presumably, predators that roam the algal plain, such as barracuda, certain snappers, and sharks, prey upon fishes that are exposed, away from the reef or other cover. Small fishes can escape predation by hiding among the plants on the algal plain, but those more than 10 to $15 \mathrm{~cm}$ long would find cover with difficulty in this area. Small surgeonfishes, parrotfishes, triggerfishes, puffers and filefishes (under $10 \mathrm{~cm}$ long) were seen throughout the algal plain to the limit of plain cover.

Trunkfishes, cowfishes, and boxfishes, with anatomy that discourages many predators, were seen close to the reef on the open algal plain, day and night. Except for Ostraciontids, all plant-eating fishes observed during this study sought cover at night. All grazing activity apparently takes place during daylight, starting for most species just after sunup, and ending just before sundown. Despite concerted efforts, it was virtually impossible to find a plant-eating fish during the night except for the exposed Ostraciontids, partially concealed queen triggerfishes and parrotfishes, and occasional angelfishes and surgeonfishes, found only with moderate cover. Damselfishes, gobies, and blennies remained deep within crevices which they stayed near during the day.

Distribution of herbivorous marine fishes on a worldwide basis shows a remarkable concentration (both in diversity and biomass) on tropical reefs, and a proportionately small number in temperate and arctic seas (Hiatt and Strasburg, 1960). To a botanist, it is even more remarkable to note, in parallel, that plants in tropical areas, although diverse in kinds, are in general small and inconspicuous, while in cold and temperate seas, forests of giant kelps and other large seaweeds are characteristic. 
Mead (1970) conjectured: "The extent of the algal forest (but not its diversity) increases poleward. The abundance of the advanced percoid herbivores decreases poleward. Is there a causal correlation?" There may well be, although other factors, such as respirationphotosynthesis ratios, amount of dissolved oxygen, and available nutrients in cold versus warm seas must be considered.

Percoid fishes, which include most marine herbivorous fishes, are believed to have evolved in the tropics, and radiated into temperate, and to a lesser extent, polar seas (Mead, 1970).

Most herbivorous marine fishes are recent, structurally advanced and specialized, with striking morphological and physiological adaptations to obtain and digest plant material (Hiatt and Strasburg, 1960; Mead, 1970; Suyehiro, 1942). This represents influence of plants on the evolutionary history of fishes. It is tempting to speculate (as had Mead, 1970) about the nature and extent of the algal forest of tropical seas prior to the appearance of percoid herbivores, and to wonder if morphology, distribution and general aspect of tropical marine plants have developed in part in response to heavy grazing, clearly a significant environmental factor.

The Food Web

Ecologists have puzzled over the apparent anomaly presented by coral reefs that characteristically abound with animal consumers, but are almost devoid of conspicuous plant producers. Odum and Odum (1955) helped to solve the question at Eniwetok Atoll by finding that zooxanthellae living within the tissues of coral and filamentous algae in the coral skeletons may make coral heads more plant than animal by a ratio of about $3: 1$. This, together with dense but inconspicuous turfs of filamentous algae on rocks and sand provide food for many reef species. At Eniwetok and in the Marshall Islands, corals and associated algae apparently contributed substantially to the food available to fishes (Odum and Odum, 1955; Hiatt and Strasburg, 1960). But in the West Indies, corals are apparently not utilized much for food by fishes of any kind (Randa11, 1967).

Randal1 found three families of West Indian Fishes to be almost entirely dependent on benthic algae as primary food (Kyphosidae, the sea chubs; Scaridae, the parrotfishes; Acanthuridae, the surgeonfishes), and many species in other families to rely wholly or partially on attached plants for sustenance. 
It is significant that fishes of the second trophic layer, the herbivores, are commonly the most abundant fishes in a reef community. Odum and Odum (1955) found a striking predominance (on a weight basis) of herbivorous parrotfishes, surgeonfishes, damselfishes, and butterflyfishes in comparison to wrasses, groupers, and other carnivores. Hiatt and Strasburg (1960) found herbivores to dominate reefs in the Marshall Islands, and Bardach (1959) found that omnivores (said to be mostly herbivorous) far outnumbered carnivores on a large Bermuda reef (but not on a smaller, isolated reef).

Randa11 (1963) surveyed the fishes to two natural reef areas at St. John, Virgin Islands, one a $600 \mathrm{~m}^{2}$ part of a fringing reef in Lameshur Bay, averaging $3 \mathrm{~m}$ depth, the other $297 \mathrm{~m}^{2}$ of fringing reef in about the same depth at Ram Head Bay. The two sites yielded (by weight) $24.3 \%$ herbivores (Scaridae, Acanthuridae, and Blennidae), $15.8 \%$ omnivores (Pomocentridae, Chaetodontidae, and Monocanthidae) and $59.9 \%$ carnivores (the remaining families). Randall emphasized that many fishes that live on coral reefs depend on food that does not come from the reef proper. He cited certain grunts, snappers, and certain plankton feeders, but in Lameshur Bay, this would certainly apply as well to many species that graze throughout the day on the adjacent algal plain, notably parrotfishes and surgeonfishes.

The parrotfishes were found to be the largest family by weight, at both reef sites studied by Randa11, and dominance of this family as a rule throughout the West Indies was suggested.

It has been established that plant-eating fishes influence the kind and number of marine plants on and near coral reefs. But some significant questions presently are unanswered. To what extent do carnivores influence the kind and number of plant-eating fishes; i.e., what influence do carnivores have on plant distribution? Bardach (1959) concluded that (in Bermuda) "carnivorous fish rarely feed upon omnivorous ones; no angelfish or surgeonfish were found in the stomachs of carnivores, and young parrotfish were only partially ingested." He attributed most herbivorous activity, and most food for carnivorous fishes, to invertebrates.

Randall's evidence (1963, 1967) contradicts Bardach's conclusions, at least in part, as parrotfishes and surgeonfishes were found to comprise a significant percentage of the food of carnivores in the West Indies. Parrotfishes are regarded by Randall (1963) as perhaps the principal family of West Indian fishes eaten by predators except on isolated patch reefs. 
What happens when 1 arge predators are selectively removed from a reef--the snappers, groupers, barracudas, and sharks? Is a chain of events set in motion that can be likened to certain food chains on land? For example, when hawks and owls are selectively killed in a farm area, a notable increase in small rodents frequently results, and certain plants, especially grain crops, may be markedly reduced. Where cougars and coyotes are eliminated, deer and rabbits may become so common that vegetation is overgrazed, to the ultimate detriment of the deer, rabbits, and an entire ecosystem (Leopold, 1943, 1947; Clarke, 1954). What happens on a reef where large predators are reduced in numbers? It is certain that change occurs, but documentation of what happens remains to be done. 
Backus, G. J., 1964. The effects of fish-grazing on invertebrate evolution in shallow tropical waters. Allan Hancock Found., Occ. Pap. no. 27:29 pp.

Bardach J. E., 1959. The summer standing crop of fish on a shallow Bermuda reef. Limnol. and Oceanogr. 4(1):77-85.

Beebee, W. and J. Tee-Van, 1928. The fishes of Port-an-Prince Bay, Haiti with a summary of the known species of marine fish of the island of Haiti and Santo Domingo. Zoologica 10(1):1-279.

Bohlke, J. E. and C. G. Chapin, 1968. Fishes of the Bahamas and adjacent waters. Livingstone Pub1. Co., Wynnewood, Pa. 771 pp.

Borgesen, F. 1913-1920. The marine algae of the Danish West Indies. I. Chlorophyceae. Dansk Bot: Arkiv, 1:1-158 + 2, 1913. Id., II, Phaeophyceae, ibid., 2:1-66+2, 1914. Id., III, Rhodophyceae, a, ibid., 3:1-80, 1915. Id., b, ibid., 3:81-144, 1816. Id., c, ibid., 3:145-240, 1917. Id., d, ibid., 3:241-304, 1918. Id., e, ibid., 3:305-368, 1919. I.., $\mathrm{f}$, ibid. , 3:369-504, 1920.

Breder, C. M., 1948. Field book of marine fishes of the Atlantic coast from Laborador to Texas. G. P. Putnam's Sons, New York. XXXVII + $332 \mathrm{pp}$.

Clarke, G. L. 1954. Elements of ecology. John Wiley and Sons, Inc., N.Y. XIV + 534 pp.

Darnell, R. M. 1959. Food habits of fishes and larger invertebrates of Lake Pontchartrain, Louisiana, and estaurine community. Pub. Inst. Mar. Sci., Univ. Texas, 5:353-416.

Dawson, E. Y., A. A. Aleem, and B. W. Halstead, 1955. Marine algae from Palmyra Island with special reference to the feeding habits and toxicology of reef fishes. Allan Hancock Found., Occ. Pap. 17:39 pp.

De Sylva, D. P., 1963. Systematics and life history of the great barracuda, Sphyraena barracuda (Walbaum). Stud. Trop. Oceanogr. Miami, 1:viii $+179 \mathrm{pp}$.

Diaz-Piferrer, M., 1963. Adiciones a la flora marina de Puerto Rico. Carib. J. Sc. 3:215-235.

Ebeling, A. W., 1957. The dentition of eastern Pacific mullets, with special reference to adaptation and taxonomy. Copeva, No. 3:173-185.

Gudger, E. W., 1929. On the morphology, coloration and behavior of seventy teleostean fishes of Tortugas, Florida. Pap. Torongas Lab., 26 (Carnegie Inst., Wash. Pub. 391):149-204. 
Hiatt, R. W. and D. W. Strasburg, 1960. Ecological relationships of the fish fauna on coral reefs of the Marshall Islands, Ecol. Monogr. 30:65-127.

Humm, H. J., 1956. Sea grasses of the northern Gulf coast. Bull. Mar. Sci. Gulf and Carib. 6(4):305-308.

Jones, N. S. and J. M. Kain, 1967. Subtidal algal colonization following the removal of Echinus. Helgol. Wissen. Meeres. $15: 460-466$.

Kain, J. M. and N. S. Jones, 1966. Algal colonization after removal of Echinus. IN: Proc. V. Int. Seaweed Symp., Halifax. pp. 139140 .

Kumpf, H. E. and H. A. Randa11, 1961. Charting the marine environments of St. John, U.S. Virgin Islands, Bull. Mar. Sci. of the Gulf and Carib. 11(4):543-551.

Leighton, D. L., L. G. Jones and W. J. North, 1966. Ecological relationships between giant kelp and sea urchins in Southern California. V Int. Seaweed Symp. pp. 141-153.

Leopold, A. C. 1943. Deer irruptions. Wisconsin Conserv. Dept. Pub1. 321:1-11.

Leopold, A. C. 1947. Game management. Scribner, New York.

Limbaugh, C. 1955. Fish life in the kelp beds and the effects of kelp harvesting. Univ. Calif. Inst. Mar. Res., I. M.R. Ref., 55-9:1158 .

Longley, W. H. and S. F. Hildebrand, 1941. Systematic catalog of the fishes of Tortugas, Florida with observations on color, habits, and local distribution. Pap. Tortugas Lab. 34:xiii + $331 \mathrm{pp}$.

Longley, W. H., W. L. Schmitt and W. R. Taylor, 1925. Observations upon the food of certain Tortugas fishes. Ann. Rept. Tortugas Lab., Carnegie Inst. Wash. Yearbook, no. 24:230-232.

Lowe, R. H., 1962. The fishes of the British Guiana continental shelf, Atlantic coast of South America, with notes on their natural history. J. Linn. Soc. London, Zool. 44(301):669-700. 
Margalef, R. and J. A. Rivero, 1958. Succession and composition of the Thalassia community. Assoc. Is. Mar. Labs., Second Meeting: $19-21$.

Mead, G. W. 1970. A history of South Pacific Fishes. In Scientific Exploration of the South Pacific. National Acad. Sci. st. book 309-01755-6. Washington, D.C., pp. 236-251.

Moore, D., 1962. Development, distribution and comparison of rudder fishes Kyphosus sectatrix (Linnaeus) and $\mathrm{K}$. incisor (Cuvier) in the western north Atlantic. Fishery Bull, , Fish and Wild1. Serv. $61: 451-480$.

Moore, H. B., T. Jutare, J. C. Bauer, and J. A. Jones, 1963a. The biology of Lytechinus variegatus. Bu11. Mar. Sci. Gulf of Carib. $13: 23-53$.

Moore, H. B., J. A. Jones, B. F. McPherson, and C. F. E. Roper, 1963 b. A contribution to the biology of Tripneustes esculentus. Bull. Mar. Sci. Gulf and Carib., 13:267-281.

Odum, H. T. and E. P. Odum, 1955. Trophic structure and productivity of a windward coral reef community on Eniwetok Atall. Ecol. Monagr. 25:291-320.

Quast, J. C. 1968. Observations on the food of the kelp-bed fishes; In: W.J. North and C. L. Hubbs, eds., Utilization of the ke1pbed resources in Southern California. California Dept. Fish and game, Fish. Bul1. 139, 264 pp.

Randa11, J. E., 1958. A review of ciguatera, tropical fish poisoning, with a tentative explanation of its cause. Bull. Mar. Sci. Gulf and Carib. 8(3):236-267.

Randa11, J. E., 1961. Overgrazing of algae by herbivorous marine fishes. Ecology 42(4): 812 .

Randall, J. E., 1963. An analysis of the fish populations of artificial and natural reefs in the Virgin Islands. Carib. J. Sci. 3(1):31-47. 
Randall, J. E., 1964. Contributions to the biology of the queen couch, Strombus gigas. Bull. Mar. Sci. of the Gulf and Carib. $14(2): 246-295$.

Randal1, J. E., 1965. Grazing effect on sea grasses by herbivorous reef fishes in the West Indies. Ecology 46(3):255-260.

Randall, J. E. 1967. Food habits of reef fishes of the West Indies. IN: Studies in tropical oceanography no. 5. Univ. of Miami Inst. Mar. Sci. pp. 665-847.

Randall, J. E. 1968. Caribbean reef fishes. T. F. H. Publ., Inc., Jersey City, N.J. 318 pp.

Randa11, J. E. and H. A. Randa11, 1963. The spawning and early development of the Atlantic parrot fish, Sparisoma rubripinne, with notes on other scarid and labrid fishes. Zoological 48(2): 49-59.

Randall, J. E., R. E. Schroeder, and W. A. Starck, II, 1964. Notes on the biology of the echinoid Diadema antillarum. Carib. J. Sci. $4: 421-433$.

Reid, G. K., Jr., 1954. An ecological study of the Gulf of Mexico fishes, in the vicinity of Cedar Key, Florida. Bull. Mar. Sci. of the Gulf and Carib. 4(1):1-94.

Stephenson, W. and R. B. Searles, 1960. Experimental studies of the ecology of intertidal environments at Heron Island. I. Exclusion of fish from beach rock. Austral. J. Marine and Freshwater Res. $11(2): 241-267$.

Suyehiro, Y. 1942. A study on the digestive system and feeding habits of fish. Jap. J. Zool. 10(1):1-301.

Taylor, W. R., 1960. Marine algae of the eastern tropical and subtropical coasts of the Americas. Ann Arbor. ix $+870 \mathrm{pp}$.

Taylor, W. R., 1961. Distribution in depth of marine algae in the Caribbean and adjacent seas. IN: Recent advances in botany. Univ. of Toronto. pp. 193-197.

Warmke, G. L. and L. R. Almodovar, 1963. Some associations of marine mollusks and algae in Puerto Rico. Malacologia 1(2):163-177. 
The marine plants of the Virgin Islands were studied in detail by the Danish botanist, F. Borgesen, who visited the islands in 1892 , 1895-96, and 1905-06, and published numerous papers based on his collections. Most significant is, "The Marine Algae of the Danish West Indies," issued in parts from 1913 to 1920 , in which 327 species of algae (90 Chlorophyta, 45 Phaeophyta, and 192 Rhodophyta) were obtained, including many new species. Dr. Harold Humm is continuing systematic studies on the marine plants of this area. During the present study, 153 species of plants were obtained (54 Chlorophyta, 26 Phaeophyta, 70 Rhodophyta, and 3 Spermatophyta) including 26 species newly recorded for the Virgin Islands.

The following list summarizes known depth distribution, consumers, and habitat notes:

CHLOROPHYTA. Green algae.

*Acetabularia pusilla (Howe) Collins. Found twice on Strombus shells on the algal plain in $20 \mathrm{~m}$ depth. Known from Florida, the Bahamas and Jamaica, but reported here for the first time from the Virgin Islands.

Acicularia schenckii (Mobius) Solms-Laubach. Locally common on the algal plain in 15 to $31 \mathrm{~m}$ depth, but most conspicuous in open areas of fine shell attached to shell fragments or small rocks. Reported by Taylor (1960) to $73 \mathrm{~m}$ depth.

Anadyomene stellata (Wulfen) C. Agardh. Common on the algal plain, occasional on the reef and in sea grass beds, often epiphytic, particularly on Avrainvillea and Digenia, but also at tached to rock or forming loose, unattached masses. Found in 3 to $24 \mathrm{~m}$ depth. During feeding trials, no fishes were seen eating Anadyomene, but samples usually disappeared, apparently eaten, within 48 hours.

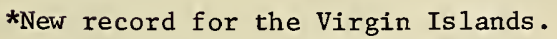


Avrainviliea asarifolia Borgesen. An uncommon plant of the algal plain in 20 to 22 m depth. Known only from Florida, Jamaica and the Virgin Islands, reported by Taylor (1960) from 4.6 to $90.0 \mathrm{~m}$ depth.

Avrainvillea geppi Borgesen. Found twice on the algal plain in 20 and $23 \mathrm{~m}$ depth. Previously known from Borgesen's original collection at St. John, Virgin Islands, from $16 \mathrm{~m}$ depth.

*Avrainvillea levis Howe. Three plants were obtained from a bed of Syringodium in $13 \mathrm{~m}$ depth, $325 \mathrm{~m} \mathrm{~N}$. of the habitat. Known from many places in the Caribbean, but reported here for the first time from the Virgin Islands.

Avrainvillea longicaulis (Kutzing) Murray and Boodle. Obtained from several places on the algal plain in 20 to $22 \mathrm{~m}$ depth where it occurred with A. nigricans, which it closely resembles. Reported by Taylor (1960) to $30 \mathrm{~m}$ depth.

Avrainvillea nigricans Decaisne. The most common and conspicuous member of the genus, occurring in sea grass beds and on the algal plain from 10 to $31 \mathrm{~m}$ depth. Recorded by Taylor (1960) in depths to $30 \mathrm{~m}$. When other plants are available, $\underline{A}$. nigricans is often ignored by grazing fishes, but on the plain the following fishes were observed eating this species: Canthigaster rostrata, Pomocanthus arcuatus, Scarus croicensis. During feeding trials, $\underline{S}$. croicensis and Sparisoma aurofrenatum sampled this species, and Randall (1967) found it in the stomach contents of Pomacentrus fuscus.

Bryopsis pennata Lamouroux. Occasional on the reef and on hard surfaces on the plain to $20 \mathrm{~m}$ depth. Randall (1967) reported the following consumers: Abudefduf saxatilis, Pomocentrus fuscus, Acanthurus bahianus, and Cantherhines pullus.

Caulerpa ashmeadii Harvey. Occasional plants were found on the algal plain from 50 to $180 \mathrm{~m}$ from the reef in 15 to $24 \mathrm{~m}$ depth.

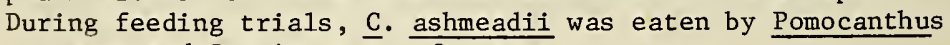
arcuatus and Sparisoma aurofrenatum.

Caulerpa cupressoides (West) C. Agardh. Occasional on the algal plain to $22 \mathrm{~m} \mathrm{depth}$. Forms of this species have been reported from the intertidal to $110 \mathrm{~m}$ depth (Taylor, 1960). During feeding trials, Acanthurus coeruleus ate this species, and Randa11 (1967) recorded Pomocanthus arcuatus and $\underline{P}$. paru as consurners. 
Caulerpa mexicana (Sonder) J. Agardh. Locally common on the algal plain in 10 to $21 \mathrm{~m}$ depth. Reported by Taylor (1960) from depths to possibly $110 \mathrm{~m}$. During feeding trials, Pomocanthus arcuatus ate this species, and Randall (1967) records $\underline{P}$. arcuatus as a consumer.

Caulerpa microphysa (Weber-van Bosse) J. Feldman. Common in open sand areas, frequently in association with Acicularia schenckii in 10 to $23 \mathrm{~m}$ depth. Reported by Taylor (1960) from 9 to $110 \mathrm{~m}$ depth.

Caulerpa prolifera (Forskal) Lamouroux. Occasional on the algal plain in 15 to $22 \mathrm{~m}$ depth. Reported by Taylor (1960) in depths from 1 to $110 \mathrm{~m}$. During feeding trails, Pomocanthus arcuatus ate this species, and Randall (1967) recorded

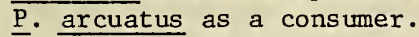

Caulerpa sertularioides (Gmelin) Howe. Occasional in sea grass beds, but not found elsewhere. Reported by Taylor (1960) from 3 to $110 \mathrm{~m}$ depth. Randall (1967) recorded the following consumers: Abudefduf taurus, Alutera scripta, Eupomocentrus fuscus and Pomocanthus paru. The queen couch, Strombus gigas, also feeds on this species (Randall, 1964).

Chaetomorpha crassa (C. Agardh) Kutzing. Found once mixed with Hypnea on the algal plain in $23 \mathrm{~m}$ depth. An uncommon species, previously reported from shallow water.

Cladocephalus 1uteofuscus (Crouan) Borgesen. Common on the algal plain with Avrainviliea and Udotea in 12 to $23 \mathrm{~m}$ depth. Previously reported from $14 \overline{\text { to } 72 \mathrm{~m}}$ depth (Taylor, 1960).

Cladophora sp. A sma11 plant, epiphytic on Udotea, was obtained from $20 \mathrm{~m}$ depth on the algal plain. Randall (1967) recorded several fishes that eat species of Cladophora: Acanthurus coeruleus, Eupomocentrus fuscus, and Scarus spp., and reported several species in the stomach contents of the queen couch, Strombus gigas (Randal1, 1964).

Cladophora sp. A sma11 plant, attached to a she11, was obtained from $20 \mathrm{~m}$ depth on the algal plain.

Cladophoropsis membranacea (C. Agardh) Borgesen. Occasionally found mixed with other algae in a bed of sea grass $350 \mathrm{~m} \mathrm{~N}$. of the habitat in $14 \mathrm{~m}$ depth. Elsewhere usually intertidal. 
Codium intertextum Collins and Hervey. Found on several large coral heads in 3 to $4 \mathrm{~m}$ depth at Virgin Gorda, but not located within Lameshur Bay. Reported by Taylor (1960) from $20 \mathrm{~m}$ depth.

Codium isthomocladum Vickers. Never found within $40 \mathrm{~m}$ of the reef, this species was occasional but conspicuous on the algal plain where it often formed bushy masses up to $30 \mathrm{~cm}$ high in depths from 14 to $31 \mathrm{~m}$. It is a common species with many forms, occurring in the Caribbean in depths to $73 \mathrm{~m}$ (Taylor, 1960). During feeding trails, the following fishes ate $\underline{C}$. isthmocladum: Acanthurus bahianus, Halichoeres poeyi and Pomocanthus arcuatus. Randal1 (1967) recorded Pomocanthus paru as a consumer.

Dictyosphaeria cavernosa (Forskal) Borgesen. Common on the algal plain and in sea grass beds usually attached to hard substrate but sometimes epiphytic in depths from 10 to $21 \mathrm{~m}$. Reported by Taylor (1960) from the intertidal to at least $55 \mathrm{~m}$ depth. Randall (1967) recorded Acanthurus coeruleus and Alutera scripta as consumers.

Halimeda monile (E1lis and Solander) Lamouroux. Common in grass beds at Salt Pond, St. John, and along the shore of Cooper Islands mixed with Thalassia, in depths from 2 to $9 \mathrm{~m}$, but not seen in Lameshur Bay. Randall (1967) recorded Alutera scripta and Lactophrys trigonus as consumers.

*Halimeda scabra Howe. Found twice on the algal plain on calcareous substrate in association with Avrainvillea spp. and $\underline{H}$. incrassata in $22 \mathrm{~m}$ depth. Reported by Taylor (1960) from shallow water to $20 \mathrm{~m}$ depth. Recorded here for the first time from the Virgin Islands.

Halimeda simulans Howe. Common on the algal plain with $\underline{H}$. incrassata and Avrainvillea sp. and in beds of Syringodium in depths from 12 to $20 \mathrm{~m}$. Reported by Taylor (1960) to $73 \mathrm{~m}$ depth. During feeding trials, the following fishes ate $\underline{\mathrm{H}}$. simulans: Acanthurus bahianus, $\underline{\mathrm{A}}$. chirurgus, Scarus croicensis, Sparisoma aurof renatum and $\underline{\text { s. }}$ coeruleus.

Halimeda tuna (Ellis and Solander) Lamouroux. Occasional in grass beds and on the algal plain in 10 to $21 \mathrm{~m}$ depth. Reported by Taylor (1960) from $80 \mathrm{~m}$ depth. 
Neomeris annulata Dickie. Occasional on the reef and algal plain in open areas on rocks, shell, and dead coral in 3 to $31 \mathrm{~m}$ depth. Reported by Taylor (1960) to $50 \mathrm{~m}$ depth.

Penicillus capitatus Lamarck. Common in grass beds and throughout the algal plain in 3 to $31 \mathrm{~m}$ depth. Reported by Taylor (1960) from shallow water to $30 \mathrm{~m}$ depth. During feeding trials, Sparisoma aurofrenatum sampled this species.

Penicillus dumetosus (Lamouroux) Blainville. Common in grass beds and locally abundant on the algal plain in 4 to $23 \mathrm{~m}$ depth. Reported by Taylor (1960) to $30 \mathrm{~m}$ depth. During feeding trials, this species was sampled by Sparisoma aurofrenatum.

Penicillus lamourouxii Decaisne. Occasional in grass beds and on the algal plain in 10 to $23 \mathrm{~m}$ depth. Reported by Taylor (1960) from $40 \mathrm{~m}$ depth.

Penicillus pyriformis A. and E. S. Gepp. Common in grass beds and occasional on the algal plain in 18 to $20 \mathrm{~m}$ depth. Primarily a plant of shallow water, but Taylor (1960) reported a deep water form from $40 \mathrm{~m}$ depth. Randall (1967) recorded Pomocanthus arcuatus as a consumer, but no fishes were observed eating $\underline{\text { P. pyriformis }}$ on the algal plain or in feeding trails during this study.

Phaeophila dendroides (Crouan) Batters. Found epiphytic on many algae (Laurencia, Avrainvillea, Ceramium, Dictyota, Sargassum) from various places on the algal plain 18 to $23 \mathrm{~m}$ depth.

*Diplochaete solitaria Collins. A common minute epiphyte on various algae (Ceramium, Spermothamnion, Cladophora, Laurencia, Chaetomorpha, etc.) on the reef, algal plain and in sea grass beds from 3 to $21 \mathrm{~m}$ depth. Previously known from Jamaica and Bermuda in shallow water but newly reported here for the Virgin Islands.

Entocladia vagans (Borgesen) Taylor. Found twice in and on Griffithsia globulifera in 16 and $21 \mathrm{~m}$ depth on the algal plain. This is apparently the second report of this plant, described by Borgesen (1920) from St. Croix, Virgin Islands.

Entocladia viridis Reinke. Common on various algae (Acanthophora, Padina, Anadyomene, Laurencia) on the reef and the algal plain in 10 to $21 \mathrm{~m}$ depth. 
Ernodesmis verticellata (Kutzing) Borgesen. Found occasionally on rocks and once on a small shell in 16 to $20 \mathrm{~m}$ depth on the algal plain. Reported by Taylor (1960) from various places in the Caribbean in shallow, very quiet, shaded pools, reaching a depth of $9 \mathrm{~m}$. Randall (1964) found this species in the stomach contents of the queen couch, Strombus gigas.

*Halicystis osterhoutii L. R. and A. H. Blinks. Collected twice on calcareous rubble on the algal plain in 16 to $18 \mathrm{~m}$ depth. A new record for the Virgin Islands.

Halimeda discoidea Decaisne. Occasional low plants were found on the algal plain 40 to $150 \mathrm{~m}$ from the reef in 16 to 20 m depth. Reported to $50 \mathrm{~m}$ depth by Taylor (1960).

Halimeda incrassata (E1lis) Lamouroux. A common, conspicuous plant of the algal plain, dominant over wide areas, often in association with Lobophora variegata, Anadyomene stellata, species of Avrainvillea, and numerous epiphytes. Found in 5 to $31 \mathrm{~m}$ depth, most abundant 50 or more meters from the reef (to more than $200 \mathrm{~m}$ distant), but in places within $20 \mathrm{~m}$. Also common mixed with Syringodium in grass beds, and forming stands in open areas within the beds. Reported from shallow water to $40 \mathrm{~m}$ depth by Taylor (1960). On the algal plain, the following fishes were observed eating H. incrassata: Acanthostracion quadricornis, Balistes vetula, and Pomocanthus arcuatus. During feeding trials, it was eaten by Acanthurus bahianus, A. coeruleus, A. chirurgus, Halichoeres poeyi, Pomocanthus arcuatus, Scarus croicensis, Sparisoma aurofrenatum, S. coeruleus, and $\underline{S}$. rubripinne. Randall (1967) reported only Balistes vetula as a consumer of $\underline{H}$. incrassata, but found "Halimeda sp." in the stomach contents of the following fishes: Alutera schoepfi, Eupomocentrus fuscus, Lactophrys trigonus, Lactophrys triqueter, and Sparisoma rubripinne. Fragments of Halimeda, probably including $\underline{H}$. incrassata, were found in the stomach contents of Strombus gigas (Randall, 1964).

*Pseudotetraspora antillarum Howe. Common on the surface of the TEKTITE habitat, on blades of Syringodium in grass beds, but most conspicuous on blades of Udotea conglutinata and $\underline{U}$. flabellum from grass beds and the algal plain in 10 to $22 \mathrm{~m}$ depth. Previously reported only from shallow water in the Bahamas and Florida; a new record here for the Virgin Islands. 
Rhipilia tomentosa Kutzing. Collected twice on the algal plain in 20 and $22 \mathrm{~m}$ depth, growing with species of Avrainvillea and Udotea. Reported by Taylor (1960) to $30 \mathrm{~m}$ depth.

Siphonocladus rigidus Howe. Occasional on the reef in 5 to $10 \mathrm{~m}$ depth. Typically a shallow water plant, previously recorded to $1 \mathrm{~m}$ depth by Taylor (1960).

Struvea anastomosans (Harvey) Piccone. Collected twice on the reef in 10 and $12 \mathrm{~m}$ depth, and once on the algal plain on an isolated coral head in $20 \mathrm{~m}$ depth.

Udotea conglutinata (E1lis and Solander) Lamouroux. Abundant throughout the algal plain, common in grass beds, and occasional in open areas on reefs in 6 to $31 \mathrm{~m}$ depth. Reported by Taylor (1960) to $57 \mathrm{~m}$ depth. On the algal plain, the following fishes were observed eating $\underline{U}$. conglutinata: Acanthurus bahianus, A. coeruleus, A. chirurgus, Scarus coeruleus, Sparisoma aurofrenatum, S. rubripinne, and Pomocanthus arcuatus. During feeding trials, it was taken by Pomocanthus arcuatus, Scarus coeruleus and Sparisoma aurof renatum.

Udotea cyathiformis Decaisne. Occasional in grass beds and common on the algal plain in 10 to $31 \mathrm{~m}$ depth. Reported by Taylor (1960) to $90 \mathrm{~m}$ depth. During feeding trials, U. cyathiformis was sampled by Sparisoma aurofrenatum.

Udotea flabellum (E11is and Solander) Lamouroux. Occasional throughout the algal plain and common in sea grass beds in 5 to $23 \mathrm{~m}$ depth. Reported by Taylor (1960) to $70 \mathrm{~m}$ depth. Randall (1967) recorded Diplodus caudimacula and Balistes vetula as consumers of $\underline{\mathrm{U}}$ flabel1um.

Udotea spinulosa Howe. Occasional among other Udotea species on the algal plain and in grass beds in 10 to $31 \mathrm{~m}$ depth. Reported by Taylor (1960) in depths to $90 \mathrm{~m}$.

Udotea verticillosa A. and E. S. Gepp. The most common and conspicuous species of Udotea in Lameshur Bay, occurring in extensive beds, sometimes in nearly pure stands, but usually mixed with other algae including other species of Udotea, in 5 to $31 \mathrm{~m}$ depth. Reported only from the Virgin Islands, based on Borgesen's 
original collections. On the algal plain, the following fishes were observed eating $U$. verticillosa; Acanthurus bahianus, A. coeruleus, A. chirurgus, Balistes vetula, Canthigaster rostrata, Holocanthus tricolor, Pomocanthus arcuatus, Scarus coeruleus, S. rubripinne. During feeding trials, it was taken by Scarus coeruleus, Sparisoma aurofrenatum and Pomocanthus arcuatus.

*Udotea wilsoni Gepp and Howe. Collected once in a grass bed in $15 \mathrm{~m}$ depth and obtained from several places on the algal plain in 18 to $23 \mathrm{~m}$ depth mixed with U. spinulosa, $\underline{\mathrm{U}}$. verticillosa and $\underline{U}$. conglutinata. Reported from several places in the Caribbean in shallow water, but this is the first record for the Virgin Islands.

Ulve1la lens Crouan. Epiphytic on Halimeda tuna, Caulerpa mexicana and Acanthophora spicifera on the algal plain in 18 to $22 \mathrm{~m}$ depth. Found by Randal1 (1964) in the stomach contents of the queen couch, Strombus gigas.

Valonia aegagropila C. Agardh. Occasional, lightly attached to calcaroues substrates on the algal plain, in 15 to $23 \mathrm{~m}$ depth. Previously recorded to $7 \mathrm{~m}$ depth Taylor, 1960).

*Valonia utricularis C. Agardh. Occasional in areas on the algal plain where plant cover is dense, 18 to. $22 \mathrm{~m}$ depth. Reported by Taylor to $2 \mathrm{~m}$ depth; common in the Caribbean but newly recorded here for the Virgin Islands. Randal1 (1967) found V. utricularis in the stomach contents of the batfish, ogcocephalus natutus.

Valonia ventricosa $\mathrm{J}$. Agardh. Conspicuous on reefs growing in crevices in coral heads and rocks, but also common on the algal plain, often rolling free among other algae, and occasional in grass beds. Found in 2 to $23 \mathrm{~m}$ depth. Reported by Taylor (1960) in depths to $30 \mathrm{~m}$. Randa11 (1967) found $\underline{v}$. ventricosa in the stomach contents of Alutera scripta. 
*Acinetospora pusilla (Griffiths) Bornet. Found only on the exterior of the TEKTITE habitat but probably present on other hard surfaces. A new record for the Virgin Islands.

Ascocyclus hypneae Borgesen. Endophytic in Laurencia collected on algal plain in $23 \mathrm{~m}$ depth. Previously known only from Borgesen's original material obtained in Lime Tree Bay, St. Croix, growing in Hypnea musciformis.

Dictyopteris justii Lamouroux. Found once in $21 \mathrm{~m}$ depth on the algal plain $30 \mathrm{~m}$ from the face of the reef, growing on limestone. Reported by Taylor from shallow water to 40 m depth. Randall (1967) reported Kyphosus sectatrix as a consumer of this species, and Holocanthus tricolor as a consumer of Dictyopteris sp. Other species of Dictyopteris were found in the stomach contents of Abudefduf saxatilis, A. taurus, Balistes vetula,

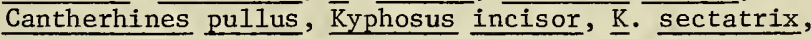
Melichthys niger, Pomocanthus arcuatus, $\underline{p}$. paru and Scarus coelestinus (Randa11, 1967).

Dictyota bartayresii Lamouroux. Typically found on dead coral and at the base of living coral heads, but also present throughout the algal plain in depths to $23 \mathrm{~m}$. Recorded by Taylor to $33 \mathrm{~m}$ depth. Randall (1967) recorded this species in the stomach contents of Kyphosus sectatrix, Pomocanthus arcuatus and $\underline{P}$. paru, and Dictyota sp. in Acanthurus coeruleus, A. chirurgus, Blennius cristatus, Catherhines pullus, Eupomocentrus fuscus, Lactophrys trigonus, Pomocanthus arcuatus, Sparisoma radicans, and S. rubripinne.

Dictyota dichotoma (Hudson) Lamouroux. Occasional among other algae on the algal plain in 15 to $23 \mathrm{~m}$ depth. Reported by Taylor (1960) from shallow water to $55 \mathrm{~m}$ depth. During feeding trials, this species was eaten by Pomocanthus arcuatus and Sparisoma aurofrenatum. 
Dictyota divaricata Lamouroux. Common in grass beds and on the algal plain in 3 to $23 \mathrm{~m}$ depth. Reported to $55 \mathrm{~m}$ depth by Taylor (1960). Randall (1964) found D. divaricata in the stomach contents of the queen conch, Strombus gigas and the following fishes (Randa11, 1967): Acanthurus bahianus, A. coeruleus, Cantherhines macroceru and $\underline{\mathrm{C}}$. pullus. On the algal plain, Acanthurus bahianus, A. coeruleus, A. chirurgus, Eupomocentrus partitus, Canthigaster rostrata, Pomocanthus arcuatus, Sparisoma aurofrenatum, $\underline{S}$. viride were seen eating this species.

Dictyota indica Sonder in Kutzing. Common on the algal plain mixed with other algae in 18 to $23 \mathrm{~m}$ depth. Occurs in various parts of the Caribbean, reported by Taylor (1960) to $27 \mathrm{~m}$ depth. Randall (1964) found D. indica in stomach contents of the queen conch, Strombus gigas.

Dictyota linearis (C. Agardh) Greville. Common mixed with other algae and epiphytic on sea grasses in 8 to $22 \mathrm{~m}$ depth, in grass beds and throughout the algal plain. Randall (1967) reported Kyphosus sectatrix as a consumer.

Ectocarpus rhodochortonoides Borgesen. Found only on the exterior of the TEKTITE habitat, but probably present on other hard surfaces. Originally described from the Virgin Islands (Borgesen, 1941) from plants found in exposed places in the littoral region. Randall (1967) reported Ectocarpus sp. in the stomach contents of Diplodus caudimacula and Acanthurus coeruleus, and it is likely that all Ectocarpus species are regularly browsed.

Giffordia conifera (Borgesen) Taylor. Growing in the habitat, and on Anadyomene stellata in 12 and $22 \mathrm{~m}$ depth. Originally reported from St. Croix, Virgin Islands (Borgesen, 1914).

Giffordia indica (Sonder) Papenfuss and Chihara in Papenfuss. Obtained from the exterior of the TEKTITE habitat, experimental cages, a dead sea fan, dead coral heads, sea grasses and rocks in 5 to $20 \mathrm{~m}$ depth. Reported by Taylor (1960) from shallow water to $20 \mathrm{~m}$ depth. Probably grazed by the many species observed eating filamentous algae, and definitely identified from a sea fan where Scarus croicensis was actively browsing. 
Giffordia mitchelliae (Harvey) Hamel. Obtained from the surface of the TEKTITE habitat, experimental cages, dead coral heads, rocks, and epiphytic on Syringodium filiforme and Hypoglossum tennuifolium in 5 to $23 \mathrm{~m}$ depth. Randall (1967) reported Chaetodipterus faber as a consumer, and this species was among filamentous plants and diatoms browsed from a sea fan by Scarus croicensis. Probably common in the diet of species that feed on filamentous algae.

Giffordia rallsiae (Vickers) Taylor. Obtained from the surface of the TEKTITE habitat, dead coral, rock and shells, and epiphytic on Syringodium filiforme and Laurencia intricata in 5 to $20 \mathrm{~m}$ depth. Reported by Taylor (1960) from shallow water.

Hecatonema sp. Found once on Udotea conglutinata from the algal plain in $18 \mathrm{~m}$ depth.

*Herponema tortugense (Taylor). A common epiphyte found in 10 to 23 $\mathrm{m}$ depth on Dictyopteris justii, Halimeda incrassata, Laurencia obtusa, Dictyota bartayresii, Udotea conglutinata and $U$. flabellum, and on the surface of the TEKTITE habitat. Previously known only from Taylor's original collection at Dry Tortugas, Florida, where it was epiphytic on Zonaria in shallow water and from Puerto Rico (Diaz-Piferrer, 1963) on Udotea, Gelidiella, and Thalassia. This is a new record for the Virgin Islands.

Lobophora variegata (Lamouroux) Womersley. The decumbent form of this species was found on rock and dead coral on reefs, and the upright form was one of the most common and conspicuous plants of the algal plain, found in 3 to $31 \mathrm{~m}$ depth. Reported by Taylor (1960) from $55 \mathrm{~m}$ depth. On the algal plain, Acanthurus chirurgus, A. coeruleus, and Balistes vetula were seen eating this species, and during feeding trials, it was eaten by Acanthurus bahianus, A. chirurgus, A. coeruleus, Sparisoma

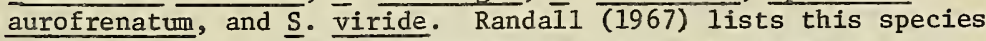
in the stomach contents of Acanthurus bahianus, Kyhosus incisor, Kyphosus sectatrix, Melichthys niger, and Pomocanthus arcuatus.

Myrionema strangulans Greville. Found once on Acanthophora spicifera on the algal plain in $21 \mathrm{~m}$ depth.

Padina sanctae-crucis Borgesen. Found in protected places on the reef and obtained from four sites on the algal plain in 10 to $21 \mathrm{~m}$ depth. Originally described from plants growing in shallow water at St. Croix, Virgin Islands (Borgesen, 1914). Randall (1967) found this species in the stomach contents of Kyphosus sectatrix and Melichthys niger.

*Padina haitensis (Thivy in Taylor). Common on rocks at Virgin Gorda, but not found in Lameshur Bay. Newly reported here for the Virgin Islands. 
Sargassum filipendula C. Agardh. Found in four places on the algal plain attached to limestone 20 to $100 \mathrm{~m}$ from the reef in 18 to $22 \mathrm{~m}$ depth. Most plants were 25 to $30 \mathrm{~cm}$ high, but the main axis of one farthest distant on the plain was a meter high. Reported by Taylor (1960) from the intertidal to $33 \mathrm{~m}$ depth. Although not recorded among stomach contents of fishes examined by Randall (1967) it is likely to be eaten by fishes that are known to eat other species of Sargassum. These include Acanthurus bahianus, A. chirurgus, Balistes vetula, Canthiderma sufflamen, Kyphosus incisor, K. sectatrix, Melichthys niger and Pomocanthus paru.

Sphacelaria furcigera Kutzing. Probably common, but collected only twice, once on the surface of the TEKTITE habitat, once epiphytic on Hypoglossum tenuifolium in $22 \mathrm{~m}$ depth $30 \mathrm{~m}$ from the reef. Undoubtedly eaten by fishes that clip the filamentous turf from rocks and coral. Randall (1964) found it in the stomach contents of the queen conch, Strombus gigas.

Sphacelaria tribuloides Meneghini. Probably common, but collected only twice, once on dead coral on the reef and once on a shell on the algal plain in $21 \mathrm{~m}$ depth $40 \mathrm{~m}$ from the reef. Randall (1967) recorded Kyphosus sectatrix and Melichthys niger as consumers, and found Sphacelaria sp. in the stomach contents of Sparisoma rubripinne.

Sphacelaria sp. Sterile plants of uncertain specific identity were found on Udotea conglutinata from a grass bed in $10 \mathrm{~m}$ depth and on Galaxura obtusata from the algal plain in $20 \mathrm{~m}$ depth.

Streblonema sp. A minute epiphyte, apparently of this genus, was found on Laurencia obtusa in $20 \mathrm{~m}$ depth $30 \mathrm{~m}$ from the reef face.

Turbinaria tricostata Barton. Common on rock in 2 to $5 \mathrm{~m}$ depth at Virgin Gorda but not found in Lameshur Bay. Randall (1967) reported Kyphosus incisor and $\mathrm{K}$. sectatrix as consumers of the closely related $\underline{T}$. turbinata.

RHODOPHYTA. Red algae.

Acanthophora spicifera (Vah1) Borgesen. Common throughout the algal plain in 15 to $23 \mathrm{~m}$ depth and found conce on the reef at the base of a living coral head. Reported by Taylor (1960) to only $3 \mathrm{~m}$ depth. During feeding trials, Acanthurus chirurgus and Pomocanthus arcuatus ate this species and Randall (1967) found it in the stomach contents of the following fishes: Alutera scripta, Blennius cristatus, Eupomocentrus fuscus, Lactophrys trigonus, Ophioblennius atlanticus, Scarus coelestinus, $\underline{S}$. vetula, Sparisoma radians. It was also found by Randall (1964) in the stomach contents of the queen conch, Strombus gigas. 
Acrochaetium spp. Species of Acrochaetium of uncertain identity were frequently found as epiphytes on larger algae and seagrasses as well as on rock on the reef and the algal plain. Randall (1967) recorded Sparisoma rubripinne and Melichthys niger as consumers of Acrochaetium sp.

Acrochaetium sargassi B $\phi$ rgesen. Found once on Gracilaria cylindrica in $22 \mathrm{~m}$ depth $30 \mathrm{~m}$ from the face of the reef. Originally described from the Virgin Islands.

Amphiroa fragilissima (Linnaeus) Lamouroux. Occasionally mixed with other algae on the algal plain in 15 to $20 \mathrm{~m}$ depth. Randall (1964) found this species in the stomach contents of the queen conch, Strombus gigas, and (1967) in the following fishes: Abudefduf taurus, Acanthurus chirurgus, A. coeruleus, Alutera scripta, Balistes vetula, Blennius cristatus, Cantherhines

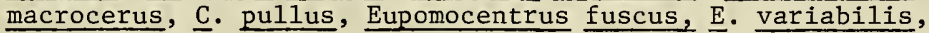
Melichthys niger, Ophioblennius atlanticus, Scarus coelestinus, S. guacamai.

Asterocystis ramosa (Twaites) Gobi. Occasional as an epiphyte on larger algae (Laurencia, Acanthophora, Lobophora, Sargassum) on the algal plain in 15 to $23 \mathrm{~m}$ depth, and found once on Udotea in a seagrass bed (Syringodium) in $10 \mathrm{~m}$ depth. Randall (1 $\overline{967}$ ) found this species in the stomach contents of Blennius marmoreus and Eupomocentrus fuscus.

Callithamnion byssoides Arnott in Hooker. Found on Chrysymenia enteromorpha and Gracilaria cylindrica on the algal plain in $20 \mathrm{~m}$ depth, and once on Syringodium in $10 \mathrm{~m}$ depth. Randall (1967) found Callithamnion sp. in the stomach contents of Ophioblennius atlanticus, and the queen conch, Strombus gigas (Randa11, 1964).

Centroceras clavulatum (C. Agardh) Montagne. Occasional throughout the algal plain as an epiphyte on Gracilaria cylindrica, Halimeda incrassata, Udotea conglutinata, and on shell in 15 to $20 \mathrm{~m}$ depth, and found once at the base of a coral head on the reef, once as an epiphyte on Syringodium in $10 \mathrm{~m}$ depth. Taylor (1960) reported this species from shallow water to at least $20 \mathrm{~m}$ depth. Randa11 (1964) found $\underline{\mathrm{C}}$. clavulatum in the stomach contents of the queen conch, Strombus gigas. In 1967 he reported this species in the diet of the following fishes: Abudefduf taurus, Acanthurus bahianus, A. chirurgus, $\underline{\text { A. }}$ coeruleus, Cantherhines macrocerus, Eupomocentrus fuscus, E. planifrons, Diplodus caudimacula, Microspathedon chrysurus,

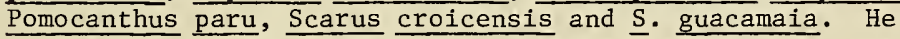
further reported Centroceras sp., almost certainly $\underline{\mathrm{C}}$. clavulatum, from Scarus coelestinus, $\underline{S}$. croicensis, $\underline{S}$. taeniopterus, $\underline{S}$. vetula, Sparisoma aurofrenatum, s. rubripinne, and $\underline{\mathrm{s}}$. viríde. 
Ceramium byssoideum Harvey. Found on Sargassum filipendula in $16 \mathrm{~m}$ depth on the algal plain N.W. of the TEKTITE habitat. Randall recorded the following fishes that had eaten $C$. byssoideum: Abudefduf taurus, Acanthurus bahianus, Cantherhines pullus, Blennius cristatus, Eupomocentrus planifroms, Lactophrys trigonus, Melichthys niger, Microspathodon chrysurus, Ophioblennius atantiicus, Scarus vetula, and Sparisoma rubripinne. The queen conch, Strombus gigas, also eats $\underline{C}$. byssoideum (Randa11; 1964).

*Ceramium codii (Richards) Feldmann-Mazoyer. Found on Gracilaria cylindrica in $20 \mathrm{~m}$ depth $30 \mathrm{~m}$ from the face of the reef. Previously reported as an epiphyte on Codium; a new record for the Virgin Islands.

*Ceramium comptum Borgesen. Found on Laurencia in a bed of Syringiodium filiforme, $13 \mathrm{~m}$ depth. This is a first report for the Virgin Islands.

*Ceramium diaphanum (Lightfoot) Roth. Found on Halimeda incrassata in $20 \mathrm{~m}$ depth, $30 \mathrm{~m}$ from the reef. This is a first report for the Virgin Islands.

Ceramium fastigiatum (Roth) Harvey. Found on Acanthophora in $20 \mathrm{~m}$ depth $50 \mathrm{~m}$ from the reef. Reported by Taylor (1960) as a shallow water plant. Randall (1967) found this species in the stomach contents of Chaetodipterus faber.

*Ceramium leptozonum Howe. Found on Udotea conglutinata from a grass bed in $13 \mathrm{~m}$ depth and on Hypoglossum tenuifolium from the algal plain in $22 \mathrm{~m}$ depth. This is a new record for the Virgin Islands.

Ceramium spp. Ceramium of uncertain identity was found frequently epiphytic in grass beds and throughout the algal plain, as well as on dead coral on the reef. Undetermined species of Ceramium have been recorded by Randall (1967) in the stomach contents of the following: Abudefduf saxatilis, A. taurus, Acanthurus bahianus, A. coeruleus, Alutera scripta, Blennius cristatas, B. mormoreus, Cantherhines pullus, Diplodus caudimacula, Eupomocentrus fuscus, E. leucosticta, Kyphosus sectatrix, Lactophrys trigonus, Ophioblennius atianticus, Sparisoma rubripinne, and $\underline{\text { r. viride. }}$ 
Champia parvula (C. Agardh) Harvey. Small plants were found growing on Halimeda tuna in $20 \mathrm{~m}$ depth $30 \mathrm{~m}$ from the reef, and on dead coral from the algal plain in $18 \mathrm{~m}$ depth.

Reported from a maximum of $37 \mathrm{~m}$ (Taylor, 1960). Randall (1967) recorded Abudefduf saxatilis and A. taurus as consumers of this species, and found it also in the stomach contents of the queen conch, Strombus gigas, (Randa11, 1964).

*Chondria collinsiana. Howe. Found on Halimeda incrassata in $20 \mathrm{~m}$ depth $50 \mathrm{~m}$ from the reef on the algal plain. A new record for the Virgin Islands.

Chondria dasyphylla (Woodard) C. Agardh. Attached to shells and Halimeda incrassata on the algal plain 30 to $180 \mathrm{~m}$ from the reef in 18 to $23 \mathrm{~m}$ depth.

Chodria polyrhiza Collins and Harvey. Attached to Syringodium filiforme in $13 \mathrm{~m}$ in a sea grass bed. Reported by Taylor (1960) to $18 \mathrm{~m}$ depth.

Chrysymenia enteromorpha. Harvey. Obtained from various parts of the algal plain 40 to $160 \mathrm{~m}$ from the reef in 18 to 22 $\mathrm{m}$ depth and once from a grass bed in $13 \mathrm{~m}$ depth, in all collections, attached to limestone. Recorded from 15 to $90 \mathrm{~m}$ depth by Taylor (1960).

Corallina cubensis (Montagne) Kutzing. Found on rock and on Lobophora on the algal plain in 20 to $22 \mathrm{~m}$ depth. Recorded to $26 \mathrm{~m}$ by Taylor (1960). Randall (1967) recorded Acanthurus chirurgus, Melichthys niger and Scarus coelestinus as consumers.

Cottoniella arcuata Borgesen. A common epiphyte on the algal plain found on Acanthophora, Laurencia, Halimeda, and Udotea as well as experimental cages in 18 to $23 \mathrm{~m}$ depth. Originally described from the Virgin Islands.

Crouania attenuata (Bonnemaison) J. Agardh. Found occasionally as an epiphyte on Sargassum filipendula, Udotea flabellum, and Avrainvillea in 18 to $23 \mathrm{~m}$ depth on the algal plain and once in $13 \mathrm{~m}$ depth of Syringodium in a grass bed. Reported from shallow water to $20 \mathrm{~m}$ depth by Taylor (1960). 
Dasya mollis Harvey. Collecced once on Udotea from the algal plain $120 \mathrm{~m}$ from the reef in $20 \mathrm{~m}$ depth. Recorded by Taylor (1960) in 8 to $33 \mathrm{~m} \mathrm{depth.}$

Dasya pedicellata (C. Agardh) C. Agardh. Found occasionally in all parts of the algal plain in 18 to $31 \mathrm{~m}$ depth growing on rocks, shell, and as an epiphyte on Halimeda. Reported by Taylor (1960) to $110 \mathrm{~m}$ depih.

*Dasya rigidula (Kutzing) Ardissone. Found once attached to rock $30 \mathrm{~m}$ from the reef in $20 \mathrm{~m}$ depth. This is the first record from the Virgin Islands.

Digenia simplex (Wulfen) C. Agardh. Common throughout the algal plain in 16 to $23 \mathrm{~m}$ depth attached to rock, dead coral, Halimeda, Udotea and in grass beds on limestone. One small plant was found at the base of a living coral head on the reef in $10 \mathrm{~m}$ depth. Reported by Taylor (1960) to $20 \mathrm{~m}$ depth. Randall (1967) recorded Kyphosus sectatrix as a consumer.

Erythrocladia subintegra Rosenvinge. Found on Acanthophora and Chrysymenia in $20 \mathrm{~m}$ depth on the algal plain. Recorded

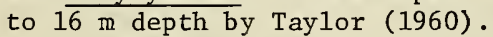

*Erythrocladia vagabunda Howe and Hoyt. On Acanthophora in $20 \mathrm{~m}$ depth on the algal plain. A new report for the Virgin Is lands.

Falkenbergia hillenbrandii (Bornet) Falkenberg. Found on Gracilaria debilis in $20 \mathrm{~m}$ depth $40 \mathrm{~m}$ from the reef on the algal plain. Recorded from depths to $14 \mathrm{~m}$ by Taylor $(1960)$.

*Fosliella lejolisii (Rosanoff) Howe. Common on Syringodium in 5 to $20 \mathrm{~m}$ depth in grass beds and on the algal plain. A new record here for the Virgin Islands.

Galaxura flagelliformis Kjellman. Found on the algal plain in $20 \mathrm{~m}$ depth $50 \mathrm{~m}$ from the reef. Reported from shallow water to $18 \mathrm{~m}$ depth (Taylor, 1960). Species of Galaxura were found by Randall (1967) in the stomach contents of Acanthurus bahianus, A. coeruleus, and Melichthys niger. During feeding trials, this species was sampled by Pomocanthus arcuatus. 
*Galaxura obtusata (E1lis and Solander) Lamouroux. Found on algal plain in 18 to 20 m depth 50 to $80 \mathrm{~m}$ from the reef and mixed with Syringodium in a grass hed in $13 \mathrm{~m}$ depth. Recorded from shallow water to about $53 \mathrm{~m}$ depth (Taylor, 1960). Reported here for the first time from the Virgin Islands.

Galaxura subverticellata Kjellman. Found on the algal plain in $18 \mathrm{~m}$ depth $50 \mathrm{~m}$ from the reef. Reported from shallow water by Taylor (1960).

Gelidium corneum (Hudson) Lamouroux. Found on rocks and dead coral heads in protected places on the reef, and on isolated rocks and coral on the algal plain in 12 to $17 \mathrm{~m}$ depth. Usually reported from shallow water (Taylor, 1960). Randall (1967 recorded the following consumers of this species: Abudeduf taurus, Acanthurus chirurgus, Kyphosus sectatrix, Scarus guacamaia, $\underline{\text { S. vetula }}$, and Sparisoma rubripinne. Undetermined species of Gelidium were found in Scarus croicensis, $\underline{\text { s. guacaima, }}$

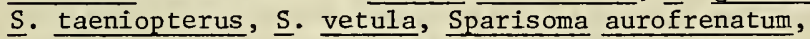
$\underline{\text { s. chrysopterus, }}$ s. rubripinne, and $\underline{\text { s. }}$ viride.

*Gloiophlaea caribaea Taylor. Found attached to Halymenia floresia and Udotea wilsoni in $20 \mathrm{~m}$ depth $50 \mathrm{~m}$ from the reef. New1y reported for the Virgin Islands.

Goniotrichum alsidii (Zanardini) Howe. A common epiphyte on larger algae (Halimeda, Laurencia, Acanthophora) on the algal plain in 15 to $20 \mathrm{~m}$ depth, and mixed with other filamentous species attached to the habitat and on rocks and dead coral on the reef. Previously reported from shallow water (Taylor, 1960).

Gracilaria cylindrica Borgesen. Occasional on the algal plain attached to shel1 and limestone in 20 to $31 \mathrm{~m}$ depth 50 to $180 \mathrm{~m}$ from the reef. Originally described from the Virgin Islands. During feeding trials this species was eaten by Pomocanthus arcuatus and Sparisoma aurofrenatum.

Gracilaria debilis (Forskal) Borgesen. Occasional on the algal plain in 20 to $21 \mathrm{~m}$ depth 50 to $100 \mathrm{~m}$ from the reef. Usually obtained in shallow water (Taylor, 1960). Randall (1967) found this species in the stomach contents of Cantherines macrocerus. 
Griffithsia globulifera Harvey. Common on the algal plain on shel1, limestone, and epiphytic on Halimeda in 18 to $23 \mathrm{~m}$ depth 60 to $180 \mathrm{~m}$ from the reef. Reported from shallow water to $33 \mathrm{~m}$ depth (Taylor, 1960).

Halymenia floresia (Clemente) C. Agardh. Found once on the algal plain attached to limestone in $22 \mathrm{~m}$ depth. Reported from depths to $40 \mathrm{~m}$ (Taylor, 1960). Randall recorded this species in the stomach contents of Pomocanthus paru.

Herposiphonia pecten-veneris (Harvey) Falkenberg. Occasionally found on other algae (Halimeda, Acanthophora, Lobophora) from the algal plain in 15 to $20 \mathrm{~m}$ depth. Previously reported from shallow water (Taylor, 1960).

Herposiphonia secunda (C. Agardh) Ambronn. A common epiphyte on various larger algae (Halimeda simulans, Caulerpa

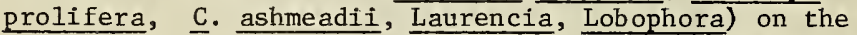
algal plain in 18 to $23 \mathrm{~m}$ depth, and on Laurencia from a grass bed in $13 \mathrm{~m}$ depth. Usually found in shallow water (Taylor, 1960). Randall (1967) recorded the following consumers of this species: Abudefduf taurus, Entomacrodus nigricans, Melichtyhs niger, and Microspathodon chrysurus, and found it in the stomach contents of the queen conch, Strombus gigas, (Randa11, 1964). Undetermined species of Herposiphonia were found in the stomach contents of Acanthurus bahianus, A. chirurgus, Eupomocentrus variabilis, Microspathodon chrysurus, Ophioblennius atlanticus, Scarus coelestinus, $\underline{S}$. croicensis, $\underline{S}$. guacamaia, $\underline{S}$. vetula, Sparisoma aurofrenatum, $\underline{S} \cdot \underline{\text { chrysopterum, }} \underline{\text { S. }}$ rubripinne, and S. viride.

Hypnea musciformis (Wulfen) Lamouroux. Occasional small plants mixed with other algae occurred on the algal plain in 18 to $20 \mathrm{~m}$ depth 50 to $100 \mathrm{~m}$ from the reef. Usually recorded from shallow water (Taylor, 1960). Randall (1967) found this species in the stomach contents of the following: Abudefduf taurus, Acanthurus bahianus, Blennius cristatus, Kyphosus sectatrix, Melichthys niger, and Pomocanthus paru.

Hypnea sp. A small plant of uncertain identity was obtained from $18 \mathrm{~m}$ depth on the algal plain mized with larger algae. 
*Hypoglossum inyolvens (Haryeyl J. Agardh. Found twice on the algal plain attached to Halimeda in $20 \mathrm{~m}$ depth $120 \mathrm{~m}$ from the reef. Previously known from Florida from specimens collected adrift. (Taylor, 1960).

Hypoglossum tenuifolium (Harvey) J. Agardh. Occasional on the algal plain usually at tached to Halimeda incrassata in 18 to $23 \mathrm{~m}$ depth 75 to $180 \mathrm{~m}$ from the edge of the reef. Recorded from drift material and dredged from 58 to $90 \mathrm{~m}$ depth (Taylor, 1960). During feeding trials, this species was eaten by Pomocanthus arcuatus.

Jania adhaerens Lamouroux. Found on a piece of dead coral on the algal plain in $15 \mathrm{~m}$ depth. Reported by Taylor (1960) from shallow water to $18 \mathrm{~m}$ depth.

Jania capillacea Harvey. A common species epiphyte on various algae (Digenia, Sargassum, Halimeda, Laurencia), on limestone on the algal plain in 15 to $23 \mathrm{~m} \mathrm{depth}$, and on hard surfaces in protected places on the reef. Previously recorded from shallow water to $15 \mathrm{~m}$ depth (Taylor, 1960). Randall (1964) found this species in the stomach contents of the queen conch, Strombus gigas, and recorded it from the following fishes (Randa11, 1967): Abudefduf taurus, Acanthurus bahianus, A. chirurgus, Kyphosus sectatrix, and Melichthys niger.

Jania pumila Lamouroux. Found once on Avrainvillea in $17 \mathrm{~m}$ depth $80 \mathrm{~m}$ from the edge of the reef. Previously reported from shallow water (Taylor, 1960).

Laurencia chondrioides Borgesen. Found once mixed with Acanthophora spicifera in $20 \mathrm{~m}$ depth $60 \mathrm{~m}$ from the edge of the reef. Originally described from the Virgin Islands, and apparently not discovered elsewhere.

Laurencia intricata Lamouroux. Common on the algal plain attached to other algae (Halimeda, Sargassum, Digenia), to limestone and shell in 15 to $23 \mathrm{~m}$ depth, and in grass beds epiphytic on Syringodium in 10 to $13 \mathrm{~m}$ depth.

Reported from shallow water to $36 \mathrm{~m}$ depth. During feeding trials, this species was eaten by Acanthurus bahianus, A. coeruleus, and Sparisoma aurof renatum. 
*Laurencia nana Howe. Found attached to Sargassum filipendula in 20 m depth $60 \mathrm{~m}$ from the edge of the reef. Recorded here for the first time for the Virgin Islands.

Laurencia obtusa (Hudson) Lamouroux. Occasional on the algal plain mixed with other algae in 18 to $20 \mathrm{~m}$ depth and in grass beds attached to Syringodium in $13 \mathrm{~m}$ depth. Randall (1967) recorded the following consumers: Alutera scripta, Balistes vetula, Canthigaster rostrata, and Lactoprys trigonus. During feeding trials, it was eaten by Sparisoma aurofrenatum. Randal1 (1964, 1967) recorded the following consumers: Alutera scripta, Balistes vetula, Canthigaster rostrata, Lactophrys trigonus, and the queen conch, Strombus gigas.

Laurencia papillosa (Forska1) Greville. Occasional on the algal plain attached to limestone and epiphytic on Sargassum and Digenia in 18 to $22 \mathrm{~m}$ depth, and in grass beds on limestone 10 to $13 \mathrm{~m}$ depth. Randal1 (1967) recorded this species from the stomach contents of the following: Abudefduf saxatilis, Alutera scripta, Blennius cristatus, Kyphosus sectatrix, Scarus coelestinus, Sparisoma viride.

Liagora ceranoides Lamouroux. Occasional on the algal plain attached to limestone, once on Udotea flabellum, in 18 to $20 \mathrm{~m}$ depth. Reported from shallow water to $20 \mathrm{~m}$ depth (Taylor, 1960). Randa11 (1967) recorded the following consumers: Acanthurus bahianus, Cantherhines macrocerus, Cantherhines pullus.

Lithophyllum sp. Probably more than one species, crustose on limestone and dead coral on the reef and algal plain.

*Lomentaria baileyana (Harvey) Farlow. Attached to Halimeda in $21 \mathrm{~m}$ depth $120 \mathrm{~m}$ from the edge of the reef on the algal plain. Reported here for the first time for the Virgin Islands. Randall (1967) recorded Sparisoma rubripinne as a consumer of $\underline{L}$. uncinata (L. baileyana).

Lophocladia trichoclados (Mertens in C. Agardh) Schmitz. On Sargassum filipendula and Acanthophora spicifera in $20 \mathrm{~m}$ depth $60 \mathrm{~m}$ from the edge of the reef on the algal plain. Recorded from depths to $20 \mathrm{~m}$ (Taylor, 1960). 
*Lophosiphonia saccorbiza Collins and Harvey. On Halimeda and Idotea in 18 to 20 in depth, on the algal plain. Preyiously recorded from Bermuda and Florida, but reported here for the first time for the Virgin Islands.

Melobesia membranacea (Esper) Lamouroux. On Halimeda incrassata, H. simulans, and Syringodium filiforme on the algal plain and in grass beds in 15 to $21 \mathrm{~m}$ depth. Usually found in shallow water (Taylor, 1960).

Peyssonnellia rubra (Greville) J. Agardh. On limestone on the algal plain in $20 \mathrm{~m}$ depth. Reported to $33 \mathrm{~m}$ depth (Taylor, 1960). Randall (1967) recorded Melichthys niger as a consumer of Peyssonnellia sp.

Peyssonnellia simulans Weber-van Bosse. On limestone on the algal plain in 18 to $20 \mathrm{~m}$ depth. Originally obtained in the Virgin Islands in 18 to $46 \mathrm{~m}$ depth and apparently not discovered elsewhere.

Polysiphonia havanensis Montagne. Attached to Halimeda incrassata in $21 \mathrm{~m}$ depth on the algal plain. Previously reported from shallow water (Taylor, 1960). Undetermined species of Polysiphonia were recorded by Randall (1967) in the stomach contents of the following fishes: Abudefduf saxatilis, A. taurus, Acanthurus bahianus, A. coeruleus, Blennius marmoreus, Cantherhines pullus, Entomacrodus nigricans, Eupomocentrus fuscus, E. leucostictus, Kyphosus incisor, Melichtys niger, Microspathodon chrysurus, Ophioblennius atlanticus, Scarus coelestinus, s. croicensis, $\underline{\mathrm{S}}$. guacmaia, $\underline{\text { S. }}$ taeniopterus, $\underline{\mathrm{S}}$. vetula, Sparisoma aurofrenatum, $\underline{\mathrm{S}}$. rubripinne, and $\underline{s}$. viride.

Polysiphonia sphaerocarpa Borgesen. Found twice growing on Sargassum in 15 to $20 \mathrm{~m}$ depth. on the algal plain.

Seirospora occidentalis Borgesen. Found on Sargassum filipendula and Chrysymenia enteromorpha in 15 to $21 \mathrm{~m}$ depth. Previous $1 \mathrm{y}$ reported from depths to $27 \mathrm{~m}$ (Taylor, 1960).

Spermothamnion investiens (Crouan) Vickers. Occasional on Halimeda incrassata, Caulerpa prolifera, and Gracilaria cylindrica in 16 to $21 \mathrm{~m}$ depth on the algal plain. Recorded from depths to $27 \mathrm{~m}$ (Taylor, 1960). 
Spyridia filamentosa (Wulfen) Hayey. Mixed with other algae and epiphytic on Halimeda on the algal plain in 15 to 21

m depth. Reported from shallow water to $20 \mathrm{~m}$ depth. (Taylor, 1960). Randal1 (1967) recorded the following consumers: Abudefduf taurus, Acanthurus bahianus, Kyphosus sectatrix, Lactophrys trigonus, Melichthys niger, Pomocanthus paru, and scarus guacamaia.

Wrangelia argus Montagne. Occasional on the algal plain in 18 to $21 \mathrm{~m}$ depth and once found in a grass bed attached to Halimeda in $13 \mathrm{~m}$ depth. Randall (1967) recorded the following consumers: Eupomocentrus fuscus and Microspathodon chrysurus.

Wrangelia bicuspidata Borgesen. Occasional on the algal plain attached to Halimeda in 18 to $23 \mathrm{~m}$ depth, 50 to $180 \mathrm{~m}$ from the edge of the reef. Reported from depths to $40 \mathrm{~m}$ (Taylor, 1960).

Wrightiella tumanowiczi (Gatty) Schmitz. Occasional throughout the algal plain in 18 to 31 depth 60 to $180 \mathrm{~m}$ from the edge of the reef attached to Halimeda, limestone, and shel1, and found once in a Syringodium bed in $15 \mathrm{~m}$ depth attached to Halimeda. Reported from 18 to $27 \mathrm{~m}$ (Taylor, 1960). During feeding trials, this species was eaten by Pomocanthus arcuatus and Sparisoma aurofrenatum.

SPERMATOPHYTA. Flowering plants.

Halophila baillonis Ascherson. This species was encountered occasionally on silty, calcareous substrates in 12 to $31 \mathrm{~m}$ depth, but was found in greatest abundance forming pure stands and mixed with Syringodium in $15 \mathrm{~m}$ depth bordering a bare area surrounding a reef approximately $300 \mathrm{~m}$ south of the habitat. This site was exceptional not only because of the abundance of this seldom-seen species, but the plants were also flowering, apparently a very rare occurrence. Halophila baillonis was found by Randall (1967) in the stomach contents of the following fishes: Acanthurus bahianus, A. coeruleus, Cantherhines pullus, Canthogaster rostrata, Lactophrys triqueter, Pomocanthus paru, and Sphaeroides spengleri. It is also consumed by the queen conch, Strombus gigas, (Randal1, 1964). 
Syringodium filiforme Kutzing. (Cymodocea manatorum, "manatee grass)." This species is the most abundant vascular plant in Lameshur Bay in depths from 10 to $23 \mathrm{~m}$ depth, and is common mixed with Thalassia in 5 to $10 \mathrm{~m}$ depth. Randall (1963) reported it from a maximum of 72 feet in the Virgin Islands. Epiphytes are often numerous and algal associates include several species of siphonous green algae and Dictyota. Randall (1967) reported the following fishes as consumers: Acanthurus hahianus, A. chirurgus, A. coeruleus, Alutera schoepfi, Archosargus rhomboida is, Chaetodipterus faber, Eupomocentrus fuscus, Hemiramphus brasiliensis, Kyphosus sectatrix, Lactophrys bicaudalis, $\underline{\text { L. trigonus, Melichthys niger Pomocanthus }}$ paru, Scarus guacamaia, sparisoma aurofrenatum. On the plain, Canthigaster rostrata, Sparisoma rubripinne and Pomocanthus arcuatus were seen eating this species, and during feeding trials, the following fishes selected it among various plants offered: Acanthurus babianus, A. chirurgus, A. coeruleus, Pomocanthus arcuatus, Sparisoma aurofrenatum and scarus coeruleus. The queen conch, Strombus gigas, also feeds on Syringodium (Randal1, 1964).

Thalassia testudinum Konig. "Turtle grass." This species was found from the intertidal area to about $13 \mathrm{~m}$ depth. Randal1 (1963) reported its occurrence in the Virgin Islands to a maximum depth of 43 feet. It is frequently mixed with Syringodium and an assortment of algae, especially siphonous green algae and species of Dictyota. Randal1 (1967) recorded Thalassia in the stomach contents of the following fishes: Acanthostracion quadricornis, Acanthurus bahianus, A. chirurgus, Alutera schoepfi, A. Scripta, Archosargus rhomboidalis, Cantherhines pullus, Canthigaster rostrata, Eupomocentrus planifrons, Hemiramphis brasiliensis, Lactophrys bicaudalis, L. trigonus, L. triquerter, Moncanthus ciliatus, Mugil curema, Scarus coelestinus, $\underline{\text { s. guacamaia, } \underline{\text { S. Taeniopterus, }} \text { s. vetula, }}$

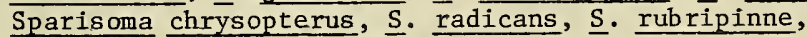
S. viride, and Sphaeroides spengleri. The urchin, Diadema antillarum and the queen conch, Strombus gigas also eat Thalassia (Randa11, 1964; Randa11, et al. 1964). 
CYANOPHYTA. The Blue-green Algae.

No attempt was made to classify the diverse kinds of bluegreen algae that were obtained during Mission 6-50, principally because current taxonomy is unsettled and identification a specialists task. I did submit a sample of a particularly abundant blue-green algae to $\mathrm{Dr}$. Francis R. Drouet for naming, however, because it formed a conspicuous ground cover among Udotea and Dictyota plants in many areas close to the reef face, a region actively grazed by numerous species of herbivorous fishes. I was particularly curious because ciguatera, fish poisoning, often is attributed to blue-greens and incidence is common in the Virgin Islands (Randall, 1958). Dr. Drouet kindly determined the species as Oscillatoria submembranacea but said that to his knowledge, it had never been implicated as a cause of ciguatera. It may be worthy of further study, however, for among the blue-greens observed, this was the most abundant and heavily grazed. It occurred in dark sometimes reddish tufts lightly attached to calcareous sand substrate and later forms dense mats and rolls that are nosed and worked over daily by flocks of grazing fishes. 


\author{
Peter H. Hartline \\ Ann C. Hartline \\ Alina M. Szmant \\ Arthur 0. Flechsig \\ Scripps Institution of Oceanography
}

\begin{abstract}
We have quantitatively studied the visual cues which evoke escape responses in a small pomacentrid fish which schools around particular landmarks in coral reefs. Models of different shapes, sizes, and colors were used to explore characteristics of the response-triggering stimuli. Contrast, or dark color, of the model relative to the background and size are important in triggering the response. The proximity of the models at the time of response was independent of model speed. Our observations of natural behavior suggest that the fish may recognize more complex characteristics of intruding fish (such as color pattern, details of shape, and sounds) in evaluating escape evoking stimuli.
\end{abstract}

\title{
OBJECTIVES
}

Escape responses are among the overt ways in which one species may affect the behavior of another. They have been studied in many land vertebrates in the context of trigger features, social communication, and fixed action patterns. We wanted to study escape responses in the coral reef environment, where the density of species and individuals is high. The species Chromis cyanea was selected because of its schooling tendency, and its characteristic escape response. When startled, the fish in a school turn toward their home landmark (e.g. a coral head) and swim toward it as a group. We wished to film the responses for later careful analysis, in which quantitative estimates of the important parameters which control the responses could be made.

We designed experiments to assess the role of model shape and size, speed of approach, and model color and pattern, in evoking escape. We wanted to determine the extent to which auditory or vibratory components of stimuli were important in generating responses. Finally, we wanted to make observations of natural behavior of the Chromis and relate these observations to our experimental results.

\section{EQUIPMENT AND PROCEDURES}

Flat plastic models were cut into circular, square, or elliptical shape, and were pulled through the water near a coral head which was the home of a school of blue chromis (Chromis cyanea). The behavior 
of the school was filmed, and the distance from the center of the group of responding fish to the model was calculated from model speed and reaction time.

Model trajectory was controlled by guide wires, and model speed was controlled by a weight and pulley system. The speed of the model was variable between $0.3 \mathrm{~m} / \mathrm{sec}$ and $2 \mathrm{~m} / \mathrm{sec}$, and was constant for any given run. Three different sizes of models were constructed for each of three shapes: circular, square, and elliptical (with major axis equal to twice the minor axis). These were designated "small" (area $100 \mathrm{~cm}^{2}$ ), "medium" (area $200 \mathrm{~cm}^{2}$ ), and "large" (area $400 \mathrm{~cm}^{2}$ ). These models were all opaque and white and are referred to as the sizeshape series. A set of medium ellipses was constructed with opaque models of colors black, red, silver, yellow, and white. In this "color series" was a model of clear plexiglas ("clear") and a white model which was wrapped with monofilament nylon at $2 \mathrm{~cm}$ intervals ("strings"). These last two models were controls designed to evaluate the role of vibratory and visual stimuli in evoking the escape responses.

A super-8 movie camera in an underwater housing with remote cable control was mounted on a tripod and used to record both the speed of the model and the escape response of the fish. High speed Ektachrome film was used. At the depth of the habitat, the camera's automatic meter system maintained a lens opening between $f 2$ and $f$ 4.5. The depth of focus under these conditions is not ideal, but was adequate to show escape responses. Suspended matter in the water was a more severe problem. About $25 \%$ of our data films were difficult to analyze, and an additional $25 \%$ of them were useless.

To analyze the films, we modified a projector to permit viewing at 2 to 3 frames per second. Frames were counted electronically so that the time required for the model to pass from one edge of the screen to the other could be determined, as could the time from the instant of the fishes' response to the time when the model passed the location where the response started ("reaction time"). From the model's screen transit time and a distance calibration sequence, the model's speed could be accurately determined. Reaction time and model speed were used to calculate the distance of the model from the fish at the instant of response (reaction distance).

In the analyses where lines were fit to data points, a computer program (borrowed from Dr. E. W. Fager) employing the Bartlett linear regression procedure was used. This procedure assumes normal distribution of error in both $\mathrm{x}$ and $\mathrm{y}$ measurements. Because $\mathrm{x}$ values (speed and reciprocal speed) were essentially accurate, and $y$ deviations from the Bartlett lines were approximately normal, the confidence limits set on the slope by the Bartlett method are likely to be reasonable. 
General

Chromis aggregate in schools of 10 - 100 individuals, and usually stay in the vicinity of some fixed landmark. If they are confronted with a potential threat, such as a bar jack, (Caranx ruber), or an unfamiliar plastic model, they turn and swim toward this "home" landmark. They choose the same landmark regardless of the direction of the intruder's approach. If the intruder is approaching rapidly $(1 \mathrm{~m} / \mathrm{sec}$ or more) an observer notices rapid motion, with all fish in the school responding simultaneously. If the intruder's speed is $\mathrm{slow}(1 / 2 \mathrm{~m} / \mathrm{sec}$ or $1 \mathrm{ess})$ the fish react more gradually and apparently not at the same time.

To quantify the response, we chose reaction time and reaction distance (see previous section) in preference to a subjective measure of reaction strength, percent of failures to respond, or number of responding fish. Trials were run about $2 \mathrm{~min}$. apart. A series of trials in which 4 min., 2 min., 1 min., and $1 / 2$ min. inter-trial intervals were used showed no significant habituation (decrement in response with decrement in interval) in the escape response. This justifies the arbitrary choice of $2 \mathrm{~min}$. used in all other experiments.

\section{Effect of Mode1 Speed}

It was remarkable that for a given model, the reaction distance seemed to be independent of the model's speed. Our subjective impression had been that the reaction was considerably stronger at faster speeds. We thus expected that the fish would react at a greater distance for a faster model than for a slower one. Fig. 1 shows graphs of reaction distance as a function of speed for various models. The lumped data for all runs, all days (medium white ellipse) shows a great deal of variability, but fails to show a slope significantly different from 0 at the $90 \%$ level. It is not clear from this line whether the mean distance represents a characteristic of the response, or whether there is so much scatter that it makes no sense to consider reaction distance as a measure of the response. If the fish were reacting at a constant distance, one would have the relationships

(1) $\quad \mathrm{D}=\mathrm{V} \times \mathrm{T}$

(2) $\quad T=D \times(1 / V)$

where $\mathrm{D}$ is the reaction distance, $\mathrm{T}$ is reaction time, and $\mathrm{V}$ is speed of the model. Therefore, if $D$ is a constant, a plot of $T$ versus $1 / V$ should yield a line with slope $=D$ and intercept $=0$. The data of Fig. 1 are replotted in this manner in Fig. 2. Evidently there is a strong tendency for an early reaction at faster speeds, since the slopes of these lines are positive and not greatly different from the predicted values (mean reaction distances from Fig. 1). In most 
cases, the $90 \%$ confidence bands include the origin, which was also predicted by equation 2 . We tested data for various days and models, and found that the slopes of $\mathrm{T}$ Vs $1 / \mathrm{V}$ lines were approximately the same as the mean reaction distances for the same data in $D$ vs $V$ plots. The three pairs of graphs in Fig. 1 are representative of the fits obtained, and justify the use of reaction distance as a single parameter which expresses the strength of the escape reaction elicited by a given model. Below, we will compare this parameter of strength by Student's $t$ tests. Comparisons are only made in cases for which $F$ tests showed the variances of the two sets of data not to differ. We will compare reaction distances for experiments conducted on different days, because we found that reaction distance did not differ significantly from day to day.

Size and Shape

Table 1 shows averages for reaction distance for models of different shapes and sizes. By ranking the models according to this parameter it is seen that there is no significant difference between shapes which is consistent for all sizes. But the ranked data for different shapes shows the same order for all sizes in all cases. This would happen by chance less than $0.3 \%$ of the time; the trend toward greater reaction distance with increasing size is therefore highly significant. One cannot, however, distinguish between a logarithmic and a linear relation between area and effectiveness.

TABLE 1

\begin{tabular}{lccc} 
Shape & $\begin{array}{c}\text { Sma11: } \\
\text { Area }=100\end{array}$ & $\begin{array}{c}\text { Medium: } \\
\text { Area }=200\end{array}$ & $\begin{array}{c}\text { Large: } \\
\text { Area }=400\end{array}$ \\
\cline { 2 - 2 } & $1.00 \pm 0.22$ & $1.23 \pm 0.17$ & $1.26 \pm 0.34$ \\
Circle & $0.79 \pm 0.12$ & $1.15 \pm 0.22$ & $1.27 \pm 0.24$ \\
Square & $0.85 \pm 0.18$ & $1.15 \pm 0.38$ & $1.43 \pm 0.43$
\end{tabular}

Table 1: mean reaction distance $\pm 95 \%$ confidence 1 imits for white models of different size and shape. The matrix of ranks shows a significant size trend, but no shape trend.

Color

In a series of experiments designed to test whether the fish pay attention to color or contrast, a series of medium ellipses were painted different colors. We found that light colored models did not differ significantly from each other (white, silver, yellow). Similarly, dark colored models did not differ from each other (red, black). A Student's t test comparing lumped dark to lumped light 


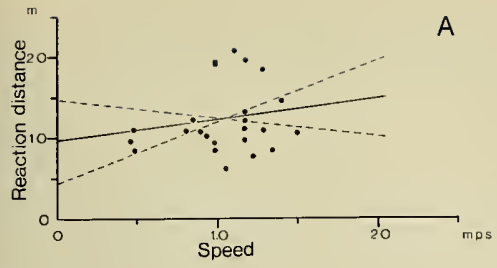

B
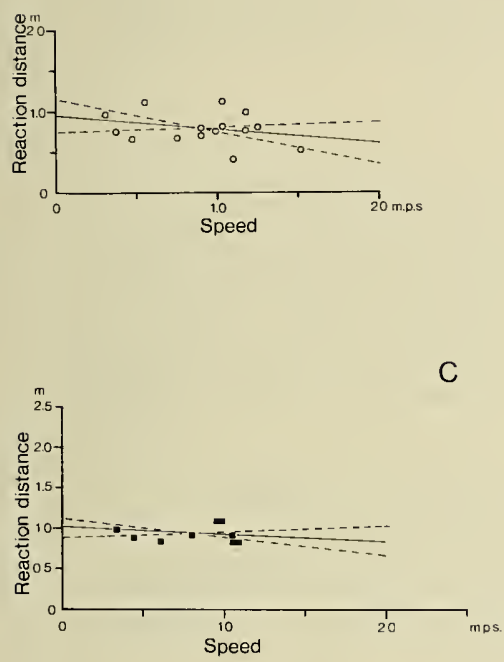

Fig. 1: Reaction distance (m) as a function of speed of model approach for different models. A: medium white ellipse, 4 days data Iumped, mean $=1.23 \pm .13 \mathrm{~m}$ ( $90 \%$ confidence 1 imits). Lines are Bartlett regression lines in a11 figures.

B: small circle, 2 days data. mean $=0.79+0.08 \mathrm{~m}$ C: smal1 square, 1 day. mean $=0.94 \pm 0.04 \mathrm{~m}$
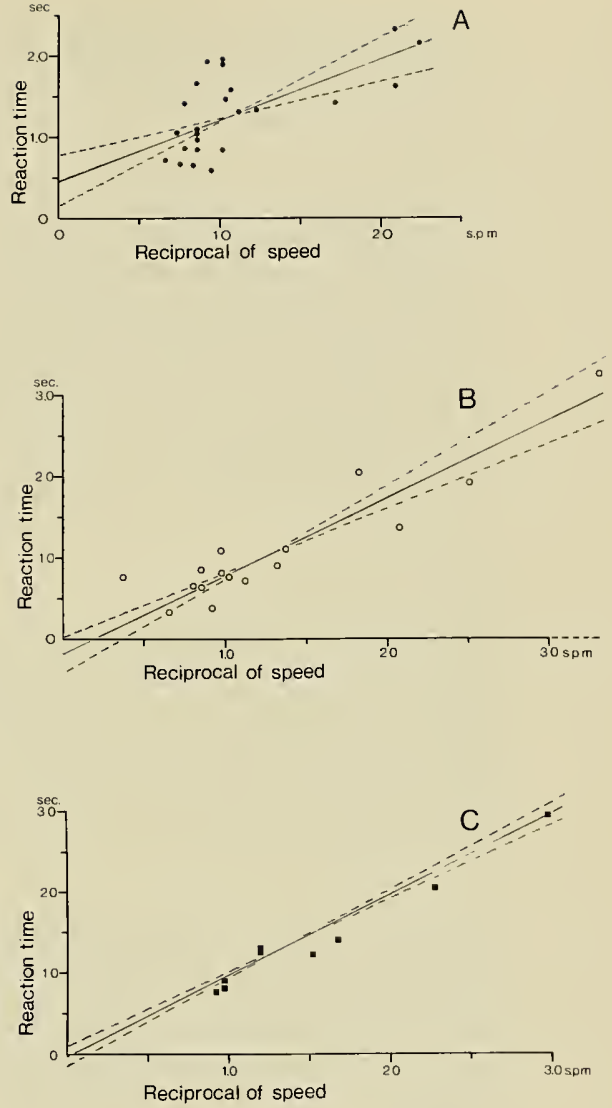

Fig. 2: Reaction time (sec) as a function of reciprocal speed of model approach for the same data as in Fig. 1. If reaction distance is independent of speed, the slopes of these lines should be equal to the mean reaction distances of fig. 1 , and intercepts should be zero. A: medium white ellipse, 4 days mean slope $=0.77 \pm 0.35 \mathrm{~m}$ ( $90 \%$ limits) B: small circle, $\overline{2}$ days mean slope $=0.95 \pm 0.24 \mathrm{~m}$ C: small square, $\overline{1}$ day. mean slope $=0.97 \pm 0.10 \mathrm{~m}$ 
data did show a difference between the two shades, significant at the $98 \%$ level (two-tailed).

\section{Role of Sound and Sight}

Along with the color series, the strings and clear models were run in an effort to demonstrate the extent to which sound was triggering the escape response. Neither model provoked reactions at distances significantly different from those of the light models. The strings model was designed to produce turbulence and thus sound, and the clear model should have produced the same sound as opaque models, but a less noticeable visual stimulus. Thus these results are ambivalent. In an abbreviated series of experiments in which closed circuit rebreather units were used by the experimenters, in lieu of the normal open circuit SCUBA, there was a tantalizing, but not highly significant indication that the fish were more tolerant of relatively quiet visual stimuli, but less tolerant of noisy ones.

Natura1 Behavior

Divers spent a total of 33 hours stationed near Chromis schools, filming or taking notes on natural behavior of the fish, while subjecting them to as little disturbance as possible. In addition, about half of the time during experiments was available for observation of responses to natural stimuli. The site of most of the observations was a cleaning station and was visited by many species of fish. The reactions of the local school of Chromis to these visitors were noted.

Whenever a large bar jack (Caranx ruber) arrived, the Chromis exhibited escape responses indistinguishable (on film or to a diver) from those elicited by fast model approaches. Similar escape responses were elicited by the arrival of schools of up to 50 small jacks, although the reaction was not as rapid or distinct. We have never observed aggressive action of small or large jacks toward the Chromis, but they are known to prey on small fish. Chromis also reacted to the presence of the trumpetfish (Aulostomus maculatus), which we did observe eating them. The slow approach of the trumpetfish caused the Chromis to swim gradually toward the home coral head and remain there until it departed.

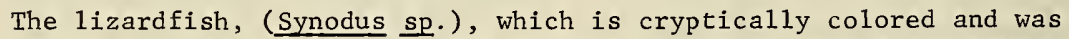
seldom noticed by observers until it had attacked, was a successful predator on Chromis. It attacked suddenly from below, and while the Chromis reacted to this lunge with an escape response, they were unsuccessful in avoiding the attack much of the time.

The majority of other fish in the area caused few escape responses. This was surprising, since some of them were large (grey angelfish, 
Pomacanthus arcuatus) or had shapes similar to that of the jacks (parrotfishes, Scaridae; goatfishes, Mullidae). These fish moved relatively slowly, and this may have accounted for the absence of observed responses. On one occasion when a grey angelfish made a rapid dart toward the reef, the Chromis did give a distinct escape response.

Sound or water-borne vibration caused escape responses on some occasions. Objects dropped on the metal barge overhead or on the bottom of a few meters from the school provoked distinct escape responses, but the fish paid no attention to the continuous sounds of passing motorboats. There were some escape responses whose causes were not apparent. They may have been correlated with passing mackeral or barracuda at a distance of 3 to 7 meters, but not all such events caused responses. On the other hand, they could have been caused by sounds not audible to the divers.

\section{CONCLUSIONS}

The absence of a difference between reaction distance for the clear vs the light opaque models could be interpreted to mean that sound plays a major role in evoking the responses. But it could also mean that Chromis easily saw the clear model (as did the divers) which was thus not a good control for sound. The results of the strings model point toward the latter explanation. Several other results demonstrate that vision does play a role in evoking the escape responses. One is the independence of reaction distance and speed of the model. If noise generated by the model triggered the escape, a faster model which generates more noise, would cause a reaction at greater distance. We have not measured noise as a function of model speed, and we cannot set limits on the extent to which sound might contribute to the response. The significant difference between reaction distance for dark and light models can only be interpreted to implicate visual involvement. The models of different color were identical with the exception of color. Further experiments might elucidate the importance of sound and vibration in triggering escape.

To a diver, the contrast between the light models and the background (either grey coral sand, light surface, or slightly darker water) was less than the contrast between the dark models and the background. We cannot tell whether it is the darkness of dark models, or their greater contrast which made them more effective at evoking escape. A more complete grey series would have to be evaluated to allow this distinction.

The trend toward earlier response with increasing model size could have been an area effect, but probably not a maximum diameter effect. This is because the small ellipse was of the same maximum dimension as the medium circle, but the latter was more effective (this was not a highly significant result, but was suggestive). 
It may be of interest that the divers subjective evaluation of fish responses led them to the conclusion that the model's speed was highly important, but that shape, size, and color were marginally important if they had any effect at a11. This is probably because the fish reacted more synchronously, and swam faster when a fast model approached. The great variability of response distance masked the more subtle effects of color and size. Speed of the model affected parameters of the response which were clearly seen by divers, but did not affect the distance at which the response was initiated.

The possibility that Chromis recognize some shapes and respond differentially to different ones is not ruled out by our shape series. In this series, no natural shapes were used. The novelty of the square, circular, and round models could have been their overriding characteristic. We did run a model with the area of the medium series, and with the basic shape and color of a bar jack. But most of our films of this experimental comparison of natural and unnatural shapes were not possible to analyze, or produced extremely meager and variable data. There is need for more careful assays of the role of shape and pattern in evoking the escape response.

There is little question that we could use models to study parameters affecting an escape response in Chromis in a quantitative way. There is little reason to doubt that the response we studied was the same type that is evoked by some natural occurrences. There was reasonable correspondence between the sizes and speeds of fish and models which evoked response. Our models were most often run at speeds exceeding those of all but a few species of local fish, but the independence of reaction distance and mode1 speed over such a range as we found would have led us to predict an extension of the principle to lower speeds. In addition, some fish did not provoke responses which we would have predicted, and some fish which did not approach sufficiently close to evoke responses (according to our experimental data) did cause escape responses. We suspect that more complex visual and auditory cues associated with such intruders are recognized by the Chromis and influence their escape responses. 
THE ECOLOGY AND BEHAVIORAL PATTERNS OF THE MOTILE FAUNA

ASSOCIATED WITH TROPICAL MARINE SOFT BOTTOM COMMUNITIES

Renate Schlenz True

Bio-Oceanic Research, Inc.

\section{ABSTRACT}

The study of the behavior of the small motile fauna present among the leaves of Syringodium filiforme, a marine sea grass, showed that crustaceans are the predominant group of organisms present at daytime, while molluscs are the ones more abundant at night.

Daily variations of dissolved oxygen ranged from 5.2 to $7.2 \mathrm{ppm}$ and the temperature from 28.2 to $28.8^{\circ} \mathrm{C}$ (July 1970).

A patch of plastic artificial sea-grass of $1.5 \mathrm{~m} \times 1.5 \mathrm{~m}$ showed that juvenile fish found protection from the opened environment among the plastic blades. After a week's time one species of foraminifera and one species of a red calcareous algae were present on the plastic leaves in the same percentage as they were found on the natural sea-grass. After two weeks a small branched green algae had attained the size of $1 \mathrm{~cm}$.

\section{OBJECTIVE}

The purpose of this study was to find out the daily variations on the number of individuals as well as the zoological composition of the small motile fauna accompanied by the variations of dissolved oxygen present among the leaves of marine sea-grasses.

A patch of artificial sea-grass was introduced in the environment for additional information on the behavior of the small motile fauna by having the major daily dissolved oxygen variation ruled out, as well as the additional food source (from the sessile organisms growing on the leaves). Also, a study on the rapidity of organisms' settlement over the artificial sea-grass was to be followed to compare to the already existing sessile fauna and flora present on the natural leaves.

EQUIPMENT

30 cc plastic syringes

Plastic bags

Note boards

Nets with $1 \mathrm{~mm} \times 1 \mathrm{~mm}$ mesh (size of squares) mounted on a metal frame of $30 \mathrm{~cm}$ in diameter

A patch of artificial sea-grass made of plastic green ribbons $5 \mathrm{~mm}$ wide and 50 to $70 \mathrm{~cm}$ long, mounted on a base of chicken wire $1.50 \mathrm{~m} \times 1.50 \mathrm{~m}$

Thermometer

Dissecting scope

Weston and Stack dissolved oxygen analyzer 
Water samples were taken using plastic syringes which were completely filled with water and then closed with caps to prevent any loss. These syringes were also differently labeled to avoid confusion among the samples and enclosed in a plastic bag for transportation. Once back in the habitat, the dissolved oxygen was immediately measured by introducing the probe of the apparatus directly into the now carefully opened syringe, through the large end.

The Weston and Stack dissolved oxygen analyzer was calibrated against values obtained through the chemical analysis of the water by the Winkler method. The water used for the calibration had been previously saturated in oxygen by letting air bubble in sea water for a period of two hours. Before additional measurements of dissolved oxygen were taken, the apparatus was recalibrated against known values of samples using sea water saturated in oxygen. The apparatus gave the readings directly in ppm.

\section{The Collecting and Analysis of the Motile Fauna}

Using a net, 40 fast strokes were done among the vegetation (artifical and natural) always in the same way to collect the small motile fauna. The net was then enclosed in a plastic bag to avoid losses of organisms during transportation. Once back in the habitat, the organisms were separated from the debris, then identified as well as possible with the available bibliography and their numbers counted. The organisms were then released back into the marine environment.

\section{Additiona1 Manipulations}

Samples of sea-grass leaves (artificial and natural) were also taken. A record of temperatures was also kept.

\section{Sampling Plan}

The sampling was planned for different times every day so as to cover a 24-hour pattern of the behavior of the motile fauna and dissolved oxygen in the water in the period of two weeks.

\section{RESULTS}

The area studied was at about $360 \mathrm{~m}$ north of the TEKTITE II habitat location in $15 \mathrm{~m}$ depth. It is an extensive sea-grass bed of the species Syringodium filiforme. The leaves are up to $40 \mathrm{~cm}$ long, with an average of $\overline{30 \mathrm{~cm} \text {, and their }}$ rhizomes and roots are up to $5 \mathrm{~cm}$ deep in the coralligenous sand and are less developed than the leaves system. This fact shows that the plant itself, for its survival, depends more on the photosynthetic activity than upon absorption of substances from the sediment (which is a clean sand--poor in chemicals--as opposed to mud). The marine sea-grass follows a vegetative starlike growth pattern on the sediment and is mixed with different species of algae that occasionally form patches, like the green algae: Penicillus pyriformis, P.capitatus, Udotea flabellum, U.conglutinata, Halimeda incrassata, and Avrainvillea nigricans. 
The brown algae Dictyota divaricata and the red algae Laurencia papillosa grow in bundles, not epiphytic but intermingled with the leaves of the marine seagrass. As shown in Figure 1, the values for dissolved oxygen found among the blades of Dictyota divaricata were always extreme, showing that this algae was actually the species responsible for greater daily changes in dissolved oxygen in the surrounding waters, in its microenvironment.

Found on patches of exposed coralligenous sands were blue-green algae that actually kept the sediment in place, forming crests. The sea-grasses in this area (generally known factor) also retained at the base of their leaves the particles of sediment that move with water currents, thus speeding up the rate of sedimentation.

On Figure 1 are shown the compilation of the data obtained during 11 days, spread over a period of 24 hours, of the dissolved oxygen present among:

\section{Leaves of natural sea-grasses \\ 2. Leaves of artificial grasses \\ 3. Blades of Dictyota divaricata \\ 4. The water mass $2 \mathrm{~m}$ above the ground}

The growth on the artificial sea-grass blades was not yet significant enough to show daily variations in the content of dissolved oxygen, and thus its values were the same as the oxygen content present in the water $2 \mathrm{~m}$ above the grasses.

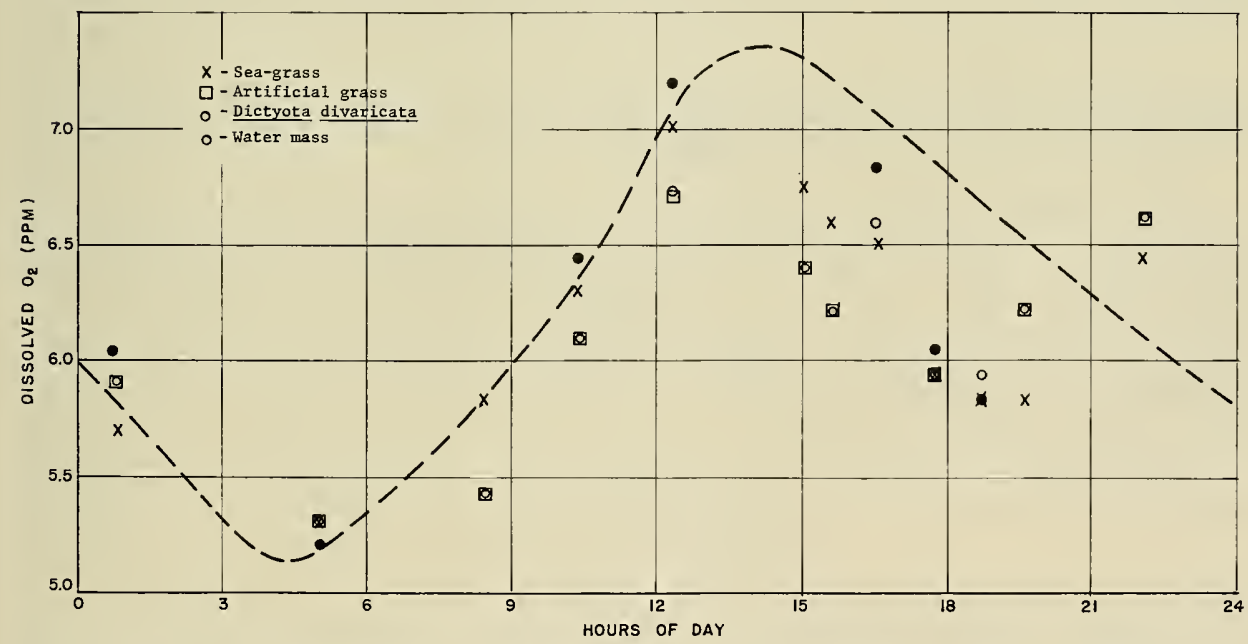

Figure 1. Compilation of data obtained during 11 days. Note: Differences in luminosity and water currents over the 11-day period account for the extremes of the expected curve. 
For the sessile fauna it was found that the visible first settlers were present after one week and were the incrustant forms of one species of foraminifera and one species of a red calcareous algae. Secondary settlers, and not so abundant, were the branched forms of small green and red algae, some hydrozoans and occasional polychaetes worm tubes. The fish that came to the artificial sea-grass to find refuge were mainly of the following species - for the daytime: Small sharpnose puffers (Canthigaster rostrata), yellowtail snappers (Ocyurus chrysurus), smal1 tiger grouper that was always at the same place (Mycteroperca tigris), and at night little caribbean pipefish were seen (Syngnathus rosseau). For the small invertebrate motile fauna, it was found that the small mobile cnidaria (Boloceroides sp) did not migrate but just moved around on the leaves, day and night.

Among the crustaceans, the amphipods and small (ovigerous at the time) caridean shrimp were the predominant forms at daytime. The numbers of crustaceans was reduced up to $75 \%$ at night, mainly because the majority of amphipods and shrimp would migrate vertically into the water mass. Around dawn and sunset, molluscs and crustaceans were found in about equal abundance, but at the day hours crustaceans made for about $80 \%$ of the totality of the motile fauna. At the middle of the night, molluscs (gasteropods Prosobranchs were the majority) only came up to $60 \%$.

\section{CONCLUSIONS}

1. The behavior of the small motile fauna follows a set pattern of daily vertical migrations related to the plants metabolism and to the food supply. Only when the artificial sea-grass leaves are covered secondarily by other organisms, the small invertebrate motile fauna move in. The majority of crustaceans present at daytime among the seagrass leaves move away at night to the open waters, while the molluscs partly move away during daytime down to the sediment.

2. The different species of small juvenile fish, grunts, yellowtail snappers, groupers, are definitely among the leaves (natural and artificial) mainly for protection from bigger predators.

3. Artificial sea-grasses as well as any other type of surfaces, when introduced in a marine environment, offer additional bare substratum for organisms to settle down and grow, thus increasing the available food supply. In shallow waters, small algae are the predominant organisms that attach and grow on artificial surfaces, thus, other than being available food for grazers, they enrich the environment with a supply of oxygen. (This same principle is used in farming mullets commercially.) 
OBSERVATIONS ON THE BIOLOGY AND BEHAVIOR OF THE ARROW CRAB, STENORYNCHUS SETICORNIX (HERBST), IN LAMESHUR BAY, ST. JOHN, VIRGIN ISLANDS

\author{
by
}

\author{
Louis Barr \\ National Marine Fisheries Service \\ Auke Bay, Alaska
}

\begin{abstract}
A study of the arrow crab population near the TEKTITE II habitat showed that these crabs are present in densities of up to 2 per square meter of reef area. These crabs mature at about $8.5 \mathrm{~mm}$ in carapace length and appear to have an extended, or year-round, reproductive season. They perform a diel migration, leaving the crevices in the stony corals at dusk and spending the nights on the soft corals and gorgonians. They serve as scavengers on the reef and appear to be subjected to little predation.
\end{abstract}

\title{
INTRODUCTION
}

The arrow crab, Stenorynchus seticornis (Herbst), family Majidae, is widely distributed in the tropical and subtropical Atlantic. Its known range is from North Carolina and Bermuda to Rio de Janeiro in the western Atlantic and from Madeira and Canary Is lands to Angola in the eastern Atlantic (Williams, 1965). Arrow crabs have been collected at depths ranging from very shallow to 1,488 meters ( 814 fathoms), on rock, coral, pebble, sand, and sand-shell substrates and on wharf pilings and rock jetties (Williams, 1965).

During my participation from July 23 to August 12, 1970, in the TEKTITE II saturation diving experiment in Lameshur Bay, St. John, Virgin Is lands, I conducted an intensive in situ study of the biology and behavior of the arrow crabs near the TEKTITE habitat. Approximately 40 hours were spent making in situ observations of the crabs during routine excursions from the TEKTITE habitat on standard scuba and closed-circuit, oxygen rebreather equipment. In addition to the in situ observations, approximately 100 crabs were collected and brought into the wet room of the TEKTITE habitat for further behavioral observations and for determination of sex and size composition of the population in the study area.

\section{HABITAT}

The study area ranged in depth from 8 to 22 meters and included several types of substrate. Much of the bottom was extensive live coral reefs. Areas of sand substrate occurred among the various large reefs and in an unbroken expanse west of the reefs. On the sand areas, generally near the interface between coral reef and sand substrate, were numerous patch-reefs of living coral, ranging from a fraction of a meter to several meters in diameter.

Arrow crabs were more abundant in areas of coral substrate than in sand substrate areas. Although crabs were found throughout the coral areas, they were generally most abundant at or near the edges of the reefs; that is, near the coral-sand 
interface. In the areas of extensive reefs, the crabs were almost invariably in direct contact with either the stony corals (Order Scleractinia) or the soft corals (Order Alcyonacea) and gorgonians (Order Gorgonacea) of the reef. In a few instances crabs were found on the sand substrate immediately over the overhanging corals at the reef edge. Even in these instances, however, the crabs usually maintained contact with the coral substrate with their posterior walking legs. Crabs associated with the small patch-reefs were generally on the sand substrate under the overhanging corals, but also were in direct contact with the coral.

Arrow crabs were also found on the extensive areas of sand substrate. Here, however, they were almost invariably associated with relatively prominent, stable objects such as sponges, anemones, and small "boulders" of dead coral. Among 19 crabs observed in the sand substrate area, 8 were associated with sponges, 7 with small "boulders" of dead coral, and 3 with anemones. Only one crab found on the sand was not associated with any prominent object. Most crabs seen on the sand areas were equivalent in size to the smaller crabs found in the coral reef areas (carapace lengths of approximately $3 \mathrm{~mm}$ to $6 \mathrm{~mm}$ ). The only medium and large individuals (carapace lengths estimated greater than $6 \mathrm{~mm}$ ) seen in the sand area were associated with the largest object--a "boulder" of dead cora 1 approximately $1.0 \mathrm{~m}$ by $0.3 \mathrm{~m}$ in size.

The TEKTITE habitat was placed on an area of sand substrate and crabs had co1onized the crevice between the base of the habitat and the sand during the 5 months the habitat was in place.

\section{POPULATION DENSITY}

The population density of arrow crabs was measured along two transects within approximately 10 meters of the TEKTITE habitat. Both transects were located along the edge of large reef areas; transect $A$ was along the reef face immediately west of the TEKTITE structure, transect $B$ was along the reef face southeast of the structure. Each transect was 10 meters 1 ong and 1 meter wide from the edge of the reef inward on the reef. Total counts of crabs within each of these two areas were made 9 times, including 4 counts during daylight, 2 counts during darkness, 2 counts at dawn, and 1 count at dusk (Table 1). Counts during night and twilight periods were made with a hand-held diver's light.

Table 1.--Numbers of arrow crabs counted along two transects at various times of day.

\begin{tabular}{|c|c|c|c|c|}
\hline \multirow[b]{2}{*}{ Date } & \multirow[b]{2}{*}{$\begin{array}{l}\text { Count } \\
\text { number }\end{array}$} & \multirow[b]{2}{*}{$\begin{array}{l}\text { Time of } \\
\text { day (hour) }\end{array}$} & \multicolumn{2}{|c|}{ Number of crabs } \\
\hline & & & $\begin{array}{c}\text { Transect } \\
\mathrm{A} \\
\end{array}$ & $\begin{array}{c}\text { Transect } \\
\text { B } \\
\end{array}$ \\
\hline August 1 & 1 & Daylight (1800) & 17 & 12 \\
\hline August 1 & 2 & Dusk (1900) & 19 & 15 \\
\hline August 1 & 3 & Night $(2200)$ & 20 & 14 \\
\hline August 2 & 4 & Night $(0500)$ & 19 & 14 \\
\hline August 2 & 5 & Dawn $(0600)$ & 13 & 8 \\
\hline August 2 & 6 & Daylight (0700) & 16 & 11 \\
\hline August 2 & 7 & Daylight (1200) & 8 & 5 \\
\hline August 2 & 8 & Daylight (1400) & 13 & 8 \\
\hline August 3 & 9 & Dawn $(0530)$ & 18 & 10 \\
\hline
\end{tabular}


Counts of crabs along each of the two transects varied with time of day--counts at night and at dusk were higher than counts during daylight or dawn. This variation can be explained by the crabs' tendency to move from relatively concealed positions during daylight to more exposed positions at night, making them more available to the diver's view.

The highest count obtained for each transect is accepted as the closest measure of the total population of crabs in the transect area. Thus, the apparent population size within the two 10-square-meter areas of transects $A$ and $B$ were 20 and 15, respectively. These counts were probably quite complete for all crabs larger than approximately $4 \mathrm{~mm}$ in carapace length. Crabs less than $4 \mathrm{~mm}$ carapace length were difficult to see because of their small size and tendency to remain in protected locations even at night.

The indicated population densities of 1.5 to 2.0 crabs per square meter were probably maximums in the study area. As previously mentioned, the crabs usually were most abundant along the marginal portions of the large reef areas such as where the transects were located. Observations of crab abundance in other areas of habitat similar to that of the transect areas indicated that crabs were considerably more abundant in the transect areas than elsewhere. It appeared that the proximity of the transects to the TEKTITE habitat may have had a positive influence on the population density of crabs. The greater abundance of crabs may have been a result of one or more of the artificial conditions created by the presence of the habitat and the attendant human activity. The lights of the TEKTITE habitat altered the normal night darkness conditions, especially along transect $A$ which was within the influence of the bright outside light located on the west side of the structure. The high level of diver activity in the transect areas with the resulting water turbulence and turbidity may have enhanced the transect locations as suitable feeding areas for crabs.

\section{POPULATION STRUCTURE}

Samples totaling 103 arrow crabs were collected and brought into the wet room of the TEKTITE habitat to obtain information on size and sex composition of the population. Samples were intended to represent the general population, but smaller crabs were probably not completely represented because of greater difficulty in capturing them.

The sex of each crab was determined by examining the shape of the abdomen. A series of morphometric measurements of each crab including carapace length and width, rostrum length and chela length, were made to the nearest $0.5 \mathrm{~mm}$ with a vernier caliper.

The ratio of female to male crabs in the sample was 55:48 indicating a slightly greater abundance of females than males in the general population. Females ranged from $4.5 \mathrm{~mm}$ to $13.0 \mathrm{~mm}$ and averaged $9.2 \mathrm{~mm}$ in carapace length. Males ranged from 3.5 to $16.5 \mathrm{~mm}$ and averaged $9.4 \mathrm{~mm}$.

\section{MATURITY AND REPRODUCTION}

Maturity of the arrow crabs was determined solely by examination of external features. Hartnoll (1969) mentions the prominent changes in the abdomen, pleopods, and sternum of most brachyuran crab females at the moult of puberty. 
Watson (1969) used relative abdomen width to determine maturity of female Chionoecetes opilio. Relative abdomen width was used as the criterion of maturity of female arrow crabs in the present study. In male brachyuran crabs, external morphological changes, particularly affecting the chelae, may coincide with maturity (Hartno11, 1969). Onset of sexual dimorphism, as shown by allometric growth of the chelae, was used as the criterion of maturity of male arrow crabs.

Maturity in both sexes of arrow crabs appears to occur when the crabs measure about $8.5 \mathrm{~mm}$ to $9.5 \mathrm{~mm}$ in carapace length. The smallest adult female crabs were $8.5 \mathrm{~mm}$. In females, presence of eggs on the pleopods provides functional proof of maturity; one individual of $8.5 \mathrm{~mm}$ with eggs was found. Among 35 females of $9.0 \mathrm{~mm}$ or larger, all but two (one $9.0 \mathrm{~mm}$ and one $10.5 \mathrm{~mm}$ ) were mature and 27 were ovigerous. It is more difficult to provide functional proof of maturity in male crabs. Males as small as $11.0 \mathrm{~mm}$ were observed grasping or mating with females, indicating that those individuals were mature. Such observations were few, however, and do not provide a complete indication of the minimum size at maturity. The fact that male crabs larger than $8.0 \mathrm{~mm}$ showed strong morphometric differences from females indicates that maturity of the males probably occurs soon after they exceed $8.0 \mathrm{~mm}$.

Mature female arrow crabs were categorized according to presence or absence of eggs on the pleopods and state of development of the eggs. Among 35 mature females, 28 were ovigerous and 7 were not. Among the ovigerous crabs, 17 had early, uneyed eggs; 9 had late, eyed eggs; and 2 had eggs that were hatching. The wide range of reproductive stages observed among the mature females in early August indicates that this species probably has an extended (or possibly yearround) reproductive season.

Arrow crabs were observed displaying various aspects of mating behavior. Most mating activity seemed to occur during the late afternoon and early evening. Seven pairs of mating crabs were observed on various days between $1630 \mathrm{hr}$ and $1930 \mathrm{hr}$. One sighting of a pair of grasping crabs at $0200 \mathrm{hr}$ was the only instance of mating behavior observed outside the late afternoon-early evening period.

The mating behavior was basically of two types--grasping and copulation. During both, the male is the active participant and the female is passive. When grasping, the male loosely holds the female, usually by a walking leg, in one of his chelae; both crabs are in normal upright posture, side by side, and facing the same direction. Sometimes a pair moves while grasping, the male providing all or most of the locomotion while dragging or herding the female along. During attempted or actual copulation, the male crab assumes a ventral side-up position, brings the female, still ventral side-down, directly over him, and grasps her tightly with his chelae and posterior three pairs of walking legs. The ventral surfaces of the two crabs are then pressed closely together, the abdomen of the female is extended posteriorly, and the weight of both crabs is supported above the substrate by the female's walking legs. Crabs remain in the copulatory position for 3 to 9 minutes. The actual mechanism of sperm transfer was not observed.

Three pairs of mating crabs were collected and placed in water-filled containers in the wet room of the TEKTITE habitat. Copulatory behavior was not inhibited 
by the handling and placement in an artificial environment. In fact, on several occasions when the male member of a mated pair was removed for measuring and then replaced in the container with the female, he immediately grasped her and brought her to the copulatory position. Disturbance actually seemed to intensify the males' mating behavior.

Among the female members of the three mated pairs collected, one was without eggs and two had hatching eggs at the time of copulation. Those with hatching eggs completed hatching soon after copulation. Within 19 hours after copulation (in one case within 6 hours) each of these females had ovulated and deposited new eggs on her pleopods. All new eggs were lost within 2 days after deposition --probably a result of unsatisfactory conditions in the artificial environment in which the crabs were being held. None of the females moulted during the period of observation indicating that the reproductive cycle is independent of the moult cycle or, more likely, that females cease to moult after attaining maturity as happens in other species in the family Majidae (Hartno11, 1969).

The larvae that hatched from females held in the wet room were approximately $2 \mathrm{~mm}$ in total length and exhibited strongly positive phototropic behavior. Because of this attraction to light, the newly-hatched larvae in the natural environment probably occupy the upper portion of the water column at least during the daylight hours.

\section{DIEL MIGRATIONS}

Arrow crabs in the coral reef habitat demonstrated a very definite pattern of diel migrations. Observations were made of the specific locations of crabs within the reef habitat during 13 periods at various times throughout several diel cycles. The results of these observations are sumarized in Table 2 .

Table 2.--Distribution of arrow crabs on stony and soft corals at various times of the day.

\begin{tabular}{|c|c|c|c|c|}
\hline $\begin{array}{c}\text { Time } \\
\text { of day (hour) }\end{array}$ & $\begin{array}{c}\text { Total } \\
\text { crabs } \\
\text { observed }\end{array}$ & $\begin{array}{c}\text { Percent } \\
\text { On stony } \\
\text { coral }\end{array}$ & $\begin{array}{c}\text { On crabs } \\
\text { coral }\end{array}$ & Additiona1 observations \\
\hline Daylight (1200) & 13 & 100 & 0 & Al1 in protected 1ocations $2 /$ \\
\hline Day1ight (1400) & 28 & 100 & 0 & A11 in protected locations \\
\hline Daylight (1700) & 8 & 100 & 0 & A11 in protected locations \\
\hline Daylight (1730) & 6 & 100 & 0 & A11 in protected locations \\
\hline Dusk (1900) & 6 & 33 & 67 & \\
\hline Dark (2200) & 34 & 18 & 82 & \\
\hline Dark (0100) & 8 & 12 & 88 & \\
\hline Dark (0500) & 33 & 33 & 67 & $\begin{array}{l}\text { Most of those on stony coral in } \\
\text { exposed locations at or near } \\
\text { bases of soft coral }\end{array}$ \\
\hline Dawn $(0530)$ & 28 & 43 & 57 & Crabs descending from soft corals \\
\hline Dawn $(0600) 1 /$ & 27 & 100 & 0 & $\begin{array}{l}\text { About half in protected locations, } \\
\text { others in exposed locations on } \\
\text { stony coral \& moving toward crevices }\end{array}$ \\
\hline Daylight $(0700)$ & 27 & 100 & 0 & A11 in protected 1ocations \\
\hline
\end{tabular}


During daylight all crabs are in contact with the stony coral substrate of the reef, and most are located in crevices, holes, or under overhangs; i.e., in relatively protected and concealed locations. In late afternoon (between $1730 \mathrm{hr}$ and $1900 \mathrm{hr}$ ), however, most crabs emerge onto the more exposed surfaces of the stony coral substrate. Shortly before dusk (judged as the time when it became necessary to use artificial lights to make observations) at about $1900 \mathrm{hr}$, the crabs begin to ascend various soft corals and gorgonians. The periods of transition is quite short and by the time it becomes dark (about $1930 \mathrm{hr}$ ) most have left the stony coral substrate and are in contact only with the soft corals and gorgonians. The crabs ascend to the upper parts of these corals, some reaching a height of a meter or more above the stony coral substrate. Throughout the period of darkness most crabs are found on the upper parts of the soft corals and gorgonians. Promptly at dawn ( $0530 \mathrm{hr}$ to $0600 \mathrm{hr}$ ) the crabs descend from the soft corals and return to their daytime locations in the relatively concealed spaces among the stony corals.

Although individual crabs were not recognized and followed from particular day to night locations, it appeared that individuals probably did not travel far during their diel migrations. At night crabs were often found on soft corals or gorgonians attached within one or two meters of crevices which contained crabs during the daylight. It appeared likely that at least some individual crabs returned to the same crevice each day and to the same soft coral each night; observations at specific stony coral crevices and soft corals during successive days and nights showed that locations occupied at one time were usually occupied at a similar time in following diel cycles.

\section{FOOD AND FEEDING}

Arrow crabs appear to be principally omnivorous, opportunistic scavengers. They were observed feeding on bits of detrital filamentous algae, fish fecal pellets, dead fish, soft edge of a tarpon scale, and the moult or remains of another species of crab. When crowded together in an artificial situation, some cannibalistic feeding occurs. Most of their food, however, appears to be the filamentous algal detritus.

To collect the detritus that forms the bulk of their diet, the crabs either gather it from the substrate or pick it off their own bodies. In feeding from the substrate, the crabs actively probe with their chelae. Potential food items are apparently recognized by a tactile sense and are quickly grasped and transferred to the mouth. When gathering food from the surfaces of their own bodies, crabs methodically and continually perform grooming-like movements with the chelae, picking detritus from wherever it has lodged on the pubescence or spinules that cover much of the external surface and transferring the detritis to the mouth. Even the chelae themselves are cleaned, one by the other. One crab that was lacking a left cheliped removed detritus from the surface of the right chela with the dactyl of the first left walking 1 eg, then removed the detritus from that appendage with the chela and carried it to the mouth.

The self-cleaning method of food gathering was the one used most by the crabs. Sixty-two feeding crabs ( 37 females and 25 males) were observed for 2 minutes each and the methods of food gathering were noted. Among the females, 12 were self-cleaning only, 19 were self-cleaning and bottom-searching, and 6 were bottomsearching only. Among the males, 15 were self-cleaning only, 5 were self-cleaning and bottom-searching, and 5 were bottom-searching only. 
The feeding activity of the arrow crabs varied strongly within each diel cycle. Feeding activity was measured by recording the number of chela-to-mouth movements of an individual crab during a 2-minute period. Observation periods at different times of the day included measurements for six to eight crabs each. Summarized results of these observations (Table 3) show that the crabs feed mostly during the daylight period, with a peak of feeding activity late in the afternoon. Between dusk and dawn, feeding activity is at a very low level.

Table 3.--Summary of feeding activity of arrow crabs at various times throughout the diel cycle.

\begin{tabular}{lccc}
\hline \multirow{2}{*}{$\begin{array}{c}\text { Time } \\
\text { of day (hour) }\end{array}$} & $\begin{array}{c}\text { Number of crabs } \\
\text { observed }\end{array}$ & $\begin{array}{r}\text { Number of chela-to-mouth movements } \\
\text { per crab per 2-minute period }\end{array}$ \\
\cline { 3 - 4 } Dark (0100) & 8 & 0.7 & Range \\
Dawn (0600) & 6 & 2.3 & $1-3$ \\
Daylight (0700) & 6 & 13.7 & $0-21$ \\
Daylight (0815) & 6 & 9.2 & $1-27$ \\
Daylight (1000) & 6 & 7.2 & $1-15$ \\
Daylight (1345) & 7 & 9.0 & $1-13$ \\
Daylight (1600) & 6 & 6.8 & $1-18$ \\
Daylight (1645) & 8 & 19.7 & $1-18$ \\
Daylight (1730) & 6 & 17.7 & $6-39$ \\
Daylight (1800) & 7 & 12.4 & $11-31$ \\
Dusk (1900) & 6 & 3.8 & $4-18$ \\
\hline
\end{tabular}

The relative lack of feeding activity at night and the occurrence of a nightly migration up onto the soft corals leads to speculation on the possible reason for the diel movements. When the crabs do feed heavily during the day, they are largely dependent upon the detritus clinging to their bodies. Perhaps, therefore, it is necessary for them to expose themselves to conditions in which they can accumulate large amounts of detritus during the night. Possibly this is accomplished by the crab's remaining poised high above the hard substrate throughout the night. At that level water currents will be somewhat greater than at the hard substrate level and the amount of drifting detritus passing any given point may likewise be greater, allowing a crab to accumulate more detritus than it could at a lower level. A food gathering sequence of this sort could also explain the relatively high abundance of arrow crabs near the TEKTITE habitat. The increased water turbulence and turbidity caused by concentrated diver activities in the area may simply make more detrital food available to the crabs during their nighttime collection periods.

If this proposed mechanism of food gathering is correct, arrow crabs display a unique feeding method among marine invertebrates. In effect, they would be filter feeders, filtering drifting detritus from the water with the entire surface of their bodies and later gathering and concentrating the detritis for ingestion.

\section{DEFENSE MECHANISMS AND PREDATION}

No instance of natural predation on arrow crabs was observed during this study. The crabs have several well developed passive and aciive defense mechanisms which probably protect them from most potential predators of the reef environment. 
The crab's anatomy provides a passive, but effective, defense against some fish. The extreme length and spininess of the appendages apparently make them difficult to eat. When releasing live arrow crabs in the entry well of the TEKTITE habitat, I noticed them attracting the small coneys (Cephalopholis sp.) and snappers would often dart in, grab the crab by a leg, and then release it, allowing it to settle to the bottom without further harassment. When a crab without all or most of its legs was dropped, however, it was quickly taken and eaten. It appeared that the crab itself is a desirable food item, but the legs provide a deterrent to potential predators.

The arrow crabs displayed two forms of active defense, fending and retreat, during my attempts to collect individuals from the reef. The way in which each form was employed depended upon the stimulus to which a crab was reacting. When I would reach slowly for a crab, it would typically raise one or both walking legs of the first pair and direct them at my hand in an apparent effort to fend it off. At the same time, the crab would slowly retreat, usually toward a more protected position. The reaction of a crab to a rapid approach by my hand was to retreat quickly by a series of erratic, darting movements, and, secondarily, to display the fending behavior. At times the crab would retreat among the spines of one or more urchins (Diadema $\mathrm{sp.}$ ). Whether this reaction was by design or chance is unknown, but the net result was extremely effective. Crabs would often react to closely approaching fishes by displaying fending behavior. Larger or rapidly approaching fish would elicit a fending response from a greater distance than a smaller or slowly approaching fish.

\section{ROLE OF ARROW CRABS IN REEF ECOLOGY}

Arrow crabs appear to fit into the overall ecology of the coral reef environment principally as scavengers. They apparently do not prey upon any of the other living organisms, nor do they serve as important food to the predators. The crabs utilize the abundant dead organic matter present and then probably are themselves consumed by other scavenging organisms of the reef.

\section{LITERATURE CITED}

Hartno11, R. G. 1969. Mating in the Brachyura. Crustaceana 16: 161-181.

Watson, J. 1969. Biological investigations on the spider crab Chionoecetes opilio. Industr. Dir. Serv., Dept. Fish. Can., Ottawa. Meeting on Atlantic Crab Fishery Development, March 4-5, 1969. [Processed.]

Williams, Austin B. 1965. Marine decapod crustaceans of the Carolinas. U.S. Fish Wild1. Serv., Fish. Bul1. 65: 1-298. 


\title{
BIOLOGY OF CEPHALOPODS
}

\author{
F. G. Hochberg \\ University of California \\ and \\ John A. Couch \\ National Marine Fisheries Service \\ Oxford, Maryland
}

\begin{abstract}
Few studies of cephalopod molluscs have been made in situ. Mission 8-50, TEKTITE II, made possible a threeweek study (July-August) of octopods and squids in Greater Lameshur Bay, St. John, U. S. Virgin Islands. A cross sectional study revealed the presence of at least three species of Octopus: $\underline{0}$. briareus; $\underline{0}$. macropus; and $\underline{0}$. vulgaris. Observations on activity periods, territoriality, feeding, and general behavior of these octopods were made. Three different genera and species of squid were observed: Sepioteuthis sepioidea; Pickfordiateuthis pulchella; and Loligo plei. Observations on schooling behavior, space requirements, mating, and feeding were made on these squid.
\end{abstract}

\section{OBJECT IVES}

Little information, concerned with cephalopod molluscs in their natural environment, is available in the scientific literature. Most studies of cephalopods in the tropical western Atlantic have been concerned with taxonomy (Voss, 1964; Voss and Solis, 1966). The few field observations made on octopods, for example, have been extremely short-term and casual (Storr, 1965). Divers attempting prolonged field studies have been hampered by the great mobility, camouflage ability, and predominately nocturnal habits of cephalopods. The presence of highly developed visual and nervous systems in cephalopods often leads to the occurrence of the "observed observer" phenomenon when divers attempt short-term field observations.

The objective of our project was to conduct a cross sectional study of cephalopod abundance, species composition, distribution, diet, activity patterns, and parasites in Greater Lameshur Bay. Further, we also hoped to carry out short-term longitudinal studies of specific individuals or groups of cephalopods concerning behavioral patterns including feeding methods, territoriality, color patterns, and species interaction. 
For excursions from the habitat we used SCUBA (double tanks) and the GE Mark 10 rebreather units as breathing devices. General equipment consisted of underwater lights, plastic slates and clip boards upon which to record our observations, pencils, and nylon mesh bags for holding live specimens. Ten percent formalin seawater and mercuric chloride in plastic squeeze bottles were used to drive reluctant octopods from dens or hiding places. Octopods were narcotized with $3 \%$ urethane-seawater in the habitat. Glass slides, coverslips, and 1ight microscopes in the habitat were used for parasite diagnoses. Trypan blue was used to mark (tag) individual octopods.

\section{PROCEDURES}

Octopods.

Animals when encountered were recorded; their location, relative sizes, and behavior noted. A total of 30 individuals were sighted and of these, 10 were captured and brought to the habitat for examination (Table I). Once narcotized with urethane they could be handled easily for identification (we used the Key to Octopod Species of the Western Tropical Atlantic by Voss, 1966). The mantle 1igament (Adductor muscle) was cut, the mantle folded back, and the individual was sexed, aged, and examined for parasites. To determine if dicyemid mesozoans (unique octopod parasites) were present, a sample of urine was removed from the renal sacs by pipette and examined under the microscope. Another sample was taken from the rectum and a visual examination was made of the viscera and gills for macro-parasites. Subcutaneous injections of trypan blue in varied patterns on the dorsal mantle and arms allowed for subsequent recognition of specific individuals (Fig. 1). Before being returned to the site of capture for release, the animals were placed for recovery (30 to 45 minutes) in a mesh bag suspended in the trunk.

Squid.

Incidental observations of behavior were made when squid were encountered. No attempt was made to capture, examine, or mark individuals.

\section{RESULTS}

\section{Octopods:}

Three, possibly four, species of Octopus were observed (See Table I for general summary of observations on three identified species). The results of observations on each of the three species are given separately. 


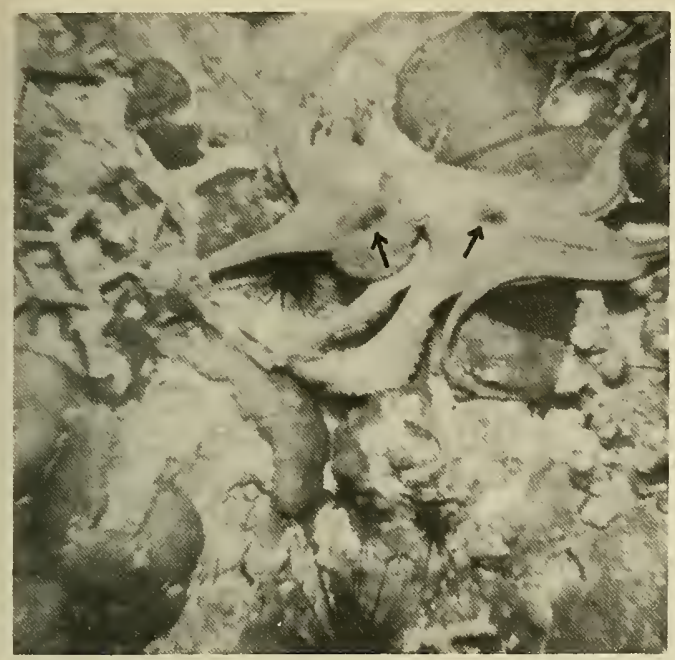

Figure 1. Octopus briareus at night on reef. Note trypan blue tag-mark pattern (arrows).

Figure 2. Octopus briareus at night on coral heads. Note coverage of coral by web and arms.
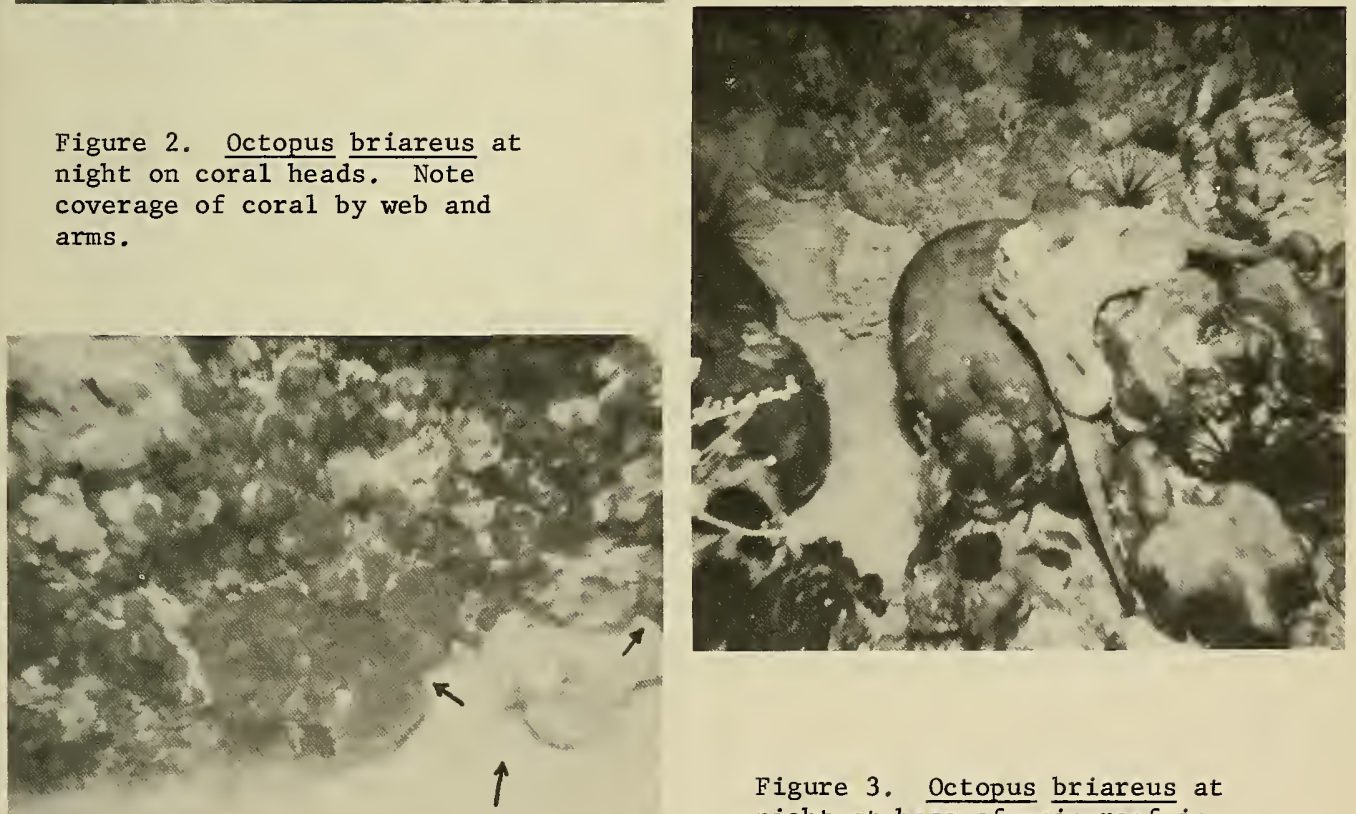

Figure 3. Octopus briareus at night at base of main reef in undisturbed web-feeding posture. Note extensive spread of web to cover the reef-sand juncture (arrows). 


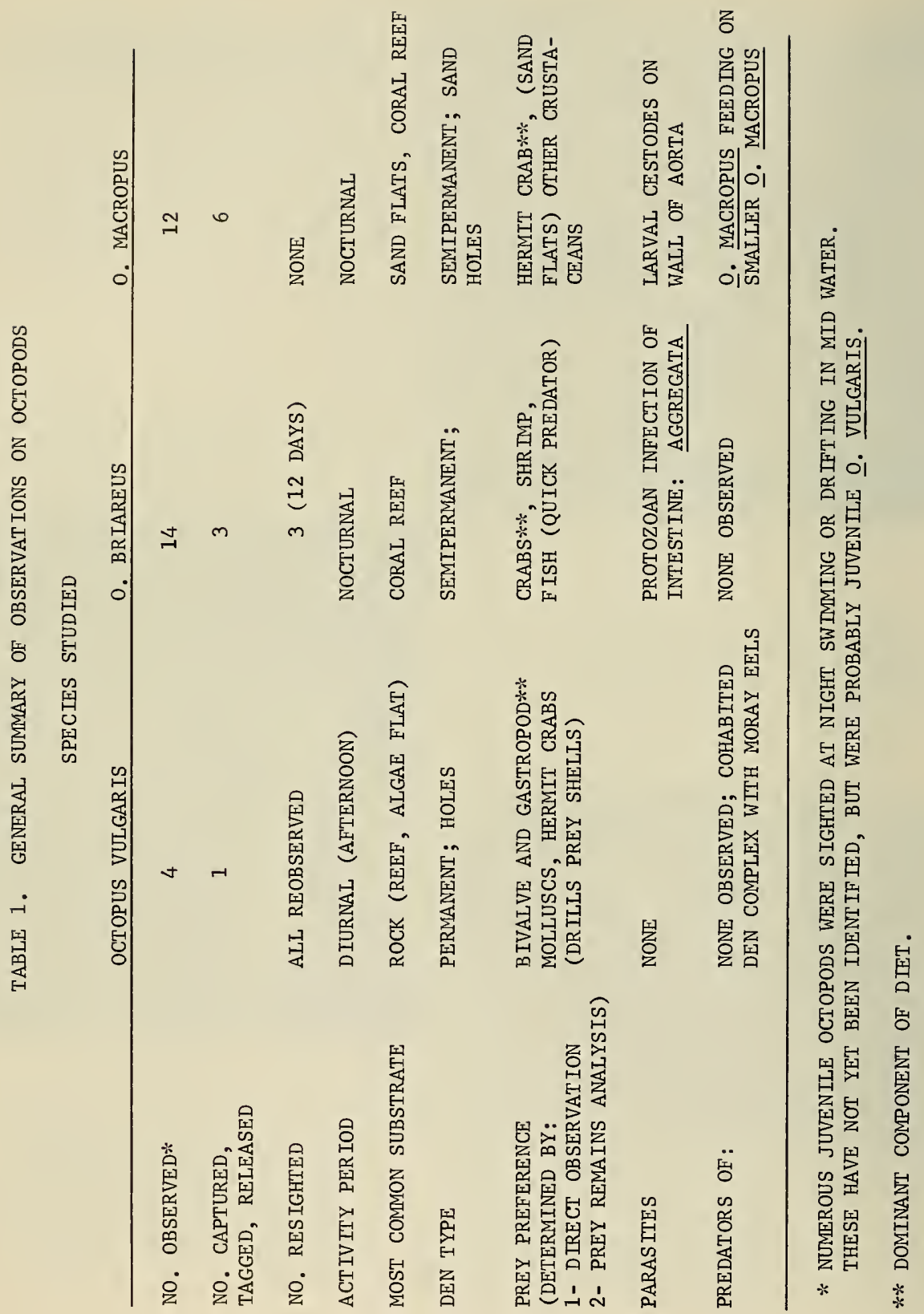


Of fourteen animals sighted, three (a11 females) were captured, marked and released. All were resighted on several occasions during the course of the mission (Fig. 1). One (T4) was observed twelve days after capture. Nocturnally active, this species ranges throughout the reef area seeking crustaceans and small fish which abound there. The fact that this species is regularly capable of capturing fish demonstrates an agility and predator-prey relationship that has not often been reported for Octopods. They hunt by throwing themselves over small coral heads (Fig. 2) or crevices, spreading the web (Fig. 3) to trap unwary prey and then reaching under with the arms to capture the victims or to drive them to the beak or mouth. Individuals appear to be territorial since resightings were made in much the same areas as captures. Semipermanent dens are located along the edge of the reef where the coral abuts with the sand. The openings are often marked by a finger of red sponge. Two size classes were present in the area studies (DML* $10 \mathrm{~cm}$ and $7 \mathrm{~cm}$ ). No juveniles were observed.

No mesozoans were recovered from the renal sacs. The kidneys of the three animals examined were unusual in being dark red. This may indicate a large proportion of $\mathrm{fish}$ in the diet. The wall of the caecum and intestine in all three was 1 ined with white cysts of the protozoan coccidian parasite, Aggregata. This would indicate a predominately decapod crustacean diet at some previous time, since the alternate hosts for this protozoan parasite are usually decapod crustaceans.

Octopus macropus Risso, 1826.

Twelve animals were sighted, six ( 3 males and 3 females) were examined in the habitat, and five were subsequently tagged and released. No resightings were made. This large octopus species is active at night on the sand flats to the west of the habitat. During the day they live deep under the reef in semipermanent dens which are blown out of the sand. Not territorial, they appear to range widely over the flats. Predominately hermit crab feeders, they use their exceedingly long arms to feel out shells and explore around and under isolated coral heads. Three size classes were observed (DML* $18 \mathrm{~cm}, 8 \mathrm{~cm}$ and $2 \mathrm{~cm}$ ), the largest were mature.

No mesozoans were recovered. No Aggregata nor cestode cysts were present in the gut wall. Several small white cysts (probably cestode) were attached to the wall of the aorta.

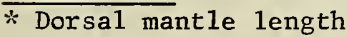


Four large individuals and numerous juveniles of this muscular, shortarmed species were observed. One was captured and dye marked, while another could be recognized by injuries to several arms. These two individuals were resighted on numerous occasions. This species lives in shallow dens up on the reef face (Fig. 4) and on isolated coral heads where they can command a view. A single specimen, which lived in a den in a small coral-rock complex on the algae flats, was found in or near the same den on many subsequent inspection trips. This suggests a strong territorial behavior. Active during the day, in particular the afternoon hours, they range over the sand flats near their dens gathering food. They bring live shells back to the den or a protected feeding area where they are drilled and the contents eaten. The diet, consisting mainly of bivalves and conchs, was analyzed from the debris or prey midden surrounding each den. A partial list of food organisms is given below. Bivalves: Glycymeris decussata, $\underline{G}$. pectinata, Laevicardium laevigatum, Arcopagia fausta, Antigona rigida, Anadara notabilis; Gastropods: Strombus gigas, S. costatus, and Conus sp. This is the same species that drills Livona pica in shallow inshore waters. Hermit crabs probably also supplement the diet. Only two size classes (DML $* 10 \mathrm{~cm}$ and $2 \mathrm{~cm}$ ) were found. Large individuals were immature. Smaller juveniles were extremely abundant in the water column around the night light or on the bottom near the habitat.

No parasites were observed in the animal examined.

Squid:

Three genera and species of squid were encountered and observed during the mission.

Sepioteuthis sepioidea (Blainville, 1823).

The largest and by far the most common squid in the area. Extensive observations were made on their social heirarchy and schooling behavior. Attracted by the night light, small aggregations were found around the habitat during hours of darkness. No daylight observations were made. Schools were most commonly composed of from 4 to 6 individuals (Fig. 5) arranged in the water column in a predictable fashion depending on size and possibly sex. The integrity of each school was maintained through use of characteristic posture and color pattern displays by peripheral individuals. The initial establishment of schools was not observed but aggressive displays appeared to prevent outsiders from joining pre-existing schools.

* Dorsal mantle length 

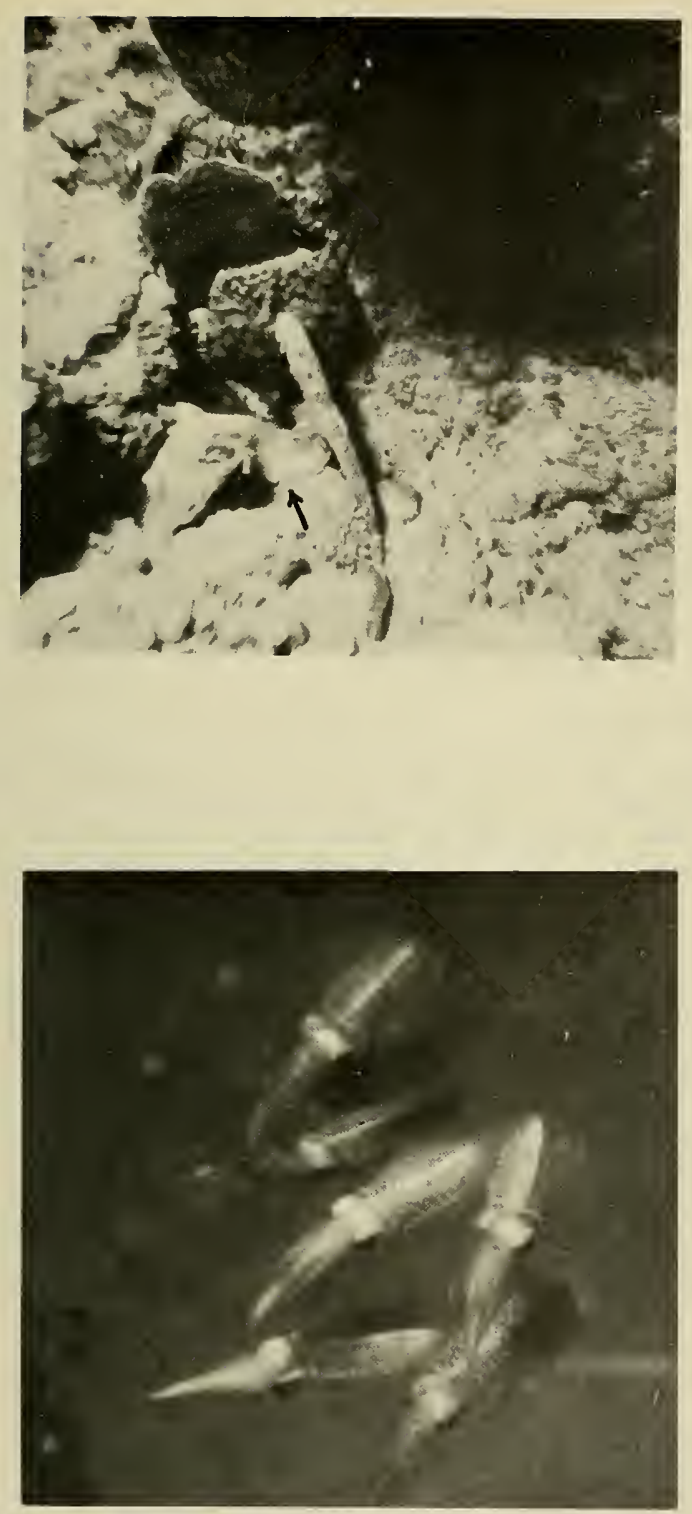

Figure 4. Octopus vulgaris in shallow den on face of main reef (arrow).
Figure 5. Sepioteuthis sepioidea. Complete school of six individuals in close formation. Adjacent to habitat. 
Pickfordiateuthis pulchella Voss, 1953.

Though considered rare, this sma11, epibenthic squid was observed to be quite common in the area to the west of the habitat on the sand-algal plain. They were consistently found during daylight hours in schools of 30 to 60 individuals or in most cases male and female mate pairs. The mate pairs, and occasionally individuals, were without exception found close to the sand bottom, usually among green algal growth. However, the larger schools (sometimes 60 individuals) were found suspended from one to three meters above the bottom in close formation. These squid were not observed over or near the reef at any time.

Loligo (Dorytheuthis) plei Blainville, 1823.

Larval squid, belonging to this species were noted occasionally at night in the vicinity of the habitat. Single individuals or schools of 20 to 30 were observed when found. Members of a given school are oriented at random, unlike the pattern found within Sepioteuthis schools. No posture or color displays were seen, though this may be a function of their age.

\section{CONCLUS IONS}

Our main project was designed to test the feasibility of in situ investigations of cephalopod biology. The results far exceeded our expectations. No single previous study, to our knowledge, has been able to collect as much observational data on behavior and biology of as many different species of cephalopods in such a short time period. None of the projects could be carried to completion due to time limitations, but the amount of information obtained and the nature of this information demonstrates the value of saturation diving. Of particular note was the advantage of making in situ observations at night from the convenience of the habitat. It is obvious that our observations could not have been accumulated by surface based diving alone, nor by laboratory (aquarium) studies, or random sampling techniques. However, when combined with the above methods, in comparison or contrast, valuable information is provided which fills gaps in our knowledge of coral reefs and their inhabitants.

\section{LITERATURE CITED}

Storr, John F. 1965. An underwater ecological survey of the western end of St. Thomas Island. Underwater Naturalist. 3(2): 24-41.

Voss, G. 1964. Octopus defilippi Verany, 1851, an addition to the cephalopod fauna of the Western Atlantic. Bul1. Mar. Sci. of the Gulf and Caribbean. 14(4): 554-560.

Voss, G., and Solis, Ramairez M. 1966. Octopus maya, a new species from the Bay of Campeche, Mexico. Bu11. Mar. Sci. of the Gulf and Caribbean. 16(3): 615-625. (included in this paper is a key to the shallow water species of Octopus of the Tropical Western Atlantic.) 
EFFECTS OF MAN-MADE POLLUTION ON

THE DYNAMICS, OF CORAL REEFS

\author{
by \\ Lawrence R. McCloskey \\ Systematics-Ecology Program \\ Marine Biological Laboratory \\ and \\ Richard H. Chesher \\ Westinghouse Ocean Research Laboratory
}

\begin{abstract}
Respiration, feeding, and other activities of corals were monitored in situ near the TEKTITE site. Artificial, short-term dosing of reef corals with a mixture of chlorinated hydrocarbons ( $p, p^{\prime}-D D T$, dieldrin, and Aroclor 1254) produced a significant decrease in photosynthetically-generated oxygen production. When subjected to a $1 \mathrm{ppm}$ mixture of these compounds, all corals tested exhibited an increase in the compensation values, and a decrease of 12 to $22 \%$ in the photosynthesis to respiration proportion. Photosynthesis remained depressed up to four days after dosing. No other changes in dosed corals were observed. It appears unlikely that coral reefs have yet been deleteriously affected by present residues of organo-chlorines.
\end{abstract}

\title{
INTRODUCTION
}

Evidence from a previous study on a primary coral predator, Acanthaster planci, led us to believe corals may sometimes contain significant residues of several chlorinated hydrocarbon compounds (McCloskey \& Deubert, in press). In preparation for our participation in TEKTITE II we determined (1) the types and present quantities of chlorinated hydrocarbons in sea water and coral tissue taken from Key West, Florida; and (2) the uptake rates of doses of chlorinated hydro-carbons administered to two species of cora1s. From this, and the information on organochlorines in Acanthaster, we selected for further experimentation the three most abundant organochlorines-p,p'-DDT, dieldrin, and Aroclor 1254 (a PCB). From the uptake data we determined the dose times and concentrations to be used.

\section{OBJECT IVES}

For our mission in TEKTITE, we outlined these objectives:

(1) determine present residue levels in a variety of reef corals;

(2) determine the uptake rate, internal dispersa1, and abatement rates (i.e., decrease in residue load with time, through metabolism or exchange of the compounds with the environment) of artificially administered doses of chlorinated hydrocarbons in corals; 
(3) study the possible effects of these compounds on coral respiration and photosynthesis;

(4) examine the effects, if any, on coral growth and regeneration (calcite formation); and

(5) look for behavioral and ecological changes correlated with residue increase in the corals, their associates, and predators.

\section{EQUIPMENT}

Aside from a considerable assortment of miscellaneous supplies, the major items used in the habitat were pre-packaged ampoules of the chlorinated hydrocarbon mixtures; plastic bags and tubing for enclosing coral heads, respiration chambers with associated Kanwisher-type polarographic electrodes. stirrers, and recorders; and materials for analyzing the specific activity of carbonic anhydrase.

of equal importance, though not used during the mission in the habitat, was the gas-1iquid chromatograph (GLC) and expertise of Dr. Karl H. Deubert, in whose pesticide laboratory all the quantitative analysis has, and is being done.

\section{PROCEDURES}

Heads of coral, located on the reef about 120 meters NE of the habitat, were selected and marked with smal1, numbered styrofoam floats. These were then enclosed, in situ, with 3-liter clear plastic bags fastened securely around the coral base with rubber tubing. Leakage from the bag was negligible. Three ampoules each containing pre-measured quantities of one of three compounds (DDT, dieldrin, or Aroclor 1254) suspended in 1-2 m1 acetone, were placed in each bag. The ampoules were broken by manipulation through the walls of the bag. Control corals were subjected to a $3 \mathrm{ml}$ dose of uncontaminated acetone. Dose time was three hours \pm 30 minutes, with initial concentrations of approximately 10,100 and $10 \overline{0} 0 \mathrm{ppb}$ of each of the three compounds .

The first series of corals were reserved primarily for abatement studies. Four heads of each of three species--Montastrea annularis, Acropora cervicornis, and Madracis mirabilis--were selected for uniformity of size and configuration, and the first dosed with $1 \mathrm{ppm}$, the second with $100 \mathrm{ppb}$, the third with $10 \mathrm{ppb}$, and the fourth (control) dosed with pure, uncontaminated acetone. Immediately after the dosing bag was removed, one-fourth of the colony was collected and preserved in 5\% formalin. The branching corals were simply partitioned by snipping off one-fourth of the branches at the dead base. In massive forms, like Montastrea annularis, we selected heâds which were composed of at least four "subheads" connected at their bases by dead skeleton. One of these could be removed without damaging the other. Abatement samples were then taken on days 4,10 , and 17 of the experiment. 
A second series was composed of three heads each of Montastrea annularis, Montastrea cavernosa, Agaricia agaricites, and Meandrina meandrites.

These were dosed with $1 \mathrm{ppm}, 100 \mathrm{ppb}$, and 0 concentrations of the organochlorine mixture, and observations made on the response of predators and symbionts to the dosed heads and on the coral's feeding behavior, clearing of siltation, polyp expansion and contraction. Shallow holes were drilled in these specimens, and coral tissue removed from $1 / 2$ " diameter circles, to observe recruitment of invertebrates on the newly exposed surface or repair of the breach by the coral.

A third series of experiments was conducted on respiration of individual coral heads. Corals were selected for undamaged condition, size (maximum diameter $17.5 \mathrm{~cm}$ ), ease of dislocation from the dead base, and absence of associated invertebrates. The heads were gently pried free from their dead bases and placed in the plexiglass respiration chamber.

Because only one respiration chamber was available, we were unable to obtain simultaneous comparisons between dosed and undosed heads, thereby insuring identical light regimes. Rather, we obtained a respiration history of 48 to 72 hours for each head, dosed the heads with $1 \mathrm{ppm}$ organochlorine mixture for the standard 3 hour period, and recorded post-dose respiration for 24 to 96 hours. We recorded incident light at the site of the experiments, and were able to compare oxygen uptake rates for both pre-dose (control) and post-dose periods ( 1 to 3 hours) of identical incident light. Dark period respiration rates were compared for time of night; day period rates had to be compared for average incident light per hour-long periods because of wide daily fluctuations in light level.

Additional controls were run for each coral species to determine the effects of pure, uncontaminated acetone on respiration raites. Coral heads were subjected to as much as twice the quantities of acetone used in organochlorine doses with no observable change in the base rate.

At the termination of the acetone control runs, the coral tissue was removed from the skeleton by jets of water from a dental Water-Pik, and the bare coral skeleton again run in the respirometer. No oxygen uptake or generation was observed.

Because a closed respirometer was used, the chamber was manua11y opened and flushed at 1 to 4 hour intervals. This is necessary because during daylight hours, $\mathrm{pO}_{2}$ increases to concentrations two to three times greater than ambient, and at night nearly all the oxygen may be removed from the chamber.

\section{RESULTS}

Preliminary studies, done prior to the TEKTITE mission, included an analysis of the present levels of organochlorines and experimental assessment of the uptake rates in a coral (Acropora cervicornis) from Key West, and a non reef forming coral from Woods Hole (Astrangia danae). The Acropora had 3 to 12 $\mathrm{ppb}$ (of total weight of tissue) DDT, 260 to 320 ppt dieldrin, and 200 to 320 ppt DDE plus PCBs. Astrangia showed detectable quantities of dieldrin only: 220 ppt. Both of these species rapidly concentrated an experimental dose of these same types of organochlorines (pure recrystallized p, p'-DDT, dieldrin, 
and Aroclor 1254) dissolved in acetone. Astrangia concentrated a 1 ppm dose of the mixture at a rate of $1 \mathrm{ppm}$ per hour over a three hour period. Acropora concentrated a $0.5 \mathrm{ppm}$ dose at the rate of $380 \mathrm{ppb}$ per hour. From this data, we chose the dose range of 10 to $1000 \mathrm{ppb}$, and a three hour dose time for our TEKTITE experiments.

In respiration experiments, pre-dose and control measurements indicated: (1) boring algae contributed insignificantly to oxygen production in the coral heads (thus corroborating prior data by Kanwisher \& Wainwright); (2) compensation values of subtidal corals were 1 ow, less than 100 footcandles in some species, and photosynthesis to respiration proportions were much lower than those published previously for intertidal or shallow subtidal corals; and (3) in spite of reduced 1 ight levels (maximum $1500 \mathrm{fc}$ ), corals monitored in situ at 50 feet appeared to release as much oxygen as they consumed in a complete diurnal cycle.

Respiration values for three of the coral heads are shown in Figure 1 a-c. Values above the dashed horizontal line represent photosynthetically generated oxygen in $\mathrm{ml}$ per liter, while the values below the dashed line represent oxygen utilized by respiration. The length of the lines (abcissa) represents one hour. Net photosynthesis $(N)$ and respiration (R) are from direct measurements. Gross photosynthesis $(G)$ is calculated from net photosynthesis plus respiration. The ratio of gross photosynthesis to respiration $(P / R)$ is given at the termination of the lines at " $G$ ". Slopes labelled "O" are those obtained prior to dosing, while "I" represents a first, and "II" a second dose of 1 ppm organochlorine.

In every instance, respiration increased slightly after dosing with the organochlorines. At the same time, photosynthesis decreased significantly, usually more than twice the rate of the respiration increase. The total effect is revealed by the $P / R$ ratio, which at $1000 \mathrm{fc}$ is decreased between 16 and $22 \%$ (or between 12 and $20 \%$ at 500 fc). A second dose (II), elicited an additional, approximately equal drop in the $P / R$ ratio, so that photosynthes is/respiration was depressed about $33 \%$ over norma1 (pre-dose) values. The results are summarized in Table 1 .

A coral must reach an average $P / R$ value of 2.0 for the 12 hours of daylight to obtain a 24 hour average of 1.0 . It is obvious from the $P / R$ values in Table 1 that only above $1000 \mathrm{fc}--\mathrm{a}$ situation which prevails only for about 4 hours of the day, with a maximum of $1500 \mathrm{fc}$--does the $P / R$ ratio exceed 2.0. The appropriate calculations have not been made, but it is likely that the 12 hour daylight averages for our undosed corals do not exceed 2.0. The corals we tested at 50 feet, then, were generating about as much oxygen during a diurnal period as they use.

Another measurement which reveals the alterations in coral metabolism brought about by organochlorines is the compensation value, which is the light level at which $\mathrm{O}_{2}$ produced by photosynthesis equals the $\mathrm{O}_{2}$ used in metabolism. $(P / R=1.0\}$. The organochlorine 1 oad consistently increases the compensation value, as shown in Table 2 . 
A

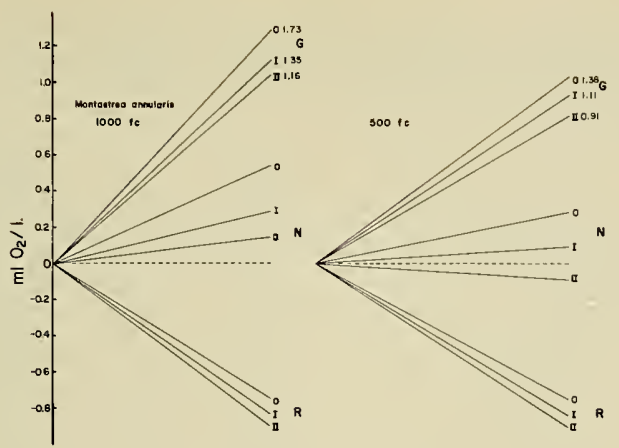

B

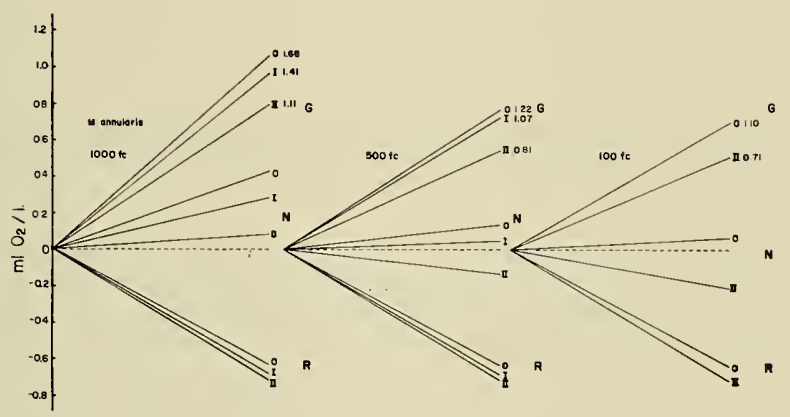

C

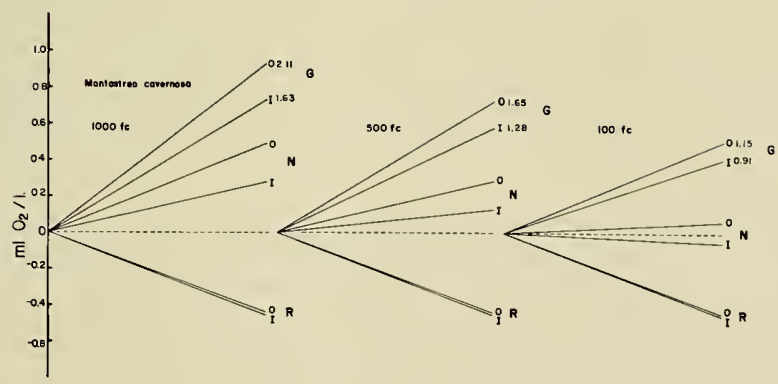

Figure 1 a-c. Graphs of gross (G), and net $(\mathrm{N})$ photosynthesis, and respiration in $\mathrm{ml}_{2} / 1 / \mathrm{hr}$. for 3 heads of coral. Light regimes shown in average foot-candles per hour. 0 indicates predose figures, I indicates initial dose of organochlorines, and II a second dose. 
Tab1e 2. Compensation values, in foot candles, for four species of corals, before dosage, after dosage with a 1 ppm organochlorine mixture (I), and after a second dosage of the same concentration (II)

\begin{tabular}{cccc} 
Species & $\begin{array}{l}\text { Pre- } \\
\text { dose }\end{array}$ & $\begin{array}{c}\text { I } \\
\text { Post- } \\
\text { dose }\end{array}$ & $\begin{array}{c}\text { II } \\
\text { Post- } \\
\text { dose }\end{array}$ \\
\hline Madracis mirabilis & 435 & 570 & 750 \\
Montastrea annularis & 100 & 350 & 200 \\
Montastrea cavernosa & 100 & 840 & \\
Mussa angulosa & 745 &
\end{tabular}

It is significant that up to four days after dosing, photosynthesis remained depressed. Time did not permit us to investigate whether these corals would, if ever, recover.

We did not record any observable alteration in the behavior of organochlorine dosed corals--feeding, polyp expansion, sediment clearing, settling of coral associates, or crystal formation. One of us (LRM) has been studying crystal formation of dosed and undosed corals with the aid of a scanning electron microscope, but again, no differences between dosed and undosed corals is obvious. That is not to say that deposition of calcite is not inhibited, however, we have some preliminary evidence that carbonic anhydrase is inhibited in organochlorine dosed corals, but the method has not been fully exploited.

In the process of determining normal feeding rates, one of us (RHC) made some significant observations on natural feeding behavior of corals. Previous researchers have concluded that corals feed on zooplankton, at night, at levels too low to meet their metabolic demonds. The balance of their requirements are supposedly derived from symbiotic algal cells (zooxanthellae) living in the coral tissues.

Long term, in situ observations during TEKTITE revealed another, important food source for corals. Many corals were observed feeding on fecal pellets of fish and on other organic detritus. Experiments were conducted on the rate of fecal pellet bombardment and on the rate of fecal pellet feeding of various types of corals. All species of corals examined ate fecal pellets. Feeding was not time dependent and pellets were caught and eaten by the corals both during the day and at night. Following final analysis of the nutritive value of the detritus and fecal pellets a paper will be prepared for publication on this subject. 


$$
\begin{aligned}
& \text { 인 }
\end{aligned}
$$

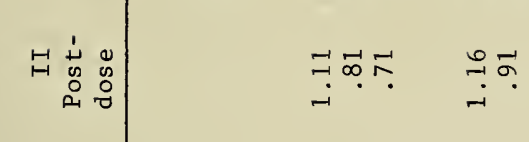

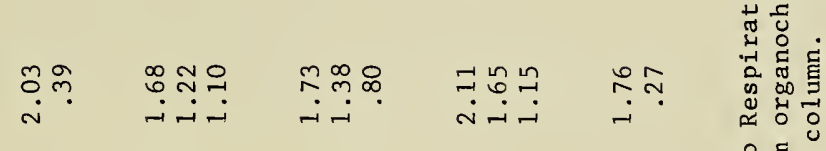

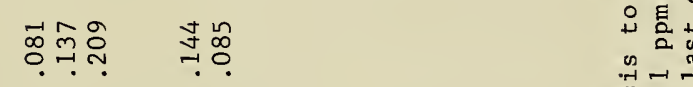

$$
\begin{aligned}
& \begin{array}{ccc}
1 & 0 \\
H & \infty & 0 \\
H & 0 \\
\text { A } & 0
\end{array} \\
& \text { 我咅哭 }
\end{aligned}
$$

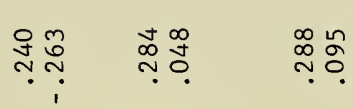

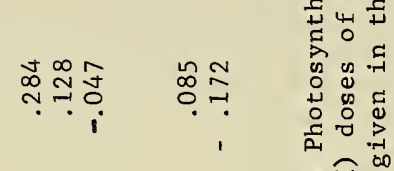

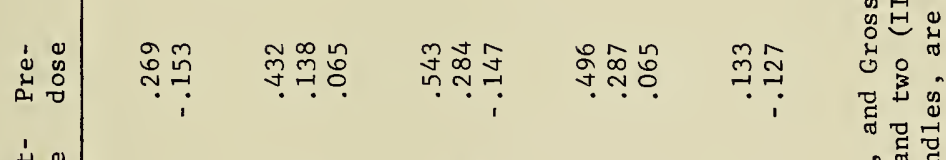

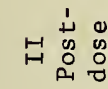

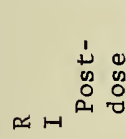

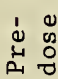

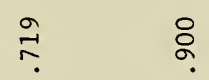

$$
\begin{aligned}
& \text { ले ? }
\end{aligned}
$$

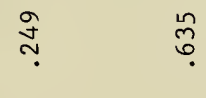

$$
\begin{aligned}
& \stackrel{m}{\mathfrak{T}} \\
& \text { 옳 } \\
& \text { ๙ } \\
& \text { ЕЕ } \\
& \text { क् }
\end{aligned}
$$

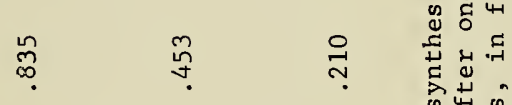

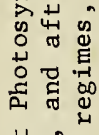

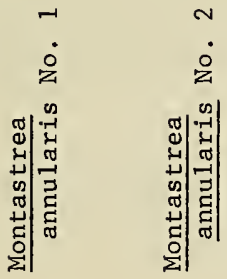

$$
\begin{aligned}
& \text { 党| }
\end{aligned}
$$

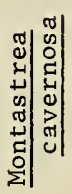

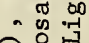

$$
\begin{aligned}
& \text { क्षे }
\end{aligned}
$$

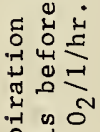

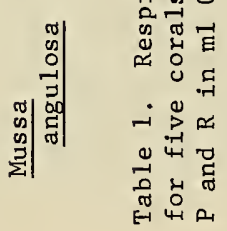


If, as it appears, subtidal corals at the depth studied are maintaining a diurnal $\mathrm{O}_{2}$ balance at very close to 1.0 , then any alteration which drops this value to significantly less than 1.0 may result in profound alterations in the reef community. Reef-associated animals are well known to be physiologically and genetically ill-adapted to fluctuations in their environment, and probably would respond adversely to a decrease in productivity of reef corals and associated algae.

Convincing evidence exists that the photosynthetically-active zooxanthellae not only contribute to the over-all coral metabolism, but also mediate coral growth. If this ability is inhibited, as our data suggests, the deposition rate of calcium carbonate in the form of coral skeleton versus the rate of dissolution by mechanical, biological (such as the activities of boring organisms), and chemical means could be reduced to the extent that a gradual decrease in reef mass results.

Our data on the effectiveness of organochlorines in inhibiting photosynthesis indicates that diurnal $\mathrm{P} / \mathrm{R} \mathrm{O}_{2}$ balance can be decreased below 1.0. We believe this information justifies a critical examination of the effects of organochlorines on the reef ecosystem. We wish to state clearly, however, that our present information does not suggest that reefs are threatened by organochlorines.

Aside from the lack of completed GLC analysis on our experimental material, a valid question regarding the ecological significance of the data is whether organochlorines do, or could, ever occur in the water impinging upon coral reefs in the concentrations we used. The answer is, probably not. We believe, however, that the dosage of $1 \mathrm{ppm}$ is not more than one order of magnitude greater than can be found in marine waters adjacent to some industrial or agricultural centers. Certainly a dosage of $10 \mathrm{ppb}$ is within the expected range, even if the compounds must be dissolved in the water.before being absorbed by the animals. (There is good evidence that solution is not necessary, and that undissolved, suspended particles of chlorinated hydrocarbons can be taken up directly by animals). We subjected the corals to higher doses, but. for comparatively brief time spans, on the theory that we might rapidly obtain as high residue loads as might occur in corals subjected to lesser concentrations over longer time spans (corals are known for their longevity, which may approach perpetuity). An additional objection might be that corals could acclimate to slowly accumulated residue loads, or lose them by metabolism or exchange with the environment, but react in the manner we describe when subjected to a rapid build-up of residue load. The validity of our method cannot be further tested until we can compare the analysis of residue loads in our experimental corals with residues presently found in corals from "naturally" polluted areas. The quantitative analysis should tell us the rate of organochlorine uptake, the rate at which these compounds are exchanged or metabolized, and provide data on presently normal residue levels in corals from Lameshur Bay.

To date, none of the GLC analysis has been done on the corals from Mission 1050 due to lack of funds. As of March 1, however, support has been obtained. The results will be available by late April. 
Another potentially objectionable factor in the experimental method is the use of acetone to dissolve the organochlorines. Whatever the artifact which it may introduce, however, when corals are subjected to uncontaminated acetone in the same concentrations as used in the organochlorine experiments, no change in $\mathrm{O}_{2}$ generation or uptake was observed.

Our initial respirometry apparatus proved to be inadequate, and we found we had not anticipated some of the conditions under which it was required to operate. The early failure rate was high, and the reliable respiration data eventually came from a respirometer improvised from parts of other inoperable apparatus. Because several day's time was required for each experiment, the sampling is rather small. We were also thereby restricted in the range of dosages in testing respiration effects. From our experience, we have now designed a vastly improved underwater respirometer.

Whatever the significance of our organochlorine dosing experiments, we are confident of the reliability of our respiration measurements. For the first time, it has been possible to do in situ physiological measurements of the metabolism of individual corals at depth. Bringing a laboratory facility to the reef, together with such accoutrements as electrical power, etc., has opened up exciting opportunities for increasingly sophisticated research endeavors. Hopefully, the habitat's obvious advantages for field natural history endeavors will be augmented by the installation of instruments and equipment capable of measuring standard oceanographic and physiological parameters. 


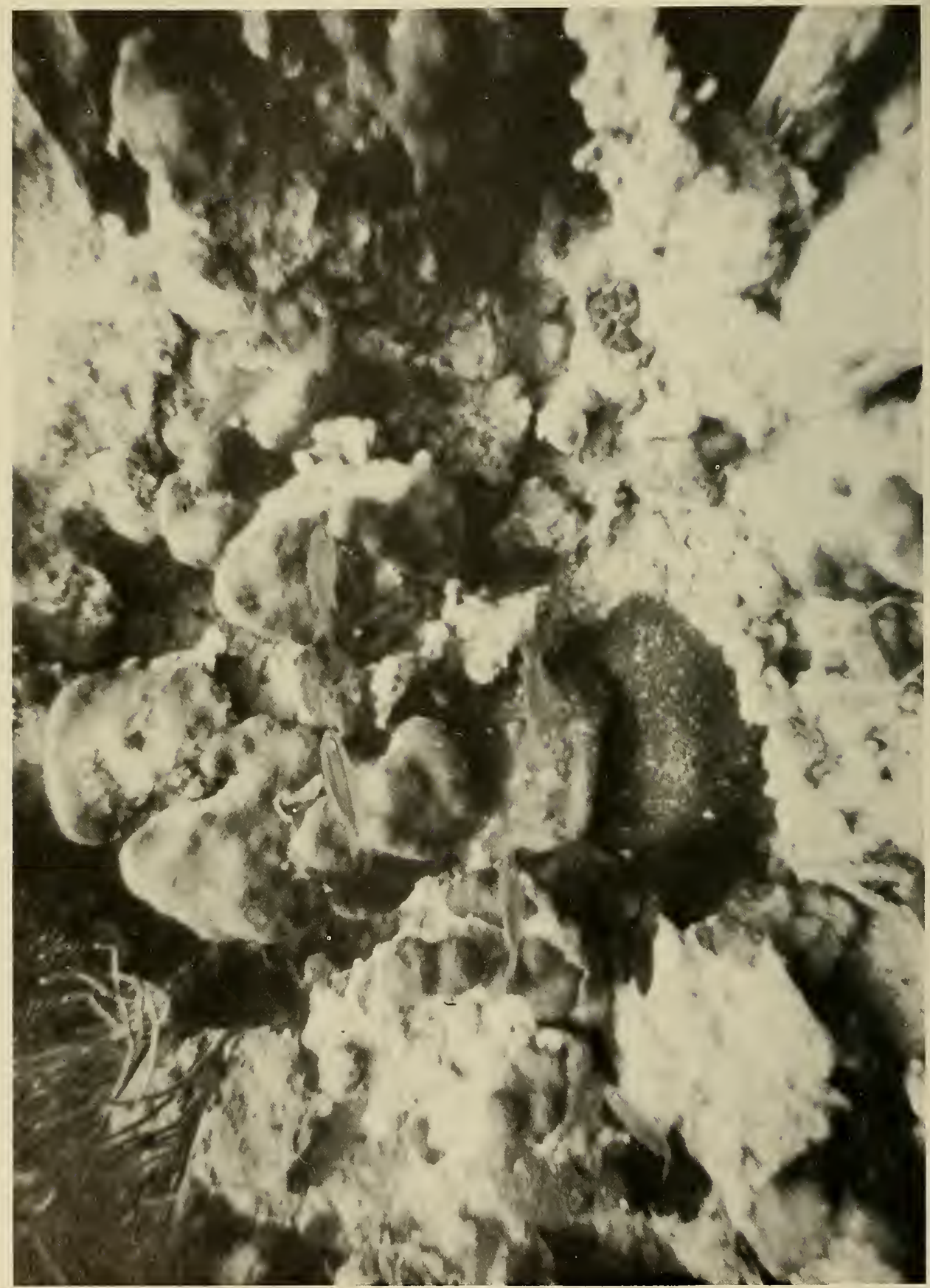


J. Morgan Wells and Anna H. Wells

Wrightsville Marine Bio-medical Laboratory

Wilmington, North Carolina

\section{ABSTRACT}

Measurements of the rates of photosynthesis or respiration of coral-algal systems were made under a variety of natural light conditions and artificially imposed darkness. The maximum photosynthetic rate was found to be from 1.1 to 2.9 times the respiratory rate, depending on species. This means the potential exists for corals to obtain a major portion of their nutrition from algal symbionts.

\section{INTRODUCT ION}

The existence of physiological symbiosis involving algae and invertebrates is a we11-known fact $(1-4)$. While there has been considerable speculation as to the exact nature and magnitude of the interdependence of algae and invertebrates, little direct quantitative information is available.

On the basis of changes in the oxygen concentration and plankton densities of water flowing over coral reefs, Odum and Odum (5) have concluded that coral reefs are essentially self-sustaining systems and are not dependent on outside sources of nutrition. Kawaguti (6) reports on excess of $\mathrm{O}_{2}$ over $\mathrm{CO}_{2}$ production in some reef corals. Likewise, Wells and Haxo (7) have measured a three-fold increase in $\mathrm{O}_{2}$ production in light over consumption in darkness in several species of tridacnid clams and coral Pocillopora damicornis. While such measurements do establish the maximum photosynthetic rate of the association, they do not in themselves define the contribution which the photosynthetic products make to the metabolic budget of the invertebrates.

Muscatine (8), however, has shown that in the presence of homogenated animal tissue, zooxanthellae from the respective animal (coral or tridacnid clam) liberate from $35-50 \%$ of the photosynthetic products, of which glycerol comprised about half. Liberation of photosynthesates was negligible in the absence of anima1 homogenate.

Goreau (9-10) has suggested still another aspect of the relationship of coral and algae, that being the facilitation of calcium deposition by the photosynthetic activities of the algae. This view is supported by his finding that carbonic anhydrase inhibitors reduce the rate of calcification as much as $51 \%$ in light, and the inhibitor and darkness another $34 \%$.

\section{OBJECTIVE}

It was the purpose of this investigation to determine the magnitude of the potential contribution of zooxanthallae to the metabolic budget of corals. In situ measurements of photosynthetic capacity and respiration of coral-algal systems were made under a variety of natural light conditions, and in artificially imposed darkness. 
Rates of photosynthesis and respiration were determined by measuring rate changes in the oxygen pressure in closed plexiglass vessels containing coral. The vessels were either $8^{\prime \prime}$ diameter hemispheres placed over the corals or for small isolated corals a $3^{\prime \prime}$ diameter by $3^{\prime \prime}$ high cylinder with a 1 id. The hemispheres were sealed to large coral heads with clay or when placed over small heads on the sand, the edges were covered with sand to prevent mixing with outside water. The clay sealant did not alter photosynthesis or respiration when placed in the small sealed container with coral, and was thus considered inert as far as these measurements were concerned.

Each vessel was equipped with two ports, each with an attached 10cc glass syringe. Mixing was accomplished by pushing water back and forth between the syringes via the coral vessel. After mixing ( 4 cycles), one syringe was removed and the contents were passed through a small curvette containing an oxygen electrode. The leads from the oxygen electrode assembly passed into the TEKTITE II habitat and the meter readout was positioned in the window of the wet $1 \mathrm{ab}$. This arrangement allowed an aquanaut to inject oxygen samples into the electrode curvette and read the meter through the window. Figure 1 contains photographs taken during this operation.

Measurements were made at time intervals from 15 minutes to 3 hours, and the rates of photosynthesis or respiration were calculated from the slope of the oxygen pressure vs. time curve. Light intensity measurements were made at the same time with a submarine photometer. To determine whether diurnal patterns of dark respiration existed, measurements of respiratory rates were made at various times of the day and night with the coral containers covered with a black opaque plastic sheet.

\section{RESULTS}

Figure 2 is a plot of relative rates of oxygen production or consumption by Acropora cervicornis as a function of time of day. Integration of the curves above or below the compensation line (zero rate line on the graph) gives a value of net oxygen production or consumption for the 24-hour period. The ratio of oxygen production to consumption may be considered as the photosynthetic potential of the coral-algal association, and used as a maximum value for the possible contribution of algal photosynthesates to the carbon budget of the corals. 1 These values are tabulated in Table 1 for several species studied. Table 2 contains the ratios of the maximum observed rate of photosynthesis to respiration. The data in Figure 2 also show that respiration during artificially imposed darkness during daylight does not differ significantly from that during night. This was true of all species studied.

1 Refer to the basic equation of photosynthesis relating carbon to oxygen:

$$
6 \mathrm{CO}_{2}+6 \mathrm{H}_{2} \mathrm{O} \longrightarrow \mathrm{C}_{6} \mathrm{H}_{12} \mathrm{O}_{6}+6 \mathrm{O}_{2}
$$



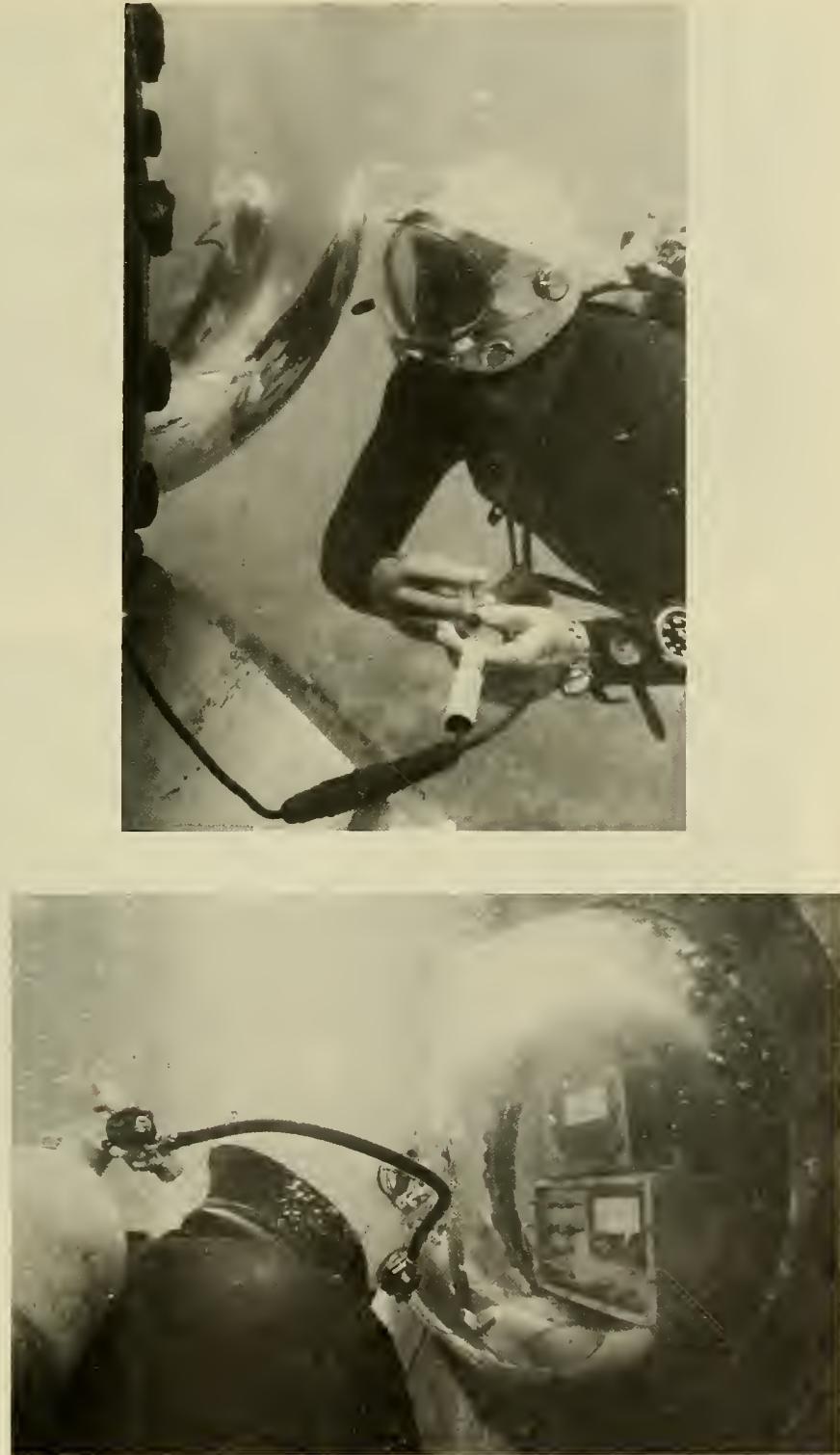

Figure 1. (Upper) Aquanaut injecting sample into small curvette containing oxygen electrode. (Lower) Aquanaut reading values on meter located on window sill inside of TEKTITE habitat. 


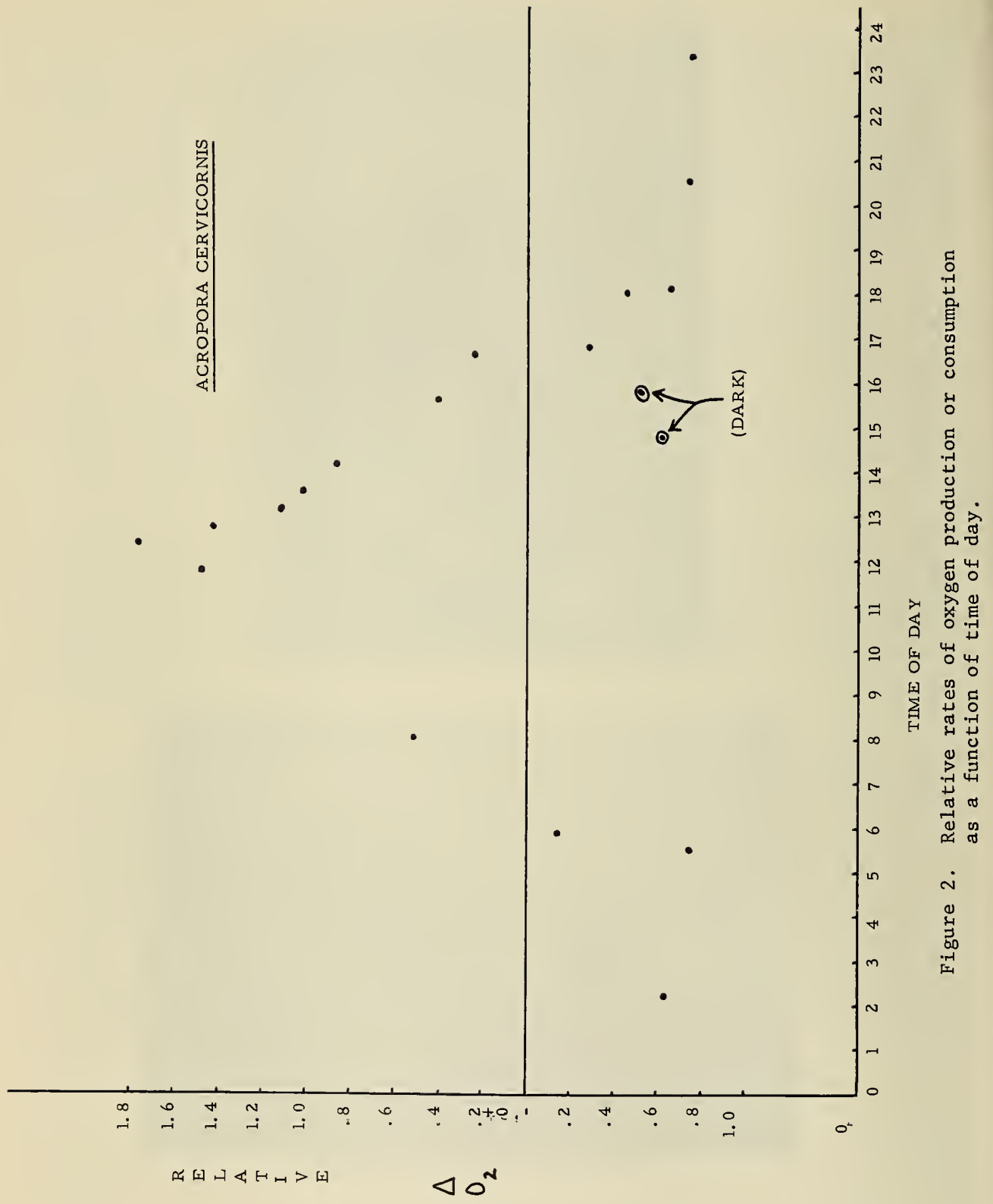



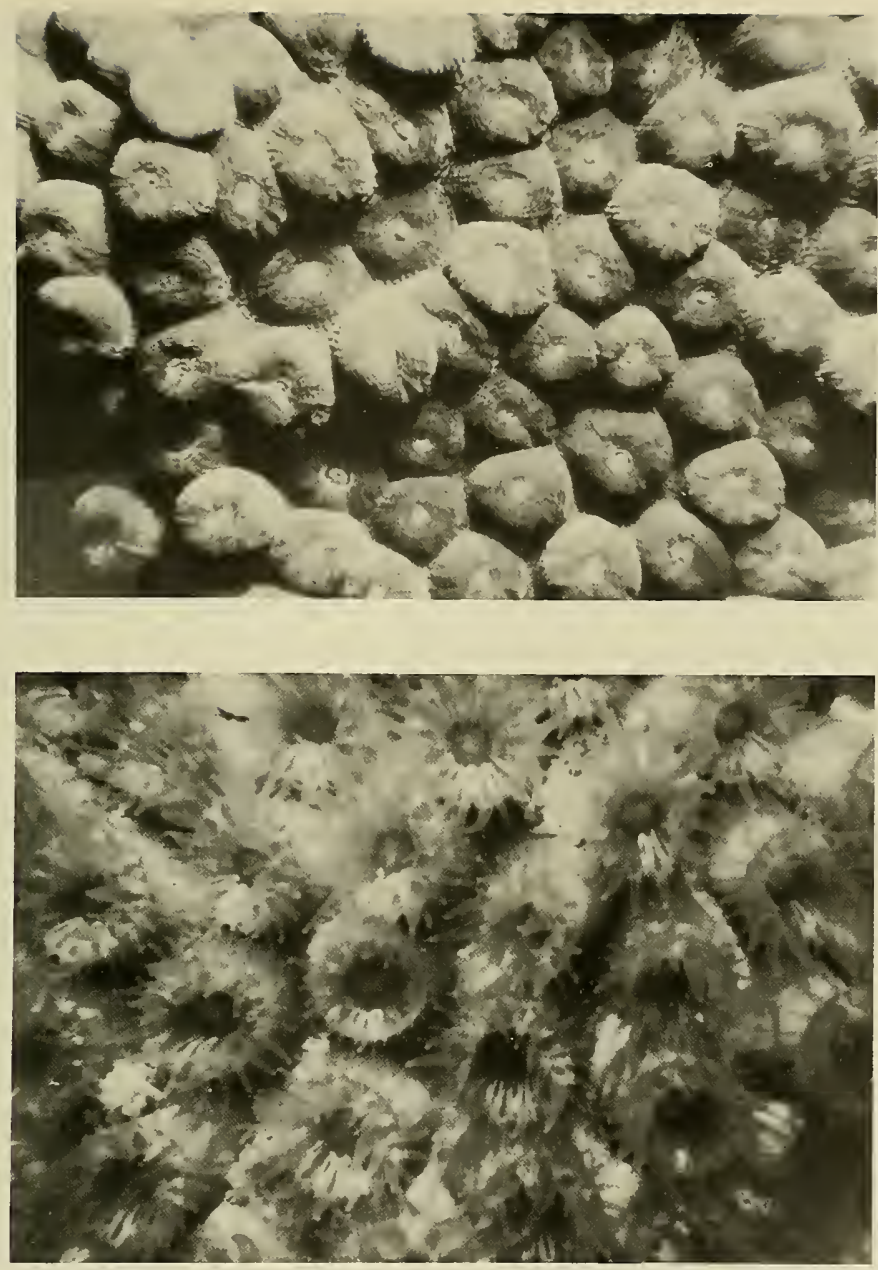

Figure 3. Polyps of Montastrea cavernosa in the retracted daylight position (upper photograph) and extended position (lower photograph) during artificially imposed darkness. 
Table 1.-- Integrated Daily Values of the Ratio of

Total Photosynthesis to Respiration

Acropora cervicornis

Montastrea cavernosa

.89

Manicina areolata, variety danaei

Table 2.-- Maximum Photosynthesis to Respiration Ratios

Manicina areolata, variety danaei $\quad 2.84$

Mussa arrgulosa $\quad 1.15$

Montastrea cavernosa $\quad 2.90$

Acropora cervicornis $\quad 2.76$

Manicina areolata, variety areolata $\quad 2.91$

Colpophyllia natans $\quad 1.87$

Siderastrea siderea $\quad 2.15$

The oxygen consumed by areas of sandy bottom between coral reefs was measured by the same technique as that used on coral heads. Such areas were found to use an average of $1.35 \times 10^{-3} \mathrm{~m} 1 / \mathrm{cm}^{2} / \mathrm{hr}$ during daylight.

The oxygen pressure 10 feet off the bottom at the TEKTITE II habitat reached a maximum of $153 \mathrm{~mm} \mathrm{Hg} \mathrm{\textrm {P } _ { 2 }}$ shortly after noon and a minimum of about $118 \mathrm{~mm} \mathrm{Hg}$ $\mathrm{pO}_{2}$ shortly before sunrise. Among the coral heads (not in deep holes) on the nearby reef, values as low as $100 \mathrm{~mm} \mathrm{Hg} \mathrm{p0} 2$ were recorded in the predawn hours.

Photographs and direct observation showed that the extension and activity of coral polyps is related to light. The "nighttime position" (tentacles extended and active) is assumed shortly after sunset, and the polyps retract promptly at the first light of dawn. The polyps likewise assume their nighttime position during periods of artificially imposed darkness (Figure 3). This made it impossible by the present methods to determine whether the true respiratory rate of the system was the same during periods of illumination as in darkness.

Light intensity measurements throughout the water column from the surface to 65 feet were made by a surface diver. A GE Type 213 1ight meter with a variety of neutral density and colored filters was used to determine the penetration of the various colors of light. Approximately $33 \%$ of the total surface light penetrated to 65 feet. Light of wavelengths near $460 \mathrm{~m} \boldsymbol{\mu}$ was absorbed least (20\%); above this, the longer wavelength, the greater the absorption. These data closely resemble those of Jerlou (1951) for Caribbean water.

\section{CONCLUSIONS}

At depths at least up to 65 feet, where the maximum measured 1ight intensity was found to be 2500 foot candles, the integrated 24-hour photosynthesis almost equals the comparable value of respiration in several coral-algal associations 
studied. ${ }^{2}$ The maximum photosynthetic rate was found to be from 1.1 to 2.9 times the respiratory rate, depending on species. This means that the potential exists for corals to obtain a major portion of their nutrition from algal symbionts. In view of what is known about the pathways of soluble photosynthesates within plant-animal associations, it is very probable that the corals utilize a large portion of the photosynthetic products of their zooxonthellae.

\section{REFERENCES}

1. Yonge, C. M. 1944. Experimental Analysis of the Association Between Invertebrates and Unicellular Algae. Bio1. Rev. 19: 68-80.

2. Yonge, C. M. 1936. Mode of Life, Feeding, Digestion and Symbiosis with Zooxanthellae in the Tridacnidae. Gt. Barrier Reef Expd. Sci. Rep.

1: 283-321.

3. Nico1, J. A. C. 1960. The Biology of Marine Animals. Pitman, London.

4. Wiens, H. J. 1962. Ato11 Environment and Ecology. Yale Press.

5. Odum, H. T. and E. P. Odum. 1955. Trophic Structure and Productivity of a Windward Coral Reef Community on Eniwetok Atoll. Ecol. Monogr. 25. 291-320.

6. Kawaguti, S. 1937. On the Physio1. of Reef Corals. Palao Tropical Biol. Station Studies. 2: 187-198.

7. Wells, J. M. and F. T. Haxo. Photosynthesis in Giant Clam - Alga1 Associations. In preparation.

8. Muscatine, L. 1967. C1ycerol Excretion of Symbiotic Algae from Corals and Tridacna and its Control by the Host. Science 156: 516-519.

9. Goreau, T. F. 1959. The Physiology of Skeleton Formation in Corals. Biol. Bul1. 166: 59-75.

10. Goreau, T. F. 1961. The Biology of Hydra. Univ. of Miami Press.

11. Jerlov, N.C. 1951. Optical Studies of Ocean Water. Rept. Swedish DeepSea Expedition. 3: 1-59.

2 The rates of photosynthesis and respiration measured in this study include the epifauna and epiflora as well as coral and zooxanthellae. The contributions of the former are considered sma11, however. 


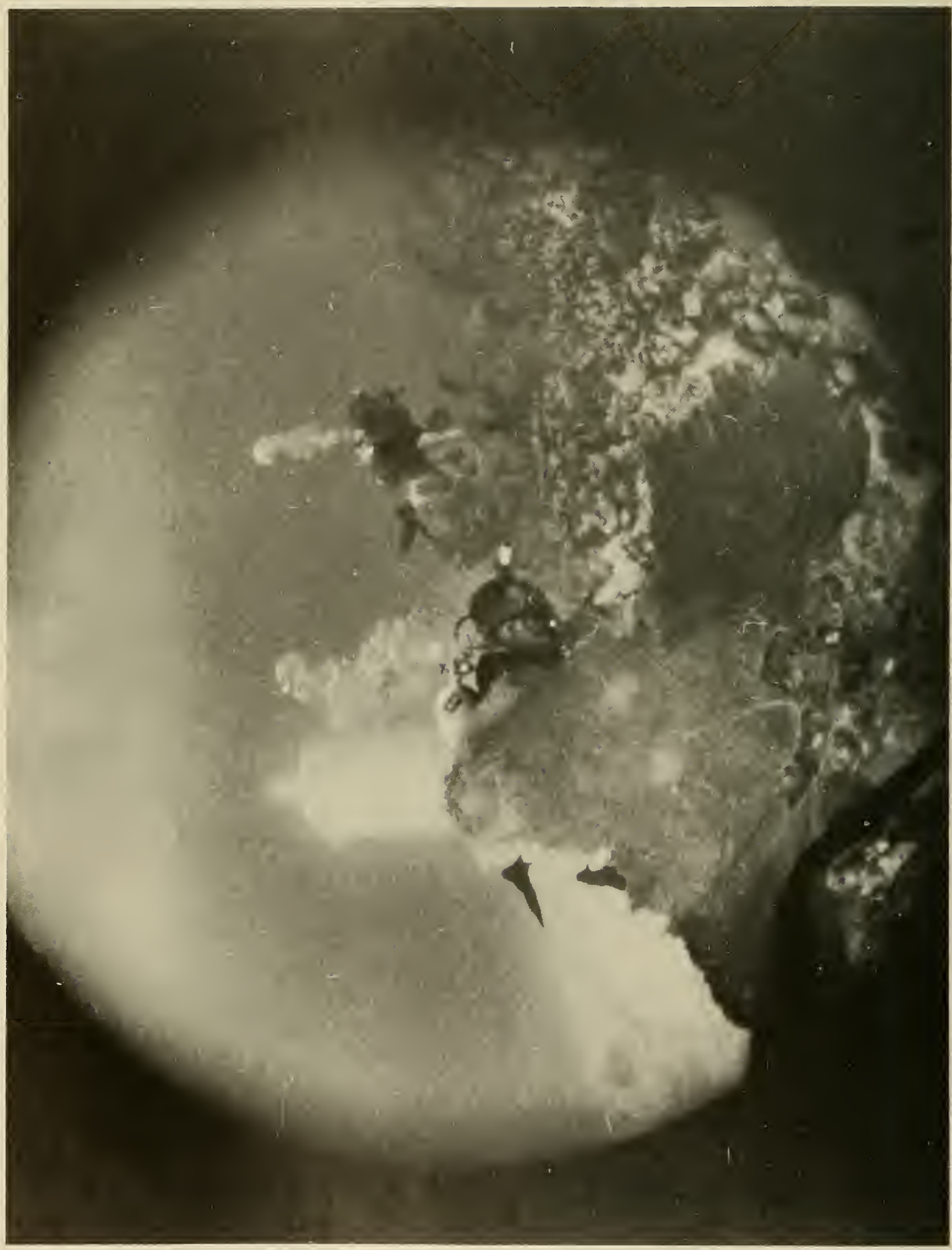


J. S. Bunt, K. E. Cooksey, M.A. Heeb, C. C. Lee and B. Taylor Rosenstiel School of Marine and Atmospheric Science

University of Miami

Rickenbacker Causeway

Miami, Florida 33149

\begin{abstract}
This study had several distinct objectives. In situ acetylene reduction assays were run with a wi $\overline{\text { de }} \overline{\text { range }}$ of benthic algae and sediment materials for the detection of possible nitrogen fixation. Results were uniformly negative and extensive search failed to disclose obvious existence of heterocystous blue-green algae. A second series of assays based on phytoplankton rich in Trichodesmium, however, gave strong indications of acetylene reduction. A typical area of reef was selected for a description of biomass distribution. This phase of the work required systematic sampling and photography along a marked transect with subsequent analysis of the corals and other materials recovered. Measurements were made of carbon-14 fixation in situ by typical reef corals.

ASSAYS FOR MARINE NITROGEN FIXATION IN THE VIRGIN ISLANDS
\end{abstract}

\title{
BENTHIC ALGAE
}

\section{OBJECTIVE}

Bunt et al. (1970) have adapted the acetylene reduction technique (Stewart, Fitzger $\overline{l d}$ and Burris, 1967) of detecting nitrogen fixation for submarine application. We report here the results of its use during Mission 12-50 of TEKTITE II.

\section{EQUIPMENT AND PROCEDURE}

The method itself is described in Bunt et al. (1970). It need be added only that syringes containing argon and acetylene were prepared for use at the surface and lowered to the aquanauts as required. Algal samples were collected in the general vicinity of the habitat both over the reef and the algal flats. Incubations were made at $20 \mathrm{~m}$ for $3 \mathrm{hrs}$. between 1115 and $1415 \mathrm{hrs}$. local time. Gas samples, returned to the surface by syringes, were transferred immediately to serum-stoppered, water-filled tubes, taking care to leave several cms. of water in each tube and to keep the tubes inverted. All samples were returned within two days to Miami for gas chromatographic analysis at these laboratories. Prior trials had shown losses of ethylene to be negligible under these conditions. 
A total of 36 samples of algal material was examined, 20 of which were dominated by Schizothrix calcicola (Agardh) Gornont. Several unidentified corals were also tested. The macroalgae checked included Halimeda sp., Sargassum sp., Udotea sp., and Penicillus sp., some of which were rich in epiphytes. Although ethylene was detected, the amounts were very small ranging from essentially zero to $1.8 \mathrm{n}$ moles/mg protein/hr., suggesting that nitrogen fixation was taking place at negligible rates in the reef community.

Extensive surveys made from the habitat and from the surface failed to disclose any heterocystous blue-greens, forms normally associated with nitrogen fixation.

\section{CONCLUSIONS}

From this and similar studies elsewhere by this group, it seems unlikely that biological nitrogen fixation takes place actively in the coral reef and associated communities of the western Atlantic. We have, however, discovered isolated colonies of the general Calothrix and Anabaena growing successfully and the question remains why these organisms are not more prominent in this type of environment.

\section{PHYTOPLANKTON DOMINATED BY TRICHODESMIUM (OSCILIATORIA} ERYTHRAEA)

\section{OBJECTTVE}

There is presumptive evidence based on isotopic nitrogen (Dugdale, Menzel and Ryther, 1961) and acetylene reduction (Bunt et al. 1970) that Trichodesmium, a common tropical phytoplankter, is capable of nitrogen fixation, With rich blooms of Trichodesmium entering Lameshur Bay during our TEKTITE II mission, an excellent opportunity presented itself to make further checks.

\section{EQUIPMENT AND PROCEDURE}

Experimental material was gathered from the surface by making four, $20 \mathrm{~m}$ vertical towings with a suitably fine net. Three aliquots were taken from each of the plankton samples and prepared for acetylene reduction assay as described. The experimental bottles were immersed at the water's edge in natural shade and the gases recovered for analysis at $1500 \mathrm{hrs}$. after an incubation period of 2 hours.

At the same time, duplicate aliquots of each towing were transferred into 1 I pyrex bottles, diluted to a known extent with Millipore-filtered sea water to provide approximately lug chlorophyll/bottle and injected with $20 \mu \mathrm{Ci}$ each of $\mathrm{NaH}^{14} \mathrm{CO}_{3}$. One bottle of each pair was then wrapped in several layers of heavy duty aluminum foil and all bottles incubated alongside the acetylene assays, allowing the same incubation period. Addition- 
al aliquots were used at once for pigment determinations following Strickland and Parsons (1965) and another set preserved with

glutaraldehyde for later examination. After incubation, particulate materials were recovered on Millipore filters, washed with Milliporefiltered sea water, dried and counted within 2 days on a Widebeta II planchet system.

\section{RESULTS}

The mean photosynthetic index was $5.8 \mathrm{mg}$ carbon $/ \mathrm{hr} / \mathrm{mg}$ chlorophyll a. Mean values for acetylene reduction from each of the plankton samples were $8.7,19.5,14.0$ and $48.5 \mathrm{n}$ moles ethylene/ $\mathrm{hr} / \mathrm{mg}$ protein, taking the ratio of cell protein/chlorophyll a as 30 .

\section{CONCLUSTONS}

The values obtained average $22.7 \mathrm{n}$ moles ethylene/hr/mg protein and compare with the results obtained with material collected in the Florida Current (Bunt et al. 1970). Stewart, Fitzgerald and Burris (1968) reported figures between 24 and $282 \mathrm{n}$ moles ethylene/hr/mg protein based on pure cultures of heterocystous blue-green algae. The current data approach this range and exceed rates obtained by Bunt et al. (1970) with a marine Nostoc sp. Especially when considered in relation to the very low values obtained at the same time with benthic algae, the current results demand attention and call for renewed efforts at achieving laboratory culture of Trichodesmium.

\section{REFERENCES}

Bunt, J. S., Cooksey, K. E., Heeb, M. A., Lee, C.C. and Taylor, B. F. 1970. Assay of algal nitrogen fixation in the marine subtropics by acetylene reduction. Nature, 227, 1163-1164.

Dugdale, R. C., Menzel, D. W. and Ryther, J. H. 1961. Nitrogen fixation in the Sargasso Sea. Deep-Sea Research, 7, 297-300.

Stewart, W. D. P., Fitzgerald, G. P. and Burris, R. H. 1967. In situ studies on $\mathrm{N}_{2}$ fixation using the acetylene reduction technique. Proc. Natl. Acad. Sci., 58, 2071-2078.

Stewart, W.D.P., Fitzgerald, G. P. and Burris, R. H. 1968. Acetylene reduction by blue-green algae. Arch. Mikrobiol., 62, 336-348.

IN SITU MEASUREMENTS OF CARBON FIXATION AND TURNOVER IN

\section{SEVERAL REEF CORALS}

OBJECTIVES

The relatively few attempted measurements of reef productivity (see review by stoddart, 1969) indicate high rates of carbon fixation 
generally in the range $1500-3500 \mathrm{~g}$. carbon/m²/year. By comparison, rich upwelling waters are believed to produce only around $300 \mathrm{~g}$ carbon/m2/year (Ryther, 1969). The question whether photosynthetic carbon fixation by the zooxanthellae of the coral exceeds respiratory losses by the symbiotic association is still at issue and may depend on location. This study was undertaken to explore the field and subsequent laboratory problems of measuring carbon fixation and turnover in individual reef corals in situ. Working in $20 \mathrm{~m}$ of water out of the TEKTITE II habitat made it possible for two divers to complete repetitive sampling operations without intervening periods spent in decompression. The experiment, however, required support from research divers stationed at the surface.

\section{EQUIPMENT, PROCEDURES AND EXPERIMENTAL MATERIAL}

Of the many species of coral available, Monastrea annularis and Siderastrea siderea were selected because of their convenient size and form, the fact that they fragment easily and evenly and do not exude mucoid substances excessively when handled. These two species are attractive also because they are major Caribbean reef builders.

Selected coral heads were dislodged gently from the substrate and labeled with the technique described by Muscatine and Cernichiara (1969) using $60 \mu \mathrm{Ci} \mathrm{NaH}{ }^{14} \mathrm{CO}_{3}$ and a 3 -hour exposure period in the late morning at $18 \mathrm{~m}$ when bottom illumination was maximal. Sampling, according to a predetermined schedule and continuing for 11 days was initiated immediately following removal of the coral heads from the plastic bags. The pattern of sampling, which required hammer and chisel, is shown in Figure 1.

Concerned at the possibility that labeling over the surface of the coral heads may not have been uniform, a separate coral head was examined in detail by taking a series of samples immediately following exposure to ${ }_{14} \mathrm{C}$ as shown in Figure 2. In this case, the specimen was dissected after return to the surface.

At each sampling on the bottom, triplicate pieces of coral were sent to the surface in small plastic bags and there transferred within 5 minutes to glass jars of $70 \%$ ethanol. The material was returned to Miami for extraction and determination of radioactivity.

The $70 \%$ ethanol used as preservative served also as the first extracting liquid, a second aliquot of ethanol being used after the first was decanted. Combined, the volume of the extracts was measured and subsamples counted at infinite thinness in thin end window counters. The radioactivity in the ethanol extract was not lost by gentle heating with dilute $\mathrm{HCl}$.

The alcohol-treated coral was then extracted twice with boiling $6 \mathrm{~N}-\mathrm{NH}_{4} \mathrm{OH}$ and the radioactivity counted. A third ammonia extract and the remaining skeletal parts were negligibly radioactive. 


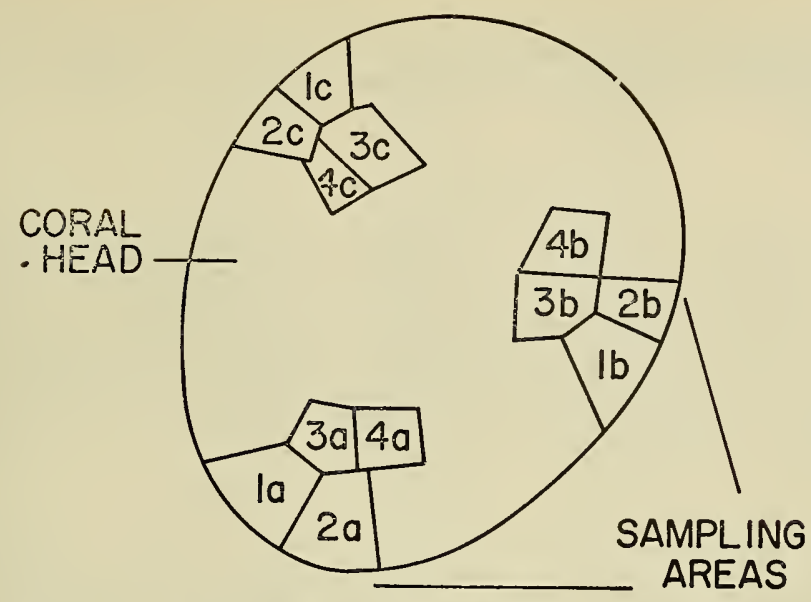

Figure 1. Sectioning of coral head of Siderastrea siderea to determine uniformity of labeling with $\mathrm{NaH}^{14} \mathrm{CO}_{3}$ A coral head was labeled with $1+\mathrm{C}$ as described, and cut up with a chisel. Figures are sample numbers in Table $I$.

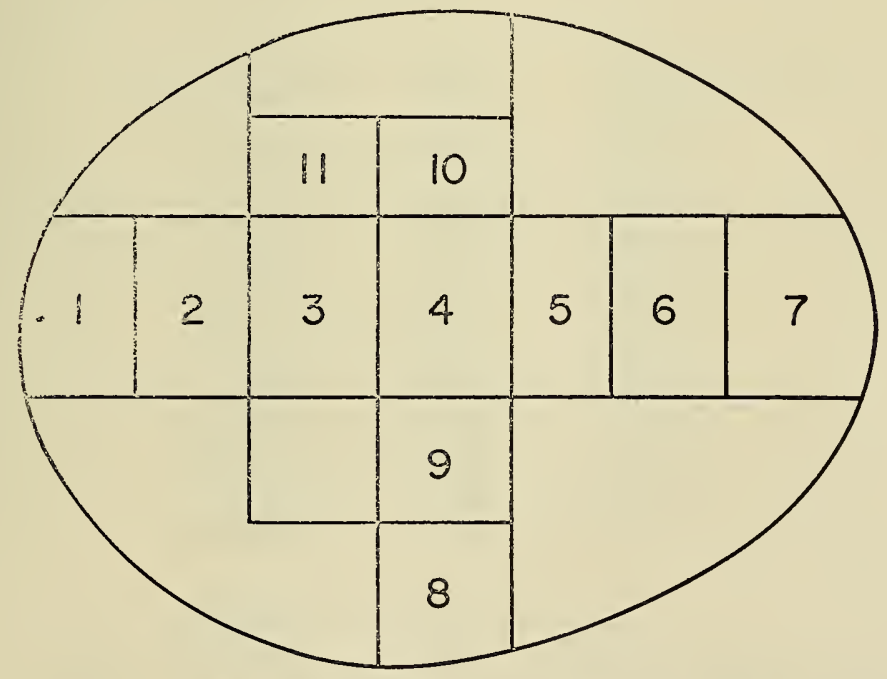

Figure 2. Samples were taken from the coral heads in the following order. A number refers to a sampling occasion, a letter refers to one of the triplicate samples. 
For comparisons of radioactive counts, the areas previously occupied by polyps were measured in all samples by tracing on to stiff cards which were then cut out and weighed. Plastic film was used for samples of irregular shape.

\section{RESULTS}

Data from the coral head checked for uniformity of labeling appear in Table 1. The standard deviation represents approximately $+18 \%$ of the mean value for the radioactivity per $\mathrm{cm}^{2}$ of coral surface. The total radioactivity extracted from triplicate samples of $\mathrm{M}$. annularis and $\mathrm{S}$. siderea taken over a period of 11 days after exposure to $\mathrm{Na}^{14} \mathrm{CO}_{3}$ was converted to counts $/ \mathrm{min} / \mathrm{cm}^{2}$ of surface and plotted against time in Figures 3 and 4 . The figures also show counts in the alcohol and the $\mathrm{NH}_{4} \mathrm{OH}$ extracts.

Table 1. Labeling of coral head: a check on the uniformity of labeling. Siderastrea siderea was labeled with $\mathrm{NaH}^{14} \mathrm{CO}_{3}$ (40uCi) as described and then sectioned according to the diagram (Figure 1 ).

Sample

1

2

3

4

5

6

7

8

9

10

11
Counts per min per sq. cm. of surface

33,200

32,700

31,650

21,200

30,800

25,200

27,000

33,500

25,950

21,300

19,700

Standard Deviation

$\pm \quad 4,870$ 


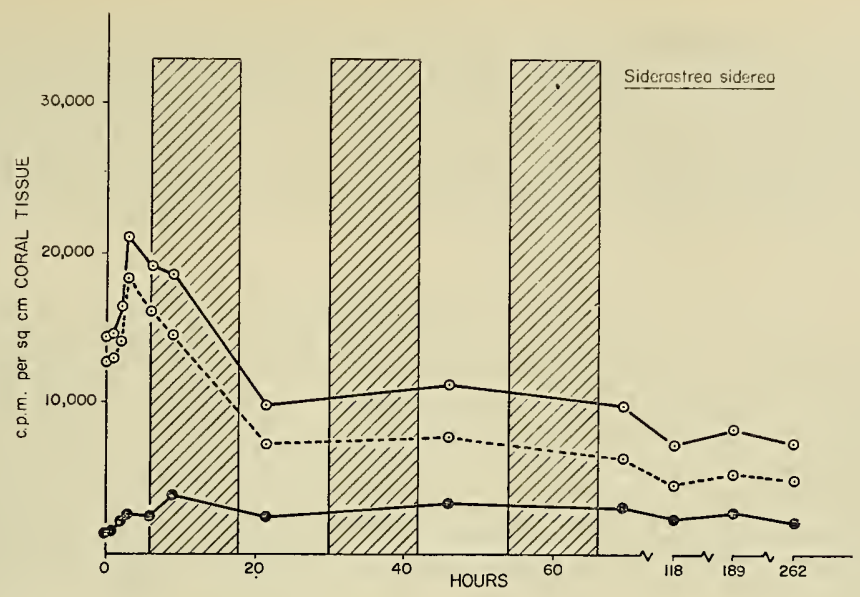

Fig. 3. A head of Siderastrea siderea was labeled with $14 \mathrm{C}$ by incubation with 60 uCi $\mathrm{Na}_{2} \mathrm{H}^{14} \mathrm{CO}_{3}$. Pieces were broken from the head at the times indicated and their radioactivity and surface area determined $(0-0)$ total radioactivity per sq. cm.; (0---0), radioactivity in an ethanol extract. (-) radioactivity in a $6 \mathrm{~N}-\mathrm{NH}_{4} \mathrm{OH}$ extract. Hatched areas represent hours of darkness.

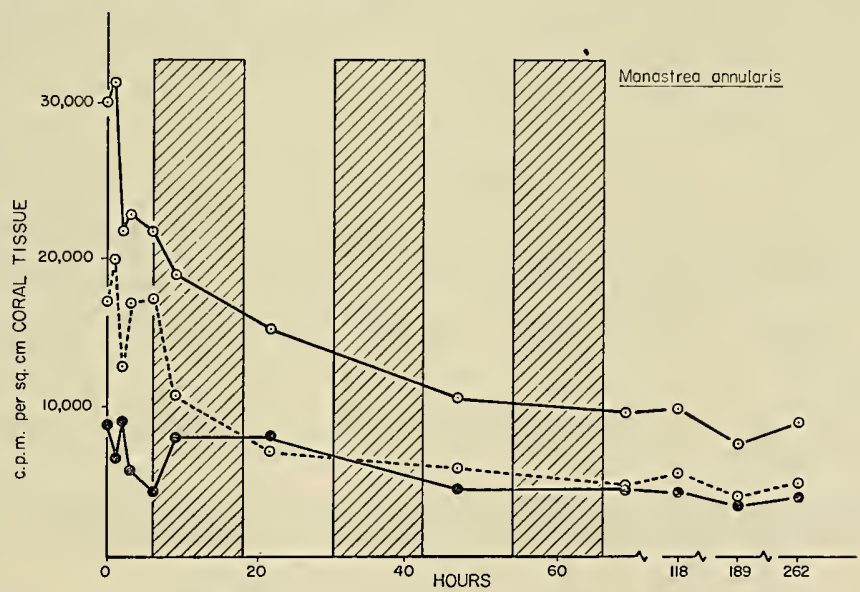

Fig. 4. A head of Monastrea annularis was labeled with $14 \mathrm{C}$ by incubation with $60 \mathrm{uCi} \mathrm{Na}_{2} \mathrm{H}^{\mathrm{I}} \mathrm{CO}_{3}$. Pieces were broken from the head at the times indicated and their radioactivity and surface area determined. $(0-0)$, total radioactivity per $\mathrm{sq} . \mathrm{cm}_{.} ;(0--)$ ) radioactivity in an ethanol extract; (-), radioactivity in a $6 \mathrm{~N}-\mathrm{NH}_{4} \mathrm{OH}$ extract. Hatched areas represent laws of darkness. 
M. annularis and $S$. siderea gave generally similar patterns in loss of radioactivity. Initially, the radioactivity in the ethanol fraction rose, particularly in $\mathrm{S}$. siderea, and then fell as the $\mathrm{NH}_{4} \mathrm{OH}$-extractable fraction rose. This took place over the first $48 \mathrm{hrs.}$, after which there was a generally slow decline in activity in both corals, leaving approximately $33 \%$ of the original activity after 11 days. The half life of loss of activity was not constant, indicating contributions from an unknown number of distinct metabolic sources.

The initial rise in radioactivity in $\underline{S}$. siderea after the source of label had been removed, requires comment. It seems reasonable to discount irregularity of labeling as an explanation since the rise persisted over a period of $4 \mathrm{hrs}$. and involved some samples not taken from the edge of the colony. An inherentIy more attractive explanation for the result is that a fraction with water soluble components was lost during sampling or subsequent transfer to ethanol. Cell intermediates e.g., leading to lipids would fit this category. The curves show that radioactivity in ethanol soluble components is transferred to ammonia soluble compounds, e.g., proteins. Note that this appears to occur most obviously in the hours of darkness.

\section{CONCLUSIONS}

Although this experiment did not provide information applicable directly in estimating rates of production and turnover by corals, it demonstrated the feasibility of obtaining this information, and the time scale involved, when working at depths well beyond those employed in earlier studies. Furthermore, the necessity for additional controls, particularly to recover excreted products was made apparent. It will be possible to attend to these deficiencies in future studies.

\section{REFERENCES}

Muscatine, L. and Cernichiari, E. 1969. Assimilation of photo-synthetic products of zooxanthellae by a reef coral. Bio. Bull., 137, 506-523.

Ryther, J. H. 1969. Photosynthesis and fish production in the sea. Science, 166, 72-76.

Stoddart, D. R. 1969. Ecology and morphology of recent coral reefs. Biol. Rev., 44, 443-498.

\section{STANDING STOCKS OF ORGANIC CARBON AND NITROGEN IN SESSIIE}

\section{ORGANISMS ALONG A TYPICAL REEF TRANSECT}

\section{OBJECTTVES}

Stoddart (1969) has discussed the obvious difficulties associated with quantitative studies of the sessile components of coral reef communi-

$$
\mathrm{VI}-254
$$


ties. He was referring primarily to estimating percentage cover, counts of species and genera and related problems. There is virtually no information on standing stocks of cell material, even in major organic elements. Our objective was to explore some of the difficulties, both field and laboratory, to be faced in gathering this type of information and to provide guiding data for studies of productivity.

\section{EQUIPMENT AND PROCEDURE}

After becoming familiar with the Lameshur Bay reef, an $80 \mathrm{~m}$ transect was marked with light nylon line running east and west from a depth of approximately $10 \mathrm{~m}$ to $20 \mathrm{~m}$, in a typical area some $150 \mathrm{~m}$ south of the habitat position. The gross profile of the transect was established at $3 \mathrm{~m}$ intervals with wrist depth gauges and a marked reel line. At intervals of $6 \mathrm{~m}, 35 \mathrm{~mm}$ color photos were taken in plan for later reference in making qualitative observations and biomass estimates. At the same intervals, samples were taken within $1 \mathrm{~m}^{2}$ quadrats and notes taken on features such as percent cover by coral, sponges, sediment, bare rock and algae, as well as diversity of the sessile fauna and flora. In areas of sediments, samples were taken by coring the surface layers. Portions of the most abundant hard corals in each quadrat as well as the least common were taken by hammer and chisel. Soft corals were measured for height and total length of all branches or for area, in the case of "fans", and representative portions taken for analysis. Individual whole algal thalli were collected. All samples were placed in plastic bags and frozen in the habitat until the mission was completed when transfer to cold boxes was arranged for immediate return to Miami.

Several more or less arbitrary decisions were necessary in preparing samples for chemical analysis. Lacking support for an extensive exploration of organic constituents, it was necessary to limit attention to determinations of organic carbon and nitrogen. In the case of hard corals, the size of the originally living surface was determined for each sample; in massive forms the calcareous understructure was cut away with a band saw leaving a surface layer for analysis. All samples were dried overnight in an oven at $70^{\circ} \mathrm{C}$, weighed, and then pulverized by hand in a dead-end steel tube fitted with a solid steel piston. Crushing was continued until each sample could be passed through a $0.5 \mathrm{~mm}$ sieve. Small replicate aliquots of these materials were used for chemical analysis.

Organic carbon was determined with the method of Strickland and Parsons (1965) while, for nitrogen, the procedure of Holm-Hansen (1968) was followed.

\section{RESULTS}

The analysis of all the collected samples is well advanced but not yet complete so that we are unable to provide this part of our report. Under the circumstances, it will be necessary to publish this sector of the work independently. 
Holm-Hansen, 0. 1968. Determination of particulate organic nitrogen. Limnol. \& Oceanogr., 13, 175-178.

Stoddart, D. R. 1969. Ecology and morphology of recent coral reefs. Biol. Res., 44, 433-498.

Strickland, J. D. H. and Parsons, T. R. 1965. A manual of sea water analysis. Fish. Res. Bd. Canada, Bull. No. 125. 


\title{
ACTIVITY PATTERNS OF CORAL REEF FISHES WITH EMPHASIS ON NOCTURNAL-DIURNAL CHANGEOVER
}

\author{
Bruce B. Collette \\ National Marine Fisheries Service \\ Systematics Laboratory \\ and \\ Frank H. Talbot \\ Australian Museum
}

\begin{abstract}
Two hour dives were made at morning and evening changeovers for 17 days. Fish activity was recorded at 5 minute intervals on two reefs. The first appearance of diurnal species was as early as 0540 hours and all were usually active before 0645 hours. Damselfishes became active earlier and stayed out longer than parrotfishes and wrasses. The sparse nocturnal fish fauna, primarily cardinalfishes and squirrelfishes, became active between 1812 and 1835 hours, after most diurnal fishes had disappeared (1732-1812 hours). Delay and extension of changeover in several species of fishes correlated with storm-caused turbidity one morning indicates that these fishes may have a primarily exogenous clock.
\end{abstract}

\section{OBJECTIVE}

Our objective was to describe in detail rhythms of activity that are correlated with the daily light-dark cycle in coral reef fishes. Previous work has demonstrated general patterns of day and night behavior; however, earlier workers found it difficult to directly observe the complete changeover. We tried to find out when each species became active and when it became quiescent relative to ambient light levels.

\section{EQUIPMENT}

Equipment consisted of underwater light, pencils, and plastic slates upon which to record our observations. The use of the rebreather permitted us to gather observations much more quickly than standard SCUBA because of the absence of bubbles. Additional work along these lines should have a recording photometer available to record the amount of light throughout the observations.

\section{PROCEDURES}

Two reefs were selected for study. "Habitat Reef," 1ay immediately adjacent to the Habitat at a depth of $15 \mathrm{~m}$ and was selected because of its proximity and because we could watch the changeover while on hookah from the habitat. The presence of the habitat, diver activity, 
and night-time illumination probably made the fauna of the near side of this reef behave in an abnormal fashion, hence we concentrated on the opposite side of the reef from the habitat. However, we supplemented our normal morning and evening rebreather dives with observations from the portholes and by short excursions on hookah, especially when adverse weather conditions limited us to the habitat (due to restrictions on surface support). "Sewer Reef," so named because the easiest route to the reef was along the sewer line from the habitat, was chosen for its accessibility (a 5-10 minute swim from the habitat), lack of human interference, and greater depth $(23 \mathrm{~m})$. We picked a deeper reef as the second study site because it was easily available to us and more difficult of access by surface-based workers. Also, two other members of Mission 15-50 (C. L. Smith and J. C. Tyler) were intensively working a shallower $(11 \mathrm{~m})$ reef.

Morning and evening observations were conducted, beginning before any changes in activicy patterns and continuing until all major changes had occurred. This plan entailed dives approximately two hours long at about 0500-0700 and 1700-1900 hours eastern daylight time. Notes were recorded by both of us at 5-10 minute intervals on reef fish activities--resting, feeding, hovering in the water column, parasite picking, etc. Observations were concentrated on basic activity patterns--when a given species was active and when it was "sleeping" or resting. We also recorded day-night color pattern differences. Notes were transcribed from the underwater slates after each dive or two and then summarized by species.

\section{RESULTS}

Morning and evening changeovers were defined based on the time of replacement of nocturnal by diurnal species in the morning and the reverse process in the evening. We identified 107 species of fishes in 36 families; data is of reasonable quality for about 35 species. A species by species account summarizing our observations has been prepared for publication elsewhere.

The first appearance of diurnal species was as early as 0540 hours and all were usually active before 0645 hours. Species in some groups of fishes, for example the damselfishes (Pomacentridae) were early risers (mean times of first appearance 0556-0605 hours) and remained active throughout the day (until 1743-1808 hours). Species in other groups, such as the parrotfishes (Scaridae) and wrasses (Labridae) became active later (mean times of first appearance 0613-0618 hours) and disappeared sooner (1735-1756 hours). The sparse nocturnal fish fauna (primarily cardinalfishes and squirrelfishes) became active between 1812 and 1835 hours, after most of the many colorful diurnal fishes had already disappeared (1732-1812 hours). The best example of the replacement of one fauna by another involves midwater particulate plankton feeders. The cardinalfish Apogon affinis moved out of its daytime caves at about 1800 hours to replace the diurnal aggregations of the damselfishes Chromis cyanea and $\underline{C}$. multilineata. At morning 
changeover, the Apogon returned to their caves as the Chromis moved up over the reef.

C1ues as to whether the activity patterns were basically endogenous or exogenous were derived from a natural experiment that was arranged by the weather on the morning of october 9. The combination of high waves and a large amount of run off caused by heavy rainfall made the water around the habitat very turbid. Also, the greater amount of cloud cover and the greater surface reflection caused by the high waves may have helped reduce the amount of available light. But both these conditions had existed earlier and we believe that most of the reduced amount of light on October 9 was due to the greatly increased amount of sediment in the water. We were not permitted to leave the habitat on SCUBA or rebreathers because the high waves prevented the safety boat from remaining above us. We were, however, able to observe the changeover on hookah from the habitat. The data from this one morning is highly significant because changeover began 25 minutes later than the usual 0555 hours.

To measure the effects of this storm-caused turbidity on the morning changeover, comparisons were made between the usual time of appearance of the first active individual of a species and the time of appearance on October 9. Minimum delay is the difference between the latest time of first appearance and the time on October 9. This ranged from no delay to 55 minutes, mean 17 minutes. Mean delay was calculated by subtracting the mean usual time of first appearance from the time on October 9 for the three nocturnal and 17 diurnal species that were observed that morning. This delay ranged from only seven minutes in the case of Bodianus rufus to 72 minutes for Thalassoma bifasciatum. Overal1, the mean delay in changeover was 33 minutes for these 17 diurnal species.

Another measure of the effect of the turbidity was the time it took for the species of Chromis to reach their usual height of 2-3 m over the reef. This process usually took 20-45 minutes, but on October 9 it took 55 minutes for $\underline{\mathrm{C}}$. cyanea and 65 minutes for $\underline{\mathrm{C}}$. multilineata, an increase of 15-20 minutes.

As measured by the appearance of Thalassoma bifasciatum, a laterising species, changeover was not complete until 0730 hours, an hour and 10 minutes after it began.

Thus, in several different ways, changeover was delayed and extended on the morning of October 9. We believe this delay was caused by turbidity preventing sufficient light from reaching the fishes to stimulate changeover. This indicates that most of these reef species have a basically exogenous clock that requires the stimulus of light to change from nocturnal to diurnal activities. Several species were not delayed by the turbidity so perhaps they have a primarily endogenous clock. Obviously, controlled experiments are necessary to test these preliminary hypotheses. 
Use of the habitat (no decompression) and rebreather (no bubbles) allowed us to gather information in 17 days (a total of about 100 hours in the water for the two of us) that is comparable to that pub1ished by Hobson $(1965,1968)$ based on 1200 hours underwater and that published by Starck and Davis (1966) based on 100 night and many more daytime dives. In addition, we can describe the changeover in activity patterns in some detail. Data on the effects of storm-caused turbidity could not have been gathered except for a habitat. We are convinced that studying fish behavior from a habitat with a rebreather is an important and effective way of solving many ichthyological problems. Additional work on the changeover is stil1 needed and this work should include recording of available light throughout the study period.

\section{LITERATURE CITED}

Hobson, Edmund S. 1965. Diurnal-nocturnal activity of some inshore fishes in the Gulf of California. Copeia 1965 (3): 291-302.

- 1968. Predatory behavior of some shorefishes in the Gulf of California. U.S. Fish. Wild. Serv. Res. Rept. 73, 92 pp.

Starck, Wa1ter A. II and William P. Davis. 1966. Night habits of fishes of Alligator Reef, Florida. Ichthyologica, Aquar. J. 38(4): 313-356. 


\author{
C. Lavett Smith \\ The American Museum of Natural History \\ and \\ James C. Tyler \\ Academy of Natural Sciences of Philadelphia
}

\begin{abstract}
Coral reef fish communities are highly diverse assemblages of interacting species. Present observations indicate that the resident species are present in approximately the same numbers over long periods of time although there are probably annual cycles of abundance for each and therefore seasona1 changes in relative abundance. Direct observation of a small patch reef during a two week period has revealed patterns of space utilization that are interpreted as mechanisms for avoiding interspecies competition. Seventythree resident and visitor species were studied. Important aspects of space sharing are: location and type of shelter during inactive periods, timing of activity cycles, home range size, and special behavior patterns such as schooling and territorial defense. It is suggested that intraspecies competition for space may play a major role in maintaining numerical stability within the community.
\end{abstract}

\title{
INTRODUCTION
}

Coral reef habitats support fish communities that are among the most diverse known. Patch reefs only four or five meters across frequently house fifty to one hundred species of small fishes, apparently living together in reasonably stable dynamic equilibria. These communities offer rewarding challenges to ecologists interested in the fundamental principles that govern the development and maintainence of high diversity communities. With the availability of suitable diving gear and efficient collecting methods these and other shallow marine habitats are now accessible for gathering reliable quantitative data for analysis of community structure.

\section{OBJECTIVE}

The object of this study has been to examine the space utilization patterns of the fishes of a small patch reef in an effort to learn how these patterns influence the stability of the community. The density of fishes in coral reef habitats as measured by both numbers of species and numbers of individuals suggests that space sharing is 
a critical aspect of the community structure. Encounters between individuals of the same and different species are frequent and selection for sharing, rather than competing for, space resources must be intense.

\section{EQUIPMENT}

The availability of the facilities of the TEKTITE II habitat and in particular the General Electric Mark X rebreather units made it possible to make direct observations of the fishes of a small patch reef during the mission from September 26 to October 11, 1970. The reef (hereafter called observation reef) was selected because of its convenient size - small enough to be studied thoroughly, its general location about 10 minutes swim from the habitat, its isolation from other nearby reefs, and because it appeared to support a rich resident fish fauna.

\section{PROCEDURES}

Once the reef was located a guide line of bright yellow nylon was laid between the umbilical line and the reef to facilitate our being able to find it with no loss of time, day or night. During the first few observation periods we made sketches and photographed the reef. Base maps sealed between sheets of lucite were then used for notes and to plot the distribution of the fishes on the reef. In the course of the two week period the reef was observed for a total of 41 hours ( 82 manhours) mostly during the daylight hours but sometimes at night and also during morning and evening twilight.

\section{RESULTS}

Observation reef (fig 1 ) is a mixed coral patch reef surrounded by a flat sandy open area. Its position is approximately 330 feet northeast of the habitat in water 35 feet deep. Its maximum dimensions are roughly 3 meters by 3 meters. Four smaller reefs were close enough to the main observation reef to be considered with it because fishes were observed to swim back and forth between them and the main reef. Three of these satellite reefs were large Montastrea colonies; the fourth consisted of several species of coral attached to a Diploria colony. The main reef was dominated by helmet shaped and globose Montastrea annularis colonies with other corals including Montastrea cavernosa, Porites astreoides, Porites porites, Diploria stringosa, Diploria labyrinthiformis, and representative of the general Dichocoenia, Agaricia, Isophyllia and Siderastrea. Several plexaurids were also present. Three large sea fans, Gorgonia sp., 2 near the north tip and one near the south, formed prominent land marks. Like other sea fans of the area they were oriented with the plane of the body east-west, i.e. perpendicular to the prevailing currents. Other prominent invertebrates were: ophuiroids some of which extended their arms out of small holes at night, sessile clams, tunicates, Diadema sea 


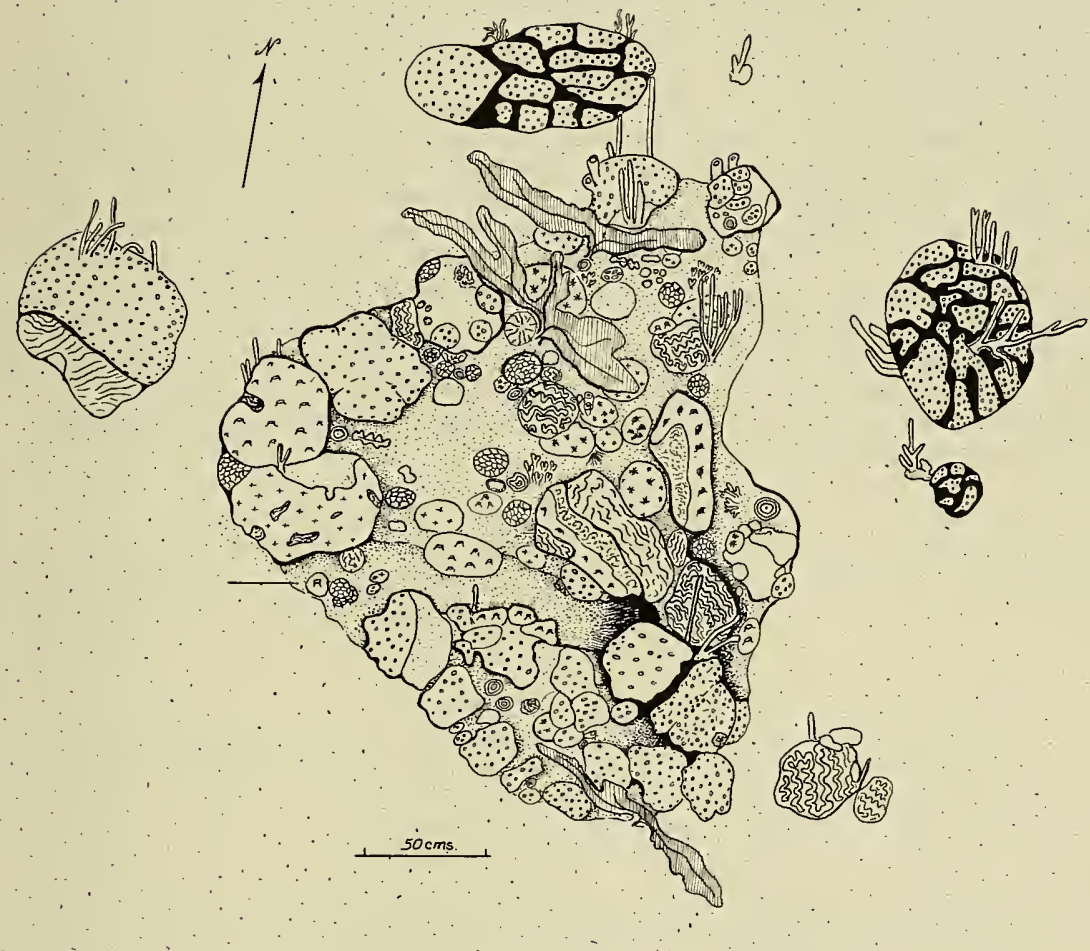

Figure 1. Plan view of Observation Reef, Lameshur Bay, St. John.

urchins, and sponges. Two larger Diploria colonies were partially dead and the dead areas were partially covered with a bright red sponge in which small white anemones were embedded. This sponge appeared to be attacking the dead part of the coral skeleton which was clearly delimited from the living corals. Prominent Spirobranchus worm gills protruded from many of the globose coral colonies. 
The coral colonies were attached to a rocky substrate with a variety of algae between them. The substrate itself was penetrated by many deep holes and some of the colonies at the edge of the reef grew out over the adjacent sand. Near the southern tip of the reef some coral colonies had coalesced to form a bridge across an east to west channel that partially divided the reef into a northern and a southern part. In general appearance this patch reef did not seem atypical of the many patch reefs in the area northeast of the TEKTITE II habitat.

Although our study was aimed at the residents of the observation reef, it soon became apparent that the area in which these residents live included more than the reef itself. Reef associated fishes occupy interstices in the reef structure, the outer surface of the reef complex, and the water space surrounding the reef. Many of the fishes leave the reef to feed on midwater over the reef or on the adjacent sand flats and these contiguous areas must be considered part of the reef habitat. We estimate that 75 percent of the activities of resident fish species occurred within 2 meters of the reef and that 95 percent occurred within 7 meters horizontally and 2 meters vertically (fig 2). The adjacent areas are also shared with fishes from nearby reefs.

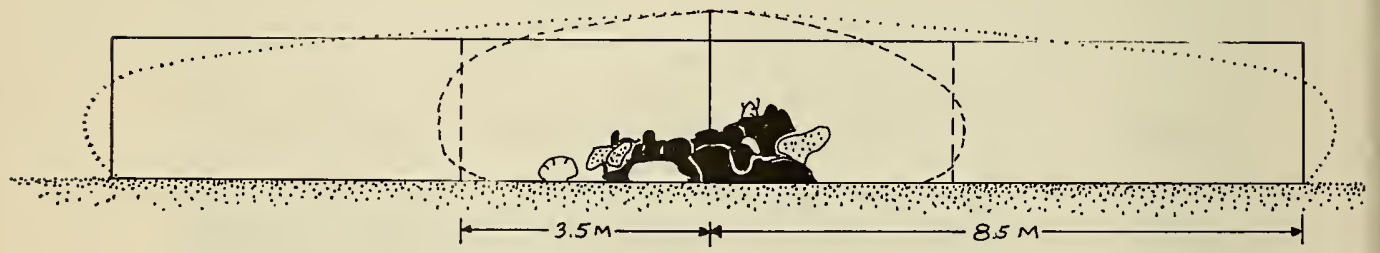

Fig. 2 Observation Reef as seen from the west side showing estimated volumes in which 95 percent (dotted Line) and 75 percent (dashed line) of the resident fishes' activities take place. Rectangular areas are the approximations used in calculations described in the text. 
Our best estimates suggest that this space is utilized by approximately 700 individual fish. The volume of a cylinder with a radius of 8.5 meters and an average height of 2.0 meters is 454 cubic meters. Substracting 5.3 cubic meters for the reef structure indicates an average density of $1.56 \mathrm{fish}$ per cubic meter. With an average weight of 3.9 grams per fish this suggests a density of 6.05 grams per cubic meter of living space. Similar calculations of the smaller volume in which 75 percent of the fishes' activities take place yields a density of $7 \mathrm{fish}$ ( 27 grams) per cubic meter. Such average figures, while interesting, tel1 us 1ittle about the actual partitioning of the available space. For example, the amount of space per individual need not be directly related to the volume required by each individual. The planktivorous Chromis cyanea hovers over the reef usually near the northernmost sea fan but with occasional forays to the rest of the reef and well up into the water column. In the course of an hour each individual probably patrolled a volume of 100 cubic meters but at the same time this space was also utilized by approximately 34 other members of the same species (2.9 cubic meters per fish). On the other hand an individual Pomacentrus may defend territory at the most one meter in diameter and $35 \mathrm{cms}$ deep and because it will not tolerate other individuals of the same species the density is approximately 1 fish per 2 cubic meters. This means that in spite of the greater area required by the Chromis they are using only slightly more space per individual than the sparse Pomacentrus. Column 1, table 1 lists the species recorded from observation reef and the second column lists our best estimates of the numbers of individuals present.

The third column of table 1 classifies each species as a resident, visitor or transient. Resident species are those represented by individuals that actually live in the area, that is, their home range at least includes the habitat patch under consideration. Whether or not a resident species will be present all of the time depends on the size of the individuals home range. If their home ranges are larger than the habitat patch under consideration there will be part of the time when the individuals are away from the habitat. In other words, continuous presence in the patch is not a necessary criterion of residence.

Some resident species with home ranges smaller than the reef patch

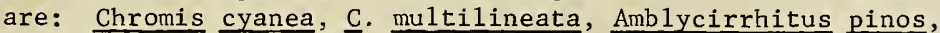
Pomacentrus planifrons, Pomacentrus partitus, Quisquilius hipoliti, and several other species of gobies and blennies. Species with home ranges that include the observation reef but were larger than the reef area were Epinephelus striatus, Scarus vetula, and adu1t Canthigaster rostrata. Column 4 table 1 compares our estimates of home range size with the size of the reef patch itself excluding the area of the adjacent sand flat used by the reef residents. 
Visitors are species whose members live in other habitats and only occasionally visit the reef. Such species may be important to the economy of the reef as predators, prey, or competitors but they are not consistently represented by the same individuals. An outstanding example of an important visitor species is the yellowtail Ocyurus chrysurus. One or more individuals of this predator were often at the reef but they were of different sizes and therefore not the same individual. Gooding and Magnusen (1967) distinguished between species that visit a habitat and remain there for a short while and those that pass through without being influenced by the habitat. We have called the later transients and because they do not play important roles in the reef economy we have excluded them from all standing crop calculations. On observation reef 54 species appeared to be residents, 15 were visitors and 4 were transients.

The patterns of space utilization among fishes are generally related to their modes of living and particularly to their feeding adaptations. Herbivores such as surgeon fishes (Acanthuridae) range over wide areas in small groups. Except for three juvenile Acanthurus coeruleus they were transients at the observation reef. Pomacentrus planifrons, however, is also herbivorous and yet strongly territorial. Apparently the reproductive pattern of egg guarding dominates even when the fish are not actively breeding. Chromis cyanea and $\underline{c}$. multilineata are plankton croppers. They feed by chasing down individual zooplankters over the reef and they feed constantly during daylight hours. Large resident carnivores such as Petrometopon cruentatum spend much time hovering near the bottom or being groomed by parasite pickers but were rarely observed actually feeding. Wrasses (Labridae) feed on small invertebrates and spend an intermediate amount of time hunting or feeding. Parasite cleaners (Gobiosoma evelynae, Holacanthus ciliaris juveniles) were at work almost constantly during daylight hours. Gnatholepis thompsoni, a goby that feeds on arenicolous smal1 invertebrates seemed to feed at irregular intervals.

General adaptations to broad classes of food organisms determine where and on what the species can feed. The presence of similar and hence potentially competing species refines the pattern, sometimes dictating specific areas of feeding and sometimes influencing the species preyed upon.

While some species such as Halichoeres garnoti feed wherever the opportunity arises, most species had special feeding areas either within the reef, in midwater above the reef or over adjacent sandy areas well away from the reef structure. These are listed in table 1, column 5. The size of the area covered during the feeding periods also varied with the species. The goby Quisquilius hipoliti was never observed to move more than $10 \mathrm{cms}$ from its home hole and even less movement was displayed by the blenny Acanthemblemaria 
spinosa which was never seen with more than its head protruding from the abandoned worm tube in which it lived. The grunts Haemulon aurolineatum and $\underline{H}$. flavolineatum leave the reef at night and apparently range over a wide area of the adjacent sand plain.

Activity cycles (table 1, column 6) also provide a means by which more species can use a limited volume of habitat. Some species are nocturnal, moving off the reef just after sunset and returning to it just before daybreak; others are diurnal. We did not detect any species that were truly crepuscular, i.e. active only during daylight and dusk, although some diurnal species seemed to be more active shortly before sunset. It was difficult to determine whether some species were diurnal or nocturnal. For example, Hypoplectrus puella hovers around the reef during the daytime but it was not seen at night and we could not tell whether it takes refuge in holes at night or moves off the reef to feed. At or immediately preceding the departure of night active species, the daytime species retire to their nocturnal retreats and in the morning the process is reversed. The changeover periods are short and definite and generally span less than fifteen minutes (for details of the sequence during the changeover see Talbot and Collette, this volume).

The inactive periods during which the fishes are not actively feeding or engaging in any other special activity must be considered in any discussion of space sharing. There are a variety of ways in which fish spend their resting hours. Some such as the species of Chromis insinuate themselves into the shelter of crevices or holes in the reef - others such as the cardinalfishes and squirrelfishes gather into small groups in caves or around the bases of coral colonies. Apogon conklini takes refuge in the spines of a sea urchin. Some wrasses burrow into the sand and so on. During the inactive periods the fish relies heavily on structural and behavioral adaptations for defense against predators. When the fish are actively feeding they are alert and prepared to flee or seek shelter to avoid danger but in their resting places they are unprepared for flight and hence depend on camouflage and remaining motionless so that predators do not locate them. Many species school during the day and disperse to feed at night. Schools in this case appear to be the quiescent refuge. It appears that defense mechanisms are generally more closely related to the inactive periods than to the active periods.

It is a common impression that tropical species have no true annual seasons but there is a growing body of evidence that this is not true. Although the seasons may not be well-marked, they are none the less present. During our two week study of the observation reef we found no evidence of spawning activity in any species although we suspected that one or more cardinal fishes were brooding eggs in their mouths 
but we were not able to confirm this. We also observed that there were numerous large juveniles at the reef and that some species (Haemulon flavolineatum, $\underline{H}$. aurolineatum and Chromis cyaneus) were represented by very distinct size classes - juveniles and adults. At the time of our study a large mixed school of Haemulon juveniles was consistently present over the reef during daylight hours. One suspects that this school might have consisted of different species at another time of year. It is our hypothesis that the juveniles of the species of Haemulon all have similar niches which they share at least partly by using the space at different times of the year. At present we do not have sufficient data to confirm or deny this hypothesis.

\section{CONCLUSIONS AND RECOMMENDATIONS}

The observations described here confirm the general hypothesis that the fishes of small patch reefs are true communities of interacting species and not merely random assemblages of forms that happen to find suitable conditions in the reef. The existence of resident individuals, particularly of those species that disperse daily and return to the same shelters, in itself is evidence of at least short term stability. The large numbers of species constituting this community implies that there is a fine partitioning of the space available and this is confirmed by our observations that each species has a characteristic regimen of space utilization that can be described in terms of activity cycling, feeding areas, shelter sites, home range size, numerical abundance, and social patterns. High diversity communities are generally not subject to drastic population cycles partly because predators have alternate prey species to which they can turn when the most readily available prey species becomes scarce. We suggest space sharing mechanisms also impose a maximum population limit on each species and that this prevents overpopulating with resultant food depletion and abrupt population crashes. This can be operative in shelter sites, feeding area, general home range or territories. Territoriality is most crucial during the breeding season but some species seem to be territorial the year around. Recruitment takes place during a definite limited time of the year and therefore newcomers must compete with larger, established members of the same species not only for food but also for hiding space and feeding area and eventually nesting sites. It is unlikely that a small recruit will be able to displace an established larger individual of the same species and therefore its success is dependent upon the availability of vacant sites. In coral reef environments it appears that shelter competition may be more important than food competition. Since the number of shelter sites is fixed, the maximum population levels are also fixed. Space sharing adaptations permit more species to use the habitat but impose stricter limits on the numbers of any one species. 
Community structure can only be understood fully when many kinds of data are available. Some of these data can be obtained from quantitative sampling but others must be based on detailed long term observations. Under most conditions the presence of the observer is a disturbance that lessens the chanees of making meaningful unbiased observations. The use of rebreather units, rather than conventional scuba, makes possible longer periods of observation with much less disturbance to the fishes. Future studies should include concentrated work on seasonal changes, feeding habits, and social interactions as well as expanding the observations described here. 


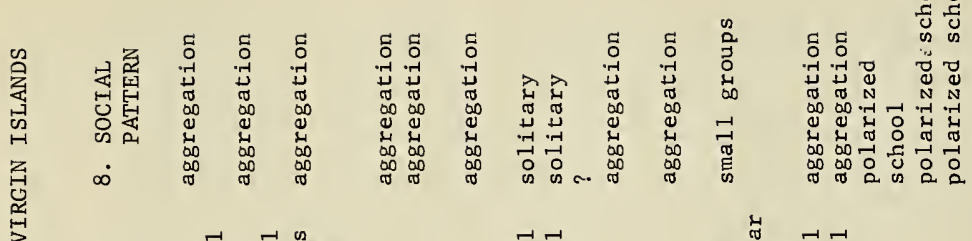

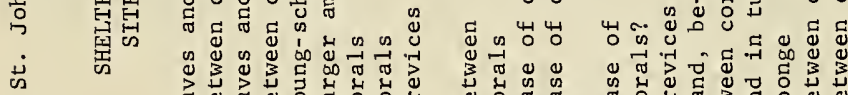

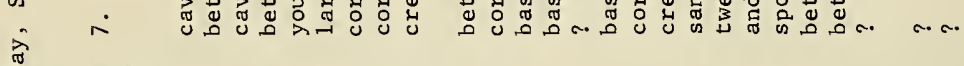

m

4 되으

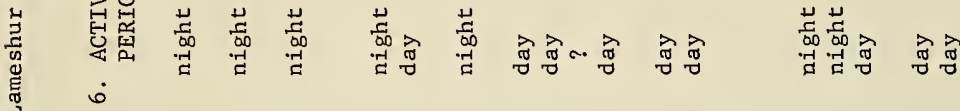

选

:

年

อิ

总

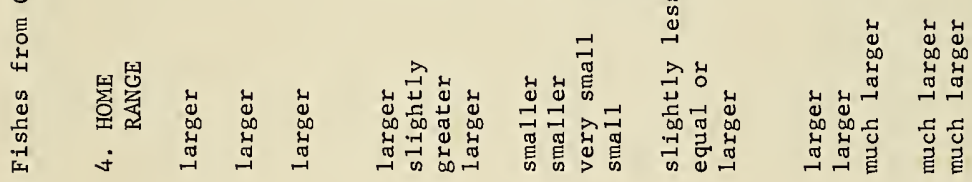

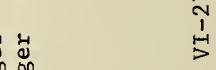

4

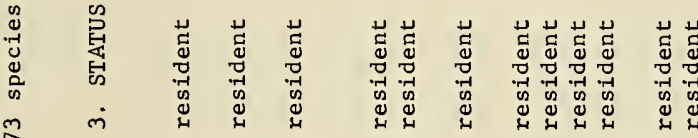

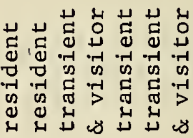

4

:

ב.

离

$\underset{\substack{0 \\ 0}}{0}$

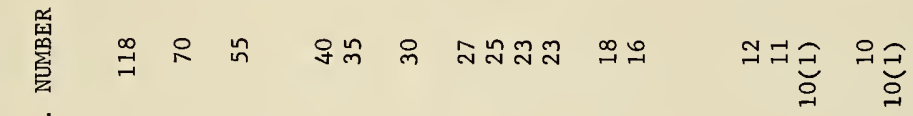
N

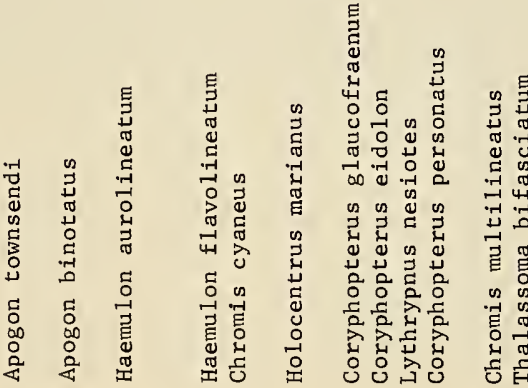

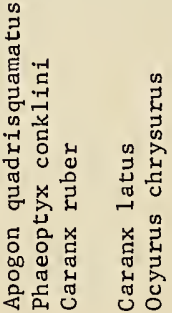




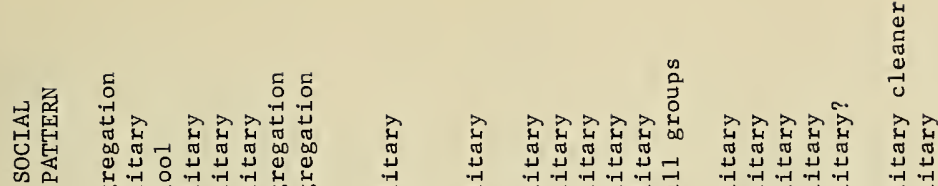

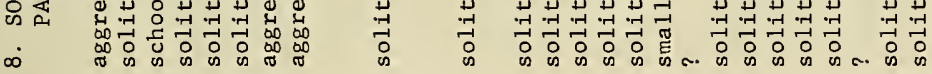

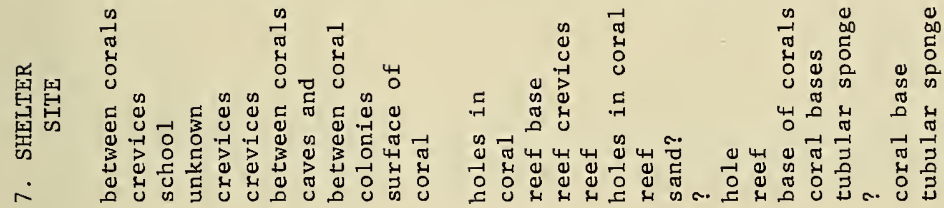

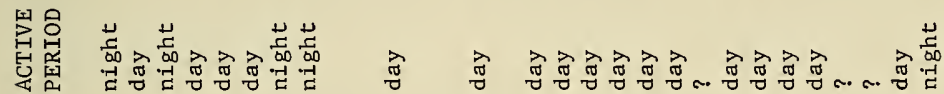
i

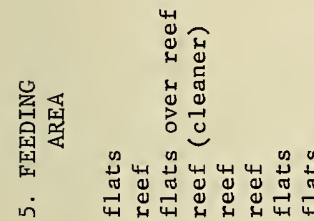

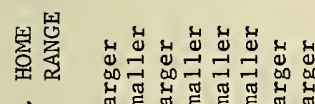

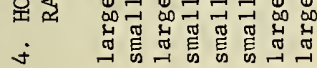

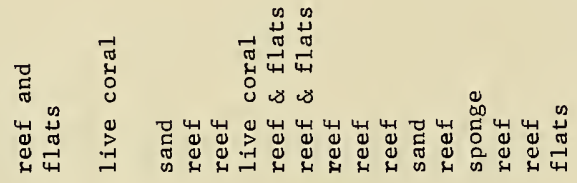

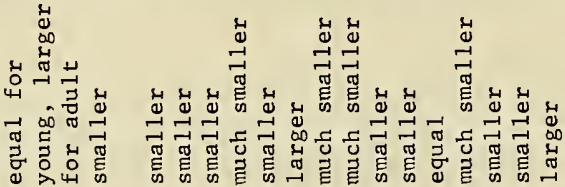

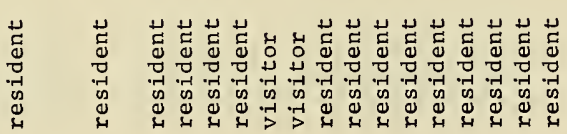

N N $0000 \mathrm{~m} n t+t \operatorname{tanmm}$

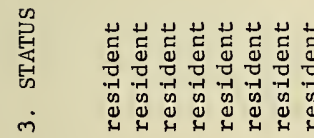

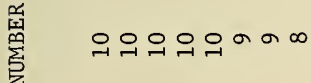

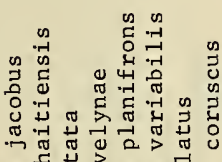

䱛

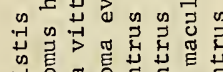

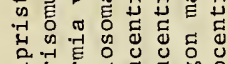
thy

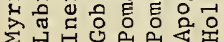

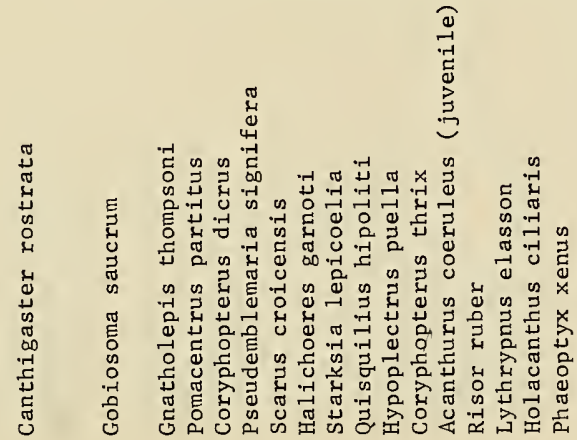




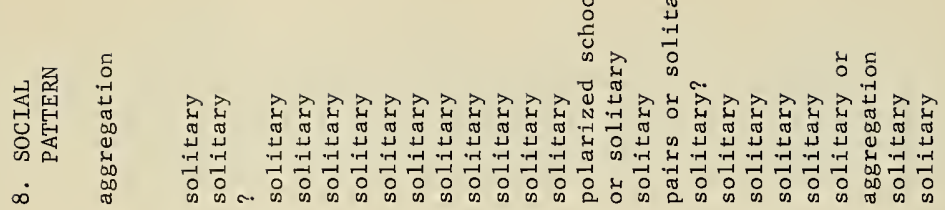

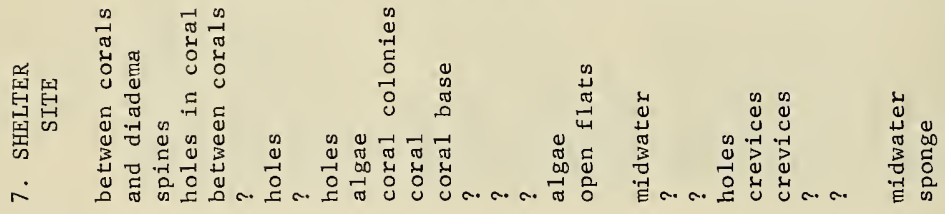

岂总

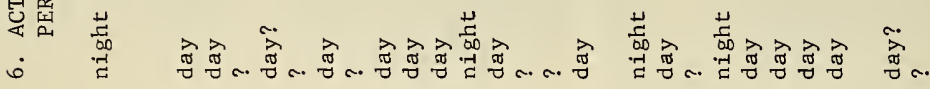

爵

फल

म 8 प

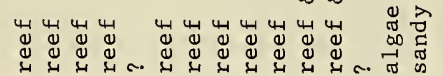

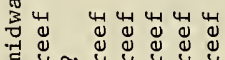

嵌狊

章节

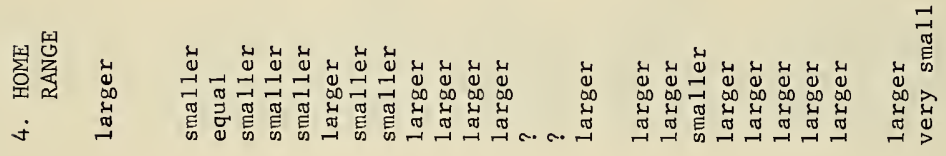

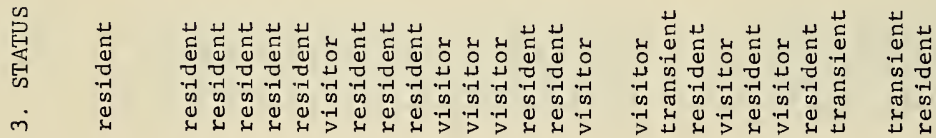

茎

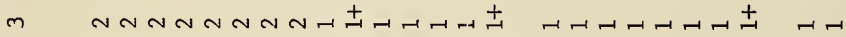

$\dot{\sim}$ 


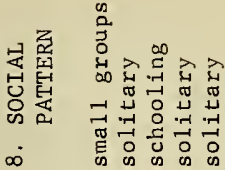

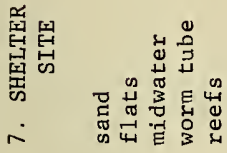

똑으

苞最

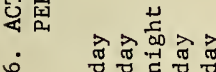

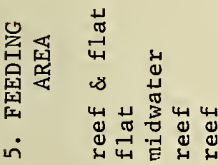

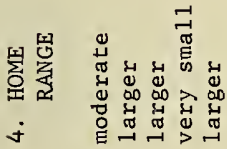

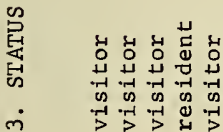

赵

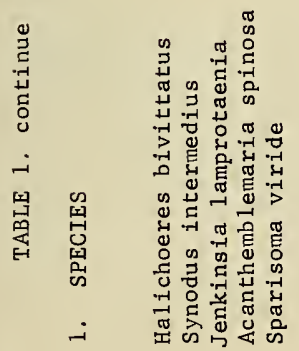




\section{Reference Cited}

Gooding, R.M. and J.J. Magnuson.

1967. Ecological significance of a drifting object to pelagic fishes. Pacific Science. 21(4): 486-497 
GREAT LAMESHUR BAY

Wolfgang Hicke1

Biologische Anstalt Helgoland

Hamburg, West Germany

\section{ABSTRACT}

During October 19. to 26., 1970, investigations of seston quantity and quality were carried out at three locations near the TEKTITE habitat. A table (p.3) shows the data of organic carbon of seston and phytoplankton as well as of nitrogen in the seston. The distribution and composition of seston in the bottom water was fairly homogeneous.

\section{OBJECTIVE}

The aim of these investigations was to analyze the quantity and quality of the seston in the near bottom water layer of the Great Lameshur Bay. The possible influence of the kind of bottom substrate and of the vertical distance from the bottom was to be considered. The qualitative composition of phytoplankton, the phytoplankton biomass, the weight, organic carbon and nitrogen content of the seston were investigated.

\section{PROCEDURES}

During TEKTITE Mission No. 15, water samples were taken near the habitat usually twice a day in the period from October 19. to 26., 1970. The sampling of 5 to 10 liters was done using plastic bags. Three locations were selected for repeated sampling:

1. Coral reef west of the habitat: $30 \mathrm{~m}$ southwest of habitat entrance at $0.5 \mathrm{~m}$ above the bottom in a depression between the coral growth. Water depth $14 \mathrm{~m}$.

2. Over the sandflat which extends west of this reef. $50 \mathrm{~m}$ west-northwest of habitat entrance, $25 \mathrm{~m}$ apart from the edge of the reef.

2.a. $0.5 \mathrm{~m}$ above the sand bottom. Water depth $18 \mathrm{~m}$.

2.b. $5 \mathrm{~m}$ above the bottom. $13 \mathrm{~m}$ of water depth.

Following subsamples were taken:

1. $100 \mathrm{ml}$ of water were preserved with Lugol's iodine solution. Phytoplankton cells were counted using the sedimentation technique with an inverted microscope. 
2. 2 to 5 liters of water were filtered through a nylon bolting cloth of 45 microns mesh size. The plankton and larger detritus particles were formalin preserved.

3. 2-liter-samples were filtered through an ignited and weighted Whatman GF/C glasfiber filter, which as a pore size of $1-1$ microns. Using a Millipore filtration apparatus and a vacuum pump the seston was carefully removed. The dried filters were stored airtight.

The counted phytoplankton cells were grouped according to their size and systematic categories. Applying the known relations between cell volume and organic carbon content the phytoplankton biomass was calculated in terms of carbon.

Further differentiation of more species and their possible heterogenous distribution as well as their frequency at day and night have still to be worked out. Furthermore, size and frequency determinations of detritus particles and chemical analyses of the sedimentated material which was sampled from a variety of bottom surfaces for comparison are not yet available at this time.

The dried $\left(70^{\circ} \mathrm{C}\right)$ glasfiber filters were reweighted using a Cahn electrobalance. From the obtained total particulate matter (seston dry weight) the carbonate was removed by treatment with fumes of hydrochloric acid. After drying, the weight of the carbonate-free seston was determined (see table, column 2). The same filters were analyzed for organic carbon and nitrogen by dry combustion in an Hewlett Packard carbon-hydrogen-nitrogen analyzer Mod. 185 (column 5 and 6 in table).

\section{RESULTS}

The seston distribution and quality were fairly uniform in the water column observed and there was little change during the investigation time. The seston weight at the bottom was slightly higher $(1.76$ and $1.75 \mathrm{mg} / 1$, see table, column 1) than at $5 \mathrm{~m}$ above it $1.67 \mathrm{mg} / 1$ ). The carbonate content of the seston was highest at $5 \mathrm{~m}$ above the bottom (48.4\%, column 3 ) and lowest at the reef bottom $(42.6 \%)$.

The biomass values as evaluated from phytoplankton counts (column 4) were the same at $5 \mathrm{~m}$ above the sand bottom ( $13 \mathrm{~m}$ of water depth, 41 micrograms carbon per liter) as over the reef ( $14 \mathrm{~m}$ of water depth). Little more (44 ug carbon per liter) was found near the sand bottom in $18 \mathrm{~m}$ water depth.

The organic carbon content of the seston as determined by combustion (column 5) however was higher at $5 \mathrm{~m}$ above the bottom and over the coral reef (68 and $71 /$ ug carbon/1) than near the sand bottom (63/ug carbon/1).

The percentage of the direct determined carbon from total seston weight (column 8 ) was slightly higher near the sand and coral bottom $(4.1 \%)$ than at $5 \mathrm{~m}$ above the sand $(3.8 \%)$. 


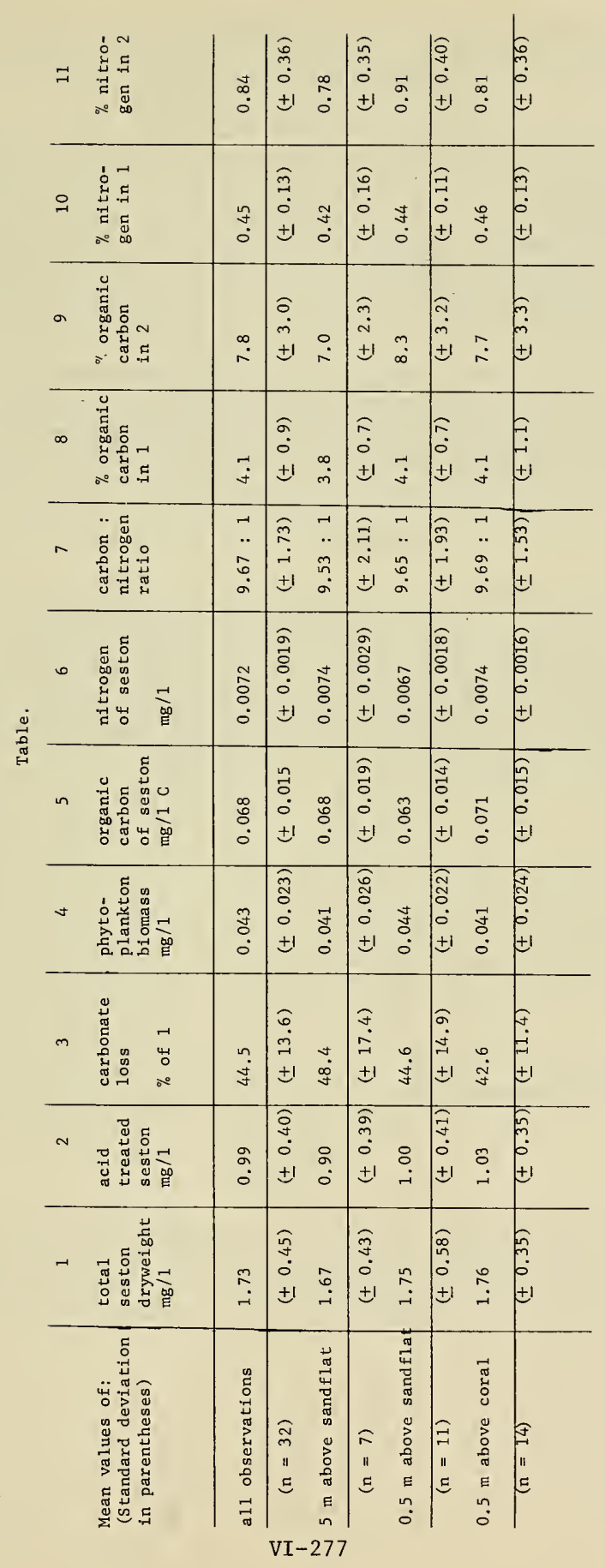


From these data no marked trend of stratification of the seston components in the bottom water can be found. The water depth seems to have more influence on it than has the kind of bottom substrate.

The dominant proportion of phytoplankton biomass was formed by small ( 20 to 28 microns long) and medium (29 to 56 microns long) peridinians. Sma11, naked flagellates ( 8 to 12 microns long) were found very frequently, but did not contribute much to the biomass. Centric diatoms formed at least 12 to $20 \%$ of total biomass. During the first days of observation (October 19. to 21.) this percentage was higher (about 30\%). The table shows that the standard deviation in phytoplankton carbon is much higher than in direct analyses of the seston.

There was no good correlation between seston and carbon values. The correlation coefficient was best between total seston (column 1) and direct determined organic carbon (column 5), being +0.38 , compared with a coefficient of +0.35 between the acid treated seston (column 2) and the organic carbon. Correlation between seston and nitrogen were worse.

\section{RECOMMENDATIONS}

It is obvious that there was a need for parallel plankton and seston investigations from the surface and of hydrographical observations at the same time. The investigations should extend over a longer period. Changes of hydrographical and chemical conditions in the water - such as the extreme turbidity after the heavy rainfalls prior to Mission 15 - would provide a good opportunity to observe the responses of plankton development and of the significance of the seston for the coral reef fauna. 
Roland T. von Hentig

Biologische Anstalt Helgoland

Hamburg, West Germany

\section{ABSTRACT}

An attempt was made to gather information about the distribution, stability, and diurnal periodicity of the zooplankton population in relation to different substrates and to the habitat. By means of a swimmer operated net quantitative samples were taken at various stations at 0900,1300 , and 2200 hours over a ten day period. In spite of the relatively small number of samples, some patterns emerged, populations differed characteristically according to location. A pilot experiment was conducted to test the varying response of zooplankters to different wavelengths of light.

\section{OBJECTIVE}

Qualitative sampling at specific locations in the vicinity of the fringing reef of St. John island was expected to yield information concerning the size and composition of the permanent plankton population and conversely the degree of exchange of zooplankton near the various substrates in the course of a 24 hour period, as well as over the entire time of investigation. Possible effects of pollution caused by the habitat were to be considered.

Collections made at night in front of the habitat lights permitted comparison of frequency distributions made at the regular collecting stations at about the same time. Considering the importance of zooplankton as being the main first-order consumers in the community, investigations of vagility and distribution are basic to considerations of the energetics of such a system.

A study concerned with the preference of various plankters for different wavelengths of light was intended to test the possibility of differential attraction of such organisms.

\section{EQUIPMENT}

The plankton net was designed to be operated by a swimmer. This limited the size of the mouth; a diameter of $35.7 \mathrm{~cm}$ was chosen to give a swept area of $0.1 \mathrm{~m}^{2}$. The bias caused by avoidance reactions was to be balanced against the bias inherent in the slow movements 
of a larger, more cumbersome net. The catching power of this net was

tested and found to be comparable to $40 \mathrm{~cm}$ nets available commercially. The netting was NYTAL - bolting cloth of 300 microns mesh size. At the cod end there was a ring of $5 \mathrm{~cm}$ inside diameter, into which exchangeable collectors could be fitted. The latter were perforated PVC-cylinders, sides and bottom being covered with $260 / \mathrm{u}$ bolting cloth to allow free passage of water. A lid held in place by guides capable of sliding into the cylinder allowed instantaneous closing of the collector and subsequent exchange without leaving the water.

For the light experiments two iodine quartz lamps, HYDRO-PRODUCTS Mode1 LQ-10, were used. Specifications: output 10,000 lumens, color temperature $3000^{\circ} \mathrm{K}$. The three types of filters used transmitted blue at $475 \mathrm{~m} \mu$, yellow from $550 \mathrm{~m} \mu$ upward and red from 650 myrpward. A11 three filters had a transmittance factor of $85 \%$.

\section{PROCEDURE}

Measured courses (Fig. 1) allowing for a $1 \mathrm{~m}^{3}$ sample were marked off at each of five collecting stations which are described as follows:

Station I - on the sand flat, $10 \mathrm{~m}$ from the foot of the reef and $50 \mathrm{~m}$ from the habitat, at a depth of $23 \mathrm{~m}$.

Station II - on top of the reef between coral growths, $30 \mathrm{~m}$ from the habitat, depth $14 \mathrm{~m}$.

Station III - along the unilluminated rear side of the habitat, $2 \mathrm{~m}$ above the bottom, $13 \mathrm{~m}$ deep.

Station IV - over the sandy bottom of a trench between two reef formations, $40 \mathrm{~m}$ from the habitat and at a depth of $15 \mathrm{~m}$.

Station V - at the end of the sewer line, about $100 \mathrm{~m}$ from the habitat, in the middle of a garden eel colony; sandy bottom, depth $25 \mathrm{~m}$.

These stations were visited at 0900,1300 , and 2200 hours, the first collection being carried out on the 16 th of October, two days after full moon, the last on the 27 th of october, three days before new moon. The samples were made with the lower rim of the net approximately six inches above the substrate. Station II was chosen to give clearance to the net between higher growths of coral and with only a few small crevices at the bottom. The samples were rinsed in fresh water and preserved in $4 \%$ formalin. In the case of the light experiments, 2-1iter samples were taken by means of a plexiglas syringe. Sixteen combinations of light (two lamps, three color filters and white light) were tested for half hour periods. 


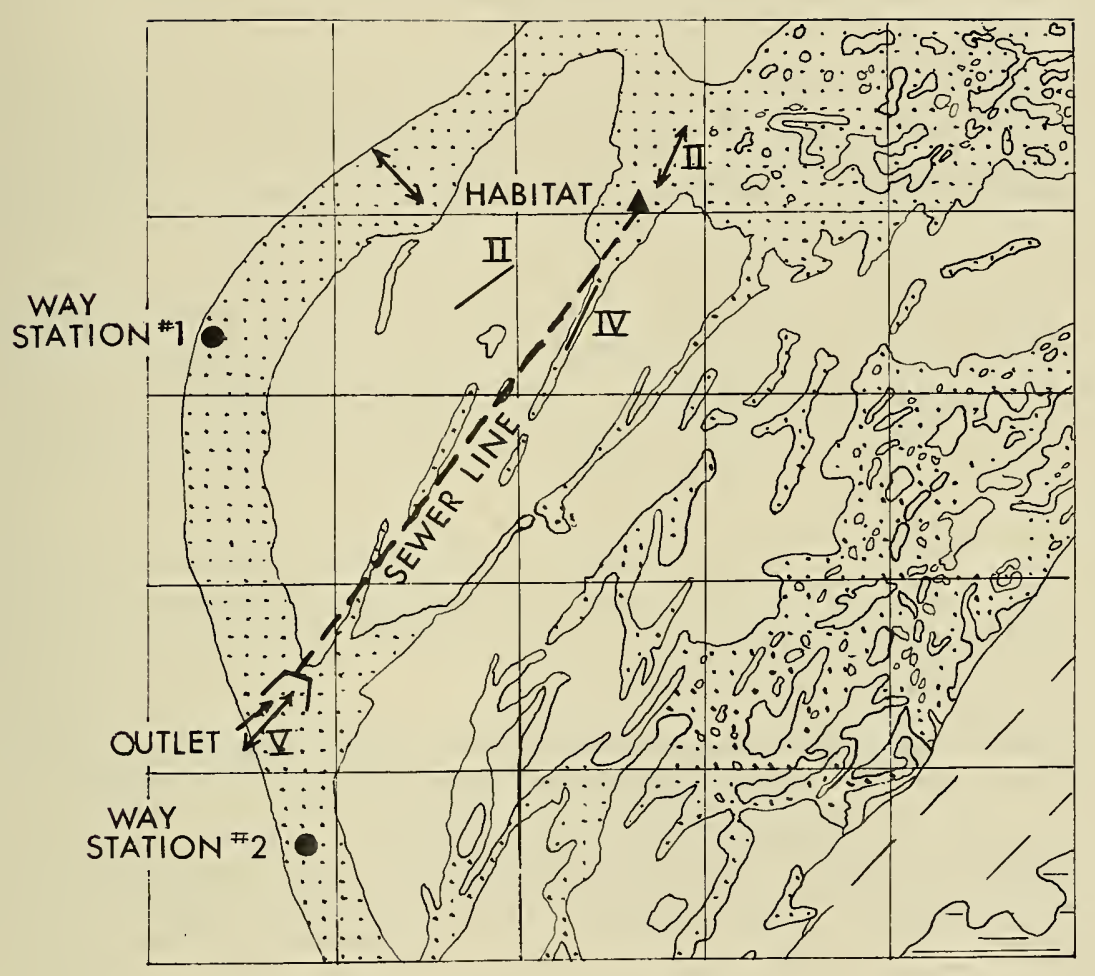

Figure 1. Measured courses allowing for a $1 \mathrm{~m}^{3}$ sample were marked off at the five collecting stations I, II, III, IV, and $V$ are shown on map. X marks position of TEKTITE II habitat. Scale: 1 square $=10,000 \mathrm{sq}$. ft. 
The specimens collected represented 45 different groups of animals, most of them identified to the family level. Table 1. gives the counts for the most common organisms.

Table 1. Total number of individuals collected per station and time of day over a ten-day period. Each figure represents the sum of ten $1 \mathrm{~m}^{3}$ samples.

\begin{tabular}{|l|rrrrr|rrrrrrrrrr|}
\hline TIME & I & I I & II I & IV & V & I & II & II I & IV & V & I & II & III & IV & V \\
\hline Calanoidea & 89 & 27 & 17 & 13 & 66 & 127 & 97 & 184 & 736 & 90 & 330 & 332 & 425 & 173 & 645 \\
Macrura & 0 & 1 & 0 & 1 & 3 & 0 & 2 & 0 & 4 & 0 & 79 & 29 & 74 & 19 & 11 \\
Chaetognatha & 0 & 0 & 1 & 0 & 0 & 0 & 0 & 0 & 0 & 0 & 54 & 70 & 30 & 107 & 110 \\
Mysidacea & 6 & 0 & 0 & 14 & 1 & 7 & 7 & 4 & 77 & 2 & 30 & 13 & 34 & 50 & 30 \\
Brachyuran zoea & 3 & 0 & 0 & 0 & 0 & 0 & 0 & 0 & 3 & 0 & 10 & 9 & 18 & 10 & 11 \\
Cladocera & 0 & 0 & 1 & 0 & 1 & 1 & 0 & 0 & 0 & 4 & 10 & 12 & 23 & 18 & 26 \\
Larvacea & 0 & 1 & 0 & 0 & 0 & 7 & 3 & 0 & 0 & 2 & 14 & 10 & 3 & 1 & 4 \\
Fish larvae & 0 & 0 & 0 & 0 & 0 & 0 & 0 & 0 & 0 & 0 & 34 & 6 & 4 & 7 & 3 \\
Thaliacea & 0 & 0 & 0 & 0 & 0 & 0 & 0 & 0 & 0 & 0 & 0 & 18 & 10 & 1 & 1 \\
\hline
\end{tabular}

The following observations were made:

Calanoid copepods formed throughout the most common component of the catches. They were apparently overrepresented on some occasions, when a school of Acartia spinosa or A. tonsa happened to be located at a collecting station. Such schools, ranging in size from ten thousands to hundred thousands of individuals generally appeared in sheltered places on the reef, behind sea fans and branching gorgonias, and on the deeper algal bed between stands of Sargassum. These schools seemed to stay together during the entire day. On the following day the same location was often vacant. While copepods could not be observed at night, the night catches are highly variable, thereby indicating uneven distribution.

Mysids were also frequently found to be schooling. The aggregations were usually between 10 and $50 \mathrm{~cm}$ in diameter and occurred invariably close to shelter, either near a cave, crevice, or near clusters of 
the sea urchin Diadema antillarum, retreating between the spines if approached.

Macrurans consisted mostly of penaeids, rough1y one third belonging to the genus Lucifer. Macrurans as well as chaetognaths, thaliaceans, brachyuran and anomuran zoea, and cyclopoid copepods were caught mostly during the first few days, possibly in relation to the lunar phases, as was true for bipinnaria larvae, which appeared only on the 16 and 17 , October at night, primarily at station III.

Polychaetes were relatively rare in the samples but were attracted in large numbers to hand lamps held near the sandy bottom. Phyllosoma larvae were collected only at the 1ights. Large specimens of over $20 \mathrm{~mm}$ length were observed at the beginning of the mission, but the samples taken later on contained only smaller specimens up to $7 \mathrm{~mm}$ in length.

Gnathiids were found mostly at night, but away from the lights, mainly at station IV. The isopods found at stations II and IV were nearly all Portunion, Epicaridea, which are parasitic on copepods. At night, there was invariably a much greater number of individuals present, also many more species were represented. The biomass collected ranged in the order of a few milligrams in the daytime to several hundred milligrams per cubic meter at night.

The following characteristics were noted in the distribution of planktonic animals in relation to the substrate:

Station I - Most of the ostracods, harpacticoids, larvaceans, fish larvae, many macrurans; few cyclopoid copepods; generally few species represented.

Station II - Some larvacea, thaliacea, brachyuran megalopa; generally many species but with a moderate to low frequency of occurrence.

Station III - Relatively many macrurans, brachyuran zoea, cyclopoids, bipinnaria larvae, but very few chaetognaths. The greatest species diversity was found at this station; the plankton contained the most open water forms.

Station IV - Mysids and chaetognaths very frequent; ostracods and cyclopoids relatively frequent. Macrurans were uncommon, as were calanoids except for a few cases of schooling.

Station V - Chaetognaths and thaliacea frequent; macrurans and fish larvae relatively rare. Calanoids frequent at night; the greatest number of organisms were taken at this station at night. The 
pollution effect of the sewer line seemed negligible, as its outflow was intermittent with prolonged intervening pauses and only a small effluent volume. The presence of the garden eels is presumed to have had a greater effect on plankton counts during the daytime.

At night, some organisms seemed to pass by in aggregates, among them cephalopod larvae, phyllosoma larvae, macrurans, calanoids, chaetognaths, and bipinnaria larvae.

The results of the light experiment are difficult to evaluate, since a number of factors introduced a probable bias of unknown magnitude. Among these were the construction of the habitat, which caused an outflow of air resulting in some turbulence near one of the lights. The periods allowable for each lighting arrangement were too short and need to be repeated under more leisurely circumstances. Natural fluctuations in plankton density almost certainly had an effect on the sampling. Nevertheless, certain preferences were apparent. In most instances, the blue light was favoured; this was the case with calanoid copepods, macrurans, polychaetes, hyperiids, and the various kinds of zoea. For all of these animals yellow was a strong second choice. Yellow light was definitely preferred by chaetognaths and mysids over other colors. Some groups, such as stomatopods, showed no clear preference. Red 1 ight was the least attractive throughout. More extensive studies of this kind are to be carried out from the underwater laboratory at Helgoland.

\section{CONCLUS IONS}

In the vicinity of the coral reef the bottom plankton shows definite distribution patterns in relation to substrate type. From the frequency distribution found in all samples it appears, that the bulk of the reef zooplankton is of local origin. It would be of interest, to carry out this type of collection over longer periods of time and with a simultaneous analysis of plankton in the upper strata, in order to obtain estimates of standing crop, local production and oceanic invasions of zooplankton. 
FAUNAL COMPOSITION AND BEHAVIOR OF A CORAL ISLET IN THE SAND-FLAT

Jean-Georges Harmelin

Station Marine d'Endoume

Marseille, France

\begin{abstract}
Sketching the life history of one of the small coral patches of the sand-flat was the purpose of this field study. Activity rhythms, trophic relationships, and social behavior of the various sessile and motile components of this community have been noted during the 24-hour cycle by visual and photographic recordings. The diversified fauna form an individualized "microcosm." Diurnal-nocturnal activity changeover proceeds according to a chronological order depending on specific critical light levels. Social behavior of some motile components is directed towards maintenance of the community's equilibrium. Most of the inhabitants' feeding patterns involve outer sources of food and the impact of the foreigners' foraging seems to be weak.
\end{abstract}

\title{
OBJECTIVE
}

Owing to a lack of knowledge of the West Indies marine fauna and of the working site, much of the planning of this research program was not defined accurately until the first days of the mission. Its main objective was to report the events happening during a 24-hour cycle in an animal community located in a small patch-reef of the sand-flat. To this end, I have tried to define the faunal stock, the trophic activities, the social behavior of some motile components and the interaction with surrounding biotopes. The degree of similarity existing between these small coral islands and artificial reefs is one of the major concerns in this study.

\section{PROCEDURES}

This work was based upon visual observations. The most important tools were, in addition to the breathing apparatus, plastic sheets for recording notes and stil1-cameras. The unobtrusiveness and the length of the observations were imperative, and the silence and lack of bubbles of the rebreathers were a great advantage. Observations were carried out during dawn, day, dusk, and night. Diurnal or crepuscular observations began at 6 to 7 meters from the islet in order to note without disturbing it the activity of the most perceptible motile fauna. After that, detailed observations were pursued at closer range. At night, observations were made using artificial illumination. These periods were kept short to avoid disturbing the organisms affected by 1 ight.

\section{RESULTS}

\section{$\underline{\text { Site }}$}

The small coral island chosen was lying on the sand-flat, SW of the habitat, at 50 meters from the main reef. Its proximity to "Way-Station" 3 allowed an easy 
locating, even during night dives. Its measurements were: length $120 \mathrm{~cm}$, width $80 \mathrm{~cm}$, height $60 \mathrm{~cm}$. Its main axis was $\mathrm{N}-\mathrm{S}$. The depth was 21 meters. This 1ittle block was formed by organic construction built principally by corals, bivalves, serpulid worms, and calcareous algae. Its relief offered to the motile fauna two kinds of shelter: large sized shelters, i.e., a large transferse crevice (E-W) with accessory chambers and a transverse tunne1 in the vicinity of the sediment; small sized shelters: very numerous, hollows in the rock or interstices in the epifauna buildings. Around the small patch reef, the bottom was coarse sand strewn with organic pebbles carrying sea-fans, sponges, large algae like Sargassum or Udotea. On this flat the coral blocks were regularly scattered every 10 meters.

\section{Partial Faunal Inventory}

In spite of the smallness of this coral block, the diversity of the sessile and motile organisms is great; they form a "microcosm" largely independent of the surrounding benthic biotopes. Faunal identifications were made from in situ drawings, photos, and by means of some small samples. In this limited inventory, symbolic letters mark the period of activity for most species and, for motile fauna, the range of action as these elements were noted during this field work (Table 1).

Table 1. Symbols keynoting period of activity and range of motile fauna

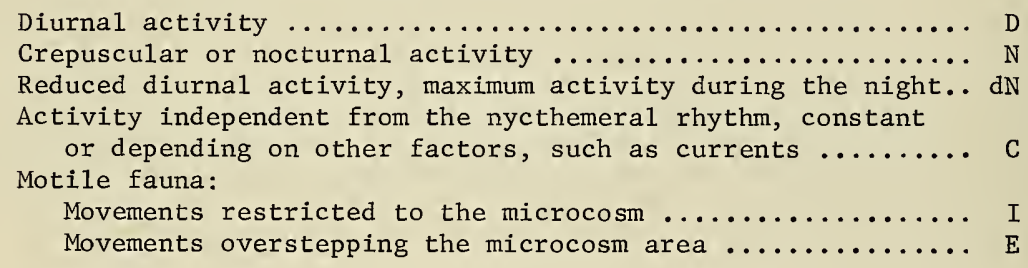

The flora of the block consisted of a covering of small algae, in Dyctyotales, and in four big Udotea at the top of the block.

Very close to the coral islet, within a radius of one meter, a diurnal sedentary fauna could be seen inhabiting the sediment. There was a mantis shrimp sp.2, in its burrow against the east side of the block; a family of six gobies (Gnatholepis thompsoni) inhabiting the pebbles emerging from the sand in the sourthern base of the islet; two jawfishes (Opisthognathus aurifrons) NW of the block, one of them incubating eggs in its mouth; and a sand tilefish (Malacanthus plumieri), its shelter beneath a pebble in the north end.

\section{Life History of the Microcosm}

NOON: The first thing perceptible to the eyes is the dance of the damsel-fishes (Pomacentrus) and of the Thalassoma above the block. The first have a very jumping, active swimming. They catch suspended particles or browse the surface of the rock. The small Thalassoma swim in clusters around the islet, swallowing 
planktonic microorganisms and following the largest individual which sometimes breaks away from the group and goes foraging on the neighboring sand. On the surface of the block, blennies grub among the algal covering, between the retracted corals. On the north side a black mantis-shrimp goes quickly from one nook to another, chattering its claws; it seems to be busy with nest building. Above it, brittle-stars can be seen, rather inactive in the fire-coral cluster. On the other hand, Serpulids Spirobranchus spread their double colorful branchial crowns. The crab Stenorhynchus sits up under a sma11 ledge near the second mantis-shrimp which digs its burrow. A sea anemone with dichotomic tentacles (sp. 2) and others with nodulous tentacles (sp. 1) are well spread out; small specimens of Periclimenes are visible among the tentacles of the latter. Sea-fans are also opened out. The squirrelfish (Holocentrus) often stands under the larger of them (Eunicea) or swims around the block. In the first days of observation, it often swam to the main crevice but owing to the rebreathers, these manifestations of fear turned quickly to indifference. The crevice is permanently occupied during daytime by the moray eel, which lives harmoniously with the squirrelfish. Near the block, the young tilefish is clearing its burrow. under a pebble, carrying small stones with its mouth; it sometimes stops its work to swim on the west side in search of food. At that time its swimming is very characteristic: it moves horizontally at $40 \mathrm{~cm}$ from the bottom and stops every $30 \mathrm{~cm}$ for a few seconds, staying head down with a $45^{\circ}$ angle, and then from time to time it dives down blowing water and digs the sand. It didn't seem to go father than 2-5 meters from its shelter. The two triggerfishes (Balistes) are absent.

NIGHT: At first sight, the microcosm seems to be asleep, but this is a misleading impression caused by the absence of the Pomacentrus and Thalassoma ballet. In fact, activity is intense. All the corals are spread out, particularly the Eusmilia which present huge polyps catching plankton attracted by the light beam. Ophiurids erect their arms from many nooks and Terebellidae worms spread their very long tentacles over the rock. Small Serpulids Hydroides with intricated tubes show the red clump of their branchiam crowns. Small sea anemones (sp. 3) are opened out on algae Udotea and on a big sponge. The ascidians and the sponges seem to be very turgescent. Crabs run on the base of the fire-coral. This place is the center of intense activity, small Periclimenes and Polychaetes climb on its branches, brittle-stars use this support to erect their netting arms. Serpulids Spirobranchus and Sabellids are opened out as during daytime. Three beautiful long-antennaed shrimp Stenopus stand before the opening of the main crevice. The red tentacles of a widely open Lima bivalve are seen in a hollow. The arrow crab (Stenorhynchus) is absent, but several are seen on the sand-flat. The main crevice is nearly entirely filled by two triggerfishes sleeping, their tail turzed towards the outside. The moray and the squirrelfish are absent. Some sleeping damselfishes can be seen in the small nooks; the Thalassoma, blennies and gobies, better sheltered, are not visible.

Dawn and dusk are the most exciting periods for studying the behavior of the microcosm fauna. A changeover from the diurnal fauna to the crepuscularnocturnal one, and conversely, happens during these periods in a rather short space of time, with a very precise, always identical scenario.

DUSK: 17:30. The whole diurnal fauna is still awake. The damselfishes and the Thalassoma are active above the block. The moray appears at the entrance of the crevice and shows much less timidity than during daytime. The 
squirrelfish swims around the block or stands in the crevice. The smaller triggerfish (B.1) arrives from the NW direction (algal-flats) and takes up a dark livery; it tries to enter the crevice but is chased by the squirre1fish.

17:35 The Lima are opened out, the Stenopus come out from their shelters. The tilefish disappears.

17:40 The damselfishes and Thalassoma activity begins to decrease, they swim low before their night shelters. Some quarrels happen between these two species in search of the best sleeping places. Blennies have disappeared but gobies are still present.

17:45 A very slight turgescence begins to appear on the corals, mainly on Eusmilia. The Thalassoma and Pomacentrus swim more and more peacefully. The jawfish is not often seen now and it does not come entirely out of its burrow. The large sea-fan (Eunicea) begins to retract. This fact was regularly noticed at dusk whereas at night it was found open; we noted that during these night dives there was always a rather strong current perpendicular to the sea-fan.

17:50 Damselfishes are still swimming weakly very near the surface of the block; Thalassoma have disappeared by now; the triggerfish B.1 enters the crevice and invites the moray to go out, this one leaves the place and gets to the $\mathrm{N}$ tunnel. The squirrelfish starts to forage on the neighboring sand. Nodulous tentacled sea-anemones are still visible but the one with dichotomic tentacles has disappeared in a nook.

17:55 to 18:00 Observations without artificial light become difficult. The second triggerfish (B.2) arrives from NW. The first one comes quickly to the east entrance of the crevice while B.2 comes to the $W$ entrance. Staccatos and very fast tail rustlings are emitted by B.1. They keep on leaving the crevice and returning to it and when they are inside, B. 1 always takes on an intimidating behavior. B.1 has always been seen at the $E$ entrance and $B .2$ at the $W$ one. The squirrelfish is more and more active, it gets away and returns; some other Holocentrus pass near, the food quest has started for this species. The corals begin to open out.

19:00 Corals are now very turgescent. Sea-anemones sp. 1 and sp.2 are retracted, the specimens of sp.4 are opened. The shrimps Periclimenes have left the actinia sp.1 and are found on the block. The triggerfishes are sleeping; the moray is still in its second shelter, but its reactions are much livelier than during day-time. The squirrelfish is still here. It is pitch dark by now.

DAWN: 6:00 There is very little light, much as at 18:00. The two triggerfishes stand outside the block, near their night shelters. The moray has gone back to the main crevice. The squirrelfish swims actively around the islet. The damselfishes wake up but don't go far from their night shelters. The Thalassoma are still invisible, as are the blennies, the jawfish and the tilefish. Some gobies stand near their hollows. The corals are still a little opened, especially the Eusmilia. Stenopus are visible on $1 \mathrm{y}$ by their antennae, the Terebellids have retracted their tentacles. 
$6: 10$ The livery of the triggerfish B.2 is getting clearer, repeatedly a white spot develops, then fades out. B.I remains dark and stays near its night shelter; sometimes it tries to enter it, but the place is occupied by the moray. B.2 becomes active but without going off the block, it forages something on the sand or on a big spheric sponge. The Thalassoma start to awake, the first to be seen is the larger of the family. Damse1fishes have a more active, jerky and higher swimming.

$6: 20$ B.2 is getting again clearer for a moment; it swims in an excited manner, close by the block. B.1 stays in dark livery before its hollow or comes up to the block and eats something on it. These two fishes seem to wait for a signal.

$6: 25$ The jawfishes and the tilefish wake up, the last one cleans its burrow. The triggerfish B.2 does a succession of false starts during which it goes further and further away and becomes clearer and clearer. Getting brighter too, B.1 also begins to stand away from the microcosm.

$6: 40$ At 1ast this couple of fishes depart together towards the NW algal flats. As for bed time, the triggerfishes' rising is being enacted according to a very precise ceremonial. More generally, the start and the fall of the activity of most species seem to be induced by definite and specific light levels; and so the species that retire earliest are also the last to awaken.

\section{Social Organization and Trophic Inter-relations}

According to these fragmental observations, the microcosm appears as an example of a balanced animal society; the arrangement and the social organization of which maintain this equilibrium. This balance is seen in the fact that all available places are occupied at all times and that no inhabitant remains without a shelter; and also in a harmonious correspondance between the production and the consumption of food.

\section{Norma1 saturation of available places}

A11 the places are occupied. The occupation relay of the main crevice between the moray + the squirrelfish during daytime and the triggerfishes at night is a good example. The most active motile species (fishes) are involved in action against the peril of a supernumerary occupation by foreigners. So, for instance, at the end of a morning, a $20 \mathrm{~cm} \mathrm{small}$ triggerfish is repulsed by the biggest damselfish which bites it and drives it out of the microcosm boundaries. Another day, at dusk, the same (?) small triggerfish is driven away by the squirrelfish and the triggerfish B.1. This is an interesting social behavior: the microcosm inhabitants, as Holocentrus and Pomacentrus, that would not be directly penalized by an additional occupant participate actively in its elimination.

\section{Productivity-consumption balance}

In order that the community composition remains steady, the feeding of the inhabitants and of the foreigners must equilibrate the microcosm productivity. All the trophic levels are present in the community. According to 
the food origin, there are outside and inside consumers. Outside consumers feed on the water mass organisms or particles (sea-fans, corals, ophiurids, ascidians, young Thalassoma ... etc.) or on the benthic fauna of the neighborhood (Holocentrus, Balistes, moray). Inside consumers feed on the microcosm. They are algae browsers or omnivores (damselfishes, blennies), microcarnivores (po1ychaetes, crabs), detritivores (polychaetes). So the greatest consumers are the outside ones. The effect of the foraging foreigners seems to be $1 \mathrm{im}-$ ited. Only two Serranus tabaricus, one Canthigaster and a young parrotfish have been sporadically seen. This danger seems to be checked by the microcosm inhabitants; for instance, a parrotfish which wanted to browse on the block was pushed away by the squirrelfish.

A summary of the observed activity patterns of behavior observed is shown in Tables 2, 3, and 4 .

Table 2. Activity pattern of sessile fauna found in the study area.

Species

Sponges

4 different species

Cora1s

Montastrea annularis

Eusmilia fastigiata

Montastrea cavernosa

Meandrina meandrites

Porites astreoides

Sidastrea radians

Astrangidae

$\underline{\text { Sea-Fans }}$

Pseudopterogorgia americana

Eunicea calyculata

\section{$\underline{\text { Ascidians }}$}

A pedunculate species

sp. 1

sp. 2 and sp. 3 - Didemnids
Activity

Pattern

Comments
The last two are in crevices of the block, the others on the sides or on the top of it.
A $35 \mathrm{~cm}$ high speciment at the top of the block.

A large specimen, $90 \mathrm{~cm}$ high, growing obliquely on the lowest part of the west side. 
Table 3. Activity of weakly motile fauna found in the study area.

\section{Species}

Hydroids

$\underline{\text { Pennaria }}$ sp.

Millepora alcicornis

(dN?)

$(\mathrm{dN} ?)$

$(\mathrm{dN}$ or $\mathrm{C})$

Lima scabra tenera

Chama sp.

(N)

Two in a nook of a large crevice.

Several specimens hardly visible.

\section{Polychaetes}

Serpulids

Spirobranchus giganteus

(C)

Hydroides parva

(N)

Savellids

Terebellids

8 to 9 specimens growing on the fire-coral (Millepora) or immersed in corals.

Their intricate tubes build a small ledge on the east side.

3 specimens of an unidentified species.

Several specimens spread their white tentacles from hollows of the south side. 
Table 4. Activity of motile fauna that really belonged to the microcosm studied

\section{Species}

Mo11usks

Cyphoma sp.

Polychaetes

Eunicidae

Crustaceans

Stenopus sp.

Periclimenes Periclimenes sp.

$(\mathrm{dN}-1)$

Mantis-shrimp sp. 1

Stenorhynchus setiformis

Crabs sp. 1

\section{$\underline{\text { Echinoderms }}$}

Ophiurids

Fishes

Gymnothorax moringa

Holocentrus ascensionis

Pomacentrus partitus

Blenniidae

Thalassoma bifasciatum

Quisquilius hipolitii
Activity

Pattern

Comments
$(\mathrm{dN}-\mathrm{I})$

$(\mathrm{dN}-\mathrm{E})$

One individual sporadically seen on the sea-fan Eunicea.

Several specimens hidden in nooks during daytime.

3 specimens of this beautiful shrimp.

These sma11 blue-spotted shrimp live in the sea-anemone sp.1 during the day and on the block at night.

A black specimen with white claws living in a nook at the top of the block.

One under north end of block.

Several specimens visible on the block at night.

Severa1 specimens in the nooks or in the fire-coral.

(dN-E) One of about $12 \mathrm{~cm}$.

(D-I) 5 young ones (1 to $2 \mathrm{~cm}$ ), one 1arger $(8 \mathrm{~cm})$.

(D-I) $\quad 3(3-4 \mathrm{~cm})$ on the top of block.

(D-I) 5 in a group, measuring $2 \mathrm{~cm}$, and one $4 \mathrm{~cm}$ long; they are at the yellow phase.

(D-I) A small specimen $1.5 \mathrm{~cm}$ long in a nook of the south side. 
1. The microcosm forms a well defined community with diurnal and nocturnal components; its fauna is much diversified and well balanced at most of the trophic levels.

2. The relay of the activity at dusk and dawn happens in a rather short time and always according to the same chronological order, depending on the light sensitiveness of the species.

3. Inhabitants biovolume can be higher than the shelters volume during the dusk-dawn relay system.

4. Social behavior of some inhabitants is directed towards maintenance of the community stability by checking foreigners wanting to occupy a place or to forage on the microcosm.

5. The microcosm might be considered as a dwelling place of consumers that feed on surrounding plankton and benthos rather than as a foraging place for foreigners. 
IN-SITU MEASUREMENT OF THE METABOLIC ACTIVITY OF TROPICAL BENTHIC COMMUNITIES

\author{
Merrill True \\ Bio-Oceanic Research Inc.
}

No Report Received 
TECHNICAL ASPECTS OF DOME-CORRECTOR-PORTS

AND FLAT-PORT OPTICS IN UNDERWATER PHOTOGRAPHY

\author{
Flip Schulke \\ Black Star \\ 450 Park Ave. So., New York, N.Y. \\ Frank Pugliese \\ General Electric Co. \\ Philadelphia, $\mathrm{Pa}$. \\ Robert Farrelly \\ Underwater Explorers Club \\ Freeport, Grand Bahama
}

\begin{abstract}
By testing both underwater cameras and housings, fitted out with flat-port and dome-corrector-port "windows," on a direct lens, distance, F-stop, test pattern test, we found dome-correctorports did increase edge sharpness, and corrected refraction magnification. We documented the slight differences between domes of $3,5,6$, and 8 inches. The 8 -inch dome gave the best test results, though differences between the various smaller domes versus the 8 -inch dome were not significant.
\end{abstract}

\title{
OBJECTIVES
}

Because of time constraints and lack of constant water clarity, some of our original objectives were not accomplished in the 6 days of our mission.

We had planned on the underwater testing of various commercial brands of color films, on the same color-test pattern, for color rendition and color saturation. We also had planned on testing various underwater flash and strobe 1 ights for color balance.

We began testing in al1 these areas but saw that the limited time within the habitat would not permit us to make equal comparison tests in all these aspects of UW photography. In addition, the water clarity varied during our mission. We decided to concentrate on the last objective, that being the on-site, empirical testing of various lens, cameras, and housing combinations. Our primary interest was in getting photographic test pattern evidence, in black and white, to confirm or deny conflicting optical theories of spherical-ports versus flatports as correcting lenses.

One of the major problems in underwater photography has been the cost of the equipment needed to do the job. It was our objective to compare inexpensive lens corrector systems, represented by the spherical, hemispherical or what is common1y known as "dome-port" correctors. Our hypothesis, reinforced by our regular UW photography, was that for practical purposes, these "dome-correctors" would give results which would enable photographers to overcome the inherent problems of the plane or flat-port. 
Optical problems in underwater photography are primarily due to the fact that in most cases the cameras used are designed for operation in air. To operate under water, the air-camera must be housed in a water-tight container. There obviously must be a "window" or port in front of the lens. This port, in most cases, is a flat piece of glass or plexiglass. Herein is the optical problem. Due to the laws of refraction, light passing through a flat or plane "window" makes objects look closer than they actually are. This apparent object appears $1 / 4$ th closer than the real object being photographed. "The field of view of the camera will be reduced by approximately $1 / 1.33$ as a result of refraction at the port. This means that a wide-angle lens will be converted to a normal lens and a normal lens will be converted to a mild telephoto lens by the magnifying characteristics of the port. In-water applications almost always require the widest fields of view, and this reduction can be quite detrimental."* It is necessary to get close to the subject being photographed underwater for two major reasons: 1) Any sediment, or other matter in suspension, causes a lack of sharpness of the image in the resulting photograph. 2) The more water between the camera and the subject, the more degraded will be the saturation of the color of the object being photographed due to the water acting as a blue filter. Therefore it is of prime importance that an UW photographer be able to utilize his wide-angle lenses at their full focal length. Besides the magnifying effect, the flat-port causes other aberrations that degrade the image, one of the most important being chromatic abberation, especially bothersome to the UW color photographer.

Flat-ports also cause serious "pin cushion" distortion of straight lines with wide-angle lenses. The flat-port also has serious out-of-focus areas at the outer edges of the image. For a complete scientific discussion of the physicaloptical aspects of underwater photography, see G. T. McNeil in Optical Fundamentals of Underwater Photography, Photogrammetry, Inc., Rockville, Md. (1968). It is not our objective to set forward here the scientific aspects of UW optics. Our approach has been entirely empirical.

\section{The Dome-Corrector}

Various solutions or partial solutions to some of the aberrations of underwater optics have been effected by the Ivanoff-Rebikoff correcting lens. This system comprises a reversed Galilean telescope in which the front concave lens is used for the watertight window. The UW Nikkor $28 \mathrm{~mm}$ lens (which we included in our test) and the UW lenses designed by E. Leitz of Canada, known as Elcan lenses, are examples of such solutions. These systems are quite costly, and since the dome-corrector is quite inexpensive, we felt that what was needed were practical tests of the dome-corrector system versus the flat-port system on a direct lensby-lens comparison basis, photographing an underwater test pattern, so that edge sharpness and other linear distortions could be compared. We also planned on the testing of various diameter spherical dome-ports to learn how they changed camera-lens focus as opposed to real UW camera subject focus distance. We had learned by trial and error methods that there were distinct and drastic differences. In other words, we found that when using dome-ports, magnification was almost entirely absent. When, for example, an UW subject was 10 feet

* Mertens, Lawrence E., "In-Water Photography," John Wiley and Sons, New York, p. 146 . 
from the camera, the proper focus for the lens-plus-dome was in the close-up ranges, such as perhaps $1 \mathrm{ft} .2$ inches. What we needed to know was the relationship between the various diameter domes and changed focus distances.

\section{EQUIPMENT}

The following cameras were tested:

\section{Cameras Tested}

1. Kodak Instamatic Model 174 camera, in a Sea Research and Development Co. plexiglass housing, with a flat-port.

2. Kodak Instamatic Model X-45 camera, in an Ikelite cast-Lexan housing, with a flat-plexiglass port.

3. Ricoh Hi-Color 35m camera, in the Ricoh Marine Capsule, plastic housing, with a flat-glass port.

4. Nikon model "F" $35 \mathrm{~mm}$ camera, in a Schulke plexiglass housing, with a dome-port, 6 inches diameter (Danforth-White compass cover).

5. Nikon mode1 "F" $35 \mathrm{~mm}$ camera, in a Sea-Glove cast-Lexan housing, with a dome-port, 5 inches diameter. (Danforth-White)

5B. Nikon mode1 "F" $35 \mathrm{~mm}$ camera, in a Sea-Glove cast-Lexan housing, with a flat plexiglass port.

6. Nikonos $35 \mathrm{~mm}$ Underwater camera, with $35 \mathrm{~mm}$ Nikkor Lens, and UW corrected $28 \mathrm{~mm}$ Nikkor 1ens. $21 \mathrm{~mm}$ lens with a 3 inch dome-port.

7. Nikon model "F" $35 \mathrm{~mm}$ camera, in an Ocean-Eye housing, with a dome-port, 8 inches diameter. (Dome supplied by Ocean Eye.)

8. Nikon mode1 "F" $35 \mathrm{~mm}$ camera, in a Nikko-Mar II housing, with a dome-port, 8 inches diameter, (Danforth White). This dome had been attached to housing by Flip Schulke.

\section{Lenses for Nikon - "F"}

1. $20 \mathrm{~mm}$ Nikkor, F 3.5

2. $24 \mathrm{~mm}$ Nikkor, F 2.8

3. $28 \mathrm{~mm}$ Nikkor, F 3.5

4. $35 \mathrm{~mm}$ Nikkor, $\mathrm{F} 2$

5. $50 \mathrm{~mm}$ Nikkor, $\mathrm{F} 2$

\section{Dome-Ports Tested}

1. 3 inch Hemisphere dome-port. (Replacement compass cover, Ritchie Pilot compass -Plexiglass.)

2. 5 inch Hemisphere dome-port. (Replacement compass cover, Danforth-White compass-P1exiglass.) 
3. 6 inch Hemisphere dome-port. (Replacement compass cover, Danforth-White compass -Plexiglass.)

4. 8 inch Hemisphere dome-port. (Replacement compass cover, Danforth-White compass-Plexiglass.)

5. 8 inch Hemisphere dome-port. (Supplied as standard port, for Ocean-Eye Housing, Plexiglass, Photogrammetry, Inc.)

\section{Lighting}

1. Sub Sea UW strobe light.

2. Housing for Honeywe11 strobe light, by Idelite, Plexiglass.

3. Ikelite Movie 1ight.

4. 1000 Watt underwater flood lights, with glass dome covers, by Birns and Sawyer.

\section{Miscellaneous}

1. Underwater Test Pattern, of red-white-blue geometrical patterns, mounted flush on a $4 \mathrm{ft}$. by $8 \mathrm{ft}$. $1 / 4$ inch Marine Plywood.

\section{$\underline{\text { Films }}$}

1. For black and white test pattern tests with a11 cameras and lenses, Kodak Panatomic $X 35 \mathrm{~mm}$ film.

2. For random tests of cameras and lens and lights (testing not completed) Kodak Ektachrome-X color film.

\section{PROCEDURES}

We placed the 4/8 test pattern, which was mounted on a steel frame, in an upright position. It was then possible to mount the cameras to be tested equidistant from the center of the test pattern.

We decided on a distance of 2 feet from the center of the test pattern for the lens and corrective port tests so that we would fill the frame with the test pattern to the corners of the photograph.

Since the test was done in black and white, it was found that artificial light was of no use; therefore exposures for $35 \mathrm{~mm}$ cameras were made with an UW light meter (Seconic). The Panatomic film was rated at ASA 32.

Number tags on the test pattern were used to identify camera housings and lenses. 
1. Kodak Model 174: This camera has automatic exposure control, and is set for sharp lens focus at approximately 7 feet in air. The housing used had a flat Plexiglass port. The camera was tested at 1 ft., $1 \frac{1}{2} \mathrm{ft} ., 2 \mathrm{ft} ., 2 \frac{1}{2} \mathrm{ft} ., 3 \mathrm{ft} ., 3 \frac{1}{2} \mathrm{ft}$., $4 \mathrm{ft}$, and $5 \mathrm{ft}$. A Plus-one Diopter closeup lens was also tested, in water, at the same footage distances.

2. Kodak Mode1 X-45: This camera has automatic exposure control; it also has a closeup setting of 2 to $6 \mathrm{ft}$. All the tests were made at this closeup setting. The housing used had a flat port. The camera was tested at distances of $1 \mathrm{ft}$., $1 \frac{1}{2} \mathrm{ft} ., 2 \mathrm{ft.}, 2 \frac{1}{2} \mathrm{ft} ., 3 \frac{1}{2} \mathrm{ft} ., 4 \mathrm{ft} .$, and $5 \mathrm{ft}$. A Plusone Diopter closeup lens, in the water, was also tested at the same footage.

3. Ricoh Hi-Color This camera has automatic exposure control. It also has 35mm camera: a focus setting of $3 \mathrm{ft}$. The tests were made at this setting. The housing used had a flat port of glass. The camera was tested at distances of $1 \mathrm{ft} ., 1 \frac{1}{2} \mathrm{ft}$. , $2 \mathrm{ft} ., 2 \frac{1}{2} \mathrm{ft} ., 3 \mathrm{ft} ., 3 \frac{1}{2} \mathrm{ft} ., 4 \mathrm{ft}$, , and $5 \mathrm{ft}$. A Plusone Diopter closeup lens was also tested in water.

4. Nikon "F" 6 inch dome:

5. Nikon "F" 5 inch dome:

5B Nikon "F" flat port:

6. Nikonos:

7. Nikon "F" 8 inch dome:

8. Nikon "F" 8 inch dome:
Tested at $F$ 5.6, 8, and 11 using a Plus-3 Diopter lens in all tests at $2 \mathrm{ft}$. using $20 \mathrm{~mm}, 24 \mathrm{~mm}, 35 \mathrm{~mm}$, and $50 \mathrm{~mm}$ lenses.

Same procedure as camera 非 with a Plus-3 Diopter closeup lens in all tests.

Same procedure as camera 非 (no closeup lens used)

Tested with $35 \mathrm{~mm}$ lens, at 2 ft. using F 5.6, 8, and 11 . Tested with $28 \mathrm{~mm}$ UW corrected lens at $2 \mathrm{ft}$. using $\mathrm{F} \mathrm{5.6}$, 8 , and 11. Both lenses were focused at $2 \mathrm{ft}$. on the lens-focus-scale, $21 \mathrm{~mm}$ lens, with 3 -inch dome port, and $5 \frac{1}{2}-$ Plus Diopter closeup lens.

Tested at $5,6,8,11$, with the following lenses: $20 \mathrm{~mm}$, $24 \mathrm{~mm}$, 35mm; camera set at $2 \mathrm{ft}$. distance.

Tested at $5.6,8,11$. With the $20 \mathrm{~mm}$ lens on1y. Camera set at $2 \mathrm{ft}$.

\section{RESULTS}

Figures 1-10 show the resulting photographs taken with the various cameras, lenses, housings, F-stops, and distances. These test patterns are only representative samples and are included for purposes of general comparison. The original prints must be seen to fully appreciate the real qualitative differences. They can be obtained on request from the author. 


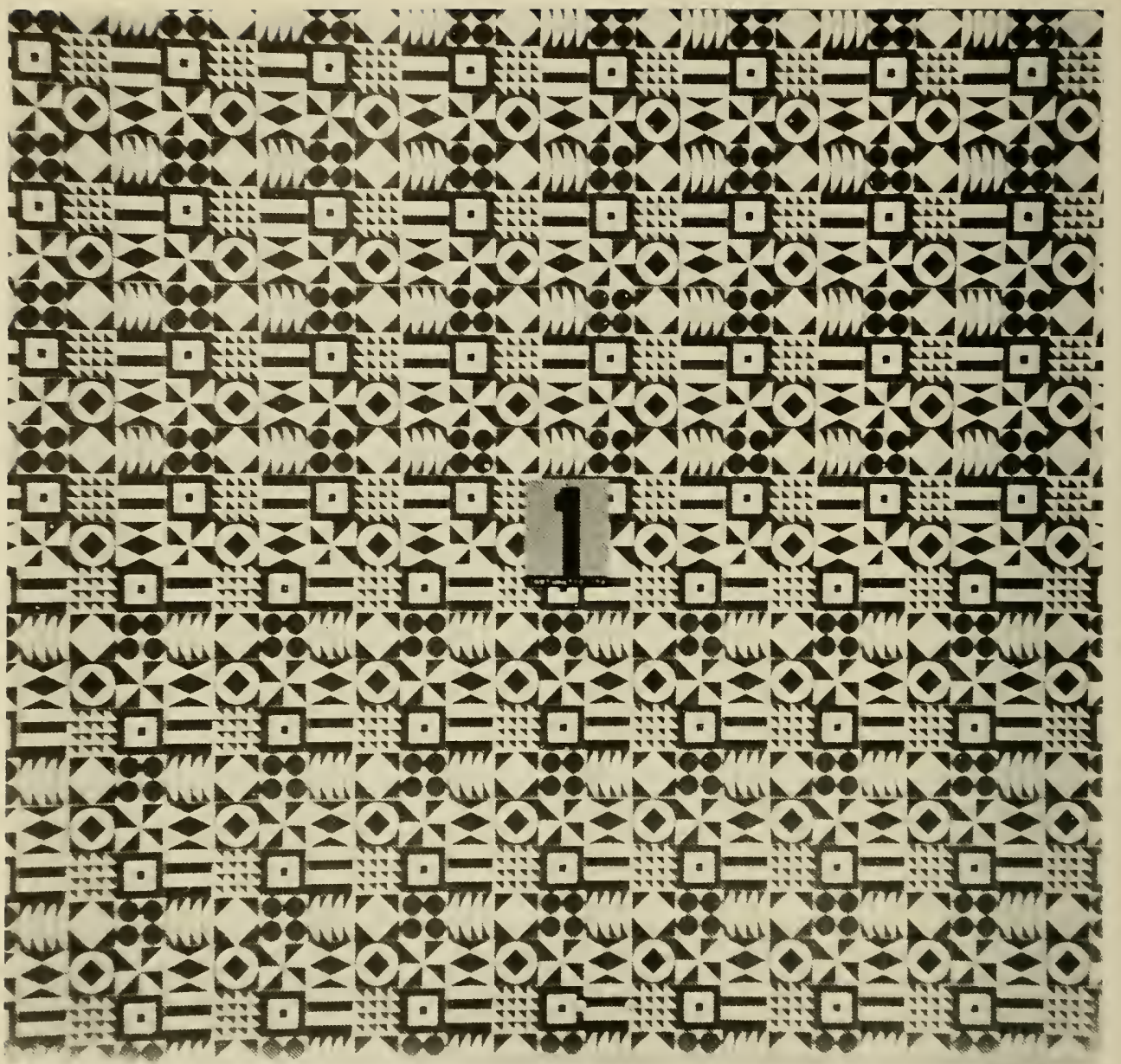

Figure 1

Camera 非, Print 1-1

5 feet from test pattern

Acceptable Sharpness 


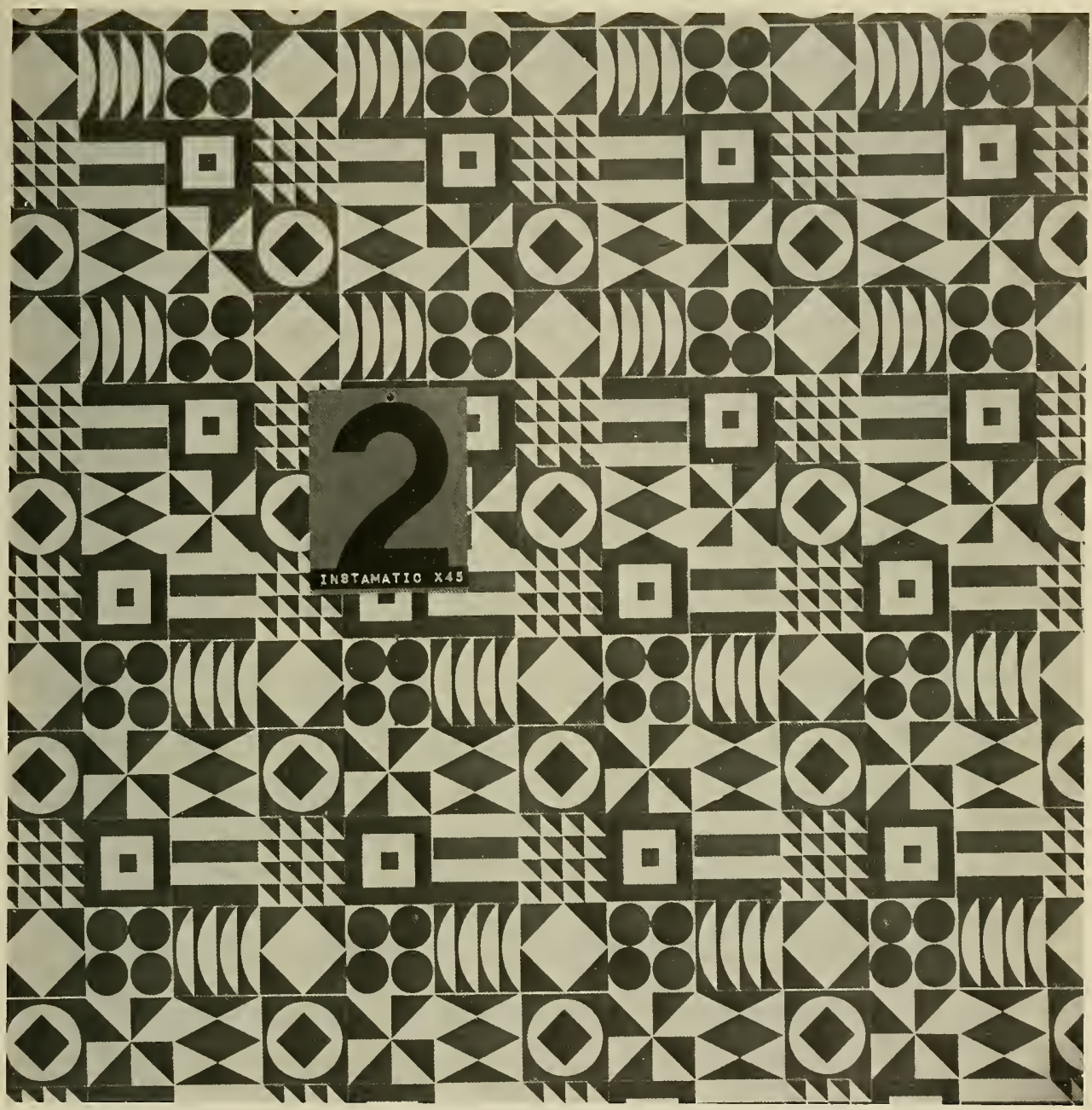

Figure 2

Camera 非, Print 2-1

3 feet from test pattern

Very sharp to edges

Lines quite straight

VI -301 


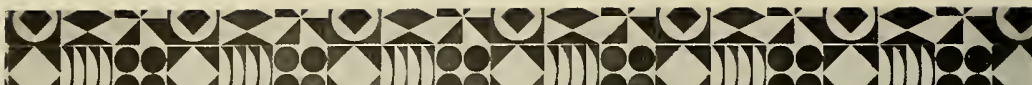

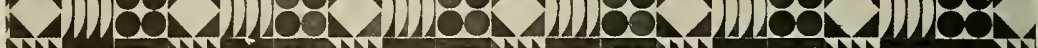

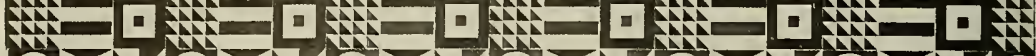

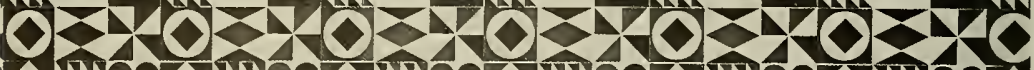

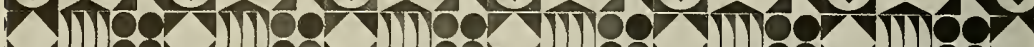

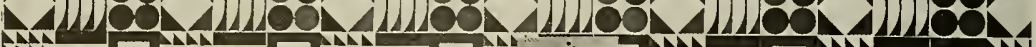

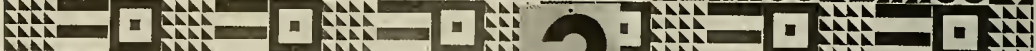

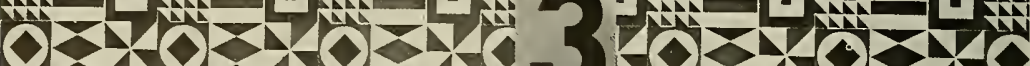

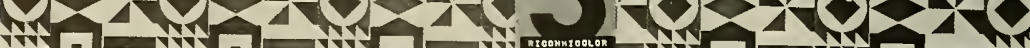

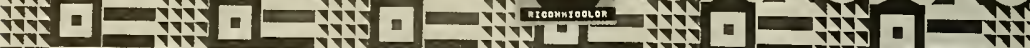

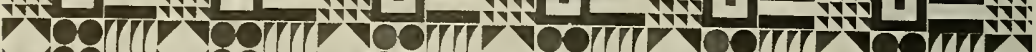

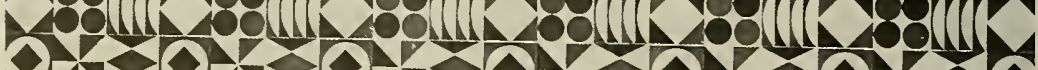

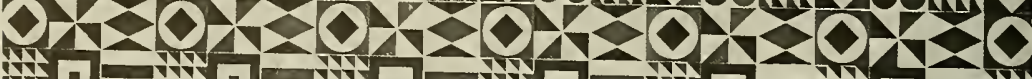

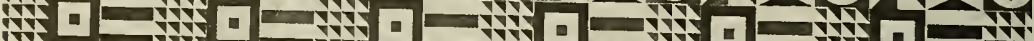

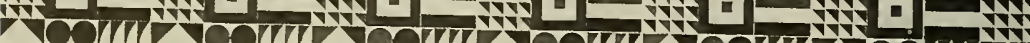

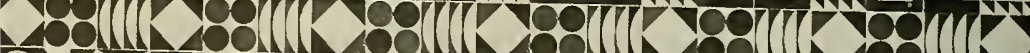

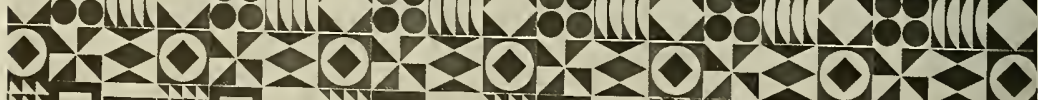

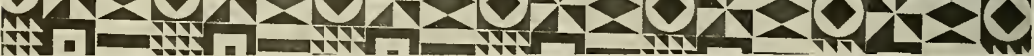

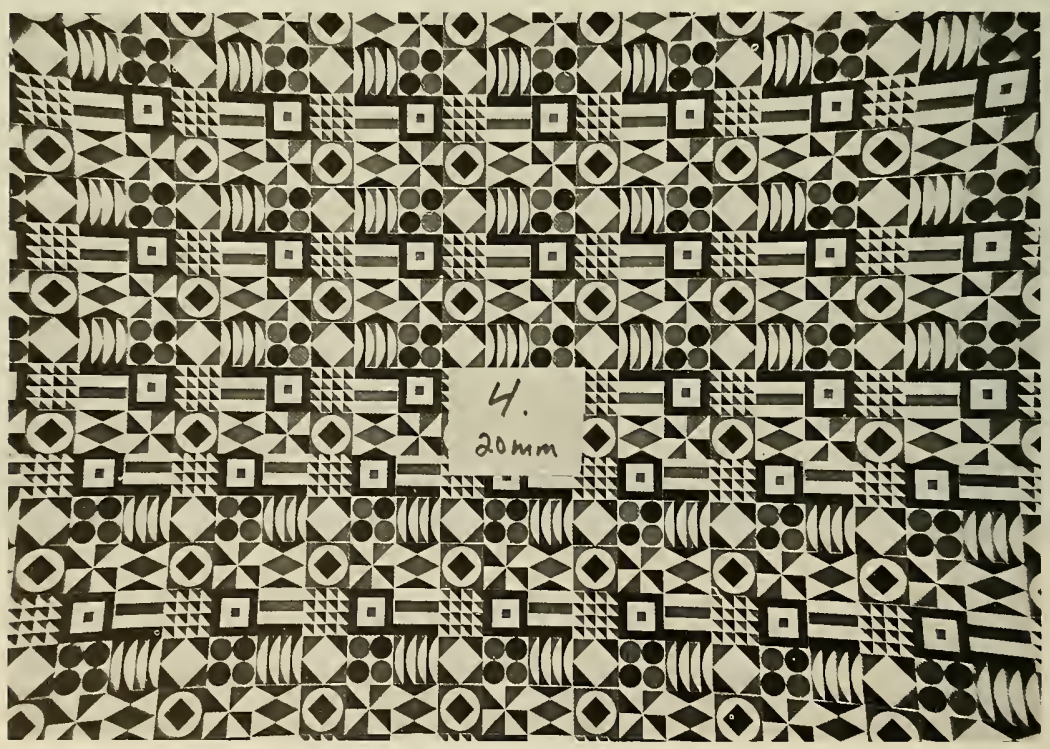

Figure 3 (Upper)

Camera 非3, Print 3-1

4 feet from test pattern Sharp edges, sharp center Very slight pincushioning
Figure 4 (Lower)

Camera 非, Print 4-1 (20mm)

2 feet from test pattern

Very sharp center

Slightly blurred edges Medium pincushioning 


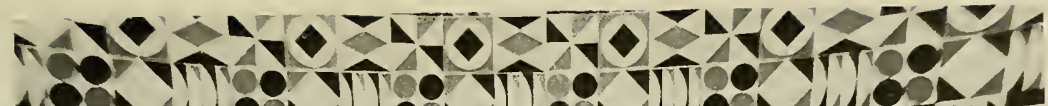

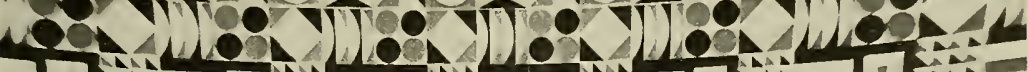

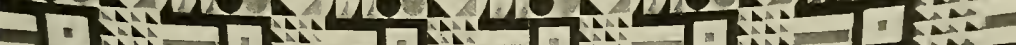

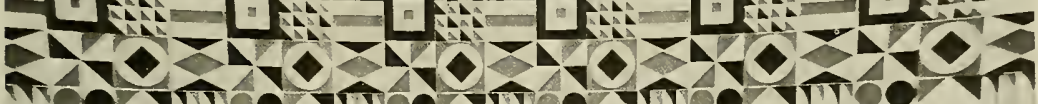
To

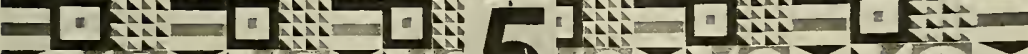

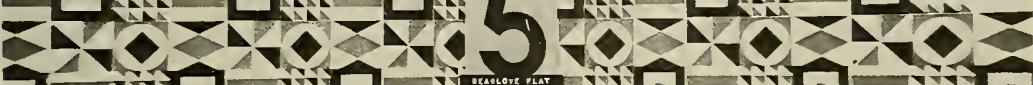
a

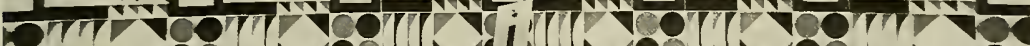

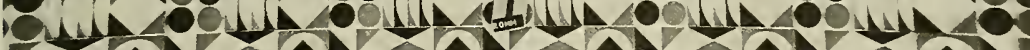

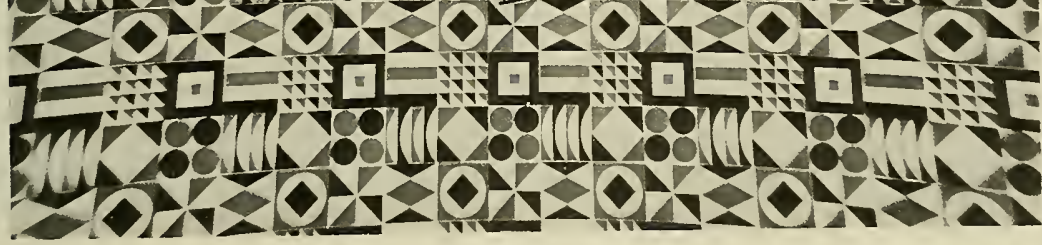
(1)

Figure 5 (Upper)

Camera 非5-B, Print 5-B-1

2 feet from test pattern Sharp centers, going blurred to edges very quickly Much pincushioning Refraction magnification $1 / 4$ th
Figure 6 (Lower)

Camera 非 (with plus 3)

Print 5-1 (20 $\mathrm{mm})$

Sharp center, falling off very gradually, to slightly blurred edges Pincushioning 

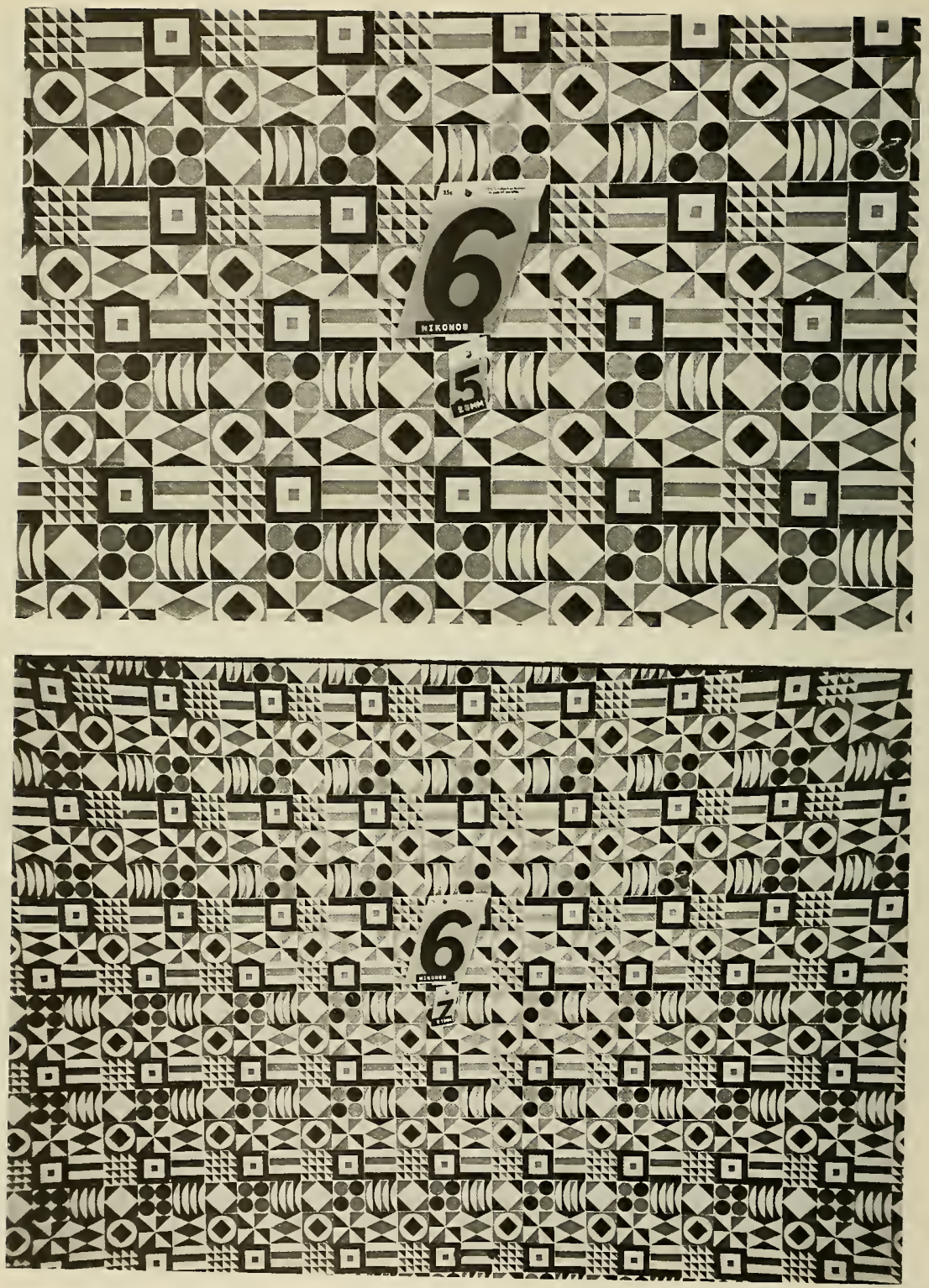

Figure 7 (Upper)

Camera 非6, Print 6-2 (28mm)

Sharp edge to edge

Sharp center straight lines

Refraction magnification $1 / 4$ th
Figure 8 (Lower)

Camera 非, Print 6-3 (21mm) Sharp center falling off only slightly on edges Medium pincushioning 


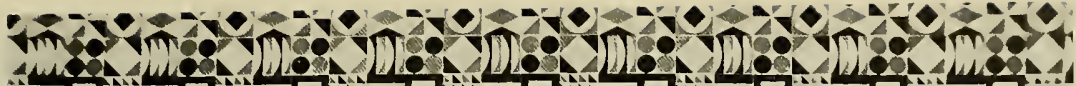

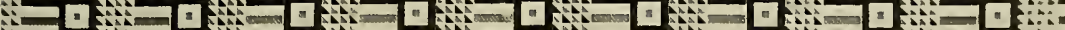

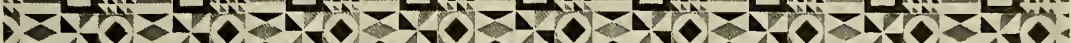

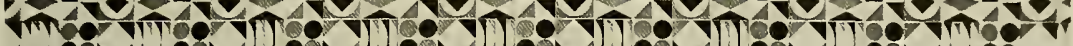

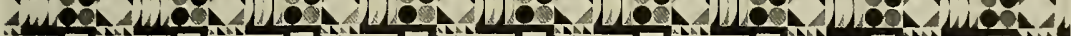

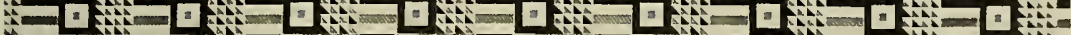

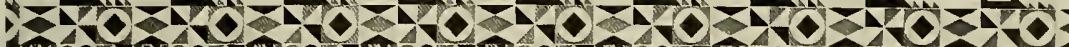

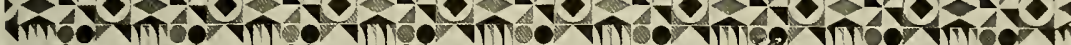

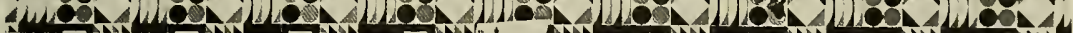

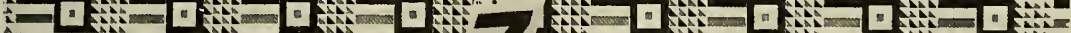

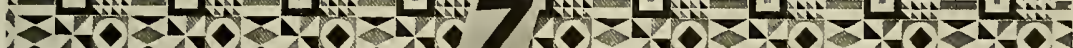

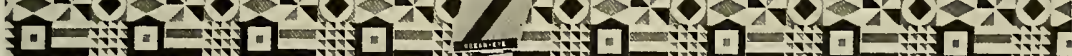

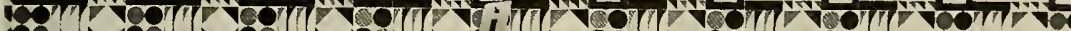

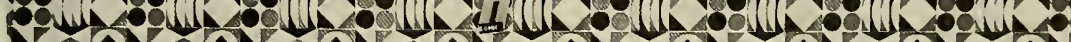

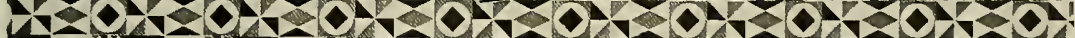

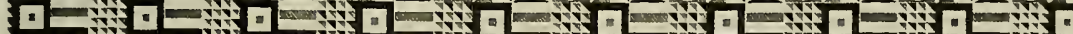

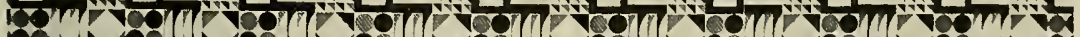

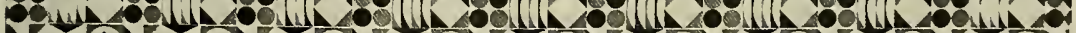

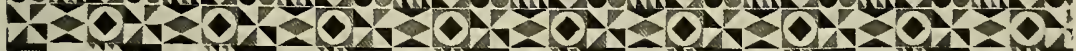

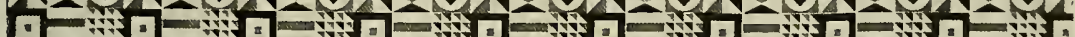

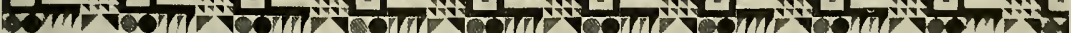

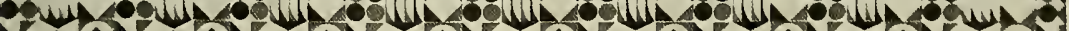

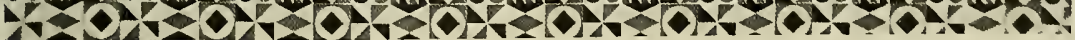

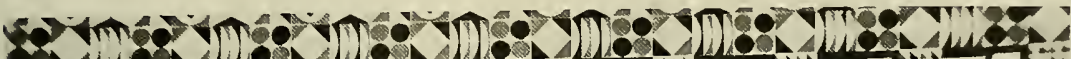

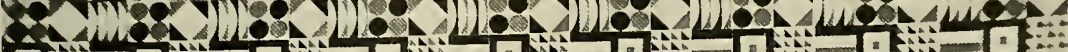
6. In

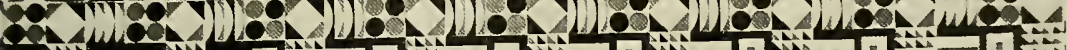

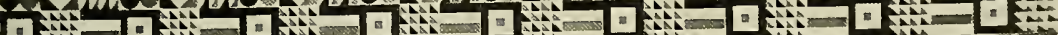
L

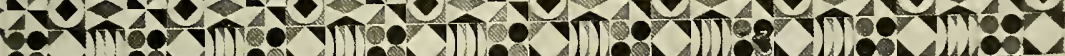

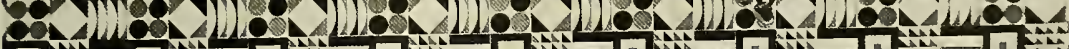

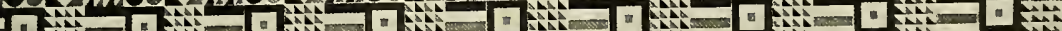

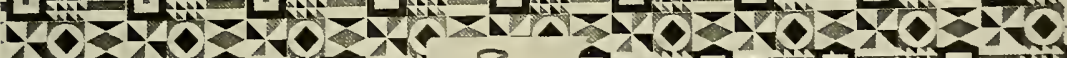

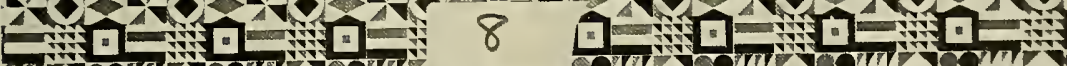
mirit

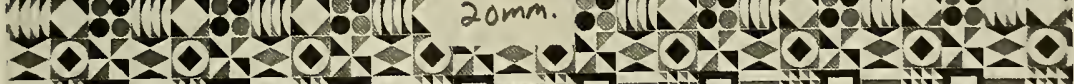
miric

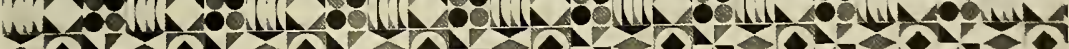

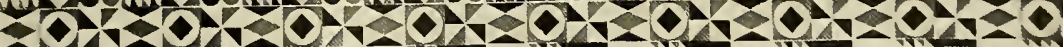

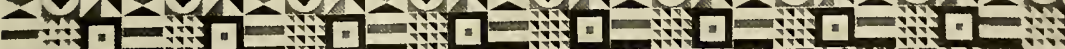

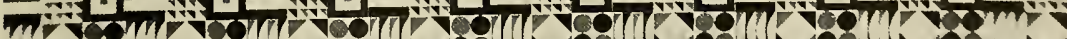

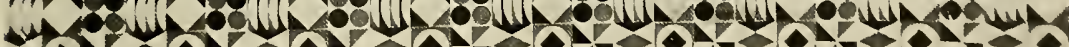
-

Figure 9 (Upper)

Figure 10 (Lower)

Camera 非7, Print 7-1 (20mm)

Sharp center, falling off very, very slightly to edge

Slight barrel distortion
Camera 非8, Print 8-1 (20mm) Sharp center, very slight fall off at extreme edge Very slight pincushioning 
It is obvious, from looking at the test prints, that the dome-ports do correct for refraction-magnification. They also correct some of the pincushioning of the flat-port (with the exception of the 非 dome, which had a very slight barrel distortion effect). Edge fall-off was more extreme in the flat-port combination. Though there was edge fall-off to a minor extent in all the tests except for the longer lenses and the $28 \mathrm{~mm}$ Nikkor UW lens (which did have refraction magnification), we feel that further studies should be made to see if it is possible to correct the slight pincushioning and barrel distortion of the dome-ports. Contrary to previous theory, we found that the $50 \mathrm{~mm} 1 \mathrm{ens}$ seemed to have the same edge fall-off with both the flat-port and dome-port, but one had the refraction magnification, the other did not. It is also obvious that the $\# 7$ combination gave the best edge sharpness on a comparison basis. But the edge sharpness of the 3, 5, and 6 inch dome, utilizing the Plus-diopters, was of such minor difference, in practical photography, the difference would only show up in photogramic photography underwater.

One of the largest problems of habitat UW photography is the problem of pressure inside the habitat. If cameras are taken down, wet, they can be on $1 y$, opened in the habitat if the housing has an air-intake valve. If a diver goes outside the habitat with an UW camera at the habitat pressure, he risks the housing interna1. air expanding, and bubbling out of the housing, and water coming in. What is badly needed is a two-way, automatic pressure relief valve so that the camera can regulate its own pressure. Early devices of this nature were used years ago but there is a real need for an updated valve for further work of photography in habitats. This problem becomes greater as the size of the housing increases and reaches major problem proportions in $16 \mathrm{~mm}$ and $35 \mathrm{~mm}$ movie housings due to their large size.

We have found increased color saturation with the dome-ports, but since careful comparison tests (such as the black and white test) could not be accomplished, we cannot say to what degree the dome increases color saturation.

The results of the automatic-exposure-control cameras (非1, 2, 3) were striking because of the simple lenses of 非 and 非. Examples of photos taken with automatic exposure control are shown in Figures 11 and 12 . Further research should be made into the advantages of automatic-exposure control cameras under natural light, artificial, flash, and strobe conditions. 


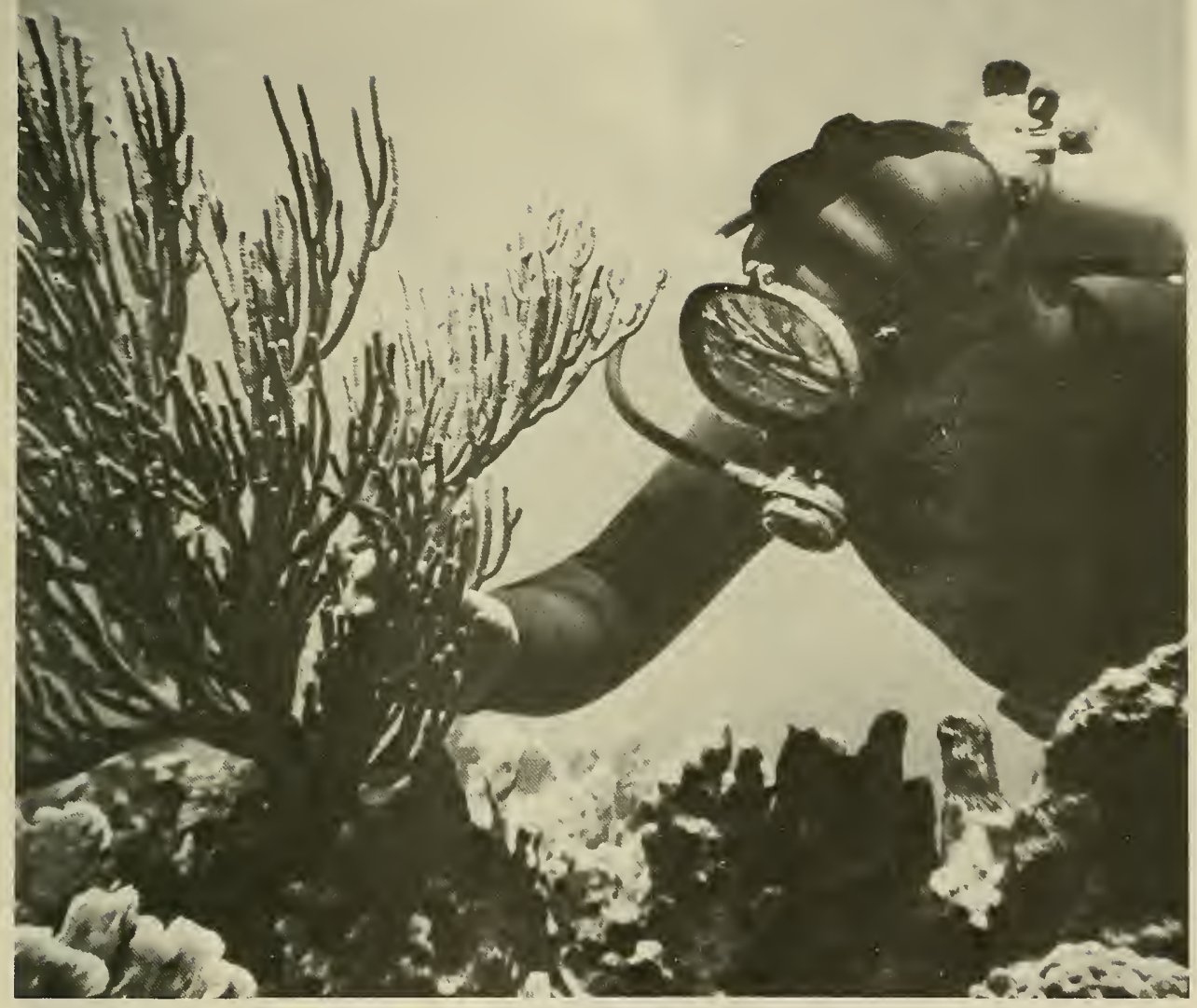

Figure 11

Underwater scene taken with Kodak Instamatic X45 in Ikelite UW housing. Black/white copy from EK-X color film 


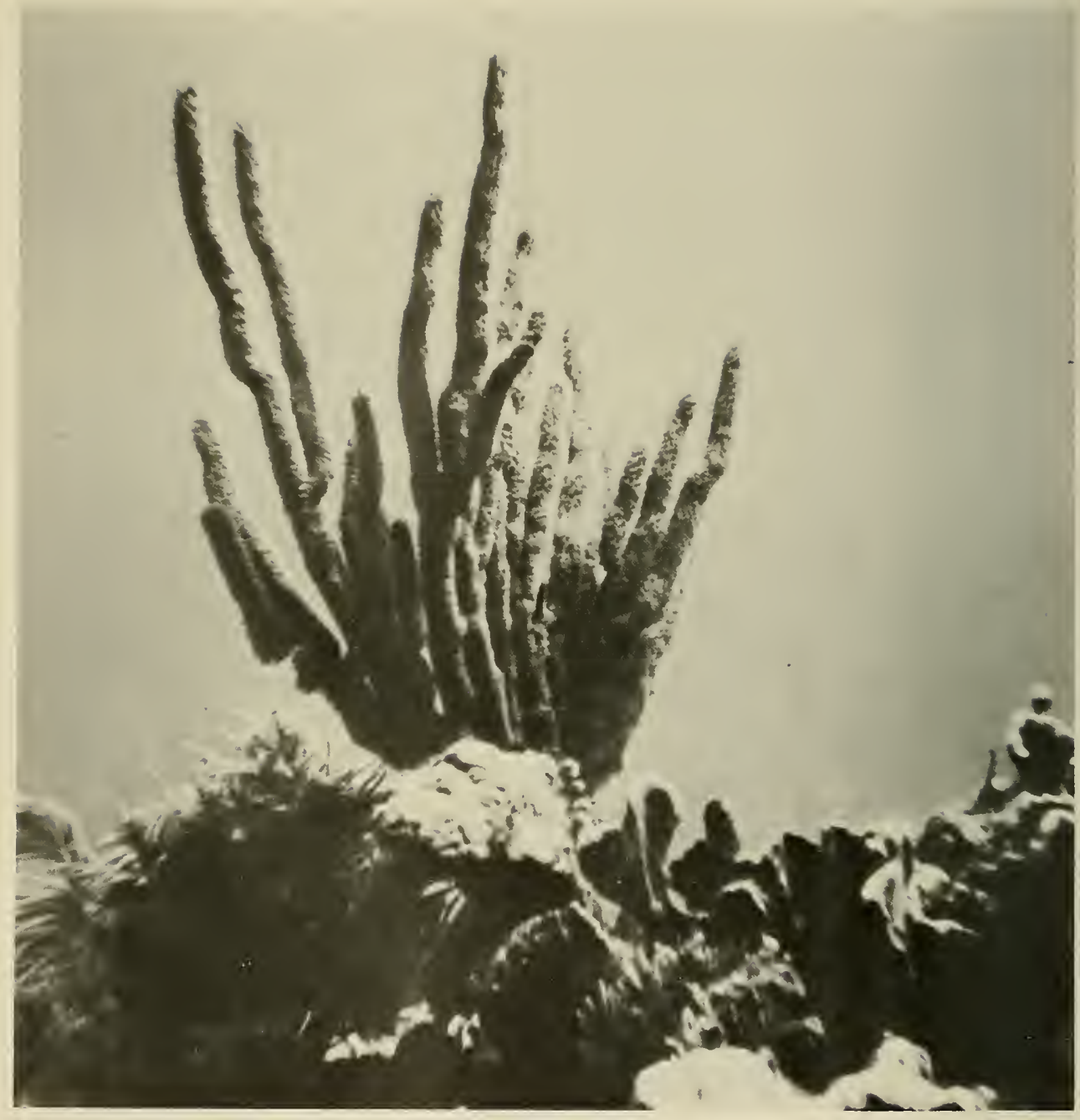

Figure 12

Underwater scene taken with Kodak Instamatic 174 in Sea Research Inc. housing

Black/white copy from EK-X color film 
The program concept was formulated by an Ocean Survey Program Committee organized by Mr. Harold Goodwin of the Office of Sea Grant. The Committee functioned under the Chairmanship of John Van Derwalker, TEKTITE II Marine Sciences Program Coordinator, Department of Interior. The general objectives of the program were: (1) to provide the necessary logistic support for the underwater habitat program, (2) to conduct a descriptive oceanographic survey of the Virgin Island Platform, (3) to conduct a series of special experiments and studies relating to the marine environment of the Virgin Islands, with emphasis on the operational area of the TEKTITE II habitats, and (4) to provide framework for marine technology training activities as an integral part of the TEKTITE II Program. Sea Grant universities and training institutions were invited to submit project proposals for the Ocean Survey Program. Projects were selected for inclusion in the program on the basis of their contribution to the above objectives.

A routine descriptive oceanographic survey was planned which would provide data for a detailed analysis of the physical and chemical properties of the nearshore waters at periodic time intervals. The survey plan included nineteen transects around the Virgin Island Platform between the ten and one thousand fathom lines. This phase of the project was conducted entirely by the marine technology students from the Cape Fear Technical Institute and the Southern Maine Vocational Technical Institute. Priority was given the special studies, so there was not adequate time to conduct the routine survey as frequently as desired.

In summary, the Ocean Survey Program consisted of: (1) a composite of geological, geochemical, physical, and biological studies, (2) special experiments involving new or improved instrumentation and sampling techniques, and (3) student training in marine technology. Brief descriptions of the individual Ocean Survey Projects, and available results, are given in the following section. 
Student trainees were aboard the ADVANCE II throughout the Ocean Survey Program. Air National Guard flights were scheduled and flown at two-week intervals to transport the marine technology students from the Cape Fear Technical Institute and the Southern Maine Vocational Technical Institute. In addition to shipboard indoctrination and training, these students participated in all experiments and studies conducted aboard the ADVANCE II. A number of the students also participated in the underwater activities. A breakdown of the total sea training time by institutions and instructors follows:

1) Institution: Cape Fear Technical Institute (CFTI)

Edward L. Foss

S. Thomas Rhodes

James R. Martin

Dale R. Buck

Subject: Marine Technology

No. of Student Trainees: 125

No. of Faculty: 4

Total Student Training Days: 7,000

2) Institution: Southern Maine Vocational Technical Institute (SMVTI)

$$
\begin{aligned}
& \text { Tapan Banerjee } \\
& \text { Robert Goode } \\
& \text { Robert Siegel } \\
& \text { Luigi Lormoriello } \\
& \text { Robert Soucy } \\
& \text { Richard Acheson } \\
& \text { Richard Arlinder } \\
& \text { Weston Eayrs, III } \\
& \text { Charles Hall }
\end{aligned}
$$

Subject: Marine Technology

No. of Student Trainees: 90

No. of Faculty: 9

Total Student Training Days: 2,730

3) Institution: College of the Virgin Islands

Dr. John S. Rank Subject: Marine Ecology

Dr. James F. Howard Subject: Marine Geology

Dr. William P. McLean Subject: Marine Ecology

No, of Student Trainees: 55

No. of Faculty: 3

Total Student Training Days: 295 
4) Institution: Fairley-Dickinson University

Dr. Robert B. Abel

Subject: Marine Sciences

No. of Student Trainees: 20

No. of Faculty: 1

Total Student Training Days: 20

5) Institution: University of North Carolina at Raleigh

Dr. Charles Welby

Subject: Marine Geology

Mr. James R. Smith

Subject: Physical Oceanography

No. of Student Trainees: 6

No. of Faculty: 2

Total Student Training Days: 138

INDIVIDUAL INVESTIGATIONS

The following are brief descriptions of individual investigations conducted as a part of the Ocean Survey Program. This material was provided by the Principal Investigators. When available, results have been included; however, in many cases the data are still being analyzed. 
Dr. Curtis C. Mason, Dr. Dean R. Norris, and Ivan D. Browne NASA Manned Spacecraft Center

Houston, Texas

\section{ABSTRACT}

A specially designed underwater resolution target was photographed from an aircraft equipped with 3 - and 6-inch focallength cameras. The target was positioned at depths from 5 to 60 feet and photographed from 2000-, 4000, and 12,000foot altitudes, with sun angle varying from $34^{\circ}$ to $70^{\circ}$ and exposure varying from one stop underexposed to two stops overexposed. Seven filter combinations and five film types were used. A visual inspection of the photography indicates Kodak SO-397 color Ektachrome file and Kodak 2405 high-speed Panchromatic film (black and white) with Wratten $2 \mathrm{E}$ and 47 , Wratten 57, and Wratten 21 and 57 filters gave approximately the same results, and were better than other filter-film combinations. Varying optimum exposures plus or minus one stop had little effect on resolution. At a 5-foot submergence depth, 1- by 3-foot bars could be easily resolved. At a 15-foot submergence depth, 2- by 6-foot bars were separable. At a 30-foot submergence depth, 2- by 6-foot bars were visible. At a 45-foot submergence depth, 4- by 12-foot bars were clear and sharp, and at a 60-foot submergence depth, 4- by 12-foot bars were becoming faint. With the target at a 40-foot submergence depth, sun angle had little effect, as long as the target was not in the sunglint area.

\section{OBJECTIVE}

To determine the effects of factors such as submergence depth, sun angle, film and filter type, exposure, aircraft altitude, and polarization on the photographic resolution of an underwater object.

\section{PROCEDURES}

A specially designed target (Fig. 1) with resolution-bar dimensions of 4 by 12 feet, 2 by 6 feet, 1 by 3 feet, and $1 / 2$ by $1-1 / 2$ feet was used to evaluate the effects of the parameters mentioned previously on underwater resolution. Divers from the TEKTITE project were used to develop target deployment techniques. For data collection, divers from the Cape Fear Technical Institute Research Vessel ADVANCE II positioned the target at depths ranging from 5 to 60 feet below the surface in the clear water in Lameshur Bay, St. John Island (Fig. 2).

The buoyant 12- by 24-foot target was positioned at the proper depth by four winches mounted at the corners of the target, and was fastened by cables to weights positioned on the bottom. The target was photographed from an 


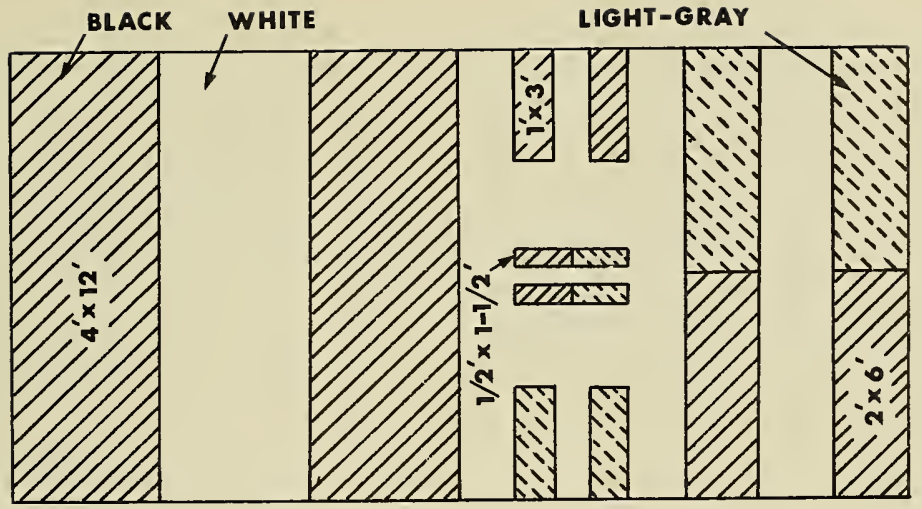

Figure 1. Target pattern used in the test program

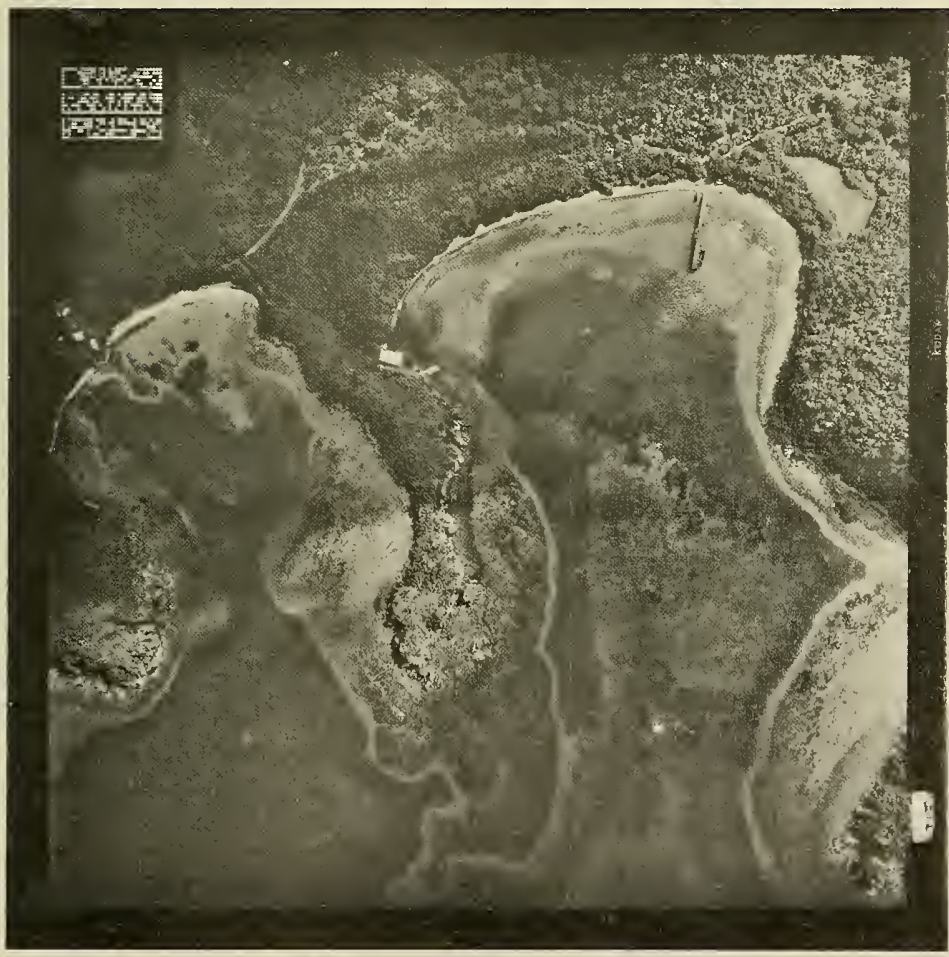

Figure 2. View of Lameshur Bay showing clarity of water VII -5 
altitude of 2000 feet for a11 parameters examined, except altitude variations. The aircraft, a P3A, was equipped with a 6 -inch focal-length RC-8 camera, four 3-inch focal-length KA62 cameras, and four 80-millimeter focal-length electric Hasselbad cameras. The RC-8 camera used a clear antivignetting filter and a specially manufactured Ansco D500 color film that did not have the blue sensitive layer. One of the KA62 cameras used Kodak S0-397 color Ektachrome film, the other three KA62 cameras used Kodak 2405 high-speed Panchromatic film with Wratten 57, 47, and 25A filters. The camera equipped with the Wratten 47 filter malfunctioned during the mission. Three of the Hasselbad cameras used Kodak 2405 film with Wratten $2 \mathrm{E}$ and 47, Wratten 45, and Wratten 21 and 57 filters. The fourth Hasselbad camera used Kodak 2424 black and white infrared film and a Wratten $89 \mathrm{~B}$ filter. The nominal transmittance of the filters used with the Kodak $2405 \mathrm{film}$ is shown in Fig. 3. On one flight, the four Hasselbad cameras were replaced with a second RC-8 camera that was loaded with specially manufactured Kodak S0-397 color Ektachrome film without the blue sensitive layer. The submerged target was overflown with the aircraft heading north. For control, a duplicate resolution target was laid out on the beach so that the submerged target and then the beach target would be photographed.

\section{RESULTS}

As expected, submergence depth was the most important factor affecting resolution (Fig. 4). A careful examination of the data obtained from an altitude of 2000 feet reveals that for the target on the beach, the 1ight gray 1- by 3-foot bars, as well as the black 1- by 3-foot bars, were visible; but the black 1/2- by 1-1/2-foot bars appeared only as smudges. At a 5-foot submergence depth, the black 1 - by 3-foot bars were visible; however, the 1ight gray 1 - by 3 -foot bars were not visible, the 1 ight gray 2 - by 6 -foot bars were barely visible, and the black 1/2- by 1-1/2-foot bars appeared only as smudges. At a 15-foot submergence depth, the black 2- by 6-foot bars were visible, and the black 1 - by 3-foot bars appeared as a smudge. At a 30-foot submergence depth, one of the black 2- by 6-foot bars was visible, but no trace of the black 1- by 3-foot bars could be seen. At a 45-foot submergence depth, the black 4by 12 -foot bar was still clearly visible. At a 60-foot depth, the target was barely visible, and there was only an indication of the black 4- by 12-foot bar.

A comparison of the effect that filter and color film had on resolution revealed the following (Fig. 5): The target was submerged 30 feet. Except for the view taken with the Wratten $25 \mathrm{~A}$ filter, it was difficult to discern any appreciable difference in the target resolution. When using the Wratten 25A filter, the target at the 30-foot submergence depth could be imaged although it was clearly visible at the 15-foot depth. A more critical comparison of the filter performance by viewing the original negatives for all submergence depths indicated that the image obtained with the Wratten 45 filter was slightly poorer than the image obtained with the Wratten $2 \mathrm{E}$ and 47 , the Wratten 57 , and the Wratten 21 and 57 filters.

The images obtained with the specially manufactured Ansco D500 film, the specially manufactured Kodak SO-397 color Ektachrome film, and the Kodak So397 Ektachrome film, with the target submerged to 30 feet were compared (Fig. 6). Comparison of the two films without the blue sensitive layer as 

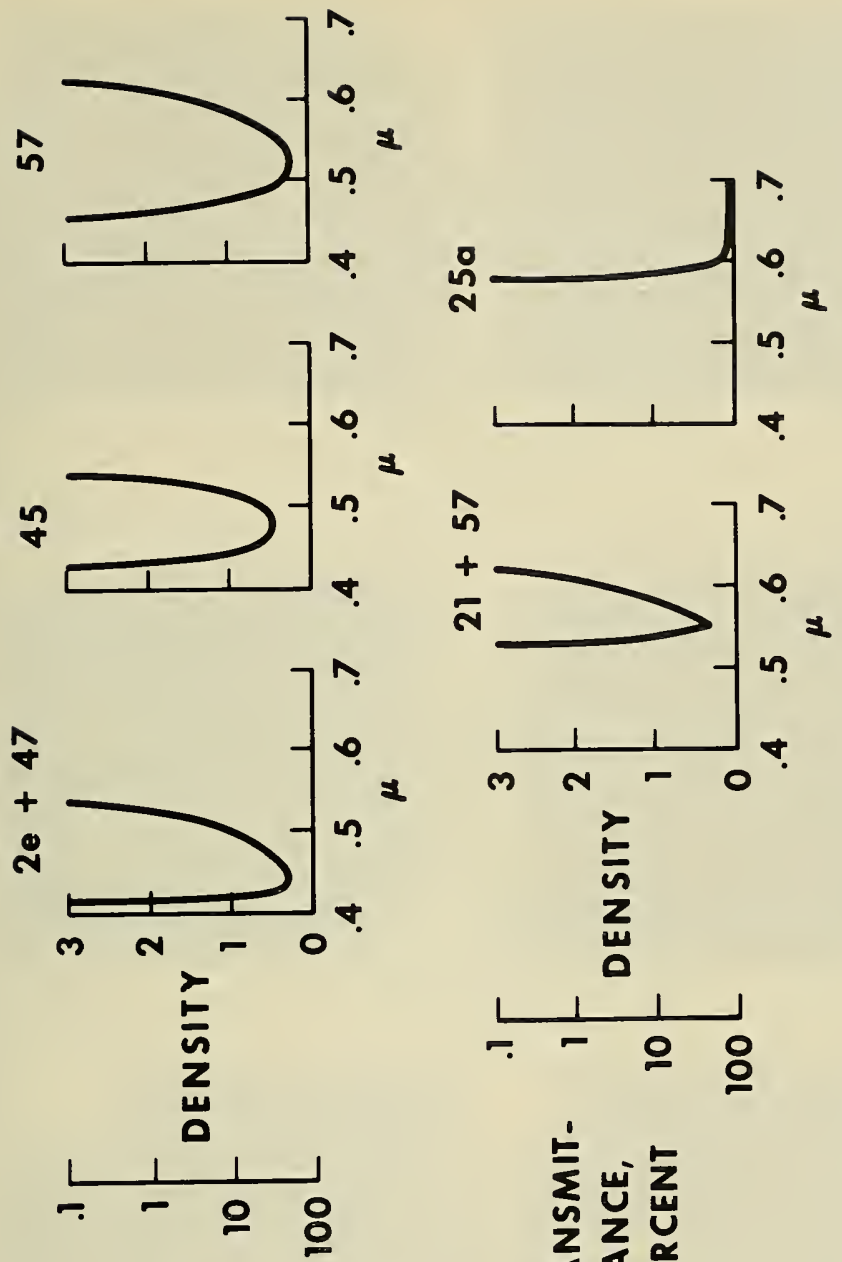

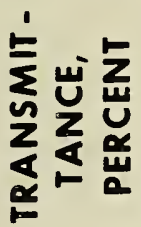
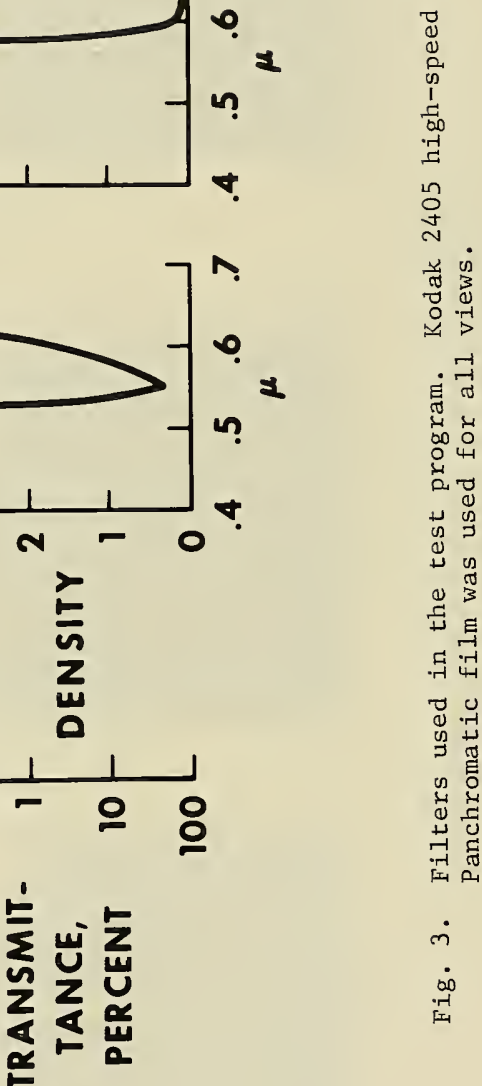

$\dot{n}$ 

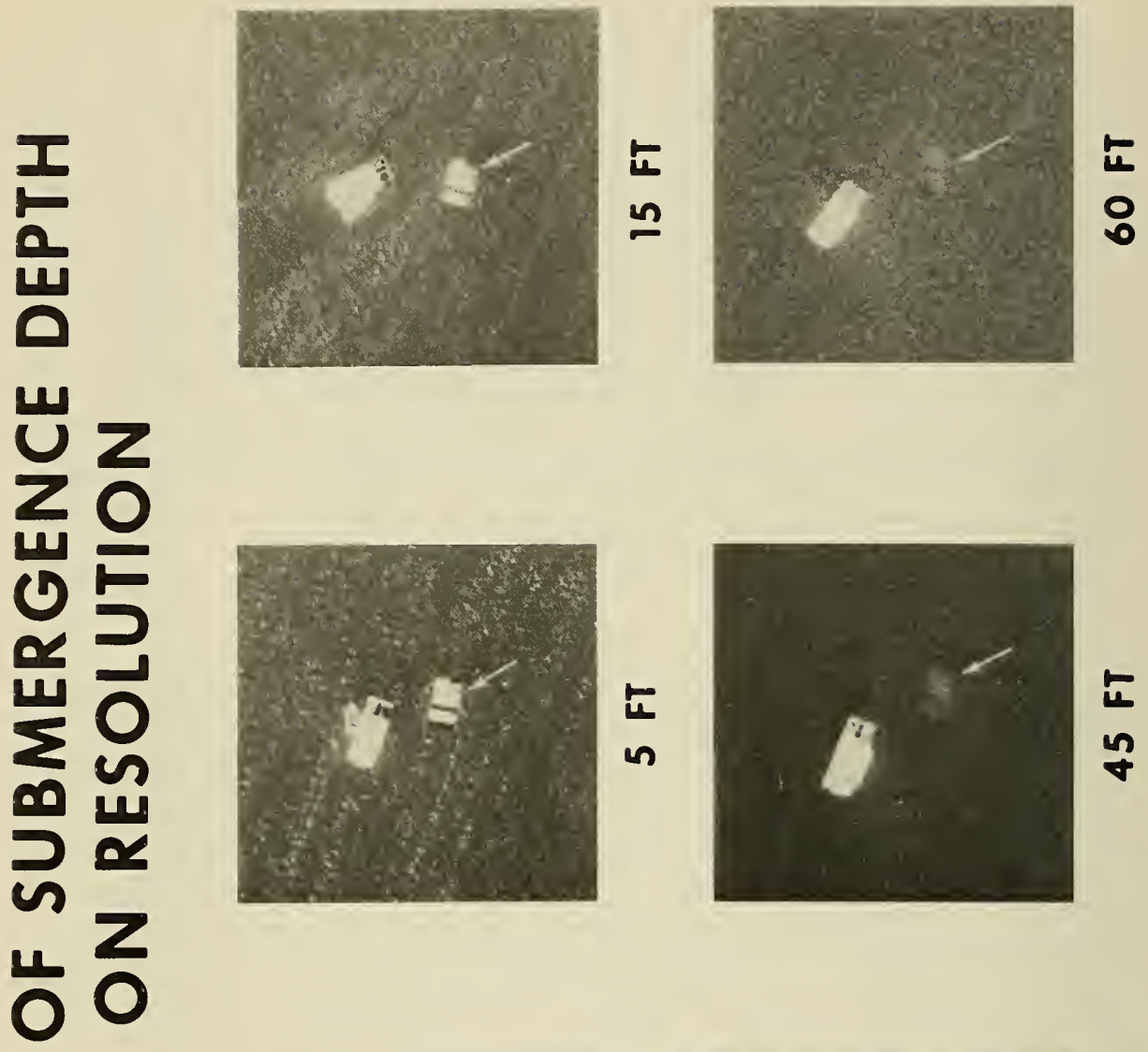

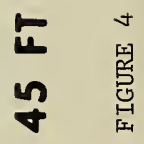
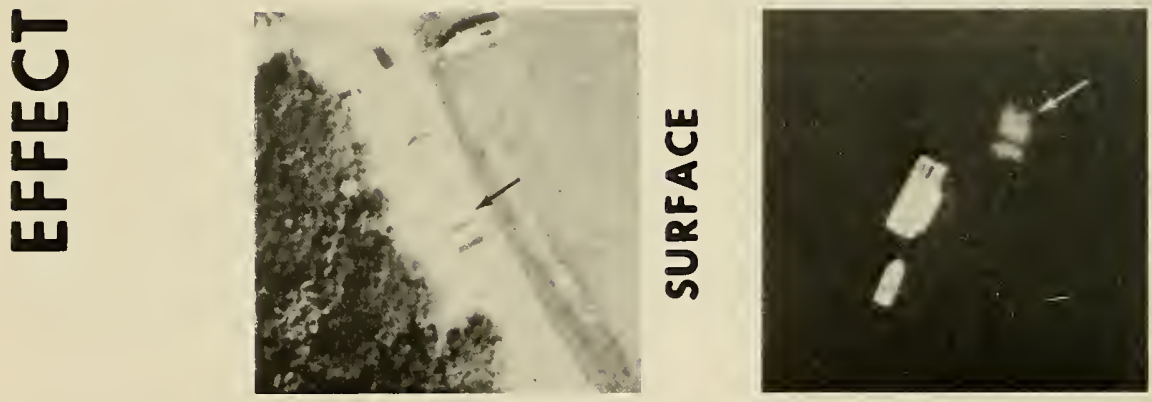

r
m

VII -8 


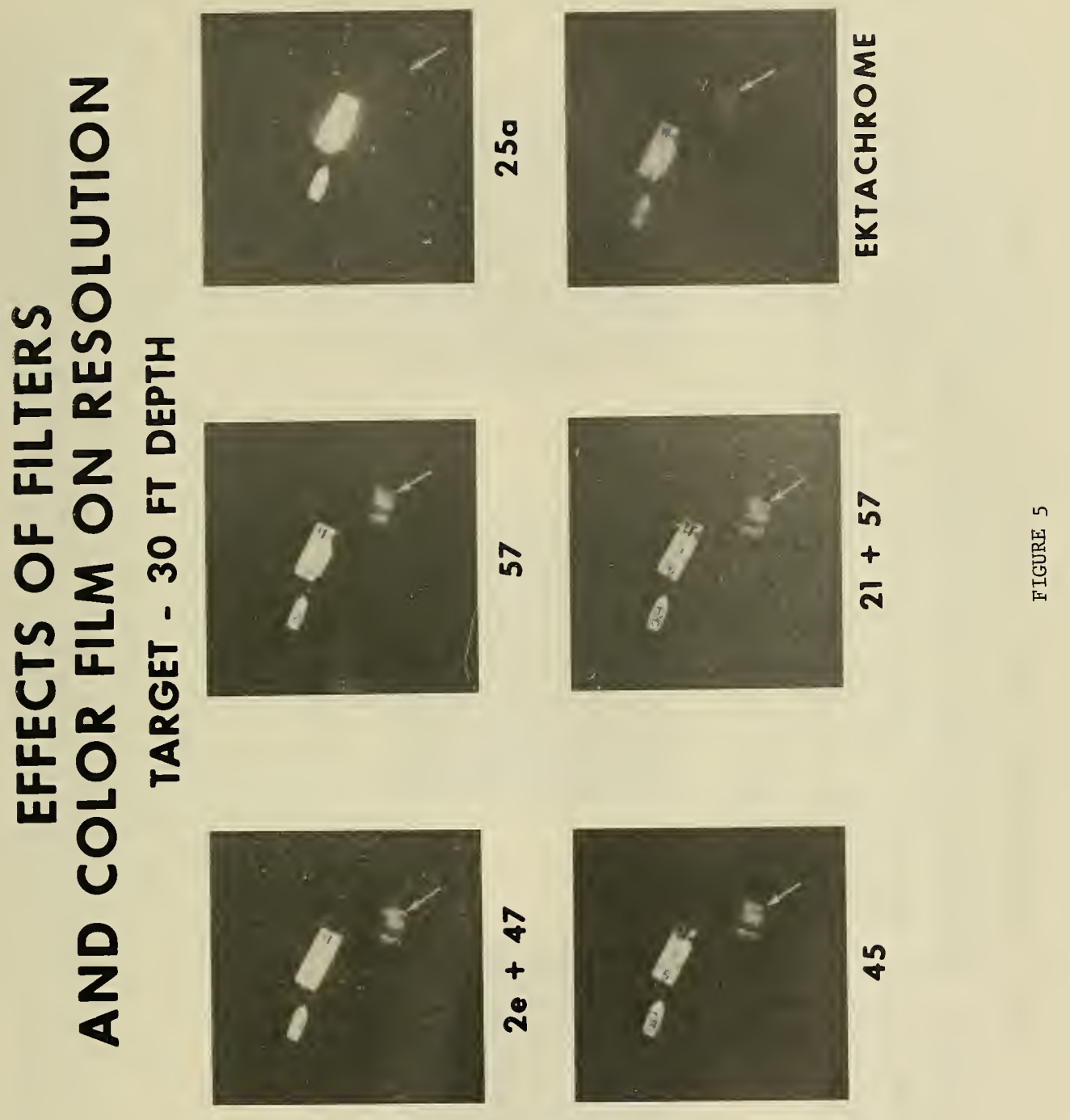

VII -9 


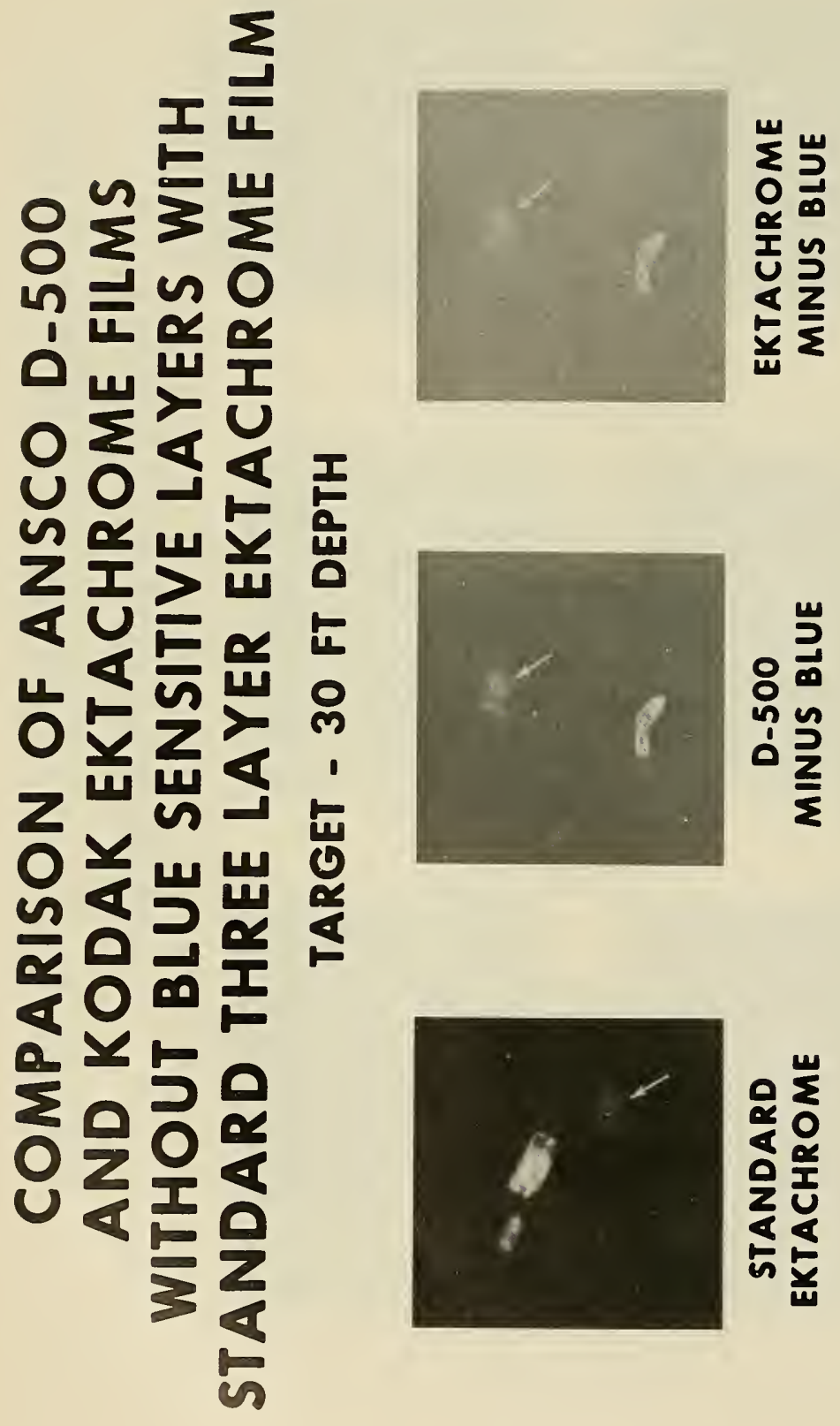


opposed to standard color film was hampered by the standard color film being exposed in a camera with a 3-inch rather than a 6-inch focal length. Even so, it was difficult to determine visually any significant difference in resolution.

The effect of sun angle on resolution was examined (Figs. 7 and 8 ). The target was submerged to a depth of 40 feet and photographed with the Wratten 57 filter. It was difficult to determine visually any difference in resolution due to sun angle changes as long as the target was not in the sunglint area. The main effect of varying sun angle was to increase the area of the frame covered by sunglint. At the $56^{\circ}$ and $71^{\circ}$ sun angles, the photographs taken with the 80-millimeter focal-1ength Hasselbad camera and a 56-millimeter film format were almost entirely covered by sunglint.

The effect of exposure on resolution was examined (Fig. 9). The target was photographed at a depth of 40 feet with the camera set for one-stop underexposure, normal exposure, and one- and two-stop overexposure on four successive overpasses. Normal exposure had been determined by a sequence of test exposures made 1 month prior to the actual test program. The exposure that gave the best contrast of bottom features was chosen for normal exposure. Although the total film density varies for the one-stop underexposure, normal exposure, and one-stop overexposure, the resolution of the 4- by 12-foot bars on the target did not change. For the two-stop overexposure, little could be seen other than the boat on the surface.

The effect of aircraft altitude on resolution was investigated (Fig. 10). Photographs were taken with the target submerged to a depth of 40 feet and the aircraft flying at 2000-, 4000-, and 12,000-foot altitudes, using Kodak $2405 \mathrm{film}$ and a Wratten 57 filter. The target could be readily identified in both the 2000- and the 4000-foot-a1titude photographs, but not in the 12,000-foot-altitude photograph, due to the low contrast between the target and the water so that the target is lost in the grain of the image. The 4- by 12-foot bar was distinguishable in the 2000-foot-altitude photograph, but was difficult to distinguish in the 400-foot-altitude photograph.

The effect of using a polarizing filter was studied (Fig. 11)。 Photographs were taken from a 2000-foot-altitude with the target submerged to a depth of 30-feet. Both photographs were taken with Kodak $2405 \mathrm{film}$ and a Wratten 57 filter, one with and one without a polarizing sheet. A polarizing filter was oriented so as to cause a maximum reduction of glare from the water surface. The camera was opened up two stops to compensate for the polarizing filter. In both cases, the 4- by 12 -foot bar was clearly visible in the photographs. There was a slight indication of the 2- by 6-foot bars in the photograph obtained without the polarizing filter.

The conclusions presented above are based on a visual analysis and are consequently subjective. Analysis of the data by using isodensitiometer readings on the original film and normalizing the readings to the control target set up on the beach is in progress. This analysis will be performed both on the underwater target and on selected natural features on the bottom of Lameshur Bay. This instrumental analysis will eliminate the subjective judgment and may modify the conclusions reached by visual examination of the data. However, it is believed that only minor revisions of the following conclusions will be necessary. 

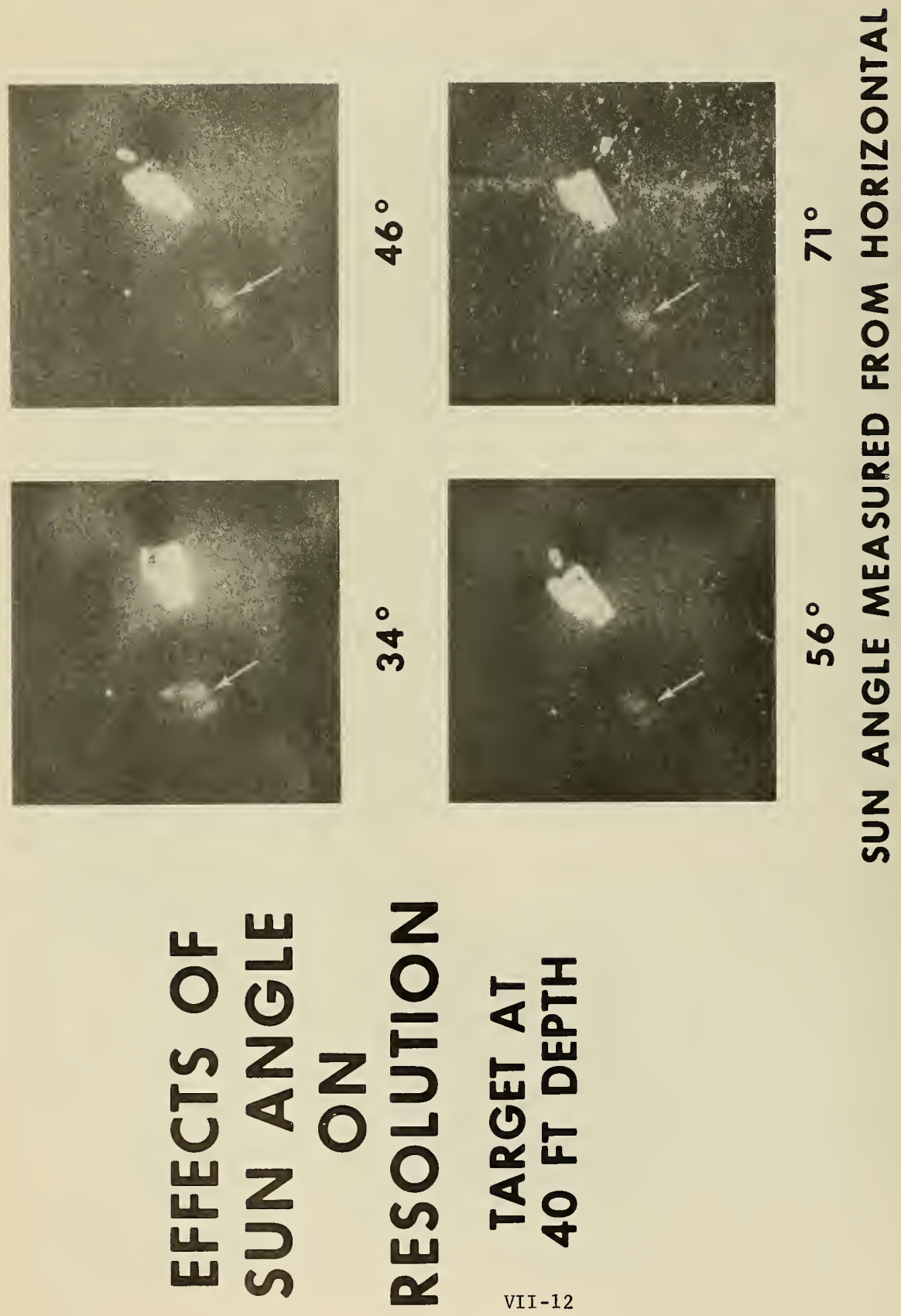


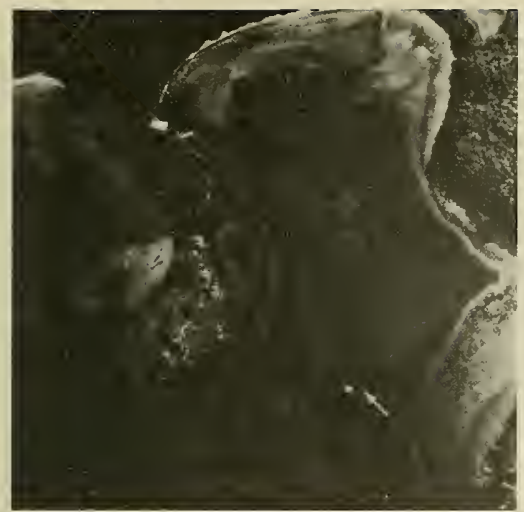

\section{$34^{\circ}$ SUN ANGLE}

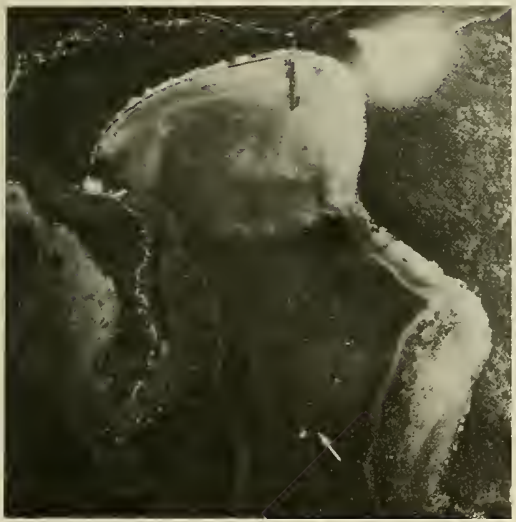

\section{$56^{\circ}$ SUN ANGLE}

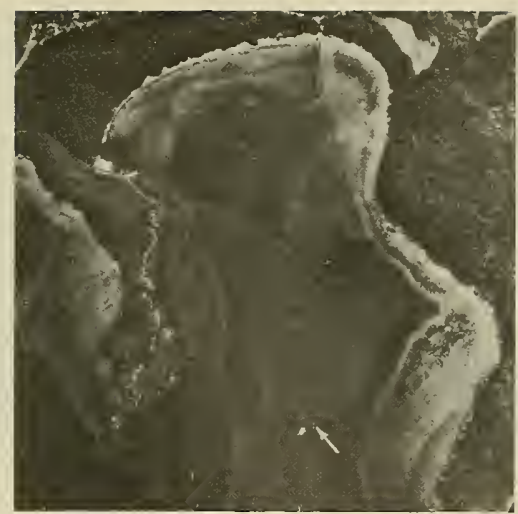

\section{$46^{\circ}$ SUN ANGLE}

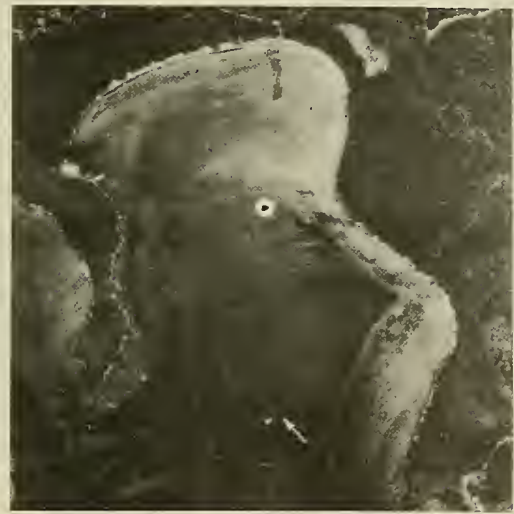

\section{$71^{\circ}$ SUN ANGLE}

Fig. 8. Portion of 4-1/2-inch frame covered by sunglint with the sun at various angles.

VII -13 

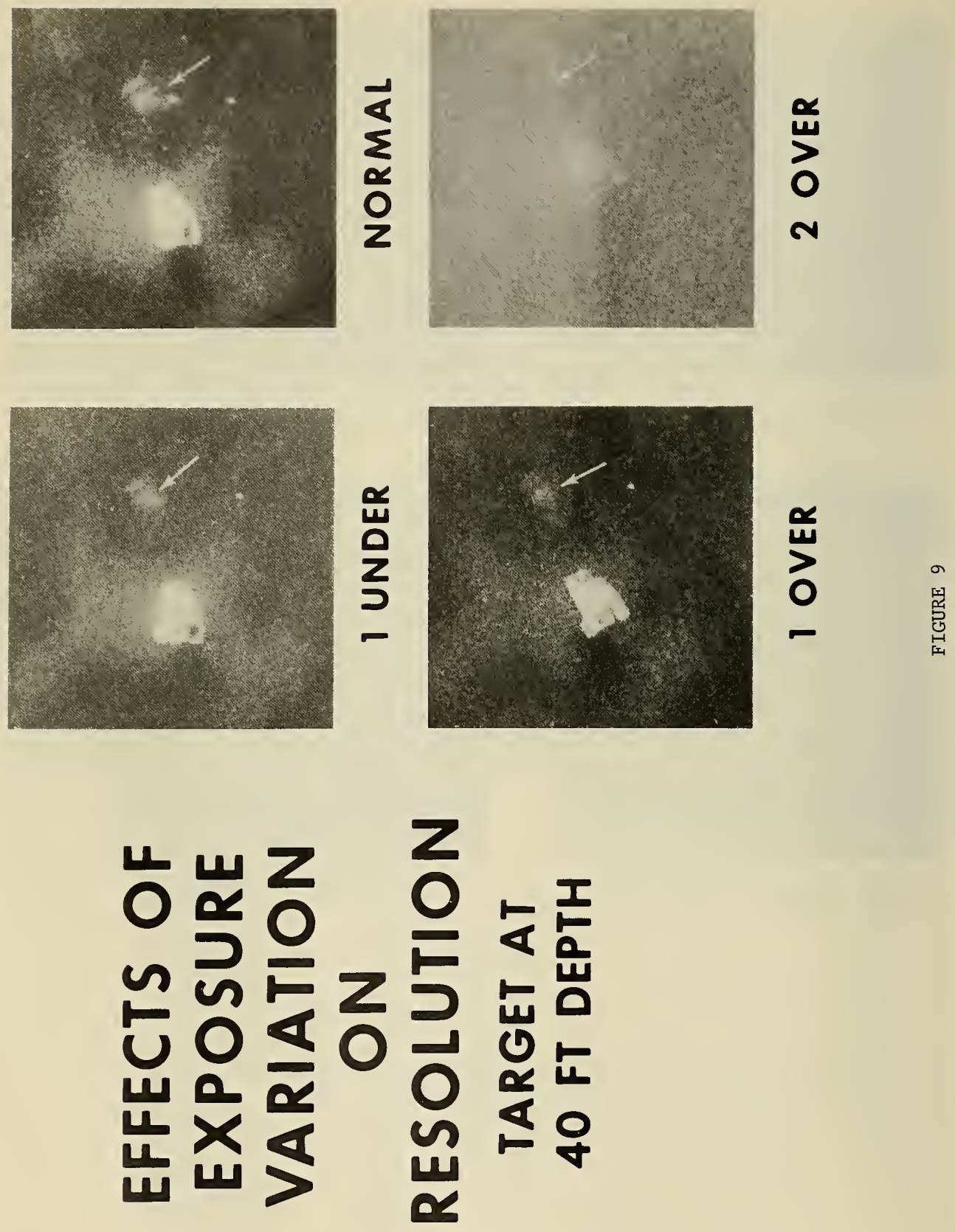

VII -14 

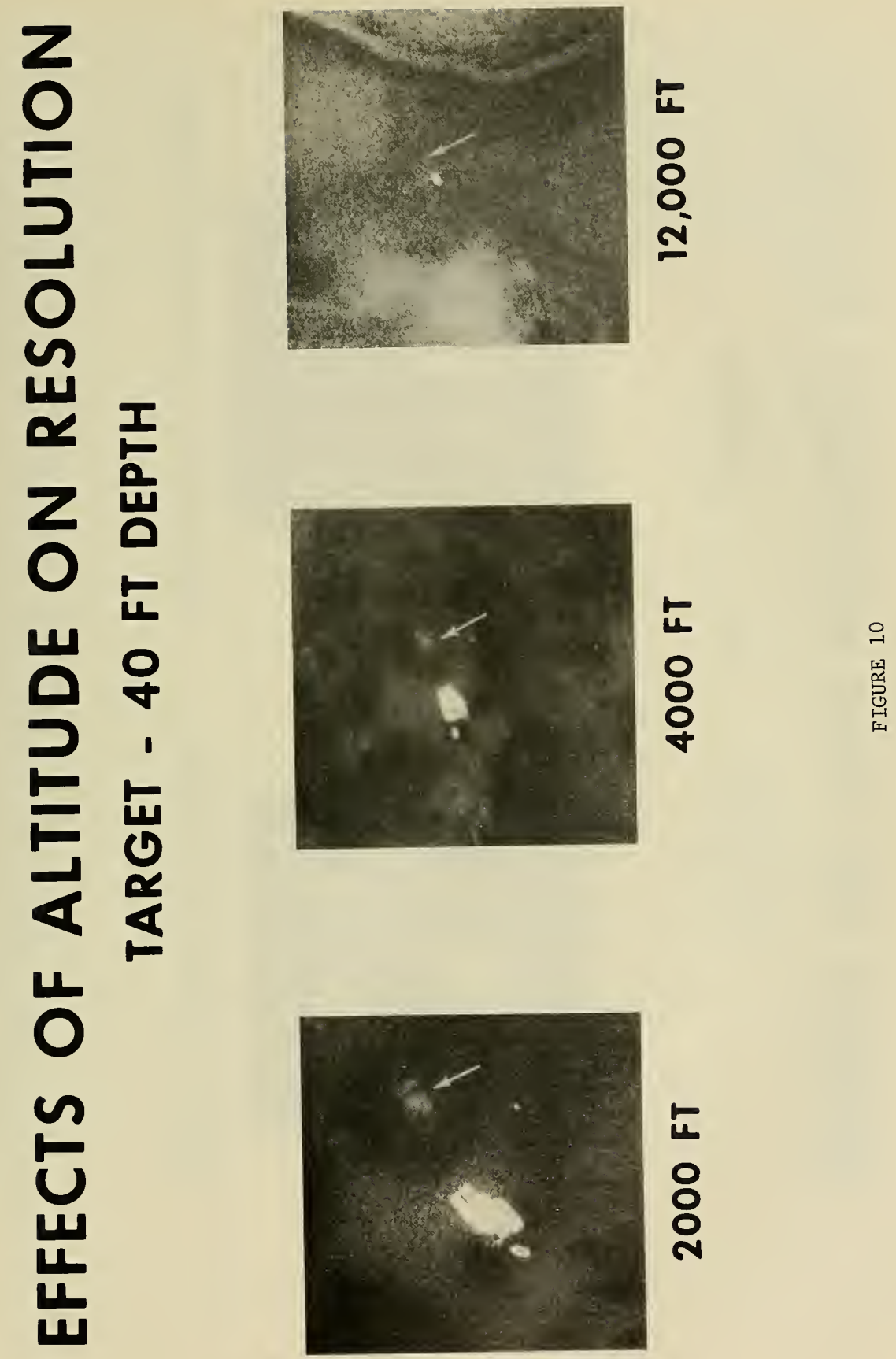

VII - 15 
U1

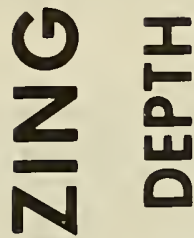

는

- 0

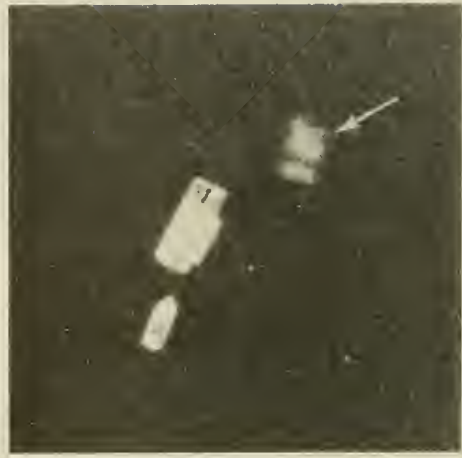

z

$=$

$-$

$N$

$-$

0

a

5

$\frac{1}{5}$

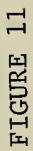

0
0
1

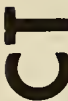

บU

U

L

U

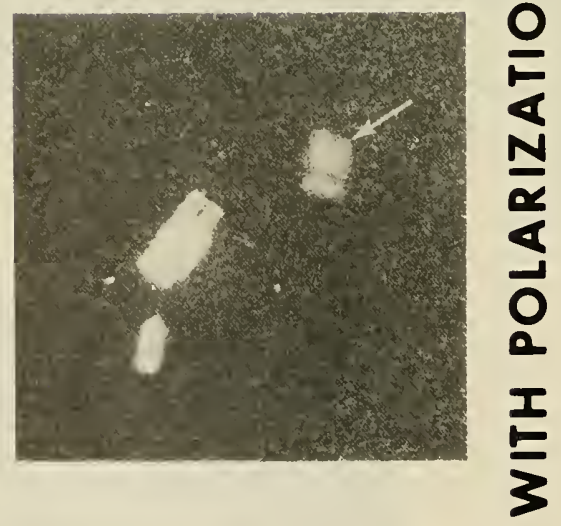

VII-16 
As expected, the most important factors affecting resolution of bottom features are submergence depth and image scale on the original film. Smal1sized bars or low contrast features (or both) disappeared quickly with submergence. As long as the film and filters recorded adequate energy in the 410- to 600-millimeter wavelength region, water depth penetration was not seriously affected. Resolution of bottom features was relatively independent of sun angle and exposure as long as sunglint was avoided and exposure was within plus or minus one stop of optimum. Use of a polarizing filter did not improve target resolution. 


\author{
Lloyd Lewis \\ Research Associate in Ocean Engineering \\ University of Rhode Island \\ James Gallagher \\ Oceanographer, USNUSC \\ New London, Connecticut
}

\begin{abstract}
The DOSP was tested and evaluated in shallow water off Ponce, Puerto Rico. Ten stations in depths to 200 feet were occupied by the R/V ADVANCE II. Grab samples, Pheleger cores, DOSP and correlation Ewing gravity cores were taken at each station. In situ acoustic and temperature data were recorded and compared to physical properties determined in the laboratory at URI. Grab samples and Pheleger cores taken at stations in the vicinity of the U.S. Virgin Islands indicated a thin surface sediment layer of compacted coral sand and debris. Operations with the DOSP in this region proved impossible.
\end{abstract}

\title{
INTRODUCTION
}

The primary task for the DOSP participation in the TEKTITE II Ocean Survey Program was to contribute to the ocean sediment survey on the Virgin Islands plateau. This effort was undertaken as an aid to extending the detailed geological investigations at Lameshur Bay. Extensive sampling from the R/V ADVANCE II (Phase I) and the AVR VAST (Phase II) resulted in a pattern of coarse sand and shell debris covering and filling shallow pockets among coral reef structures at all sites investigated. As a result, DOSP operations in this area were not possible. A summary of these investigations is given along with other activities during these phases. Phase III studies involved actual DOSP operations off the south coast of Puerto Rico from the R/V ADVANCE II. In situ and laboratory data from this work has served as the basis for a doctoral dissertation in ocean engineering (Lewis, 1971) and further DOSP sensor development (Rose, 1971; Erchul, 1971). Operations during this phase were quite successful, and the resulting observations have led to positive verification of the usefulness of in situ investigations.

\section{INSTRUMENTATION}

The DOSP and its associated components have been described in some detail in Lewis, et.al. (1969 and 1970). Referring to Figure I, the DOSP should be regarded as a unique, station keeping, bottom mounted platform from which a variety of marine sediment investigations can be undertaken. It has the capability of common, incremental, nonrotating penetration to 5.0 feet of four probe sensors situated at the corners of a 4.2 foot square. A centrally located, thin walled, 3-inch diameter corer can take a relatively undisturbed sample up to 5.0 feet in length with a slow, steady, nonrotating motion. 


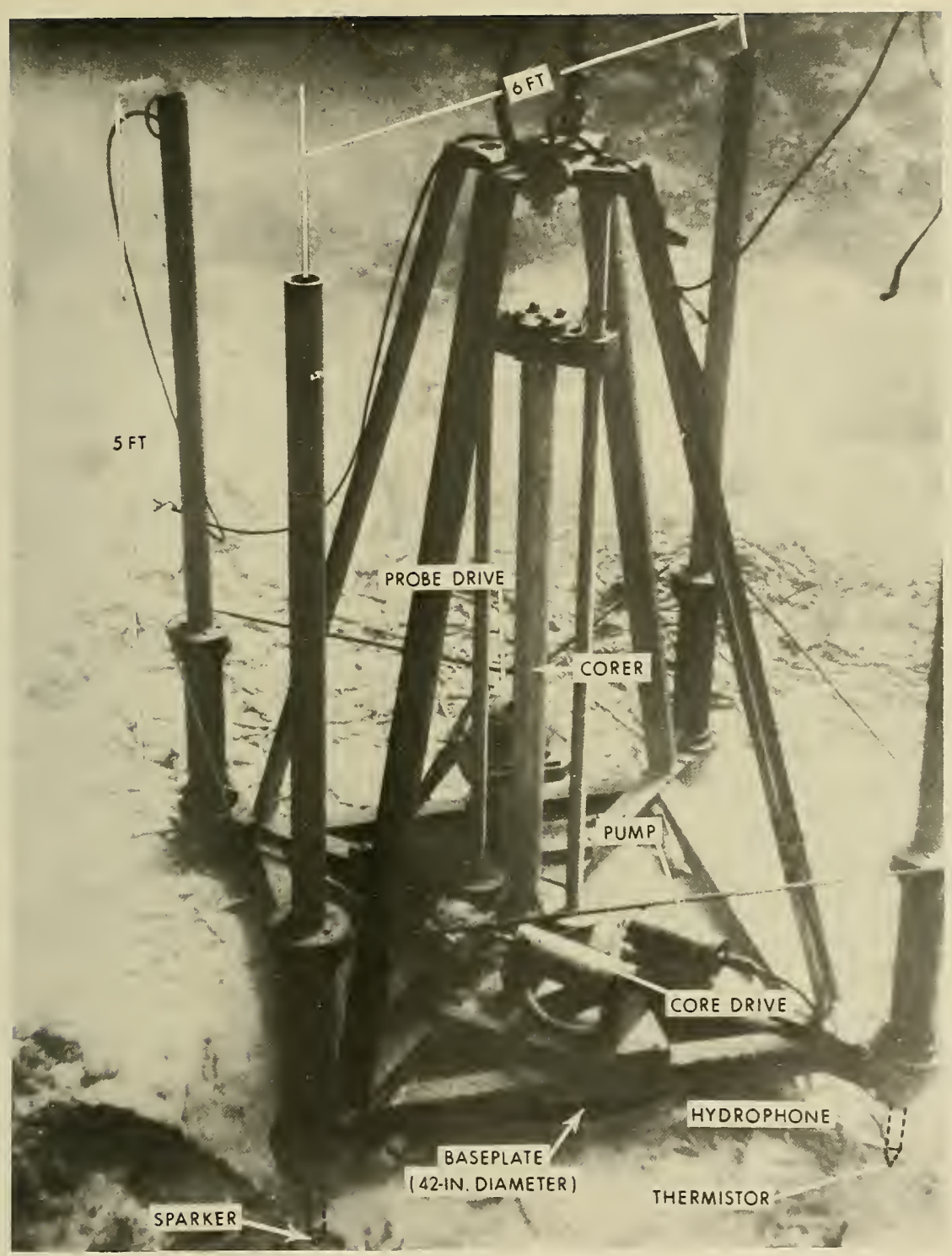

Figure 1

Deep Ocean Sediment Probe 
Figures 2 and 3 illustrate the umbilical ties to the support ship for electrical power and data acquisition. Current effort at URI is to reduce this cabling requirement to a single coaxial conductor strength member over which data and command signals will be passed through an FM multiplex telemetry system, and power will be in the form of direct current from DOSP mounted, submersible, pressure compensated batteries. A unique feature of this lightweight aluminum structure is the ability to hydrostatically self-anchor by means of a pump acting through taps in the large baseplate (Figure 1). Only three pounds/inch ${ }^{2}$ pressure differential distributed across this plate will give the DOSP a net negative weight in water of 2,000 pounds in addition to its submerged weight of 400 pounds.

Maximum sediment resistance to penetration for all four probes is less than 1,500 pounds (Lewis, 1971) in the sediments anticipated in the deep sea. Forces larger than this are encountered in the grainy, low porosity continental shelf sediments (as on the Virgin Islands plateau) and therefore the DOSP has limited shallow water application.

In terms of core disturbance parameters, the DOSP sampler has clearance ratios (Rosefelder, 1967) that are 20-50\% smaller than the average values of 11 ocean sediment coring instruments in current use, but still somewhat larger than the ideal conditions discussed by Horslev (1949).

In the present study, the data retrieved in situ were the velocity and attenuation of compressional sound waves through the sediment and the thermal gradient into the sediment to depths of 5.0 feet. Additional sensors monitor the command and control functions, bottom engagement and tilt in two axes to give the operator an instantaneous view of DOSP electro-mechanical behavior. All of these data are monitored directly in the ship's laboratory (Figure 3) and also recorded on high speed magnetic tape (analog) for later analysis in the laboratory. The sound source for the acoustic tests is a common automotive sparkplug which is fired on command from the surface ship through a pulsed discharge capacitor electronic system on the DOSP. Hydrophones are $\mathrm{BaTiO}_{2}$ piezoelectric crystals located in each of the remaining three probe legs. The frequency content of this sparker signal is such that a fast rise time leading edge is recorded for velocity determinations, and a broad band $(5-50 \mathrm{kHz})$ signal is also recorded for attenuation studies.

\section{SEA TRIALS}

Phase I Studies: March 31-Apri1 8, 1970

Consultation with personnel at the Caribbean Research Institute, St. Thomas, prior to beginning this phase warned of coarse sediment at the Lameshur Bay site, but suggested other potential "soft" sediment areas for DOSP operations. Table 1 lists these sites and the sampling results using either Pheleger corers (P) or grab samplers (G). Geographically, these stations are as follows:

P-1 near Ram's Head, St. John

P-2 in Francis Bay, St. John

P-3 off White Harbor, Jost Van Dyke

$\mathrm{P}-4$ in Lameshur Bay, St. John 


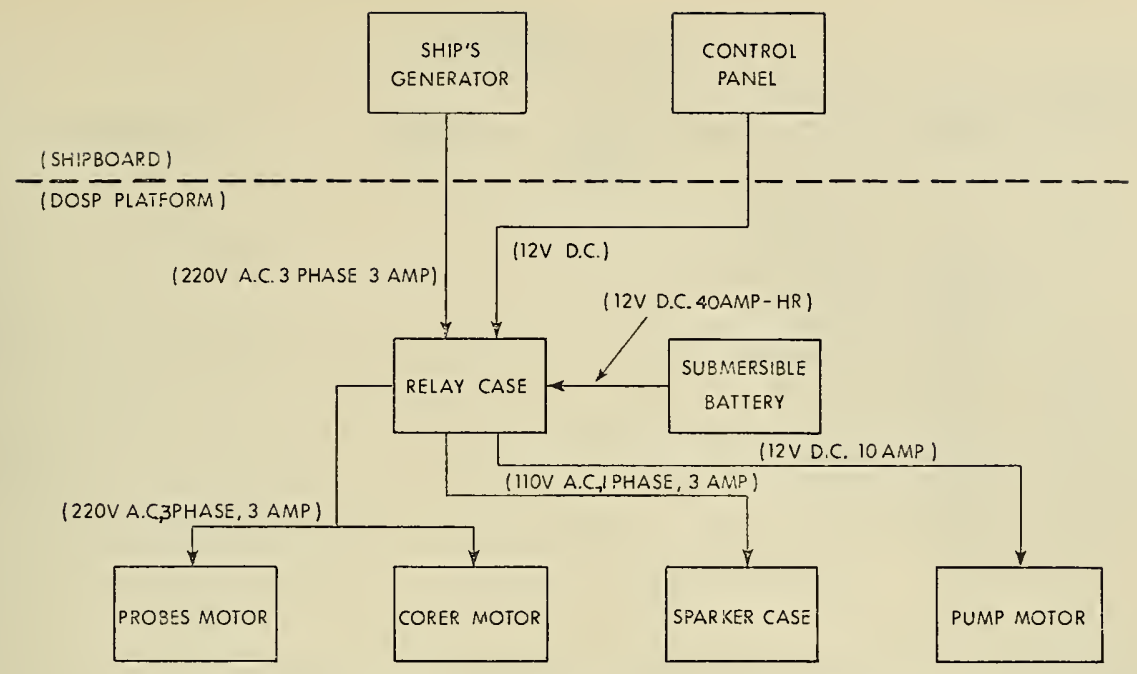

Figure 2. DOSP Power Distribution System

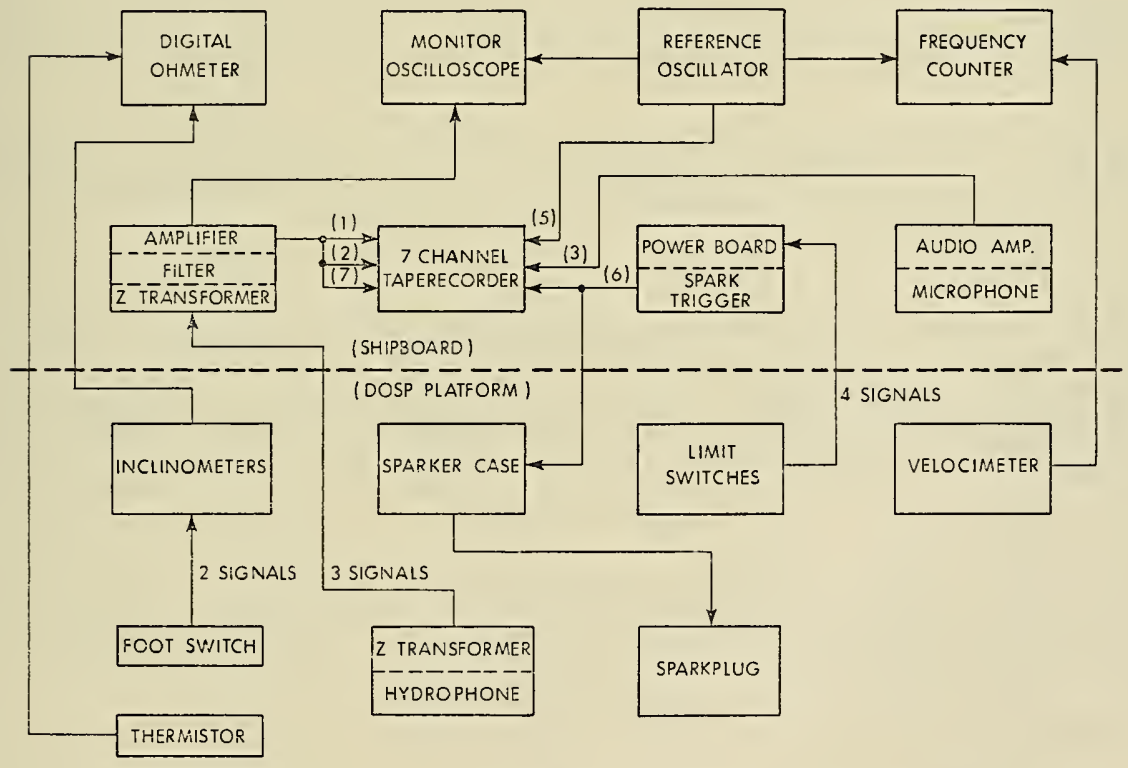

Figure 3. DOSP Data Acquisition System

Note: (1-7) indicates input channels to tape recorder 


\begin{tabular}{|c|c|c|c|c|c|}
\hline station & $\frac{\text { Date }}{\text { Time }}$ & Co-ordinates & $\begin{array}{l}\frac{\text { Water }}{\text { Depth }} \\
\text { (ft.) }\end{array}$ & Sampler & Recovery \\
\hline$P-1$ & $\begin{array}{l}4 / 1 / 70 \\
0800\end{array}$ & $\begin{array}{l}18^{\circ} 12.5^{\prime} \mathrm{N} \\
64042.3^{\prime} \mathrm{W}\end{array}$ & 138 & $\mathrm{P}$ & $1-2 "$ coarse shelly sand \\
\hline$P-2$ & $\begin{array}{l}4 / 1 / 70 \\
1400\end{array}$ & $\begin{array}{l}18^{\circ} 21.5^{\prime} \mathrm{N} \\
64^{\circ} 45.7^{\prime} \mathrm{W}\end{array}$ & 30 & $P$ & $\begin{array}{l}\text { 4" coarse sand, reef debris } \\
\text { coral heads visible }\end{array}$ \\
\hline$P-3$ & $\begin{array}{l}4 / 2 / 70 \\
0820\end{array}$ & $\begin{array}{l}18^{\circ} 25.9^{\prime} \mathrm{N} \\
64046.6^{\prime} \mathrm{W}\end{array}$ & 102 & G & $\begin{array}{l}1 / 3 \text { bucket fine to coarse sand } \\
\text { no shells, coral visible }\end{array}$ \\
\hline$P-4$ & $\begin{array}{l}4 / 4 / 70 \\
0800\end{array}$ & $\begin{array}{l}18^{\circ} 19.0^{\prime} \mathrm{N} \\
64^{\circ} 43.5^{\prime} \mathrm{W}\end{array}$ & 28 & G & $\begin{array}{l}1 / 4 \text { bucket shelly sand } \\
\text { coral visible }\end{array}$ \\
\hline
\end{tabular}

Although all these stations proved too granular for DOSP operations, ample time was available for DOSP "dry" runs aboard ship (some time was spent on ship's repairs, provisioning, other experiments, and servicing the TEKTITE site during this period). At station P-2, water clarity afforded an opportunity for scuba diver examination of the DOSP and extensive $35 \mathrm{~mm}$ still camera and underwater television coverage of its mechanical performance. This period was also useful for working out optimum handling techniques with the ship's crew.

Examination of ship's charts indicated soft sediment areas off Ponce, P.R., and at the end of this first operation period the ship moved to that area. Discussion of DOSP operations are included in Phase III below.

Phase II Studies: Apri1 8-22, 1970

During this period, the DOSP system was secured aboard the ADVANCE II and the authors undertook an extensive investigation of potential soft sediment areas on the Virgin Islands plateau. From Phase I studies, further discussion with CRI personnel, and examination of all available Coast and Geodetic Survey charts, the only likely local area remaining was the south coast of St. Croix. In cooperation with USNUSC, the AVR VAST was leased for a 1-day sediment sampling survey (April 21, 1970). Table 2 expresses the results of this survey.

In Table 2, the number of attempts with any particular sampler at a given station is indicated parenthetically. Scuba surveys were made at a number of sites to 100 feet water depths near Fredriksted, St. Croix, and indicated coarse shelly sand in pockets between coral reef structures.

\section{Phase III Studies: April 6, 7 and Apri1 26-28, 1970}

As noted in Phase I above, operations with the DOSP were begun at the end of the first test period aboard the R/V ADVANCE II in the vicinity of Ponce, P.R. These operations were continued in that region in the second test period as a result of Phases I and II studies above. Figure 4 illustrates the study area with stations noted and described in Table 3 . 
TABLE 2

PHASE II STATION DATA

\begin{tabular}{|c|c|c|c|c|}
\hline Station & Co-ordinates & $\frac{\text { Water Depth }}{\text { (feet) }}$ & Sampler & Recovery \\
\hline Sl & $\begin{array}{l}17^{\circ} 40.6^{\prime} \mathrm{N} \\
64^{\circ} 45.5^{\prime} \mathrm{W}\end{array}$ & 39 & $G(2)$ & None \\
\hline S2 & $\begin{array}{l}17^{\circ} \mathrm{O}_{40} .3^{\prime} \mathrm{N} \\
64^{\circ} \mathrm{O}_{45} .9^{\prime} \mathrm{W}\end{array}$ & 30 & $\begin{array}{l}G(1) \\
P(1)\end{array}$ & Live coral section \\
\hline s3 & $\begin{array}{l}17^{\circ} 39.9^{\prime} \mathrm{N} \\
64^{\circ} 48.6^{\prime} \mathrm{W}\end{array}$ & 42 & $P(2)$ & Coral fragments, sand \\
\hline S4 & $\begin{array}{l}17^{\circ} 39.0^{\prime} \mathrm{N} \\
64^{\circ} 48.0^{\prime} \mathrm{W}\end{array}$ & 39 & $P(1)$ & Single piece fresh coral \\
\hline S5 & $\begin{array}{l}17^{\circ} 39.9^{\prime} \mathrm{N} \\
64^{\circ} 50.1^{\prime} \mathrm{W}\end{array}$ & 21 & $\begin{array}{l}G(1) \\
P(1)\end{array}$ & None \\
\hline S6 & $\begin{array}{l}17^{\circ} 39.4^{\prime} \mathrm{N} \\
64^{\circ} 49.9^{\prime} \mathrm{W}\end{array}$ & 27 & $G(3)$ & Live coral \\
\hline s7 & $\begin{array}{l}17^{\circ} 39.5^{\prime} \mathrm{N} \\
64^{\circ} .52 .5^{\prime} \mathrm{W}\end{array}$ & 27 & $G(2)$ & Live coral \\
\hline S8 & $\begin{array}{l}17^{\circ} 45.3^{\prime} \mathrm{N} \\
64^{\circ} 54.8^{\prime} \mathrm{W}\end{array}$ & 48 & $G(3)$ & Coarse shelly sand \\
\hline s9 & $\begin{array}{l}17^{\circ} 44.9^{\prime} \mathrm{N} \\
64^{\circ} 53.9^{\prime} \mathrm{W}\end{array}$ & 48 & $G(1)$ & None \\
\hline S10 & $\begin{array}{l}17^{\circ} 44.3^{\prime} \mathrm{N} \\
64^{\circ} 53.9^{\prime} \mathrm{W}\end{array}$ & 42 & $G(1)$ & Coarse shelly sand \\
\hline
\end{tabular}

TABLE 3

PHASE III STATION DATA

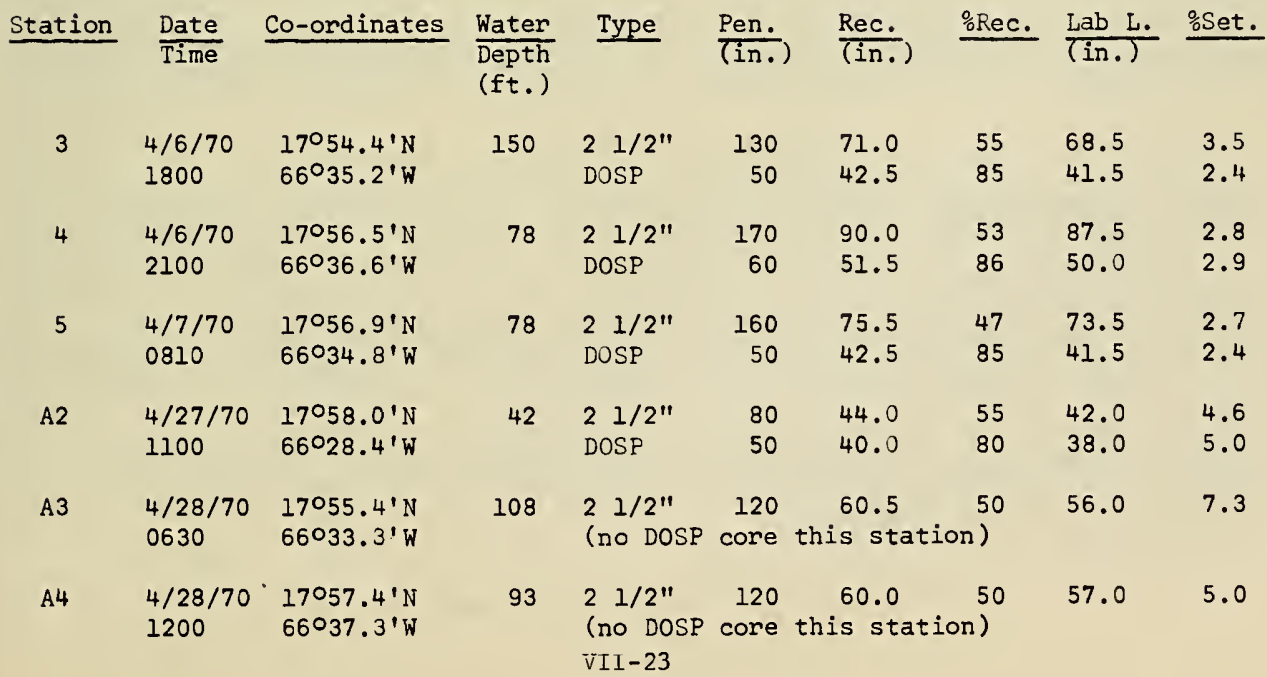




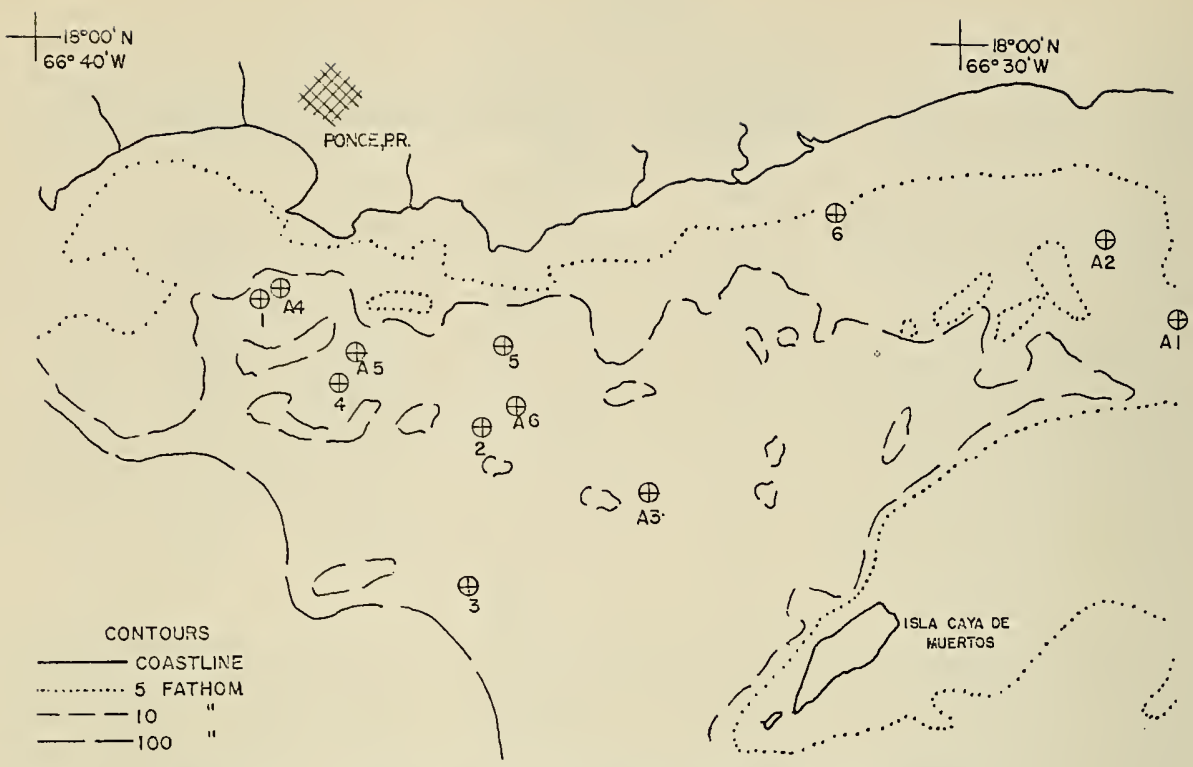

Figure 4. DOSP Data Stations for Phase III Studies

Penetration, recovery, percent recovery, length of sample in the laboratory (after transportation) and percent settlement are as noted in Table 3 . Operations at each station indicated involved preliminary sampling with Pheleger and grab samplers, collection of a gravity core and anchoring for DOSP operations. The latter were accomplished by initial operations in the water column, 20 feet above the ocean floor, probe cycling and data acquisition in the sediment, DOSP sampling of the sediment, recycling in the water column, and securing on deck to move to the next station. Of the stations shown in Figure 4, only six were analyzed in detail in this study. Four of the stations produced samples used in an auxiliary core disturbance study, and two others proved too granular for DOSP operations. All cores collected were velocity logged, described and sent (courtesy USN) via air freight in dry ice to URI for further laboratory analysis.

\section{LABORATORY INVESTIGATIONS}

Routine laboratory tests following the procedures in Lambe (1961) were run on

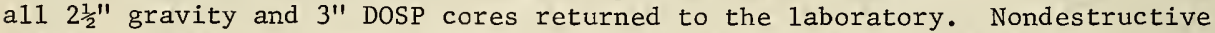
tests included $x$-ray radiography for structure delineation and velocity logging. At each foot level in the cores, representative samples were selected for triaxial shear strength tests and determination of general physical properties. Table 4 summarizes the range, mean $(\bar{x})$, standard deviation, number of determinations ( $n$ ) and units used for all properties determined in situ and in the $1 \mathrm{ab}$.

In Table 4, derived acoustic properties $(\mathrm{Z}, \mathrm{R}, \mathrm{BL})$ are as defined in Bartberger (1965). Mineralogical identification was done by x-ray diffraction analysis as described in Cullity (1967). 
TABLE 4

DATA SUMMARY

\begin{tabular}{|c|c|c|c|c|c|c|}
\hline Property & Symbol & Range & $n$ & $\overline{\mathrm{x}}$ & s.d. & Units \\
\hline Velocity & $v_{c}$ & $4937-5129$ & 30 & 5020 & 52 & $\mathrm{ft} / \mathrm{sec}$ \\
\hline Attenuation & $\alpha$ & $0.86-6.00$ & 9 & 2.59 & 2.07 & $\mathrm{db} / \mathrm{ft}$ \\
\hline Shear Strength & $q_{f} / P_{f}$ & $0.222-1.214$ & 25 & 0.538 & 0.225 & dimensionless \\
\hline$\frac{1}{2}$ Sum Principal Stresses & $P_{f}$ & $0.28-7.76$ & 25 & 1.94 & 1.55 & $1 \mathrm{~b} / \mathrm{in}^{2}$ \\
\hline Water Content & W.C. & $43.8-130.1$ & 36 & 66.9 & 24.1 & percent \\
\hline Liquid Limit & L.L. & $38.0-72.2$ & 36 & 51.1 & 10.2 & percent \\
\hline Plastic Limit & P.L. & $26.0-53.8$ & 35 & 34.2 & 5.5 & percent \\
\hline Specific Gravity & S.G. & $2.64-2.96$ & 36 & 2.78 & 0.07 & dimensionless \\
\hline Void Ratio & e & $1.35-3.59$ & 36 & 1.74 & 0.80 & dimensionless \\
\hline Dry Density & $\gamma_{d}$ & $38.5-84.5$ & 36 & 65.0 & 11.7 & $1 \mathrm{~b} / \mathrm{ft}^{3}$ \\
\hline Total Density & $\gamma_{t}$ & $88.5-119.4$ & 36 & 105.7 & 7.8 & $1 \mathrm{~b} / \mathrm{ft}^{3}$ \\
\hline Buoyant Density & $\gamma \mathrm{b}$ & $24.5-55.4$ & 36 & 41.7 & 7.8 & $\mathrm{Ib} / \mathrm{ft}^{3}$ \\
\hline Mean Grain Size & $\phi_{\mathrm{m}}$ & $5.0-6.8$ & 36 & 6.2 & 0.5 & dimensionless \\
\hline Porosity & $\theta$ & $54.5-77.9$ & 36 & 63.5 & 6.3 & percent \\
\hline \&Sand & $\% S$ & $20-49$ & 36 & 34 & 7 & percent \\
\hline \&Silt & $\$ z$ & $30-64$ & 36 & 45 & 8 & percent \\
\hline \&Clay & $8 \mathrm{C}$ & $14-27$ & 36 & 21 & 4 & percent \\
\hline Sorting Coefficient & $\mathrm{S}_{\mathrm{O}}$ & $3.2-4.7$ & 10 & 3.3 & 0.4 & dimensionless \\
\hline \&Carbonates & $\mathrm{CO}_{\overline{3}}$ & $25-59$ & 6 & 45 & 9.1 & percent \\
\hline sorganics & Org. & $0-1$ & 6 & 0.2 & 0.4 & percent \\
\hline Impedance & $\mathrm{Z}$ & $2.12-2.91$ & 36 & 2.55 & 0.20 & $\mathrm{gm} / \mathrm{cm}^{2}-\mathrm{sec}$ \\
\hline Reflection Coefficient & $R$ & $0.15-0.26$ & 6 & 0.19 & 0.04 & dimensionless \\
\hline Bottom Loss & $\mathrm{BL}$ & $11.8-16.1$ & 6 & 14.4 & 1.7 & decibels \\
\hline
\end{tabular}

\section{RESULTS}

Sediment Classification

From the field observations and average properties (Table 4), the following generalizations can be made about the sediments in the study area (Figure 4):

1. The area is one of active circulation and fairly irregular bottom topography. Little recently derived terrestrial material remains in the area primarily because of strong currents and low sources (Ehlmann, 1968).

2. The sediment is composed predominantly of reworked reef material, shells and locally derived reworked sand and silt. The prevalent mineralogy is aragonite and calcite with smaller amounts of quartz and plagioclase (x-ray diffraction).

3. Sorting is poor to unsorted at all sites with equal amounts of sand and silt and a lesser amount of clay. The sediment is almost uniformly sandy mud to sandy silt (Folk, 1964).

4. The relative increase of $\mathrm{V}_{C}, \mathrm{qf}, \gamma_{\mathrm{t}}$ (and therefore $\mathrm{Z}$ ), and decrease of W.C. and $\theta$ with depth in the sediment (Lewis, 1971) is probably a result of in situ cementation due to an excess of carbonates and warm temperatures and 
(to a lesser extent) to local consolidation effects. The area appears to be reworked to a large extent by organisms which probably contributes to its nonlayered or mixed depositional character.

5. There is little apparent variation with depth or lateral variation in: P.L., L.L., $\phi_{\mathrm{m}}, \% \mathrm{CO}_{3}^{-}$or $\% \mathrm{~S}, \% \mathrm{z}$ or $\% \mathrm{C}$, and this is $1 \mathrm{ikely}$ due to a rapid sedimentation rate and reworking as discussed above. The organic content (excluding carbonates) is negligibly low. There does not appear to be a significant organic decay and associated gas formation in situ.

\section{Average Elastic Properties}

From Table 4 and the assumption of a homogeneous, isotropic, elastic model for the sediment (Jaeger, 1962), one can calculate average elastic properties including: incompressibility $(\mathrm{k})$, Poisson's ratio $(\nu)$, elastic or Young's modulus (E), shear modulus $(G)$, Lame's parameter $(\lambda)$, and shear wave speed $\left(V_{S s}\right)$. Average constants used in these determinations are listed in Table 5 (conversion to cgs system is to facilitate comparisons in correlation section below):

TABLE 5

CONSTANTS FOR AVERAGE ELASTIC PROPERTIES

\begin{tabular}{|c|c|c|c|}
\hline Property & Symbol & Value & Units \\
\hline Water Density & $\gamma_{w}$ & 1.03 & $\mathrm{gm} / \mathrm{cm}^{3}$ \\
\hline Solids Density & $\gamma_{s}$ & 2.78 & $\mathrm{gm} / \mathrm{cm}_{3}^{3}$ \\
\hline Total Density & $\gamma_{t}$ & 1.69 & $\mathrm{gm} / \mathrm{cm}^{3}$ \\
\hline Porosity & $\theta$ & 63.5 & percent \\
\hline Water Sound Speed & $\mathrm{V}_{\mathrm{W}}$ & $1.541 \times 10_{5}^{5}$ & $\mathrm{~cm} / \mathrm{sec}$ \\
\hline Sediment Sound Speed & $v_{c}$ & $1.530 \times 10^{5}$ & $\mathrm{~cm} / \mathrm{sec}$ \\
\hline Solids Sound Speed & $v_{s}$ & $6.000 \times 10^{5}$ & $\mathrm{~cm} / \mathrm{sec}$ \\
\hline
\end{tabular}

In Table 5 the solids sound speed $\left(V_{S}\right)$ is as suggested in Nafe (1957), and $V_{W}$ is the average in situ water sound speed (Lewis, 1971). Table 6 1ists the

TABLE 6

AVERAGE ELASTIC PROPERTIES

\begin{tabular}{|c|c|c|c|c|}
\hline Properties & Definition & Units & L & $\mathrm{H}$ \\
\hline k & $\left\{\frac{\phi}{\rho_{W}\left(V_{w}\right)^{2}}+\frac{(1-\phi)}{\rho_{S}\left(V_{S}\right)^{2}}\right\}^{-1}$ & $x 10^{10}$ dyne $/ \mathrm{cm}^{2}$ & 3.79 & 3.58 \\
\hline \multirow[t]{2}{*}{$v$} & $3-\left(\rho_{t}\right)\left(v_{c}^{2} / k\right)$ & \multirow[t]{2}{*}{ dimensionless } & \multirow[t]{2}{*}{0.483} & \multirow[t]{2}{*}{0.463} \\
\hline & $3+\left(\rho_{t}\right)\left(v_{c}^{2} / k\right)$ & & & \\
\hline G & $\left\{\rho_{t} v_{c}^{2}-k\right\}^{3 / 4}$ & $x 10^{10}$ dyne $/ \mathrm{cm}^{2}$ & 0.084 & 0.273 \\
\hline \multirow[t]{2}{*}{$E$} & $9 k\left(0_{t} v_{c}^{2}\right) /(k-1)$ & \multirow[t]{2}{*}{$\times 10^{10}$ dyne $/ \mathrm{cm}^{2}$} & \multirow[t]{2}{*}{0.379} & \multirow[t]{2}{*}{0.776} \\
\hline & $\left(\rho_{t} V_{c}^{2}\right) /(k+3)$ & & & \\
\hline$\lambda$ & $k-(2 / 3) G$ & $\times 10^{10}$ dyne $/ \mathrm{cm}^{2}$ & 3.74 & 3.40 \\
\hline \multirow[t]{2}{*}{$v_{\text {ss }}$} & $\mathrm{v}_{\mathrm{c}}$ & $\mathrm{cm} / \mathrm{sec}$ & \multirow[t]{2}{*}{0.277} & \multirow[t]{2}{*}{0.409} \\
\hline & $\left\{\frac{1-v}{0.5-v}\right\}^{1 / 2}$ & $I-26$ & & \\
\hline
\end{tabular}


average (derived) elastic properties and includes defining relationships. The total compressibility $(k)$ ) is assumed to be derived from the porosity fractional contribution of that for water and dry sediment (Hamilton, 1965). The column headed "L" is for properties determined herein, and that headed " $\mathrm{H}^{\prime}$ corresponds to average continental terrace (North Pacific) properties determined by Hamilton (1971).

In general, the properties determined herein fit those described by Hamilton (1971) for continental terrace materials, with the slightly higher moduli and sound propagation speeds for the latter associated with the presence of relatively coarser material (silty sand to sand). The comparison is fair although Hamilton does not report any investigations in carbonate sediments, but the percent carbonate does not generally determine these elastic parameters unless it is entirely in the form of oolitic shells (Greffard, 1969). In both studies the shear wave sound speed is approximately $1 / 5$ to $1 / 4$ of the compressional wave sound speed and this is due entirely to the rather low rididity (G) of these high porosity sediments.

\section{Correlation of In Situ and Laboratory Data}

Sound speed and laboratory properties were correlated at corresponding sediment levels for all sites. A complete statement of this analysis is given in Lewis (1971). Figures 5-9 illustrate these correlations where the symbol " $x$ " represents gravity corer data and " $\theta$ " indicates DOSP sample data. Curves are labeled: "L" = this report; "H" = Hamilton (1971); "C" = Cernock (1970); "F" = Faas (1969); "M" = McLeroy (1968); and "K" = Kermabon (1968). (Units are given in Table 4.)

Figure 5: Velocity versus Shear Strength

$$
\begin{array}{ll}
L_{1}: & v_{c}=170.5(\mathrm{~d} / \mathrm{P})_{f}+4906 \\
L_{2}: & v_{c}=177.0\left(q_{f} / P_{o}\right)+4915
\end{array}
$$

Subscripts ' $f$ ' and ' $O$ ' refer to conditions at failure and at primary consolidation respectively in the consolidated undrained triaxial shear strength test (D'Andrea, 1966).

Figure 6: Porosity versus Density

$$
\begin{array}{lll}
\text { L: } & & \theta=146-49.3 \rho_{t} \\
\text { H: } & & \theta=156-57.0 \rho_{t} \\
\text { C: } & & \theta=165-62.7 \rho_{t}
\end{array}
$$

Figure 7: Impedance versus Density

$$
\begin{array}{ll}
\text { L: } & Z=1.615 \rho_{t}-0.146 \\
\text { C: } & Z=1.608 \rho_{t}-0.153
\end{array}
$$




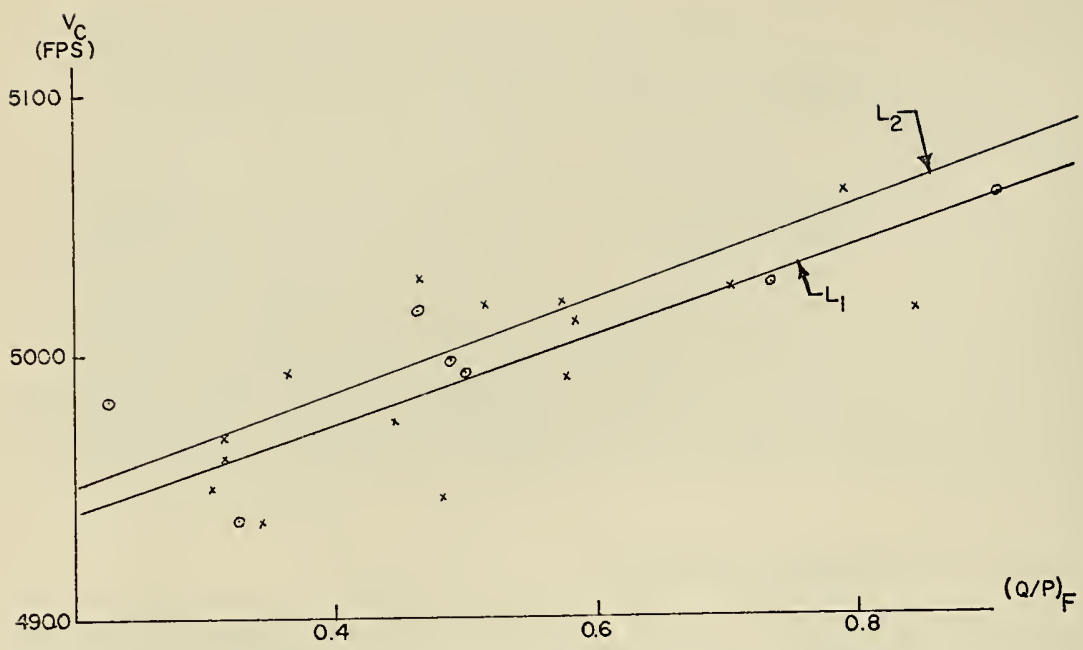

Figure 5. Sound Speed Versus Shear Strength

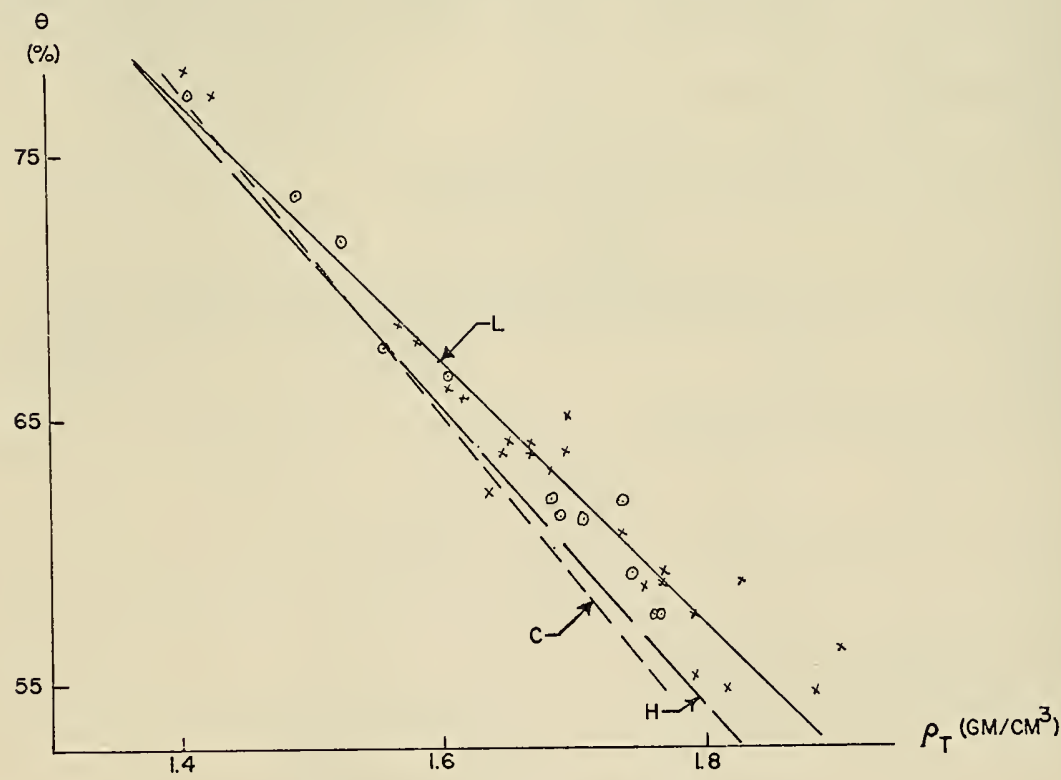

Figure 6. Porosity Versus Density 


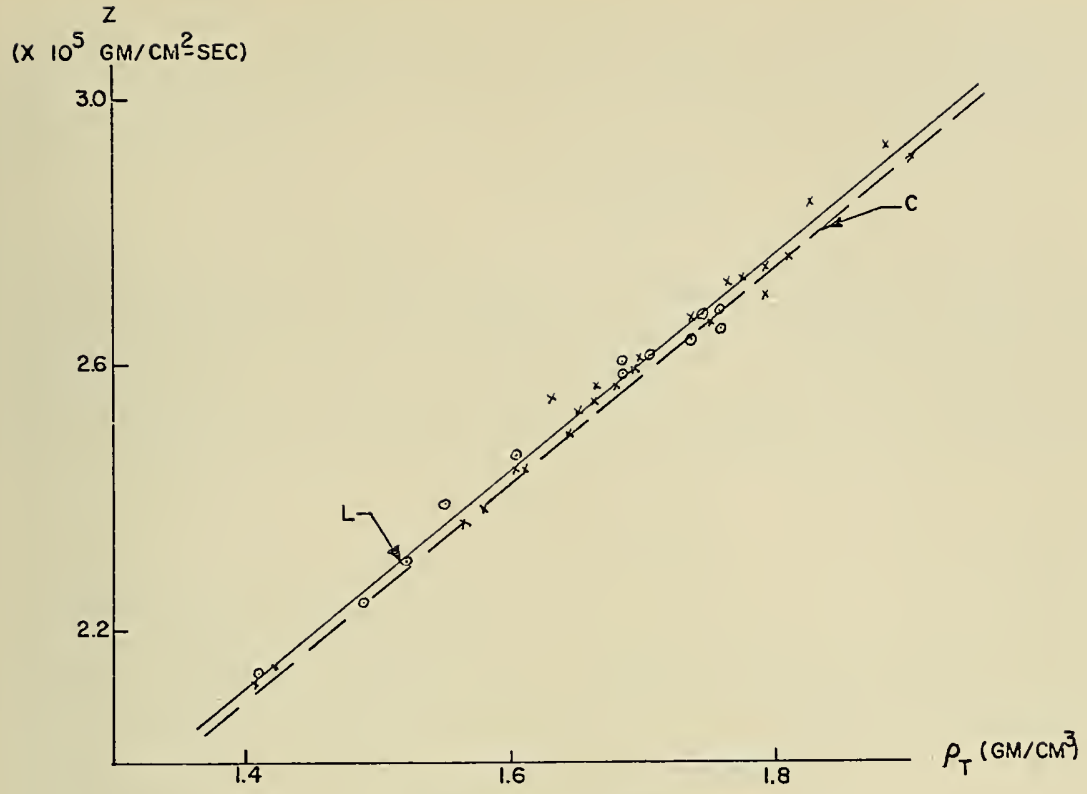

Figure 7. Impedance Versus Density

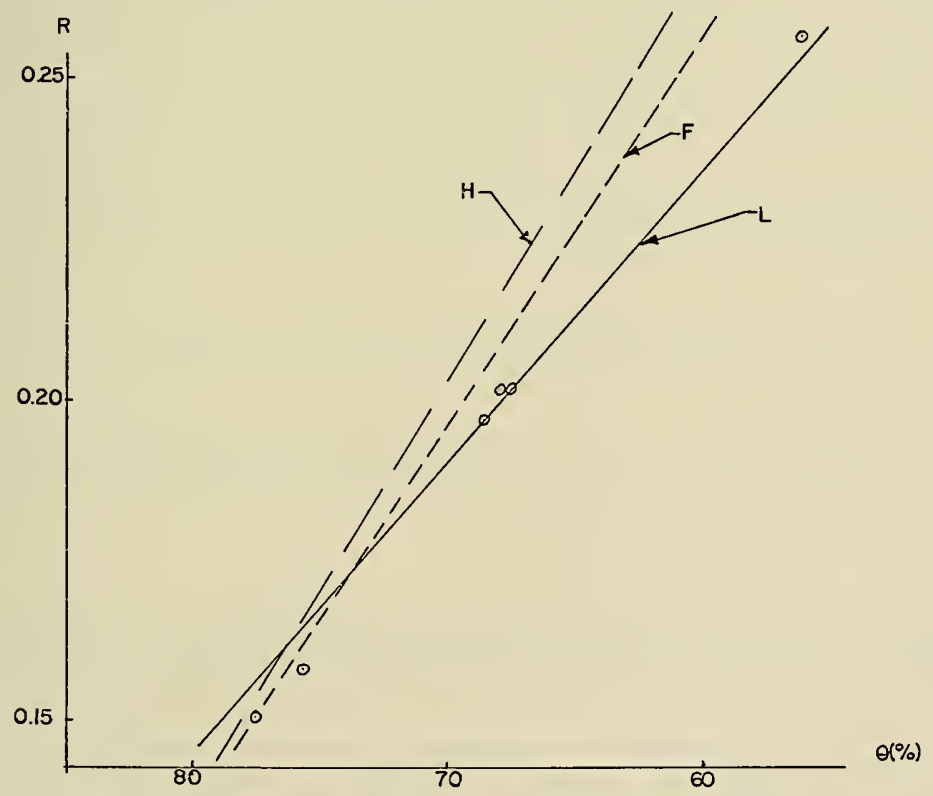

Figure 8. Reflection Coefficient Versus Porosity 


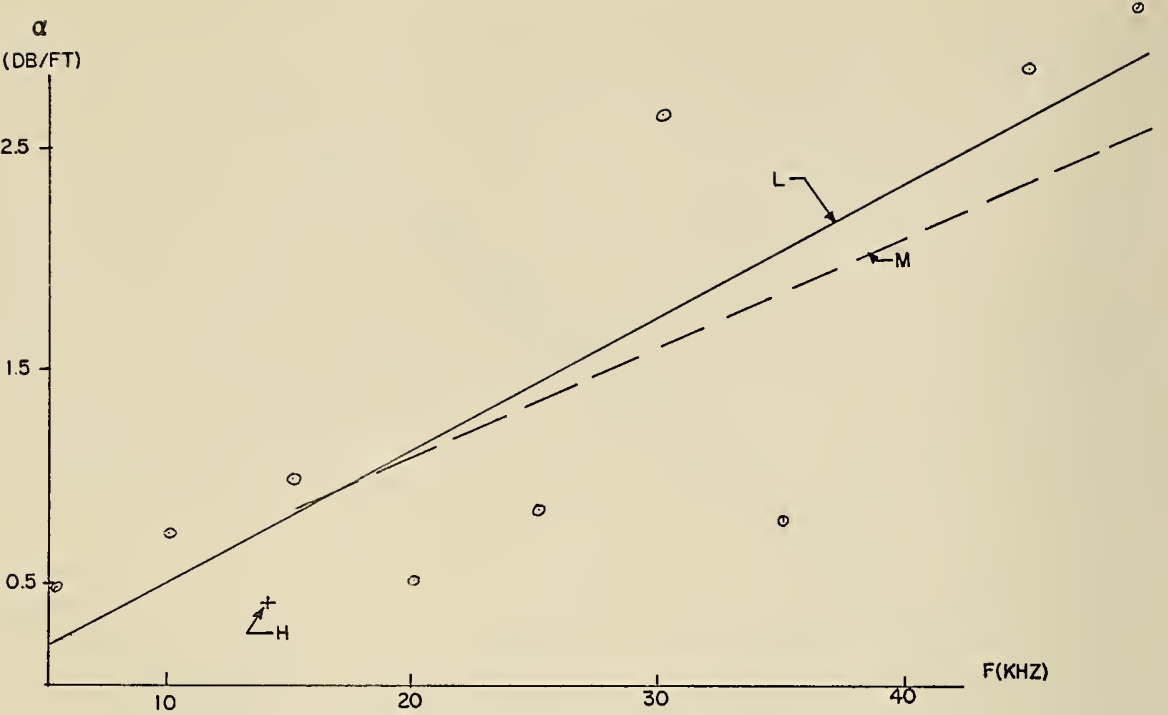

Figure 9. Attenuation Versus Frequency

Figure 8: Reflection Coefficient (normal incidence) versus Porosity

$$
\begin{array}{ll}
L: & R=0.497-0.0044 \theta \\
F: & R=0.647-0.0065 \theta \\
H: & R=0.669-0.0066 \theta
\end{array}
$$

Figure 9: Attenuation versus Frequency

$$
\begin{array}{ll}
\mathrm{L}: & \alpha=0.062 \mathrm{f}-0.154 \\
\mathrm{M}: & \alpha=0.05 \mathrm{f}
\end{array}
$$

For all these relationship plots, the linear regression coefficient ( $r$ ) is at least as large in absolute value as that required for a $95 \%$ assurance of 1 inear correlation (Young, 1962).

\section{CONCLUS IONS}

This report describes a unique instrument for in situ investigation and samp1ing of ocean sediments. Precise sound speeds determined with the DOSP, coupled with density or porosity determined in the laboratory on the sample that the DOSP provides, are the only parameters required to characterize the sediment in terms of its elastic properties. This DOSP also provides a means of obtaining attenuation of compressional sound waves in situ in sediment. Empirical relations have been given whereby (to first order) sediment shear strength for high porosity marine sediments can be predicted from the precise in situ measurement of 
only sound speed. No sound speed relation to other physical or compositional properties was determined in this study. Future use of the DOSP, including the application of density and/or porosity gages (Erchul, 1971; Rose, 1971) may provide sufficient data to characterize the sediment without the need for recovering a sample.

\section{ACKNOWLEDGEMENTS}

The DOSP is being co-developed under contractual agreement between URI and the U.S. Navy Underwater Systems Center, New London, Connecticut. The authors wish to thank Dr. E. Towle of the Caribbean Research Institute, Col. J. Smith of the Research Triangle Institute, and personnel of the TEKTITE II office, U.S. Department of the Interior, for their cooperation in providing use of the $\mathrm{R} / \mathrm{V}$ ADVANCE II and transportation of personnel and equipment for this investigation.

\section{REFERENCES CITED}

Bartberger, C. 1965. Lecture notes on underwater acoustics. USN Air Dev. Center Rept. NADC-WR-6509, 415 p.

D'Andrea, R. 1966. In situ shear strength characteristics of a saturated silt. M.S. Thesis. Dept. Civil Engr., Univ. Rhode Island. 62 p.

Ehlmann, A. 1968. Clay mineralogy of weathered products and of river sediments, Puerto Rico. J. Sed. Petr. 38: 885-894.

Erchul, R. 1971. The use of electrical resistivity measurements to predict porosity of marine sediments. A paper to be presented at the United Nations UNESCO Conf. on Ocean Floor Engineering, Seattle, Wash. (July 1971)

Faas, R. 1969. An empirical relationship between reflection and ocean bottom sediments. Geophysics 34: 546-553.

Folk, R. 1964. Petrology of sedimentary rocks. Univ. Texas Press, Austin, Texas. $64 \mathrm{p}$.

Greffard, J. 1969. Contribution of L'etude des relations entre la propagation $\mathrm{du}$ son et la nature physico-chemique des sediments marins. (In French)

Cahiers Oceanog. XXI: 145-171.

Hamilton, E. 1965. Geoacoustic model of the ocean floor. USN Undersea Research and Dev. Center Rept. 1283, 52 p.

Hamilton, E. 1971. Elastic properties of marine sediments. J. Geophysical Research 76: 579-604

Hvorslev, M. 1949. Subsurface exploration and sampling of soils for civil engineering purposes. USA Corps of Engineers, Waterways Experiment Sta., Vicksburg, Miss. 521 p.

Jaeger, J. 1962. Elasticity, fracture and flow. John Wiley and Sons, New York. $208 \mathrm{p}$. 
Kermabon, A., C. Gehin and B. Balvier. 1968. The relationship of porosity with density, electrical resistivity and sound velocity of some unconsolidated deep sea sediments taken from the Tyrrhenian Sea. SACLANT ASW Research Centre TR 114, La Spezia, Italy. 30 p.

Lambe, W. 1961. Soil testing for engineers. John Wiley and Sons, New York, $165 \mathrm{p}$.

Lewis, L., V. Nacci and J. Gallagher. 1969. In situ investigation of ocean sediments. Proc. Amer. Soc. Civil Engr. Conf. on Civil Engineering in the Oceans II, Miami Beach, Fla., 641-655.

Lewis, L., V. Nacci and J. Gallagher. 1970. In situ marine sediment probe and coring assemb1y. USN Underwater Systems Center Rept. NUSL 1094. 18 p.

Lewis, L. 1971. An investigation of marine sediments using the Deep Ocean Sediment Probe (DOSP). Ph.D. Thesis. Dept. Ocean Engr., Univ. Rhode Island. $206 \mathrm{p}$.

McLeroy, E. and A. DeLoach. 1968. Sound speed and attenuation at $15-1500 \mathrm{kHz}$ measured in natural sea floor sediments. J. Acous. Soc. Am. 44: 1148-1150.

Nafe, J. and C. Drake. 1957. Variation with depth in shallow and deep water marine sediments of porosity, density, and the velocity of compressional and shear waves. Geophysics 22: 523-552.

Rose, V. and J. Roney. 1971. A nuclear gage for in place measurement of sediment density. Proc. Third Ann. Offshore Technology Conf. (Paper 1329)

Rosefelder, A. and F. Marshal1. 1967. Obtaining large, undisturbed and oriented samples in deep water. In A. Richards (ed.) Marine Geotechnique, Univ. Illinois Press, Urbana, I1l., 243-263

Young, H. 1962. Statistical treatment of experimental data. McGraw Hill Book Co., New York. 172 p. 
IN SITU MEASUREMENTS OF SMALL ANGLE SCATTERING

OF A LIGHT BEAM IN THE SEA

Dr. Eric J. Softley

Genera1 Electric Company

\section{ABSTRACT}

An instrument was designed, constructed, and operated for the measurement of scattering of light in the sea. Particular attention was paid to scattering near the beam axis (small angle scattering). Experiments were run near St. John, V.I., as part of the TEKTITE II Ocean Survey Program. Water samples were taken and analyzed during the experiment. Considerable scattering data were obtained.

\section{INTRODUCTION}

The design and operation of systems in the sea which depend on optical radiation necessitate the need for knowledge about the transmission of energy in the optical band through the sea. This energy, as it propagates, is attenuated by scattering and absorption. The scattering, when due to the transmission through a volume of water, is highly dependent on the angle from the initial beam. For a parallel beam of 1 ight through an elemental volume $\mathrm{dV}$, the volume scattering, as defined by:

$$
\mathrm{dP}_{\mathrm{S}}=\sigma(\theta) \mathrm{PdV}
$$

has the form shown in Figure 1.

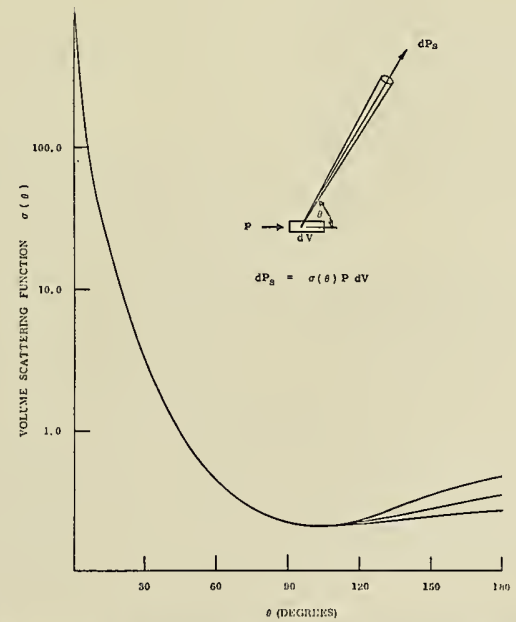

Figure 1. The volume scattering function 
It is readily seen from the figure that the scattering peaks strongly in the forward direction and in fact may be orders of magnitude higher than the scattering at, say, $90^{\circ}$. This forward scattering has an important relationship when considered in terms of the performance of an optical system underwater. The resolution of any underwater viewing system is very strongly dependent on the small angle scattering function.

One of the most interesting features of the small angle scattering is its variability. This variability of the small angle scattering could be due to turbulence within the water. If this is true, then one would expect the small angle scattering to be strongly time dependent with time constants characteristic of turbulence within the water. This means that the beam cannot be enclosed, as is characteristic of optical instruments used in the sea. Therefore, the experiment described here is aimed at the measurement of small angle scattering with attendant measurements of scattering at other angles and with the light beam external to the instrument.

\section{OBJECTIVE}

The objectives of the experiment are to measure the distribution of light in a plane normal to a parallel beam of light in the ocean. These measurements are then converted to a measurement of small angle scattering through an integral relationship. This scattering will be referenced to scattering measurements at other values of the scattering angle $\theta$.

\section{EQUIPMENT}

The requirements for the instrument can be summarized as:

1. Deployable in both shallow and deep water.

2. Produce a parallel, narrow beam of light.

3. Beam external to the instrument.

4. Measurement of light distribution in a plane normal to beam

(including unscattered $\mathrm{flux}$ ).

5. Measurements of scattering at $\theta=45^{\circ}, 90^{\circ}, 135^{\circ}$, and near $180^{\circ}$.

6. Beam near $5000 \mathrm{~A}$ (to minimize absorption).

7. All high voltages internal to instrument.

8. Real time measurement and recording.

9. Variable length.

The instrument was designed to accommodate all of these requirements. The basic instrument is depicted in Figure 2. An $8^{\prime \prime}$ diameter tube served both as an optical bench and as a housing for the electronics. This was intersected by housings

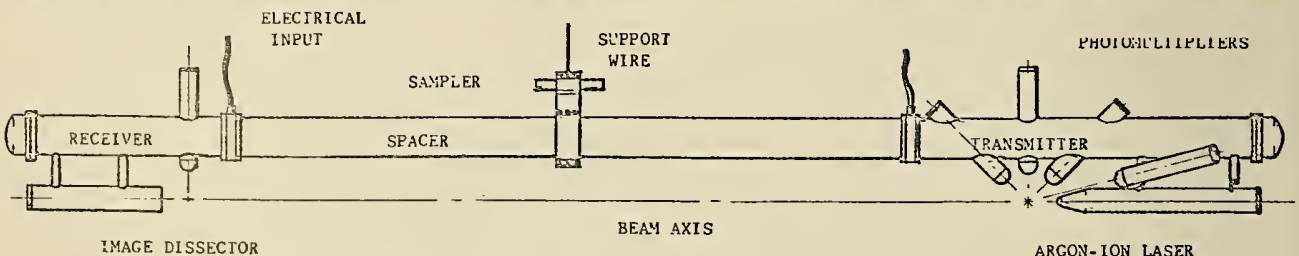

Fig. 2. Basic instrument layout 
for five photomultipliers. The light source was a modified pulsed argon-ion laser and beam collimator in its own pressure housing and located at one end of the main beam. At the other end, a separate pressure housing holds an image dissector tube, focus and deflection coils. By sweeping the dissector at a rate $(4 \mathrm{~Hz})$ much slower than the laser pulse rate $(400 \mathrm{~Hz})$ continuous sweeps of the light flux distribution on a plane normal to the beam were obtained.

The beam housing was in three parts with the electronic and optical components housed in the transmitter or received subsections. The center section serves as a spacer and was either $1^{\prime}, 6^{\prime}$, or $3^{\prime}$ in length. The instrument can be assembled for measurement with beam lengths of from 3' (no spacer) to 24' (al1 spacers) in $3^{\prime}$ steps. All beam housing components were of $6061 \mathrm{~T} 6$ aluminum alloy, hard black anodized. The aluminum was chosen to optimize requirements of weight, external pressure capability, stiffness, corrosion, and availability. Final instrument weight with the $12^{\prime}$ spacer was about $5501 \mathrm{bs}$. and the instrument was capable of $500 \mathrm{ft}$ depth.

The final assembly is shown in Figure 3 where an assembled instrument is shown as located on the boat used for the TEKTITE II experiments. The laser beam has about 5 milliradian divergence. This was unacceptable for the measurements planned and a beam collimator was added to provide a parailel beam. The final beam output was through a flat window in the laser housing.

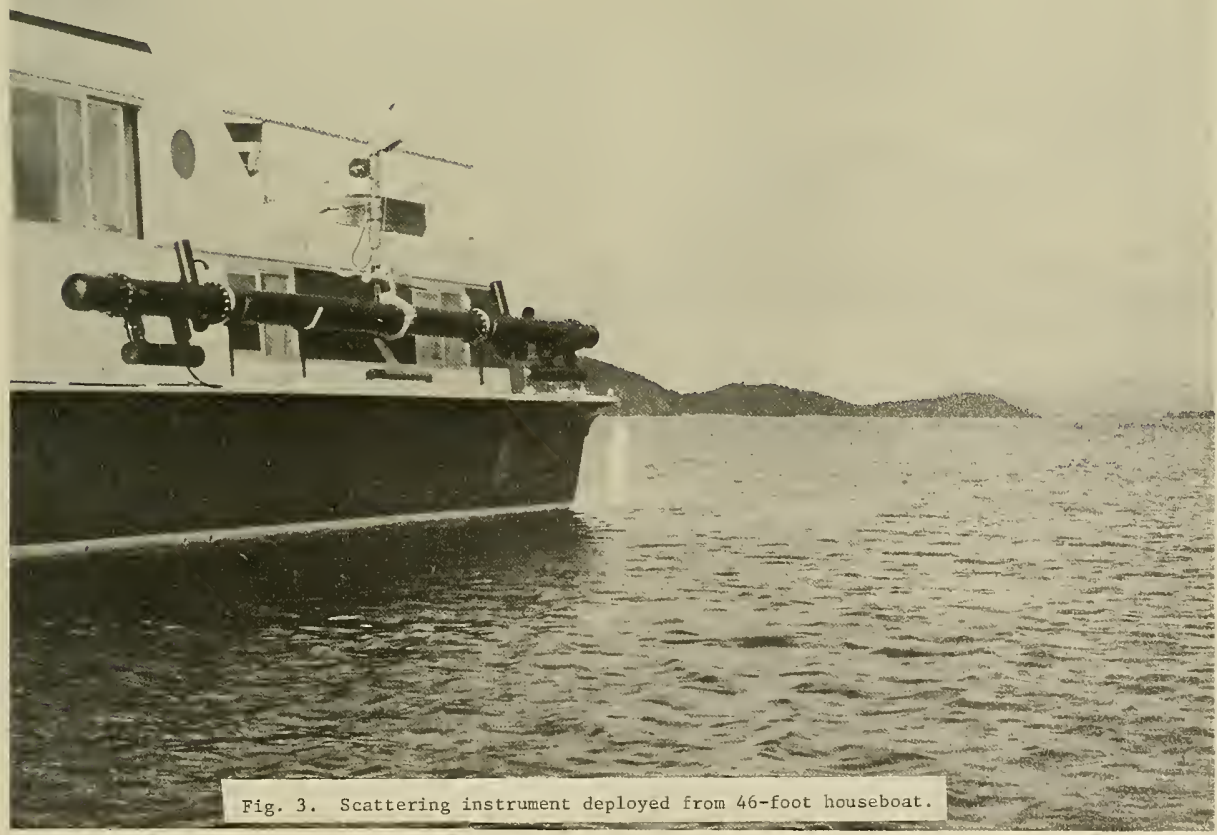


The image dissector provides an output dependent on the distribution of light on the photocathode. For flexibility in design the initial light flux is projected onto a ground glass screen. This screen is the back face of the dissector housing window. The resulting light distribution is then imaged onto the dissector photocathode through an interference filter. The dissector is chosen as the scanning instrument principally because of its wide dynamic range. The device uses a photomultiplier amplifier and high gain with low noise is an important characteristic. The output current from the dissector is

$$
I_{D}(r)=\frac{1}{8} K_{D S} k_{D P} G_{D} A_{p}\left(\frac{1}{I_{N}}\right)^{2}\left(\frac{M_{D}}{I+M_{D}}\right)^{2} P(r) .
$$

The photomultipliers collect scattered radiation, integrated over a small solid angle of view and over the beam volume.

$$
\mathrm{P}_{\mathrm{n}}=\int_{\boldsymbol{\gamma}^{\mathrm{N}}} \int \mathrm{V}_{\mathrm{N}} \boldsymbol{\sigma}(\boldsymbol{\theta}) \mathrm{dPd} \boldsymbol{\Omega}
$$

and a sufficiently accurage approximation gives

$$
\mathrm{P}_{\mathrm{N}}=\boldsymbol{I N} \sigma\left({ }_{\mathrm{N}}\right) \mathrm{P}_{\mathrm{O}} \text {. }
$$

The output current of the photomultiplier is then

$$
I_{N}=K_{N} k_{N} G_{N} \nearrow_{N} \sigma\left(\theta_{N}\right) P_{0}
$$

The basic instrument electronics are shown in block form in Fig. 4. Power comes from a battery pack located in the shipboard power supply. An inverter and regulator produce an output of $115 \mathrm{~V}, 400 \mathrm{~Hz}$. The output voltage is regulated to $.01 \%$. This power is transmitted to the instrument through the power cable and is used as input to the laser and high voltage power supplies. The high voltage for the photomultiplier and dissector bias is generated in a separate supply. Each component has a stacked zener diode supply for individual regulation. With the regulated input power the final high voltage is sufficient constant that variation in the gains are negligible.

The signal current from the photomultiplier is a pulse instantaneously proportional to the input light pulse. The signal processing circuit integrates this current during the dissector sweep. The capacitance of the signal cable from the instrument and an added variable input capacitor collect the current pulse. An FET source follower and second transistor emitter follower maintain signal voltage while reducing output impedance. At the end of the dissector sweep the capacitor is discharged to zero. Hence, the gradient of the output voltage is proportional to the integrated or average laser power. The dissector output is treated differently. The output pulse is fed into a small capacitor and a source follower used for impedance charge. However, the circuit acts as a boxcar maintaining a voltage proportional to the integrated pulse current.

The dissector output, as mentioned earlier, has a wide dynamic range. Hence, after the final emitter follower output a log amplifier is used to reduce the dynamic range of the signal. All signals were recorded continuously on a 14 track Sangamo recorder. Frequency modulation was used to eliminate drop out. The tape was supplied with power directly from the battery pack. 


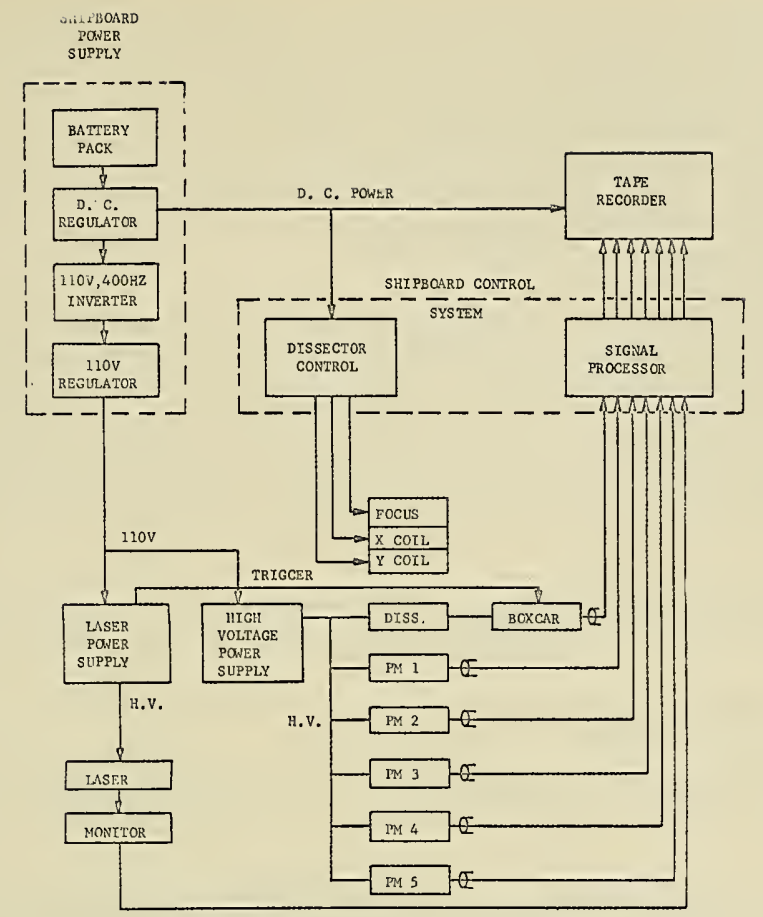

Fig. 4. Block diagram of electronic system

Water samples were obtained with a marine sampling unit attached above the instrument. Sampler can be seen in Fig. 3. A conventional messenger unit is used to operate the sampler during the operating period.

\section{PROCEDURES}

The instrument outputs are $I_{N}, I_{D}$, and the laser monitor. The constants in the photomultiplier and dissector equations are obtained by calibration. For the dissector the signal is read with the instrument in air. A special calibrating rig is used for the photomultiplier calibration. A front-surface mirror deflects the beam into the photomultiplier window. A calibrated neutral density filter reduces the level 5 orders of magnitude. This calibration gives the product

$$
\mathrm{K}_{\mathrm{N}} \mathrm{k}_{\mathrm{N}} \mathrm{G}_{\mathrm{N}}
$$

The factor $\xi_{\mathrm{N}}$ depends on the photomultiplier geometry and the measured attenuation length which can be determined from the dissector output.

The operating procedure for the instrument at sea involves calibration, surface deployment, washing, deployment to depth, operation and retrieval. The on-deck calibration involves recording the dissector output with the laser on. This 
gives the unattenuated beam distribution as a reference. It also allows for checking of the dissector sweep settings and is a critical check of cleanliness of the windows. The instrument is deployed into the water. Whilst at the surface, the windows are swabbed to make sure that they are fully wetted. The instrument is then lowered to the required depth using marks on the cable as depth indicators. During the operating period the signals are recording and water samples taken. After the experiment was completed the instrument was retrieved and replaced on its deck support. The windows are cleaned with fresh water and a second on-deck calibration taken.

The instrument was set at $24-\mathrm{ft}$ total length for the waters off St. John, V.I. A 46-ft Chris Craft houseboat was used for deployment of the instrument, and is shown in Fig. 3. The measurements were made in shallow waters generally, i.e., 50-ft depth. Francis Bay, north of St. John, was the site of most of the measurements. It provided a sheltered location for initial operation of the instrument. Later readings were taken in Lameshur Bay, site of the TEKTITE habitat. Considerable data were obtained with the bulk of the data being in three sequences of measurements:

1. Time Sequence, Francis Bay. A 5-minute period of data was taken each hour from 1800 hrs to $2400 \mathrm{hrs}$, with the instrument on the surface.

2. Depth Sequence, Francis Bay. Readings were taken with the instrument lowered in 10-ft depth steps.

3. Continuous Sequence, Lameshur Bay. A continuous sequence of data for a 15-minute period was taken with the instrument on the surface.

The boat was anchored for operation of the instrument. Because of the large forward "sail area" of the houseboat, the principal anchor was deployed from the stern. This reduced swing to about $\pm 15^{\circ}$ and a light bow anchor reduced this to a much smaller quantity. Some swing of the boat over the submerged instrument was unavoidable but no difficulty in handling was encountered.

\section{RESULTS}

The scattering data has been transferred from magnetic tape to 8 channel chart and an initial analysis of the results started.

The dissector data is shown in Fig. 5. From this can be determined a first evaluation of the small angle scattering (from the scattering extrapolated to zero) and of the attenuation length.

It is, of course, possible to examine this in terms of variation of the center beam and the scattering with time. The peak of the attenuated light is remarkably steady and the scattering also shows little timewise variation.

Some of the reduced data for the depth sequence is shown in Fig. 6 . The variation of attenuation length and scattering with depth can be observed.

Since an accurate calibration of the instrument is not yet available, the resulting volume scattering function cannot yet be shown. Estimates have been made using a nominal calibration only and these indicate that the small angle scattering is on the high side of the band of values as determined by other experimenters. 


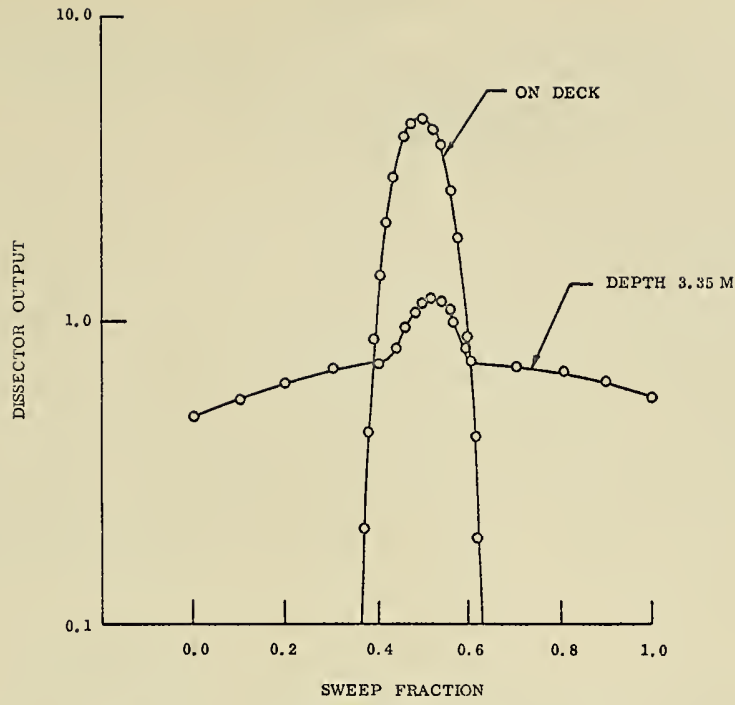

Fig. 5. Typical dissector output

$$
\hat{\mathrm{P}} / \hat{\mathrm{P}}_{\mathrm{o}}, \quad \hat{\mathrm{P}}_{\mathrm{s}} / \hat{\mathrm{P}}_{\mathrm{o}}
$$

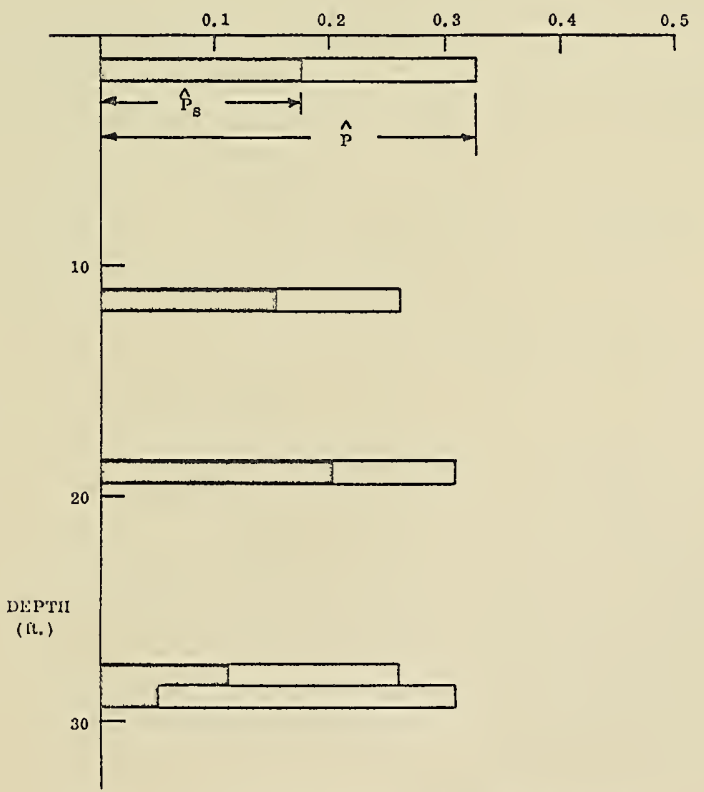

Fig. 6. Proportion of peak attenuated and peak scattered light

$$
\text { VII }-39
$$




\section{CONCLUSIONS}

The instrument was deployed and operated satisfactorily with no major problems. Deployment was made from a leased boat with no modifications to the boat. An extensive amount of data was accumulated.

If the observation that turbulence in the water is not important is later upheld, then the light path can be enclosed allowing operation of the instrument during the daylight hours. 
Dr. Charles Holmes and Dr. Louis E. Garrison Office of Marine Geology, Geological Survey, U. S. Department of Interior

\begin{abstract}
Data for these studies were gathered aboard the $R / V$ ADVANCE II in two phases. The first phase consisted of high-resolution seismic profiles made from April 7-14 by Louis Garrison and Jack Lee of the USGS. The second phase consisted of water samples and grab samples of the bottom sediments. These were collected from April 14 to 18 and from October 18 to 23 by Charles Holmes of the USGS. A11 data collected are being analyzed under a cooperative program between the USGS and the Caribbean Research Institute. A final report will be made in 1971 .
\end{abstract}

Objective: To study the structural geology of the Virgin Island Platform.

To construct a preliminary map of the distribution of certain trace elements in the water and bottom sediments around St. Thomas.

To map and date submerged features around the Virgin Island Platform and St. Croix which relate to former glacially lowered sea levels.

Equipment: High resolution seismic equipment, and water and bottom sampling equipment.

Procedures: Seismic and sampling profiles were conducted aboard the ADVANCE II.

Results: Some preliminary results of interest are:

1) an apparent geochemical anomaly in the waters south of St. Thomas,

2) a widespread distribution of calcareous nodules which may be an important source of sediment on the platform,

3) the subsurface division of the southern part of the Virgin Islands platform into a) a northwestern area of incoherent reflections and small scale roughness on the surface, and b) a southeastern area of distinct, we11-layered reflections and an undulatory surface. A rather sharp boundary zone running southwesterly from Bovocoap Pt., St. John divides the two areas. This could be interpreted as a fault displacement which downdropped the southeastern block, allowing 
a rather thick accumulation of sediments to cover its surface in contrast to a thin veneer of sediment covering bedrock on the upthrown northwestern block.

\author{
FACTORS AFFECTING OZONE CONCENTRATION IN \\ A MARINE ATMOSPHERE \\ Dr. Lyman A. Ripperton \\ University of North Carolina at Chapel Hill
}

\begin{abstract}
Ozone and organic zerosol samples, and supporting meteorological data, were obtained in the vicinity of the Virgin Islands for use in characterizing the behavior of ozone concentration in a marine atmosphere. Ozone measurements were made at two levels above the sea surface using a chemiluminescent type ozone meter. A measure of visibility was obtained using a Charlson Integrating Nephelometer, and samples of aerocollodial material was obtained using a Goetz Moving Slide Impactor. Solar radiation was monitored with a Kipp-Zonen Radiometer. Gas samples were obtained through a Teflon line with the intake positioned in an uncontaminated area. Analysis of the data has not yet been completed.
\end{abstract}

GEOLOGICAL SEDIMENT STUDY

Dr. Alan Lewis Smith

University of Puerto Rico at Mayaguez

\begin{abstract}
This project was not completely successful, since the ADVANCE II only had enough cable to dredge the upper levels of the submarine topographic highs. The only rocks dredged were carbonate rocks. Some, as from the Anegada Bank, appear to be recent fairly shallow water sediments. From the Groppler and Investigator Banks, however, limestones were obtained which initially show similarities to the Tertiary limestones of southern Puerto Rico. Samples of volcanic rocks which are supposed to underlie these limestones were not obtained, since the dredging capability was limited.
\end{abstract}


WEATHER PROGRAM

James R. Smith

Research Triangle Institute

Jesse R. Gulick

National Oceanic and Atmospheric Administration

\section{ABSTRACT}

The National Weather Service (formerly ESSA-Weather Bureau) was contacted in early March 1970, regarding the provision of operational weather support for the TEKTITE II activities in the Virgin Islands area during the months of April through October. Utilization of existing facilities was deemed adequate for the required level of support. The Miami Section of the Spaceflight Meteorology Group, under the direction of $\mathrm{Mr}$. J. R. Gulick, undertook the coordination of these facilities, drawing primarily upon the adjacent National Hurricane Center in Miami and the NWS forecast office in San Juan, Puerto Rico. Arrangements were made for the provision of routine daily weather and sea condition forecasts by the San Juan office. Longer range forecasts, particularly in regard to tropical storm threats, and climatological studies were to be furnished by the Miami office.

The required support was provided, for the most part, according to the plans outlined above. San Juan provided the daily support with backup and special outlooks from Miami. A special study of all recorded storm tracks was made in order to obtain the unconditional probability of tropical storm occurrence near the Virgin Islands during any specified portion of the season. Furthermore, a computerized technique was developed for determining from any given location of an existing tropical storm the probability of that storm eventually affecting the TEKTITE II area of operations and the most likely time of its doing so.

Fortunately, 1970 was a year of low storm incidence in that part of the tropics. No hurricanes and only one named tropical storm threatened the area. The center of tropical storm "Dorothy" passed some two hundred miles south of the Virgin Islands on August 21 . However, this storm had already declined from its state of greatest intensity, and it continued to weaken as it moved westward across the Caribbean.

Several lesser weather systems affected or threatened the area. Probably the most significant of these lesser systems was a very slow moving "depression" which caused a week of excessive rains and attendant flooding throughout Puerto Rico and the Virgin Islands in early October. This system was near tropical storm intensity at times, but apparently 
strong winds in the TEKTITE II area were confined mostly to passing squalls. However, the prolonged period of southerly winds did cause abnormally high seas along the southern coasts including Lameshur Bay.

From the viewpoint of the National Weather Service units involved, only minor difficulties were encountered in supporting TEKTITE II. Most of these were communications problems. Knowing that there were times when the Base Camp at St. John could not contact San Juan by phone and might not have received the latest forecast by other means, we adopted the practice of initiating calls whenever, in our judgement, some feature of the weather situation deserved special mention. Often these calls were merely a check with the San Juan office to determine if they had been in contact with the TEKTITE II office. If not, we usually contacted the office of the Scientific Coordinator, Ocean Survey Program. On some occasions we received calls from the Virgin Islands when attempts to contact San Juan failed. Thus the value of having two weather offices familiar with the project was demonstrated.

In an effort to provide additional upper air coverage for the area of the Virgin Islands during the hurricane season, and to provide adequate wind data in support of oceanographic experiments, the NASA Wallops Island Station made available and installed upper air sounding equipment on St. John, including expendables and logistic support. Unfortunately equipment damage resulting from heavy rains made it necessary to terminate the effort.

STUDY OF SEDIMENTATION ON THE VIRGIN ISLAND PLATFORM IN THE VICINITY OF ST. THOMAS

Dr. Charles W. Welby

North Carolina State University

\begin{abstract}
Geochemical work on the approximately 90 samples collected during the TEKTITE II Ocean Survey Program is underway. The bulk of the samples collected are carbonate mud.

The fathograms suggest the presence of some interesting topography on the platform, and the possibility that evidence for sea level changes may be present. A good High Resolution Boomer survey is needed as well as some coring.

The bottom sampling done suggests that a program of coring to 20 feet, if not deeper, may be feasible.
\end{abstract}


Dr. Lyon P. Wallace

Bureau of Solid Waste Disposal

Environmental Protection Agency

Dr. Jack B. Pearce

Sandy Hook Marine Laboratory

National Marine Fisheries Service

\begin{abstract}
This project was initiated on June 19, 1970, with the successful mooring of six bales of refuse--two at each of three adjacent sites located two and one half miles south of Virgin Gorda Island. This was accomplished only after extensive logistical arrangements moved the experimental materials from the U. S. Mainland and Puerto Rico to the Virgin Islands and the crew of the research vessel ADVANCE II prepared the mooring apparatuses.
\end{abstract}

On September 11, 1970, it was found that two of the buoys were either lost from wave action or had been stolen and their mooring lines were not recoverable, but the ADVANCE II successfully recovered one mooring system for observation of the attached bales.

Visual and photographic observations were made of the bales and samples of the organisms were found. No encrusting micro fauna or flora were found on the anchor weights, chains, or bales that had remained three months in depths exceeding 200 meters (100 fathoms). With close scrutiny three distinct species of polychaete worms were found in the surface layers of the baled refuse. The most abundant (2-3 worms per $100 \mathrm{~cm}^{2}$ ) was a worm $15-20 \mathrm{~mm}$ in length belonging to the family Phyllodocidae, and the other two species found were a Nereidae worm and one belonging to the family Opheliidae ( $<1$ worm per $100 \mathrm{~cm}^{2}$ ). A large spider crab, Nibilia antilocapra ( $\mathrm{f}$ : Majidae), and a small crab belonging to the family Xanthidae were also identified. A snail and several dozen foraminifera of the family Rotaliidae were recovered from among materials returned to the laboratory for analysis. Total coliform bacteria counts of 96,000 MPN and fecal coliform counts of 1,300 MPN were reported after laboratory analysis. The complete report is available.

The study is being continued so that observations can be made after much longer period of time ( 1 year). Since two of the mooring systems were no longer available for observation, it was decided to replace the recovered bales in approximately the same location and allow them to interact with the ocean until the sumner of 1971. 
Dr. J. S. Bunt, Dr. C. C. Lee, and Dr. M. A. Heeb School of Marine and Atmospheric Sciences University of Miami

\begin{abstract}
Between August 8 and August 12, 1970, twenty stations were occupied in the waters around St. Croix and between St. Thomas, St. John, and St. Croix in the Virgin Islands. At each station, STD runs were made by the staff of the Cape Fear Technical Institute. In addition, surface phytoplankton material was recovered by hand hauled surface tows for use in studies of the relations between photosynthesis and respiration by mass spectrometry. Mass spectrometer runs were made successfully at seventeen stations. This is the first time that this technique has been used at sea in this application and has proven the feasibility of its use to measure oxygen production and consumption independently and directly during illumination.

An account of this work, augmented with data collected subsequently, is being prepared for publication. We believe it is of special interest partly because our data demonstrates how the component of photosynthetic $\mathrm{O}_{2}$ production can be detected when net exchange shows heavy $\mathrm{O}_{2}$ consumption.
\end{abstract}


Robert Gerard and Chris Ceike Lamont-Doherty Geological Observatory of Columbia University

\begin{abstract}
Continuous measurement of near-bottom currents were made for a period of 76 hours at the southwestern end of the Virgin Island Passage, using a free-fal1, pop-up currentmeter package. Observations were made 2 meters above the ocean floor in 1800 meters of water at $17^{\circ} 39.2^{\prime} \mathrm{N}, 65^{\circ} 16^{\prime} \mathrm{W}$ from 31 August to 4 September 1970. The current speed record showed a semi-diurnal period with two high and two near-zero nodes every 24 hours. The high current peaks increased in magnitude with time (from 7 to $11 \mathrm{~cm} / \mathrm{sec}$ ), indicating a longer term periodicity which could not be resolved due to insufficient observation time. The direction of this current also exhibited a semi-diurnal period which appears to have a phase shift in relation to speed. The average direction is towards $168^{\circ}$ ( $\mathrm{SxE}$ ) with a turning from $\mathrm{SE}$ to $\mathrm{S}$ as the average velocity increased with time.

Another measurement was attempted at the sill of the Anegada Passage to the northeast during the same period, but the current meter was not recovered.
\end{abstract}


Dr. William L. Wood

Department of Natural Science

Michigan State University

\begin{abstract}
Extended use of habitats precludes their placement in hydrodynamically active areas. Although the TEKTITE II habitat was located in a relatively quiescent area, preliminary measurements of the hydrodynamic regime around the TEKTITE II habitat indicated potential effects of habitat-flow field interactions. The utilization of underwater photography of small scale dye releases was an efficient method of monitoring the flow field around the habitat. The most important recommendation arising from this study is that similar measurements must be made on habitats placed in more hydrodynamically active areas to insure both the safety of the habitat personnel and the reliability of data collected in the vicinity of the habitat.
\end{abstract}

The primary objective of this investigation was to measure and evaluate the fluid flow characteristics associated with the TEKTITE II habitat. Although this problem involves both the effect of the fluid on the habitat and the reciprocal effect of the habitat on the ambient flow field, this study focused primarily on the later interaction.

The rationale behind this investigation is that the interpretation of data collected in the vicinity of a habitat is dependent upon the hydrodynamics of the observing and collecting area. Specifically the distribution and variation of bottom sediments, the micro and macro faunal distributions, and the physical exertion of the habitat personnel outside the habitat are all dependent upon the flow regime.

A secondary objective of this investigation was to evaluate the effectiveness of underwater photography of subsurface dye releases for tracing fluid flow. The development of underwater photographic dye monitoring would provide a direct method of observing subsurface current patterns, diffusion, and microturbulent flow structure. The development of this technique coupled with the subsurface excursion time available through the use of habitats would provide an extremely valuable method for studying subsurface fluid flow fields. In order to optimize these techniques, aerial photographs of nearsurface dye releases were taken synchronously with subsurface photographs. The anticipated results from this portion of the study should provide information on three dimensional diffusion of coastal water masses. 
Equipment: Photographic techniques were used extensively throughout the study. This resulted from logistical difficulties encountered in attempting to deploy the ducted impellor flowmeters originally proposed for use in this investigation. Photographs of subsurface dye releases also provide details of the flow field which are not obtainable from flowmeter measurements.

One Nikonos II underwater camera equipped with a $35 \mathrm{~mm}$ lens and one equipped with a $28 \mathrm{~mm}$ lens were used for most of the subsurface photography. Aerial photographs were taken by NASA's NP3A aircraft. Dye releases were made using both Rhodamine-B and red commercial food coloring. The later dye proved to be superior for underwater photography because it provided a greater contrast with the ambient water and did not have the persistent staining quality of the Rhodamine-B dye. Subsurface dye releases were made with a one liter manually operated piston type cylindrical injection gun with an orifice opening of $0.6 \mathrm{~cm}$. The injection gun is $0.5 \mathrm{~m}$ long and has a slight negative buoyancy when loaded. This makes the unit easy to handle underwater. Surface dye releases were made from a 15 liter container, gravity fed through a $1.2 \mathrm{~cm}$ hose.

A Gurley current meter was used to make in situ profiles of the upper portion of the water column, above the habitat. This meter was deployed from the diving barge above the habitat and from small boats provided by the Cape Fear Institute vessel S. S. Advance II.

Procedure: The primary site for this investigation was the area immediately adjacent to the TEKTITE II habitat. A secondary site was necessary because of the large amount of dye which was released for the aerial photography. Both of these sites are shown in Figure 1.

The TEKTITE II habitat was located in fairly quiescent waters owing to both its juxtaposition to the coastline and the nature of the prevailing wind conditions during the investigation period (July 19-July 26). Three current profiles were made at the start of each current monitoring dive. These profiles, Figure 2, showed that the mean current speed at the top of the habitat was extremely low $(0.09-0.19 \mathrm{~m} / \mathrm{sec})$ under these conditions. A series of linear dye releases were made at positions around the habitat, Figure 3 , with the injection gun. Photographs of the dye releases were taken with high speed ectachrome film and a Kodak $80 \mathrm{~B}$ filter.

On July 23 fifteen liters of Rhodamine - B dye were released at a rate of $1 / 2$ liter per minute from the site shown in Figure 1. Aerial overflights of the dye were made every ten minutes for one hour. During the overflights three divers were deployed with underwater cameras and a calibrated grid to photograph the vertical diffusion of the dye. High speed ectachrome film and an $80 \mathrm{~B}$ filter were used for these photographs also. 


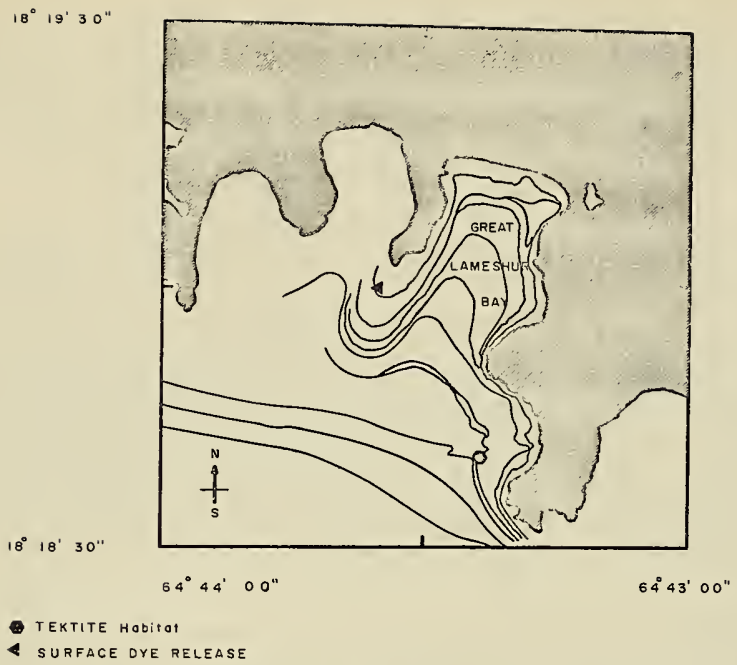

Figure 1. Location map showing the position of the TEKTITE II habitat and the surface dye release for the aerial photographic study.
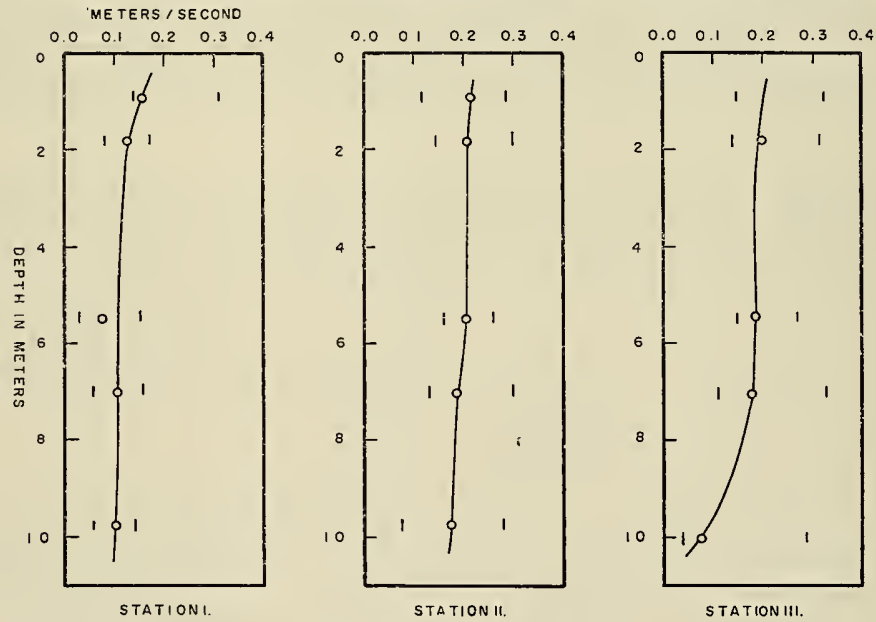

Figure 2. Current meter flow profiles taken above the TEKTITE II habitat prior to subsurface dye photography. These three profiles are representative of those measured during the period of this investigation. 


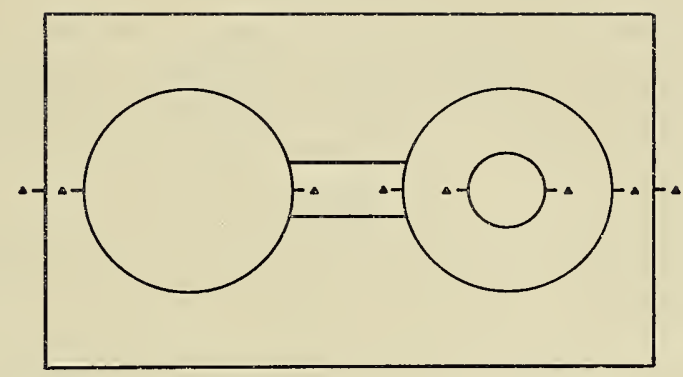

PROFILE I.

PROFILE II.

PROFILE III.

- POINT OF DYE RELEASE

Figure 3. Positions of the three profiles shown in Figure 2 and of the subsurface dye injections made on the habitat.

The deployment of both of these investigations was designed to provide preliminary information on the usefulness of underwater photography of dyes to delineate subsurface flow fields. Thus the cursory nature of the experiments was inherent in their design.

Results: The flow patterns observed around the TEKTITE II habitat were pronounced even though the flow velocities in the vicinity of the habitat were extremely low. Streamlined flow was observed to occur near the vertical cylindrical portions of the habitat. The low velocity flow was quite turbulent close to the cylinders and may reflect the effect of thermal diffusion set up by the habitat. The streamlined flow broke off abruptly when it reached the main direction of current efflux from the area. Turbulent flow was experienced near the stagnation point of the down current side of the cylinders. In the area between the two vertical cylinders, extremely turbulent flow was observed and some vertical upwe11ing and overturning was noted. Flow around the base of the habitat was abrupt and followed the contour of the platform to the point of current efflux from the area.

The aerial photographic investigation was not conclusive in establishing any three dimensional diffusion patterns. The low velocity coastal currents failed to show any micro-turbulent edge structure in the aerial photographs. Likewise only two of the aerial photographs showed sufficient contrast between the dye and the ocean surface to be useful in the study. 
The subsurface photographs showed some development of vertical edge structure, but the photographs also lacked good definition of the dye plume. No significant results on the three dimensional photographic study are available at this time. However, photographic enhancement techniques may supply further information from this study.

Conclusions/Recommendations: The utilization of underwater photography is potentially one of the most effective techniques which could be developed for studying subsurface flow. The initial experiments conducted during the TEKTITE II program showed that even low velocity flow structure can be easily and economically monitored with photography of subsurface dye releases. The potential applications of this technique are: to study boundary layer flow around submerged piles and structures; to investigate the boundary layer structure over bottom sediments and bottom features; and to study the vertical structure of currents and their vertical mixing processes.

An extremely important aspect of subsurface dye photography is its expanded potential when used by habitat divers. Saturation diving would provide the critical bottom time required to throughly map the afore mentioned flow fields. Likewise the continuous presence of observers in the habitat would provide an opportunity to monitor and photograph a wide variety of flow conditions. It is conceivable that remote dye releases could be made from the habitat under storm conditions, thus providing critical information on the turbulent flow induced by the habitat under high energy conditions. The potential of this technique should be taken into account in future planning for subsurface habitat programs. The amount and type of both applied and basic information which could be obtained by a habitat based investigation would be orders of magnitude greater than could be obtained by a similar surface based investigation. 
A MAN-SYSTEMS INTEGRATION

STUDY OF THE BEHAVIOR OF CREWS

AND HABITABILITY IN SMALL SPACES

Stanley Deutsch, Ph.D.

Life Sciences Directorate

National Aeronautics and Space Administration

\begin{abstract}
The curiosity of men leads them to venture further and further away from the benign environment found on the earth's surface. TEKTITE II provided a unique opportunity to advance our scientific knowledge of the behavior of men in small groups operating under conditions of stress and to improve the technology for development of habitable areas for living and working surrounded by a hostile environment. An extensive Man-Systems Integration Program with emphasis on behavioral research and habitability assessment was undertaken to provide meaningful field study data for application to manned exploration under the seas and in space.
\end{abstract}

\title{
INTRODUCTION
}

In a report on the Biomedical Foundations of Manned Space Flight, the President's Science Advisory Committee stated:*

\begin{abstract}
"Major engineering decisions, controlling the character of possible future space stations, logistic systems and other manned spacecraft depend on evaluation of man's potential for useful work in space. Given the present great expense of transportation to and from space, should we expect high level performance for ten days, thirty days or even ninety days at a time? What is the optimum sleep, rest and work schedule? What crew size is optimum?"
\end{abstract}

We have only an imperfect understanding of the characteristics of man and his performance, both as an individual and as a member of a small highly skilled group, that permit him to function in a satisfactory manner under the various stresses in alien surroundings.

Information on the functioning and interrelationships of small groups of men performing useful work in space while living in confined areas under stressful conditions in a relatively hazardous environment is needed by the National Aeronautics and Space Administration, the Navy and other organizations. Data are required on the "in vivo" study of the behavior of smal1

* The Biomedical Foundations of Manned Space Flight, A Report of the Space Science and Technology Panel of the President's Science Advisory Committee, Executive Office of the President, The White House, November 1969. 
crews and the development of efficient work, rest, sleep schedules and the generation of methods to ameliorate long duration isolation.

Simulation studies in various test chambers have provided useful information on discrete aspects of man's performance under adverse conditions. Other studies have been made in the field where individuals and crews are observed under operational conditions. The chamber runs frequently were used to study a small spectrum of human performance or were oriented to other types of measures as the primary goals (e.g. study of life support systems.) Earlier field studies, although they dealt with the global characteristics of man performing in a real environment, were constrained by the available resources and methodology to sampling performance and group dynamics or using subjective measurement techniques.

The TEKTITE habitat provides a remarkably well-suited analog to a small space vehicle for studying man's capabilities for performing useful work and the social structure in a dynamic environment.

\section{TEKTITE I BEHAVIORAL RESEARCH}

In TEKTITE I, the behavioral research program was designed to study individual and group dynamics and the work habits of the aquanauts while accomplishing a real life mission over a long period in a hazardous environment. The behavioral study was designed to provide information on the aquanauts personal adjustment, social interaction, and task performance. The research was carefully planned to provide information that would be useful to the man-in-space program as well as man-in-the sea. Data were gathered in the areas of crew selection; habitability for working, eating, sleeping, and recreation; and psychomotor performance. The behavioral data were obtained primarily by direct observation using television cameras and open microphones located strategically around the four chambers in the habitat. The aquanauts were observed continually while in the habitat from 0615 to 2345 each day. A team of psychologists on the surface monitored the video and audio transmissions in a special behavioral room not accessible to other topside personnel. In addition, selected pieces of equipment in the habitat were fitted with timers and automatic switches to provide information on usage.

\section{TEKTITE I Resu1ts}

In summary, results of TEKTITE I provided that the habitat was adequate to house the aquanauts for 60 days, although there was a serious shortage of working and stowage space. The settling-in period was longer than anticipated, showing the need for a more extended training period including spending some time in the habitat prior to the mission. The dinner meal, sometimes lasting as long as three hours, was a great source of relaxation, group interaction, and work planning. The act of food preparation was a source of creative recreation for at least one crew member. The crew members frequently and voluntarily performed housekeeping tasks that had not been assigned. However, it was unanimous $1 y$ agreed by the aquanauts that an operational crew member was needed for routine reporting to the surface, habitat equipment maintenance, and performance of various non-scientific duties. 
When the crew members did not feel well due to ear infections, they became somewhat depressed. Buddy relationships changed with time, but intra-crew hostilities were generally surpressed or directed against the topside personnel. The aquanauts felt a strong need to escape into the water, but they always felt that the habitat was home and security.

\section{TEKTITE II BEHAVIOR AND HABITABILITY RESEARCH}

As a direct result of the experience on TEKTITE I, it was decided that a larger study using more aquanauts with more varied scientific and engineering skills could provide useful information on the psychological characteristics of the underwater station. Many of these findings could also apply to space vehicles and their crews. Thus a human behavior and habitability research program for TEKTITE II was developed with the following goals:

- To evaluate behavioral dynamics of small groups during missions in hostile environments

- To perform research studies on crew selection, composition, command structure and crew rotation

- To study habitability preferences of aquanauts living and working in confined quarters

- To study the effects of unexpected perturbations on crew behavior and performance

- To determine the possible effects of nitrogen narcosis on performance

- To observe the effects of two-way video between the habitat and "mission control"

- Identify food preferences and acceptability of pre-packaged foods.

A main advantage of the TEKTITE II program was that a large number of volunteer crews performed real-life work activities in the marine sciences. Their activities, interactions, and responses to confined living conditions provided useful information on crew behavior. These data supplement those obtained in chamber studies where the subjects engage in make-work tasks, and can abort on short notice. The TEKTITE habitat and undersea environment provided a uniquely advantageous analog for the study of small group dynamics and evolving social structure of man assigned to an isolated vehicle similar to that which would occur in future space stations.

Under the chairmanship of Stanley Deutsch, a Behavioral and Habitability Research Programs Planning Committee was established with membership from the National Aeronautics and Space Administration, the Navy and the Smithsonian Institution (Figure 1.) This Committee established program objectives described above and developed a research strategy to meet the requirements of the agencies interested in obtaining such data. 


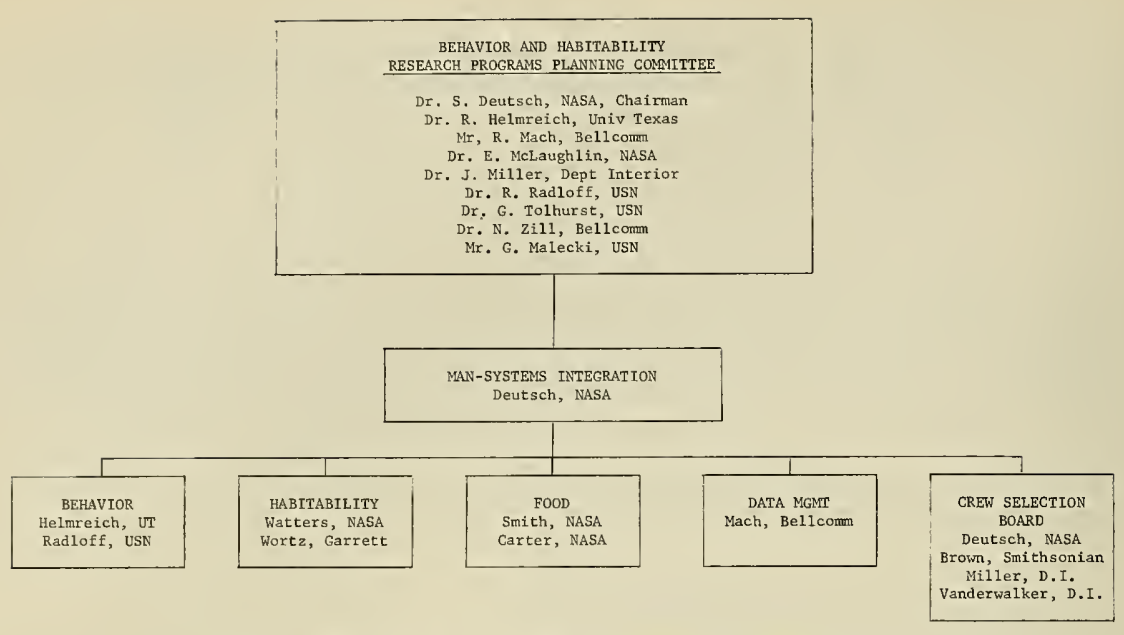

Figure 1. ORGANIZATION CHART: BEHAVIOR \& HABITABILITY RESEARCH PROGRAMS

A summary of the Behavioral and Habitability Research Program includes 12 psychological and 9 habitability items.

\section{BEHAVIOR RESEARCH}

The major areas of interest in the Behavioral Research Program are shown in Table 1. Dr. Robert Helmreich, University of Texas, was responsible for leading this effort. The results are described in a later section of this report.

\section{Command Structure}

The senior man was designated as the team leader prior to each mission. It was important to determine shifts in leadership in various activities and the informal organization structure and personal relationships that would evolve during the mission and as leadership roles were changed when crews were rotated.

\section{Crew Composition}

Interactions between engineers and scientists were studied because of the implications for future crew selection and composition.

\section{Individual and Crew Selection}

A behavioral battery was developed to permit the identification of characteristics of crew members for later comparison with performance and ability to function as a team member under stress. Selection of individuals and crews for future space or undersea systems will be based on various criteria including; medica1, psychologica1, operational, scientific or technical training and experience and compatibility with mission objectives. 


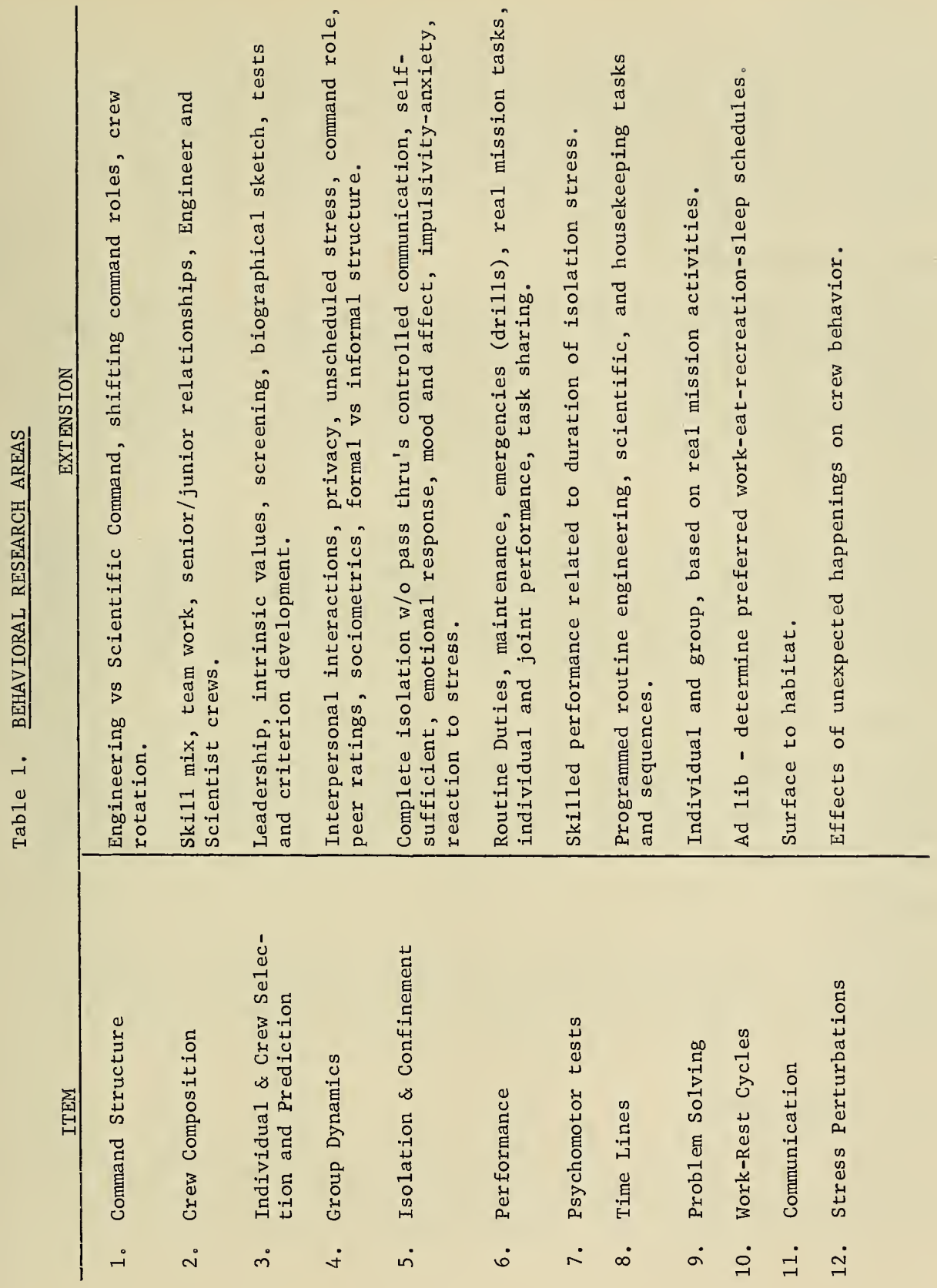


The ability of dedicated scientists to perform effectively as a team even though they have individual scientific projects was an important experimental variable. The formal relationships that were established and the informal social groupings that developed during the missions could provide meaningful habitat design and mission planning information. Reactions to stress due to unscheduled activities and to living and working relationships, will provide useful selection criteria data.

\section{Isolation and Confinement}

Although complete isolation from the "topside world" was not achieved, there was a tendency for the aquanauts to respond to non-crew members as outsiders. This was expected to occur and was studied to determine the extent to which the TEKTITE crews depended on topside activities and to what extent they resented topside involvement. The crews were confined to a small world bounded by the habitat and the limited excursions in the area of the habitat required for their marine sciences activities.

\section{Performance}

Scientific performance is always difficult to quantify. In this study immediate performance criteria were substituted for ultimate criteria. Length of time in the water shile involved in marine sciences, time spent in the analysis of data, and preparation for following scientific efforts were all used as immediate measures of performance. Time spent on routine duties and maintenance of self and habitat was measured.

\section{Psychomotor Tests}

Several psychomotor performance tests were planned for use in the 100 foot missions in the Minitat primarily to provide sensitive measures of nitrogen narcosis. Although these tests were used in the 100 foot simulator studies, they were not used in the 50 foot missions. There were no 100 foot missions using the minitat.

\section{Communication}

Communication could occur in a number of modes including open microphones, private phone, standard radio systems and two-way video phone. The extent, nature, and who initiated various types of communication was recorded. The dependency of the aquanauts on the ability to communicate with topside was observed.

\section{Stress Perturbations}

A critical area of study included stress caused by unprogrammed and unexpected happenings. There were several earthquakes that rocked the area and one potential hurricane that resulted in an aborted mission. The reactions of the crew members to these and other unanticipated occurrences were recorded. 


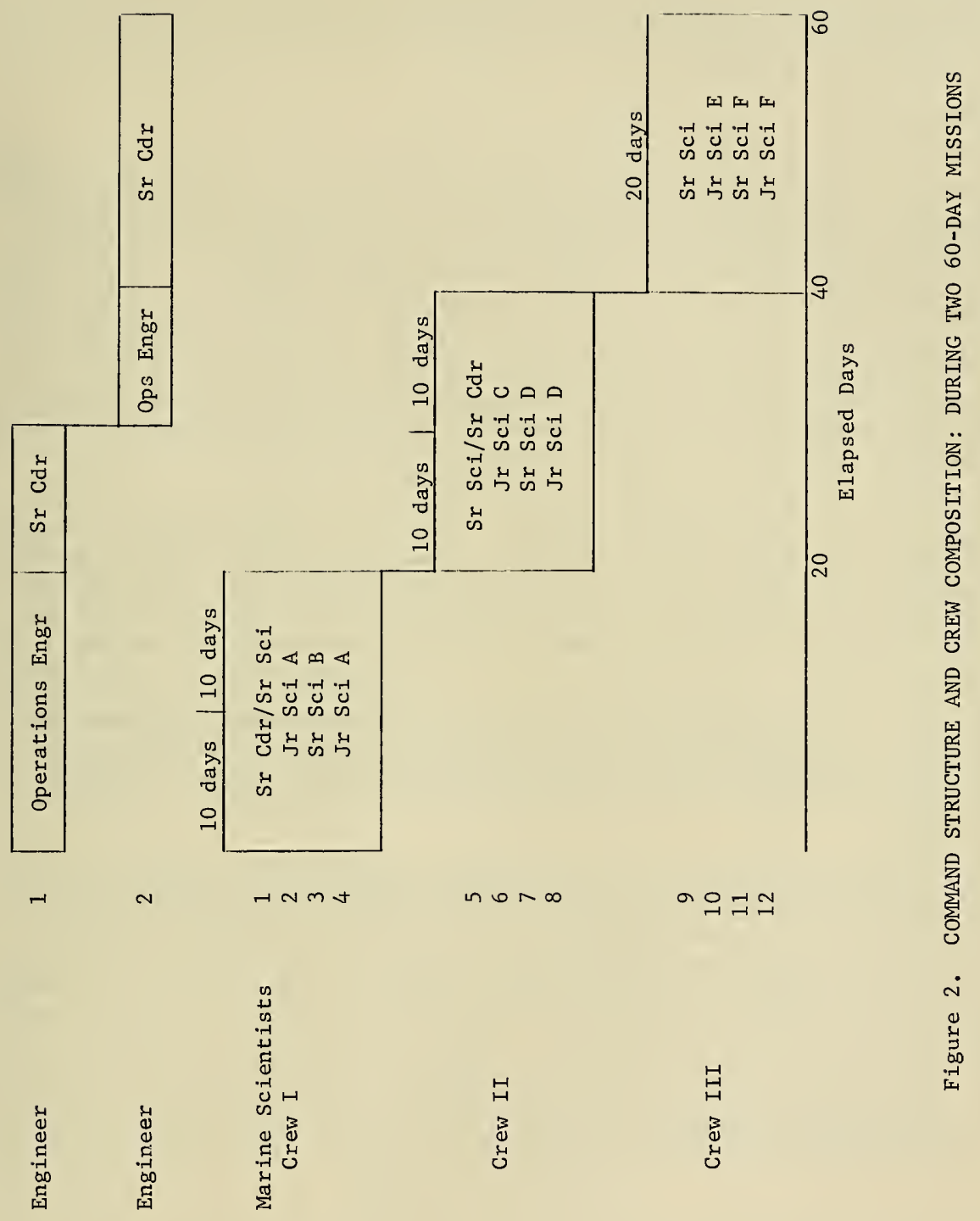


Ten separate missions were established as described in the Introduction. Behavior and Habitability data were gathered on each dive. For the 12-14 day missions, the crews dove together and were retrieved as a single crew. This occurred in missions $1,6,15$ and 17 .

\section{Crew Rotation}

The most complex dives for the behavioral program were the two 60 day periods, consisting of three interactive missions (missions 2,3,4, and 8,10,12.) See Figure 2. During these periods, studies were made on command structure, changing command roles, crew composition and crew rotation. One engineer and four marine scientists constituted the initial crew. The scientist crew was composed of two teams each with one senior and one junior scientist. One of these senior scientists was also designated as the senior commander for the entire crew as well as the senior scientific commander. The role of the scientific crew was to carry out their pre-determined marine sciences research program. The role of the engineer was habitat maintenance including on-board equipment, diver preparation support, some housekeeping, maintaining equipment logs, and life support system monitoring.

At the end of 20 days, the second scientific crew dove to the main habitat to replace all of the original scientists. Only the original engineer remained on board. He assumed the role of senior commander at that time. This second scientific crew consisted of two senior and two junior scientists, working together as two teams, with a senior and junior member in each team. One of these senior scientists was designated as senior scientific commander.

Ten days later a second engineer dove to the habitat to replace the original engineer. The second engineer assumed the role of operations engineer, i.e., he was not the habitat senior commander but assumed only the engineering duties. During the next 10 day period (Days 31-40), the on-board senior scientific commander was designated as senior commander (i.e., overal1 command).

At the end of 40 days, the third scientific crew of four aquanauts entered the habitat and the second scientific crew surfaced. The third marine scientific crew also was composed of two teams with a senior and junior scientist in each. One senior scientist had been designated as senior scientific commander. At this time the engineer assumed the role of senior habitat commander for the remainder of the dive.

At the end of the 60 day period, all aquanauts surfaced.

The same sequence of activities and crew structuring was completely replicated in the second 60 day period (missions $8,10,12$ ).

\section{HABITABILITY RESEARCH}

To date, manned space flights have demonstrated the ability of the astronauts to adapt to austere living conditions. Space stations of the future will require larger crews who will spend longer periods in orbit. Therefore, it is necessary to improve the habitability of future space vehicles to provide a 
living and working environment that will maintain flight crew morale and motivation at a high level. The Habitability Research Program was devised to provide information in the areas of interest shown in Table II. Mr. Harry Watters, NASA, and Dr. Edward Wortz, Garrett Corporation were responsible for leading the research program effort in the Habitability Research Program. The results of this program are described in their section of this report.

Table II. HABITABIIITY RESEARCH AREAS

ITEM EXTENSION

1. Food Acceptability, freeze dried, wet pack, frozen steaks and
sauces, equipment for preparation and eating, eating habits and patterns.

2. Sleep Areas Size and shape, privacy, frequency of use, how used.

3. Storage Area

Personal area-size and location. Universal area-size and location.

4. Work Area

5. Off-Duty Activities

Personal area - size and location. General area-size and location.

Eating, sleeping, recreation, type, location, frequency, individual and group.

6. Illumination \& Decor

Work areas, recreation areas, private and sleep areas, eating area.

7. Hous ekeeping

8. Mobility

Allocation of tasks, efficiency, frequency.

Ability to move about within habitat, equipment and transfer.

9. Privacy Needs Territoriality (how expressed), space needs, frequency of use of private areas.

\section{Food}

Because food and mealtime is such a morale factor, preferences and changes in these preferences were carefully noted. The importance of nutritional value, taste and appearance were al1 recognized. In addition, mealtime provides an opportunity for other social and work relationships and for well earned relaxation. Reactions of crew members to space foods and other types of packaged foods was considered to be an important study area for TEKTITE II.

\section{Sleep Areas}

The design of sleep areas to provide maximum rest with minimum interference is important for crew well being, morale, and safety. Methods for making crowded crew quarters, including sleeping arrangements, more acceptable 
without sacrificing space in a limited volume vehicle, becomes an important design factor.

\section{Storage Areas}

No matter how much stowage space is made available at the beginning of a mission, it generally turns out to be both inadequate and improperly used. Methods for improving storage facility design and utilization must be derived to optimize the limited volume available. Accessibility of frequent1y used items as well as retrieval of equipment that is important even though seldom used is a challenge to the vehicle designer. The study attempted to determine how available stowage facilities were used and to identify deficiencies.

\section{Work Area}

The primary purpose of a mission is to accomplish specified tasks. Design of a habitat to facilitate work efforts is frequently not adequate, either due to poor task-equipment analyses studies or their implementation or because the available volume in the vehicle is not sufficient to provide all the work area required. The manner in which the aquanauts coped with this problem, either by sharing or by allotting permanent space, and the effects on crew dynamics were studied.

\section{$\underline{\text { Off-Duty Activities }}$}

Although almost all of the aquanauts felt that they would have little or no time for off-duty leisure activities, a substantial amount of time was spent in this manner. Off-duty activities increased with the mission duration. The aquanauts were allowed to take personal preference equipment with them. What these were and the extent to which they were used was observed. A1so noted was the use of on-board recreational gear such as television, radio, pre-recorded tapes, books, and closed circuit TV. Group participation and individual preferences were recorded.

\section{Illumination and Decor}

The aquanauts were able to change the level of illumination in the various rooms as they desired. Different light levels were selected according to the activities in which they were involved. Decor was relatively fixed, but subject to some modification by the crew members. It is an important variable for missions requiring long periods of confinement.

\section{Hous ekeeping}

Housekeeping practices and facilities are important from both a health and a morale standpoint. Allowing refuse to collect could provide a haven for microbiological contamination. It can also reflect crew attitudes and morale. Provisions for housekeeping were limited since most of the trash was passed out of the habitat for collection. Who assumed unassigned housekeeping chores such as cooking, cleaning up, washing dishes was noted as well as who cluttered the areas and misused facilities. 
The ability to move about inside the habitat with and without equipment has a direct bearing on the design of transfer areas where space is at a premium. While an aquanaut can negotiate a narrow passage when he is not encumbered by equipment, he should not collide with the walls and consoles when trying to move about with his gear. Appropriate location of equipment to allow for easy use with minimum carrying requires careful analysis.

\section{$\underline{\text { Privacy Needs }}$}

Areas set aside for the personal use of crew members is related to sleep, work, and storage areas. With limited space available, is it necessary to provide private space as well? If so, how much? Where is it best utilized? Where is it most important? What is kept in private areas? Expressions of territoriality by individual crew members is sometimes overt; at other times it may be quite subtle. The relationship of the individual to other crew members and his rank in the command structure all affect his expressions of territoriality. The frequency and manner in which invasions of privacy occur, and by who, also provide useful vehicle design information.

\section{CREW SELECTION}

Two crew selection boards were established. Scientific selection was chaired by Dr. Dail Brown, Smithsonian Institution, for marine scientists. The habitat engineers were selected by the Engineer Crew Selection Board chaired by Dr. Stanley Deutsch, National Aeronautics and Space Administration.

The crew selection procedures were essentially the same for both the scientists and the engineers except that the marine scientists were required to have an approved scientific research program. The scientists submitted proposed research projects to the Smithsonian Institution. These proposals were evaluated from the standpoint of scientific merit and feasibility. The scientists whose proposals were accepted were then grouped so as to best achieve program compatibility.

\section{Successive Selection Hurdles for Engineers}

1. For consideration, engineers had to have:

a. Diving certificate from certified diving school or equivalent experience

b. Minimum experience requirements

1. age 26 (female engineer excepted)

2. 5 years technical experience

c. Familiarity with diving equipment

d. Engineering or practical experience sufficient for minor equipment maintenance

e. Familiarity with 1 ife support systems 
2. Engineers were required to express willingness to:

a. Assume housekeeping chores

b. Assist in diver support

c. Monitor on-board systems

d. Make necessary internal and external inspections

e. Maintain routine logs

f. Assist in behavior, biological, medical, and marine science programs

g. Participate in behavioral, biological, medical, and psychomotor programs

h. Perform other pertinent engineering duties

i. Participate as either primary or back-up engineer

Added Selection Hurdles for All Crew Members

1. Completion of biographical and questionnaire form

2. Pass physical exam and personal interview

3. Complete battery of tests

4. Meet psychological criteria for crew structure

5. Pass diving test

6. Be accepted by Crew Selection Board

7. Satisfactorily complete TEKTITE II training programs

Only qualified divers who expressed a willingness to meet the program requirements were selected.

The psychological screening (Table III) consisted of two items. These items were also used for the Behavioral Research Program. The first was a biographical description. The second was the Life Crisis Scale. Both of these were administered as part of the medical exam for psychiatric screening. Negative findings could have resulted in disqualifying candidates for safety purposes.

The remaining measurements were obtained for research purposes only and had no effect on aquanaut selection or rejection.

Engineering crew selection was completed in January. The engineer crew received 3 days of intensive training in the habitat at the General Electric Company in February 1970. 
Biographical Data - * (Part of medical exam)

Life Crisis Scale - * (Part of medical exam)

Edwards Personal Preference Inventory

Texas Social Behavior Inventory (University of Texas

Swimming Questionnaire (Navy)

Sociometric and Acquaintance Forms

* Only tests to affect selection

The psychological test battery was administered to the selected aquanauts prior to their dives. However, the test scores were used only for research purposes and were not analyzed until the dives were completed. The scores were then correlated with the data gathered on the aquanauts during the missions to determine their potential value as selection devices for future crews. These tests are described in Human Behavior Program Section by Dr. Helmreich.

The members of the Behavior Research Program Panel are:

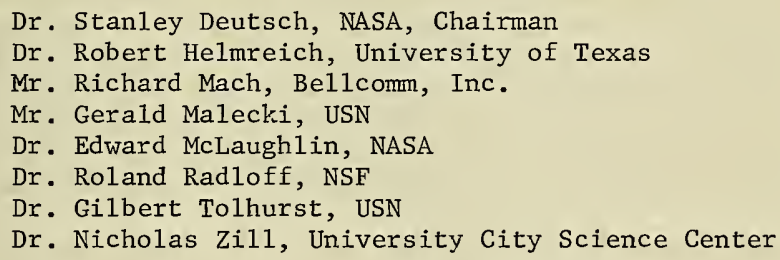

\section{DATA COLLECTION}

Techniques for the collection of data were designed to provide information for the most part that required no overt effort by the aquanauts. The vast majority of the data points were gathered by topside personnel using a closed circuit constant monitoring TV and an open microphone in each chamber to provide passive visual and auditory observation.

Due to the hundreds of thousands of data points to be collected, the use of computers for data analyses was incorporated in the data management plan. The data collection and management procedures for TEKTITE II were developed by Bellcomm, Inc. and the University of Texas and will be discussed in a later section.

To facilitate data collection and later analyses, the IBM Porta Punch System was used requiring manual punching of machine readable pre-perforated IBM cards. On the data recording templates, each of the four chambers in the habitat was 
divided into zones to facilitate the recording of aquanaut location and activities.

Identifying information such as mission, dates, observer, and other routine data was punched in early, leaving the observer free to punch new data once every six minutes or as activities occurred. Specific events and unusual events were added on an ad-1ib basis.

Special templates were prepared to permit recording of aquanaut activities such as communication, posture, location, diving times, meal behavior (i.e., preparation, cleanup, etc.), and sleep.

Communications with topside were recorded to the nearest minute. The initiator of communications (either topside or the specific aquanaut) and method and duration of the communication were noted, along with the time of day.

Specific events and unusual events were logged. The specific event categories included housekeeping activities, habitat maintenance, habitat repair, baralyme change, use of the head, time spent showering and doing the laundry, handling food stores or the pressure pot, use of outside TV or TV tapes, use of radio, use of general or personal leisure items.

The Mood Adjective Checklist (MACL) was administered twice daily. The MACL is described in detail in the Human Behavior Section.

In addition to the above data, two special forms were completed by the aquanauts for the Habitability program. These are the Habitability Assessment Rating Scales (HARS), administered five days prior to termination of the dives, and the TEKTITE Environmental Assessment (TEA) administered four days before the dives terminated. These two rating scales were used to provide information on the subjective reaciion of the aquanauts to important habitability features of the habitat that might have implications for manned space vehicle design. The HARS and TEA are described in detail in the Habitability Assessment Program.

Finally, an extensive, highly structured debriefing session for each aquanaut was conducted immediately following emergence from the decompression chamber after each dive. 


\author{
Robert Helmreich \\ Principal Investigator \\ The University of Texas at Austin
}

\begin{abstract}
The objectives of this program were to study and assess the psychological dynamics of small groups under stress in a hazardous environment. The program was designed to obtain information applicable to crew selection, concepts, and command structure. The data were collected utilizing closed circuit television and open microphones. The results were recorded directly on computer cards. The findings indicated that the techniques used and the criteria applied should provide valuable information with respect to the selection of crews for future under sea and space missions.
\end{abstract}

\title{
INTRODUCTION
}

The TEKTITE II Human Behavior Program was a large-scale field investigation of ongoing human behavior in an isolated, confined environment. The program sought to advance basic research on individual and group behavior, to provide information useful for selecting crews and manning future underwater habitats, and to obtain data applicable to problems of long duration space flight.

The multiple goals of the research necessitated a broad approach to the collection of data with defined subareas of interest. A primary concern was the development of batteries based on pre-mission testing which can effectively predict performance and behavior in this and other settings. The research strategy was to attempt to refine general measures which can be validated against objective criteria and should have many applications in selecting personnel for a variety of tasks. Another major goal was to describe and explain patterns of adjustment to isolated and stressful environments. Directly related to this was comparison of these trends in missions of different lengths. This aspect of the study also included determination of the intercorrelations between such components of behavior as crew composition and its effects on performance. Components of this research area were leadership roles, scientist-engineer relations, and the effects of partial crew rotation.

Secondary research goals encompassed detailed studies of communication patterns, social dominance, utilization of space within the habitat, meai behavior, energy expenditure, mood fluctuations, and territoriality.

Four modes of data collection were employed: (1) psychological testing prior to each mission; (2) continuous observation of in-habitat behavior by closed circuit television and open microphones; (3) self-reports on emotional state by aquanauts; and (4) structured debriefing of each aquanaut immediately after decompression. The systematic, quantified observation of in-nabitat benavior was the heart of the program. Behavior was monitored 24 hours a day during the 182 days that the habitat was occupied by the cen scientific missions. 
The TEKTITE research was conducted at a time when a serious division has arisen in American social psychology. The controversy is between those who advocate experimental, laboratory, social psychology and those who favor observational, materialistic research in real-life situations. The points of contention have been extensively argued elsewhere (cf. Willems and Rausch 1969; Aronson and Carlsmith, 1968; Radloff and Helmreich, 1968). Briefly, however, the laboratory exponents hold that only in a controlled, experimental situation can valid conclusions about causality be reached and that field research, by its correlational nature, can only describe relationships without defining causes. Field researchers contend that their findings can be more easily generalized to real situations. They also argue that modern statistical techniques can provide much information about causal relations from correlational data and that field techniques may be the only ethical way to study some phenomena such as prolonged stress.

The TEKTITE behavior program, one of the largest systematic field studies undertaken in social psychology, may be a significant source of data on the usefulness of field techniques. Accordingly, it may be of value to review briefly the development of the research design and to note some of the advantages and disadvantages associated with it.

\section{Origins of the Behavior Program}

The present study is a direct outgrowth of research conducted on aquanauts during the Navy's SEALAB program (Radloff and Helmreich, 1968). The SEALAB research was undertaken because the investigators felt that the systematic observation of men under high stress in a situation where good criteria of performance were available could provide unexcelled data on individual and group reactions. A number of significant findings emerged from the SEALAB study which led to renewed interest in developing techniques for collecting and handling the large amounts of data obtainable. These techniques were tested during TEKTITE I and modified and refined for TEKTITE II.

There are numerous advantages of an underwater habitat as a naturalistic research setting:

1. The research situation is completely real. Stress, isolation, and confinement are not simulated. Accordingly, reactions to the pressures of the situation are valid measures of behavior. Related to this is the fact that research subjects are participating to fulfill professional goals and not merely to serve as psychological guinea pigs. Thus, the goal of the subject is primarily to get his work done and not to serve as a cooperative and obedient psychological subject.

2. The habitat provides a relatively stable and constant environment. Unlike many field situations, all subjects could be observed under the same living conditions. This enables statistical comparison across individuals and across teams.

3. The design of the habitat provides excellent audio and video coverage. Observers could monitor almost all in-habitat activity. 
4. An extensive battery of psychological data could be obtained on each aquanaut prior to his mission--an unusual situation in field research.

5. The natural situation provided excellent objective criteria of performance and adjustment. These variables form the criteria for prediction of individual reactions and the study of trends in behavior over time. Between four and six thousand observations (depending on mission length) were taken on each of the criterion variables on each aquanaut.

6. It is impossible to gather such comprehensive and detailed information on astronauts in space.

Offsetting some of the desirable characteristics noted above are several disadvantages. The number of subjects (48) and missions (10) is relatively smal1. A large sample with more replications would give broader and more stable data.

The TEKTITE habitat was fairly shallow and was located in warm, clear water; as a result, the stress levels were less extreme than those found in projects such as SEALAB II and III. The shallow depth also made it more difficult to maintain isolation. A larger sample of female aquanauts and mixed crews would have enabled better evaluation of the obtained results. Only additional research will show how well the findings based on this sample of volunteer scientists and engineers will generalize to other situations and populations.

Overa11, however, the advantages clearly seem to outweigh the 1 imitations of such research and the methodology developed should be applicable to many settings.

Scope of the Report

Time and space limitations make it impossible to present more than a fraction of the data in this report. The concentration here will be on a general description of some of the major findings. The areas to be emphasized will be (1) overal1 behavior in the habitat, (2) team and individual differences in reactions, (3) trends in behavior over time, (4) crew composition, and (5) prediction of behavior.

Topics for Subsequent Analysis

It may be useful to 1 ist here aspects of the data which will be the subject of later analyses and will be reported in more detailed technical reports. These include:

1. Habitat utilization.

2. Territoria1 behavior.

3. Diving behavior

4. Meal behavior

5. Communications (including within-habitat and habitat-to-surface communication). 
6. Content analysis of video tapes.

7. Mood data.

8. Analysis of diurnal cycles.

9. Effect of external and internal perturbations (storms, illness, etc.) on behavior.

10. Sociometric evaluations.

11. Rod and Frame Test.

12. Self-esteem data.

13. Social dominance.

14. Gregariousness.

15. Detailed analysis of leisure activities.

16. Comparisons with data from other isolated environments.

METHODOLOGY

James H. LeFan and Robert Helmreich

The University of Texas at Austin

Data collection was conducted in four ways: (1) pre-mission testing; (2) continuous observation of in-habitat behavior; (3) self-report questionnaires filled out daily by aquanauts during their dive; and (4) structured debriefing of aquanauts immediately after decompression.

\section{Pre-Mission Testing}

After arrival at the base camp, each aquanaut was given a complete briefing on the scope and goals of the Behavior Program. The nature of data to be collected and provisions to ensure the confidentiality of all responses were explained. Following the briefing, each aquanaut completed a battery of demographic and personality measures. These measures are listed in Table 1. The major premission measure was the Life History Questionnaire. Its theoretical importance is such that it is described in detail later in this section. Variables from these instruments are used both to describe the aquanaut population and to predict performance and adjustment during missions.

\section{Behavioral Observations During Missions}

The major source of data during TEKTITE II was the direct observation of aquanauts 24 hours a day during their 1 ife in the underwater habitat. These data were collected by three teams of male observers from the University of Texas at Austin. Each team served on site for approximately $2 \frac{1}{2}$ months. Team 1 had eight observers; Team 2, ten (augmented to collect data on the aborted minitat missions); and Team 3, eight. Observers were undergraduate or graduate students 
at the University of Texas who were trained in systematic observational techniques. They were also qualified divers who provided logistic diving support for each aquanaut team. This common interest in diving and aquanaut support served to build rapport between the psychological mission and the aquanauts.

The variables on which data were collected were developed and defined from research programs conducted during SEALAB II and III and TEKTITE I (see Radloff and Helmreich, 1968, and Radloff, 1969, for further exposition of the research design). The final definition of variables was determined by the authors in conjunction with Richard S. Mach of Bellcomm, Inc. and Roland Radloff of the Naval Medical Research Institute.

Table 1.--Pre-Mission Measures

I. Specially Developed Tests

*A. Aquanaut Background Questionnaire

Variables

1. Current occupation

2. Age

3. Sex

4. Highest grade level attained

5. Current participation in organized religion

6. Parents' current status (deceased, divorced, etc.)

7. Number of brothers

8. Number of sisters

9. Birth order

10. Adopted or not

11. Family mobility (number of moves)

12. Father's education

13. Mother's education

14. Father's occupation

15. Military service

16. Smoking habits

*B. Life History Questionnaire

Items

1. Geographical residence

2. Hometown size

3. Distance of home from larger population centers

4. Type of residence

5. Condition and status of residence

6. Family size and composition

7. Clothing quality

8. Food--quantity and quality

9. Father's employment

10. Mother's employment

11. Height

12. Weight
Age Range (by year)

$0-18$

$0-18$

$0-18$

$0-18$

$0-18$

$0-18$

$0-18$

$0-18$

$0-18$

0-18

$0-18$

0-18 
13. Health

14. Education--type of school

15. Education--size of school

$0-18$

16. Education--academic perform

$5-18$

$5-18$

17. Athletic achievement and awards

$5-18$

18. Intellectual achievements and awards

$5-18$

19. Other awards and honors

$5-18$

20. Religious activities

$5-18$

21. Going out at night

$5-18$

22. Dating

$5-18$

23. Fights with peers

$12-18$

24. Clashes with authority

$5-18$

25. Financial independence

$5-18$

26. Work--school year

$5-18$

27. Work--summer months

$5-18$

28. Parental praise

$5-18$

$5-18$

29. Parental physical affection

$5-18$

30. Parental verbal criticism

$5-18$

31. Parental physical punishment

$5-18$

32. Community homogeneity and personal similarity

$0-18$

C. Texas Social Behavior Inventory

A measure of general social competence based on 40 multiple-choice questions

D. Swimming Questionnaire

48 items related to swimming experience

E. Prior Acquaintance Questionnaire

Assessment of familiarity with members of own and other missions

1. Professional acquaintance

2. Social acquaintance

II. Standard Tests

*A. Allport-Vernon-Lindzey Study of Values

Derived scales

1. Theoretical values

2. Economic values

3. Aesthetic values

4. Social values

5. Political values

6. Religious values

B. Minnesota Multiphasic Personality Inventory

(Standard personality test administered prior to selection, but not used in selection) 
$* *$ C. $16-\mathrm{PE}-$ Test

* Indicates that variable or measure is discussed in this report.

$* *$ Only the IQ score derived from this test is used.

Relevant categories of in-habitat behavior were specified and explicitly defined in a Behavior Observer's Manual which each observer was required to master.* The manual contains an introduction to the observer's role, a description of each behavioral measure and its mode of collection, and a description of the habitat. Considerations of confidentiality and the operation of the IBM Information Recorder which was used for data collection are also included.

Video training tapes were made inside the habitat before it was shipped to the Virgin Islands and were used to refine observational measures and to train observers under realistic conditions of simulated observation. The second and third teams of observers also received on-the-job refresher training by standing watches on site for a week with the observers they replaced.

Behavioral observation was conducted in a restricted area of the Command Van located on shore. The behavioral area was equipped with six 18" TV monitors-one showing each compartment of the habitat, one showing a TV picture in the water outside the habitat, and one reserve unit. Three video tape recorders were also installed, enabling instantaneous recording of any signal received on the TV monitors. Two playback monitors for display of video tape were installed.

Three loudspeakers and two headphone jacks were installed with two switching controls permitting observers to monitor conversations in any area of the habitat.

Data were collected 24 hours a day by observers standing watch in pairs for 4-hour shifts. Observers were instructed not to discuss behavior observed with anyone other than supervising personnel, and access to the observation area was strictly 1imited. Persons not associated with the Behaviora1 Program were permitted in the observation area only with the consent of the aquanauts.

Most data were collected by being punched directly onto IBM cards using the IBM Model 3000-I or Mode1 3000-II Information Recorder. Separate recorders were prepared with guide templates for recording aquanaut status, dive behavior, meal behavior, arising-retiring and sleep duration, communications with topside, and specific events such as use of leisure facilities, housekeeping, baralyme changes, etc. An example of an Information Recorder Template (for aquanaut Status Record) is shown in Figure 1. The aquanaut Status Record was completed for each aquanaut every six minutes, 24 hours a day. Other records were punched whenever the event in question occurred. A summary and description of the variables collected by observation is presented in Table 2 .

* A copy of the Behavior Observer's Manual can be obtained on request from Robert Helmreich. It will be published later as an Office of Naval Research Technical Paper. 
Figure 1.
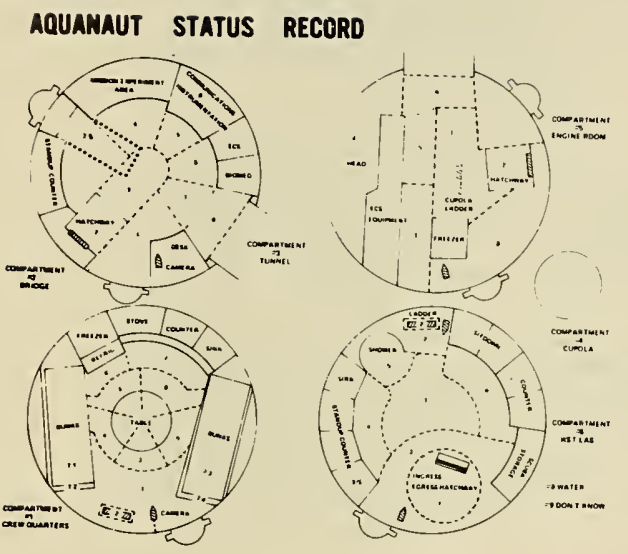

\begin{tabular}{|c|c|c|c|c|}
\hline & $\begin{array}{l}\text { ACTIVITY } \\
\text { CATEGORIES }\end{array}$ & $\begin{array}{l}\text { CONMUNICATION } \\
\text { CATEGORIES }\end{array}$ & $\begin{array}{l}\text { POSTURE } \\
\text { CATEGORIES }\end{array}$ & HOVEHEMT CATEGOR IES \\
\hline & $\begin{array}{l}\text { OIRECT HARIME } \\
\text { SCIEMCE }\end{array}$ & & $\begin{array}{l}\text { "I STANOING - } \\
\text { ERECT }\end{array}$ & \\
\hline 0 & $\begin{array}{l}\text { MAR SCIENCE } \\
\text { SUPPORT }\end{array}$ & & $\begin{array}{l}0 \text { STANOING } \\
\text { SLOUCHIHG }\end{array}$ & O MO MOVEMENT \\
\hline 1 & LOCOMOTING & $\begin{array}{l}\text { I MOT COMWUNICAT- } \\
\text { ING WEITHER } \\
\text { TALKING NOR } \\
\text { LISTENING }\end{array}$ & $1 \operatorname{STANOING-}^{\text {SEAMING }}$ & $\begin{array}{l}1 \text { LIGHT } \\
\text { TR ANSLAT IONRL }\end{array}$ \\
\hline 2 & $\begin{array}{l}\text { MAOITAT MAINTMC } \\
\text { ANOREPAIR TNC }\end{array}$ & $\begin{array}{l}2 \text { TALKING NITH } \\
\text { ANOTHER AQUA- } \\
\text { MAUT }\end{array}$ & $2 \begin{array}{l}2 \text { SITTING- } \\
\text { FORWARO }\end{array}$ & 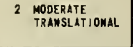 \\
\hline 3 & $\begin{array}{l}\text { SELF } \\
\text { MAIMTENAMCE }\end{array}$ & $\begin{array}{l}3 \text { LISTEMING TO } \\
\text { IQUAMAUT }\end{array}$ & 3 SITTING- & $\begin{array}{l}3 \text { VIGOROUS } \\
\text { TRAMSLATIOMAL }\end{array}$ \\
\hline 4 & $\begin{array}{l}\text { MALTERAANCE } \\
\text { OF OTHERS }\end{array}$ & 4 LISTERING TO & $\begin{array}{l}4 \text { Siting- } \\
\text { SLoucning }\end{array}$ & $\begin{array}{l}4 \text { light } \\
\text { hanipulative }\end{array}$ \\
\hline 5 & CO RECREATIOH & 5 LISTEMING TO & 5 RECLIMIMG & $\begin{array}{l}5 \text { MOOERATE } \\
\text { MAMIPULATIVE }\end{array}$ \\
\hline 6 & $\begin{array}{l}\text { SOLITARY } \\
\text { RECREATION }\end{array}$ & 6 LISTENING TO & 6 SQUATTING & $\begin{array}{l}6 \text { VIGOROUS } \\
\text { MAMIPULXTIVE }\end{array}$ \\
\hline 7 & $\begin{array}{l}\text { RELARING, } \\
\text { RESTING IOLING }\end{array}$ & 7 LISTENIMG IO & 7 KMEELIIMG & $\begin{array}{l}7 \text { LIGHT } \\
\text { EXPRESSIVE }\end{array}$ \\
\hline 8 & $\begin{array}{l}\text { MAPPING } \\
\text { SLEEPING }\end{array}$ & $\begin{array}{l}8 \text { TALKING OR } \\
\text { LISTEEMING TO } \\
\text { TOPSIOE }\end{array}$ & O ALL FOURS & $\begin{array}{l}\theta \text { MOOERATE } \\
\text { EXPRESSIYE }\end{array}$ \\
\hline & DON'T KNOW & & 9 LYING 000 & $\begin{array}{l}9 \text { VIGOROUS } \\
\text { EXPRESSIVE }\end{array}$ \\
\hline
\end{tabular}

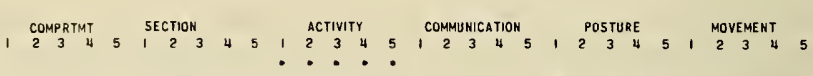

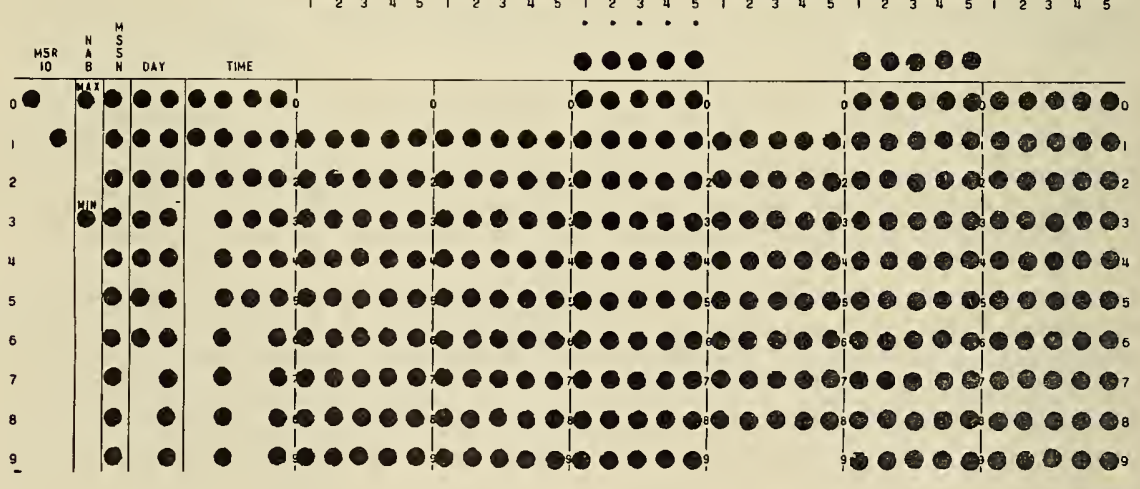


Table 2.--Measures Collected by Observation During Missions

IBM Portapunch Template

I. Aquanaut Status Record

Variables

A. Location by compartment and section of each aquanaut

B. Activity of each aquanaut

Categories of activity

1. Direct marine science

2. Marine science support

3. Locomoting

4. Habitat maintenance and repair

5. Self-maintenance

6. Maintenance of others

7. Co-recreation

8. Solitary recreation

9. Relaxing, resting, idling

10. Napping, sleeping

Composite variables composed by grouping activity categories for summary data

1. Total work--sum of time spent on direct marine science, marine science support, habitat maintenance, and maintenance of others

2. Total marine science--sum of time spent on direct marine science and marine science support

3. Total leisure--sum of time spent in corecreation and resting, relaxing, id1ing

*C. Communication of each aquanaut

Categories

1. Not communicating

2. Speaking to another aquanaut

3. Listening to aquanaut 非

4. Listening to aquanaut 非 2

5. Listening to aquanaut $\|_{3}$

6. Listening to aquanaut 非

7. Listening to aquanaut 非

8. Communicating with surface

D. Posture of each aquanaut Categories

1. Standing erect

2. Standing slouching

3. Standing leaning
Frequency or

Time of Collection

Every 6 minutes

Every 6 minutes
Every 6 minutes

Every 6 minutes

* Measures discussed in this report. 
4. Sitting forward

5. Sitting upright

6. Sitting slouching

7. Reclining

8. Squatting

9. Kneeling

10. A11-fours

11. Lying-down

E. Movement of each aquanaut Categories

0 . No movement

1. Light translational movement

2. Moderate translational movement

3. Vigorous translational movement

4. Light manipulative movement

5. Moderate manipulative movement

6. Vigorous manipulative movement

7. Light expressive movement

8. Moderate expressive movement

9. Vigorous expressive movement

II. Dive Record

Variables
A. Dive start time
B. Equipment used
C. Order of egress
D. Dive duration
E. Ingress order

\section{Meal Record}

\section{Variables}
A. Start of meal
B. Primary cook
C. Waiter
D. Duration of mea1
E. Primary clean-up diver

\section{Arising-Retiring Record}

Variables
A. Time of arising
B. Time of retiring
C. Duration of time asleep

Every 6 minutes

$\begin{array}{cc}\text { Each } & \text { occurrence } \\ " 1 & " 1 \\ " 1 & 11 \\ " 1 & " 1\end{array}$

$\begin{array}{cc}\text { Each } & \text { occurrence } \\ " 1 & " 1 \\ " 1 & " 1 \\ " 1 & \text { " }\end{array}$

Each occurrence

" " "




\section{Specific Events Record}

\section{Variables}

A. Maintenance of habitat by each aquanaut Categories
1. Housekeeping
2. Habitat maintenance
3. Habitat repair
4. Baralyme change

B. Maintenance of self or other by each aquanaut Categories
1. Head usage
2. Use of shower
3. Laundry
4. Handling of food

C. Use of Facilities by each aquanaut Categories
1. Watching outside TV
2. Watching TV tape for entertainment
3. Watching TV tape for training
4. Listening to radio
5. Using general leisure package
6. Using items from personal leisure package
7. Use of pressure pot
8. Use of winch

VI. Communication with Topside Record

Variables

A. Initiator of communication

Categories

1. Topside

2. Aquanaut

B. Device used

Categories

1. Open microphone

2. Intercom

3. Telephone

4. Videophone

C. Duration of conversation

D. Content of communication Categories

1. Operational

2. Social
Each occurrence

Frequency or

Time of Collection

Each occurrence

Each occurrence

Each occurrence

Each occurrence

Each occurrence 
In addition to punching data on cards, observers maintained a log with entries concerning any unusual events occurring in the habitat or at the dive site.

Video tape recordings of habitat behavior were also made. Systematic samples of group interactions with all aquanauts present were taken and emergencies, interpersonal disputes, and other events judged significant by observers were recorded. The tapes will later be subjected to content analyses by trained judges.

\section{$\underline{\text { Self-Report Data }}$}

Each aquanaut was asked to fill out a mood adjective checklist twice a day. The mood checklist tapped areas of emotionality such as fear, arousal, we11being, depression, etc. Although less than $100 \%$ cooperation in filling out these forms was obtained, the data promise much information on individual perceptions of the environment and their relations to performance and adjustment. These results will be reported in a subsequent technical report.

\section{$\underline{\text { Post-Mission Debriefing }}$}

As soon as post diver medical examinations were completed, each aquanaut was debriefed alone by the principal investigator and/or supervisor of the Behavior Program (Helmreich and/or LeFan) and a representative of the Habitability Program. The interviews were tape recorded and covered a wide range of topics including reactions to the habitat, interpersonal relations, achievement, physiological changes, and other concerns. Much useful information was derived from these interviews. However, difficulties in transcription make it necessary to defer results of this portion of the study to subsequent technical reports.

Although no systematic data from debriefing will be presented in this report, one finding consistent with earlier research should be noted here. This is that self-reports of performance elicited after an experience are not valid indices of the actual behavior exhibited. Frequently those aquanauts expressing most pride in their achievements rated among the lower performers, while those expressing personal dissatisfaction with personal performance were high on objective indices of performance. Radloff and Helmreich (1968) have discussed problems with self-report in detail. The present body of data may offer a chance to analyze the systematic distortions present in self-evaluation of behavior.

Following the interview, each aquanaut was asked to fill out a sociometric questionnaire nominating those aquanauts he would most like as teammates on a subsequent saturation dive and those he would most like as team leader.

\section{Summary}

As noted, the bulk of the research effort was directed at collecting complete quantitative data on personal and interpersonal activities during the total stay underwater. The variables observed can be used to form criterion variables or factors for the prediction of behavior and can also be used for analyses of trends in behavior over time and the study of interrelations of discrete behaviors. The pre- and post-dive measures provide variables to correlate with 
the highly detailed objective data available on each aquanaut's reactions to the undersea environment.

\title{
DATA MANAGEMENT PROCEDURES
}

\author{
John Wilhelm \\ The University of Texas at Austin
}

Two major types of data were collected in the Virgin Islands. Observational data were punched on site by University of Texas behavior observers onto IBM portapunch cards. Other measures were collected before and during each mission on questionnaires and mailed to Austin or California for keypunching.

Each card punched was hand checked on site for obvious errors; mistakes were often corrected before distance from the event made this impossible. Cards were airmailed to Bellcomm, Inc. weekly. Bellcomm time-sequenced the cards, stored reformated data on magnetic tape, and relayed to Texas the data as punched IBM cards, formated printouts of the sequenced data, and card listings. At the University of Texas, data were screened by computer to eliminate any invalid data values and machine processing errors. Due to the large volume of data generated during each mission, four preliminary data reduction programs were written.* STATDAY gives daily totals on each variable for each diver from Status Record; MEALDAY, COMMAY, and DIVEDAY similarly combine data from the Meal Record, Communication Record, and Dive Record to give daily summaries. A11 data reduction programs compute values for either a complete day or for a whole mission and print and punch these summaries for inspection and further statistical analyses.

The major preliminary analyses to date have been on the Aquanaut Status Record using program STATREC. This program and several others were written before the project began to enable tabulation of Status Record data as missions progressed. A11 variables are totaled and converted to percentage scores to allow comparison across teams. From the various activity categories, composite criteria for total leisure, total marine science, and total work are computed.

The utilization of each compartment and section of each compartment by each diver is calculated. Some communications analyses are also derived from Status Record; for example, talk/listen to topside, talk/listen to other aquanauts, and noncommunication. A detailed gregariousness matrix is also computed consisting of the time spent by each diver talking to each of all possible groups formed from the other aquanauts.

The combination of variables recorded on the Aquanaut Status Record lends itself to easy calculation of location-specific activities. Territoriality scores for each diver in each section, and the sections most used by each team as a whole, have been derived for leisure activities, for work activities, and for total activities.

* A listing of any program mentioned in this report may be obtained on request from the authors. 


\section{Robert Helmreich \\ The University of Texas at Austin}

The aquanauts, as a group, formed a highly qualified and educated population. There were, however, large individual differences in experience and in personality characteristics. In this section, descriptive statistics from the Aquanaut Background Questionnaire and other pre-dive measures will be presented to provide an indication of the characteristics of the research group and to show the range of variation present. Predictive variables derived from the Life History Questionnaire are not included as they will be discussed in detail in a later section. Table 3 shows data for Scientist-Aquanauts and Engineer-Aquanauts.

The most striking variability in scores is on age and diving experience. As can be seen in Table 3, engineers had significantly less diving experience than scientist-aquanauts, although differences on most measures between scientists and engineers were not great. Overall, the aquanauts came from generally middle-class or upper-class, stable families.

The two special teams (the Female Mission and the International Mission) did not differ significantly from other teams in background and personality variables. Forty-six of the aquanauts were of Caucasian descent, one of JapaneseAmerican origin, and one of Chinese ancestry. Seven aquanauts were born in foreign countries ranging from Europe to South America and the Orient.

\section{A Note on the Allport-Vernon-Lindzey Study of Values}

The Allport-Vernon-Lindzey Study of Values (Allport, Vernon and Lindzey, 1960) is a widely used test which measures the relative strength of six major value areas (theoretical, economic, aesthetic, social, political, and religious). Norms have been developed for the general population and for specific occupations. (The population average is 40 on each scale.) The fact that the scientist-aquanauts score significantly higher on the theoretical scale than engineers agrees with special occupational norms. Of more interest is the fact that the profiles for TEKTITE scientists and SEALAB II civilian aquanauts (Radloff and Helmreich, 1968) as well as Mt. Everest explorers (Lester, 1963) are almost identical. Scientists undertaking hazardous but professionally rewarding tasks seem to have a similar constellation of values characterized by high theoretical and aesthetic values, low religious values, and average social, economic, and political concerns.

Although teams do not differ significantly on background variables, recorded events during childhood and youth are significantly related to individual performance and adjustment underwater. These will be discussed later. 
Table 3.--Background Characteristics of Aquanauts

Scientists $(N=40) \quad$ Engineers $(N=8)$

1. Mean Age

Range

2. Mean Years Scuba *

Experience

3. Marital Status (frequency)

Single

Married

Divorced or Separated

4. Birth Order

First born

Later born

6. Number of Moves during Childhood

7. Father's Education (frequency)

Less than 8th Grade

8 th or 9 th Grade

10 th or 11 th Grade

H.S. Graduate

Some College

BA Degree

Advanced Degree

8. Mother's Education (frequency)

Less than 8th Grade

8 th or 9 th Grade

10th or 11 th Grade

H.S. Graduate

Some College

BA Degree

Advanced Degree

9. Allport-Vernon-Lindzey Study of Values (AVL) Theoretical Score*

10. A-V-L Economic

11. A-V-L Aesthetic

12. A-V-L Social

13. A-V-L Political

14. A-V-L Religious

15. Inte11igence (from 16.PF Test)

* $\mathrm{p}<.01$
31.97

32.57

25-42

$22-45$

9.82

3.86

4

34

2

22

18

1.80

2.53

$\begin{array}{rr}0 & 1 \\ 5 & 0 \\ 4 & 0 \\ 11 & 2 \\ 6 & 3 \\ 4 & 1 \\ 10 & 1 \\ & \\ 1 & 1 \\ 3 & 0 \\ 2 & 1 \\ 17 & 0 \\ 8 & 5 \\ 4 & 1 \\ 5 & 0\end{array}$

53.16

46.25

37.03

40.75

40.38

36.00

37.08

41.25

31.62

28.39

8.50 


\section{Robert Helmreich \\ The University of Texas at Austin}

This section describes overall patterns of behavior shown by the ten teams of aquanauts. These data focus on the general patterns of observed behavior in the habitat and also on group differences in behavior across missions. The data are presented in several ways: (1) all ten missions are contrasted using percentage of total mission time spent on each activity as the basis for comparison. In these analyses, missions of different lengths as well as the female and international missions are treated equally; (2) missions of different durations are compared; (3) the reactions of the female crew are related to those of other crews; and (4) relations between scientists and engineers are discussed.

\section{Two Important Notes}

(1) As this is a preliminary analysis, data have not been adjusted to account for externally caused perturbations in aquanaut behavior such as storms, equipment malfunction, and illness. These factors will be included in later analyses; their function in the present treatment is to increase the error variance in comparisons and to reduce the significance of obtained results. Thus, this preliminary analysis provides the most rigorous test of the lawfulness of the observed behavior.

(2) The stability and accuracy of the observational data should be emphasized. The variables that were recorded were objective and observers were highly trained. The reliability of the measures collected was assessed by having an independent observer recode the data from video tapes. His observations were then compared (by computing reliability coefficients) with those the observers made at the time the video tape was recorded. Across all variables, the correlations averaged between .89 and .97 , indicating that the judgment of on-site observers were highly reliable and objective. This makes it possible to place great faith in validity of behavioral indices. It should also be noted that reliabilities were highest on the more crucial criterion measures such as activity and location and were lower on secondary (and more difficult) judgments such as motion and posture. Another index of reliability was the number of times the "Don't Know" category was employed by observers (when they could not ascertain the location or activity of an aquanaut). Less than $0.5 \%$ of the observations were in this category. Given that over 35,000 observations were made per subject, this speaks well of observer ability.

Team and Individual Identity

Because pre-mission testing involved many variables concerned with personal characteristics and because the Behavior Program monitored behavior continuously during the period spent in the habitat, special efforts have been made to preserve the anonymity of teams and aquanauts. Each team has been assigned a letter code unrelated to mission designation and each aquanaut a number designator within the team. Accordingly, references to teams or individuals do not systematically identify particular aquanauts. 
The average percentage of total mission time spent on various activity categories by all aquanauts is shown in Figure 2. As the figure indicates, aquanauts spent a significant proportion of their time in productive endeavors. For all aquanauts, the average amount of time spent working was 8.04 hours per day. Scientist-aquanauts averaged 7.15 hours per day working on marine science. These mean times over several weeks represent far more undersea work than could have been achieved through operations from the surface. It is also obvious that the aquanauts were primarily work-oriented during their sojourn on the bottom. Work and sleep combined accounted for the bulk of a day's activity, with leisure activity the bull session, typically during and after meals. Little time was spent on organized activities such as games, and only occasional use was made of television tapes. Background music was widely used but typically in conjunction with other activity.

There were large differences between teams on the variables composing the graph shown here. Table 4 shows the percentage of mission time spent on each activity for each team of aquanauts. Components of composite criteria (work, leisure, and total marine science) are shown separately. The significant levels of the overall differences across teams were computed by analysis of variance and are shown in the table.

The range between the lowest and highest teams on many of the activity variables is striking. For example, scientists on the highest team spent $39.4 \%$ of their time in marine science work (average 9.4 hours per day) while those on the lowest averaged $21.1 \%$ (average 5.1 hours per day). This represents an average difference of 4.3 hours per day. The team scoring highest on sleep spent $39.6 \%$ of its time sleeping (average 9.5 hours per day) in contrast with the lowest which spent on 1 y $30.8 \%$ (average 7.4 hours per day). This represents an average difference of 2.18 hours per day. Factors leading to team differences and the interrelations of activity variables will be discussed 1ater. It should be noted that these figures represent actual time spent in the activities measured. An individual might spend 8 hours a day in an office but spend 30 minutes drinking coffee, 30 minutes in social conversation, 15 minutes relaxing, an hour eating, and the rest of the time working. In our system, he would be credited with 5.75 hours of work.

\section{Additiona1 Comparisons of Missions}

The large differences found between individual missions raise questions as to whether these variations in behavior are a function of factors within individuals and social groups or whether they result from external factors such as mission duration. To evaluate these questions, analyses were performed to determine whether there were systematic differences between types of missions. These tested the proposition that differences between teams were a function of mission length. In these comparisons, results from the six 20-day missions were combined and contrasted with results from the four 2-week missions by unweighted means analysis of variance. The results are shown in Table 5.

As can be seen in Table 5, there were significant differences between 1ong and short missions on several activity variables. These differences appear to be readily explainable as a function of circumstances related to mission duration 


\section{FIGURE 2}

Mean Percentage of Total Mission Time Spent on Habitat Activities (All Aquanauts)

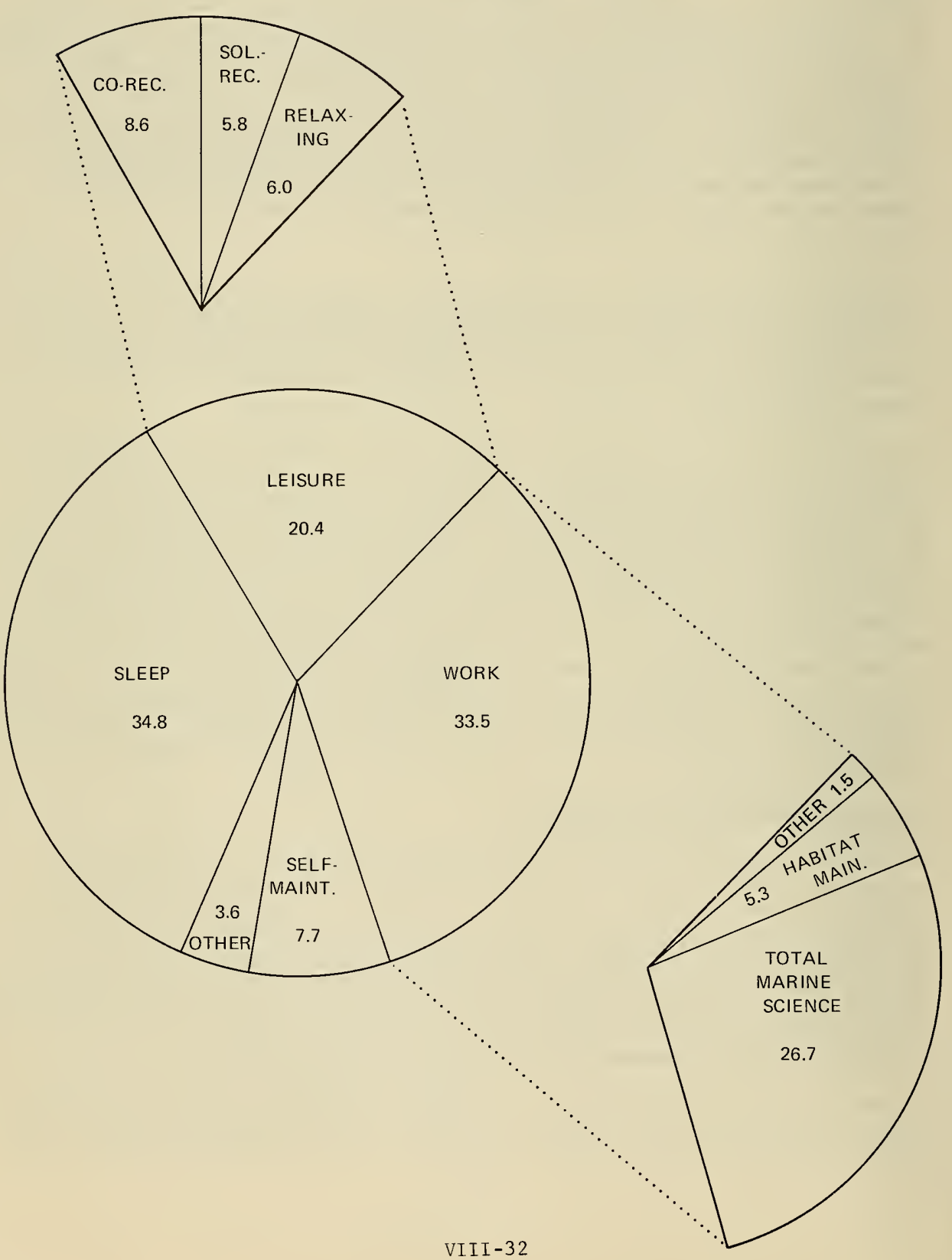




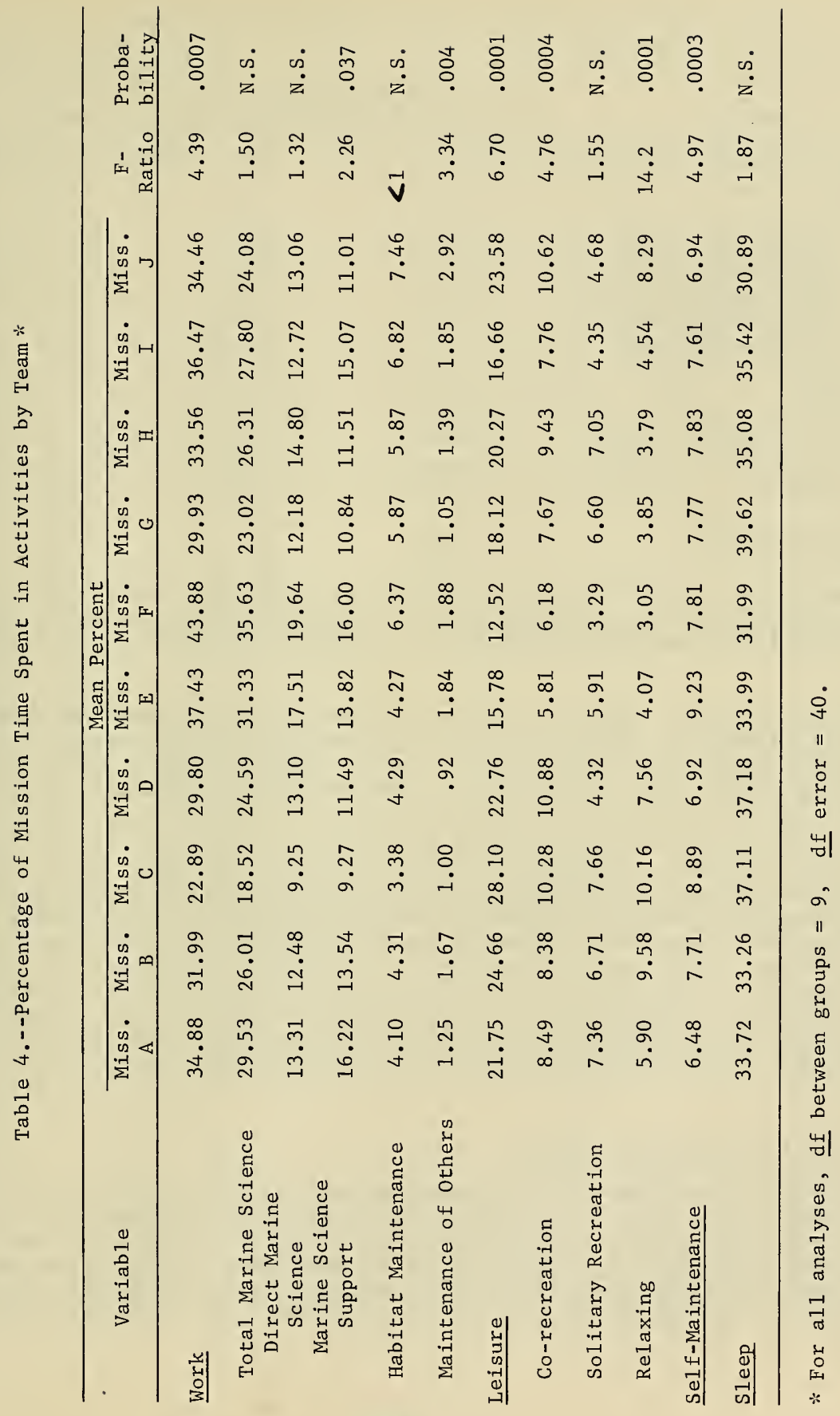


Table 5.--Comparison of Long and Short Missions

\begin{tabular}{|c|c|c|c|c|}
\hline \multirow[b]{2}{*}{ Variable } & \multicolumn{2}{|c|}{ Mean Percent } & \multirow[b]{2}{*}{ F-Ratio } & \multirow[b]{2}{*}{$\begin{array}{l}\text { Proba- } \\
\text { bility }\end{array}$} \\
\hline & $\begin{array}{c}\text { Long Missions } \\
(6)\end{array}$ & $\begin{array}{l}\text { Short Missions } \\
(4)\end{array}$ & & \\
\hline Work & 31.70 & 36.30 & 4.53 & .03 \\
\hline Total Marine Science & 25.99 & 28.81 & 1.80 & N.S. \\
\hline Direct Marine Support & 13.76 & 14.62 & $<1$ & N.S. \\
\hline Marine Science Support & 12.24 & 14.19 & 3.00 & N.S. \\
\hline Habitat Maintenance & 4.38 & 5.56 & $<1$ & N.S. \\
\hline Maintenance of Others & 1.32 & 1.93 & 5.86 & .01 \\
\hline Leisure & 19.95 & 20.62 & $<1$ & N.S. \\
\hline Co-recreation & 8.52 & 8.42 & $<1$ & N.S. \\
\hline Solitary Recreation & 5.73 & 5.51 & $<1$ & N.S. \\
\hline Relaxing & 5.70 & 6.71 & 1.40 & N.S. \\
\hline Self-Maintenance & 8.08 & 7.23 & 7.31 & .009 \\
\hline S1eep & 36.73 & 32.46 & 12.06 & .002 \\
\hline
\end{tabular}

* For all analyses, $\underline{\mathrm{df}}$ between groups $=1$, df error $=46$.

and organization. Aquanauts on longer missions were more concerned with personal well-being. They spent significantly more time sleeping and in selfmaintenance (personal hygiene, etc.). This probably reflects a perceived need to keep oneself in top shape while working on a strenuous schedule.

The fact that aquanauts on short missions worked significantly more than those on long missions is largely an artifact of food preparation. On all 20-day missions, aquanauts ate prepacked, frozen food provided by NASA. On three of the four short missions, aquanauts had to prepare their own food using standard grocery store consumables. Food preparation is coded as maintenance of others; significantly more time was spent on this component of work in short missions. of particular interest is the fact that there was not a significant difference between long and short missions in the percent of marine science work accomplished. Thus, longer mission duration did not significantly reduce the percentage of total time aquanauts were able or motivated to devote to scientific work.

\section{Comparison of 60-Day Missions}

The six 20-day missions were organized as two sets of three missions with four engineers serving for 30 days each and rotating at the halfway point of each set. The two groups of three missions were compared by analysis of variance to determine whether any unpredicted differences were present in habitat behavior. The two sets of missions were comparable on the major activity categories; no significant differences were found. These findings, and those 
noted earlier, supported the contention that differences between teams are primarily a function of group dynamics, team composition, and individual differences in motivation.

\section{Genera1 Comments on Team Differences}

It may be useful to make a few preliminary remarks on probable causes of the large differences across teams in performance (marine science and total work).

One characteristic of each mission is that groups began working at a given level (for example, $25 \%$ marine science per day) and varied around this mean. Psychologically, each group appears to have established an initial norm for work and to have generally maintained this level of output throughout the mission. This determination of performance by expectancy has been widely noted as a cognitive consistency phenomenon derived from the theory of cognitive dissonance (Festinger, 1957); Aronson and Carlsmith, 1962). The implication of this finding is that it will be advantageous for mission planners to make explicit and expected norms for performance. In TEKTITE, no transmission of expectancy from program personnel was planned or undertaken. This, of course, was because a goal of the research was to investigate the types of norms established.

An important goal of later analyses will be to uncover reasons for the establishment of different norms and to specify personal characteristics of those who deviate from group norms. Group influence in small, isolated groups is extremely powerful, and subtle pressures are exerted to enforce conformity. Individual differences will be discussed later.

One factor which appears to be strongly related to level of performance is crew composition, particularly in regard to the leadership role. In six missions, the team leader was the scientific leader; in two missions the engineer was the team leader; and in two missions leadership changed. In the latter cases, the engineer served as team leader for 10 days; then, after engineer rotation, the scientific leader served as team leader for the remainder of the mission.

Although the number of leaders in the different leadership roles is insufficient for statistical tests of significance, several tentative hypotheses about the leadership role can be advanced and may be subjected to test in subsequent research.

The differences in time spent in work between the top three teams and the bottom three teams are large (mean work, top three $=38.7 \%$; mean work, lowest three $=27.5 \%$ ). The three teams showing the highest work output had a scientist as team leader while the lowest three had an engineer as team leader for a11 or part of the mission.

The leaders of high performing teams were not necessarily top performers (in terms of time spent in work). Indeed, the within-team ranks for the leaders of the top three were 1,3 , and 5 on work. In earlier studies (see Radloff and Helmreich, 1968) it has been noted that leaders of effective groups may not themselves perform particularly well. These differences in crew performance are probably due largely to the mission role of the leader. The objective of TEKTITE was to provide a base for scientific work. When a scientist was team 
leader, his personal goals and mission goals coincided. The engineer, on the other hand, was charged primarily with the maintenance of the habitat and was not directly involved in scientific research. Habitat maintenance took an average of $5.27 \%$ of mission time overal1 and did not differ significantly across missions; it is likely that an engineer who was primarily concerned with the effective performance of his engineering duties would not aid in setting high norms for scientific work. As a general rule, it would appear advisable to have mission leaders directly involved in primary mission objectives. An exception which seems to illustrate this point is found in the case of the mission which ranked fifth in performance and was initially led by an engineer. The engineer/team leader became actively involved in participating in the scientific research of the scientist-aquanauts. This involvement seems to have facilitated group performance.

\section{Correlations Among Habitat Activities}

Table 6 shows the intercorrelations of observed categories of behavior inside the habitat for all aquanauts. The relationships shown in the table give a clear picture of how various habitat activities related to one another. Since the components of composite variables had a highly consistent relationship with each other and with other variables, discussion will be of the correlations between independent and composite variables. The reader is referred to the table for exposition of specific relationships.

Considering first the correlations for the entire sample of aquanauts (Table 6), there are strong negative correlations between work and sleep $(-.69)$ and between work and leisure (-.76). Sleep and leisure were uncorrelated (.09). Self-maintenance was not significantly correlated with work (-.07), sleep (.10) or leisure (-.18); it did, however, have a significant negative correlation with co-recreation $(-.34)$

As can be seen on Table 7, the correlations for scientist-aquanauts are highly similar to those for the total population. As a result, the following discussion applies to a11 aquanauts.

The patterns of correlations shown in both tables indicate that those who worked most spent less time both in leisure pursuits and in sleeping. This does not imply that those who worked most skimped on sleep and leisure to gain working time. The top 10 scientists on the work criterion averaged 8.5 hours a day working, 8 hours sleeping, and almost 4 hours a day in leisure. It indicates, rather, that those low on the work measure spent a very high percentage of their day either sleeping or in leisure activities. (For example, the aquanaut who worked least spent an average of 4.3 hours per day working, 9 hours per day on leisure, and 8.2 hours per day sleeping.)

Those who slept most were neither more nor less likely to spend much time in leisure activities. Thus, while both sleep and leisure predict work, they do not have a systematic relationship with one another.

Spending time diving did not result in devoting more time to self-maintenance. In other words, spending more time in the water or in general work did not result in the use of more time for prophylactic and other hygienic activities. The significant negative correlation of self-maintenance with co-recreation indicates participation in group recreational activities. 


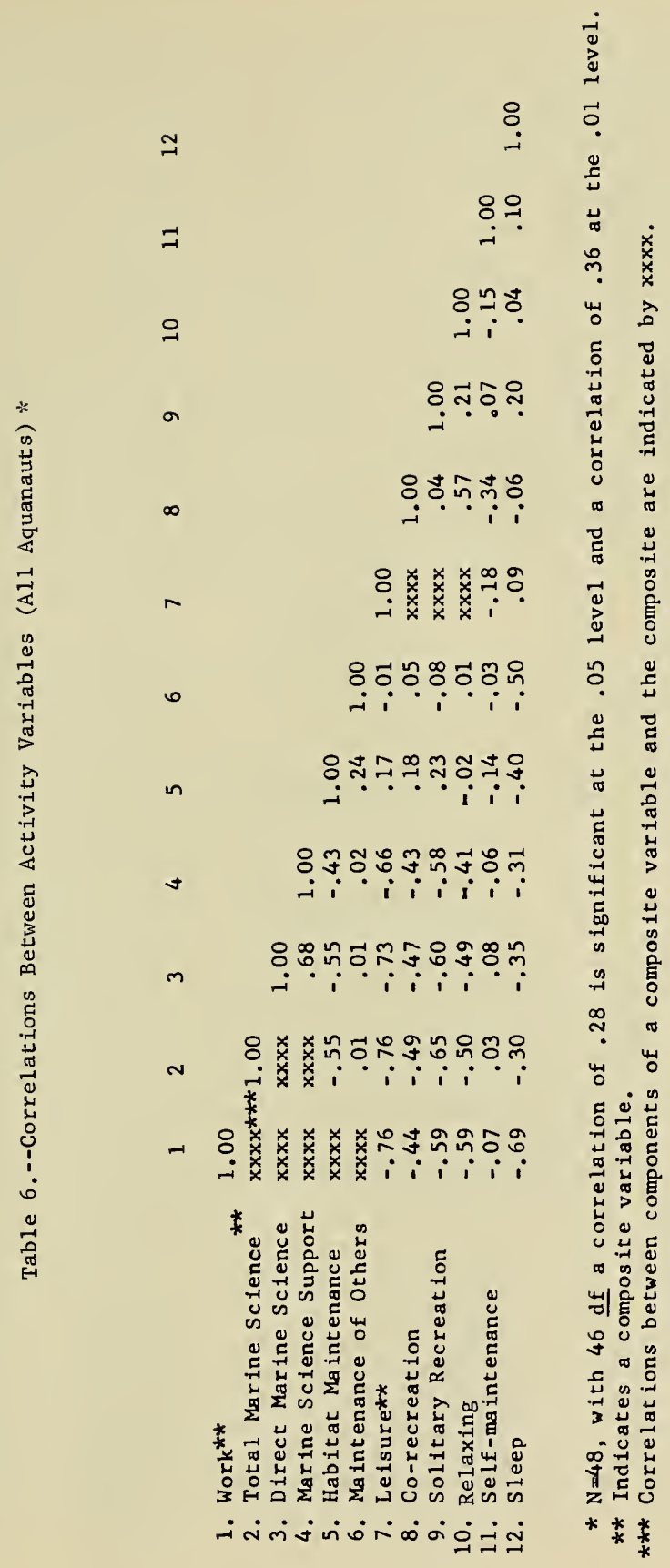




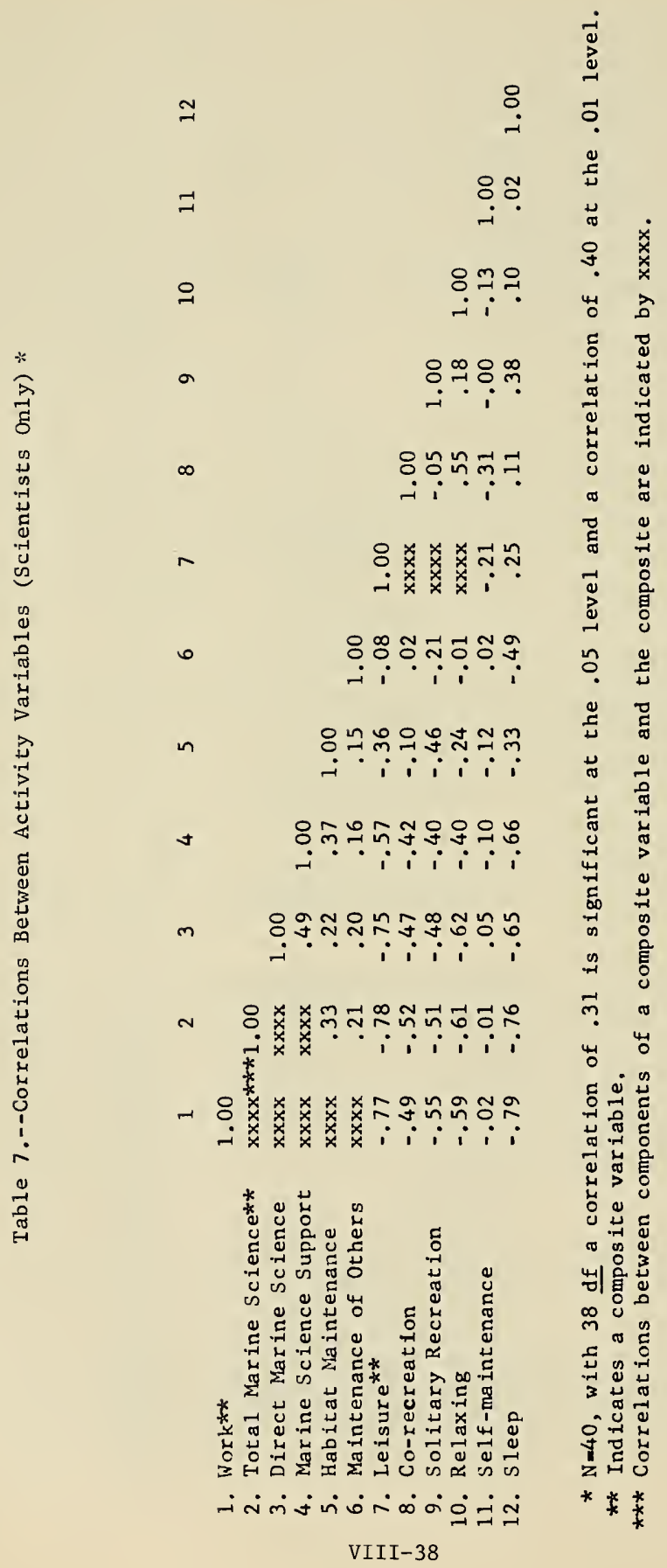


Since pre-dive baseline data on the correlations between work, leisure, and sleep are not available for the aquanaut sample, it is impossible to state whether the correlations among these variables in the habitat are a result of differential response to the isolated environment or are instead an extension of everyday life habitats. However, given the large number of significant differences on predictive variables found between the aquanauts scoring high and those scoring low on the work criterion, it is reasonable to hypothesize that the relationships found in TEKTITE are indeed related to pre-mission life patterns. If this proposition is correct, then knowledge of applicants' customary life patterns would provide a battery of extremely effective predictors which could be used in selection of candidates for sensitive and demanding missions. It should be noted that self-report does not provide a generally reliable data base for evaluation of individual characteristics (see Radloff and Helmreich, 1968, for a discussion of the relative merits of data sources). Nevertheless, the relationships discussed above are so strong that a recommendation to evaluate normal life patterns as potential predictors of performance is in order. Available data are generally weak, yet, as has been noted, past behavior remains the best predictor of future behavior. The major problem is to obtain objective, reliable data on individuals using non-reactive measures. This presents a major challenge for later research.

\section{Gregariousness}

Patterns of social interaction, their changes over time and correlations with activity variables form one of the most interesting components of the research. Data on communication and social behavior were collected on the Aquanaut Status Record, the Meal Record, the Communication Record, and video tape. Because of the complexity and volume of these data, detailed analyses have been deferred; however, a preliminary examination of several of the variables measured indicates the power and importance of this area.

Correlations between the overall gregariousness of each aquanaut ( $t$ ime spent with other aquanauts in conversation) and total marine science and between time spent communicating with the topside command van and total marine science were computed for scientist-aquanauts. The correlation between gregariousness and total marine science was .59 (p<.01), showing clearly that interaction with peers is positively associated with productivity. This finding strongly replicates the results on gregariousness among aquanauts found in SEALAB II. Communicating with topside was also positively related to time spent on marine science $(\underline{r}=.35, \underline{p}<.05)$. Those who spent most time communicating with topside personnel also spent most time performing marine science work. These findings appear to contradict results noted in SEALAB II where communication with topside was associated with poor performance. This apparent contradiction points out the need for precise specification of variables and for detailed interpretations of obtained results. In SEALAB II, on1y social communications, social and operational, initiated by the surface or by aquanauts, were monitored and noted (see Table 2 for a description of the information recorded). Although complete data on the nature of each conversation are coded, in this preliminary computation only total time spent in communication was used to provide an overall look at the effects of communication. It is probable that subsequent analyses will reveal that aquanaut-initiated, social communication with the surface is associated with poor performance while operational communication is a positive correlate of work. 
The first general conclusion which can be drawn from the data is that individual gregariousness is positively associated with performance. The isolation of conditions which promote or hinder gregariousness will be a major goal of later analyses of the TEKTITE data. In any event, this preliminary look at the information collected suggests that the available data on social interactions will account for much of the observed variance in group behavior and performance.

Comparison of Male and Female Aquanauts

One of the questions of greatest interest concerning TEKTITE is the behavior of the team of female aquanauts in contrast with that of male teams. Unfortunately, the assignment of only one female team and a number of other external factors make it impossible to draw firm conclusions about the two populations. The reader should, accordingly, keep in mind the fact that the differences described below probably reflect less on the relative capabilities of the two sexes than on social and environmental factors. These factors will be discussed after presentation of the results.

Comparisons between the five females and the 43 males were made by unweighted means analysis of variance. On the activity criteria, the females worked significantly more than the combined male population $(\underline{F}=12.49, \underline{p} 6.002)$, spent more time on marine science $(\underline{F}=5.56, \underline{p}<.025)$, and spent less time on leisure $(\underline{F}=12.08, \underline{p}<.002)$. They did not differ significantly from the males in total sleep time, time spent in habitat maintenance, and time spent on selfmaintenance.

The high work output of the female team implies that females are capable of maintaining a work pace equal to that of males in an underwater habitat. The fact that the females measured significantly higher than males on the work and marine science criteria could be an indication of the natural superiority of women or of differential motivation. Consideration of social psychological factors suggests the latter interpretation, although causal forces cannot be extracted from the data.

Some of the forces which probably acted to increase motivation in the female team can be isolated. These include selection procedures, potential effects of the mission, on-site support, and publicity about the role of women in undersea research. Considering these in order, that only one of 10 missions was for females and that it was the first female saturation dive undertaken, probably led to more intensive screening and, in general, more rigorous criteria for selection than were applied to male candidates. This probably resulted in more of a sense of uniqueness and higher motivation to achieve than was present in most male aquanauts. Directly related to this was the first-and-only type category of the mission. Comments from program personnel and the scientific community depicted this mission as determining the feasibility of women participating in both undersea and space exploration. This factor alone doubtless produced a strong pressure to produce and to excel on each of the female aquanauts. Another factor which seems to have contributed to the high work output of the female team was the fact that surface support personnel were more highly motivated to provide assistance to the female team. These natural and commendable reactions undoubtedly made conditions somewhat more propitious than they were for male teams. Finally, the publicity and press coverage surrounding the 
female mission, which far exceeded that accorded any other mission, unquestionably caused members of this team to be more conscious of their performance and more highly motivated to look good in comparison with other teams.

None of the factors cited above reflect any discredit on the performance of the female mission, which was excellent on an absolute basis; they are cited to illustrate the importance of motivational factors.

The conclusion that motivational factors probably account for most of the obtained performance differences is supported by the general lack of differences between female and male aquanauts on demographic and personality factors related to diving performance. Female aquanauts were compared with male aquanauts by unweighted means analysis of variance on general demographic and personality variables. A significant difference was found only on mean age--the females as a group were significantly younger than the males ( $X=32.7$ for males, 27.0 for females; $\underline{F}=5.43, \underline{p}<.025)$. Among the variables on which there was no difference were years of scuba experience, IQ, religious activity, and value structure (as measured by the Allport-Vernon-Lindzey). The two groups were also compared on variables derived from the Life History Questionnaire. Significant differences were found on only four variables. These were: parental physical affection (females received more); school performance (females received higher grades); fights with peers (females had fewer); and work during summer months (females were less likely to have worked). These contrasts are all in agreement with sex differences in the American population. The remarkable fact, then, is how similar the male and female groups were on a11 predictive measures.

In summary, female aquanauts logged more marine science activity and more total work than did males. They were remarkably similar to males on personality and demographic variables, and a hypothesis that their higher performance was a result of higher motivation seems warranted. It does seem possible to conclude that female aquanauts can perform as effectively as males in a saturation diving operation such as TEKTITE.

\section{Scientist-Engineer Relations}

One of the questions frequently debated in social psychology is the nature of relations between individuals with differing goals and orientations who are forced into close interaction. The issue has been raised in particular in the American space program where scientists and engineers are often described as having incompatible goals which make professional and social interaction difficult. A valid concern is how a mixed crew of engineer-pilot astronauts and scientist-astronauts would fare in close contact on a long-duration spaceflight. Could individuals with divergent roles and goals be compatible in an isolated environment for long periods of time where no opportunity for escape is present?

TEKTITE II provided one opportunity to evaluate the interactions of mixed groups in a natural setting. Each aquanaut team was composed of four scientists and one engineer; the goal of the scientists was marine research while the engineer was charged with the operation and maintenance of the habitat. The opportunities for misunderstanding and conflict were many--over work goals and schedules, space utilization, and social interests. 
In general, relations between scientist-aquanauts and engineer-aquanauts were excellent. In addition to the shared concern with the overall success of the project, most teams developed effective techniques to assure harmony and productivity in the close environment.

One aspect of scientist-engineer relations, however, appears to have a systematic relationship with performance and group cohesiveness. This is the involvement of engineers in scientific work and scientists in engineering activities. It has already been noted that teams with engineers as leaders for part or all of the mission accomplished less marine science work than teams with scientists as leaders. This was attributed to noncongruence between the engineer's mission role and the scientific goals of the other aquanauts. However, overall performance on marine science was notably higher where the engineer-leader became actively involved in the scientific programs of the other aquanauts. It seems likely that an extension of this phenomenon may be an important factor in the compatibility and productivity of isolated groups composed of individuals with divergent interests and goals.

Helmreich and Radloff (1969) proposed that the most effective social organization for a confined environment (such as a long-duration space mission) is one in which individuals have unique skills and knowledge which they communicate to others who are motivated to learn and who have their own skills to share. This form of interaction with each individual serving as both a teacher and a learner should maximize the rewards possible in a closed environment and should also increase interpersonal understanding.

It was possible to examine aspects of this type of relationship in the TEKTITE setting. We assume that the greatest engineer-scientist compatibility would be achieved when the engineer became actively involved in marine science projects and when, conversely, the scientists played a significant role in engineering/ habitat maintenance activities. A preliminary examination of the data supports this hypothesis. There was great variability on these measures. The average of marine science time for the three engineers who became most involved in working with scientists was $22.05 \%$. The average for the three engineers who participated least in scientific work was $7.89 \%$ marine science. This sharing (or avoidance) was reflected in the participation of scientists in engineering duties. Mean habitat maintenance by scientist-astronauts on the three missions where the engineer took part most in scientific work was $3.59 \%$, while on three teams where the engineer was least active in marine science, the habitat maintenance mean for scientists was $2.07 \%$. Preliminary analyses indicate that the teams with a high degree of shared scientific-engineering activity were more cohesive and compatible than those where scientists and engineers did not participate in each other's work.

Overall performance was also markedly influenced by scientist-engineer interaction. The mean for total marine science of the three teams where the engineer-scientist sharing was highest was $29.95 \%$ while the total marine science score for the three teams with the lowest amount of cross-participation was $23.61 \%$. This is a mean difference of more than an hour and a half per day.

The implications of these findings are that in selecting professionally mixed teams for isolated environments, not only the professional qualifications but also the breadth of the candidate's interests should be considered. The 
individual who is not only skilled in his own profession but eager to acquire knowledge about other lines of endeavor should be the most effective type of group member. This reasoning would suggest that the individual who is singlemindedly dedicated to his particular professional aim would not make an effective member of a mixed crew. That sharing of diverse interests aided cohesiveness and compatibility was also demonstrated in debriefing of several scientist.aquanauts who remarked that one of the high points of their experience was the exchange of professional information with other scientists who had completely different professional backgrounds.

An important aspect of subsequent analyses will be an attempt to isolate background characteristics which can predict whether or not an individual will enter into cross-professional exchange. This area appears to be of sufficient importance to merit intensive investigation.

\section{Effects of Partial Crew Rotation}

In two missions, the engineer was replaced at the midpoint of the mission. The effects of the rotation of one crew member on the behavior of the remaining members are of both theoretical and practical importance. Because there are large differences in behavior as a function of time in habitat (which will be discussed later) the analysis of the effects of a crew change in the middle of a 20-day mission must take into account the normal changes over time. As a first analysis of these data, the behavior of the four scientist-aquanauts before and after engineer change was compared with that of the four scientistaquanauts during comparable time periods in the four 20-day missions without crew rotation. This comparison was done by unweighted means analysis of variance contrasting missions without rotation and missions with rotation (between) and first-half of mission with second-half of mission (within). In other words, the first and second halves of missions with an engineer change (rotation was at mission midpoint) were compared with the first and second halves of the four 20-day missions without an engineer change. The latter missions served as a control for the former. In this analysis, behavioral effects of crew shift will be reflected in a significant group (rotation or non-rotation) by trials (firsthalf versus second-half) interaction.* Means and significance levels for activity variables are shown in Table 8 .

As can be seen in the table, changing a crew member did not significantly affect the major performance criteria, total marine science and total work. There was also no significant effect on sleep and total leisure.

Social relations were significantly influenced by engineer change. This is shown in the significant interactions for co-recreation, solitary recreation, and gregariousness. As can be seen in Table 8, the percentage of time spent in total leisure did not differ between rotated and unrotated missions over time (the F-ratio is less than 1 ). However, the types of leisure activities did

* By a significant interaction we mean that the pattern of scores between the first and second halves of the mission differs in the two groups. For example, if solitary recreation increased after engineer change in rotated crews but decreased in non-rotated crews, there would be an interaction effect. 
Table 8.--Effects of Time and Engineer Rotation on Habitat Activities of Scientists

Variable

Total Marine Science

Group

Long Missions with

Engineer Change

2 Missions; 8 Scientists

Long Missions Without

Engineer Change

4 Missions; 16 Scientists

$$
\text { Mean \% }
$$

1st Half (Before

Engineer Change)
Mean \%

2nd Half (After Interaction

Bngineer Change) F-Ratio

\section{Total Work}

$\begin{array}{lcc}\begin{array}{l}\text { Long Missions with } \\ \text { Engineer Change }\end{array} & 32.4 & 31.2 \\ \begin{array}{l}\text { Long Missions without } \\ \text { Engineer Change }\end{array} & 32.9 & 31.2\end{array}$

28.2

Engineer Change

\section{Sleep}

Long Missions with

35.9

38.5

Engineer Change

Long Mission without

36.7

38.1

N.S.

Engineer change

\section{Total Leisure}

Long Missions with

20.6

20.7

Engineer Change

Long Missions without

18.4

18.2

$<1$

N.S.

Engineer Change

\section{Co-recreation}

$\begin{array}{lcc}\begin{array}{l}\text { Long Missions with } \\ \text { Engineer Change }\end{array} & 10.7 & 9.5 \\ \begin{array}{l}\text { Long Missions without } \\ \text { Engineer Change }\end{array} & 7.1 & 7.7\end{array}$


Table 8 (cont)

Mean \%

1st Half (Before 2nd Half (After Interaction

Engineer Change) Engineer Change) F-Ratio
Probability

Solitary Recreation

Long Missions with

Engineer Change

Long Missions without

Engineer Change
$4.1 \quad 5.4$

$5.6 \quad 5.2$
3.98 .05

Gregariousness

(Time spent communicating)

Long Missions with

Engineer Change

Long Missions without

Engineer Change
33.8

30.1

28.3
16.2

28.5

.0008

differ significantly as a function of engineer change. In missions where the engineer changed, co-recreation decreased after the shift while in missions without rotation there was an increase in co-recreation during the corresponding time period. Exactly the opposite pattern is shown in the data on solitary recreation. An engineer change was followed by an increase in solitary leisure while intact groups showed decreased solitary recreation over time.

The effect of crew change on gregariousness (as measured by total conversation) is highly significant. While social interaction increased between the first and last half of missions without rotation, there was a dramatic drop when a new member entered the group.

Because of the limited number of cases, generalizations about the effects of partial crew rotation are unwarranted. However, the fact that a member of an isolated small group could be replaced in mid-mission without an adverse effect on performance is worthy of note, particularly since the change was associated with significant changes in social behavior. The shifts in leisure activity and gregariousness after rotation are in the direction of less group cohesiveness. This pattern is consistent with a large research literature indicating that the addition of a new member to a cohesive, ongoing group produces at least temporary disruption.

It should be emphasized that the crewman change in TEKTITE involved the replacement of a peripheral member. The engineer is peripheral in the sense that his role is not directly related to the scientific goals of the other team members. Replacing a scientist-aquanaut might have a far greater impact on performance. In any case, TEKTITE aquanauts managed crew rotation without major conflict or work decrement. 
Roger Bakeman and Robert Helmreich

The University of Texas at Austin

Throughout this report we have used observational data primarily in highly reduced, summary form. For example, we have referred to the total percentage of time aquanauts slept during missions but have, in general, ignored the ways in which time spent sleeping changed during the course of a mission. It seems clear that collapsing time series data during initial analyses is justified, yet it is equally clear that much richness remains to be tapped. Such analyses will undoubtedly reveal details and indicate mechanisms only vaguely suggested by first order generalizations based on summary data.

The problems presented by time series analyses are difficult but not insurmountable. There is a risk of being simply inundated by mounds of detail. Here, as elsewhere, it makes sense first to determine at a molar level if a phenomenon holds interest, then, if it appears promising, to examine it in more detail. Accordingly, our first approach to time series analyses has been simply to compare time spent in various activities during the first half of a mission with time spent on the same activities during the second half. This "split mission" comparison indicates differences not only with missions but suggests different patterns of change between short (14-day) and long (20-day) missions.

Specifically, trials by subjects analyses of variance were computed for two groups: those aquanauts participating in the short missions and those participating in the long missions. In addition, these analyses were run by team both for scientists only and for all five aquanauts. Since patterns of significance are almost identical with and without the engineers, the results reported below refer to the analyses including all aquanauts. Thus, using our standard activity variables, differences between the first-half and last-half of both the short and the long missions were examined (see Table 9).

The most striking finding from this analysis is that 8 of the 9 variables used showed a significant change from the first-half to the last-half of the short missions, but that only 4 variables were significant in the case of the longer missions. This suggests that the long missions were long enough to gain some stability over time, but that the short missions were subject to a "NightBefore-Christmas" excitement effect, i.e., people entered the short missions excited, worked very hard initially, burned out somewhat, and then relaxed more during the second-half of the mission. The data bear out the tenability of this notion.

of the significant variables for the short mission, 4 were highly significant ( $\mathrm{p}$ <.001); these were: total work, * total leisure, * total marine science, and co-recreation. Direct marine science, habitat maintenance, and gregariousness differed less significantly ( $p$ <.01) than the four mentioned above but were

* Total work is a composite variable consisting of: direct marine science, marine science support, habitat maintenance, and maintenance of others. Total leisure consists of: co-recreation, solitary recreation, and relaxing, resting and idling. 


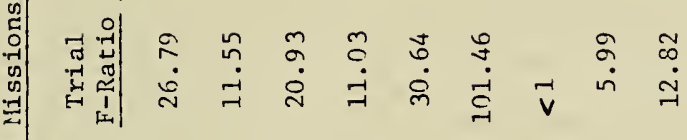

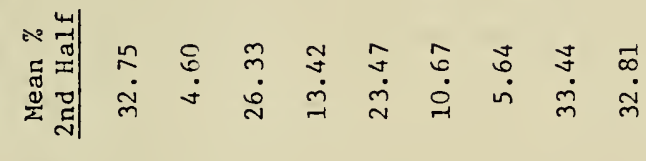

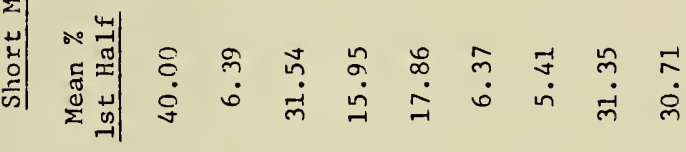

苟

竞

g. ․․․

政

कू

送

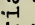

पับ

so

-

过㟧

무

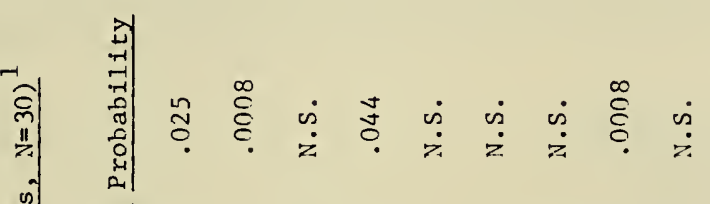

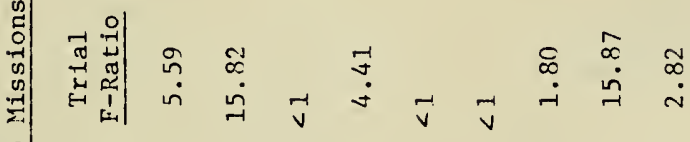

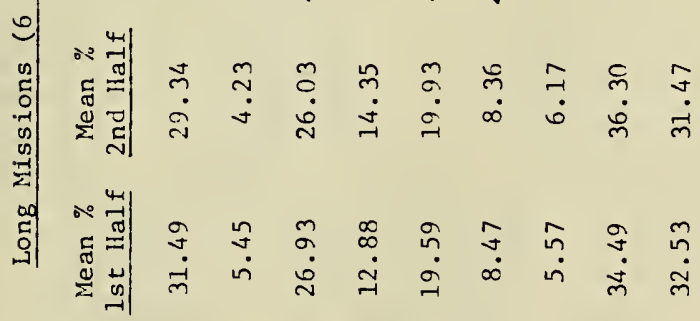

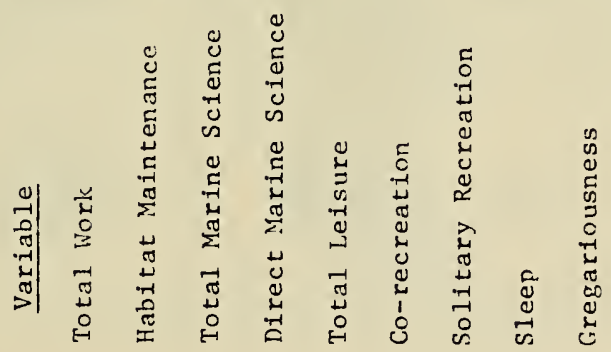

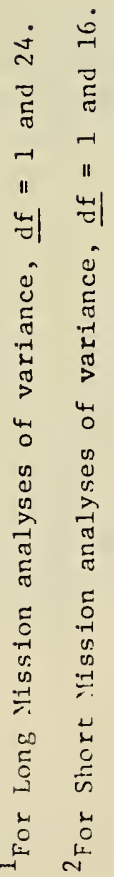


still more significant than sleep ( $\mathrm{p}$ <.03). Only solitary recreation was not significant. In all cases, time spēnt working or in categories associated with total work decreased from the first to the second half of the short missions, while time spent in total leisure pursuits or sleeping increased.

Less work and more leisure during the second-half of the mission was also the rule for long missions, but the differences are not so striking. Only 4 variables differed significantly: habitat maintenance and sleep were both highly significant ( $p$ (.001); total work ( $\mathrm{p}$ <.03), and direct marine science ( $\mathrm{p}$ <.05). Neither total leisure nor total marine science differed significantly. It appears that the difference in total work is almost totally accounted for by differences in time spent on habitat maintenance. Thus, it is not unreasonable to claim that, at least with regard to first-half/last-half comparisons, the long missions evidence greater patterns of stability than do the short missions.

Totals, percentages, and means a11 represent safe and familiar computational ground. Analysis of variance and probabilistic statements of significance are common enough tools for most social scientists. With time series data we are on less familiar ground. Thus, for our next step in examining the data, we regarded ourselves as well advised to revert to one of the most primitive yet clearest methods of data presentation--graphic representation. Graphs were prepared (by computer) which depicted the daily flow of each aquanaut's activity. A sample extracted from one of the graphs is included here (Figure 3 ).

ACTIVITY

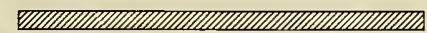

ஐ

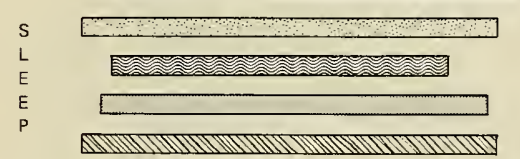

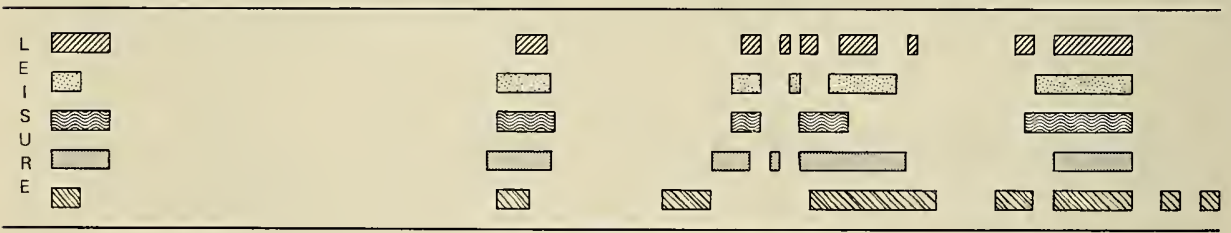

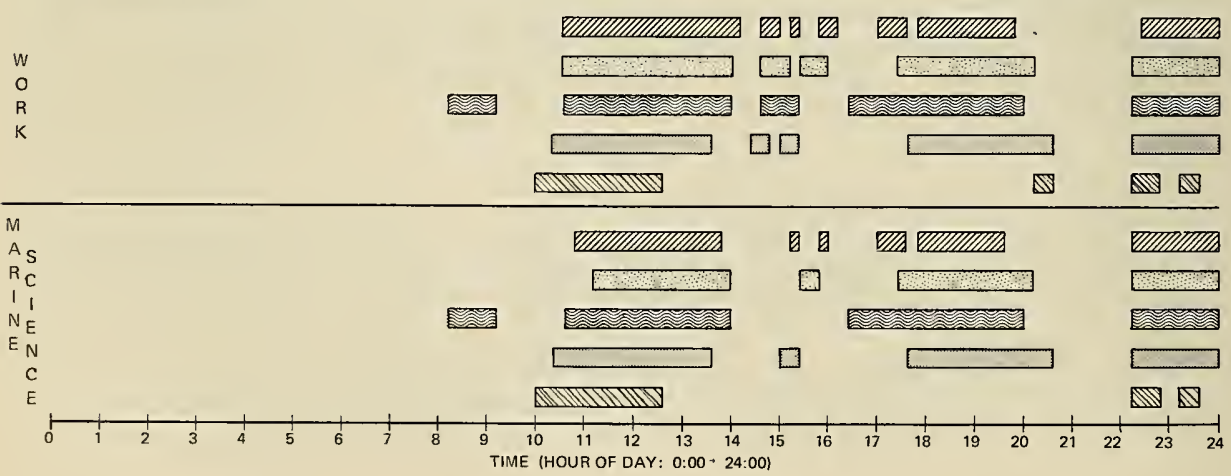

Figure 3 One Days Activity 
These graphs made manifestly clear one fact which we had previously suspected: a "day" running from midnight to midnight would not do as our next unit of analysis (after the first-half/last-half mission split). It is worth pointing out here that the analyses reported above were indeed based on mission splits --the observations were divided at the midpoint and percentages computed for the various activity variables for all observations in the first-half and then in the second-half of the missions. No assumptions involving days were necessary. But a day--defined as encompassing a person's major period of wakefulness--is a logical unit for time series analysis. Careful examination of the graphs described above indicates that a "day" running from 3 a.m. to 3 a.m. will, in almost all cases, satisfy the preceding definition. It has accordingly been adopted as the TEKTITE Standard Day for future analyses.

At this point, an embarrassing wealth of questions suggest themselves; hopefully, some answers will be forthcoming from future work. In the previous section, for example, perturbations caused by a crew change were discussed. How long these perturbations existed in various types of activity is certainly a researchable question.

The TEKTITE data indicates, as does most previous work with group processes, the strong way in which groups seem to form and enforce norms for various behaviors. It would be useful to know not only how early in time norms (especially work norms) can be determined but what accounts for later deviations from these norms.

It is generally conceded that the greater the group cohesiveness the more each member will strive to carry out the group's goals. In the case of TEKTITE II, this should be evidenced by more total marine science work. It seems likely, but not yet tested, that productive groups will evidence patterns of cohesiveness early, and will increase in cohesiveness over time, while less productive groups will be less cohesive early and will decrease in cohesiveness.

Clearly, questions are more numerous than answers at this point. Two conclusions, however, do seem warranted. The first is simply that a 2-week mission is not a sufficiently good analogue for long-term missions but that a 3-week mission probably is. Given what we now know, it seems reasonable that findings from 3-week missions will generalize to groups confined for periods of longer duration. The second, rather obviously, is the fact that a study of patterns of variables over time can immeasurably deepen our understanding of group processes and can increase the certainty of predictive statements involving the objective variables discussed throughout this report. Not only should this make for more precise theoretical descriptions of the phenomena, but (remembering Kurt Lewin's dictum that "there is nothing so practical as a good theory") should also allow for more precise interventions in on-going groups to achieve desired outcomes. 
Robert Helmreich, John Wilhelm and Roger Bakeman

The University of Texas at Austin

\author{
Roland Radloff \\ National Science Foundation
}

The development of predictive tests has been a major preoccupation of psychology. Countless hours have been spent on the design of paper and pencil measures to predict job performance, psychological states, and a variety of other behaviors. One practical need for successful prediction is obvious. When behavior can be explained as a function of antecedent conditions, individuals can be selected who have the maximum chance of success in any given role. A good example of a situation demanding precise prediction is the selection of astronauts. Training costs are high in terms of money and time, mission costs are enormous, and the psychological or physical failure of one man could not only abort a mission but also imperil the lives of teammates. Although selection of pilot-astronauts has been successful to date, the overall state of the art in psychological selection leaves much room for improvement.

As we mentioned previously, demographic variables appear to be most successful in prediction of behavior but have generally not been used or studied systematically. We have described the development of the Life History Questionnaire as an instrument for demographic investigation and prediction. In this section we will discuss the effectiveness of pre-mission predictive variables in accounting for the actual behavior recorded during missions.

\title{
Criteria for Prediction
}

One of the most persistent problems in the development of predictive instruments is obtaining valid, quantifiable criteria of performance. For example, attempts to predict adult mental health as a function of childhood experiences face the problem of defining mental health in an objective, quantifiable manner.

One solution has been to employ dichotomous criteria such as passing or failing a course, completion or noncompletion of pilot training, etc. Considerable success has been obtained in predicting such dichotomous criterion variables. However, this type of prediction has serious limitations because it forces a broad spectrum of behavior into a limited number of arbitrary categories. It does not, for example, provide information on the difference between individuals who barely meet the criterion and those whose performance is outstanding. This is particularly important when selecting from a population of highly qualified candidates, all of whom can meet the criterion. The task in this case is to discriminate between those whose performance will be superb and those whose will be merely excellent.

We have pointed out that one of the reasons for our enthusiasm about TEKTITE was the availability of continuous, objective behavioral criteria. With high reliability, a large number of observations (2866 to 4770 records on each criterion per aquanaut, depending on mission 1ength), and large individual differences, the project provided a magnificent research setting for the investigation of predictive measures. For the purposes of this discussion, we have chosen 
the criterion of total marine science work performed by scientist-aquanauts. The total marine science score is the sum of time spent in direct marine science and marine science support expressed as a percentage of total mission time. This criterion seems most appropriate for a first cut of the data since the expressed goal of the project was the accomplishment of marine scientific work by scientists.

\section{Selection of Aquanauts}

Because of our interest in obtaining a wide range of individual differences on criterion measures, no psychological selection of aquanauts was undertaken other than superficial screening for gross psychopathological disorders. No use was made of available predictive measures. Scientist-aquanauts were selected on the basis of the merits of their proposed research while engineers were chosen to provide a broad range of experience and professional skills. Employing these selection processes resulted in enormous variability on all behavioral measures, as we have illustrated earlier.

\section{Rationale for Use of Life History}

One of the most widely accepted truisms in psychology is that "The best predictor of future behavior is past behavior." Research evidence supports this; for example, the best predictor of college grades is high school grades; previous income predicts success in selling life insurance (Tanofsky et a1., 1969); completion of high school predicts completion of service school and Navy enlistment (P1ag and Goffman, 1966); it is assumed that the best jet pilots will be the best astronauts (Voas, 1961). These simple examples provide basic support for the use of life history information in prediction.

Our own previous research has also convinced us of the value of such information. Life history items were very successful in predicting performance in SEALAB II, especially in contrast with personality and interest inventory data (see Radloff and Helmreich, 1968). At a more general level, theoreticians have argued the potential power of life history information (see Guthrie, 1944, for an especially compelling argument). Finally, a recent conference of experienced users of biographical information asserted that it is "The best single predictor of future behavior where the predicted behavior is of a total or complex nature" (Henry, 1966). Thus, there appears to be compelling arguments for the use of life history information. The general proposition is straightforward, well accepted, and documented. However, it proved to be deceptively simple in its application to the research goals of project TEKTITE.

In TEKTITE, we were attempting to predict complex criteria of performance and adjustment. Our goal was to understand and explain differences among TEKTITE participants in their ability to work well, get along with fellow team members, complex real-life behavior; it followed that the best predictive information would be a total record of prior experiences. We looked for and failed to find extant measuring instruments which would yield such information.

\section{Forming Conceptual Predictors}

We reported in our introductory discussion that the investigator can create any number of conceptual variables from the matrix of yearly responses to the Life 
History Questionnaire. An example of a general variable would be computation of the mean response on hometown size or family size over the entire age range. Another type of general variable would be the number of changes found on a variable over a specified time period--for example, changes in health. More detailed predictors can also be created by looking at responses for a limited age range or by computing the direction and magnitude of differences between one age range and another--an example of the latter would be a variable formed by taking the signed difference in religious activity between ages 6-12 and 12-18. Using program LIHAN, we can form variables to test many theoretical hypotheses about the relative importance of age periods and about the effects of perturbations in experience on later behavior.

The decision to cover ages 0 through 18 is perhaps not novel, but it is an important feature of the LHQ. This age span was chosen because it is long enough to give a good picture of how a person has developed. The case for the importance of formative years has been well made by psychodynamic writers and others. Also, for many samples which the present investigators intend to study, subjects will be close to their 19 th birthdays. Thus, comparable information can be obtained on a complete sample using the 19th year as the stopping point. Finally, experiences tend to be more similar and more structured across groups and societies during childhood and adolescence, making it easier to compare life patterns. Later experiences may be quite specifically related to particular criteria. For example, amount of marine science training was of interest in TEKTITE. Supplemental questions covering such specific later experiences can and should be added to the basic core of information from the LHQ.

Clearly, the number of conceptual variables that can be formed from the LHQ is almost infinite, tempting the researcher to ever finer cuts of the data. However, at this stage in our research in the use of the LHQ, it has seemed wiser deliberately to resist this temptation and first to concentrate on rather gross conceptual variables. Accordingly, we have, on the basis of a priori assumptions, created three sets of conceptual variables.

The 39 predictors formed are 1isted in Table 10, which also shows their correlations with the total marine science criterion. The first conceptual set, which we have designated $\underline{E}$ or Environmental variables, consists of 17 variables which appear to reflect important environmental influence on the developing individual. These include such items as size of hometown, family size, parental employment, and health. The statistic employed is the mean computed for the maximum range of ages available. The second group, I or Individual variables, is composed of 12 predictors showing individual reactions during youth. This set includes items such as school performance, clashes with authority, and financial independence. Again, the statistic computed is the mean of responses during all relevant years (for example, school performance covers ages 6-18). The assignment of particular variables to either the $E$ or I category is arbitrary and is done for convenience in preliminary analysis. Some variables, such as work during childhood, could reflect either environmental pressures, such as poverty, or individual motivation. For the present analysis, this distinction is not crucial.

The third set of variables, $\underline{C}$ or Change variables, is composed of 10 items showing changes on theoreticālly important variables such as family size, academic performance, and health. Each score in this set shows the total number of changes on the selected item for the entire range of ages measured. 
The correlations between predictive variables and the criterion are shown in Table 10. The first 13 variables are general background information while the variables derived from the LHQ matrix are items 14 through 52. Looking first at the general variables, only participation in religious activity and intelligence are significantly correlated with the criterion. Less frequent attendance at religious services is associated with higher marine science scores. Higher intelligence is also associated with superior performance. This finding is somewhat surprising as the scientist-aquanauts are drawn from the upper ranges of intelligence in the general population. The strength of the correlation indicates that measured intelligence is a powerful correlate of performance, even when the predictor population has a highly truncated distribution.

Table 10.--Correlations of Predictive Variables with Total Marine Science

I. General Variables

Variable Name
TOTAL MARINE SCIENCE: (Scientists only, $N=40)^{1}$

II. Life History Questionnaire

\section{Variables}

Variable Name

14. Hometown size

15. Condition of home

16. Famfly size

17. Clothing quality

18. Food quality

19. Father's employment

20. Mother's employment

21. Height

22. Weight

23. Health

24. School type

25. Size of school
Category 2

$\begin{array}{ll}\mathrm{E} & -.31^{*} \\ \mathrm{E} & -.10 \\ \mathrm{E} & -.33^{*} \\ \mathrm{E} & -.37^{*} \\ \mathrm{E} & .08 \\ \mathrm{E} & .17 \\ \mathrm{E} & -.04 \\ \mathrm{E} & .05 \\ \mathrm{E} & .06 \\ \mathrm{E} & .21 \\ \mathrm{E} & -.20 \\ \mathrm{E} & .17\end{array}$


Table 10. (cont)

Variable Name

26. Parental praise

27. Parental physical affection

28. Parental criticism

29. Parental punishment

30. Community homogeneity

31. School performance

32. Athletic honors

33. Intellectual honors

34. Other honors

35. Religious activity

36. Going out at night

37. Dating

38. Fights with peers

39. Clashes with authority

40. Financial independence

41. Work (school year)

42. Work (summer)

43. Hometown size

44. Type of residence

45. Family size

46. Clothing quality

47. Father's employment

48. Mother's employment

49. Height

50. Health

51. School size

52. School performance
Category

TOTAL MARINE SCIENCE

\begin{tabular}{|c|c|}
\hline $\mathrm{E}$ & .07 \\
\hline $\mathrm{E}$ & .24 \\
\hline $\mathrm{E}$ & -.15 \\
\hline $\mathrm{E}$ & -.15 \\
\hline $\mathrm{E}$ & -.15 \\
\hline I & $.47^{\star *}$ \\
\hline I & -.08 \\
\hline $\mathrm{I}$ & .05 \\
\hline I & -.05 \\
\hline I & $-.31^{\star}$ \\
\hline I & .24 \\
\hline $\mathrm{I}$ & -.09 \\
\hline I & -.01 \\
\hline I & -.10 \\
\hline I & $.48^{\star \star}$ \\
\hline I & .22 \\
\hline I & -.07 \\
\hline C & .13 \\
\hline C & .16 \\
\hline C & -.11 \\
\hline C & $-.32^{\star}$ \\
\hline C & -.22 \\
\hline C & .00 \\
\hline C & -.04 \\
\hline $\mathrm{C}$ & .17 \\
\hline C & .07 \\
\hline C & .07 \\
\hline
\end{tabular}

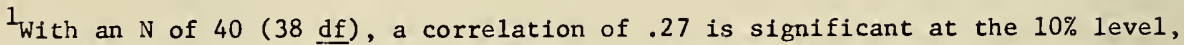
a correlation of . 30 is significant at the $5 \%$ level and a correlation of .39 at the $1 \%$ level.

${ }^{2} \mathrm{E}$ refers to Environmental variables, I refers to Individual motivational variable, $C$ refers to variables denoting number of Changes on the variable.

$$
\begin{aligned}
& { }^{*} \mathrm{p}<.05 . \\
& { }^{*} \mathrm{p}<.01 .
\end{aligned}
$$

The fact that neither age nor years of diving experience were correlated with the criterion supports a notion that motivational factors more than experience are prime determinants of performance in a situation such as TEKTITE. In SEALAB II also, there were no significant correlations between age and performance, and diving experience and performance. 
Three of the E category LHQ variables were significantly correlated with the criterion. These were hometown size, family size, and clothing quality. As in SEALAB II, aquanauts from smal1 towns showed higher performance (see Radloff and Helmreich, 1968, for a discussion of this variable). Those from smaller families also achieved more marine science, perhaps indicating more parental stimulation of children in smaller nuclear families. The negative relationship between clothing quality in childhood and the criterion may be a reflection of higher motivation among those who have achieved professional status from lower social origins.

Three of the I LHQ variables also correlated significantly with total marine science. They were: academic performance, religious activity, and financial independence. The academic performance variable (showing higher scientific achievement as a function of superior school performance during youth) parallels the correlation between IQ and the criterion. Because this variable is highly objective and strongly related to the criterion, a more detailed analyses was conducted using additional variables defined for specific age ranges. Correlations between academic performance during elementary school (ages 6-12), junior high school (ages 13-15), and high school (ages 16-18) and the criterion were computed. The positive relationship between scholastic achievement and the criterion was strong for elementary school, weaker in junior high school, and very small during high school. The mechanisms responsible for this are still unclear. What is clear is that a total response such as academic performance overall may obscure more crucial predictors. In the example at hand, high school performance does not discriminate, while grade school achievement does. This suggests that patterns of responses and responses at different ages need careful investigation and that the LHQ uniquely provides the necessary information.

The negative relationship between youthful religious activity and performance is also parallel to that between adult behavior and the criterion. It implies that families with less religious orientation foster more scientific motivation in their offspring. The significance of this variable will have to be investigated in additional research.

The positive relationship between financial independence and the criterion supports an hypothesis that those achieving autonomy early are most likely to be highly productive adults.

The Change LHQ variable defining variations in clothing quality during childhood correlated significantly with the criterion, but negatively, indicating that changes in family social status during childhood may have an adverse effect on later performance. Considering this variable in contrast with the previously noted finding that lower social status (as reflected in poorer clothing) is a positive predictor of performance, the complexities of demographic interpretation and prediction become evident. A testable hypothesis is that those who become effective adult scientists tend to originate in lower socio-economic strata and to come from families which are not socially mobile. In other words, coming from a lower class family may have a positive influence on performance but not if the family is upwardly mobile. This is pure speculation, but it is an example of the type of hypothesis which can be tested using data derived from the LHQ. 
It should be pointed out that the relationships which have been discussed above are only those where correlations with the criterion were significant at better than the $5 \%$ level. Many other variables show strong trends (often curvilinear) and discriminate between subgroups of the aquanaut population.

\section{Comparison of Top and Bottom Aquanauts}

Another example of the discriminatory power of the variables employed is a comparison of scores on predictive variables of the 10 scientist-aquanauts composing the top $25 \%$ of the sample on the criterion with the scores of the 10 with the lowest marine science output. An analysis of variance contrasting the top $25 \%$ of the sample with the bottom $25 \%$ was computed for each predictive variable. The obtained results reinforce the argument that demographic predictors can effectively differentiate between those who will perform adequately in such an environment and those who will do extremely we1l. The two groups differed significantly (with a probability less than .05) on $25 \%$ of the items while $12 \%$ of the items in the variable pool discriminated between the two groups with a probability less than .01 .

Many of the variables which significantly differentiated the two groups have been discussed in references to overall correlations. However, a number of variables which have not yet been mentioned are significant predictors of extremes of performance. These include health, family mobility (as shown by number of changes in hometown size), changes in family size, economic orientation (measured by the Allport-Vernon-Lindzey Study of Values), and birth order.

Health during childhood and youth differentiates among aquanauts but in a counterintuitive way. The top performers had significantly poorer health than the lowest $25 \%(\underline{F}=20.44, \mathrm{p}<.001$. Again, a more detailed analys is of 1 ife history clarifies this result. Although the groups show a highly significant overall difference, this is caused by large differences during early school years (ages 6-12), as the groups do not differ significantly in earliest childhood or in adolescence. A preliminary hypothesis is that physical restriction because of ill health in early school years may stimulate interest in intellectual and scientific pursuits (perhaps a comment on the intellectual excitement engendered by typical elementary education?). Later good health may be associated with heightened interest in outdoor activities, perhaps as a psychological compensation for early restriction. We have tenatively christened this phenomenon the "Teddy Roosevelt Effect" and will explore its implications more fully in subsequent research.

Families of the high achieving 10 moved significantly more than those of the lower group $(\underline{F}=4.11, p<.05)$, but the top group experienced fewer changes in the composition of the nuclear family $(\underline{F}=4.62, p<05)$. Thus both disruptions due to geographical change and disruptions or change in family composition appear to be associated with performance, but in opposite directions. The low performing group of aquanauts scored significantly higher on the economic scale of the $\mathrm{A}-\mathrm{V}-\mathrm{L}(\underline{\mathrm{F}}=7.89, \mathrm{p}<01)$. One interpretation of this finding is that those with high economic values were more motivated by the fame and profit potential involved in being an aquanaut than by scientific interest and sought more the designation "aquanaut" than the opportunity to conduct research in the undersea environment. 
An additional significant difference between the two groups was in birth order. Members of the top performing group were likely to be first-born in their families than were those in the bottom group $(\underline{F}=4.23, \underline{p}<.05)$. This significant difference between the two groups is in the opposite direction from that found in SEALAB II (where first and only-borns performed significantly less well than later-borns) but was predicted. As mentioned in the introduction, the stress level induced in the shallow, warm-water habitat was assumed on a priori bases to be significantly lower than that created in the more cramped habitat located at 200 feet in murky, cold water in SEALAB. Where stress levels are low or moderate, first-borns typically outperform later-borns (see Altus, 1966, for a review of such findings). The obtained result is, therefore, consistent with previous birth order findings and confirms the assumption that extreme levels of stress were not induced by the TEKTITE environment.

\section{Predictive Equations}

Heretofore we have been discussing predictive variables only in isolation. This is inadequate because such variables interact. That is, predictive variables may be correlated with each other to a greater or lesser degree. To obtain maximal effectiveness in the prediction of a behavioral criterion, one must consider the combined effects of the predictive measures employed. This is typically done by using the statistical technique of multiple regression. While a discussion of multiple regression is beyond the scope of this report (see McNemar, 1970, and Cohen, 1968), suffice it to say that multiple regression results in a statistic, the multiple correlation coefficient ( $R$ ); $\underline{R}$ squared is the percentage of variance on a criterion measure which is accounted for by a given set of predictors. The multiple regression procedure consists of the calculation of weights for each predictive variable which produce the highest possible correlation between the criterion measure and the group of predictive variables used.

The ability of Life History Questionnaire variables to account for observed variance in behavior was tested by performing multiple regression analyses using the three sets of conceptual variables independently. It must be emphasized that these analyses are preliminary and that the development of final, predictive, test batteries will be undertaken only after extensive cross-validation studies of the LHQ in other populations have been completed. Despite this disclaimer, it can be seen that impressive multiple correlations with the criterion can be obtained using conceptually discrete sets of predictors.

The multiple correlation between nine Environmental LHQ variables and the criterior was .79. Variables were selected from the $\underline{E}$ pool using the Wherry Test Selection method (Wherry, 1946; Hutchins, 1970). The obtained multiple $\underline{\mathrm{R}}$ means that more than $62 \%$ of the criterion variance was accounted for by this group of predictors. The variables used for prediction were: clothing quality, food quantity and quality, family size, height, parental physical affection, parental physical punishment, father's employment, hometown size, and size of school.

A second multiple regression was computed using I LHQ variables as predictors. Five I variables formed the equation, again using the Wherry technique. The resultant multiple $\underline{R}$ was .69 , accounting independently for $48 \%$ of the criterion variance. The variables used in this prediction were: financial independence, school performance, religious activity, work (during the school year) and work (during summer vacations). 
The third multiple regression was computed using the Wherry technique with the C pool of LHQ variables reflecting changes during childhood and youth. Five variables produced a multiple $\mathrm{R}$ of .54 accounting for $29 \%$ of the criterion variance. The variables resulting in this correlation were: changes in quality of clothing, changes in type of residence, changes in health, changes in fathers employment, and changes in mother's employment.

The crucial point for this discussion is that, using three conceptually independent sets of predictors derived from LHQ, variables from each set can independently account for a meaningful percentage of the variance recorded on the criterion variable. These results provide considerable evidence that the LHQ is a highly sensitive instrument.

\section{Cross-Validation of LHQ Predictors}

The results from multiple regression with LHQ variables as predictors are so strong as to raise questions about whether they might be accounted for by peculiarities in the relatively small sample of scientists employed in the analysis. As a first cross-validation of the instrument, one of us (Radloff) obtained complete LHQ responses from a class of U.S. Navy enlisted men attending 2nd Class Diver's School $(n=38)$. As a criterion measure for the LHQ of this population, we used completion of school defined as $0=$ failure, $1=$ completion of SCUBA training, 2 = completion of SCUBA and Hard Hat Diving courses. This group provided a difficult test sample for cross-validation. Not only was a highly restricted criterion employed, but the two populations were dramatically different on almost every possible dimension. In addition to the fact that the mean age of the Navy sample was 10 years younger than that of the TEKTITE aquanauts (21 vs. 31), the two groups differed significantly $(p<.05)$ on 16 of the 39 variables derived from the LHQ. To note a few of the major differences between the samples, the TEKTITE scientists came from larger hometowns, received more parental praise and physical affection, performed better in school, and had more changes in place of residence, type of school, and changes in school performance. The Navy divers received more physical punishment, came from more homogeneous communities, went out at night and dated more, and had more clashes with authority. These differences were predictable and clearly reflect, among other things, social class differences between the two samples.

The cross-validation was conducted by using the same predictors and the same Beta-weights employed in the TEKTITE sample to predict the 3-point school completion criterion. The results are extremely encouraging. The multiple $\underline{R}^{\prime} s$ obtained were: E predictors, $\mathrm{R}=.37$; I predictors, $\mathrm{R}=.33$; $\underline{\mathrm{C}}$ predictors, $\mathrm{R}=.46$. Given the great differences in the nature of the two populations, the fact that the same variables weighted in the same way predict so well in both groups attests to the overwhelming importance of a limited number of demographic variables. Predictors derived through consideration of the requirements of the Navy Diving task and the characteristics of the available population of potential divers should be far more effective in accounting for variance on the school completion criterion. This research needs to be undertaken.

In conclusion, the research conducted during TEKTITE II has provided an opportunity to validate a sophisticated technique of demographic prediction against a highly reliable and objective criterior of behavior. The results obtained 
indicate that an extremely effective predictive test has been developed which needs only refinement and validation to become generally applicable to both research into antecedents of behavior and selection of candidates for specialized roles. The applications of the LHQ seem almost unlimited; a wealth of data are available; the limitations are in the sampling technique employed and the ingenuity of the researcher.

\title{
CONCLUSIONS AND RECOMMENDATIONS
}

\author{
Robert Helmreich \\ The University of Texas at Austin
}

The first conclusion which can be drawn from the research conducted on human behavior in TEKTITE is that both male and female aquanauts can adapt successfully to life in a confined environment such as the habitat. Not only can individuals cope adequately with confinement and isolation, they can also perform work roles effectively in such a setting. The amount of work accomplished by the aquanauts was great--probably surpassing the average daily time expenditure of most scientists and engineers in normal, terrestrial environments. Within this overall, excellent work output, there were, however, large team and individual differences, and the prediction of this variability forms a major aspect of the research.

The significant difference in performance found between teams probably results in large part from the setting by crews of group norms for behavior in the absence of externally imposed standards. In operational programs (where research on human behavior is not a primary concern) it would seem highly advantageous to communicate realistic performance expectancies to crew members. Such external control should serve significantly to reduce between-crew variability in work output.

Teams in which a scientist-aquanaut was leader achieved more marine science than those with engineers as leaders. This was attributed to the fact that the mission role of the scientist was congruent with program goals while the engineer's mission role was largely one of support. Thus, the engineer as leader should not be expected to facilitate performance of the primary mission task--scientific research. A general recommendation is that, where operationally feasible, mission leaders should be individuals whose professional training is in the area most relevant to project goals. In the case of programs such as TEKTITE, a marine scientist should be the most effective leader.

Examination of engineer-scientist relations indicates that group relations were better and performance was higher when the engineer became actively involved in scientific programs and, concurrently, when scientist-aquanauts played a more active role in habitat maintenance. Although more investigation of the phenomenon is required, it seems that those selecting crews with mixed professiona 1 interests for isolated environments should be concerned with choosing individuals who have broad interests and who are eager both to acquire new knowledge and to impart their own expertise.

Changing engineers in mid-mission did not have an adverse effect on performance although group cohesiveness and gregariousness did decrease on addition of a new 
member. One implication of this finding is that isolated groups can successfully cope with the rotation of one of their members. This must be regarded as a tentative finding since there were only two instances of change and since the engineer was a peripheral member of the group.

There were strong overall relationships between in-habitat activity variables. The percentage of time spent sleeping was negatively related to performance criteria as was time spent in leisure. These correlations seem to reflect individual differences in motivation which are predictable. Gregariousness was significantly related to both total work and total marine science. Those who spent most time in social interaction achieved higher work output. Communication with topside personnel was also positively related to performance.

Although we have not yet analyzed specific data on patterns of communication, it appears that the provision of a 2-way video link to the surface plays an important role in maintaining good relations between aquanauts and surfacesupport personnel. Preliminary analysis of some of the behavioral data by Silverman (1970) suggests these conclusions. The video link seems to reduce feelings of isolation and overt hostility towards remote operational personnel which have been prominent in other, similar environments such as SEALAB (Radloff and Helmreich, 1968). It seems advisable to include 2-way video links between remote groups and control centers whenever feasible in future operations.

Detailed analyses of meal behavior data have not yet been undertaken. However, several comments about the effects of the NASA food program may be warranted. Prepackaged frozen meals were used on all of the long missions and one of the short missions. Although use of the frozen meals (which had only to be heated) did markedly reduce time spent by aquanauts preparing meals and cleaning up, this time-saving was not reflected in higher work output. Time gained by using packaged food was used for leisure rather than work.

Preliminary analyses of time factors in habitat behavior show significant shifts in activities over time. Aquanauts spent less time working, more time in leisure, and more time sleeping in the second half of missions that they did in the first half. The changes in behavior were much more dramatic in short missions than they were in long missions. Behavior in long missions was generally more stable than in 2-week missions, suggesting that more adaptation to the habitat environment took place in the 20-day period. This stability implies that 3-week periods are much better models of long-term confinement than two weeks, and that results from 3-week missions may generalize to much longer periods. Extensive analysis of daily patterns of behavior is needed. These analyses should provide much useful information on circadian rhythms and on causal relations between mood and activities and among activity variables such as leisure, sleep, and work.

The Life History Questionnaire has proved to be a highly effective predictive instrument. Conceptua 1 variables derived from the LHQ can account for a meaningful percentage of the observed variance on performance variables. When validation and refinement of the LHQ have been completed, it should prove to be an outstanding instrument for both personnel selection and psychological research. Preliminary cross-validation indicates that it can predict performance even in a highly different population. 
One of the most important aspects of the study is the validation of the observational methodology. The results show that reliable and meaningful data can be collected from natural groups over time. The techniques employed in TEKTITE should be easily adaptable to a wide assortment of natural situations. One obvious application is to manned spaceflight and spaceflight simulations.

A 1 ogical refinement of the methodology will be to convert data management programs developed during TEKTITE for real-time operation. This would make it possible to provide operational personnel with immediate data on reactions and patterns of behavior. This raises the possibility of more effective intervention in group processes to eliminate developing problems and facilitate performance and adjustment.

It is all too typical to end with a call for further research. Although this call could easily be issued for the follow-up of numerous important paths opened by the study, it may be more appropriate to note how much remains to be gleaned from the mass of research already completed. A large archive of highly reliable data on real behavior has been amassed in which researchers can test important theoretical hypotheses for some time. This seems to us quite sufficient to answer those who claim that the "real world" is too difficult and costly an arena for psychological research. If we were to be allowed only one conclusion from our experiences in TEKTITE, it would be this: not only is work in the field possible and rewarding, but also, the quality and breadth of the data collected more than offset the difficulties involved in their collection.

\section{REFERENCES}

Altus, W。P., Birth Order and its Sequelae. Science, 1966, 151, 44-48.

Aronson, E. and Carlsmith, J. M., Performance Expectancy as a Determinant of Actual Performance. Journal of Abnorma1 and Social Psychology, 1962, 65 178-182.

Aronson, E. and Car1smith, J. M., Experimentation in Socia1 Psychology. In G. Lindzey and E. Aronson (Eds.), Handbook of Social Psychology. Reading, Mass.: Addison-Wesley, 1968.

Cohen, J., Multiple Regression as a General Data Analytic Technique. Psychologica1 Bu1letin, $1968, \underline{70}, 426-443$.

Festinger, L., A Theory of Cognitive Dissonance. Evanston, I11.: Row, Peterson, 1957.

Guthrie, E. R., Personality in Terms of Associative Learning. In J. McV. Hunt (Ed.), Personality and the Behavior Disorders. New York: Ronald Press, 1944, pp. 49-68.

Helmreich, R. and Radloff, R., Environmental Stress and the Maintenance of Self-Esteem. Austin, Texas. Nationa1 Academy of Science Report, 1969.

Henry, E., Conference on the Use of Biographical Data in Psychology. American Psychologist, 1966, 21, 247-249. 
Hutchins, C. W., Human Factors Engineering Report 2-70. A New Approach to the Construction of a Prediction Battery. Johnsville, Pa.: Naval Air Development Center Report NADC-LS-7002.

Lester, J. T., Jr., Behavioral Research During the 1963 American Mt. Everest Expedition. ONR Contract Nonr-3930(00), NR 171-257. Final Report, Sept. 1964 。

McNemar, Q., Psychological Statistics (4th Ed.). New York: John Wiley, 1970.

Plag, J. and Goffman, Jr., The Prediction of Four-Year Military Effectiveness from the Characteristics of Naval Recruits. Military Medicine, 1966, $\underline{131}, 729-735$.

Radloff, R. and Helmreich, R., Groups Under Stress: Psychological Research in SEALAB II. New York: Appleton-Century Crofts, 1968.

Radloff, R., Mach, R., and Zil1, N., TEKTITE I Final Report. Submitted to Office of Nava1 Research, October 1969.

Silverman, M. N., Unpublished Master's Thesis, The University of Pennsylvania, 1970.

Tanofsky, R., Shepp, R., and O'Nei11, P。 Pattern Analysis of Biographical Predictors of Success as an Insurance Salesman. Journal of Applied Psychology, 1969, 3ㅜ, 136-139。

Voas, R., Project Mercury: Astronaut Training Program. In B. E. Flaherty (Ed.) Psychological Aspects of Space Flight. New York: Columbia University, 1961, pp. 96-117.

Wherry, R. J., Test Selection and Suppressor Variables. Psychometrika, 1946, $\underline{11}, 239-247$.

Willems, E. P. and Rausch, H. L., Naturalistic Viewpoints in Psychological

Research. New York: Holt-Rinehart-Winston, 1969. 
AN INTRODUCTORY STUDY ON THE EFFECTS OF

TWO-WAY CLOSED CIRCUIT TELEVISION ON A

SMALL CREW OF AQUANAUTS LIVING IN AN

ISOLATED AND STRESSFUL ENVIRONMENT

Mark N. Silverman, M. A.

\begin{abstract}
The study was based on the author's belief that all manned space and manned undersea missions should include two way closed circuit television, or video phone, as a primary means of communication. To that end a video phone link was established between the habitat and the command van on the surface. Three measures were taken to determine the aquanauts' attitude and use of the video phone:

(1) Pre and post mission questionnaires; (2) forty hours of random video taping showing the use of the video phone; (3) daily recording of communications behavior on computer cards. The results indicated that the video phone provided: (1) a valuable means of communication between the aquanauts and the command center; (2) facilitated equipment troubleshooting; (3) increased the aquanauts' feeling of c nfidence in the surface crew; (4) reduced feelings of isolation.
\end{abstract}

\title{
INTRODUCTION
}

The study was based on the author's belief that all manned space and manned undersea missions should include two way closed circuit television (CCTV) or video phone, as a primary means of communications. The basic theory is that such equipment will enhance both crew effectiveness and morale in that the video phone will improve the communications link between the aquanauts or astronauts and their surface support. Furthermore, the use of a video phone could greatly relieve the elements of stress, boredom, and isolation. The author also theorized that the use of the video phone for operational or professional requirements would decrease with time during a mission, while the social usage would increase.

To that end, the author introduced a video phone linking the habitat and the command van system.

\section{THE COMMUNICATION RESEARCH PROGRAM}

This study was undertaken as part of the total psychological research program being performed for NASA and the Navy. It was done so as not to interfere with the marine research being conducted. However, it did have several disadvantages, the primary one being that there was no time made available to teach the aquanauts how to use the communications equipment. They were simply told that the equipment was there for them to use if they desired. Second, the behavior research encoders were not thoroughly trained in how to recognize use of the video phone. 
The study had three main aspects: a) The administration of pre-mission and post-mission attitude questionnaires to determine each aquanaut's attitude towards communications in general, and the two-way closed circuit television system specifically; b) evaluation of the use of the various communications systems by each aquanaut during their mission through continusus direct observation using closed circuit audio and vides monitors: c) random video-taping of communications on the first six missions was conducted and reviewed to obtain content evaluations of the communications not otherwise available.

\section{SUBJECTS}

Subjects were twenty-nine male and female scientists and engineers. Five of the twenty-nine were women, four of whom were scientists. The female engineer was the youngest aquanaut, twenty-three, as well as the least experienced with less than six months diving experience. Of the twentynine, twenty-four were scientists, ten of whom had Ph.D's, and ten had Masters Degrees. The average age was 31.1 years. The average male age was 31.8 , average female age was 27.4 , average scientist age was 30.2 , and average engineer age was 35.4. The oldest aquanaut, forty-five, was also one of the habitat engineers. Professionally, the aquanauts came from private industry, government agencies, and universities, and ranged from students to professors to researchers to engineers. The scientists were chosen by a scientific review board which evaluated more than one hundred submitted proposals. Three criteria were used: (a) Value of research to be conducted to extend man's knowledge of the ocean--its environment and marine life; (b) scientific qualifications to complete the research proposed; and (c) qualified scuba divers.

\section{DISCUSSION}

The basic or primary hypothesis that two-way closed-circuit television is necessary for both manned space and manned underwater expeditions where the crew lives in a relatively confined, isolated and hazardous environment has been supported by the data, both subjectively and objectively, and qualitatively as well as quantitatively. Analysis of the vides tapes showed that crew used the video phone to help trouble shoot and solve equipment malfunctions in the habitat. They also used it to exchange professional information with their crlleagues on the surface. Both of these uses have particular significance for missions where the aquanauts and astronauts might otherwise have to abort a mission due to their inability to solve a mechanical problem, or they might spend needless hours examining samples and take up necessary space bringing back geological or biological specimens which could otherwise be discussed and evaluated by colleagues remaining on the surface. The questionnaires did reflect the aquanauts' belief in the value and use of the video-phone for professional purposes. Additionally, the observed and recorded uses of the video phone showed a nearly four-to-one use for operational purposes over social purposes for the system. 
Although the video phone was not used nearly as much for social purposes as operational ( 289 minutes versus 1,085), nevertheless, its use may have some highly significant, if not even more significant implications than the operational ones for future missions which may last as long as a year or more. This may particularly be the case when the distinction of being an aquanaut or astronaut is not so highly regarded as at the present time. In fact, there may soon come a time when such missions are so common that they will have lost their glamour, while retaining the high element of risk. When that happens, the costs will outweigh the personal rewards, and the sociological considerations may become even more significant. The reduction of situational stresses will permit future programs to obtain the most scientifically qualified people rather than relying too heavily on rigid crew selection criteria. The data show that the video phone may be a system which would make more people eligible for such missions. If one thing was clear in reviewing the video tapes, it was that the aquanauts often went out of their way to use the video phone for social purposes. They often spent ten, twenty, even thirty minutes or more at a time just watching the people on the surface. When visitors came into the command van, particularly women in the case of the male aquanauts, usually all the aquanauts in the habitat would congregate around the video phone to view the visitor, sometimes coming from three compartments away just to do so. When visitors came to the command van, the aquanauts would invariably use the video phone first, before speaking in private with their visitors on the private phone. The questionnaires showed significant trends in attitude change regarding the social value of the video phone and the openended questions also displayed strong feelings for its value as a social instrument. Such feelings as reduced isolation, increased confidence, and minimized hostility between top and bottom personnel have an intangible quality which is almost impossible to measure but could possibly spell the difference between success or failure of future missions. Additionally, the fact that the recorded usage shows a greater initiation of the video phone for social reasons from the surface than from the habitat ( 174 versus 115) probably indicates that the wives, lovers, and off-spring have a need to see "their" aquanauts as well as the aquanauts have a need to see them. The gratification of this need could serve to reinforce the aquanauts' belief that all is well at home and he/she need not worry about that aspect of his/her life, but instead continue and carry on with the job at hand. Thus, the data supported the hypothesis that the video phone is a valuable social instrument, reducing the feelings of isolation.

There was support shown for the hypothesis that the two-way CCTV will improve the communications flow between the aquanauts and the surface support. Although the original design recommended by the author to introduce simulated difficulties was not used, on the grounds there was enough natural stress in the situation, numerous incidents occurred where the system was used to relay video information. Examples, such as transferring map locations and displaying broken pieces of equipment, underlines the fact that without the video phone some other means of exchanging this information would have had to be found. 
The data could have been sealed in a container and sent to the top, but this would take a minimum of half an hour to do. (First, a transfer capsule had to be sent down and hauled into the wet room; then the drawing had to be sealed in the capsule, taken out of the wet room and sent to the surface; then it had to be retrieved, taken to the dive barge, and the capsule unsealed, and finally, the drawing had to be taken up to the Command Site for evaluation there.) In the case of a space vehicle this information transfer would be possible only if a separate space capsule were part of the system, but this is highly expensive and could take a minimum of three or four hours, depending on where the original space vehicle was positioned. Conversely, to send new drawings from the surface to either the aquanauts or astronauts would prove at least as time consuming and expensive as the original data transmission. Whereas, as the aquanauts demonstrated, with the video phone, such visual data could be, and was, transmitted instantaneously and in real time. They, in turn, received immediate feedback from the personnel in the Command Van.

The data exhibit some support for the hypotheses stating that there would be increased usage of the video phone with time into the mission for social, and decreased usage for operational uses. The fact that there were only a few such significant trends may indicate as well that the aquanauts' use of the video phone was either fairly consistent throughout or else without any real pattern. For the consistency approach, one explanation can be seen in that there were a continuing series of minor equipment problems in the habitat throughout each and all of the missions. Another lies in the fact that each day, the aquanauts and the engineers conducted their own work programs and they used the communications systems to maintain operational contact with the surface. If anything, their work schedules increased toward the end of each mission as the aquanauts became more accustomed to their environment, and as the fixed deadline for completing their research approached. While there was also a slight tendency for the social usage to increase toward the end of each mission, this can be attributed to the fact that most of the aquanauts' spouses, etc., came to the Virgin Islands to greet their aquanaut upon completion of the mission. Thus, there was no other opportunity to talk and/or see the aquanauts prior to this time. For those aquanauts whose social community members were present in the Virgin Islands, they used the video phone whenever their visitors came within camera range in the clommand Van. Additionally, there was a constant flow of visitors to the Command Van ranging from itinerant tourists to news media reporters to Ambassadors to other scientists to even the Prime Minister of Canada, Pierre E. Trudeau. The only other detectable trends were that the video phone was used nearly four times as much for operational uses as social; that the engineers in almost all cases, used the video phone more than the scientists. It is interesting to note that the female aquanauts, as a whole, used the video phone less than any of the other teams; and rarely used it for social purposes. Interestingly enough, they also 
spent more time in the water (outside the habitat) than any of the other teams, and as one of them said, "she was so busy working that she had little time to talk with anyone on the surface, except when absolutely necessary."

The author concedes that this introductory study by no means proves conclusively that two-way closed circuit television must be a part of all future manned space and underseas explorations. There was no conclusive measure that indicated that the video phone is a more efficient means of communicating than the presently standard intercom. The superiority of this communications system needs to be proven if NASA and NOAA (National Oceanic and Atmospheric Administration) are to expend the funds needed to ensure that video-phones are standard items of equipment in habitats, space capsules and space stations.

\section{IMPACT}

If one looks at the results of this study, strictly in terms of its impact for future manned space and undersea operation, then one can see potential savings in time and money for NASA and NOAA, and possibly increased results from the work being done by the aquanauts and astronauts. If, however, one goes beyond just these two cases where the parameters of existence (isolation in a hazardous environment) are similar, such as in the Arctic and Antarctic, then the potential significance of two-way closed circuit television is even greater. Further, if one begins to envision other situations involving stress, such as a patient in a hospital, then one begins to see just how broad the problem is and how many other areas for investigation there are. In fact, it can even be argued that the housewife stuck in her home, trying to raise one or more children, lives in a highly stressful environment, as do many businessmen. The impact of the introduction of the Picture Phone by the Bell Telephone Company has hardly been considered, let alone studied, and the ramifications upon society are not at all understood. 
David Nowlis, Ph.D., Garrett Corp., Los Angeles

Harry H. Watters, NASA, Huntsville, Alabama

Edward C. Wortz, Ph.D., Garrett Corp., Los Angeles

\begin{abstract}
This paper summarizes the results of an attempt to develop and apply evaluation techniques to measure parameters that affect the perception of life quality in an isolated habitat. Methods, procedures, and results of the program are discussed. The objectives of development and evaluation of methods for measuring habitability were met during this program. In addition, much was learned about the problems of designing habitable structures for occupancy during long periods in isolation. A series of conclusions are drawn from the data and inferences are made concerning habitat design factors such as privacy, food, task support, recreation, stimulus variety, and duration of isolation.
\end{abstract}

\title{
Introduction
}

In one decade, United States manned space flight has progressed from the suborbital flight of astronaut Alan B. Shephard to the current series of lunar journeys. It is difficult to chart the course of development in the coming decades, but some assumptions can be made: manned space flight will continue; crew sizes will probably increase; missions, whether interplanetary or earth orbital, will increase in duration; crews will be composed of individuals of varied nationalties and professional backgrounds; women will be in space; missions will become less and less exploratory and more and more operational or scientific; an element of hazard will remain; quarters will always be confining; crewmen will always be isolated. Currently efforts are under way to significantly reduce the cost of space flight, but it will always be important to assure the most effective possible missions for the dollars invested.

Questions that led to National Aeronautics and Space Administration (NASA) interest in the Tektite program include: Where does one turn for guidance in the design of spacecraft? How can we assure that crewmen are provided with a habitat that supports their mission and helps provide for their continued well-being? In short, how does one design for habitability? To date, NASA has relied upon various analogs to space missions. There is a considerable body of available research dealing with the subjects of isolation, confinement, stress, small group dynamics, etc., and much relevant information has been extracted. The Tektite II program, with its emphasis upon the scientific mission to be accomplished, its relative isolation from the shore support, and its several crews consisting of scientists and engineers, provided an opportunity to ( 1 ) conduct a directed study to confirm previous hypotheses, (2) further isolate those environmental variables which enhance or degrade habitability, and (3) begin to come to grips with a complex subject. 
The concept of habitability is a vague one. The dictionary defines habitable as "fit to live in". Another working definition that has been found useful indicates that habitability is the perception of the quality of life in a specific environment. How well individuals confined within a space can fulfill their mission defines perceived life quality. Habitability, therefore, is a function of the interaction between (1) the patterns of requirements for mission fulfillment, life support, and psycho-social maintenance, and (2) the physical and temporal characteristics of the space involved.

Since each person interprets his environment through his own cognitive system, habi tabili ty cannot be considered as a uni characteristic of the spatial configuration alone, but rather as an interactive process, differing for each individual, and changing as requirements for behavior and the capability of the environment to support the behavior are altered.

Research in habitability attempts to ascertain how the goals of individuals and groups interact with personal, social, physical, and temporal constraints to affect the adequacy of a situation. Of particular interest in this report are the physical constraints and their manipulation to help achieve habitability.

Eventually, it may be possible to develop lawful relationships and cri teriawhich, if applied to the design of particular habitats or situations, will produce a given level of habitability. This is important because the ultimate measure of habitability is the success or failure of long-duration missions.

\section{$\underline{\text { objectives }}$}

As previously stated, the ultimate aim of habitability research is the formulation of criteria that will assist in the design and evaluation of specific, isolated, work-oriented habitats. To this end, efforts were focused toward answering specific questions:

1. Can measures of habitability be developed?

2. In improving the habitability of future space vehicles, where must attention be focused; to what attributes of the physical environment does a crew become sensitive over time?

3. How important or desirable is privacy?

4. How important is leisure time; in what kinds of activities do off-duty crewmen engage?

5. How important is food to habitability; what do crewmen enjoy and what do they complain about?

6. To what extent do work provisions influence overall attitudes toward the habitat?

7. How do crew reactions to the habitat change with increased mission duration?

8. How is the personality of a crewman related to his opinion of, or adaptation to, the habitat?

9. Do engineers and scientists view the habitat differently?

10. Do men and women view the habitat differently? 
The results provided more complete answers for some of these questions than for others, but a degree of insight was gained for each.

Methods and Procedures

Three main approaches are available for obtaining measures of habitability. These are (1) measuring on-going responses (via self-report, observation, and physiological recording) during confinement in the habitat, (2) gathering background data on each person undergoing confinement in the habitat, and (3) measuring habitability by evaluation of the properties of the habitat itself. Techniques on the third approach have yet to be developed.

Measurement of these aspects of habitability allow:

1. Identification of design factors that affect habitability

2. Prediction of likely human responses to prolonged exposure to a particular habitat under study

3. Better understanding of individual variations in adjustment to a habitat

4. Provision of evaluative data on the assessable habitability of environments in general

Such information can be used to improve planning and design for particular physical habitats, to improve personal adjustment to a habitat, or to improve the selection process for choosing people to undergo prolonged stays in the habitat.

Development of general habitability scales may be premature because of the considerable complexity involved and the lack of available objective criteria. However, there is currently a need to specify as many of the factors involved as possible, and a battery of assessment techniques that incorporated such factors was deemed possible. It was decided that extant tests should be used where possible in the habitability test battery because test construction and development is a particularly slow and expensive process.

The instruments employed in this program were (1) a Habitability Assessment Rating Scale (HARS), (2) a Tektite Environmental Assessment (TEA) form, (3) Mood Adjective Check Lists, (4) personality data from the Sixteen Personality Factor Questionnaire ( $16 \mathrm{PF}),(5)$ content analysis of postdive debriefing interviews, (6) leisure time observations, and (7) content analysis of guided diary forms. In addition, the behavioral observations, done as an independent study by Dr. Robert Helmreich and his team and reported separately in this document, were found to be exceptionally useful in interpreting the habitability data.

The Habitability Assessment Rating Scale (HARS) was used by the aquanauts to rate 63 specific items in the habitat for performance of function, comfort in use, convenience of location, ease of maintenance, aesthetic value, and safety. This instrument was filled out by the aquanauts 5 days before completion of each mission. Copies of this form and other test instruments may be obtained by writing the authors. 
The Tektite Environmental Assessment (TEA) form is a separate habitability evaluation form that was filled out by the aquanauts 4 days before the end of each mission. This instrument specifically is used to evaluate various general features of the habitat environment as these features affect various activities performed by the aquanauts. Consequently, it may be reviewed as an activitiesby-support matrix. It provides information of a more general nature than the HARS.

The Mood Adjective Check List (NACL) was used to investigate what sort of feelings would predominate in the habitat, and how tendencies toward these feelings interrelate with attitudinal data already discussed. Aquanauts were asked to self-administer the form daily. We employed a short version of a test (one-minute administration time) successfully used in an earlier study (Nowl is and Cohen, 1968). Eleven factors are included in this version of the check 1 ist; the same three words are always used as the bas is for obtaining a score for any one factor. (Thus, there are 33 words altogether.) The order of presentation is random so as to offset memorization of the list and habitual checking response tendencies.

Prior to the beginning of each mission, all aquanauts completed the Sixteen Personality Factor Questionnaire (16PF), (Cattel1, Eber and Tatsouka, 1970). This measure was employed to determine whether specific personality traits could predict individual adjustment to the habitat. The I6PF test has been shown to be of particular value in predicting adjustment to real-life situations (Nowlis, 1965; Green, 1965).

Leisure time observations were made by two methods. First, all aquanauts were asked in their debriefing interview about leisure preferences in the habitat. Also, on one mission, a detailed topside observational record of leisure time activities was maintained. This record was compared with overall leisure responses.

Immediately after mission completion and prior to exposure to the press, each aquanaut was administered a standardized and private debriefing. These taperecorded interviews were subsequently content-analyzed by independent raters who demonstrated high interjudge agreement.

$\underline{\text { Results }}$

Habitat Rating

The results of aquanaut evaluation of the habitat using the HARS form revealed that the most positively rated items were those for recreation; miscellaneous touches such as carpeting were also well regarded. The most poorly rated sets of $i$ tems were those intended to provide support for scientific and engineering tasks and the provision of information. The most disliked characteristic of the habitat, rated as lower than poor, was access to news. Clearly the aquanauts would have liked to have been better informed on current events; their radio picked up few English-speaking stations, and newspapers and magazines were rare and generally out-of-date. Thirteen additional items were rated as poorer than ordinary, including specialized and general working areas, tools and tool storage, areas for private reflection, garbage and litter containers, 
cleaning equipment for the sinks and the head, instruments and equipment for program tasks, soaps, the head, and storage areas for housekeeping equipment. Numerous written comments were made by the aquanauts on the forms to clarify the problems involved. For example, the head leaked, spit water back when flushed, and was poorly ventilated; tools were not carefully matched to the sizes and requi rements of what was in the habi tat; and working areas were designed so that too many activities occurred in them, making it difficult for several aquanauts to do in-habitat research at the same time. Also, the areas for private reflection (the cupola and the bunks) were considered too small and were not private enough.

On the other hand, the most popular elements of the habitat, rated close to very good, included recorded music (there was a selection of about 20 audio cassettes in the habitat, including classical, rock, western, folk, and other types of music, the emphasis being on classical); the shower; the floor coverings (the floor covering of the wet room, however, was not liked as well as the carpet used in the other rooms); and temperature regulation.

Figure I illustrates the HARS ratings grouped into major clusters of like factors. High numbers are good, and low numerical ratings are poorer. As shown, the habitat generally was rated "above par" in terms of this particular scale.

The composite results of the TEA are listed in Table I. Each of the 138 TEA cells, as well as its 12 rows and 13 columns are shown. Of the 12 rows describing different types of environmental support in the habitat, temperature and humidity score quite high; this agrees with the high rating on the HARS of the air-conditioning or environmental control system. The two most significant problem areas are (1) lack of noise control in the habitat and (2) lack of variety. From this measure it is clear that the most unfavorably rated functional areas are those reserved for in-habitat science. The lowest rating characteristics of all the areas are acoustics and variety.

This measure correlates well with the HARS measure; both emphasize the importance of adequate work facilities.

\section{Aquanaut Moods}

What emerged in our findings about the moods of the aquanauts was somewhat surprising. As shown in Table II, it appears that aquanauts felt very little anxiety during their stay in the habitat and very little depression as well. Positive moods, including concentration, activation, social affection, pleasantness, and nonchalance, strongly predominate.*

* This predominance of positive affect is much less apparent as mission duration increases. Data pertinent to this problem are presented subsequently. 
${ }^{9} \mathrm{~N}$ " MALES 43

${ }^{90} \mathrm{~N}^{02}$ FEMALES 5

TOTAL POPULATION 48

९ FEMALE TEAM RATING

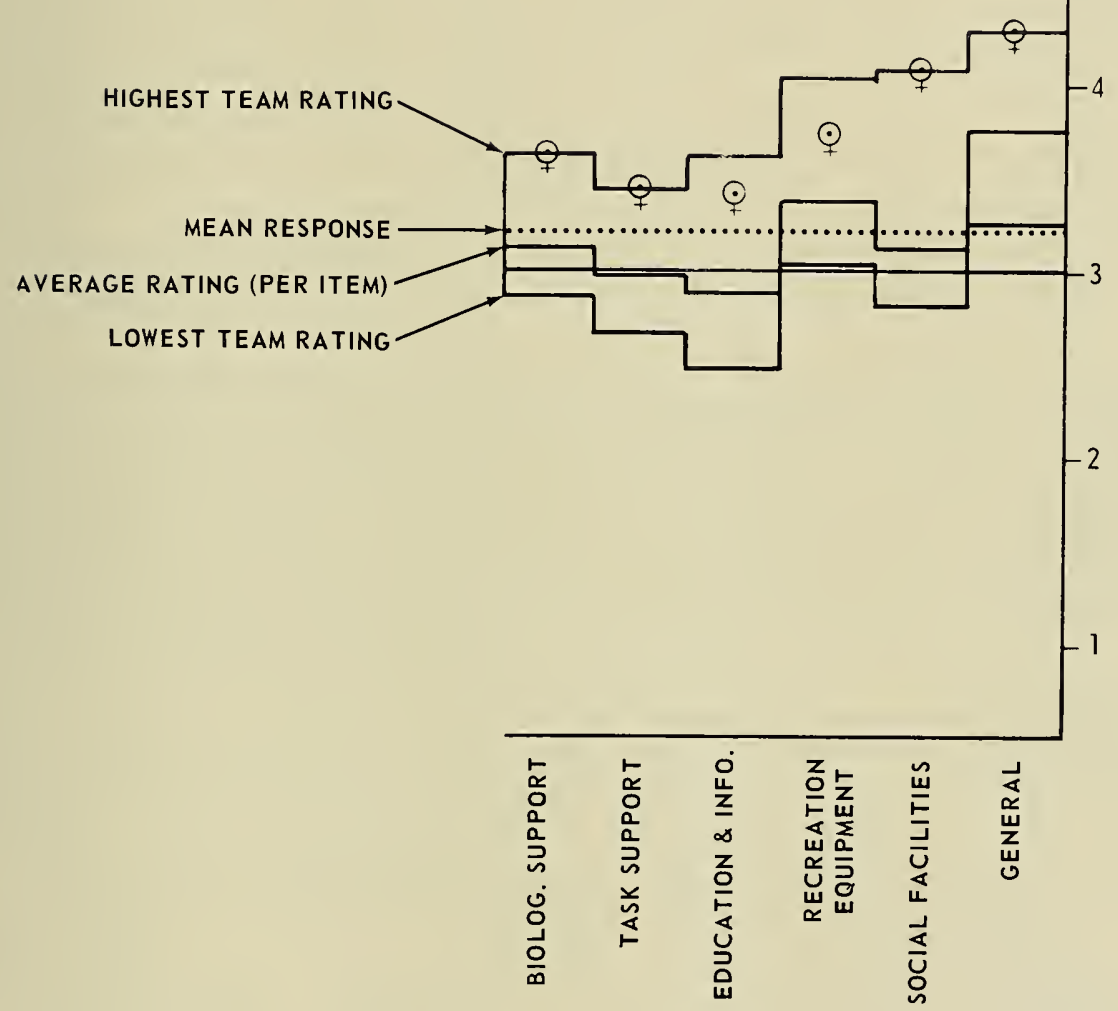

Figure 1. Habitability Assessment Rating Form 


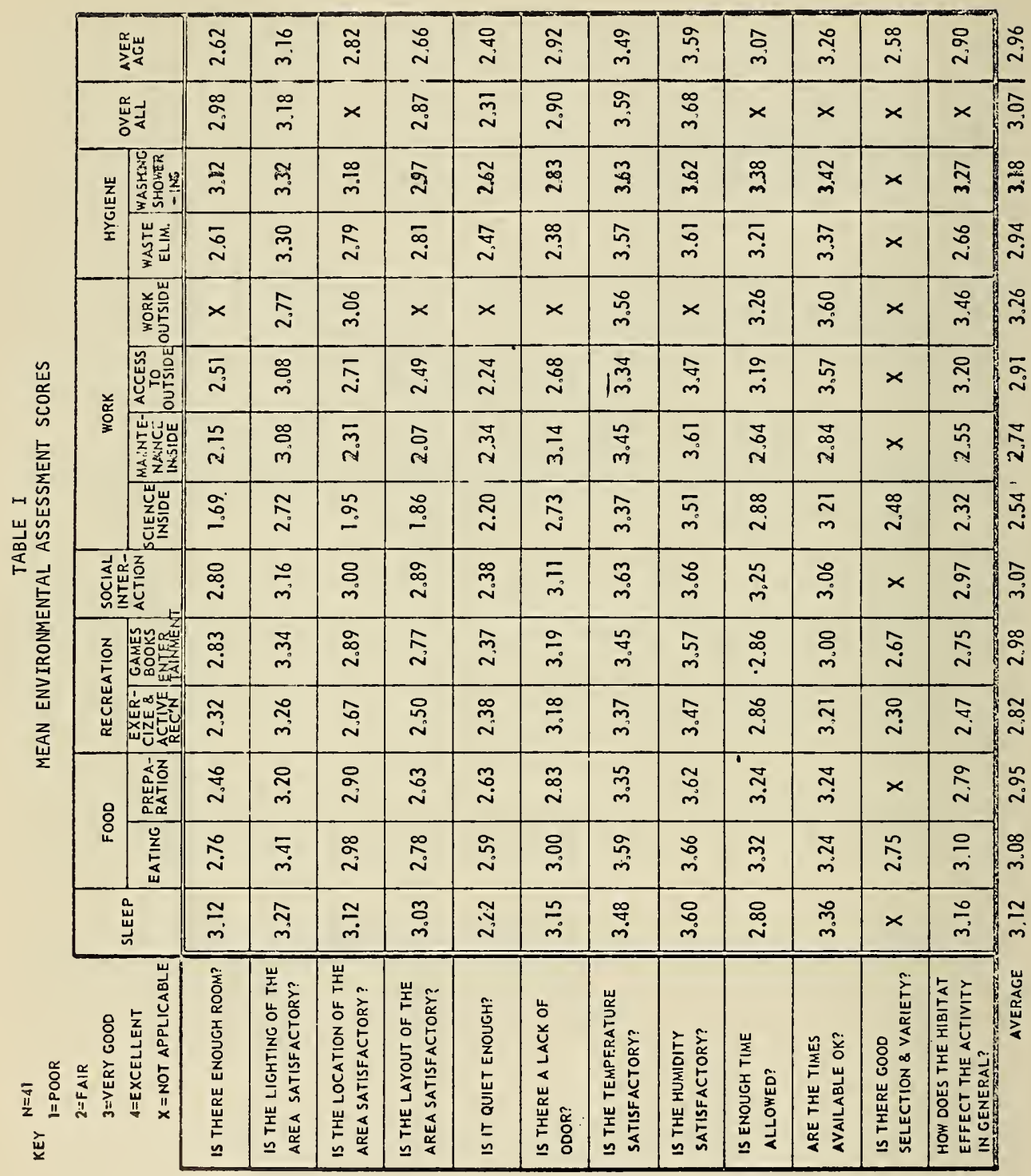


MEAN SCORES ON THE MOOD ADJECTIVE CHECK LIST

(SELF-ADMINISTERED DAILY IN THE HABITAT)

\begin{tabular}{|l|l|l|c|}
\hline \multicolumn{1}{|c|}{ Mood } & Mean Score & \multicolumn{1}{|c|}{ Mood } & Mean Score \\
\hline Concentration & 3.81 & Deactivation & 1.81 \\
Activation & 3.81 & Aggression & 0.51 \\
Social affection & 2.80 & Egotism & 0.51 \\
Pleasantness & 2.78 & Skepticism & 0.44 \\
Nonchalance & 2.10 & Depression & 0.33 \\
& & Anxiety & 0.25 \\
\hline
\end{tabular}

*The lower the score, the less common was the feeling in day-to-day life in the habitat.

This finding is supported further by the interview tapes. Aquanauts explicitly and spontaneously stated in a number of these interviews that they themselves were surprised at how little anxiety they felt during their mission. Some said they felt actually safer in the underwater environment than in the environment where they conducted their normal daily business at home. However, there was considerable variation in reported moods. It seem appropriate to examine the relationship of mood-to-habitat rating and behavioral measures collected by Dr. Robert Halmreich and his University of Texas associates. Specific correlations were developed only for the scientist aquanauts because there was a relatively small $\mathrm{N}$ for engineers.

Of particular interest were the correlates of pleasantness, depression, and anxiety in daily life in the habitat. There was a tendency for those who felt more pleasant emotions while living in the habitat to rate the habitat more favorably on the HARS $(\underline{r}=.43)$. Also, they tended to do relatively more total work $(r=.35)$ and have less total leisure $(r=.33)$.

On the other hand, those with a tendency to feel depressed while living in the habitat spent more time in solitary recreation $(r=.38)$ and in idling $(r=.32)$; rated independently as less stable and less enthusiastic by our interviewers $(\underline{r}=.39$ and .39$)$ during interviews, these people report sleeping less we $11^{-}$in the habitat $(\underline{r}=.37)$, tended to state there was not enough privacy in the habitat $(\underline{r}=-35)$, were generally less positive about the habitat $(\underline{r}=.35)$, had more complaints $(\underline{r}=.34)$, and had a more negative attitude towar $\bar{r}$ topside $(\underline{r}=.31)$. Similarly, those who felt more anxious while in the habitat were scored by interview raters as less stable $(r=.49)$ and less enthusiastic $(r=.41)$, and in the interview showed less positivity toward the habitat $(r=.47)$, less positive attitudes toward topside $(r=.45)$, and had more complaints $(r=.32)$. For an independent scale on which aquanauts rated the amount of visual, auditory, and tactile variety in the habitat, those 
tending toward depression and anxiety rated the habitat as having less variety $(r=.36$ and .37 , respectively). All of the above correlations are statistically significant $(>.01$ percent). It appears from these results that one's moods or morale in an isolated habitat are highly interrelated with one's attitudes toward the habitat and support from topside, and with one's actual work and leisure tendencies while in the habitat. It is not yet possible to state whether attitudes about the habitat influence moods or vice-versa.

\section{Personality Data}

Personality data showed, for example, that the scientist aquanauts were unusually reserved, intelligent, emotionally stable, and imaginative as compared to the normal population. The engineers differed from the normal by being unusually intelligent. Male and female aquanauts were similar on all factors except conscientiousness, the females being somewhat more conscientious.

Relationships between personality scores on the I6PF and mood responses were not of sufficient strength to be used as a basis of crew selection and are not of major theoretical importance. Further details can be obtained by writing the authors.

Two personality traits--intelligence and suspiciousness--were found to be strongly predictive of habitat adjustment: intelligence correlates with direct marine science $(r=.57)$, total leisure $(r=-.53)$, solitary recreation $(r=-.52)$, total marine science $(\underline{r}=.51)$, total work $(r=.48)$, total in-water diving $(r=.39)$, marine science support $(r=.36)$, idling $(r=-.36)$, and sleeping $\underline{r}=-32)$.

Suspiciousness correlates with direct marine science $(\underline{r}=-.42)$, total in-water diving $(\underline{r}=-.40)$, total leisure $(\underline{r}=.39)$, and solitary recreation $(\underline{r}=.34)$. In summary, more intelligent, less suspicious crewmen tend to adapt better to the habitat.

\section{Postdive Debriefing}

The debriefing interviews were examined from several aspects, and part of the interview data is presented subsequently under leisure time. Aquanaut complaints made during their interviews are discussed below. Complaint was broadly defined to include any criticism or problem that the aquanaut reported with respect to his stay in the habitat. A total of 859 such complaints were counted in the interviews, which is an average of 17.9 per aquanaut. These are classified under broad headings as shown in Figure 2. Most complaints centered around the general area of habitat design. Specifically, the aquanauts were dissatisfied with the design of the habitat affecting the performance of their tasks. A somewhat different picture appears in the interview data than the HARS and TEA data because the aquanauts can highlight their criticisms more freely in the interview. Thus, although the access to news was roundly condemned on the HARS, this issue was not nearly as great during the aquanauts' interviews as was the general issue of task support. Also, there is a fairly large area of locomotion support or mobility about which there were numerous complaints; this was overlooked in designing the HARS format. 


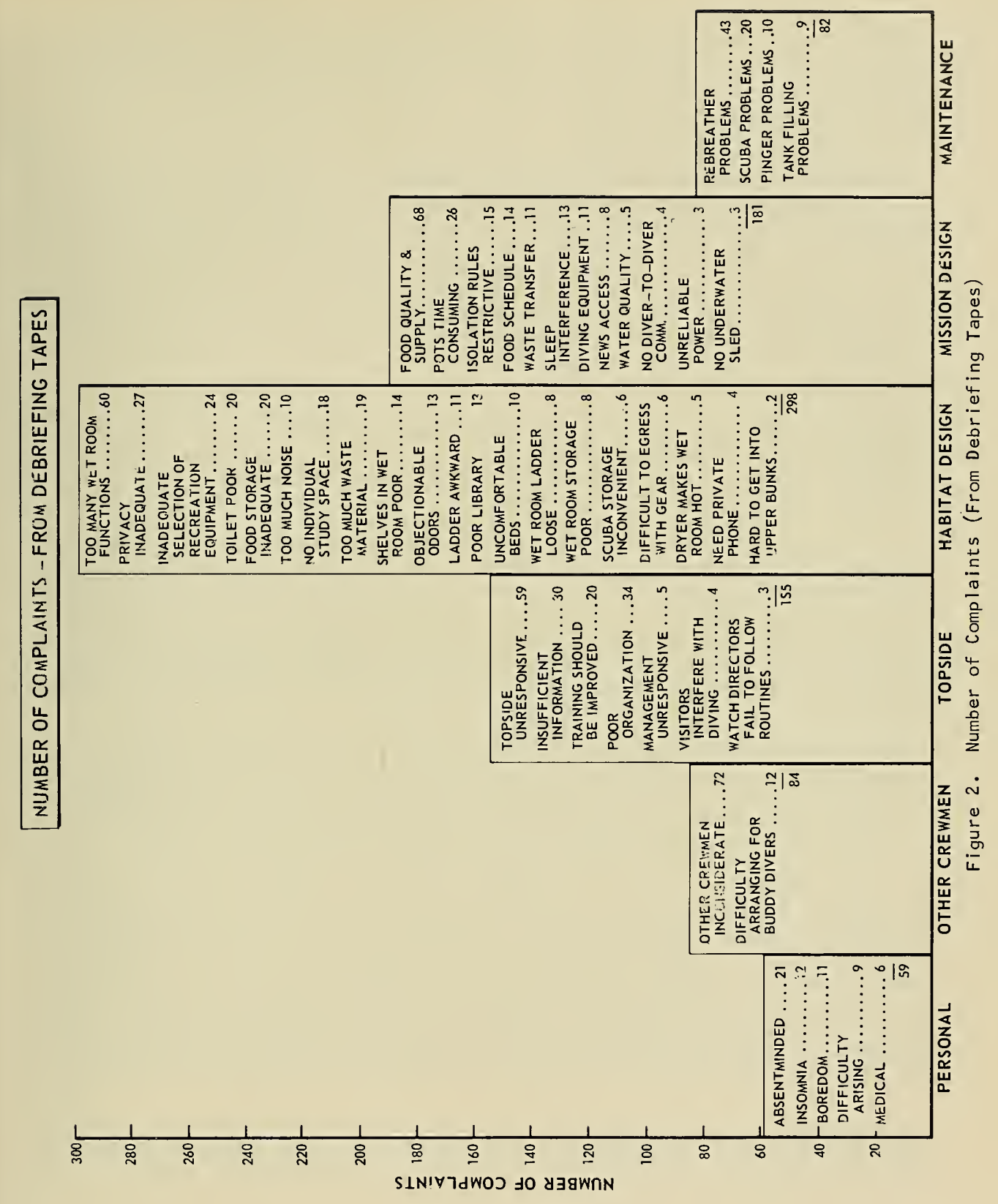


Food was also an important factor in the complaints. In three missions the aquanauts selected their own food, and their requests were met to the greatest extent possible using food from the closest supermarket, which was located some hours away on Saint Thomas Island. * In the other seven missions, a preprogrammed food selection of good nutrition and quality was offered, mostly in frozen TV-dinner-type containers.

In spite of the expense and care taken in providing these latter food menus, thirty-nine of the forty complaints made about food quality occurred in the mission with the preprogrammed foods. This is attributed primarily to the factor of self-selection. In addition, sixteen of the twenty complaints about food storage were from aquanauts in the preprogrammed food contingency, and fifteen of nineteen complaints about too much waste were from this same group. Thus, it appears that the preprogrammed food not only ignored individual choices, but also was over-packaged for a small habitat.

\section{Leisure Time Activities}

For purposes of this study leisure time was operationally defined as any nonwork, non-sleep, non-mealtime activity. This arbitrary definition may be misleading because the people comprising the subject group were highly motivated and doing the kind of "work" they most enjoy.

As part of the involvement of this study in Project Tektite II, an attempt was made to gain a degree of insight into how to select leisure provisions. To do this, a wide range of options was placed in the habitat. These were two audio tape decks with "spoken arts" cassettes and music which included classical, swing, rock, and country. There was a video tape deck with a stock of prerecorded movies and TV shows. Books ranged from Portnoy's Complaint to The History of Lat in American Art and Architecture. Games included checkers, chess, playing cards, and others. There was also a supply of drawing materials.

Leisure behavior was monitored in three ways: (1) aquanauts were asked to evaluate leisure facilities on the HARS and the TEA; (2) in the debriefing interview, all aquanauts were asked about the leisure activities that were most enjoyed and what was missed most; and (3) one mission was observed daily for location, participants, type, and duration of leisure activities.

It was immediately striking that although aquanaut trainees commonly minimized the expected importance of in-habitat recreational activities during their briefings on the leisure provisions in the habitat, behavioral data gathered by Dr. Helmreich indicates that aquanauts averaged over 4-1/2 hr of leisure time each day. In addition, HARS ratings of leisure items were very positive. Recorded music was rated very high on the HARS (only temperature regulation, floor coverings, and the shower scored higher); and games, book storage, social area layout, social area furniture, and leisure modes were also rated highly. The problems in leisure are indicated more clearly on the TEA ratings, which

* The importance of self-selection in creation of positive attitudes has been given strong empirical support in recent studies by Zimbardo (1969). 
show that aquanauts would have liked to have more selection and variety in leisure provisions, more room for exercise and active recreation, and a quieter environment for off-duty activity.

In general the comments of aquanauts during debriefings very much agreed with the HARS and TEA. Aquanauts would have particularly liked more variety in TV, tape, and both selections, and would have liked better provision for active exercise. The interview and the TEA also showed that motor noise, pump noise, and topside interruptions constitute an arbitrary distraction from leisure as well as all other in-habitat activities. Finally, all aquanauts were asked what leisure time facilities/activities they most enjoyed and what they missed the most. Results of these questions are shown in Table III.

The responses to the question on favorite leisure activity are corroborated generally by real-time crew observations. However, although crewmen reported books as their favorite pastime, they did not spend much of their time reading them. Those that were used were mostly 1 ight reading (James Bond-type adventures). The high ranking of the two-way videophone as a leisure time activity was surprising. This expressed enjoyment of the device compares to observed high usage. It was not unusual for crewmen to gravitate toward the video screen and simply watch the topside crew, who were in turn watching them. This channel, their primary link with the outside world, has been credited on Tektite with minimizing friction that frequently develops between operating and support crews.

When the answers were looked at by mission total, it was apparent that some missions particularly enjoyed certain activities; for example, one mission especially enjoyed bull sessions; but the two activities most consistently chosen as highly enjoyable were reading leisure books and listening to music on the audio cassettes. At least one aquanaut on every mission mentioned one of these two activities as most enjoyable to him.

The first two responses to the question about what was missed most--wife and family, and women and sex--are obviously from married and single aquanauts, respectively. With the possible exception of these items and a few others, it should be possible to satisfy most of the expressed desires. Note, however, that just under the biological urgings, the crew missed creative activities. Consider this in light of the research nature of their work, their unique marine environment, and the recreation package described previously.

It was interesting that although magazine reading ranked so low, in a postmission inspection of the habi tat the magazines (particularly four copies of Playboy) were found to be thoroughly worn. The centerfolds of all four Playboy magazines were missing and posted around the habitat. Games rated very low. Perhaps if the missions had been more rigidly structured such that there was a regular time when all crewmen were off duty, this would have been higher. This rating, however, agrees with other findings (notably Russian) that amusements involving intellectual competition are generally unpopular among confined crews.

On one mission very detailed observations were made from topside on the leisure time pursuits of the aquanauts. The mission is one in which, according to 
TABLE II I

LEISURE ACTIVITIES MOST ENJOYED AND MOST MISSED

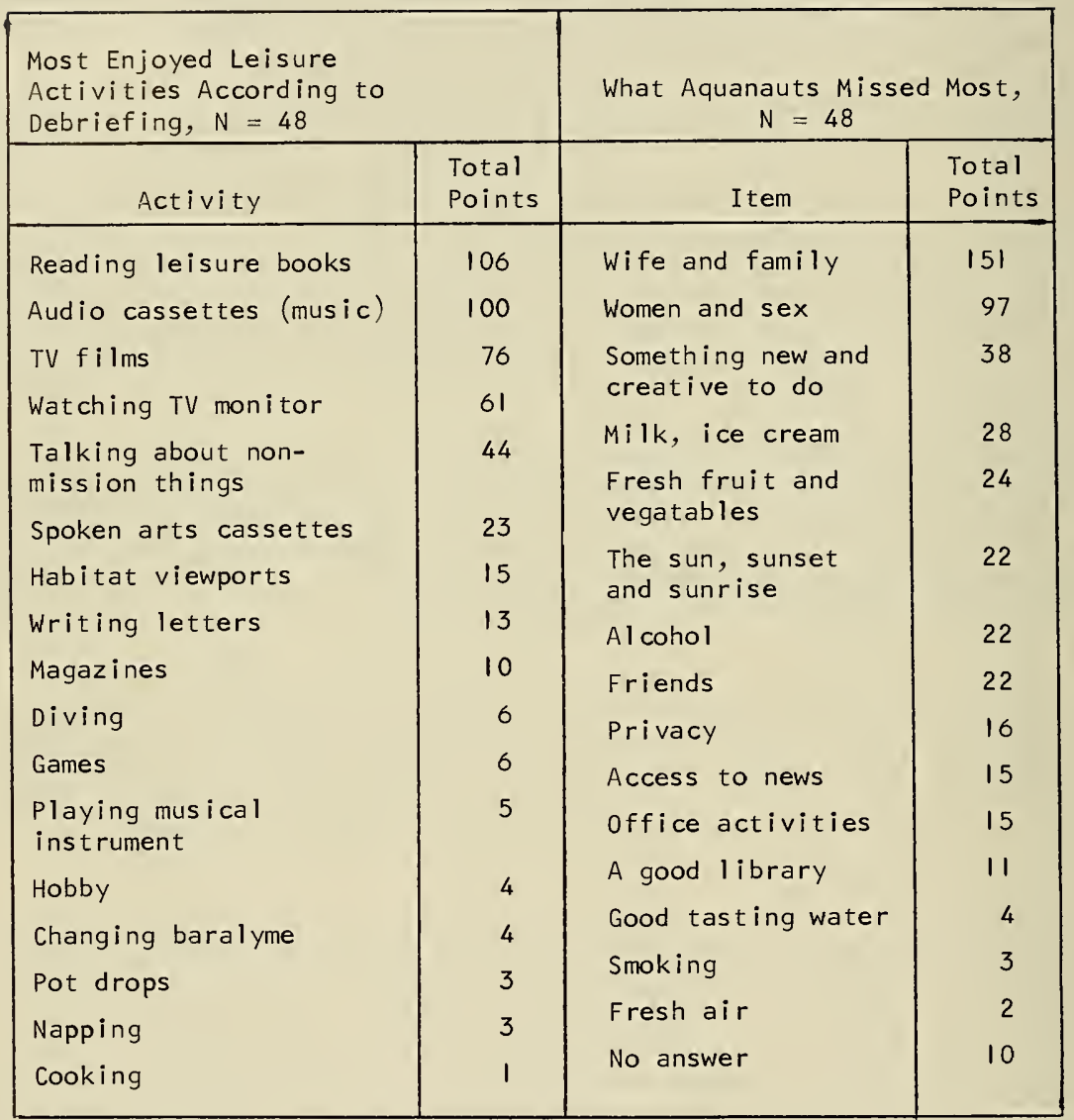


Dr. Helmreich's observations, the crew spent 21.75 percent of their total time in leisure, which is very close to the overall average of 20.23 percent. The observations reported here were gathered independently via video monitoring of the habitat*. The observation period was daily from 4:30 pm to 12:30 am, except four days during which observations were from $4: 30$ to $8: 30 \mathrm{pm}$. Observation was constant during these periods, and the time period was selected on the probability of it being rich in leisure behaviors. Table IV presents the distribution of various observed leisure activities in terms of frequency, length of duration, and total duration. The following were not included in the coding of leisure activity: conversations directly pertinent to the mission, cooking, personal hygiene, eating supper, sleeping (but napping is included), locomoting, swimming for fun when observer not certain, reading book when observer not certain if it is a leisure book, and any other activities not listed in the left-hand column of Table IV. In the observation periods, a total of 480 man-hours were observed, and during this time, 1677 leisure acts were noted, occupying a total of 215.53 man-hours. Thus, the aquanauts spent 45 percent of their time in leisure activity during the observation times. The average duration of a leisure act was 7.71 minutes.

Three out of five crewmen spent more time conversing than in any other single leisure activity.

Interview statements concerning leisure activities that were enjoyed most were compared with the data from these observations. There was good agreement between stated leisure preference in the interview and relative duration engaged in that leisure behavior while living in the habitat. Two aquanauts stated that they liked the audio cassettes best, two the audio cassettes and the magazines the best, and one liked the books best. Of the four crewmen who liked the audio cassettes, all spent a considerable amount of time listening to them, but the crewman who did not list them as a favorite did not play one cassette during the observations. This crewman, who stated books were his favorite leisure item, did in fact spend more than twice as much time as any other crewman reading books. The two crewmen who mentioned magazines as their favorite spent more time reading magazines than any other crewman. However, even though the crewman who liked books best read books considerably more than any other crewman, he still spent more time in conversation than in reading. Similarly, the two crewmen who particularly liked magazines still spent more time conversing and watching TV films than reading magazines, even though they spent more time reading magazines than the others.

Mission Duration

In analyzing the data, a number of variables especially relevant to life quality in the habitat were investigated to determine whether or not duration of stay

* We appreciate the cooperation of the crew and Dr. Helmreich in allowing us to make these observations.

**More comprehensive tables showing day by day variations in the frequency and duration of specific activities by individual crewmen and by various habitat areas can be obtained by writing the authors. 
DISTRIBUTION OF VARIOUS LEISURE ACTIVITIES IN TERMS OF FREQUENCY, LENGTH OF DURATION, AND TOTAL DURATION (MISSION A)

\begin{tabular}{|c|c|c|c|}
\hline Leisure Activity & $\begin{array}{l}\text { Number of } \\
\text { Times } \\
\text { Observed }\end{array}$ & $\begin{array}{l}\text { Average } \\
\text { Duration, } \\
\text { Minutes }\end{array}$ & $\begin{array}{l}\text { Total } \\
\text { Duration, } \\
\text { Minutes }\end{array}$ \\
\hline $\begin{array}{l}\text { Nonmission-relevant conversation between } \\
\text { crew }\end{array}$ & 701 & 5.98 & 4195 \\
\hline Listening to audio cassettes & 167 & 12.62 & 2108 \\
\hline Watching TV films & 71 & 27.45 & 1949 \\
\hline Snacking & 126 & 4.90 & 617 \\
\hline Reading a leisure book & 37 & 15.98 & 591 \\
\hline $\begin{array}{l}\text { Leafing through a book or reading a } \\
\text { magazine }\end{array}$ & 60 & 8.52 & 511 \\
\hline Writing a letter & 19 & 21.26 & 404 \\
\hline Napping & 6 & 61.83 & 371 \\
\hline Looking out view ports & 105 & 2.90 & 305 \\
\hline Resting quietly & 24 & 12.17 & 292 \\
\hline Spontaneous interpersonal actions & 38 & 6.68 & 254 \\
\hline Taking camera pictures & 61 & 3.79 & 231 \\
\hline Watching topside on TV & 73 & 2.56 & 187 \\
\hline Tinkering wi th personal gear & 36 & 5.14 & 185 \\
\hline $\begin{array}{l}\text { Nonmission-relevant conversation wi th } \\
\text { topside }\end{array}$ & 46 & 3.65 & 168 \\
\hline $\begin{array}{l}\text { Quietly watching or listening to other } \\
\text { crew members }\end{array}$ & 53 & 3.06 & 162 \\
\hline Playing musical instrument & 5 & 17.40 & 87 \\
\hline Wandering & 18 & 3.72 & 67 \\
\hline Fixing audio or TV tapes & 7 & 8.86 & 62 \\
\hline Physical exercise for fun & 3 & 13.67 & 41 \\
\hline Reading letters & 4 & 10.00 & 40 \\
\hline $\begin{array}{l}\text { Looking through leisure facilities for } \\
\text { something to do }\end{array}$ & 7 & 3.71 & 26 \\
\hline Games & 1 & 21.00 & 21 \\
\hline Waiting & 2 & 9.00 & 18 \\
\hline Reading newspaper & 2 & 8.50 & 17 \\
\hline Sketching & 2 & 6.50 & 13 \\
\hline Listening to radio & 3 & 3.33 & 10 \\
\hline
\end{tabular}


had an effect. This analysis procedure could be employed because in the mission design for Tektite II, aquanauts stayed beneath the sea for varying periods of either 14, 20, or 30 days. The principal question of concern was how people's reactions to an isolated habitat vary according to the length of time they live in it. The design of the Tektite mission program provided a good opportunity to look into this question, particularly after having not found any orderly relationships between mission duration and personality of the aquanauts.

Four missions, including 16 scientists and 4 engineers, were allowed only two weeks in the habitat. These missions were at the beginning, middle, and end of the program. Six missions, interspersed between the shorter missions, involved longer durations of habitation. Members of these missions stayed either 20 or 30 days.

A limited number of key variables thought to be particularly informative as to the quality of 1 ife in the habitat were selected. The orderly effects between those aquanauts staying 14,20, and 30 days were of interest, that is, whether or not any of the variables would show a continuous rise or continuous decline wi th increase in mission length.

These data are shown in Table $V$. Many variables do show orderly mission duration effects. The overall means from the HARS and TEA and the overall positivity score from the interview clearly decline as mission length increases, as do attitudes toward recreational possibilities on the HARS and TEA. Although aquanauts think less and less positively of the habitat as it is supportive to their research (if scientists) or engineering tasks (if engineers) as mission duration increases, this decline in positive attitudes clearly does not apply to attitudes toward topside. On the latter key variable, there is a gradual increase in positive feeling as mission duration increases.

With respect to moods, it is clear the positive moods of social affection, pleasantness, activation, and concentration tend to decline dramatically with increase in mission duration. Interpretation of this finding is not as simple as it would first appear, however, in that there is a slight but orderly decrease in negative feelings as mission duration increases. This suggests that, along with the dramatic decline in positive feeling, there is a tendency for these moods to be replaced by a state of flat and steady unemotionality. Apparently longer missions encourage aquanauts to be in a routinized, neutral mood where there is less activation, less concentration, and less intensity of feeling either in a positive or negative sense.

Finally, in the behavioral variables there is a decline in the percent time of total work with longer duration missions, and a similar tendency for percentage of time in sleep to increase. Total percent time in leisure, however, stays at a rather steady level throughout.

The data discussed above are shown in graphic form in Figures 3 and 4 . of the mood data, positive moods all show a similar slope in decline except for social affection. The latter variable shows easily the steepest negative slope for both scientists and engineers. The negative moods of anxiety and depression (shown on an expanded scale) do not show as steep a decline as the positive 
TABLE V

EFFECTS OF MISSION DURATION ON SELECTED ATTITUDINAL, MOOD, AND BEHAVIORAL VARIABLES

\begin{tabular}{|c|c|c|c|c|}
\hline Attitudes & $\begin{array}{l}\text { I4-Day } \\
\text { Scientists } \\
(N=16)\end{array}$ & $\begin{array}{l}\text { I 4-Day } \\
\text { Engineers } \\
(N=24)\end{array}$ & $\begin{array}{l}20-\text { Day } \\
\text { Scientists } \\
(N=4)\end{array}$ & $\begin{array}{l}\text { 30-Day } \\
\text { Engineers } \\
(N=4)\end{array}$ \\
\hline $\begin{array}{l}\text { HARS recreational and } \\
\text { leisure time support items }\end{array}$ & 3.51 & 3.62 & 3.28 & 3.20 \\
\hline HARS overall mean rating & 3.35 & 3.31 & 3.10 & 3.00 \\
\hline $\begin{array}{l}\text { TEA recreation environment } \\
\text { and facilities }\end{array}$ & 2.87 & 3.23 & 2.84 & 2.82 \\
\hline TEA overall mean rating & 2.98 & 3.20 & 2.95 & 2.88 \\
\hline $\begin{array}{l}\text { Was your habi tat supportive } \\
\text { of your work (interview) }\end{array}$ & 2.56 & 2.75 & 2.29 & 1.75 \\
\hline $\begin{array}{l}\text { Attitude toward topside } \\
\text { (interview) }\end{array}$ & 2.31 & 2.25 & 2.50 & 2.75 \\
\hline $\begin{array}{l}\text { Overall positivity score } \\
\text { toward habitat (interview) }\end{array}$ & 12.94 & 13.50 & 12.79 & 11.75 \\
\hline \multicolumn{5}{|l|}{ Moods } \\
\hline Pleasantness & 3.12 & 4.08 & 2.43 & 2.23 \\
\hline Anxiety & 0.38 & 0.29 & 0.20 & 0.05 \\
\hline Depression & 0.51 & 0.37 & 0.25 & 0.00 \\
\hline Social affection & 3.62 & 4.64 & 2.15 & 1.56 \\
\hline Concentration & 4.30 & 5.10 & 3.28 & 3.74 \\
\hline Activation & 4.00 & 4.81 & 3.55 & 3.54 \\
\hline \multicolumn{5}{|l|}{ Behaviors* } \\
\hline Total work & $37.24 \%$ & $32.55 \%$ & $31.96 \%$ & $30.59 \%$ \\
\hline Total leisure & $19.67 \%$ & $24.48 \%$ & $19.10 \%$ & $24.99 \%$ \\
\hline Total sleep & $32.64 \%$ & $31.75 \%$ & $37.37 \%$ & $32.49 \%$ \\
\hline
\end{tabular}

*Supplied by Dr. Robert Helmreich 


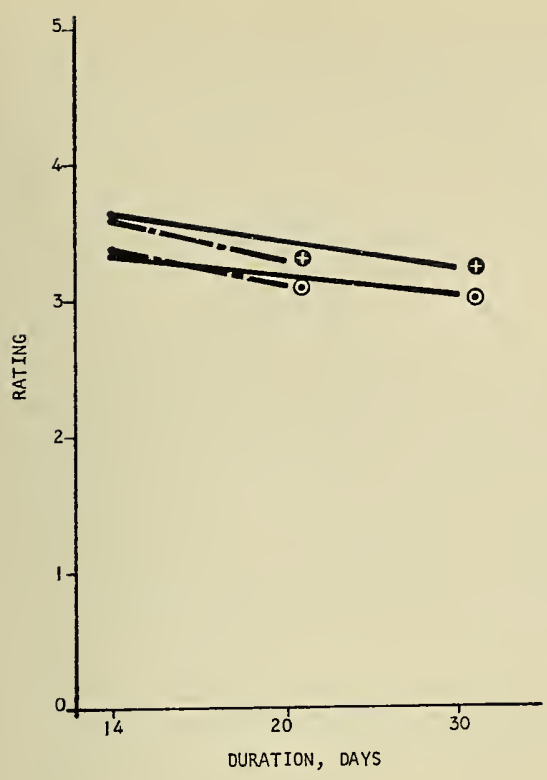

a. ATTITUDE (HARS)

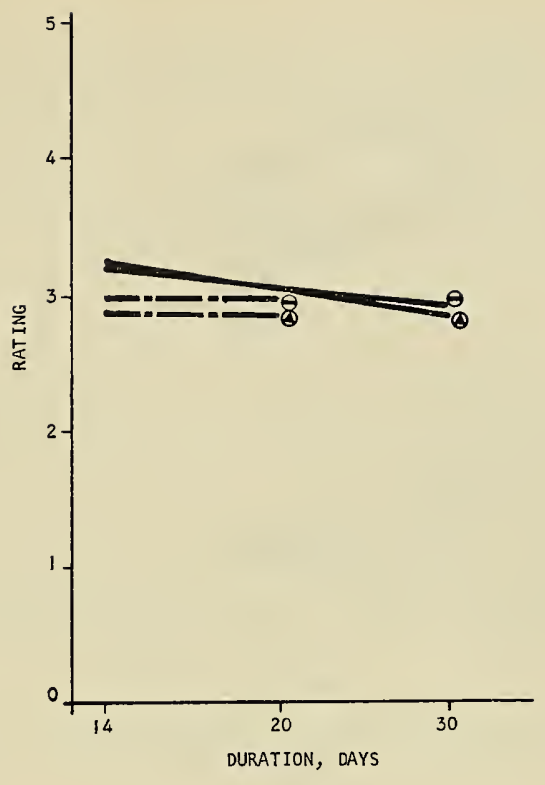

b. ATTITUDE (TEA)
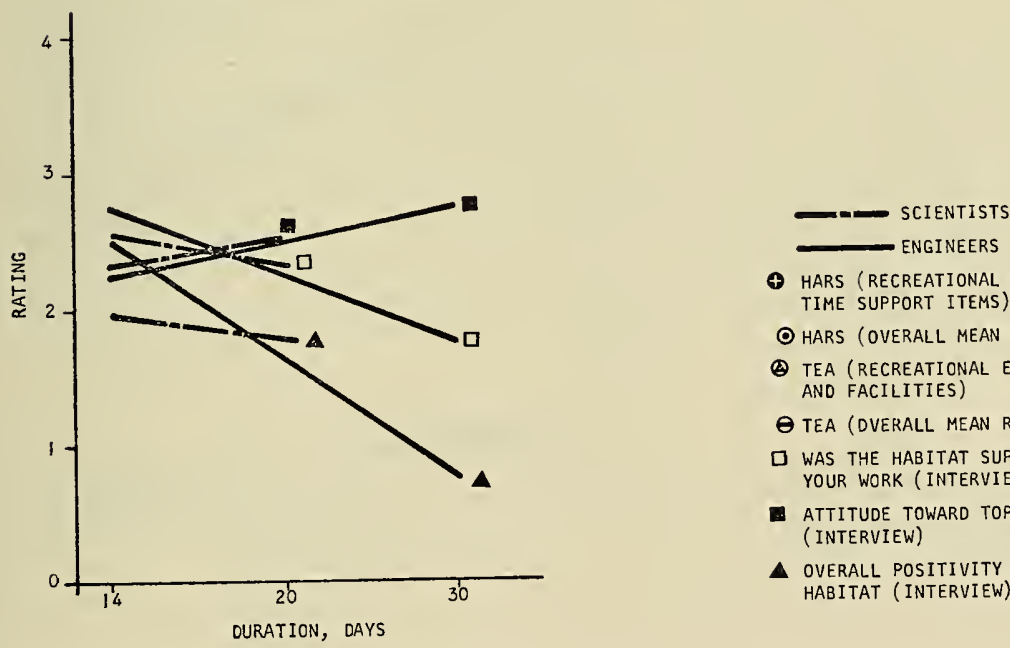

๑ haRS (RECREATIONAL AND LEISURE TIME SUPPORT ITEMS)

- haRs (OVERALl MEAN RATING)

(4) TEA (RECREATIONAL ENVIRONMENT AND FACILITIES)

$\Theta$ TEA (DVERALL MEAN RATING)

D WAS THE HABITAT SUPPORTIVE OF YOUR WORK (INTERVIEW)

ATTITUDE TOWARD TOPSIDE (INTERVIEW)

$\triangle$ OVERALL POSITIVITY SCORE TOWARD HABITAT (INTERVIEW) (MINUS II)

c. ATTITUDE (HABITAT SUPPORTIVE OF WORK, TDWARD TOPSIDE, AND OVERALL POSITIVELY SCORE)

Figure 3. Effects of Mirsion Duration on Selected Attitude, Mood, and Behavioral Variables 


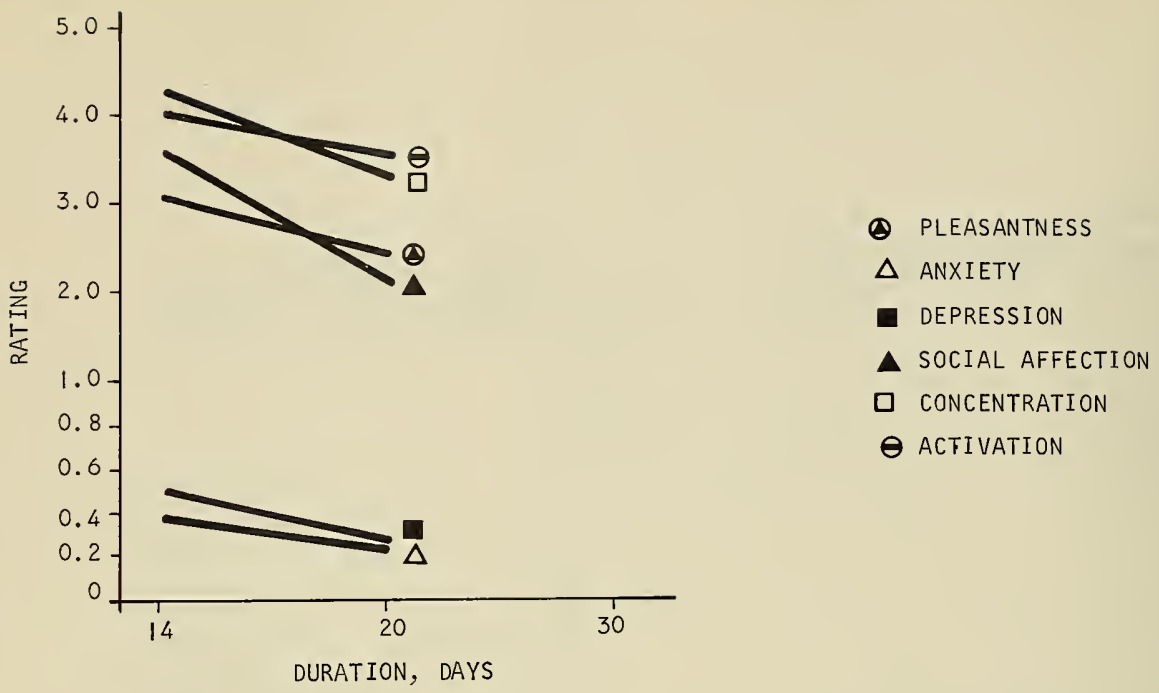

a. SCIENTIST MOOD

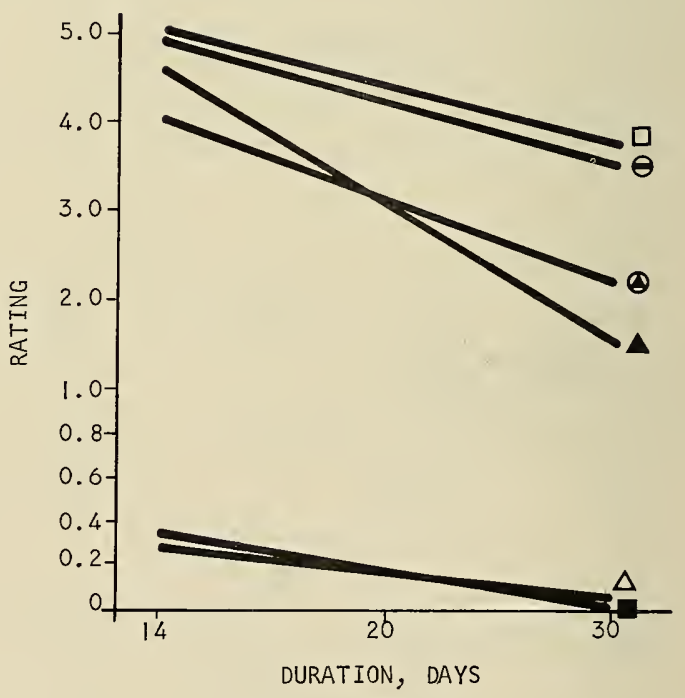

b. ENGINEER MOOD

Figure 4. Effect of Mission Duration on Mood 
moods. In the behavior data, the scientists show steeper changes in percent time at work and percent time in sleep than do the engineers. Work support, overall positivity, and HARS recreation support show the strongest uniform downward trends of the atti tudinal data analyzed.

Although statistical testing of these trends is inappropriate at this time, thei $r$ uniformity and consistency are certainly worth consideration as testable hypotheses.

\section{Summary and Conclusions}

The focal research point of this study with Tektite II had to do with the evaluations of parameters affecting life quality in underwater living in the Tektite II habitat by the forty-eight men and women who became the aquanauts of the program. These were scientists and engineers of unusual intelligence, imagination, and stability who descended into the habitat with important professional tasks to perform. Although the habitat was deficient in supporting the kinds of research programs those aquanauts wanted to accomplish and al though habitat may not have provided for enough variety of potential activities and stimuli, especially for longer duration missions, attitudes and moods were still generally quite positive in the situation.

A reasonable way to summarize the habitability assessment program is in terms of the initial objectives of the program. These objectives are reviewed below:

1. Can measures of habitability be developed?

This question cannot be completely answered on the basis of this one program. However, it is believed that the techniques employed in this study have gone a long way toward defining those factors that influence habitability in isolated situations. Important research being conducted by the aquanauts in the situation under study was of advantage in this testing program because the habitat was evaluated in a more realistic way than could have been the case otherwise. The tests selected proved viable and meaningful in this natural setting. Results should be replicated in other settings, perhaps with longer mission durations. The importance of replication is especially strong because simultaneous monitoring of attitudes, moods, overt behavior, and personality organization in a natural setting has been rare in the research done thus far.

2. How important or desirable is privacy?

This study reaffirmed previous observations that privacy has a very important impact on habitability. The results indicate that the need for variety and privacy, during which the resident can refresh himself from the routinized and flat moods that occur in isolation, increase with longer mission durations.

3. How important is leisure time, and in what kinds of activities do off-duty crewmen engage?

Leisure time was found to be very important to the aquanauts, who spent far more time at leisure activities than they or anyone had anticipated. The 
leisure activities were primarily of the unplanned, short-duration type. Leisure activities were observed in all parts of the habitat, but especially in the bridge and crew quarters. View ports, audio cassette, and books are among the leisure items that are well received by the crew because of their capacity to provide novelty in intermittent situations.

4. How important is food to habitability; what do crewmen enjoy, and what do they complain about?

The aquanauts felt that food was very important. There were far fewer complaints about food when they could select their own food even though the initial reaction to the preprogrammed food was very positive.

5. To what extent do work provisions influence overall attitude toward the habi tat?

The results of this program have lead to the conclusion that the single most important variable in the perceived habitability of this habitat was the degree to which aquanauts found the habitat supportive of their scientific and engineering tasks. It is logical to assume that their finding can be generalized to many other habitats and situations.

6. How do crew reactions to the habitat change wi th increased mission duration?

In general, although the initial impression of the habitat was highly positive, there is a clear tendency for these positive attitudes to decline wi th increasing lengths of stay in the habitat. Mission duration had a rather strong effect on many of the variables followed in this research (see 2 above). Almost all attitudes concerning life quality in the habitat were less positive in longer duration habitation periods, although the exception was attitude toward topside. Aquanauts shifted toward rather flat and unemotional dispositional states with longer duration stays, and showed less activation and less concentration. They also tended to work less and sleep more in terms of average proportion per day in the longer duration periods.

7. How is the personality of a crewman related to his opinion of, or adaptation to, the habitat?

The principal personality factors that correlate wi th adaptation to the habi tat are intelligence and lack of suspiciousness.

8. Do scientists and engineers view the habitat differently?

The data indicate that, for other than task-related considerations, there is no apparent difference between scientists and engineers on any rating or attitude toward the habitat. 
There was only one important difference between the response of men and women toward the habitat. The female aquanauts liked the habitat better. It is believed that both their smaller body size and the unique challenge afforded them had much to do with their perspective of the habitat.

10. In improving the habitability of future space vehicles, where do we turn our attention; to what attributes of the physical environment does a crew become sensitive over time?

The results of this program indicate that multiple-use spaces in isolated habitats can create a wide variety of physical and attitudinal problems for the residents. In particular, compartments utilized by the inhabitants for research must be designed with particular care because they have more impact on $1 \mathrm{i}$ fe quality than leisure areas. The results indicate that in particular, task support, variety of stimuli and behavior, privacy, and opportunity for self-selection of foods and activities are key parameters to be provided in the improvement of 1 ife quality in isolated habitats.

\section{Bibliography}

Cattell, R. B., H. W. Eber, and M. M. Tatsuoka, Handbook for the Sixteen Personality Factor Questionnaire, Institute for Personality and Ability Testing, Champaign, Il1inois, 1970.

Green, R. F., On the Measurement of Mood, Technical Report No. 10 for the Office of Naval Research, Contract Nonr-668(12), August, 1965.

Ladds, J. E., "A Study of Air Force Personnel Problems Associated with Remote or Isolated Assignments," Masters Degree thesis, University of Nebraska, Lincoln, Nebraska, 1965.

Nowlis, D., and A. Y. Cohen, "Mood-Reports and the College Natural Setting," Psychological Reports, 1968, 23, 551-566.

Nowlis, V., "Research wi th the Mood Adjective Check List," in S. S. Tomkins and C. E. Izard (eds.), Affect, Cognition, and Personality, Springer, New York, 1965.

Watters, H., D. Nowlis, and E. C. Wortz, "Leisure Time and Isolated Habitats," In Press, Aerospace Medicine.

Zimbardo, P. G., "The Human Choice: Individual, Reason, and Order versus Deindividuation, Impulse, and Chaos," in Current Theory and Research in Motivation, University of Nebraska Press, Lincoln, Nebraska, 1969. 


M. C. Smith, Jr.
National Aeronautics and Space Admi
Manned Spacecraft Center
C. S. Huber
Technology Incorporated
G. A. Swaney
Technology Incorporated
and
C. Stadler
Technology Incorporated

ABSTRACT

Food systems were designed for Dives $2,3,4,6,8,9 *, 10,11 *$, and 12 in the TEKTITE II program. Seven hundred twenty six man days of food were required to support this series of dives. The core menu for the first series of dives (2,3, and 4) was composed primarily of precooked frozen food. Core menus for subsequent dives had an equal mixture of precooked frozen, dehydrated, and thermostabilized foods. Food systems which included a variety of food types, i.e., frozen, dehydrated, and thermostabilized, had a significant effect on food monotony - longer periods of time were required to detect food monotony. Food preference data were collected from 39 aquanauts, which will be useful in the design of food systems for Skylab and subsequent manned spaceflight programs. Age distribution, technical training, and the fact that TEKTITE II subjects were highly motivated offered some similarity to the present population of astronauts.

\section{OBJECT IVE}

TEKTITE II provided an opportunity to collect and evaluate data on food preferences and food management in a unique environment, monotony as a function of food type and variety, food preservation and handling, efficiency of accountability, and techniques for measuring food intake and energy expenditure. Data obtained from TEKTITE II will be used in designing food systems for Skylab and subsequent manned spaceflight programs.

\section{PROCEDURES}

Menu design for TEKTITE II was experimental in that no attempt was made to provide an optimal system for any single mission. Current data were needed *Dives 9 and 11 were not conducted 
to predict optimal ratios of frozen, thermostabilized, intermediate moisture and dehydrated foods to supply for space missions similar to Skylab.

At that point in time, the potential of employing a Saturn $V$ to launch Skylab I offered an opportunity to increase the weight of the Skylab Food System. Considerable pressure was applied to replace freeze-dried foods with frozen foods which would have made the food system similar to those used on most commercial airline flights. Experience with high quality precooked frozen meals used for the Apollo Mobile Quarantine Facilities (MQF) had indicated that this would not be an ideal approach to the 28 and 56 day missions of the Skylab Program. However, information from the MQF systems were not adequate to substantiate the hypothesis that food monotony develops equally as a result of flavor, texture, and appearance and that variation of food preservation techniques were important in preventing monotony. The program was developed with those premises in mind.

For the first 60 day mission (Dives 2, 3, and 4), precooked frozen foods formed the core of the food system. Frozen foods were packaged as meal units on an aluminum tray and were supplemented with various snack foods and beverages. The snacks were controlled and their consumption recorded. The menu design for the first 60 day mission was repeated every eight days.

During subsequent dives, other food types, i.e., dehydrated, intermediate moisture, and thermostabilized, were included in the food system. Consequently, these menus provided greater variety than the menu design for Dives 2, 3, and 4. An 8-day menu cycle was implemented for Dives 8, 10, and 12. A 5-day cycle was proposed for Dives 9 and 11 . Three meals per man were provided for each 24-hour period. Meals were scheduled for service at approximately 8:00 a.m., 12:00 noon and 5:00 p.m. Written instructions for food preparation were included with each meal.

Food for Dives 2, 3, and 4 was procured and subsequently shipped from Andrews Air Force Base to the Virgin Islands via Military Air Transport on April 11, 1970. Representatives from the Food and Nutrition Group accompanied these and other shipments to insure proper handling and delivery.

Frozen food was placed in commercial storage on the Island of St. Thomas and staple food products were stored in a trailer adjacent to the Base Camp on the Island of St. John.

Arrangements were made to transfer food into the TEKTITE habitat every 7 days. Since it was necessary to transfer frozen food from St. Thomas to St. John and into the habitat, provisions were made to pack the containers with a refrigerant to prevent thawing. Except for the first shipment, frozen food temperature was monitored with a Dickson temperature recorder during shipment and storage. Once each week during the storage period, the recorder temperature was checked and the chart replaced. All charts were signed and dated to provide a permanent record of the storage temperature. 
A document entitled "Food Handling Procedures" was prepared and given to Base Camp personnel responsible for food transfer and control. The document contained information regarding food storage, food transfer procedures and schedules, aquanaut briefing and debriefing, and documentation and evaluation.

The aquanauts were briefed and debriefed at the beginning and termination of each dive. Whenever possible, representatives from the Food and Nutrition Group conducted the briefing and debriefing sessions. In each briefing session, the aquanauts were instructed to adhere to the menu which had been designed for that particular dive.

Fourteen aquanauts, members of three consecutive 20-day missions in the TEKTITE II series, made up the original subject pool for the energy expenditure study. However, only seven were included in the final analysis. Three individuals were excluded because of incomplete dietary consumption records. Large weight losses or gains eliminated three others. The seventh was omitted from analysis due to lack of available weight change data.

Prior to their respective missions, each aquanaut was asked to note on a meal checklist the portion of all food items consumed after each meal during the actual dive. Checklists had been preprinted on $11^{\prime \prime} \times 17^{\prime \prime}$ waterproofed placemats which could easily be torn from a supplier pad.

\section{RESULTS}

Considerable food preference data were collected during the TEKTITE program. Food preference forms were not completed for every menu component and consequently the results are incomplete. Food preference data that were collected may be obtained from the first author of this section.

In general, the data indicate that breakfast can be a very uninteresting meal for many people, and some breakfast items apparently did not store well in a frozen or canned state. The most uniform $1 y$ accepted breakfast items were coffee cake, sweet rolls, escalloped apples and French toast. Canned bacon and frozen omelettes were not well accepted initially and became less acceptable when repeated in the menu.

One meal, designed for lunch which would require minimum preparation time, consisted primarily of a frozen roast beef sandwich. During the first dive this lunch was extremely well accepted (mean rating of 8 ) and it was recommended that more frozen sandwiches be incorporated into the menus. Aquanauts on subsequent dives gave this 1 unch a mean rating of 4.6 and disliked it because the sandwich took too long to thaw and because there was no hot food in the meal.

Several items were generally well liked by the male aquanauts but not well accepted by the female group on Dive 6 . The most outstanding example of this is illustrated by the lamb chops which were the most highly accepted meat item for all male groups. The overall male mean rating for lamb chops 
was 8.1 , "like very much." The mean female rating, on the other hand, was 4.8, "dislike slightly to neither like nor dislike."

Other items which were liked by the male groups but not the female groups included spaghetti and meat, green beans, broccoli, and ham loaf. The women rated French toast and pancakes higher than the men did.

Specific food items which were extremely well accepted (mean rating of 7 or more) included sirloin steak (frozen), baked chicken (frozen) braised beef tips, short ribs (frozen), fudge brownies, both spice and Swiss chocolate, cakes, and vanilla ice cream. Dixie chicken (frozen), pot roast (freeze-dried), beef almondine (freeze-dried), and all desserts also received high overall ratings.

Salisbury steak was the least accepted item of all foods rated and was only used for two dives. Data for Dive 3 indicated that acceptance of that product decreased considerably as it was repeated.

Most of the aquanauts stated that food became monotonous at some point during the dive. During Dives 2, 3, and 4, preplated frozen food was used almost exclusively. On subsequent dives, a greater variety of foods including dehydrated and thermostabilized items were introduced into the system. The data indicates that if a food system provides 1 ittle or no variety in the physical state of the food served, the food will become monotonous more quickly than when a system is comprised of different food types. This point is substantiated by the fact that during Dives 2,3 , and 4 , when the food was primarily preplated frozen meals, monotony was experienced after about five days. With similar frozen foods supplemented with dehydrated and thermostabilized foods, food monotony was not experienced until around the tenth day on subsequent dives. This increase in the span of interest in the food is also correlated to some degree with the first repetition of the menu cycle which was increased after the first series of dives.

It may be concluded on this point that to sustain interest and food acceptance in the food, it is necessary to vary type of food and to provide a menu cycle of at least six or seven days.

Addressing the question of the acceptability of prolonged use of frozen food, it may be stated that in cases where preservation by freezing provides a highly desirable item in its most acceptable form, the use of frozen foods is advisable. Indiscriminate use or total reliance upon frozen food, however, as sole source of sustenance, detracts from the acceptance of food items which could be preserved by other means, thus adding variety in menu items.

Determination of the effect of variation in food texture, color and serving techniques on overall acceptability were difficult to quantitate. Any statement concerning this area will, because of the nature of the information received, have to be quite general.

VIII - 93 
Some of the aquanats objected to the plastic flatware. The breakage rate was high and there was a negative psychological effect associated with the use of disposable plastic eating utensils. Silver or stainless steel utensils were more acceptable even though additional work was required for cleansing and sanitizing.

Aluminum serving trays also had an effect on food acceptance because of the connotation of "T.V. Dinner" quality even though the quality of these foods was very high.

A procedure which is extremely important to the Skylab medical experiment M071 "Mineral Balance" is food accountability.

Some difficulties were encountered in food accountability. A set of food rating cards was provided with each meal. Each aquanaut was to rate each food item in the meal during or immediately after the meal. A running inventory was also to be kept on all snack items supplied to dive subjects. These data, along with crew debriefing comments, were expected to provide an accurate accounting of food intake by each crew member.

In practice this system was deficient in several ways. First, some crews were not sufficiently aware of the importance of food accountability or familiar with the forms involved in collecting this information. Secondly, the ground support personnel handling the food system were not always completely cognizant of a11 aspects of the system.

Experience with food accountability procedures in TEKTITE II point up the importance of thorough crew briefing. Only when participants in a project understand the goals and operation of a system, can they provide the required information. The problems encountered in preparing, preserving, and handling frozen foods most certainly were unique to project TEKTITE II and its location. Evaluation of the techniques employed did, however, provide valuable information.

During the preliminary planning for project TEKTITE, special microbiological requirements were imposed on suppliers of frozen and freeze-dried foods. Food safety was the prime reason for stringent requirements in this area. Since the optimum storage temperature for frozen foods could not be assured, it was important to start with foods which had a low microbiological content.

TEKTITE II experience emphasized the point that in handing food, especially frozen food, it is important to keep the number of transfers to a minimum and to monitor the temperature during transit and storage.

One major problem was encountered during the program. The frozen food which was stored at a commercial facility thawed because of mishanding at this establishment. Food, which had been thawed, was detected before it was consumed. Constant temperature monitoring by TEKTITE personnel was implemented after the thawing problem was encountered.

VIII -94 
Food preference data obtained during TEKTITE II will be used in designing food systems for Skylab and subsequent manned spaceflights. TEKTITE II data revealed that food monotony can be delayed by including various food types (frozen, dehydrated and thermostabilized) in a food system.

There was a negative psychological effect associated with the use of disposable plastic eating utensils. Consequently, stainless steel utensils will be used for the Skylab Program, even though additional work is required for cleansing and sanitizing.

Strict control and monitoring devices are required during the shipment, storage and transfer of frozen food. Unless properly monitored, it is difficult to detect food which has been thawed and refrozen. A potential health hazard exists if this remains undetected.

There has been a trend to move away from precision assessment to simpler, more rapid techniques requiring less involvement by technical personnel while permitting more individuals to be tested within a given period. 
Paul L. Chandeysson

Be11 comm, Inc.

Washington, D. C.

\begin{abstract}
Bellcomm provided support to the TEKTITE II human behavioral studies primarily in the form of data management and assistance in developing observational techniques for aquanaut behavioral monitoring. At the request of NASA, support in mission planning was also provided to the Department of the Interior.
\end{abstract}

\title{
INTRODUCTION
}

Bellcomm, Inc. is a Bell System company which provides systems analysis and study, planning, and technical support to NASA headquarters. Bellcomm participated in TEKTITE II to support the NASA aquanaut behavioral program and to provide mission planning support to the TEKTITE program management.

\section{BEHAVIORAL PROGRAM SUPPORT}

Data management for the aquanaut behavioral study constituted the largest part of Bellcomm's activity in TEKTITE II. This data management effort is described in detail in Reference 1 and is outlined schematically in Figure 1.

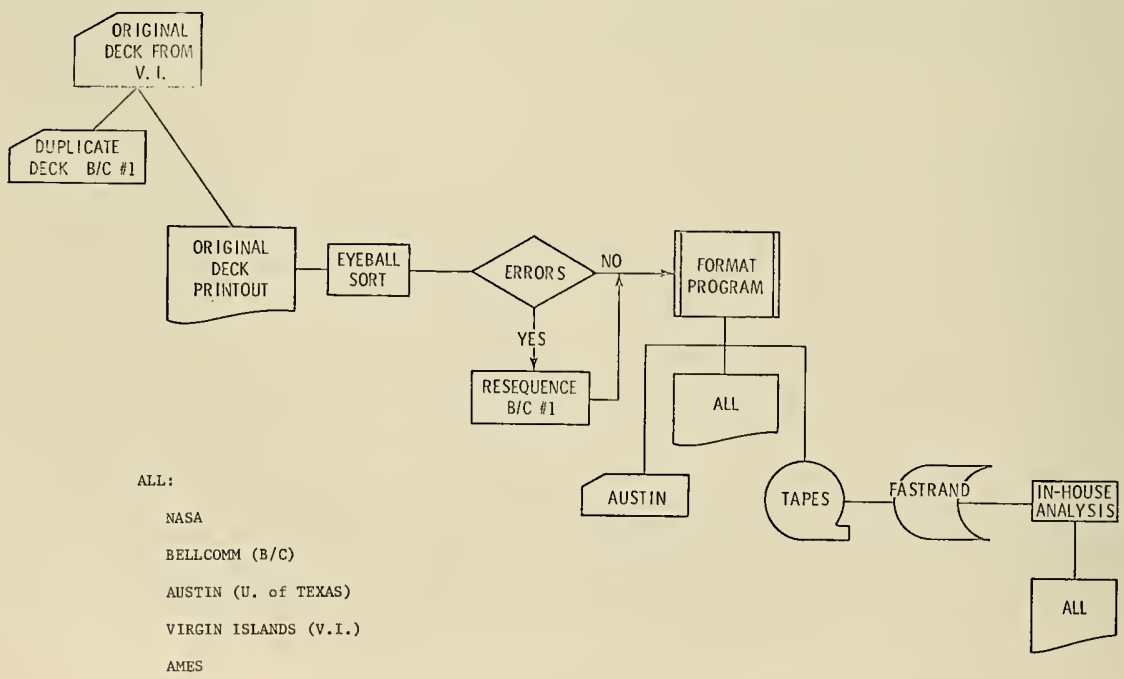

Figure 1. TEKTITE II Data Management Schematic Diagram VIII-96 
Data on hand-punched computer cards were sent to Bellcomm every week by mail from the TEKTITE operational site in the Virgin Islands. The cards were duplicated on regular computer cards and printed out. A visual check for data errors was made so that the cause could be immediately determined and corrected. The data were then reformatted into a readily interpreted format developed in collaboration with the scientific investigators. These data were then made available to the investigators in printout form; cards were sent to the University of Texas at Austin for computer analysis. The data were also stored on tapes at Bellcomm. These data are accessible via fastrand for future analysis by Bellconm or other investigators. The data management procedures were set up by R. Mach and M. Reynolds before the operational phase of TEKTITE II; data management has been done by Mrs. Reynolds during the mission.

Bellcomm also assisted in developing the observational techniques for the aquanaut behavioral study. R. Mach designed the behavioral data collection system based on the TEKTITE I system and assisted in the redesign of the behavioral observation station in the surface support facility to accommodate a more extensive observational program than in TEKTITE I. In coordination with the principal investigator of the aquanaut behavioral study, Mach developed the behavioral measures for TEKTITE II, and implemented a training program for the behavioraI observers. This included writing the scenario of a video training film and a handbook for the behavioral observers (Reference 2).

\section{MISSION PLANNING SUPPORT}

Bellcomm was asked informally by the NASA office sponsoring TEKTITE II to provide mission planning support to the Interior Department. This support was provided beginning in January 1970 and included assistance in program organization, support operations planning and scheduling, budgeting, training program planning, mission operations planning, and program documentation. Bellcomm activities in support of TEKTITE II ended in November 1970 after completion of the operational phase of the program.

\section{LITERATURE CITED}

1. Reynolds, M. J., Tektite II Data Management/Hand1ing, Bellcomm Memorandum for File, B70 09052, September 18, 1970.

2. Mach, R. S., Tektite II Behavioral Observer Handbook, Bellcomm Memorandum for File, B70 04068, April 28, 1970. 

CHAPTER IX

MEDICAL SUPPORT PROGRAM

Edward L. Beckman, M.D.

Marine Biomedical Institute

University of Texas Medical Branch

and Texas A\&M

Ri.chard G. Masson, M.D.

U. S. Public Health Service

Elizabeth M. Smith

Consultant to Marine Biomedical Institute

\section{ABSTRACT}

This report describes the organization, responsibilities, observations, and conclusions of the medical program. Included are descriptions of the staff, training requirements, physical facilities, examination and decompression procedures, the deve1opment of new decompression tables, and a review of some problems faced. In general it can be said that no serious medical problems were encountered. Of 915 man-days in the habitat, only 13 mandays in the water were lost because of medical reasons. A brief discussion of non-diving medical problems is included.

\section{BACKGROUND}

After the proposed TEKTITE II program was approved by the Department of the Interior, a medical program was proposed to the Sea Grant Program of the National Science Foundation that would provide medical surveillance during the project. Inasmuch as TEKTITE II could provide a platform for training doctors in underwater medicine, NSF was in the position of offering its backing for a project designed to provide such training. To this end, the Sea Grant Program contributed $\$ 124,000$, with one-half matching funds being contributed by the University of Texas Medical Branch (Galveston).

Medical responsibility for the program was assigned to the UT Medical Branch. Edward L. Beckman of that university and of the Marine Biomedical Institute (jointly sponsored by the University of Texas and Texas A\&M University) was named Medical Director of TEKTITE II.

MEDICAL SURVEILLANCE AND RESPONS IBILITIES

\section{Medical Advisory Board}

Soon after the inception of TEKTITE II, the Medical Advisory Board was set up at the request of the designated Medical Director. Board membership included:

1. Edward L. Beckman, M.D. (Chairman)

2. Richard G. Masson, Senior Assistant Surgeon, United States Public Health Service, Deputy Medical Director, TEKTITE II. 
3. George Bond, CAPT, MC, USN, Special Assistant for Diving Medicine to the Commanding Officer, Naval Ship Research Laboratory, Panama City, Fla.

4. Craig Fischer, M.D., Director of the Clinical Laboratories, Preventive Medicine Division, NASA Manned Spacecraft Center, Houston, Tex.

5. Christian J. Lambertsen, M.D., Institute of Environmental Medicine, University of Pennsylvania Medical Center, Philadelphia

Three additional physicians acted in an advisory capacity to the Board:

1. Robert Workman, M.D., Medical Director, Taylor Diving Co., Belle Chase, La.

2. Tor Richter, CAPT, MC, USN, Commanding Officer, Nava1 Medical Research Institute, Bethesda, Md.

3. Thomas Markham, CDR, MC, USN, Senior Medical Officer in the TEKTITE I program; Naval Submarine Medical Center, New London, Conn.

The Board's function was to advise the TEKTITE Program Manager and the TEKTITE Safety Review Board on appropriate medical procedures to be adhered to in both the 50- and 100-ft dives, particularly with respect to decompression, and to evaluate the suitability for saturation diving of any aquanaut applicant whose physiological qualifications might be questionable.

The Board met four times prior to the beginning of the project, primarily to take action on matters pertinent to the 50-ft missions. It met five times afterwards (once by conference cal1), these meetings having been convened in connection with efforts to launch the series of Minitat dives.

\section{Medical Staff in the Virgin Islands}

The nucleus of medical support for Project TEKTITE II was formed by Dr. Beckman, the Medical Director, and Dr. Masson, who served both as Deputy Medical Director and Medical Director of the 50-ft program and of the TEKTITE base camp on

St. John island. Both doctors remained on site for the duration of the project. Additional medical coverage was provided by seven physicians from the USPHS (specifically, from the Federal Health Programs Service) and seven from the UT Medical Branch. These doctors served on a rotating basis for periods of two to six or seven weeks.

In addition to the UT and USPHS doctors, specialists in diving physiology from other institutions participated in the project on a voluntary basis, prompted by the unique training opportunities it offered in the field of hyperbaric medicine. 
The TEKTITE II physicians were charged primarily with the responsibilities of

(1) evaluating the medical suitability of the individual aquanaut applicants;

(2) medically supervising the diving missions and the decompression procedures following them; (3) establishing a base-camp dispensary to serve the medical needs of the aquanauts and all support personnel; and (4) assuring maintenance of proper sanitation and hygiene in base camp and aboard the Minitat support vessel, the R/V UNDAUNTED.

In outline, on-site medical supervision during the program was thus structured:

1. At least one watch physician was on duty at all times during the 50-ft missions. An additional physician came on duty each day at 8:30 a.m. and remained until 5 p.m.

2. During decompression at least two physicians were on duty 24 hours a day. A third medical officer was available during the day to attend to any emergent medical problems unrelated to the decompression.

3. A Coast Guard medical corpsman was assigned to assist in the basecamp dispensary.

4. An assistant medical officer (Peter Philbin, M.D., of the USPHS) was assigned responsibility, under the supervision of the Medical Director, for the 100-ft missions. He remained on duty at the site of the Minitat trials from early August until the program was aborted in late 0ctober, 1970.

The medical staff's responsibility for support personnel extended to the crews of the UNDAUNTED and, to a much smaller degree, the ADVANCE II, the oceanographic research ship that offered some logistic support during the project. A small area of supervision was that of rest-and-recreation dives over the weekends. Every effort was made to have a doctor along on these expeditions, in view of the frequent bad weather and heavy seas in and around Lameshur Bay.

Dependents of TEKTITE families also came under the purview of the medical staff. The families were originaliy scheduled to use local medical facilities (principally on St. Thomas island); but it soon became apparent that this arrangement would be unsatisfactory, because these facilities were overcrowded with patients and understaffed with doctors." Although most dependents did, in fact, rely on the dispensary and the TEKTITE doctors for medical assistance, a list of local specialists was maintained to whom TEKTITE personnel might be referred for diagnosis and treatment.

The Dispensary

The dispensary, the headquarters of the TEKTITE II medical program, consisted of the rear half (measuring $9 \mathrm{ft} \times 12 \mathrm{ft}$ ) of an air-conditioned building in base camp. As far as medications and suture materials were concerned, the dispensary could have qualified as a reasonably equipped general-practitioner's office. It was, additiona11y, furnished with an electrocardiograph, ophtha1moscope, and slit-lamp binocular ophthalmoscope. Its capabilities for handling in-patients, however, were not spectacular, in that it contained only one bunk bed. 
The watch physician spent the night in this building, as did the Coast Guard medical corpsman (Jerry Deason) assigned to assist in the project. The office was connected by field telephone to the diving platform, the causeway, and the command van.

The medical corpsman ran the dispensary under the supervision of Dr. Masson. He served as a physician's assistant, and conducted sick call every morning and afternoon. Since he was a scuba diver, he would have been of particular usefulness in case of an emergency in the habitat. He also inventoried supplies, made checks of the sanitary conditions in the kitchen, toilets, and showers, and controlled the use of emergency vehicles.

The drugs and surgical stores were initially supplied by program funds. As existing stocks were exhausted, attempts to replace them were made through a drug-supply house on St. Thomas island. It was fortunate that, for the most part, the original stocks proved adequate for the entire program, since many drugs were difficult to obtain in the Virgin Islands. For example, lowmolecular-weight dextran and heparin, both important in the treatment of certain forms of dysbarism, as well as "K1ing" bandages, were unobtainable locally and had to be shipped from the USPHS medical supply center at Perry Point, Md.

\section{Other Medical Support}

Complete blood counts, routine urinalysis, reagent-stick blood sugar measurements, and initial bacterial isolation were performed in base camp. For these tests, the medical staff was permitted to use the laboratory of $\mathrm{Dr}$. Andre Cobet, director of the TEKTITE microbiology studies. Other laboratory work was performed by the Caribbean Research Institute laboratories on St. Thomas, and parasite studies were made through the courtesy of the Virgin Islands Public Health Service.

There was no adequate clinical X-ray equipment on St. John. The few X-ray examinations required during the course of the project were therefore performed by a radiologist on St. Thomas.

After much controversy over the poverty of existing emergency transportation, the medical staff was eventually assigned a jeep (turned quickly into an ambulance by the application of large red crosses) to handle any casualties on St. John. A boat was provided by the Medical Director for use by the medical staff in case of accident at the habitat site or during decompression procedures. Casualties requiring treatment on St. Thomas were taken there via the JEANETTE, the shuttle boat leased to the project for its duration.

Although the need never arose, arrangements were made with the Coast Guard for helicopter transport in the eventuality of a casualty in the TEKTITE program whose injuries or illness proved beyond the competence of the St. Thomas medical community. A helicopter based at the U.S. Naval Air Station, Roosevelt Roads, Puerto Rico, could reach St. John in one hour. 
In the opinion of the Medical Advisory Board, only the following physical abnormalities or dysfunctioning constituted absolute or possible contraindications to saturation diving.

Absolute contraindications:

1. Impaired cardiovascular or pulmonary function

2. Large emphysematous bullae or blebs revealed by a chest $\mathrm{X}$-ray

3. The subject's total inability to equalize pressure in the middle ear via the Eustachian tubes (a rare condition)

4. Demonstrable aseptic bone necrosis

5. Medical abnormalities that could produce a sudden loss of consciousness (e.g., epilepsy)

Possible contraindications:

1. A chronic medical illness that might impair swimming competence or capacity to work underwater

2. Neurologic or orthopedic pathology of sufficient severity to impair swimming competence

3. Therepeutic drug-taking, narcotics addiction, or alcoho1 dependency that might interfere with alertness

4. A psychiatric illness that might impair the ability to function well under conditions of stress (rare; diving does not appear to attract psychologically unstable persons)

Early in 1970 medical examination forms were mailed to each of the aquanaut candidates. The examinations were performed by the applicants' private physicians, who returned the completed forms to $\mathrm{Dr}$. Masson. Any questionable physical qualifications were referred to the Medical Advisory Board for a decision; only two applicants were ultimately rejected, both for reasons of cardiac inadequacy.

At the same time that each candidate was medically examined in his city of residence, he also completed the Minneapolis Multiple Personality Inventory (MMPI). The results of the MMPI were interpreted by the Psychological Corporation of Minneapolis, Minn., and submitted to the Medical Advisory Board. The Board regarded the MMPI as a minimum screening device for detection of psychopathological disorder. No candidate was rejected on the basis of the MMPI.

An attempt was also made to obtain long-bone roentgenographic surveys of all the candidates to uncover evidence of early bone necrosis. These X-rays were mandatory for the prospective crews in the 100-ft missions, but optional for those of the 50-ft missions. Those X-rays made were sent to the Navy Medical 
Research Laboratory (New London, Conn.) for analysis, as part of its bonenecrosis survey program. None of the applicants so examined was found to be affected with this malady.

Predive Physical Examinations and Briefing

Any disqualifying change in physical status occurring following the preliminary examination was expected to be detected in the predive examination. This physical, identical to the first one, was made at base camp during the requisite two-week training period preceding each mission. No aquanaut was rejected at this point in the program. (One disqualified himself, in effect, once he arrived in base camp, on the basis of recurrent nosebleeds during diving.)

A second purpose of this examination was to form a baseline for comparing any physiological changes that occurred in the aquanaut during the dive. A third reason was to acquaint the physician of prime responsibility in the mission and the aquanauts with one another.

As part of the predive briefing, members of the medical staff lectured the aquanauts on the medical problems encountered in TEKTITE I that might logica11y be expected to emerge in TEKTITE II. The aquanauts were also told of the hazards of saturation diving, in particular the importance of observing the deep- and shallow-excursion limitations (discussed hereafter). They were carefully instructed regarding procedures to be followed in the event of accidental surfacing and on the probability of injury resulting from overly rapid decompression (e.g., air embolism or severe CNS symptomatology). In addition, the aquanauts were instructed in the use of the pharmacopoeia available to them in the habitat.

The aquanauts were exhorted to use the ear solution (equal volumes of $50 \%$ alcoho1, 5\% acetic acid, 5\% tannic acid) devised to combat "swimmer's ear," a major problem in any prolonged exposure to water. Divers were instructed to fill the ear canals with the solution after the last dive of the day, allowing one to two minutes of contact. The solution was then to be removed by use of a soft wick of twisted cotton (not by cotton applicators, which might cause trauma).

After Mission 1-50 of TEKTITE II, special emphasis was placed on complete ophthalmologic examinations of each aquanaut prior to his mission, because of the bubble-like inclusions in the left eye of a participant in that mission.

Indive Procedures

A major difference between the medica1 surveillance in TEKTITE I and II was that in TEKTITE II the medical staff was allowed to conduct daily personal conferences with aquanaut by telephone from the command van; conferences that were not monitored by the psychological observers. Such direct communication had not been permitted in the earlier program because it was felt to break isolation. Because of the daily conferences in TEKTITE II, it was possible to maintain a much closer check on the physical condition of each aquanaut-especially with respect to the most mettlesome problems, i.e., otitis, ear "squeeze," and skin infections. 
In case of serious illness or injury during the course of a mission--which eventualities never materialized--a doctor was to dive to the habitat to supervise handling of the emergency. Thus the insistence on the diving proficiency of all doctors associated with the project, which is discussed hereafter.

\section{Supervision of Decompression}

The closest possible medical scrutiny was maintained throughout the 21-hour decompression. Because of the suspected bubble formation in one subject's eye during the decompression following Mission 1-50, ophthalmoscopic examination was made in the Deck Decompression Chamber in a11 subsequent missions. In one or two instances, more intensive medication (e.g., penicillin, which was not used in the habitat) for treatment of stubborn lesions was begun in the chamber.

Details of the course of decompression and the sequence of breathing mixtures used are discussed later in this section. The two schedules used in the 50-ft missions are shown in Appendices $A$ and $B$.

\section{Postdive Examinations}

Immediately following their emergence from the DDC, the aquanauts were given a physical examination identical to the one undergone prior to the mission. These examinations were conducted at the base-camp dispensary, and special emphasis was once again placed on ophthalmic evaluation, which was always performed by a doctor with special training in ophthalmology. Blood was also drawn for blood-chemistry and hematology tests, and a complete on-site blood count was made.

No follow-up examinations were routinely made of the TEKTITE subjects after the one performed immediately postdecompression. In two instances, however, later evaluation was deemed advisable: a knee X-ray of the female aquanaut who had suffered a mild attack of knee bends during decompression; and chest X-rays of another aquanaut who had experienced upper respiratory difficulties during both his mission and decompression, and who had reported subjective symptoms lasting some days thereafter. The results of all these X-rays were negative.

\section{Training}

The physicians volunteering for service in the TEKTITE II medical program obviously did so because of their particular interest in undersea medicine. As part of their on-site training, therefore, a course consisting of instruction in underwater physiology and practice sessions in the water was designed by the Marine Biomedical Institute and conducted by its diving officer, Dennis Bowman. Through the provision of diving instruction, the necessary gear, and a series of six formal lectures (lasting about one hour each), the MBI hoped that each physician would become proficient enough in scuba diving to qualify for certification by the Professional Association of Diving Instructors, a certification that Mr. Bowman was authorized by the association to grant to those applicants who met its diving criteria and had taken the cours ework. 
The instructional subject matter included such topics as the use of safety techniques and equipment; the proper use of scuba gear; the physical laws of various gases; the injuries unique to the diving community, and their causes, symptoms, and remedies; the recognition and management of dangerous marine animals; and safe methods of diving from small boats. The physician-students were required to demonstrate a series of swimming skills. They then embarked upon open-water dives in which they were instructed in such scuba techniques as buddy breathing, equalizing of pressure in the ears during descent and in the lungs during ascent, point-to-point swims by compass, diver assistance in an emergency, and night diving.

Informal instruction in hyperbaric medicine was offered throughout the project to the TEKTITE medical staff by Dr. Beckman as part of the medical program. This instruction was augmented by the practical experience of having to cope with the sequence of medical difficulties that arose in the habitat, during decompression, in base camp, and among the support divers. The medical staff was also given selected texts to read pertinent to diving theory and practice and to diving medicine.

\section{Mission-Connected Medical Experiences}

The TEKTITE II 50-ft missions were intended to validate the basic concepts and values upon which the decompression tables used in TEKTITE I had been calculated. The evidence offered by laboratory tests and the experience of the TEKTITE I aquanauts was statistically invalid because of the small number of subjects involved in each. The 50-ft missions were also intended to test the safety of the ascent-descent excursion limits established in the earlier program.

\section{Decompression sickness during excursion dives from the habitat:}

During the two-week training period preceding each dive, the aquanauts received instruction, as has been said, in saturation diving and in the limits of excursions from the habitat depth that were believed to be safe--descent to 100 feet of seawater (FSW) for a period of four hours on an air breathing mixture, and ascent to $25 \mathrm{FSW}$, also for a period of four hours on air.

The aquanauts were further instructed that, if both ascent and descent excursions were to be made during any 12-hour period, the ascent excursion should precede the descent excursion. Moreover, no descents were permitted from the habitat on the day that decompression to surface pressure was to begin.

The excursion limitations had been set after very limited testing (owing to the lack of sufficient funds) prior to TEKTITE I. The limits thus set were therefore not expected to prove safe for all subjects observing them.

During the course of the 11 TEKTITE II 50-ft missions, only three instances of bends symptoms occurred as a result of excursion diving, the first two of them in Mission 2-50. One of the latter subjects who had experienced a "hit" in excursion diving in TEKTITE I (which was not properly identified until prebriefing prior to Mission 2-50) followed the identical excursion pattern in TEKTITE II. He descended to 65 FSW for 30 minutes and then ascended to 25 FSW. Shortly after reaching the shallower depth, he experienced bends pain in the knee, the same one that had been affected in TEKTITE $I$. The pain remitted upon return to the habitat, but not as quickly as it had done the year before. (The only other difference between his TEKTITE I and II experiences 
in this regard was that, in the 1969 dive, the deep and sha1low excursions had been separated by a two-hour return to the habitat.)

A second subject in Mission 2-50 experienced bends pain in excursion diving. In this instance, the subject made a two-hour-long excursion to $55 \mathrm{FSW}$, followed by a further descent to $65 \mathrm{FSW}$ lasting a half hour. He then ascended to $25 \mathrm{FSW}$ and noted pain in his right ankle, which resolved upon his return to the habitat.

In the possible third instance of bends, in Mission 12-50, the subject reported vague joint pains, which persisted for two days, following a dive to $75 \mathrm{FSW}$. However, doubt that this was a genuine case of bends arises from the fact that the subject simultaneously had symptoms of a viral infection; this infection may well have been the source of his joint pains.

Bends symptoms during decompression procedures:

The decompression schedule used in the first two missions of TEKTITE II (Appendix A) was the same one used in the TEKTITE I decompression. Two of the Mission 2-50 aquanauts who had also served in TEKTITE $I$, as well as a third scientist, reported the same bends symptomatology that they had experienced in the earlier project: mild, fleeting joint pains immediately following ascent to the various pressure stops up to $20 \mathrm{FSW}$, which disappeared during the stop itself and were gone when the subjects reached surface pressure.

This experience suggested that the decompression table was inadequate as structured for the greater depths. Therefore, it was proposed to the Medical Advisory Board, and approved by it, that two half-hour periods of oxygen breathing be added at 30 and $25 \mathrm{FSW}$, plus the two five-minute "ascent" periods to the next stop.

From Mission 3-50 onward, the teams were decompressed according to the revised table (see Appendix B). Five subjects noted mild, fleeting pains (all recorded retrospectively on a questionnaire sent to the aquanauts in early 1971). In addition, the same subject who had had a viral infection and had experienced joint pains on an excursion dive noted similar pains for two hours at the 10-FSW stop. There was only one case of dysbarism during decompression recorded at the time.

This subject experienced a mild, persistent pain in her right elbow at the 20-FSW stop and again at the 15-FSW stop. In each instance the pain was relieved by oxygen breathing, and did not recur. Within a half hour of reaching surface pressure, however, this subject experienced a mild pain in her right knee. The pain in the knee, of Grade 1 severity, was continuous and was accentuated by standing or weight-bearing. Therapy should logically have taken the form of recompression in the chamber; but the environmental control system had failed during decompression, and the temperature in the chamber had risen to a mark over $100^{\circ} \mathrm{F}$. An attempt was therefore made to relieve the symptoms with oxygen inhalation at surface pressure. This procedure relieved the symptoms to a degree, and the pain became intermittent rather than persistent. Inasmuch as the pain persisted for two hours, another period of oxygen inhalation was introduced for an additional 45 minutes, with the result of complete relief of symptoms, of which there was no recurrence. As has been mentioned, X-ray examination made some three months later revealed no residual effect of this attach of dysbarism. 
In a11, 48 decompressions were carried out according to the modified decompression schedule. The occurrence of pains in one subject represents an incidence of $2 \%$, which is considerably above the incidence of $0.5 \%$ experienced with use of the U.S. Navy Standard Air Decompression Tables. This finding was unexpected and may, of course, be attributable to the difference in decompression susceptibility between males and females. However, the subject was trim of figure and a diver of considerable experience, rendering her less liable to dysbarism, one would have thought, than a more obese, less experienced person.

Furthermore, the decompression tables had been developed on the assumption that the pressure in the habitat would be $42 \mathrm{FSW}$ with a water depth of $49 \mathrm{FSW}$ (although the depth was commonly referred to as $50 \mathrm{ft}$ ). But the actual pressure in the habitat was found to vary $\pm 0.5 \mathrm{ft}$ from $40 \mathrm{FSW}$, with a mean value of approximately $40 \mathrm{FSW}$. The subjects were therefore saturated at an even smaller pressure than the one calculated for in the laboratory tests, which should have made dysbarism even less of a threat. That it occurred in TEKTITE II is but further demonstration of how poorly understood are the physiological effects of saturation diving.

\section{Bubble formation in the eye during decompression:}

A refractile body had been observed in the eyd of a TEKTITE I aquanaut (although never confirmed as a bubble). In the TEKTITE II program, therefore, the possibility of bubble formation during decompression was taken into ful1 account, and arrangements were made for a postdive ophthalmologic examination by a physician qualified by the American Board of Ophthalmology.

In the postdive examination following the decompression of Mission 1-50, smal1 refractile bodies were observed in the vitreous media of both eyes of one aquanaut. More refractile bodies were noted in the left eye than in the right. The subject had been aware of no alteration in his vision, and his pre- and postdive visual-acuity tests revealed no change.

The refractile bodies decreased in number with the passage of time, but were still visualized by $\mathrm{Dr}$. Masson 16 hours after decompression. An examination was made 20 hours postdecompression by an ophthalmologist, who perceived the bodies but was of the opinion that such bodies are not infrequently found in the nonpathological visual media. It should be noted, furthermore, that this subject had suffered a severe attack of iritis and uveitis in the left eye approximately six months before the dive and that the conditions had not resolved completely before the dive. The relationship between them and the disease process can only be a matter of conjecture.

Commencing with Mission 2-50, ophthalmologic observation was extended to include an ophthalmoscopic examination by $\mathrm{Dr}$. Masson at each 5-FSW decrement during decompression and an examination at Knud-Hansen Hospital two hours later failed to confirm these observations.

From Mission 3-50 onward, the decompression procedure was changed, and no further refractile bodies were detected, either by direct ophthalmoscopy or slit-lamp study. It might be mentioned that there was no correlation between the observed refractile bodies and complaints of vague, transient joint pains during decompression. 
The hazards of decompression are, quite naturally, the primary concern in any medical program attendant upon saturation diving. But there are other physical difficulties, as well, peculiar to living and working in the water under hyperbaric pressure. These were taken into account in planning the medical surveillance and compiling the drug formulary used during the program, and it is a matter of much gratification to the medical staff that no significant medical problems arose during the course of any of the 11 missions, nor were there any injuries.

As was predictable, skin lesions and infections, external otitis, and difficulty in equilibrating pressure within the ears to water pressure ("clearing the ears," as it is commonly referred to) were the disorders most frequently encountered during the entire project. However, of the 915 man days represented by the 11 missions, only 13 days in the water were lost outright because of medical reasons, and the record was almost as impressive among those subjects who, for reasons of health, curtailed thier excursion activities.

\section{Diving time 1ost}

Bilateral ear pain (ear "squeeze") - 3 days

Externa1 otitis - 2 days

Sinusitis - 2 days

Abrasions (from diving) and edema (sea urchins) - 2 days

Abdominal cramping and diarrhea - 1 day

Flu-like illness - 1 day

\section{Diving time curtailed}

One subject limited his excursions from the habitat during the entire mission because of subjective feelings of fatigue.

One subject limited scuba diving for 5 days because of a subjective sensation of "chest congestion."

One subject limited ascent excursions after the second day of his mission because of ear "squeeze."

Several engineers were disinclined to spend much time in the water, and indeed none of their duties required that they do so. One engineer, who had suffered an anxiety attack prior to the mission, spent possibly the least time in the water of the entire cadre of aquanauts. 
Topical antibiotic treatment of wounds was found to be relatively successful. Nevertheless, it is our opinion that a major contributing factor in the slow healing of some wounds was the skin's remaining moist too much of the time, a condition that could have been remedied if more careful attention had been paid to thorough drying of the wounds once the aquanauts were out of the water, and early thorough cleansing of cuts and scrapes with germicidal soap. It would also have been helpful in the management of nonhealing lesions if the psychology program had allowed for the watch physician to enter the habitat and have a firsthand look at them.

The otic solution recommended for use during the missions proved to be an effective preventive for those who used it as instructed. Of the 53 subjects, 34 used the otic solution regularly, as directed; only 3 , or $8.8 \%$, developed symptoms of otitis externa. Of the 17 subjects who elected not to use the solution daily, 11 , or $65 \%$, developed otitis externa, whereas 6 of them remained asymptomatic. (Two aquanauts did not qualify as users or nonusers, according to our criteria.) The subject who lost two days in the water because of external otitis had used the ear solution as directed.

Difficulty in clearing the ears was a curiously common experience in the TEKTITE II missions. A1though there is no immediate explanation of the frequency of its occurrence, 12 of the 53 aquanauts, or $23 \%$, were thus affected, including three cases of clinically significant ear "squeeze."

Of 58 decompressions, there were 22 incidents (35\%) of oxygen toxicity--that is, pleuritic substernal chest pain. The pain was worse when the subjects were breathing pure oxygen.

\section{Base-Camp Medica1 Experiences}

\section{Injuries, infections, and illnesses:}

A11 injuries of any significance in TEKTITE II were sustained by support personnel. The three injuries that were serious enough to cause loss of work time were: severe lacerations and compound fractures of the hand of a student (off duty); contusions of the thigh of another student, caused by a fall from a motorcycle; disc damage suffered by a safety engineer, which necessitated his transfer to the mainland for surgery. The other injuries sustained by support personnel were minor, and many were related to the injudicious use of motorbikes on the St. John terrain, which is hilly, rocky, and heavily thicketed.

Oozing sap from indigenous plants, such as the manchineel tree and the mango tree, caused mild to severe contact dermatitis in many personnel, sometimes amounting to the equivalent of second-degree burns. Sea urchins, fire coral, and jellyfish all caused the expected number of irritations and inflammatory reactions among the support teams, as well as among the aquanauts themselves.

Insect bites--primarily from mosquitoes and the ubiquitous sand flies-contributed their share of misery to those living and working on St. John. It was not unusual for personnel to leave base camp looking as if their legs had been peppered with birdshot. 
Until efforts to establish even minimum sanitary conditions in base camp were successful--regretfully, five months into the program--there were usually a few cases of dysentery each day. We were just fortunate that they were mild.

\section{$\underline{\text { Parasites: }}$}

Because of the logistic obstacles involved, routine screening for parasites was restricted to kitchen personnel (all reeults negative). Given the conditions in base camp, it is surprising that a greater number of parasitic infestations did not manifest themselves. Four persons did present symptoms, however, which were diagnosed as the following:

1. Hookwork (Necator americanus); two cases

2. Amebiasis (Entamoeba histolytica) (probably contracted on the mainland); one case

3. Tapework (Taenia saginata) (probably contracted in Germany); one case

4. Giardiasis (Giardia lamblia); one case

A11 cases were successfully treated.

\section{Problems of sanitation and hygiene:}

The struggle against infectious disease in base camp was magnified unnecessarily by general conditions in the base camp. For example, the septic tanks were positioned a mere 10 feet behind the kitchen. The sewage system having been designed for fewer people was wholly inadequate for the 70 or 80 people who occupied the camp in its heyday.

Potable water had to be hauled by truck to the base camp, a task rendered impossible when the rains came (which they did in prodigious amounts, throughout the project). The water supply was otherwise dependent upon the cooperation of the ADVANCE II. Clorox bleach, in quantities to maintain a residual of $0.2 \mathrm{ppm}$ of free chlorine, was added daily to the drinking water. But because the water supply was stored in steel tanks that were not rust-proofed internally, it was difficult to retain the chlorine residual. And the water's palatability was poor.

Because of the National Park Service regulations concerning the use of pesticides, the control of flies in the kitchen and mess hall remained totally ineffective for most of the program. So also was the control of mosquitoes and sand flies in and about the shower and toilet areas, where they multiplied with almost unrestricted abandon. The permissable insecticides protected not on $1 y$ the ecology in general but also the insects.

The kitchen was inadequate with respect to storage and preparation of food and the washing of dishes. Subsequent improvements provided by the Department of the Interior remedied some of the problems. 
The USPHS doctors serving in the TEKTITE program were assigned by the Program Manager the responsibility for ensuring basic health standards in base camp, but were not able to enforce their recommendations for improving the conditions they found there because of conflicting regulations.

\section{Medical Experiences Not Directly Related to the Missions or Base Camp}

Sanitation aboard the support ship UNDAUNTED was of particular concern when the Minitat medical officer assumed medical supervision of the 100 -foot operations in June of 1970. Dysentery had been a problem, affecting nearly one-third of the crew. This situation was rectified once the water aboard the ship, supplied from St. Thomas, was properly chlorinated.

Of more than passing interest in the TEKTITE experience was a malady of which many of us had heard but few had had any firsthand acquaintance. It is ciguatera poisoning, caused by a toxin generated in the reef-habitat food chain and ingested by certain of the indigenous fish population.

It is not known why some waters contain toxin-bearing fish whereas others do not, or why some fish (even of the same species) carry the toxin and others do not. But one of the most notorious sites of ciguatera poisoning is in the waters very near Lameshur Bay. It was here that the captain and four crewmen from the ADVANCE II caught an eight-pound dog snapper (Lutjanus jocu) on October 13, 1970, which they cooked for supper. All five developed classic symptoms of ciguatera poisoning: vomiting and loose bowels, long-term severe itching, muscular weakness, lack of energy, and in one man, violent muscle spasms. The captain was hospitalized for one week. The symptoms in all victims gradually subsided in intensity with the passage of several weeks' time.

Additiona11y, the wife of an employee of the Virgin Islands Ecological Research Station, following ingestion of a large grouper in midsummer, exhibited neurologic dysfunction, which required several months to resolve. Several others developed gastrointestinal symptoms following the same meal.

William Brownell and Willard Rainey, also of the Research Station, ate one of three silky snappers (Lutjanus vivanus Cuvier) caught near Lameshur Bay; the other fish were eaten by two other groups of people. Only Brownell and Rainey became ill. They were $i l 1$ for three days, but did not require hospitalization. (It might be mentioned that Mr. Brownell and the Medical Director were nonbelievers in ciguatera poisoning until this occurrence, thinking that most alleged cases were simply the result of local fishermen having mishandled their catch under the hot Caribbean sun.)

The research staff of the Caribbean Research Institute is presently conducting a study of ciguatera poisoning in the Virgin Islands to complement the work being done by the National Marine Fisheries Service. Studies at the University of Hawaii are also attempting to solve the mystery of this toxin.

\section{DECOMPRESS ION TABLE DEVELOPMENT}

\section{Background}

The proposed Minitat missions were, of course, unique in the history of saturation diving. Not only were there no available data on nitrogen saturation 
at $100 \mathrm{ft} .$, but also the effects of high $\mathrm{N}_{2}$ partial pressures in the production of nitrogen narcosis at that depth were unknown. Both standard and emergency decompression schedules for these missions, as well as ascent-descent excursion limits, were accordingly devised after a limited amount of experimentation at the J\&J Marine Diving Co. under the supervision of Mr. Peter Ede1, (Pasadena, Tex.). It remained, however, for the actual opensea Minitat dives to prove the validity of the tables, and the 100-ft missions were consequently of crucial interest in the medical program.

Any undersea experiment involving prolonged hyberbaric exposure requires the careful planning of decompression tables, both standard and emergency, that are safe with respect to life and health, yet efficient with respect to time.

Helium-oxygen mixtures had been used in earlier experimentation in saturation diving (notably Sealab I and II) at the same depth, or greater, as that of the proposed 100-FSW Minitat habitat. Helium's assets lie in its lightness and its minimal adverse effect on the human body. But He presents some unique problems that render its use impractical for protracted pressure exposures. It is very expensive; it is scarce in some areas, and is difficult to handle; body heat is difficult to maintain in a helium-saturated atmosphere; and He distorts speech, making vocal communications awkward--an important consideration in the circumstance of men living in cramped, isolated quarters.

The choice of nitrogen, then, as the inert-gas diluent in saturation diving becomes an attractive and logical one, because it is a simple, inexpensive gas, readily available, and physiologically normal. The experience of TEKTITE I demonstrated that at reasonably shallow depths--i.e., less than $50 \mathrm{FSW}--\mathrm{N}_{2}$ can be safely used in prolonged hyperbaric exposures, and that it will not interfere with work capability. It therefore became a primary goal of the Minitat missions to prove that marine scientists can effectively and efficiently carry out prolonged undersea research while living and working at $100 \mathrm{FSW}$ in a habitat with a $94.8 \% \mathrm{~N}_{2}-5.2 \% \mathrm{O}_{2}$ breathing mixture.

\section{Saturation Diving and Decompression Sickness}

When a diver remains for a given length of time at depth, of necessity he breathes gas compressed to the pressure of the seawater around him in order to inflate his lungs against the seawater pressure. Eventually--within 72 to 120 hours--the partial pressure of the inert gas (PI) in his tissues becomes equilibrated or saturated to the higher molecular pressure of the same gas in his breathing mixture; hence the term saturation diving.

When the PI in the diver's tissues has reached certain maximum levels, he cannot then ascend directly to surface pressure without incurring the risk of decompression sickness or dysbarism. The symptoms relate primarily to the respiratory, integumental, musculoskeletal, and central nervous systems. Severity of such attacks quite naturally vary, depending on such circumstances as the depth from which decompression has occurred and its rapidity, the gas mixture used at depth and during decompression, and the individual's particular or situational susceptibility. And the variance is wide--from vague, transitory "niggles" in the joints to coma and death. 
The first consideration in calculating decompression tables is that, when a diver ascends from depth, the PI in his tissues not exceed a certain value above that of the ambient pressure. It is genera11y accepted that the ratio between the inert gas in the tissues and in the ambient pressure, called the supersaturation ratio, should not exceed $1.5 / 1$ in the slowest tissue on surfacing (defined hereafter). It might be mentioned that oxygen partial pressure in the tissues is believed not to be a consideration in decompression, since $\mathrm{O}_{2}$ is, in general, so rapidly utilized in tissue metabolism that inert-gas bubble formation is not appreciably affected by it.

The second factor of vital concern in decompression-table computation is the rate at which the various bodily tissues become saturated with and eliminate inert gases. These rates are generally accepted as being exponential, and are typically described in terms of half-saturation time or tissue half-time--that is, the interval required for a tissue to respond to a change in the PI of the inspired breathing mixture by saturating (or desaturating) to half the gradient formed between the gas in the tissue and in the breathing mixture.

The slowest tissue--the one requiring the longest time to saturate or desaturate--is the controlling one in any decompression procedure in saturation diving. Except for blood, however, the half-times of specific human tissues $\left(\mathrm{T}_{\frac{1}{2}}\right)$ are, unfortunately, not known. The inherent difficulty in making accurate determinations is that tissue samples cannot easily be analyzed for gas uptake and elimination, although certain animal studies have suggested $\mathrm{T}^{\frac{1}{2}}$ for analagous human tissues.

Diving-table calculations are therefore predicated on an assumed value (in minutes) for the slowest $\mathrm{T}_{\frac{1}{2}}$ and on the amount of excess PI--supersaturation-which that tissue can withstand at all increments during the decompression procedure.

Decompression can be accomplished in two manners. The first is incremental, through a series of "stops" at various pressures, which are calculated to raise the slowest tissue's supersaturation ratio to its maximum safe value at each stop. The duration of each stop is calculated so that a safe PI is reached before "ascent" to the next stop and the reestablishment of another maximum supersaturation ratio. Or, alternately, decompression can be carried out at a continuous rate of ascent, so that maximum safe tissue supersaturation is never exceeded at any time.

Empirical data have confirmed that the degree of supersaturation that tissues can withstand varies with depth. Greater pressure changes are better tolerated at deep stops than at shallow ones. Furthermore, breathing $100 \%$ oxygen increases the rate of inert-gas elimination and, therefore, the safe rate of ascent; hence it decreases decompression time.

The calculation of wholly adequate decompression tables in saturation diving is hampered by lack of accurate values for the slowest tissue half-time. As an example of the inadequacy of existing data, the table that was initially calculated and tested for use in the TEKTITE I 50-ft (so-called) mission 
assumed a 240-min controlling tissue. It involved step decompression over a 13-hr period and a normoxic $\mathrm{N}_{2}-\mathrm{O}_{2}$ mixture. This table had to be abandoned, however, as both test subjects suffered an attack of bends in the first chamber run. In the second test, air was used rather than the $\mathrm{N}_{2}-\mathrm{O}_{2}$ mixture, but once more both subjects were "hit."

The table was then recalculated based upon a 460-min $\mathrm{T}_{\frac{1}{2}}$, which extended the decompression period to $15 \mathrm{hr}$. But the test results of this schedule were unsatisfactory. The decompression table was recalculated, this time based on a $\mathrm{T}_{\frac{1}{2}}$ of $500 \mathrm{~min}$, which extended decompression to $19 \mathrm{hr}, 20 \mathrm{~min}$; once more the results of testing were unsatisfactory. Periods of $\mathrm{O}_{2}$ breathing $(4 \mathrm{hr}, 25 \mathrm{~min}$ ) were then substituted for air-breathing periods, and the tests were finally deemed satisfactory and the table adopted for use in TEKTITE I.

Since decompression following TEKTITE I appeared to be uneventful, the same decompression table was accepted for use in the TEKTITE II 50-ft missions. But because of the evidence of dysbarism described in "Medical Program," this volume, the table was altered to include 70 minutes of additiona $1 \mathrm{O}_{2}$ breathing, although the entire schedule was increased only by $60 \mathrm{~min}$ (see Appendices A and $B$ ).

If the results of decompressing the aquanauts in TEKTITE II were to be used as a basis for calculation, the ultimate table for decompression from a habitat pressure of $40 \mathrm{FSW}$ (the actual habitat pressure) would be based on a slowest $\mathrm{T}_{\frac{1}{2}}$ of we11 over 1000 minutes!

\section{Decompression From 100 FSW}

The calculation and testing of decompression tables to be used in bringing the TEKTITE II Minitat aquanauts safely back to surface from their habitat pressure of 100 FSW presented a new challenge in saturation diving. A normoxic breathing mixture was planned for these missions: an oxygen partial pressure of $160 \mathrm{~mm} \mathrm{Hg}$ with a nitrogen diluent. Each mission was to last 14 days, meaning that the aquanauts' bodily tissues would become saturated with the nitrogen partia1 pressure of their breathing mixture.

The Marine Biomedical Institute of the University of Texas Medical School (Galveston) undertook the preliminary development of the 100-FSW decompression tables through a contract with the J\&J Marine Diving Co., Pasadena, Tex. Peter Edel of that organization (who had developed the emergency tables for TEKTITE I) calculated the first table for the 100-FSW dives using a $T_{1}$ of 360 min and Workman M-values. The result was a decompression schedule of 30 -ȟr duration.

In Test No. 1 it was decided, because of limited funds, not only to test the proposed decompression tables but also the calculated maximum safe descent excursion, to $175 \mathrm{FSW}$. An accelerated saturation (which began $15 \mathrm{Dec}$ 1969) of two subjects to the Minitat $\mathrm{PN}_{2}$ was accomplished by first exposing them to $137-\mathrm{FSW}$ pressure for $12 \mathrm{hr}$ in a $95 \% \mathrm{~N}_{2}-5 \% \mathrm{O}_{2}$ breathing mixture (a technique developed by Edel for the TEKTITE I tests). After saturation, the subjects were compressed to $175 \mathrm{FSW}$ for $6 \mathrm{hr}$, where they breathed air; they were then rapidly decompressed--within 3 min--to $100 \mathrm{FSW}$, at which pressure they remained for $16 \mathrm{hr}$. Both subjects remained asymptomatic. One of them, however, developed bends symptoms ( $\mathrm{L}$ knee) during decompression to surface pressure, at $50 \mathrm{FSW}$, and required recompression therapy. 
Test No. 2 was designed to determine if this attack of dysbarism might conceivably have been caused by decompression from the simulated excursion to $175 \mathrm{FSW}$, rather than from the 100-FSW habitat depth. The first test procedure was repeated, but without the simulated excursion. Test No. 2 involved the subject who had developed bends in Test No. 1, plus a second diver. The same 30 -hr table was used. Once again, the first subject developed bends during decompression, this time at $40 \mathrm{FSW}$, and both subjects had to be recompressed.

The second subject of Test No. 2 experienced an episode of apparent hypoxia during the saturation exposure at $100 \mathrm{FSW}$. His symptoms were relieved by increasing the $\mathrm{O}_{2}$ percentage to $7 \%$, thus making the breathing atmosphere $93 \% \mathrm{~N}_{2}$ and $7 \% \mathrm{O}_{2}$. The $\mathrm{PN}_{2}$ was maintained by increasing the habitat pressure to 103 FSW. Edel continued to use the 103-FSW pressure and the higher $\mathrm{PO}_{2}$ percentage in the remainder of the preliminary Minitat tests although, indeed, subsequent laboratory evaluation demonstrated later that the second subject of Test No. 2 had an abnormal hypoxic respiratory response.

The Department of Interior funded J\&a directly for continued development of a decompression table. Because of the dysbarism experienced in Tests No. 1 and 2 , the table was recalculated. The result was a $36-\mathrm{hr}$ decompression schedule that included breathing $\mathrm{O}_{2}$ for $6 \mathrm{hr}, 15 \mathrm{~min}$, to be divided among 12 stops commencing at 60 FSW.

Two tests, No. 3 and 4 , of this revised table (each involving two subjects) were uneventful during decompression itself. But in both tests the subjects developed significant signs of substernal distress and pulmonary inflammation once they reached surface pressure.

Calculations at the Institute of Environmental Medicine, University of Pennsylvania, indicated that the $\mathrm{O}_{2}$ toxicity caused by this last decompression schedule would result in an $8 \%$ decrement in vital capacity (VC). The Medical Advisory Board considered this decrement excessive. It therefore decreed that a modification of the table used in Tests No. 3 and 4 should be made, ultimately recommending that the decompression period should be extended to $50 \mathrm{hr}$, and that it include two 360-min stops. (Such prolonged stops had been found necessary by USN medical officers during development of decompression schedules for use in SeaLab III.)

The proposed new table was adjusted by computer computation at the UP, based on a maximum $\mathrm{T}_{\frac{1}{2}}$ of $500 \mathrm{~min}$ and a Workman M-value of $49 \mathrm{FSW}$. A 49-hr, 20-min table resulted, in which little $\mathrm{O}_{2}$ breathing (170 min) was involved, and in which the toxic liabilities of $\mathrm{O}_{2}$ were predicted to cause less than a $2 \%$ decrement in VC.

This decompression schedule was then tested at $J \delta_{w} J$ Marine Diving Co. in two runs (Tests No. 5 and 6 ), each involving two subjects, following a pressure exposure in which the previously described accelerated saturation technique was used. Al1 subjects remained asymptomatic of decompression sickness and oxygen toxicity.

Ascent and Descent Excursion Limitations From 100 FSW

The research program designed to develop decompression tables for the 100-FSW dives included, as well, calculation and testing of the maximum safe descent and ascent excursions from the habitat emplacement depth. The participants in 
the Minitat program were expected to use a closed-circuit rebreather system-specifically, General Electric's MK-10-MOD-3 Underwater Breathing System, which permits long excursions ( 4 to $6 \mathrm{hr}$ ) to depths in excess of $1000 \mathrm{FSW}$

Test No. 1 of the Minitat series had yielded evidence suggesting that safe ascent to 100 FSW might be made following a 6-hr excursion to 175 FSW when an air equivalent is breathed. There was, however, no available data on the depth to which the Minitat aquanauts might safely ascend on their sorties from the habitat. From a scientific point of view, Test No. 7--the final test that was (and could be) funded--should logically have been a repetition of Tests No. 5 and 6 . But the critical need for data on ascent-excursion limitations from 100 FSW forced a modification of the final dive profile to include an ascent simulation.

Computer computation on allowable excursion limits had suggested that a 6-hr ascent to $70 \mathrm{FSW}$ would be safe. Test No. 7 of this series was accordingly modified to include such an exposure. After saturation, Subject A entered the outer lock of the chamber, which was decompressed to $70 \mathrm{FSW}$; he exercised over a 4-hr period by lifting a 40-1b weight $1.5 \mathrm{ft} 800$ times. He then rested for $4 \mathrm{hr}$ at $70 \mathrm{FSW}$, breathing $90 \% \mathrm{~N}_{2}$ and $10 \% \mathrm{O}_{2}$. In the meantime the inner lock of the chamber had also been decompressed to $70 \mathrm{FSW}$. While Subject A rested, Subject B--breathing the same mixture-duplicated the former's workload. Subject $B$ did not have a rest period, meaning that he was at $70 \mathrm{FSW}$ for only $4 \mathrm{hr}$ whereas Subject B was there for $8 \mathrm{hr}$. They were both again recompressed to $103 \mathrm{FSW}$, at which pressure they remained for $20 \mathrm{hr}$; they were then decompressed to surface pressure, without incident, according to the 49-hr, 20-min schedule.

The satisfactory completion of Test No. 7 provided a decompression schedule that could be used in the 14-day chamber experimentation scheduled by the University of Pennsylvania to evaluate the pulmonary, hematopoietic, and central nervous system effects of prolonged exposure to an atmosphere of such nitrogen density as that proposed for the Minitat. The results of that experimentation are reported separately. Suffice to say that the six subjects were safely decompressed according to the 49-hr, 20-min table--meaning that, in a11, the table had been tested and proven satisfactory with 12 subjects. The decompression table as approved for the 100-FSW Minitat missions is shown in Appendix $C$.

Although funding limitations precluded the testing of more than two subjects in a simulated descent and two in a simulated ascent excursion, the Medical Board accepted the following restrictions in the Minitat excursions:

1. Descent to $175 \mathrm{FSW}$ on air for $4 \mathrm{hr}$, with direct ascent to the habitat

2. Ascent to $75 \mathrm{FSW}$ for $4 \mathrm{hr}$, either breathing air or a mixture containing no less than $10 \% \mathrm{O}_{2}$

3. An obligatory $12-$ hr interval between any descent excursion and an ascent excursion to $75 \mathrm{FSW}$ 
Accidental surfacing is one of the most serious problems in saturation diving. Prior to the 50-ft TEKTITE II missions (in which the aquanauts were actually saturated at $40 \mathrm{FSW}$ in a $91 \% \mathrm{~N}_{2}-9 \% \mathrm{O}_{2}$ atmosphere), calculations that were supported by experimental data suggested that accidental surfacing might not pose a significant threat if it lasted no longer than $15 \mathrm{~min}$. No such period of grace could be expected in the $100 \mathrm{FSW}$ missions, however.

Lack of funds prohibited experimentation to establish an emergency treatment program in the event of accidental surfacing from $100 \mathrm{FSW}$, as had been done for the 50-ft missions. It was therefore necessary arbitrarily to develop a program for handling any such emergencies, based on past diving experience and extrapolations from them.

The counsel and guidance of the Medical Advisory Board was then sought, as well as of others with experience in the field of diving physiology. The problem was carefully examined in committee. The consensus was that, if the surface interval lasted no longer than $3 \mathrm{~min}$, the subject might be repressurized and treated before the onset of acute CNS symptomatology, and ultimate death, would transpire. On the basis of this consensus, the accidental-surfacing treatment schedule shown in Appendix D was adopted.

A more complete report of the Medical Support Program and the development of the decompression schedules calculated for use in TEKTITE II, for both the 50-ft and 100-ft missions, can be found in the Summary Medical Report prepared by the Marine Biomedical Institute, University of Texas Medical Branch (Galveston), for submission to the Sea Grant Program of the National Science Foundation. Also a detailed description of the $100 \mathrm{FSW}$ decompression study can be found in "Experiments to Determine Decompression Tables for the TEKTITE II 100-FSW Mission," Peter Edel, J and J Marine Diving Co., March 31, 1971.*

*This work was supported by the National Science Foundation, Grant Number GH79, under the title of Medical Aspects of Sustained Deep-sea Operations. 
Appendix A

REGULAR DECOMPRESSION SCHEDULE USED IN TEKTITE I

and following

MISSIONS 1-50 and 2-50, TEKTITE II

\begin{tabular}{lccc}
\hline $\begin{array}{c}\text { DEPTH } \\
\text { feet of } \\
\text { seawater) }\end{array}$ & $\begin{array}{c}\text { TIME SPENT AT } \\
\text { STOP } \\
\text { (Minutes) }\end{array}$ & $\begin{array}{c}\text { CUMULATIVE DECOMPRESSION } \\
\text { TIME } \\
\text { (Minutes) }\end{array}$ & $\begin{array}{c}\text { BREATHING } \\
\text { ATMOSPHERE }\end{array}$ \\
\hline 42 & & & \\
\hline "ascent" & 12 & 12 & Air \\
30 & 120 & 132 & Air \\
"ascent" & 5 & 137 & Air \\
25 & 200 & 337 & Air \\
"ascent" & 5 & 342 & Air \\
20 & 170 & 512 & Air \\
20 & 30 & 542 & Oxygen \\
"ascent" & 5 & 547 & Oxygen \\
15 & 20 & 567 & Air \\
15 & 30 & 597 & Oxygen \\
15 & 20 & 617 & Air \\
15 & 30 & 647 & A Air \\
15 & 20 & 667 & Oxygen \\
15 & 30 & 697 & Air \\
15 & 20 & 717 & Oxygen \\
15 & 30 & 747 & Oxygen \\
"ascent" & 5 & 752 & Air \\
10 & 60 & 812 & Oxygen \\
10 & 30 & 842 & Air \\
10 & 20 & 862 & Oxygen \\
10 & 30 & 892 & Air \\
10 & 20 & 912 & Oxygen \\
10 & 40 & 952 & Oxygen \\
"ascent" & 5 & 957 & Air \\
5 & 200 & 1157 & Air \\
"ascent" & 5 & 1162 & \\
Surface & & & \\
\hline & & & \\
\hline
\end{tabular}

Total decompression time: 1162 minutes, or $19 \mathrm{hr}$ and 22 min

Total 100\% oxygen inhalation: 265 minutes, or $4 \mathrm{hr}$ and $25 \mathrm{~min}$ 


\section{APPENDIX B}

MODIFIED REGULAR DECOMPRESSION SCHEDULE USED IN TEKTITE II

\begin{tabular}{|c|c|c|c|}
\hline $\begin{array}{l}\text { DEPTH } \\
\text { (feet of } \\
\text { seawater) }\end{array}$ & $\begin{array}{l}\text { TIME SPENT AT } \\
\text { STOP } \\
\text { (Minutes) }\end{array}$ & $\begin{array}{c}\text { CUMULATIVE DECOMPRESSION } \\
\text { TIME } \\
\text { (Minutes) }\end{array}$ & $\begin{array}{l}\text { BREATHING } \\
\text { ATMOSPHERE }\end{array}$ \\
\hline \multicolumn{4}{|l|}{42} \\
\hline "ascent" & 12 & 12 & Air \\
\hline 30 & 120 & 132 & Air \\
\hline 30 & 30 & 162 & Oxygen \\
\hline "ascent" & 5 & 167 & Oxygen \\
\hline 25 & 200 & 367 & Air \\
\hline 25 & 30 & 397 & Oxygen \\
\hline "ascent" & 5 & 402 & Oxygen \\
\hline 20 & 170 & 572 & Air \\
\hline 20 & 30 & 602 & Oxygen \\
\hline "ascent" & 5 & 607 & Oxygen \\
\hline 15 & 20 & 627 & Air \\
\hline 15 & 30 & 657 & Oxygen \\
\hline 15 & 20 & 677 & Air \\
\hline 15 & 30 & 707 & Oxygen \\
\hline 15 & 20 & 727 & Air \\
\hline 15 & 30 & 757 & Oxygen \\
\hline 15 & 20 & 777 & Air \\
\hline 15 & 30 & 807 & Oxygen \\
\hline "ascent" & 5 & 812 & Oxygen \\
\hline 10 & 60 & 872 & Air \\
\hline 10 & 30 & 902 & Oxygen \\
\hline 10 & 20 & 922 & Air \\
\hline 10 & 30 & 952 & Oxygen \\
\hline 10 & 20 & 972 & Air \\
\hline 10 & 40 & 1012 & Oxygen \\
\hline "ascent" & 5 & 1017 & Oxygen \\
\hline 5 & 200 & 1217 & Air \\
\hline "ascent" & 5 & 1222 & Air \\
\hline SURFACE & & & \\
\hline
\end{tabular}

Total decompression time: 1222 minutes, or $20 \mathrm{hr}$ and $22 \mathrm{~min}$ Total 100\% oxygen inhalation: 335 minutes, or $5 \mathrm{hr}$ and $35 \mathrm{~min}$ 
APPENDIX $\mathrm{C}$

TEKTITE II 100-FSW (MINITAT) DECOMPRESSION SCHEDULE*

(As Approved by Medical Advisory Board)

\begin{tabular}{l} 
DEPTH \\
(FSW) \\
\hline
\end{tabular}

$103-90$

90

85

80

75

70

65

60

55

50

45

45

40

35

35

30

25

25

20

15

15

10

5

5
TIME AT STOP

(Minutes)

10

60

90

100

110

120

360

140

160

160

10

150

130

20

150

360

30

150

150

50

120

160

60

110
BREATHING

MIXTURE

Air

Air

Air

Air

Air

Air

Air

Air

Air

Air

Oxygen

Air

Air

oxygen

Air

Air

Oxygen

Air

Air

Oxygen

Air

Air

Oxygen

Air

Totals: Entire schedule, $49 \mathrm{hr}, 20 \mathrm{~min}$; oxygen breathing, $2 \mathrm{hr}, 50 \mathrm{~min}$

*Ascent rate between stops, I ft per min. Last 5 min of each stop used to ascend to next stop 
TREATMENT SCHEDULE FOR USE IN EMERGENCY OR ACCIDENTAL DECOMPRESSION FROM 100-FSW SATURATION

1. Recompress diver to $165 \mathrm{FSW}$ in the DDC immediately in an air breathing atmosphere.

2. If full recovery or stabilization occurs within $15 \mathrm{~min}$, proceed to step 5 herein.

3. If diver's condition does not stabilize or if it continues on a downhill course, further recompress him to $200 \mathrm{FSW}$ and change breathing mixture to $90 \% \mathrm{He}-10 \% \mathrm{O}_{2}$. If stabilization or recovery results from this procedure, proceed to step 5 .

4. If procedures of step 3 are unavailing in producing stabilization or recovery of the diver, further decompress him to $250 \mathrm{FSW}$ and maintain $90 \%$ He-10\% $\mathrm{O}_{2}$ breathing mixture.
5. Keep diver $24 \mathrm{hr}$ at whatever pressure the treatment halted or reversed symptoms. Adjust $\mathrm{O}_{2}$ percentage to normoxic value within $4 \mathrm{hr}$.

6. Decompress diver to $70 \mathrm{FSW}$ at the rate of $24 \mathrm{~min}$ per ft. Maintain the normoxic breathing mixture.

7. Follow regular 100-FSW decompression schedule from $70 \mathrm{FSW}$ to surface pressure. Switch to air breathing if diver was on $\mathrm{N}_{2}-\mathrm{O}_{2}$ previously. Otherwise he must remain on the normoxic $\mathrm{He}-\mathrm{O}_{2} \mathrm{mix}-$ ture interspersed with periods of breathing $100 \% \mathrm{O}_{2}$, as indicated in Appendix C. 


\author{
CHRONIC NITROGEN EXPOSURE STUDY \\ Christian J. Lambertsen, M.D. \\ Institute for Environmental Medicine \\ University of Pennsylvania, Philadelphia, $\mathrm{Pa}$.
}

\begin{abstract}
The study encompassed a series of interrelated physiologica1, hematological, chemical, and psychological studies carried out before, during, and after exposure of subjects for 14 days to an increased atmospheric density and increased inspired nitrogen pressure equivalent to 100 feet of sea water. Inspired oxygen was maintained at sea level pressure to avoid oxygen toxicity during the exposure.

Six subjects were used throughout the study in order to permit statistical treatment of most of the findings. No performance-limiting influences of the increased atmospheric density were found.
\end{abstract}

\title{
OBJECT IVES
}

1. To study the increased respiratory airway resistance produced by the four-fold increase in density of respired gas. At rest and in exercise this airway resistance should lead to an increase in work of breathing and, at some elevated ambient pressure, to a decrement in alveolar ventilation at work and even at rest. Such decrement, by interfering with uptake of oxygen from the lungs by the blood and elimination of carbon dioxide from the blood and lungs, should lead to hypoxia, elevation of arterial carbon dioxide tension, and decrease in motor and intellectual performance.

2. To study the narcotic influences of nitrogen.

3. To appraise the influence of ambient pressure and increased nitrogen partial pressure upon blood cellular constituents, body fluid volumes, and blood chemical composition.

\section{FACILITIES}

This program was carried out in the recently completed hyperbaric chamber complex at the Institute for Environmental Medicine of the University of Pennsylvania. A schematic of this facility is shown in Figure 1 . A functional schematic of the complex during the experimental period is shown in Figure 2 . 

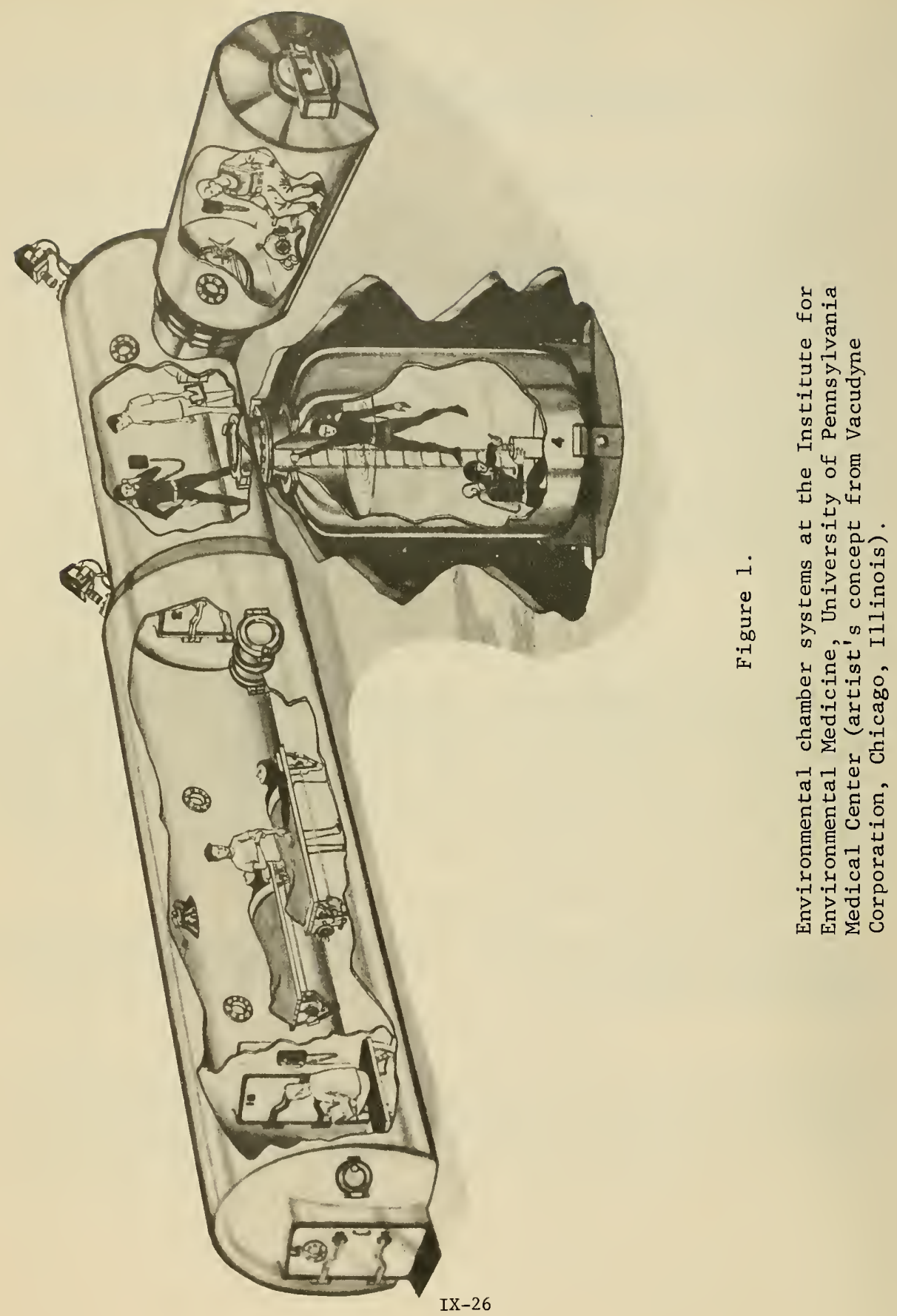

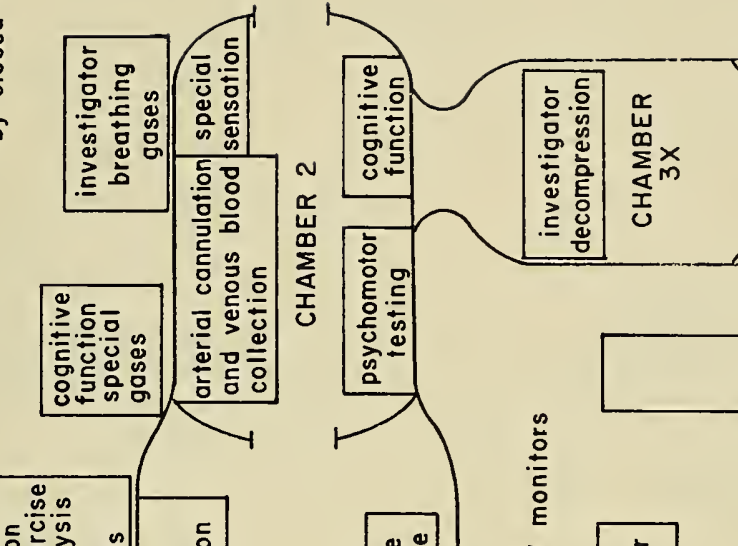

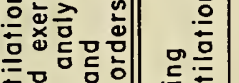

£

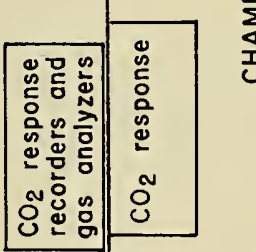

唄

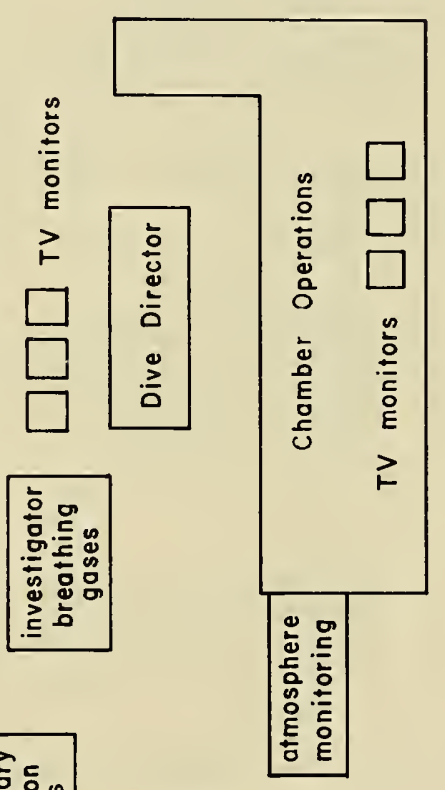



号

㫕

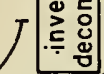
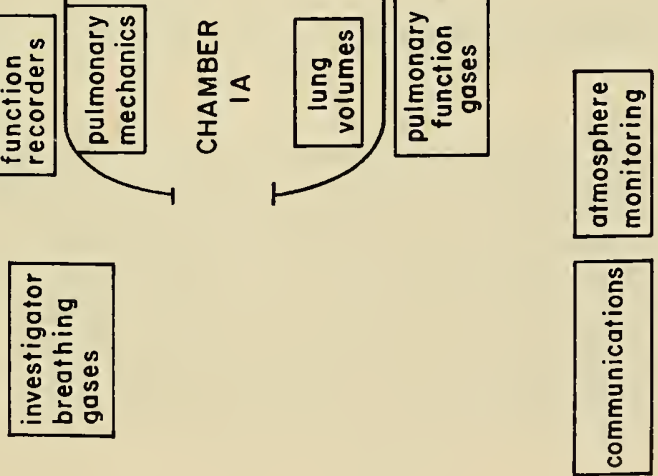
A. Decompression from $\mathrm{N}_{2}-\mathrm{O}_{2}$ Saturation Exposures

B. Decompression from Nonsaturation Exposures to Multiple Inert Gases Nitrogen Narcosis Studies

A. Cognitive Function Tests

1. Arithmetic Ability

2. Perceptual Speed

3. Inductive Reasoning

4. Spatial Orientation

5. Short-Term Memory
B. Taste and Olfactory Perception

C. Psychomotor Function

1. Information Processing and Response Latency

2. Short-Term Memory Response Latency

Pulmonary Function Studies

A. Lung Volumes

1. Vital Capacity

2. Inspiratory Capacity

3. Expiratory Reserve Volume

4. Functional Residual Capacity

5. Residual Volume

6. Total Lung Capacity

B. Lung Dynamics

1. Maximum Expiratory Flow Rate from 200 to $1200 \mathrm{cc} \mathrm{V}_{\mathrm{E}}$

2. Maximum Mid-Expiratory Flow Rate

3. Maximum Mid-Inspiratory Flow Rate

4. Percent of Vital Capacity Forcefully Expired in 1, 2, and 3 Seconds

5. Percent of Vital Capacity Forcefully Inspired in 1 Second

6. Maximum Voluntary Ventilation

C. Lung Mechanics

1. Pulmonary Resistance to Inspiration During Tidal Breathing

2. Flow Resistive Work of Ventilation During Tidal Breathing

3. Esophageal Pressures at Functional Residual Capacity

4. Esophageal Pressures at Total Lung Capacity

5. Pulmonary Resistance to Expiration During the Forced Vital Capacity Maneuver at $50 \%$ and $75 \%$ of Vital Capacity

6. Pulmonary Resistance to Inspiration During the Forced Vital Capacity Maneuver at $50 \%$ of Vital Capacity

7. Peak Flow Rates During the Expiratory and Inspiratory Cycles of the Forced Vital Capacity Maneuver 
C. Lung Mechanics (cont)

8. Inspiratory and Expiratory Flow Rates at $75 \%, 50 \%$, and $25 \%$ of Vital Capacity During the Forced Vital Capacity Maneuver

9. Dynamic Pulmonary Compliance During Tidal Breathing

10. Static Pulmonary Compliance

D. Lung Diffusion

1. Single Breath Diffusing Capacity of the Lung for Carbon Monoxide Ventilation and Respiration Studies

A. Ventilation

1. Minute Ventilation $\mathrm{V}_{\mathrm{E}}$ at Rest and Exercise

2. Tidal Volume $V_{T}$ at Rest and Exercise

3. Breathing Frequency at Rest and Exercise

4. Minute Ventilation as a function of $\mathrm{PCO}_{2}$ with Both $\mathrm{N}_{2}$ and He Used as Dilutent Gas with Subjects Resting Supine

5. End Tital $\mathrm{P}_{\mathrm{CO}_{2}}$ and $\mathrm{P}_{2}$ at Rest Only

B. Blood Gas and Acid Base Parameters Measured at Rest and During Exercise

1. $\mathrm{P}_{\mathrm{a}_{2}}$

2. $\mathrm{PaCO}_{2}$

3. $\mathrm{pH}$

4. Hemoglobin Concentration

5. Hemoglobin Oxygen Saturation

6. Base Excess

7. Buffer Base

C. Heart Rate and Body Temperature

1. Diving Exercise

Blood Cellular, Blood Chemistry, Fluid Volume, Immunological, and Endocrine Factors

A. Hematology and Isotopic Fluid Volume Studies

1. Hematocrit

2. Hemoglobin and Methemo-

$$
\text { globin }
$$

3. Red Cell Indices

4. Reticulocyte Count

5. White Cel1 Count

6. Differential Cell Count and Morphology
7. Photomicroscopy of Cells

8. Platelet Counts

9. Red Cell Mass ( ${ }^{51} \mathrm{Cr}$ tog)

10. Plasma Volume ( $125 \mathrm{I}$ - HSA)

11. Total Body Water $\left({ }^{2} \mathrm{H}\right.$ and $\left.{ }^{3} \mathrm{H}\right)$

12. Extracellular Volume $\left({ }^{35} \mathrm{~S}\right)$

13. Iron Turnover $\left({ }^{59} \mathrm{Fe}\right)$

14. Total Body Potassium Exchange $(42 \mathrm{~K})$ 
B. Immunological Studies

1. Total Serum Protein

2. Serum Electrophoresis

3. Immunoglobin Quantitation including $\mathrm{IgG}$, IgA, $\mathrm{Ig}_{\mathrm{g}}$, $B, A$ and $A_{2}$ Macroglob in

4. $\beta$ Lipoprotein

C. Blood Chemical Composition
5. Transferrin

6. Haptoglobin

7. Ceruloplasmin

8. C Reactive Protein

9. A Glycoprotein

10. $\chi_{1}$ Antitrypsin
1. Glucose
2. Cholesterol
3. SGOT
4. BUN
5. Uric Acid
6. Alkaline Phosphatase
7. Calcium
8. Magnesium
9. $\mathrm{PO}_{4}$

D. Endocrine and Urine Studies

10. Total Bilirubin
11. Creatinine
12. CPK
13. LDH
14. Serum Osmolarity
15. Sodium
16. Potassium
17. Chloride
18. Triglycerides
1. Blood Endocrines
a. Angiotensin-1
b. Cortisol
c. Triiodothyronine
d. Thryoxin

2. Urine Endocrinology

a. Cortiso 1

b. Epinephrine

c. Norepinephrine
3. 24 Hour Urine

a. Volume

b. Specific Gravity

c. Osmolarity

d. Sodium

e. Potassium

f. Ch1oride

g. Calcium

h. Magnesium

i. Phosphate

j. Uric Acid

$k$. Creatinine

\section{RESULTS}

Preliminary findings of the studies described are as follows:

\section{Airway Resistance}

While airway resistance and work of breathing were in fact elevated as predicted during residence in nitrogen-oxygen at 4 atmospheres, the degree of this respiratory stress was easily managed by all subjects, no gross change in pulmonary-blood gas exchange occurred in rest or in exercise, and the subjects were able to perform physical, psychomotor, and intellectual tasks well throughout the entire exposure period. Furthermore, no gross indication of progressive deterioration of physiological or psychomotor performance occurred during the exposure. 
General behavior and psychomotor studies showed an early influence of the narcotic atmosphere. However, by compensation, the subjects were easily able to sustain an alert and aggressive technical performance in their roles as subjects and assistant investigators. Quantitative measurement of the subjects' intellectual capabilities showed no gross difference from their high capability prior to pressurization.

Influences of Ambient Pressure on Blood Cells, Body Fluid Volumes, and B1ood Chemistry

Changes observed in the blood were largely related to shifts of fluid and not considered to be of toxicological or other pathological importance.

Detailed results related to lung function, $\mathrm{CO}_{2}$ sensitivity, arterial blood gases and acid-base changes are shown in Tables 1, 2, and 3 respectively.

\section{SUMMARY}

There appear to be no gross performance-limiting influences of the increased atmospheric density, pressure, and nitrogen partial pressure. The primary cautions are as follows:

The narcotic influence of nitrogen is expressed to different degrees in different individuals. The highly motivated, skilled, and intelligent subjects used in the laboratory study had, for physical, mental and physiological functions, such reserve and compensatory ability that their performance was superior even in the narcotic atmosphere. Other individuals are obviously more affected and would be endangered by exposure to severe physical stress in diving or by a requirement for use of fine judgment or a high order of technical skill. The dangers for such individuals would lie largely in work in the water outside the habitat. 


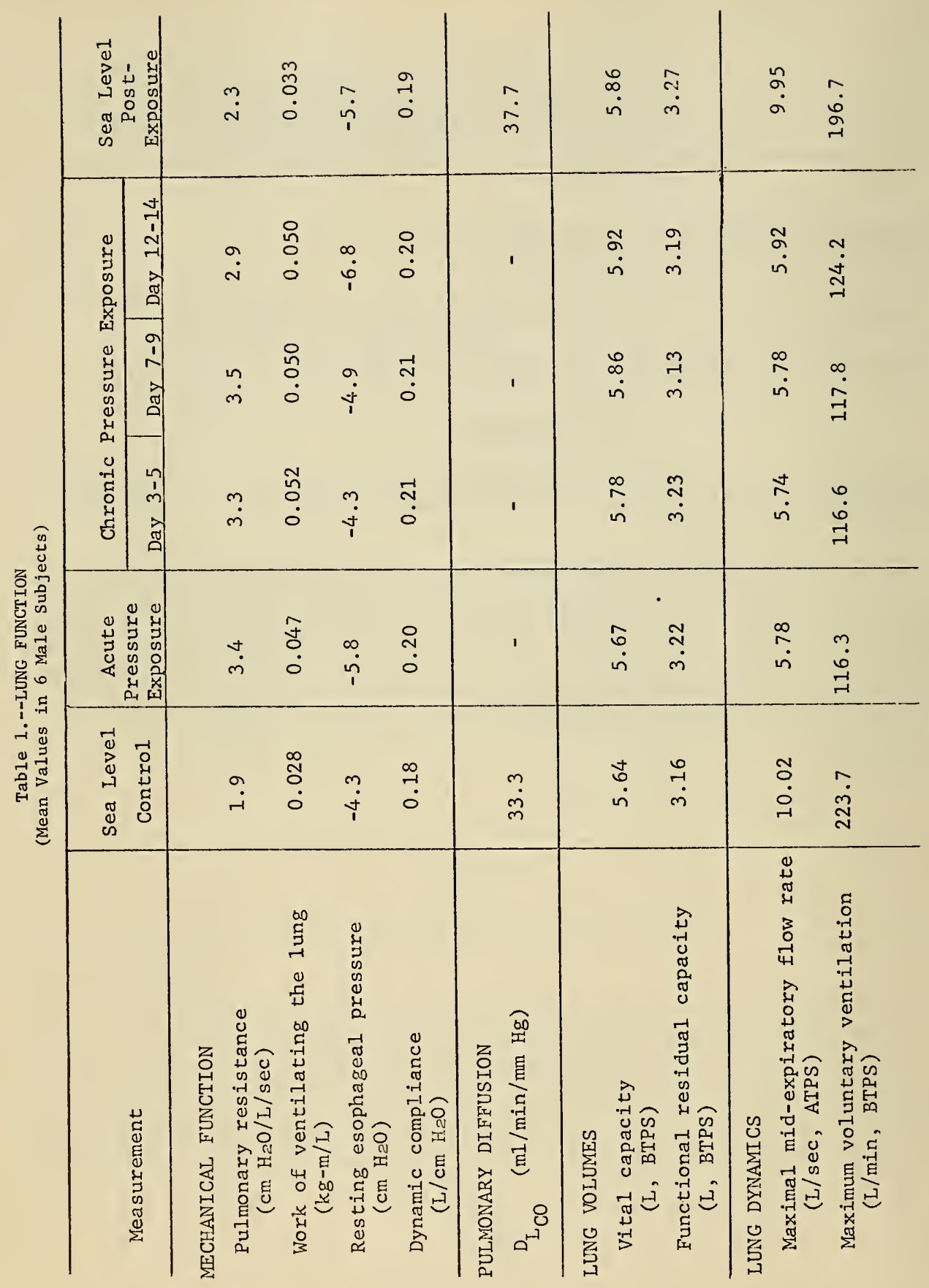




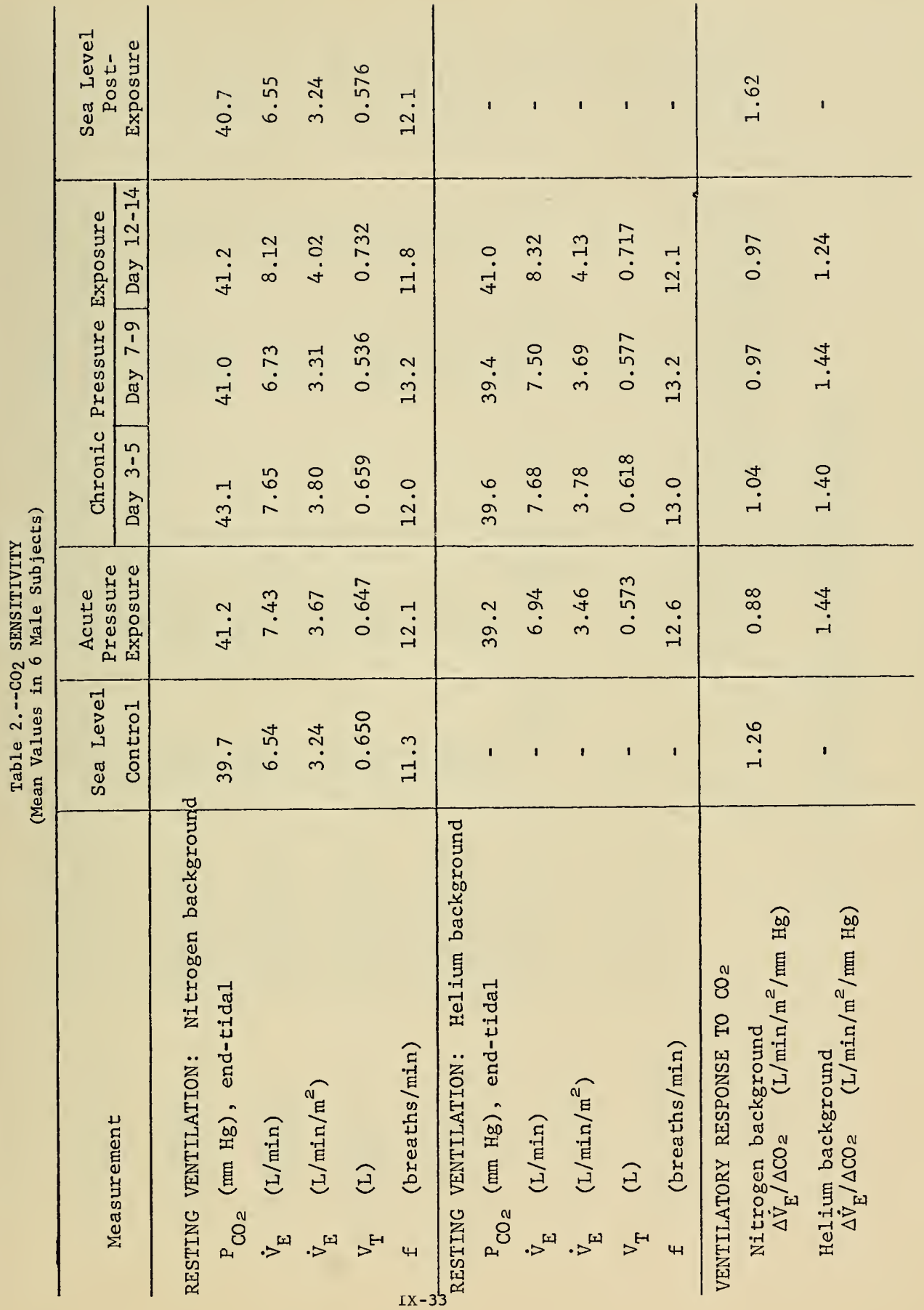




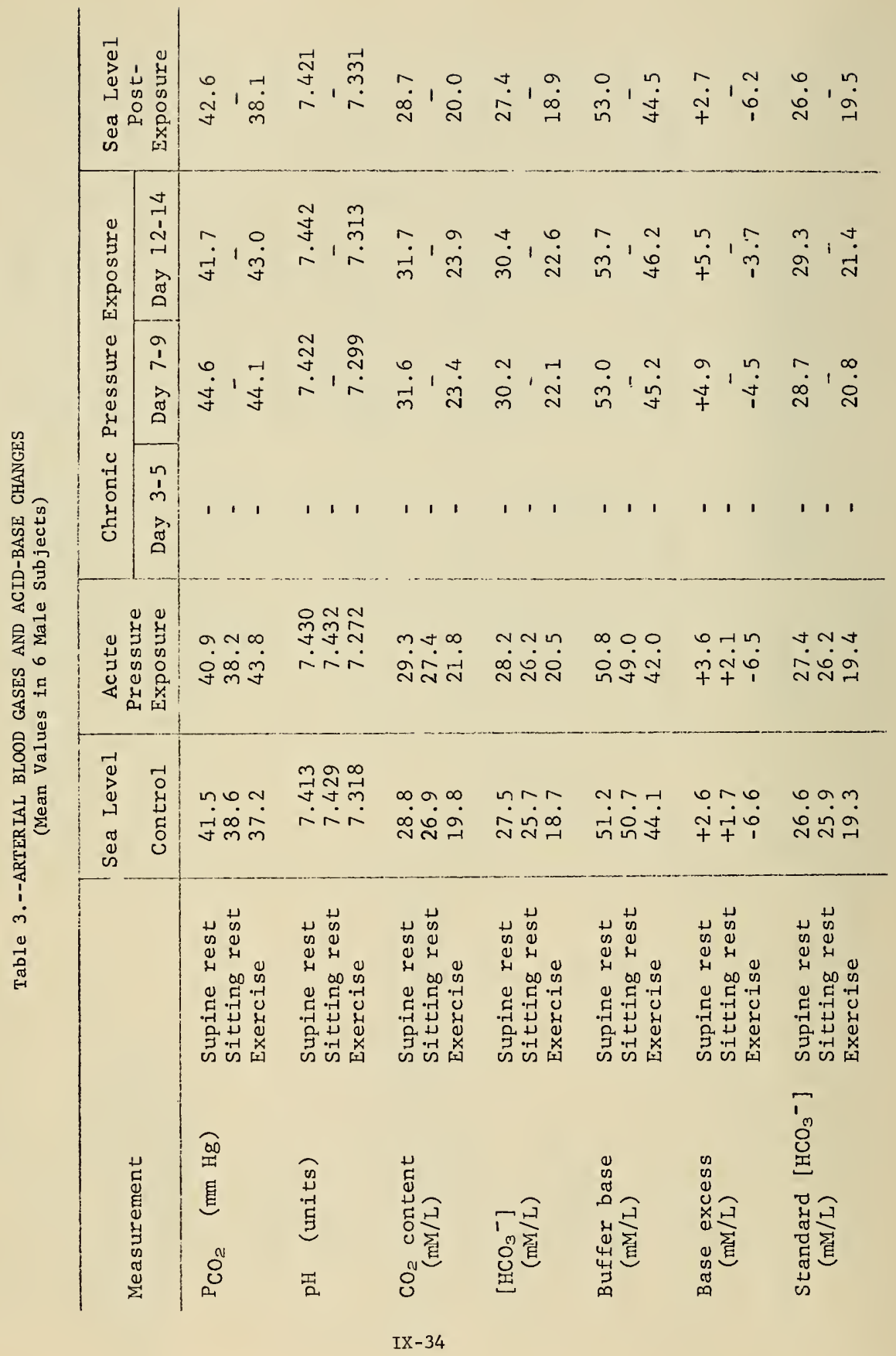




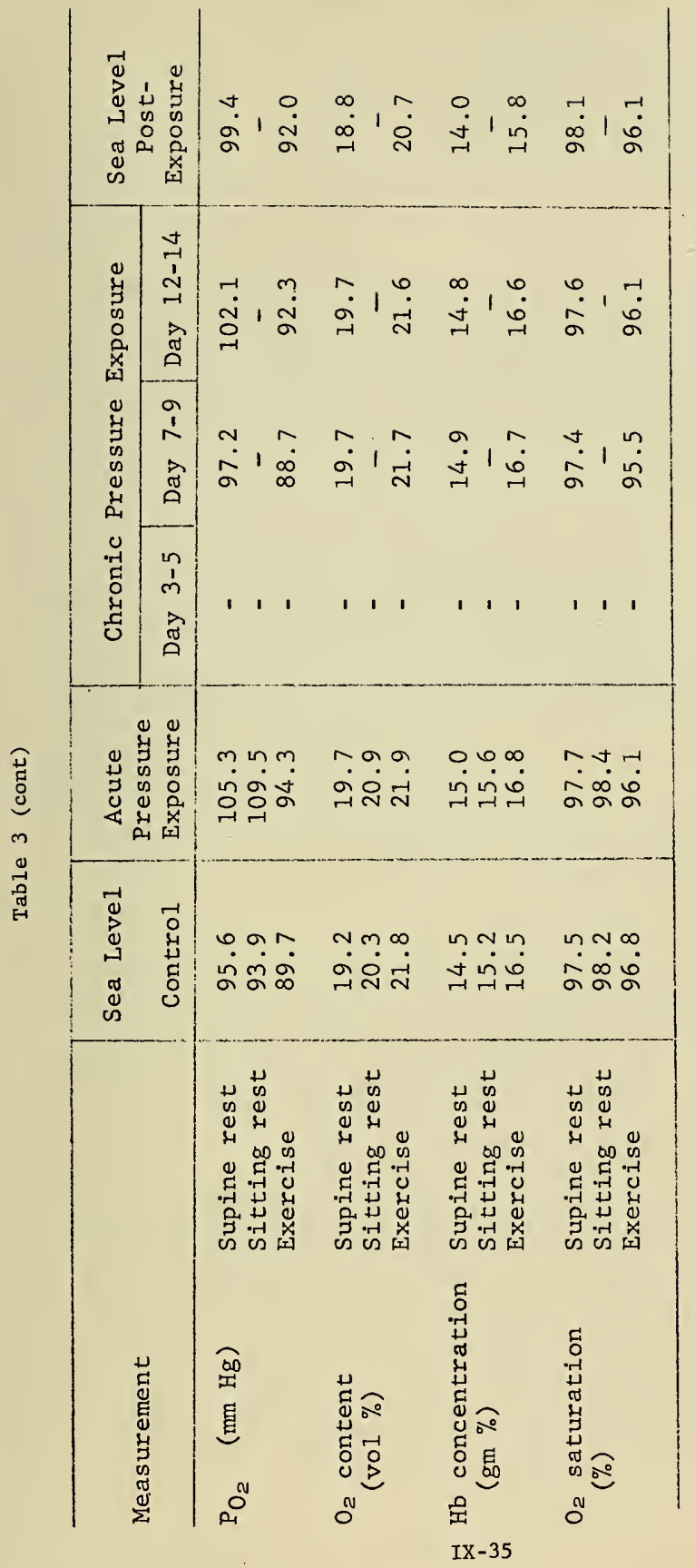




\author{
Andre B. Cobet \\ Naval Biomedical Research Laboratory \\ Naval Supply Center \\ Oakland, California
}

\begin{abstract}
The number of airborne bacteria in the atmosphere of the TEKTITE habitat was monitored during the period of its submergence. On selected occasions all the organisms growing on all six stages of the air samples were identified to group or genera. The bacterial flora of the divers skin surfaces and ears and nasal staphylococci were determined before, during and at the end of each mission. Correlations in the interaction of the microflora of the divers and the air mass are made.

The relationship between man and his environment is important in maintaining a proper balance among those microorganisms which comprise his indigenous microflora and hence his health and well-being. Slight changes in the environment may reflect themselves as an alteration in this balance. The conditions necessary to sustain the TEKTITE habitat in the submerged state from an engineering standpoint and the confinement of the aquanauts to the habitat and marine environment, the interactions of the aquanauts, both with each other and the environment, are major factors, each with its myriad of minor interacting elements which can affect man's indigenous microflora. A study of the effect of these conditions in prolonged submergence is necessary to define the effects of such an environment on the microorganisms associated with the aquanauts.
\end{abstract}

\title{
Background
}

The microbiological program of TEKTITE-I revealed a number of considerations which needed further examination in future "Man in the Sea" projects. The results of the aerobiology program indicated a buildup of both the general and marine bacterial populations. Associated with this buildup in the general population was the emergence of a dormant microbial population and an observation of a reduction in bacterial colony types appearing on the media (Cobet \& Dimmick, 1970).

This dominant population may have had its origin in the marine environment, establishing itself in the skin flora of the divers and subsequently through "shedding" in the atmosphere of the habitat. This same bacterial genus was also isolated with increasing frequency from the skin of the divers (Cobet, Wright \& Warren, 1970). Although this organism did not manifest itself as a disease, under different circumstances this may not have been the case.

On two occasions potentially pathogenic microorganisms, Pseudomonas 
aeruginosa, and Staphylococcus aureus, were isolated from the air in the wet laboratory of the habitat. There may have been a correlation between the finding of the Pseudomonas at eight organisms/ $\mathrm{ft}^{3}$ and complaints of external ear infection of three divers the following day. The etiological agent in two of these ear infections was identified as Pseudomonas. Three of the divers were nasal carriers of Staphylococcus aureus, coagulase positive, at the start of the program. No incidences of illness were associated with the airborne Staphylococcus and by the end of the program the carrier state of the three divers had been lost (Cobet \& Hresko, 1970).

The objective of the microbiology program in TEKTITE-II was to determine if on other TEKTITES the same organism that became dominant in TEKTITE-I would again become dominant or should one expect another dominant population as a result of a different seeding (i.e., divers, water mass and new atmosphere), even though the environment is nominally the same. If the latter, there will always be a potential hazard in successive trials with the emergence of unpredictable bacterial populations. The entire microbiological program of TEKTITE-II is an extension of and is based on the data acquired during the first program in this series.

An extensive study was conducted with concentration on the types and frequency of occurrence of microorganisms on three body sites of the aquanauts and the air within the $50 \mathrm{ft}$ TEKTITE-II habitat during the seven month program. Continued sampling through the entire program allowed for evaluation of the various experimental conditions in terms of their influence on the microflora.

\section{General Sampling Procedures.}

Aerobiology. The configuration of the habitat with its four compartments and three separate air conditioning units results in essentially three air masses, (1) the bridge-crew compartments; (2) the wet $1 \mathrm{ab}$ and, (3) the engineering space. Data from the TEKTITE-I behavioral study showed that the divers averaged about $65 \%$ of their time in air mass $1,15 \%$ in air mass 2 and $5 \%$ in air mass 3 (Mach \& Radloff, 1970). Based on these percentages of time spent in the various compartments, air samples were collected in the crew quarters and wet lab. The samples were collected in front of the air return ducts in the two compartments using Anderson six stage air samplers (Andersen, 1958).

The crew compartment was sampled daily using two samplers, one contained half-strength Trypticase Soy Agar (TSA) to obtain the general background bacterial population while the second sampler, on a rotational basis, contained Mannitol Salts Agar (Difco), Marine Agar 2216 (Difco) or Pseudosel (BBL) for the isolation of Staphylococcus aureus, the marine bacterial population and Pseudomonas aeruginosa respectively.

The wet laboratory was sampled daily with one Anderson sampler. Every other day the general background population was determined using TSA while on the odd days the other three media were rotated as above. 
The media was prepared on the surface and lowered to the habitat in sealed containers the day before the air sampling. The samples were taken by the group engineer for a pre-determined period of time, returned to the surface soon after exposure, and subsequently to the base camp for incubation and further processing.

The exposed plates were incubated at $28 \mathrm{C}$ for $72 \mathrm{hrs}$. The number of bacterial and fungal colonies were recorded from the TSA and 2216 plates using a Quebec colony counter. The number of mannitol fermenters was recorded from the Mannitol Salt Agar and green pigmented or fluorescence positive organisms were recorded on Pseudosel agar. Positive colonies from the latter two media were isolated to TSA mini-slants (agar slants in 1-dram vials) for conformation at NBRL. On selected days a11 organisms growing on all six stages of the TSA and 2216 samples were isolated to TSA or 2216 mini-slants and returned to NBRL for identification.

Human microbiology. The divers were sampled at three body sites, forearm (approximately $9 \mathrm{sq}$. in.) nose and ears, with the aid of saline-wetted, cotton-tipped sterile swabs. The swab tips were broken off in 1-dram vials containing $1 \mathrm{ml}$ of Trypticase Soy Broth (BBL). The samples were taken by the divers, immediately returned to the surface and subsequently to the base camp. Samples were collected from each site; the day before the dive, the day of the dive, the middle of the mission (no ear samples collected at this time) and the day decompression was to start. The swabs and vials for sampling were transferred to the divers the day before sampling so collection could be obtained prior to diving activity.

The sample vials were shaken vigorously to suspend the bacteria in the broth. A $0.1 \mathrm{~m} 1$ aliquot of the sample was plated to the surface of media according to the sample source; nose, Mannitol Salts Agar (MSA); ear, blood agar (3\% defibrigenated rabbit blood) and Pseudose1; skin, blood agar. The inoculated plates were incubated at $37 \mathrm{C}$ for $24 \mathrm{hr}$. The mannitol fermenters on MSA and pigmented organisms on Pseudosel were recorded and isolated for confirmation. On the blood agar plates the numbers of each colony type was recorded, described and three of each colony type isolated to TSA mini-slants for identification at NBRL. No effort was made to isolate the anaerobic or microaerophilic flora.

Marine microbiology. Sea water samples were collected from depths greater than 30 feet at four sites in the area of the habitat using the Cobet water sampler (Hydro Products). The sea water was analysed by the membrane filter technique as outlined in the Standard Methods for Water Analysis (1965) using m-Endo Medium (Difco) for coliform enumeration, Pseudosel for Ps. aeruginosa and Marine Agar for the total bacterial count.

Bacterial Identification. The samples were received at NBRL on minislants and were stored at 4-6C until identification procedures were started. Each isolate was streaked to blood agar to ensure purity and identified by means of standard bacteriological procedures, biochemical reactions and morphological characteristics. No attempt was made to 
identify the bacteria to the species level. When species were indicated as a result of differential procedures, they were recorded.

The criteria used for the gram-positive rods and cocci were as outlined in Harrigan \& McCance (1966) and Cowan \& Steel (1966). Separation of Staphylococcus aureus and $\underline{S}$. epidermus was based on coagulase activity. Gram negative cocci were identified according to criteria set forth by Collins (1967).

The pigmented Gram-negative rods were identified from a scheme developed from data from Hendrie, Mitchell \& Shewan (1968) and Harrigan \& McCance (1966). The non-pigmented, non-spore-forming Gram-negative rods were identified from a determinative scheme based upon that of Shewan, Hobbs \& Hodgkiss (1960) with additional information derived from Bain \& Shewan (1968), Collins (1967), Harrigan \& McCance (1966), Baumann, Doudoroff \& Stainer (1968) and Cowan \& Steel (1966). Differentiation of the Enterbacteriaceae was according to Carpenter, Lepage \& Steel (1966). Motility was determined by direct observation of young broth cultures, 18-24 hr.

The bacterial isolations obtained from and maintained on TSA medium was tested on media prepared with distilled water while bacteria isolated on Marine Agar was tested on media prepared with $30 \%$ Lyman and Fleming (1940) synthetic sea water. Inoculated determinative media was incubated at $32 \mathrm{C}$.

Mission Background. The first mission was 13 days in length with a crew of four scientific and one engineer divers. They lived in the habitat during the entire 13 days. This mission was treated as an isolated mission as far as the microbiology program was concerned since there was a six day refurbishment period between this and the next mission.

The second, third and fourth missions were 20 days each; in tandom for a total of 60 days. A crew change of the four scientific divers occurred at the start of each mission. The engineer for mission 2 stayed through the middle of mission 3 , the new engineer stayed through the remaining portion of mission 3 and all of 4. There were five divers on each crew for a total of 14 for the three missions. The group of three missions were considered a single operations phase for microbiological considerations.

The sixth mission started about 16 days after the completion of mission 4 and lasted 14 days. The crew composition was similar to mission 1 . There were a number of intrusions of press personnel during the first and last days of the mission for a total of about ten days of crew isolation. This mission will not be considered in detail for microbiological purfoses.

The eighth, tenth and twelfth missions were similar in operation to 2,3 and 4 and will be considered in the same manner. The fifteenth mission was similar to mission 1 and will be considered accordingly. 
Mission 1. The first mission provided us the opportunity to test our methodology and procedures in obtaining and handling the bacterial culture. If adjustments were indicated in the microbiological portion of the project changes could be instituted at St. John or Oakland before the longer three phase missions started.

The data will be presented under three main headings: Aerobiology, Human Microbiology and Discussion.

Aerobiology: Crew quarters. The sampling schedule in the crew-bridge compartment was on a daily basis using two air samplers to collect the general bacterial population and a selected bacterial component. The total bacterial counts/ft ${ }^{3}$ for the TSA and Marine media are presented in Fig. 1. The general bacterial population, those able to grow on TSA medium, was in a normal range during most of the mission with a moderate elevation on day 12 to $50 / \mathrm{ft}^{3}$. The marine bacterial population, those able to grow on 2216, was slightly elevated on day five to $37 / \mathrm{ft}^{3}$ but less than $10 / \mathrm{ft}$ on the other samples. The ability of the later population to grow on a marine medium, having sea water salts incorporated in its formulation, may be interpreted as a necessity for some of these colonies since this entire population is not measured on the fresh water medium. This is noted in the differences of the two populations. However, some of the organisms growing on the 2216 medium may not be so demanding in their salinity requirements and may have the capability of growing on the TSA.

No Staphylococcus aureus or Pseudomonas aeruginosa were isolated from the air on the selected media.

The total fungi count was recorded from the TSA medium and is presented in Fig. 2. There were two peaks during the mission, on days 5-6 at a level of $20 / \mathrm{ft}^{3}$ and day 9 at $16 / \mathrm{ft}^{3}$. Two types of fungi comprise the first peak while the second peak consisted of a single type of fungus but different than the other two. The fungi were not specifically identified but were common saprophites.

The entire bacterial population growing on selected air samples were collected from all six stages of the samplers and were identified to group or genera for correlative purposes. The Chi square test was applied to the distributions obtained from the TSA and 2216 media and showed a difference in the distributions of the two media at a confidence level of less than $0.1 \%$, i.e. the two media were recovering different population distributions. This was not mutually exclusive since an organism growing on one medium was not excluded from growing on the other.

The bacterial distribution of day 2-TSA is presented in Table 1. The Pseudomonas types I, II, III and IV are according to Shewan, Hobbs, \& Hodgkiss (1960) with type I being Ps. aeruginosa. The bacterial 


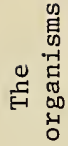

近

ㅇำ

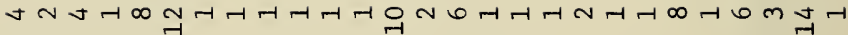

เ्่

离

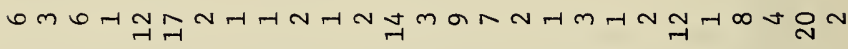

몽

压

di

$0 \quad \stackrel{0}{i}^{-1}-1$

$\sim$

3

हु

( )

$\infty$

T

至

1

谉

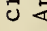

.

(19

त्र

औै

$+$

ฮั

๑

我

잉

त्र

N

m $\begin{aligned} & n \\ & \dot{1} \\ & m \\ & m\end{aligned}$

$m$ in

$-1-1-1$

$\rightarrow \quad r N$

N

㟧

ป ฮ.

के

ت-

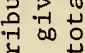

势

की

ค ్ㅗ

-

되

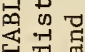

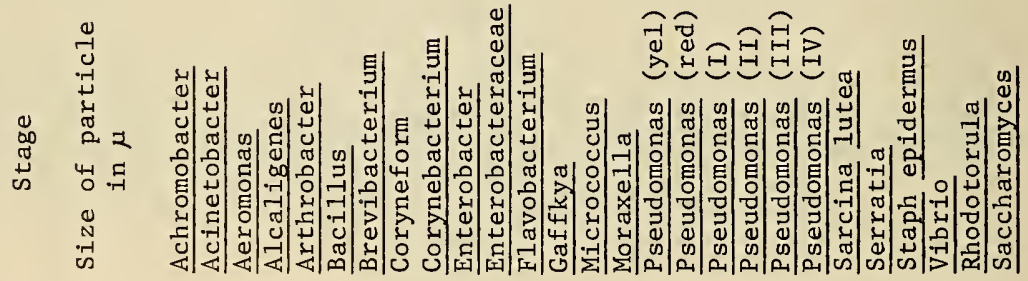


population, for this particular sample, is distributed over a wide variety of genera with no single genus predominating. The major genera were Arthrobacter, Bacillus, Gaffkya, Moraxella, Sarcina, Staphylococcus epidermus and Rhodotorula totally representing $64 \%$ of the population. Most of the organisms, $52 \%$, were associated with the first two stages which retains particles greater than 5.5 . Arthrobacter, and Bacillus are somewhat evenly distributed over the six stages while Moraxella, Gaffkya, Sarcina and Staphylococcus are predominantly found on the first stage. The latter three genera are also associated with human skin and may have originated from that source. One Ps. aeruginosa colony was isolated on stage three but no Staph. aureus was recovered.

The population distribution for the crew-bridge compartment on day 13TSA is presented on Table 2. The major genera were Acinetobacter, Arthrobacter, Gaffkya, Moraxe1la and Sarcina totally representing $56 \%$ of the population. Again, most of the organisms, $65 \%$, were associated with the first two stages while Gaffkya and Sarcina were predominantly found on the first two stages, as on day 2. One Staphylococcus aureus colony was isolated from stage 1 but no Pseudomonas aeruginosa was recovered.

In comparing the two days, 2 and 13, to determine what redistribution had occurred it is seen that Acinetobacter has increased from $2 \%$ to $9 \%$ of the organisms, Arthrobacter remained stable, Bacillus decreased but remained evenly distributed, Gaffkya and Morazella almost doubled, Staph. epidermus decreased and the yeasts dropped considerately. Aeromonas, Vibrio and a few other genera were not recovered on day 13 while Kurthia increased to $5 \%$ of the population. On day two, 27 different genera or groups of organisms were recovered with only 20 on day 13 . This may represent a slight simplification in the air flora. On day 13, 11 genera were not recovered which had previously been recovered (albeit at low levels) while four new genera were recovered. There was no redistribution of the genera within the six stages, those which were evenly distributed remained so (i.e. Bacillus) and those associated with the larger particles maintained that distribution (i.e. Gaffkya).

In grouping the organisms according to morphological and biochemical similarities (Table 3 ) comparisons can be seen more readily, Table 4. Some genera appear in more than one group, as Sarcina which is included in the pigmented, fermentative and Gram-positive group. The pigmented, Alcaligenes-Achromobacter, and Gram-positive rod groups increased with some internal rearrangement while all those in the Gram-positive cocci group increased, more notably Gaffkya. Pseudomonas, the fermentative group and the Gram-positive rods and yeasts group decreased.

The distribution of organisms on the 2216 medium for day two in the crewbridge compartment reveals 17 different genera represented with a predominence in the Acinetobacter, Arthrobacter, Gaffkya, Moraxella and Sarcina genera. The groups differed from those on TSA for the same day (Table 4) with most of the organisms in the Alcaligenes-Achromobacter group. 
ֻ

se

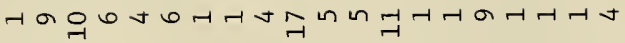

덩

-

c

莎

6

4
0

n $\begin{aligned} & 0 \\ & \dot{1} \\ & 1 \\ & 0 \\ & i\end{aligned} \quad H N m$

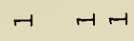

$\sim$

o

$\underset{0}{\infty}$

กั.

范

$+\quad \frac{m}{0}$

$m$
$\dot{m}$
$\dot{0}$

m $\quad$ in

nก $\operatorname{NN}$

$\operatorname{can} t a t$

N

육ำ

N

$N$

ㄴำ

ก

N

तु 0

पू तु त्र

吕

ㅇำ

-

כ

芷

os

on

(1)

$\therefore$

至

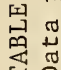

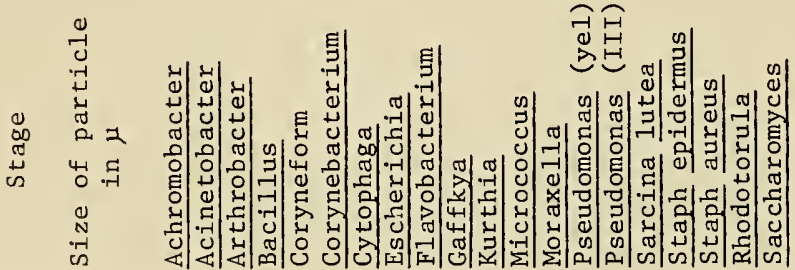


TABLE 3. Major groups of airborne bacteria according to morphological and biochemical similarities.

Pigmented

Coryneform

Cytophaga

Enterobacteriacea

Flavobacterium

Pseudomonas (pig)

Sarcina

Serratia

Fermentative

Aeromonas

Citrobacter

Cytophaga

Enterobacter

Eacherichia

Sarcina

Vibrio

$\underline{\text { Yeasts }}$

Rhodotorula

Saccharomyces
Achromobacter-Alcaligenes

Pseudomonas

Achromobacter

Acinetobacter

Alcaligenes

Moraxe1la

$\underline{\text { Pseudomonas }}$ I, II, III, IV

Gram-Positive Rods

Arthrobacter

Bacillus

Brevebacterium

Corynebacterium

Kurthia

Gram-Positive Cocci

Gaffkya

Micrococcus

Sarcina

Staphylococcus

TABLE 4. The percentage distribution of the bacteria grouped according to Table 3 from the crew-bridge and wet lab compartments.

Day

Media

Pigmented

Fermentative

Achromobacter-

Alcaligenes

Pseudomonas

Gram-pos. Rods

Gram-pos. Cocci

Yeasts $\frac{\text { Crew-Bridge }}{2}-\frac{}{2}-13$

TSA Marine TSA

$14 \quad 19 \quad 19$

1611

$13 \quad 38 \quad 21$

50

$22 \quad 29$

$26 \quad 22$

15

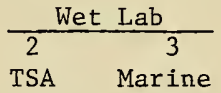

1323

$6 \quad 13$

$26 \quad 9$

12

$40 \quad 33$

$23 \quad 42$ 
Aerobiology: Wet Laboratory. Air sampling in the wet lab was based on rotating the use of four media in one Anderson air sampler. The total bacterial counts/ft ${ }^{3}$ for the TSA and 2216 media are presented in Fig. 3 . The general bacterial population remained at low levels during the entire mission, while the population was increased on day seven to a level of $85 / \mathrm{ft}^{3}$.

No Staphylococcus aureus or Pseudomonas aeruginosa were isolated from the air on the selective media.

The fungi count in the wet lab remained at a low level, never above $1 / \mathrm{ft}^{3}$, during the entire mission, Fig. 2 .

The bacterial distribution of day three-Marine Agar air samples revealed over 19 different genera with the major populations being Arthrobacter, Bacillus, Gaffkya and Sarcina and comprising $65 \%$ of the total population. Bacillus was mainly associated with the fifth stage, Gaffkya with the first three stages, while the other two genera were more evenly distributed on the six stages. The day 2-TSA samples had bacteria distributed over 17 genera with the major populations being Acinetobacter, Arthrobacter, Bacillus, Gaffkya, and Moraxella and comprising 75\% of the total population. In contrast to the first medium Bacillus was predominantly associated with the first stage. Moraxella was found mainly on stage 3 . One colony of Staphylococcus aureus was isolated on stage 3 , no Pseudomonas aeruginosa was isolated.

The comparison of groups (Table 4) shows a greater pigmentation on the marine medium while both media have a high distribution in the Grampositive catagories, and low distribution of the fermentative types.

Human Microbiology. Nasal Staphylococcus aureus. A nasal staphylococci survey of each aquanaut was made prior to the start of the mission, and at the end of the mission just prior to the start of the decompression sequence; in this first mission the mid-program samples were omitted. At the beginning of the mission, on the day of the dive and the day prior, all divers were negative for coagulase positive Staphylococcus aureus. At the end of the mission diver 1 was positive on both days 12 and 13 , the other aquanauts remaining negative.

Skin bacterial flora. The bacterial skin flora was sampled on the day of the dive before entry into the water, the middle of the mission and on the last day of the mission just prior to decompression. A composite of the frequency of isolation by divers, of the various bacteria is presented in Table 5. By looking at the five individuals as a group it is noted that the number of varieties of bacteria decreased from nine at the start to five by the end of the mission. Of course, it is recognized that the entire skin flora cannot be obtained in a single sampling using the swab technique. The predominant bacteria, both as to numbers $/ \mathrm{cm}^{2}$ of skin surface and frequency of isolation was Bacillus, with Sarcina second. By the end of the mission there were three main groups: Bacillus, 


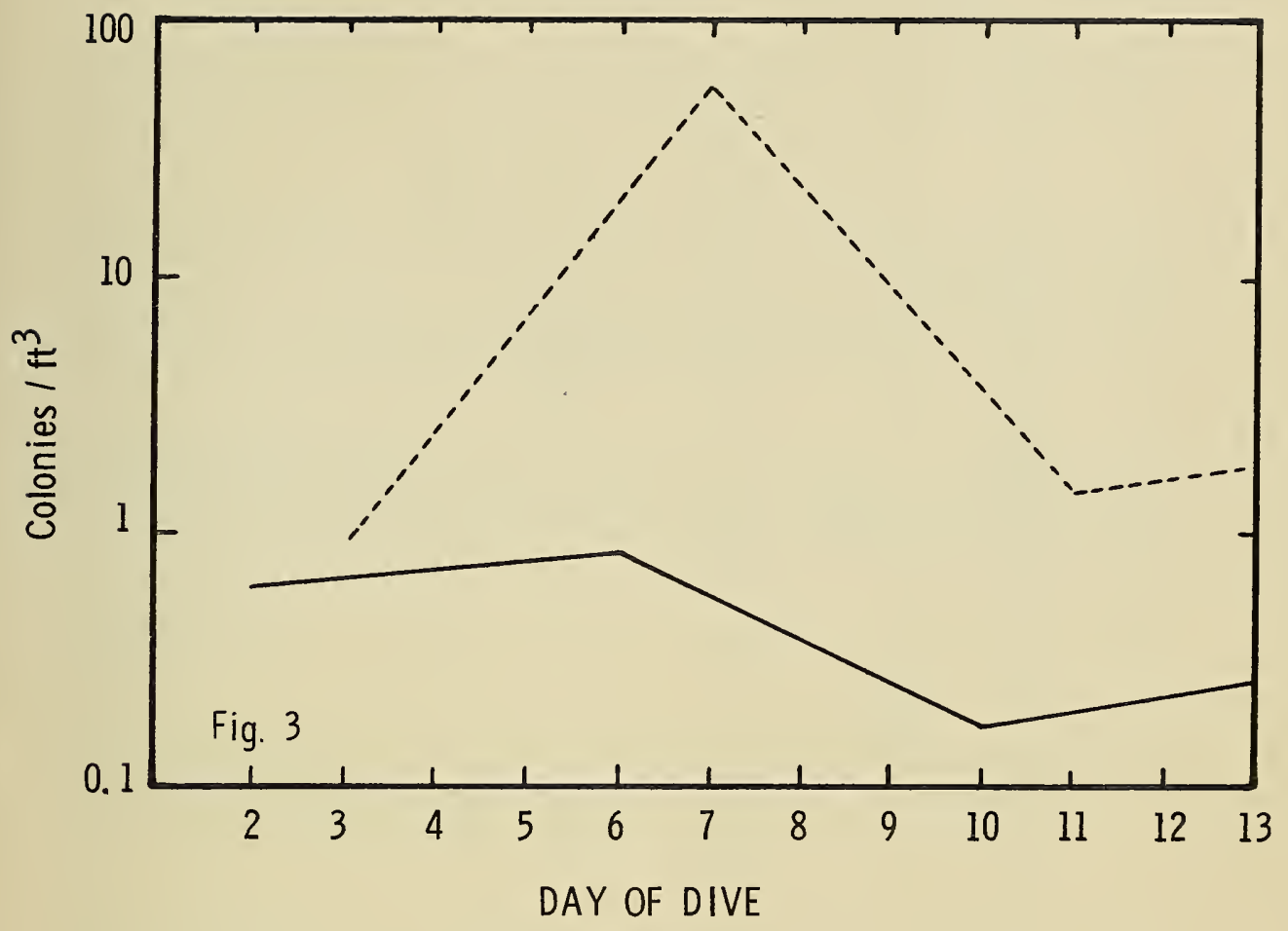

Fig. 3. Concentration of airborne bacteria in the wet 1 ab using $50 \%$ Tripticase Soy Agar (solid line) for general population and Marine Agar (broken line) for the marine bacterial population. 


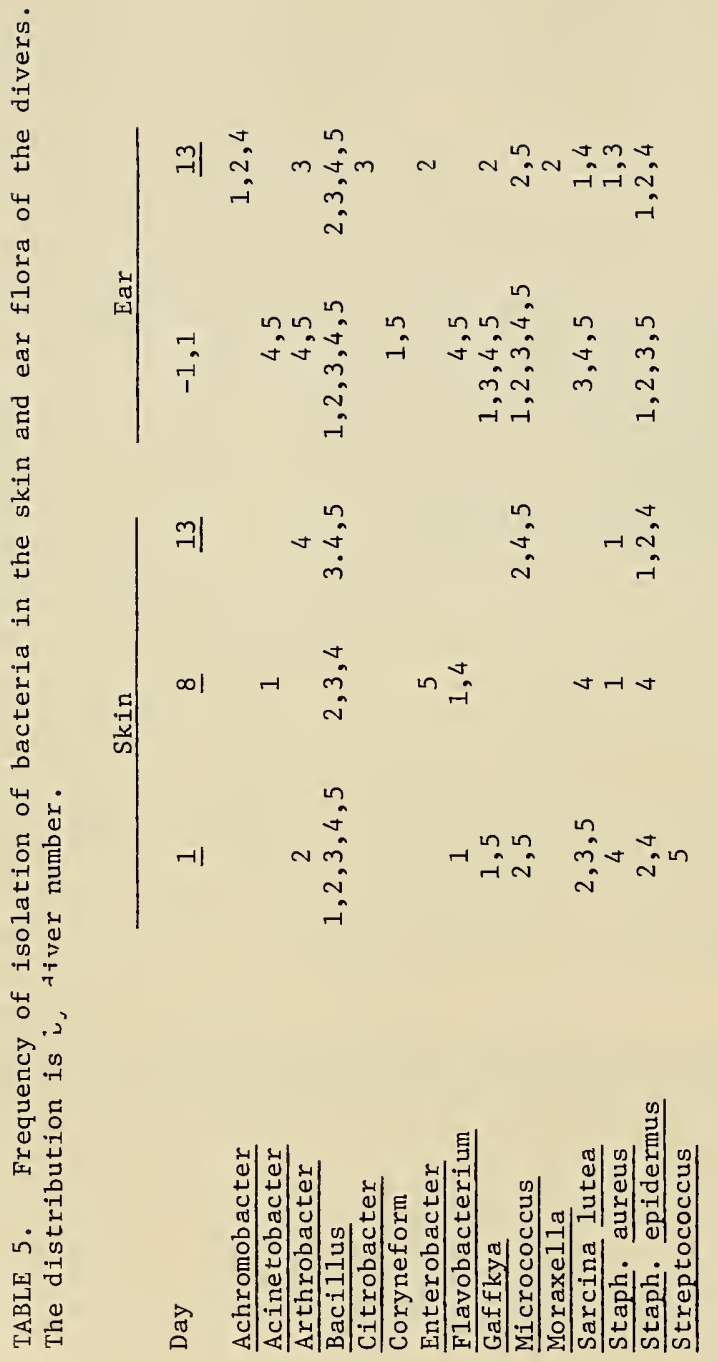


$\underline{\text { Staphylococcus epidermus and Micrococcus. }}$

Staphylococcus aureus was isolated on aquanauts 4 and 1 during the mission. Diver 1 was not a nasal carrier at the start of the mission but was both a nasal and skin carrier by the end of the mission. Nasal Staph. aureus was not recovered from diver 4 on the 3 sampling occasions.

Ear Bacterial Flora. The bacteria flora of the ear was sampled on three occasions, twice before the start of the mission and once just prior to the decompression. A composite of the frequency of isolation (by diver) of the various bacteria is presented in Table 5 .

The bacterial flora of the ears was varied for the group with nine different organisms represented at the start of the mission and 11 at the end. Those organisms which were isolated from the skin surface were also found in the ear flora. The distribution and types of organisms isolated represented a normal flora, mainly of the Gram-positive variety, with the exception of Citrobacter and Enterobacter isolated on day 13 from divers 3 and 2 respectively.

Staphylococcus aureus was not isolated from the ears at the start of the mission but was isolated from divers 1 and 3 at the end. Pseudomonas or other Gram-negative bacteria which may have caused external ear infection were not evident nor did the divers experience ear infections during the mission.

Coliforms were not isolated from sea water samples collected in the area of the habitat.

Discussion. Fortunately, the first mission of the TEKTITE-II program was uneventful as far as medical problems among the divers were concerned. The bacteriological data is supportive in that no obviously pathogenic organisms were isolated from the divers nor were there indications of infections developing at the end of the mission.

The airborne bacterial distributions in the two compartments were decidedly different as to types of bacteria and their numbers. The wet lab had a some what simplified flora in comparison to the crew-bridge compartment. This probably is a reflection of the greater activity of the divers and more opportunity for re-aerosolization from bed linen etc. in the crew-bridge compartment.

The airborne general bacterial population was within normal limits in both compartments, exceeding 30 organisms/ft ${ }^{3}$ on one occasion, day 12 in the crew quarters. Cobet \& Dimmick (1970) observed a gradual increase in the airborne bacteria during the first 13 days of TEKTITE-I. This was not observed in this mission, in fact there was a gradual decrease in the levels observed in the wet $1 \mathrm{ab}$.

The airborne marine bacterial population was within normal limits with 
the exception of a moderate peak on day five and a high peak on day seven in the crew-bridge and wet lab, respectively.

The levels of airborne fungi in the wet lab were essentially of the same levels found in TEKTITE-I, i.e. generally less than $1 / \mathrm{ft}^{3}$ (Cobet \& Dimmick, 1970). The crew-bridge compartment had two high peaks of fungi during the mission attaining a level of $20 / \mathrm{ft}^{3}$ on day six. This again may be reflecting the greater diver activity and re-aerosolization from linen and floor covering. The fungi were common saprophites consisting mainly of Aspergillus and Penicillium.

Staphylococcus aureus and Pseudomonas aeruginosa were not isolated from the air on their respective isolation media. However, one Ps. aeruginosa colony was identified in the distribution on day 2-TSA in the crewbridge compartment and Staph. aureus was identified in both the crew and wet compartments on days 13 and 2 respectively.

The "carrier" of a pathogenic organism living in close association with other people presents a potential hazard to his associates. The degree of hazard depends on such conditions as type of organism (Airborne Microbes, 1967), degree of crowding, and number of susceptibles (Miller, 1963), environmental factors such as relative humidity and the degree and type of lighting (Webb, 1961) and the temperature of the environment (Wright, et al., 1969) as well as other factors. All divers were negative for nasal Staph aureus at the start of the mission. Diver 1 was a positive nasal "carrier" by the end of the mission, the others remaining negative.

Staphylococcus aureus was isolated on diver 4 on the day of the dive only, while diver 1 was positive by the middle of the dive remaining so through the end of the mission. Staph aureus was isolated from the ears of divers 1 . and 3 at the end of the mission.

There appears to have been an introduction of Staph. aureus into the habitat on the skin of diver 4 which was picked up by diver 1 in both the nasal and skin and ear flora, and diver 3 in the ear flora by the end of the mission. Phage typing of these various isolates should reveal whether this sequence of events did indeed occur and what relationship exists between the divers and the airborne isolates from days 2 and 13 .

The skin and ear bacterial flora was of "normal" composition. However, there was a greater variety of bacteria in the ear than on the skin.

The comparing the distribution of bacteria isolated in the air of the crew-bridge compartment with the skin flora certain points are noted. At the start of the mission the major groups of organisms found in the air are also found on the skin of at least one diver and those bacteria from the skin flora were found in the air, (exceptions; Streptococcus and Staphylococcus aureus). By the end of the mission both the airborne and skin flora had simplified from 27 to 20 and 9 to 5, respectively. Those 
bacteria in the skin flora were found in the airborne flora but no longer as major groups. The major groups in the air were not found on the skin (i.e., Moraxella, Sarcina, Gaffkya, Acinetobacter) with the exception of Arthrobacter on one diver.

The entire microbiological study for all missions has not been completed. It would be premature at this point to make further speculations on the basis of this single mission which was not studied to the same extent as the other remaining missions. As stated earlier, this mission was used primarily as an opportunity to check the handling of samples and procedures of identification of bacteria; however, meaningful results were obtained. At the completion of the study a separate complete report will be made available.

Acknowledgements. Thanks are extended to the technical staff involved at the site at St. Johns Island. These people were: Mr. J. Hresko, Dr. H. Ross, Mr. J. Hebert, HMl Seelbach, Mr. G. Culver, Mrs. P. Schuchman and Mr. R. Cranford. The excellent work they did under such hardships as existed in such a remote place is greatly appreciated.

\section{Literature Cited.}

1. Airborne Microbes. 1967. P. H. Gregory and T. L. Monteith (eds.). Cambridge University Press, England.

2. Andersen, A. 1958. A new sampler for the collection, sizing and enumeration of viable airborne particles. J. Bacteriol. 76:471484.

3. Bain, N. and J. M. Shewan. 1968. Identification of Aeromonas, Vibrio and related organisms. In: Identification Methods for Microbiologists. B. M. Gibbs and D. A. Shapton (eds.). Academic Press, New York, Part B, pg. 79-84.

4. Baumann, P., M. Doudoroff and R. Y. Stainier. 1967. A study of the Moraxella group. I genus Moraxella and the Neisseria catarrhalis group. J. Bact. 95:58-73.

5. Baumann, P., M. Doudoroff, R. Y. Stanier. 1968. A Study of the Moraxella group. II. Oxidative-negative species (Genus Acinetobacter). J. Bact. 95:1520-1541.

6. Carpenter, K.P., S.P. Lepage and the late K.J. Stee1. 1966. Biochemical identification of Enterobacteriaceae In: Identification Methods for Microbiologists. B. M. Gibbs and D. A. Shapton (eds.). Academic Press, New York, Part A, pg. 21-34.

7. Cobet, A.B . and R.L. Dimmick. 1970. Tektite I Program: Aerobiological aspects. Aerospace Medicine, 41:617-620. 
8. Cobet, A. B. and J. P. Hresko. 1970. Microbiology of the aquanauts and their environment. In: Tektite-I Report, Office of Naval Research, Wash. D.C.

9. Cobet, A.B., D.N. Wright and P.I. Warren. 1970. Tektite I: Bacteriological Aspects. Aerospace Medicine 41:611-616.

10. Collins, C.N. 1967. Microbiological methods, 2nd ed., Plenum Press, New York, pp. 179-288.

11. Cowan, S. T. and K. J. Stee1. 1966. Manual for the identification of medical bacteria. Cambridge University Press, London.

12. Harrigan, W. F. and M. E. McCance. 1966. Laboratory methods in microbiology. Academic Press, New York, pg. 199-228.

13. Hendrie, M.S., T.G. Mitchell and J.M. Shewan. 1968. The identification of yellow-pigmented rods. In: Identification Methods for Microbiologists, B. M. Gibbs and D. A. Shapton (eds.), Academic Press, New York, Part B, pp. 67-78.

14. Lyman, J. and R. H. Fleming. 1940. Composition of sea water. J. Mar. Res., 3:134.

15. Mach, R. and R. Radloff. 1970. Behavioral Program. In: TektiteI Report Office of Naval Research, Wash. D.C.

16. Miller, L.F. 1963. Acute Respiratory infections in navà1 personnel. In: A Symposium on Aerobiology. Naval Biomedical Laboratory, Naval Supply Center, Oakland, Calif., p. 2-23.

17. Standard methods for the examination of water and waste-water. 1965. Twelfth Ed., Amer. Pub. Health Assoc. Inc., New York.

18. Shewan, J.M., Hobbs, G. and Hodgkiss, W. 1960. A determinative scheme for the identification of certain genera of Gram-negative bacteria, with special reference to the Pseudomonadacea. J. Appl. Bact., 23:379.

19. Webb, S. J. 1961. Factors affecting the viability of airborne bacteria. IV. The inactivation and reactivation of airborne Serratia marcescens by ultraviolet and viable light. Can. J. Microbiol. 7:607-619.

20. Wright, D. N., Bailey, G. D. and Goldberg, L.J. 1969. Effect of temperature on survival of airborne Mycoplasma pneumoniae. J. Bacteriol. 99:491-495. 


\section{LABORATORY MEDICINE}

Craig L. Fischer, M.D. Pathologist and Chief, Clinical Laboratories

Carolyn S. Leach, Ph.D. Endocrine Laboratory Section

W. Carter Alexander, Ph.D. Deputy Chief, Clinical Laboratories of

Preventive Medicine Division NASA Manned Spacecraft Center, Houston, Texas

\section{ABSTRACT}

Detailed blood analyses were accomplished in support of Project TEKTITE II. Specific emphasis was placed on hematologica1, biochemical and endocrinological parameters. Samples were acquired pre and postdive only in six, 50-foot, two-week dives. The resulting data supports previous findings of TEKTITE $I$. No significant changes were observed.

\section{INTRODUCTION}

The Laboratory Medicine evaluation was undertaken to detect any significant adaptive or pathologic changes in a population of divers exposed for two weeks at a depth of 50 feet, breathing an $8 \% \mathrm{O}_{2}, 92 \% \mathrm{~N}_{2}$ gas mixture. The specific techniques used were similar to those used in support of Project TEKTITE I; however, the diver population was significantly larger and an endocrine evaluation was added.

\section{OBJECTIVES}

The overa11 objectives were:

(a) Documentation of participating crew members physical qualifications, related to the dive, and detect problems which could require remedial or preventive action.

(b) Information relative to the etiology, time course and extent of any alterations in red cell mass and/or leukocyte function.

(c) Information referable to the humoral and cellular components of immunity from crew members exposed to the rigors of long-term saturation diving. 
(d) Data referable to any alterations in fluid and electrolyte balance and muscloskeletal metabolism as reflected by selected biochemical constituents of blood.

(e) Information about the endocrine system required to objectively quantitate the "physiological costs" or "stresses" incurred by long-term saturation diving.

Detailed studies of fluid and electrolyte balance were performed during the 100-foot, $\mathrm{O}_{2}-\mathrm{N}_{2}$ saturation dive conducted at the hyperbaric facilities of the University of Pennsylvania. This program is described elsewhere in this report. Due to operational difficulties, the 100-foot open-sea dives were not conducted

\section{PROTOCOL}

The studies were designed such that all hematologic parameters were measured within minutes of sample acquisition, whereas the biochemical and endocrine samples were appropriately stabilized for subsequent analysis at the Manned Spacecraft Center in Houston, Texas. The sample schedule for the six dive teams examined is shown in Table 1 . The predive samples were all collected in the morning before the subject entered the habitat. The postdive samples were collected as soon as possible after the divers left the decompression chamber. Table 2 shows the mean values for the test parameters considered in the laboratory evaluation.

TABLE 1

SAMPLE SCHEDULE

\begin{tabular}{cccc}
\hline Dive Number & Number of Subjects & Predive Date & Postdive Date \\
1 & 5 & $4-2-70$ & $4-17-70$ \\
2 & 5 & $4-17-70$ & $5-13-70$ \\
3 & 5 & $5-12-70$ & $6-2-70$ \\
4 & 4 & $6-1-70$ & $6-21-70$ \\
5 & 5 & $7-6-70$ & $7-22-70$ \\
7 & 4 & $8-12-70$ & $9-3-70$ \\
\hline
\end{tabular}


TABLE 2

MEAN VALUES OF TEST PARAMETERS

\begin{tabular}{|c|c|c|c|}
\hline TEST & $\begin{array}{l}\text { NUMBER OF } \\
\text { SUBJECTS }\end{array}$ & $\begin{array}{l}\text { MEAN PREDIVE } \\
\pm \text { S.E.* }\end{array}$ & $\begin{array}{l}\text { MEAN POSTDIVE } \\
\pm S . E .\end{array}$ \\
\hline 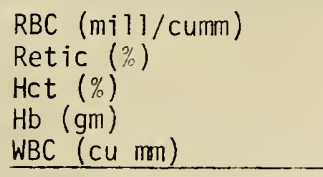 & $\begin{array}{l}27 \\
22 \\
28 \\
27 \\
28 \\
\end{array}$ & $\begin{array}{l}4.86 \pm 0.11 \\
0.65 \pm .074 \\
43.4 \pm .48 \\
14.7 \pm .23 \\
6828 \pm 427 \\
\end{array}$ & $\begin{array}{l}4.71 \pm .09 \\
0.80 \pm .079 \\
42.7 \pm .82 \\
14.6 \pm .28 \\
7629 \pm 476 \\
\end{array}$ \\
\hline $\begin{array}{l}\text { Glu (mg \%) } \\
\text { Bun (mg \%) } \\
\text { Uric Acid (mg \%) } \\
\text { Creat (mg \%) } \\
\text { Choles (mg\%) } \\
\text { SGOT (mu/ml) } \\
\text { Alk Phos (Iu) } \\
\text { LDH (mu/ml) } \\
\text { CPK (Iu) } \\
\text { Bili T (mg \%) }\end{array}$ & $\begin{array}{l}28 \\
28 \\
28 \\
28 \\
24 \\
28 \\
28 \\
28 \\
27 \\
27 \\
\end{array}$ & $\begin{aligned} & 92 \pm 2 \\
& 15.9 \pm 0.6 \\
& 5.7 \pm 0.2 \\
& 1.17 \pm .03 \\
& 190 \pm 8 \\
& 24 \pm 2 \\
& 23 \pm 1 \\
& 131 \pm 17 \\
& 32 \pm 7 \\
& 0.83 \pm .06 \\
&\end{aligned}$ & $\begin{aligned} & 101 \pm 2 \\
& 18.8 \pm 0.8 \\
& 6.1 \pm 0.2 \\
& 1.17 \pm .04 \\
& 198 \pm 6 \\
& 24 \pm 2 \\
& 24 \pm 1 \\
& 126 \pm 15 \\
& 26 \pm 5 \\
& 1.06 \pm .09 \\
&\end{aligned}$ \\
\hline $\begin{array}{l}\mathrm{Na}(\mathrm{meg} / 1) \\
\mathrm{K}(\mathrm{meg} / \mathrm{l}) \\
\mathrm{Cl}(\mathrm{meg} / \mathrm{l}) \\
\mathrm{Ca}(\mathrm{mg} \%) \\
\mathrm{PO}_{4}(\mathrm{mg} \%) \\
\mathrm{Mg}(\mathrm{mg} \%) \\
\mathrm{OSMO}^{2}(\mathrm{MOSMO} / 1)\end{array}$ & $\begin{array}{l}28 \\
28 \\
28 \\
28 \\
28 \\
28 \\
27 \\
\end{array}$ & $\begin{array}{c}140 \pm .4 \\
4.2 \pm .09 \\
102.6 \pm .2 \\
9.7 \pm .06 \\
3.1 \pm .1 \\
2.2 \pm .04 \\
287 \pm .9 \\
\end{array}$ & $\begin{array}{c}140 \pm .4 \\
4.0 \pm .05 \\
102.2 \pm .3 \\
9.6 \pm .06 \\
3.1 \pm .1 \\
2.1 \pm .04 \\
287 \pm 1.3 \\
\end{array}$ \\
\hline $\begin{array}{l}\text { Total Protein (Gm \%) } \\
\text { Alb (Gm\%) } \\
\text { Transferrin (mg \%) } \\
\text { Hapto (mg\%) } \\
\text { Cerulo (mg \%) } \\
\text { A2 Macro (mg \%) } \\
\text { A Glyco (mg \%) } \\
\text { Angio I (mu/ml/hr) } \\
\text { Cortisol (mg \%) } \\
\text { T3 Rel (Uptake) } \\
\text { T4 (pg \%) }\end{array}$ & $\begin{array}{l}28 \\
28 \\
28 \\
28 \\
28 \\
24 \\
24 \\
28 \\
28 \\
27 \\
26 \\
\end{array}$ & $\begin{aligned} & 7.3 \pm .07 \\
& 4.6 \pm .1 \\
& 224 \pm 7.4 \\
& 156 \pm 13.4 \\
& 35 \pm 4.5 \\
& 241 \pm 17.1 \\
& 78 \pm 5.7 \\
& 1.60 \pm .26 \\
& 17.4 \pm 1.7 \\
& 29.9 \pm .8 \\
& 7.9 \pm .6 \\
&\end{aligned}$ & $\begin{aligned} & 7.3 \pm .2 \\
& 4.5 \pm .1 \\
& 221 \pm 7.2 \\
& 162 \pm 19.5 \\
& 38 \pm 5.8 \\
& 236 \pm 14.3 \\
& 75 \pm 3.4 \\
& 3.69 \pm .66 \\
& 18.0 \pm 1.8 \\
& 28.8 \pm .8 \\
& 9.7 \pm .7 \\
&\end{aligned}$ \\
\hline
\end{tabular}

* Standard Error 
The original purpose of the Laboratory Medicine evaluation was to support the medical team by the documentation of participating crew members physical qualifications, related to the dive, and to detect problems which could require remedial or preventive action. This was accomplished and the information was made available, on a real time basis, to the medical support team.

If the divers are considered as a group, there were no significant changes in any hematologic or biochemical parameter. These findings are entirely consistent with data previously reported for Project TEKTITE I.

The endocrine data indicates varying trends in individuals, suggesting individual reaction to the two week dive and decompression schedule. However, when the data were evaluated for the population of divers, no significant changes were reflected.

In summary, it can be unequivocally stated that under the conditions imposed by the TEKTITE II environment, no significant biochemical, hematologic, or endocrine changes can be anticipated. More generally, this statement can be extropolated to at 1 east 60 days. 


\title{
STUDIES OF DIVER COMMUNICATION AND RETRIEVAL
}

\author{
Harry Hollien, Ph.D \\ and \\ Howard Rothman, Ph.D. \\ University of Florida
}

\begin{abstract}
The Communication Sciences Laboratory has been conducting an extensive program of research on diver communication and sound localization, and has recently extended the research to include diver detection, recall, and navigation. A series of studies was conducted at Lameshur Bay and at Buck Island, Virgin Islands. The series included studies on diver communication, navigation by auditory methods and diver retrieval.
\end{abstract}

\section{INTRODUCT ION}

Divers are not efficient workers in an undersea environment for a number of reasons; viz., 1) the absence of inter-diver communication and diver-to-surface communication with support personnel, 2) difficulties in locating and recalling divers when they are operating underwater, and 3) a lack of reliable methods of underwater navigation.

Thus, it is clear that practical communication, navigation, and retrieval systems are vital if extensive free-diving activities are to become feasible. Moreover, it has become apparent recently that acoustic approaches have the greatest potential for development of such systems. Accordingly, the Communication Sciences Laboratory at the University of Florida has been conducting an extensive program of research on diver communication which recently has been expanded to include diver detection, recall, and navigation.

In the past, much of the research conducted was either basic or specialized in nature, or was carried out in fresh water, primarily in connection with Navy programs. In time it became necessary to find a marine environment that provided a relatively shallow, warm, salt water research site--one that included 1) good project support, 2) a complement of experienced divers, and 3) a generally protected (especially acoustically) underwater environment. Nearly ideal conditions were obtained at TEKTITE II, both at Lameshur Bay and at Buck Island. The Buck Island facilities were provided by the College of the Virgin Islands.

The Communication Sciences Laboratory conducted the following projects at TEKT ITE II.

\section{Studies of Diver Communication}

a) Phase-2 of an English based diver lexicon.

b) Mixed gas (shallow water) intelligibility.

c) Diver-to-surface intelligibility of communication systems as a function of range. 
d) Effectiveness of work by divers with and without voice communication.

\section{Studies Basic to Navigation by Auditory Methods}

a) Basic research in underwater sound localization.

b) Underwater sound localization of pulses, varying sinusoids and dolphin whistles.

3. Studies of Diver Retrieval

a) Acoustic evaluation of M-80 explosives as a function of range.

b) Acoustic evaluation of $38 \mathrm{cal}$. pistol shots as a function of range.

For the purposes of this report, certain of these studies will be discussed in detail; they will include the diver communication systems evaluation (1c), the work of divers with and without communication (1d), the underwater sound localization experiment ( $2 a$ and $b$ combined), and the research on recall of divers ( $3 a$ and $b$ combined).

\section{INTELLIGIBILITY OF DIVER-TO-SURFACE COMMUNICATION SYSTEMS AS A FUNCTION OF DISTANCE}

While impressive gains have been made in basic equipment for divers, systems for voice communication are still relatively primitive. Nonetheless, a number of underwater speech communication systems, both civilian and military, have become available to divers. However, so little is known about man's basic ability to speak underwater that the design of these systems has been, of necessity, based primarily upon electronic considerations. Moreover, few systematic or independent evaluations have been carried out. The need remains, then, for an assessment of system efficiency in the transmission of intelligible speech under conditions designed to duplicate actual diver-to-1istener communication. The current project is the third in a series of six evaluations we are carrying out on such systems. They are: Diver-to-surface 1) at close range in fresh water, 2) off-shore in salt water--as a function of range (the present study), and 3 ) in a salt water harbor--as a function of range. Diver-to-diver communication is also evaluated under these conditions.

\section{$\underline{\text { Procedures }}$}

The procedures used to gather data for the current diver-to-surface study (over distance) essential1y parallel those previously used by our group (see: Hollien, Coleman, Thompson and Hunter, 1970). Basic to the standardization of such underwater procedures is our Diver Communication Research System (DICORS) which has been described by Hollien and Thompson, 1967. For TEKTITE II, we designed a mini-DICORS which was small, lightweight and portable; it may be seen in Figure 1. For the diver-to-surface study, mini-DICORS was floated at about 15 feet in approximately 30 feet of water on the Buck Island range. Hydrophones were situated at distances of 50,250, 500, 1000, 2000, and 4000 feet from the diver/talker. Since depth varied as a function of distance down-range, the hydrophone was placed halfway between the bottom and surface of each location. 


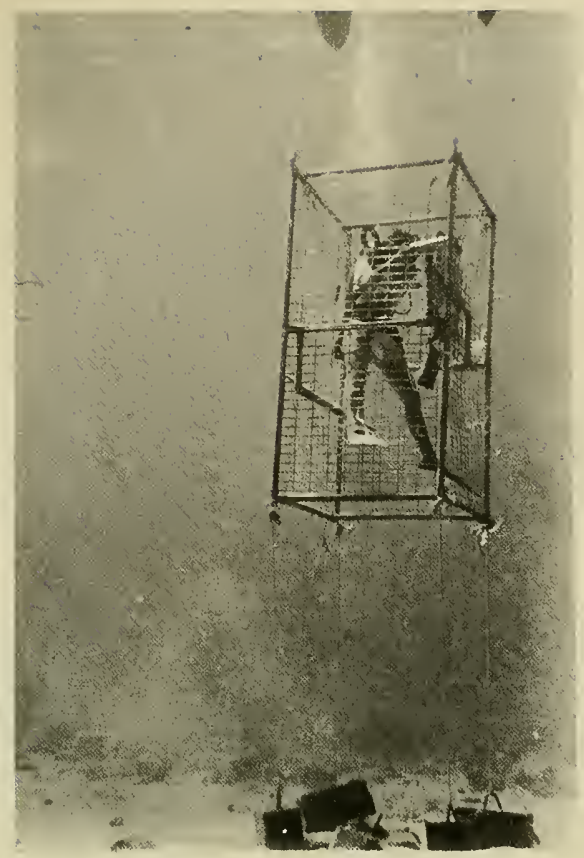

Figure 1. A mini-DICORS in use during the range study of diver communication systems.

Two basic types of communication systems were evaluated; the first group consisted of acoustic systems. An "acoustic" system includes a microphone, amplifier, power supp1y, and transducer; it characteristically transduces speech directly into the water by means of the projector (underwater loudspeaker). The signal produced can be received by a hydrophone placed in the water, or by divers without any special receiving equipment. Two of the acoustic systems studied were the Raytheon Yack-Yack and the Bendix Watercom (we had modified the Watercom to enhance its operation); both were evaluated in a configuration that included a double hose regulator and Bio-engionics (Nautilus) muzzle. A third "acoustic" system evaluated was the Scuba-com, a mechanical (rather than electronic) unit that consists of a small air filled cavity and diaphragm.

The second group of communicators consisted of amplitude (am) modulated systems and included the Aquasonics 420, the ERUS-2-3A, the Sub-Com prototype (both short-range and intermediate-range) 1 and the $\mathrm{PQC}-2$. A11 systems evaluated were rigged with the Bio-engionics "Nautilus" muzzle and a double hose regulator. In an AM system, a carrier wave is utilized and is modulated by the

1 The SCUBA-COM units operate on a slightly different principle but are included in this group for convenience. 
speech signal. Such a system ordinarily consists of a microphone, power supply, amplifier, modulator, and underwater transducer. Speech produced in this manner can be understood only by a diver or a surface observer having an appropriate receiver and demodulator.

With the Aquasonics unit, a $42 \mathrm{kHz}$ carrier signal is transduced into the water after being modulated by the speech signal and the mixed signal is picked up by a receiving coil, demodulated, and heard in the normal speech mode. The PQC-2 (a military unit) uses an SSB suppressed carrier frequency signal of $8.0875 \mathrm{kHz}$.

The purpose of this study was to provide information on how the units listed above would perform over distance and, unlike our previous fresh water studies, how they would perform in a salt water environment with its attendant sea noises. Each diver/talker $(\mathrm{N}=4)$ was assigned a 50-word Griffith 1ist (equated for difficulty) to be read with each communicator at each distance. Each word was preceded by the phrase, "You will say--." Figure 2 shows a diver/talker using a $\mathrm{PQC}-2$.

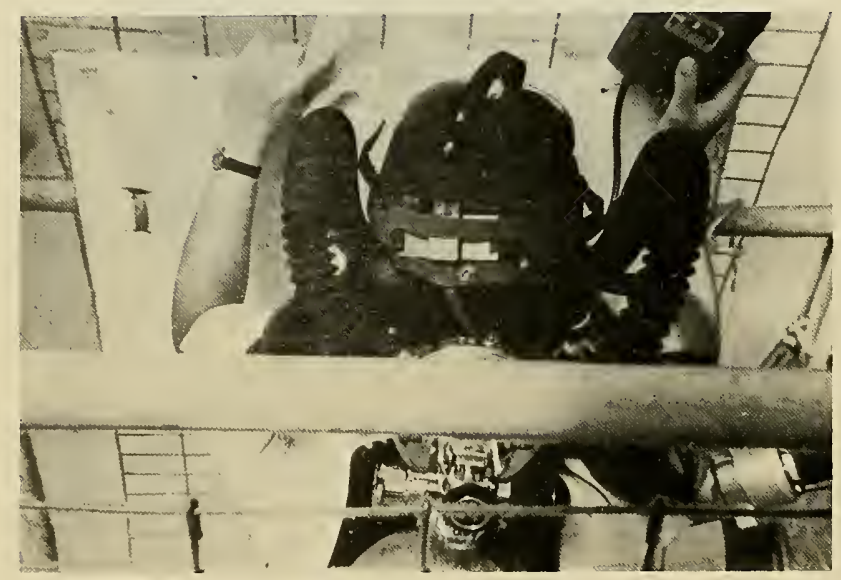

Figure 2. A diver/talker shown reading a word 1ist via the PQC-2.

In order to evaluate the communication systems, tape recordings of the lists read by the divers were brought to the University of Florida and played to a minimum of ten "semi-trained" 1isteners; i.e., students selected on the basis of 1) being native speakers of English, 2) having normal hearing, and 3) being capable of performing the required 1istening tasks. Before hearing the tapes, listeners were required to score at least $92 \%$ on a screening test.

\section{SOUND LOCALIZATION IN SALT WATER}

In air, man depends on his directional sense of hearing to locate the source of sounds, to warn him of approaching objects which emit acoustical signals, and to differentiate among competing signals. Both theory and empirical evidence 
would predict, however, that in the underwater environment humans will either totally lose their sound localizing capabilities or have them seriously impaired. This observation would appear to be supported by Bauer and Torick (1965), de Haan (1956), and others.

Directional perception of sound in air is based on the utilization of internal phase (time-of-arriva1) and/or intensity information provided to the auditory mechanism by the arriving signal. For the low frequencies, phase is most important, but at higher frequencies the head creates a shadow effect which in turn produces a marked intensity difference between the two ears. In the water, however, a different situation exists. First, sound velocity is four to five times greater in water than it is in air (depending on salinity, temperature, etc.). Due to this many-fold increase in the speed of sound, the time interval of an arriving signal across the head would be correspondingly diminished, thus virtually eliminating the directional perception attributable to time delay (phase). The process is somewhat different with respect to intensity; that is, in air, the impedance mismatch between the air and the head is sufficiently great so that the head constitutes an effective acoustic barrier. This relationship does not hold in water as the impedance of the head is similar to that of the fluid. Therefore, sounds virtually go through the sku11, reducing by a substantial amount (or eliminating altogether) this shadowing effect and its concommitant intensity differential.

A number of studies (Hollien, 1971) have suggested that divers do, indeed, exhibit at least some primitive underwater sound localization ability. The experiments in the TEKTITE series replicated our earlier experiments which had taken place in fresh water excepting that the salt water experiments were carried out with the source 40 feet from the 1 istener.

\section{$\underline{\text { Procedures }}$}

The basic protocols of the earlier studies were as follows: The first step was to develop a Diver Auditory Localization System (DALS) which allows the diver/subject's head either to be held in a rigidly fixed position or to be moved, with his body fixed. In the first experiment, 17 diver/talkers were positioned in DALS, at a depth of $40 \mathrm{ft}$, with their bodies fixed but their heads mobile; four different experimental signals (250-, 1000-, 6000- $\mathrm{Hz}$ sinusoids and thermal noise) were transduced via J-9 projectors. The site of these projects was the NRL Underwater Sound Reference Division's Bugg Springs facility. Each signal was presented to the listeners five times randomly from each of the five transducers at a distance of eight feet and consisted of five 1 -sec. bursts at $40 \mathrm{db}$ re hearing threshold. Listeners responded by means of a specially constructed $\overline{5}$-position underwater switch coupled to an IBM keypunch at the surface.

It is of some importance to study these phenomena at distances other than the relatively close range ( $\left.8^{\prime}\right)$ situation previously employed. Accordingly, a set of two related investigations were carried out in order to discover if divers exhibit the predicted levels of localization also in salt water. Procedures similar to those utilized previously were adopted except that transducers were placed at distances of 40 feet from the diver/subject. Instead of using DALS, a mini-DICORS was utilized and the transducers were suspended at the midpoint leve1 in 40 feet of water on taut 1 ines tied at one end to cement clumps and at the other to partially filled inner tubes. This arrangement prevented the 
equipment from varying in position due to the effects of currents, etc. The divers' bodies were fixed in relation to the five transducers, but their heads were mobile. In the first study, each of the four signals $(250-, 1000-, 6000-\mathrm{Hz}$ sinusoids and thermal noise) were presented in duty cycles of one second; in the second, the signals were a series of sinusoids sweeping from $500-1000 \mathrm{~Hz}$, $1000-500 \mathrm{~Hz}, 4000-6000 \mathrm{~Hz}, 6000-4000 \mathrm{~Hz}$, a dolphin whistle and pulse trains of 15 and 50 pps. A11 stimuli were presented at $100 \mathrm{db}$ SPL which is approximately $40 \mathrm{db}$ re underwater hearing threshold.

\section{Results}

A comparison of scores obtained at Bugg Springs with those during TEKTITE II can be seen in Table 1. Diver performance for the second study can be compared in Table 2 to scores collected at Bugg Springs using the same stimuli. In this regard, it will be noted that the values for the first of the present studies are lower than those obtained in fresh water and are minimally above chance. However, the depressed scores are partially due to one subject whose responses approached zero. Subjects also reported that the task was quite difficult at first. Evidence of this may be found in Table 2 where the scores now are based on the responses of "trained" divers. Since the values here relate well to previous studies, they strongly suggest that sound localization in the sea is governed by the same laws as it is in fresh water. The implications of this finding to diver navigation seem obvious.

Table 1.--Comparison of sound localization scores 1) near field in fresh water at USRD (Bugg Springs) and 2) at 40 feet in salt water at TEKTITE II.

\begin{tabular}{ccc}
\hline $\begin{array}{c}\text { Stimuli } \\
(\mathrm{hz})\end{array}$ & $\begin{array}{c}\text { Bugg Springs } \\
\text { (fresh water) } \\
\mathrm{N}=17\end{array}$ & $\begin{array}{c}\text { TEKTITE II } \\
\text { (salt water) } \\
\mathrm{N}=5\end{array}$ \\
\hline & & $36.7 \%$ \\
250 & $50.6 \%$ & $30.0 \%$ \\
6000 & $38.8 \%$ & $18.8 \%$ \\
Noise & $33.4 \%$ & $34.0 \%$ \\
\hline
\end{tabular}

Table 2.--Comparison of the effectiveness of different types of signals used in underwater sound localization tasks

\begin{tabular}{lcc}
\hline Stimuli & $\begin{array}{c}\text { Bugg Springs } \\
\text { (fresh water) } \\
\mathrm{N}=6\end{array}$ & $\begin{array}{c}\text { TEKTITE II } \\
\text { (salt water) } \\
\mathrm{N}=4\end{array}$ \\
\hline $15 \mathrm{pps}$ & $40.0 \%$ & $50.0 \%$ \\
$50 \mathrm{pps}$ & $52.2 \%$ & $46.6 \%$ \\
Dolphin \& whistle & $40.0 \%$ & $50.0 \%$ \\
500 to $1000 \mathrm{~Hz}$ & $50.0 \%$ & $40.0 \%$ \\
1000 to $500 \mathrm{~Hz}$ & $60.0 \%$ & $38.3 \%$ \\
4000 to $6000 \mathrm{~Hz}$ & $41.0 \%$ & $33.3 \%$ \\
6000 to $4000 \mathrm{~Hz}$ & $41.0 \%$ & $28.3 \%$ \\
\hline
\end{tabular}

$*$ The actual stimuli for this procedure was slightly different in most cases. 
At present, diver recall typically is accomplished by some form of explosive device. This system is crude and does not provide the diver with sensory cues that can be utilized effectively. A preliminary study of the issue of diver recall was conducted during TEKTITE II.

\section{Procedures}

M-80 explosives and a .38 caliber revolver were used (see Figure 3). They were fired both at the surface (Figure 4) and at depths of 10 feet and 20 feet. Calibrated recordings were made of the explosions at distances varying from 250-4000 feet.

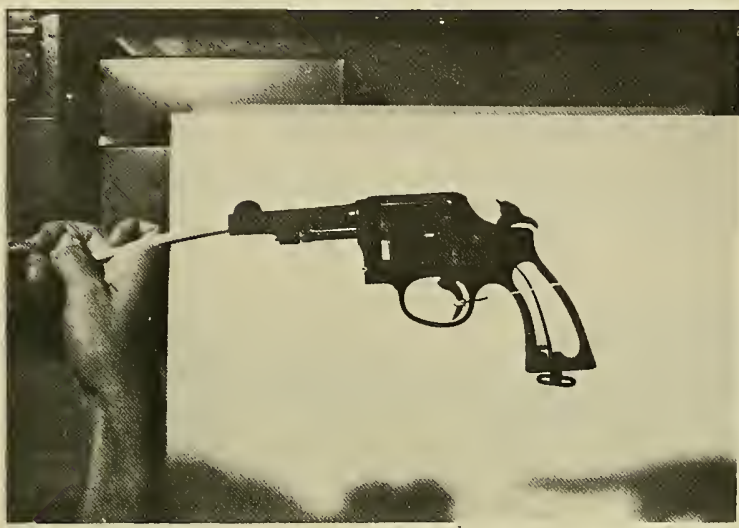

Figure 3. The Navy issue $.38 \mathrm{cal}$. revolver used in the retrieval experiments.

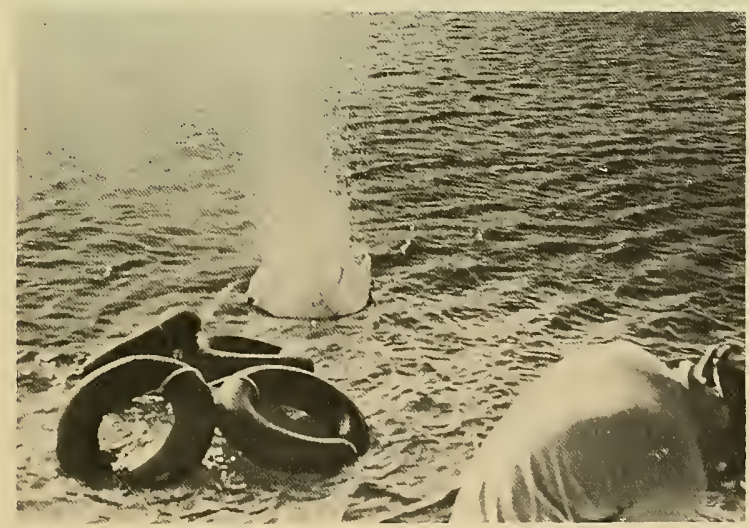

Figure 4. An M-80 exploding on the surface. 
Acoustic analysis currently is being conducted on these data; however, preliminary findings are as follows: Over a distance of 4000 feet, the sound pressure levels produced by the .38 caliber revolver were $106 \mathrm{db}$ to $110 \mathrm{db}$; for the M-80 explosives it was $106 \mathrm{db}$ to $121 \mathrm{db}$ (re 0.0002 dynes/ $\mathrm{cm}^{2}$ ) for the surface and 10-foot depth conditions, respectively. The energy drop (in SPL) between $250^{\prime}$ and $4000^{\prime}$ ranged from 20 to $31 \mathrm{db}$. From these data (and data on underwater auditory sensitivity) it appears that explosive sounds of the type studied are only minimally effective as attention-getting devices. That is, the explosive impact and energy levels of these signals at close range are such that they would override any sea or diver regulator noises. However, while audible at distances of over a mile, their levels are low enough to be masked by sea and life support equipment. Finally, due to the short duration of the signal, it appears that explosives are of little value to diver navigation.

\section{EFFECTIVENESS OF DIVERS WORK WITH AND WITHOUT THE AID OF COMMUNICATION SYSTEMS}

The site of this investigation was Lameshur Bay just off the causeway. The actual test site (as seen from the surface) was approximately that of the skiff seen in Figure 5.

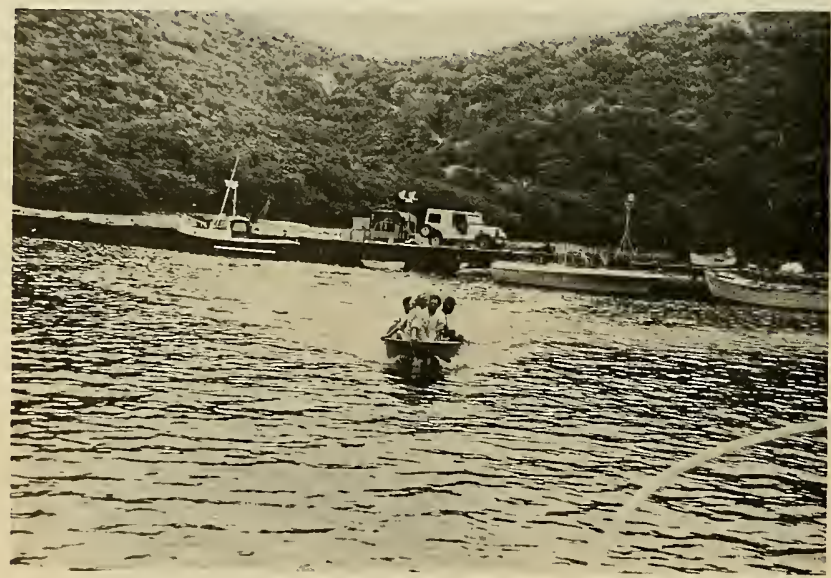

Figure 5. Site of the "Work Study"; one of the teams may be seen approaching the dive boat.

The investigation was designed to determine whether a team of divers, aided by underwater communication systems, could accomplish a complex construction task (requiring a high degree of cooperation among them) more effectively than could a similar team without communication. 
Two 4-member teams matched in ability, but unaccustomed to working together or using underwater communication systems, served as subjects. The work task required the assembly of a mini-DICORS (see again Figure 1) consisting of 132 parts in 20 feet under conditions of low visibility; four separate units were employed for this purpose. A pre-experiment briefing was conducted by the experimenters and a group meeting was held by the team. On the first trial, members of Team A wore Aquasonics 420 units; Team B had no communication gear. On the second trial (a day later), the communicators were worn by Team B; Team A had no communication aids. Time of assembly, parts not used or lost, and number and type of errors constituted the objective measures. Once these data had been obtained and weighted--and adjustments made for general team performance (one team proved to be more skillful than the other)--a performance index was calculated.

\section{$\underline{\text { Results }}$}

Not only was the index greater when the teams were not using the communication systems, but even when the paired trials were considered, the performance of the team without the communication gear was superior in both cases. It was concluded that to be aided by communication systems 1 ) divers must be extensively trained in their use, 2) they must be allowed to develop appropriate communication procedures, and 3) systems with better intelligibility than those currently available must be used.

\section{GENERAL SUMMARY}

Data resulting from a constellation of experiments in diver communication, retrieval and sound localization were obtained at TEKTITE II. The site for the research, the support by the TEKTITE administration, and the cooperation by other scientists and divers proved outstanding. Our experiences demonstrate that substantial and significant studies can be conducted at low cost under the aegis of projects such as TEKTITE II.

\section{ACKNOWLEDGEMENTS}

The authors wish to acknowledge Gilbert C. Tolhurst, Patricia Hollien, Dennis Wilson, and Patricia Phillips who will co-author one or more of the individual reports--and, indeed the Physiological Psychology Branch of the Office of Naval Research which supported these studies.

We also are grateful for assistance provided by the College of the Virgin Islands, James W. Miller, Paul Blackwe11, John Bedingfield, Thomas Giordano, Brendon P. Thompson, Car1 L. Thompson, Peter Williams, Charlotte Hardaway, Ian Koblick, and especially the TEKTITE II Highline Community College divers. 


\section{REFERENCES}

Bauer, B.B. and Torick, E.L., Experimental Studies in Underwater Directional Communication, Journal of the Acoustical Society of America, 39: 25-34 (1966).

deHaan, R.W.R., Hearing in Whales, Acta Otolaryongologica, Supp1. 134: 1-114 (1956).

Hollien, H., Underwater Sound Loca1ization in Humans, CSL/ONR Technica1 Report 非3 , 1-17 (1971).

Hollien, H. and Thompson, C.L., A Diver Communication Research System (DICORS), CSL/ONR Progress Report 非, 1-8 (1967, AD-648-935.

Hollien, H., Coleman, R.F., Thompson, C.L., and Hunter, K., Evaluation of Diver Communication Systems Under Controlled Conditions, Chapter 11, Undersea Technology Handbook, Compass Publications, Arlington, Va., A81- $\overline{A 87 ~(1970 . ~}$ 
